\title{
Effects of heating, breathing, hair style, posture, and air velocity on breathing zone concentrations for an anthropometrically- correct manikin in a wind tunnel
}

Waleed Mahmoud Elnahas

West Virginia University

Follow this and additional works at: https://researchrepository.wvu.edu/etd

\section{Recommended Citation}

Elnahas, Waleed Mahmoud, "Effects of heating, breathing, hair style, posture, and air velocity on breathing zone concentrations for an anthropometrically-correct manikin in a wind tunnel" (2005). Graduate Theses, Dissertations, and Problem Reports. 4146.

https://researchrepository.wvu.edu/etd/4146

This Dissertation is protected by copyright and/or related rights. It has been brought to you by the The Research Repository @ WVU with permission from the rights-holder(s). You are free to use this Dissertation in any way that is permitted by the copyright and related rights legislation that applies to your use. For other uses you must obtain permission from the rights-holder(s) directly, unless additional rights are indicated by a Creative Commons license in the record and/ or on the work itself. This Dissertation has been accepted for inclusion in WVU Graduate Theses, Dissertations, and Problem Reports collection by an authorized administrator of The Research Repository @ WVU.

For more information, please contact researchrepository@mail.wvu.edu. 


\title{
Effects of Heating, Breathing, Hair Style, Posture, and Air Velocity on Breathing Zone Concentrations for an Anthropometrically-Correct Manikin in a Wind Tunnel
}

\author{
Waleed Mahmoud Elnahas
}

\author{
Dissertation \\ Submitted to \\ The College of Engineering and Mineral Resources \\ at West Virginia University
}

In partial fulfillment of the requirements for the degree of

$$
\text { Doctor of Philosophy }
$$

in

Industrial and Management Systems Engineering

\author{
Steven E. Guffey, Ph.D., WVU-IMSE, Committee Chair \\ Warren Myers, Ph.D., WVU-IMSE \\ Wafik Iskander, Ph.D., WVU-IMSE \\ Michael McCawley, Ph.D., WVU-CEE \\ Christopher Coffey, Ph.D., NIOSH
}

Department of Industrial and Management Systems Engineering

Morgantown, West Virginia

2005

Keywords: Manikin, Air Sampling, Breathing Zone, Airflow Patterns, Worker's Exposure, Wind Tunnel 


\section{Abstract \\ Effects of Heating, Breathing, Hair Style, Posture, and Air Velocity on Breathing Zone Concentrations for an Anthropometrically-Correct Manikin in a Wind Tunnel}

\section{Waleed Mahmoud Elnahas}

Ethanol concentrations were measured on an anthropometrically correct, heated, breathing manikin holding a source in its hands at waist height while both sitting and standing in a wind tunnel. The manikin was oriented with its back to the cross draft velocity. Sampling probes were placed at the manikin's mouth, nose, forehead, neck, both collars, center chest and both lapels. Samples were taken from each probe concurrently for 15 minutes by drawing air at $0.15 \mathrm{~L} / \mathrm{min}$ into separate Teflon ${ }^{\mathrm{TM}}$ bags using separate sampling lines. The work was divided into two studies each having factorial study designs and two replications of each treatment combination. Study I test conditions were 5 levels of cross-draft velocities (11, 27, 48, 82 and 104 $\mathrm{ft} / \mathrm{min}$ ), two levels of body heat (unheated/heated), and two levels of posture (sitting/standing). Study II conditions included the same postures and levels of velocities as well as two levels of breathing (breathing/no breathing) and two levels of hair style (wig/no wig) for a heated manikin.

The results of Study I showed that wind tunnel velocity (V), heating, the interaction of heating and velocity, and the interaction of posture and velocity each had a statistically significant $(p<0.001)$ effect on log-transformed concentrations for all sampling locations. For the unheated manikin, concentrations for all sampling locations declined monotonically with wind tunnel velocity. However, for the heated conditions, concentrations varied with an inverted-V relationship with wind tunnel velocity. As expected, the effect of body heat was found to be more substantial at lower velocities (11 to $48 \mathrm{fpm}$ ) than at higher velocities (48 to $104 \mathrm{fpm}$ ). No unheated conditions were investigated in the second study because the first study established the importance of heating the manikin. The results of the heated conditions of Study II showed the same inverted-V relationship with velocity and similar effects of posture for all combinations of wig and breathing. Breathing was significant at all sampling locations. The interactions of breathing with other variables were significant at some locations but not at others.

In comparing ratios of concentrations of other locations to the concentrations measured at the mouth the ideal ratio is unity, but a ratio that varies little with velocity, posture, and other variables would allow use of correction factors. The results showed that the ratios deviated substantially from unity for most treatment combinations for every sampling location both for unheated and heated conditions and their deviations varied significantly with treatment conditions. These ratios were significantly related $(\mathrm{p}<0.01)$ to velocity and posture at every location. Heating and the interaction of heating with other variables were significant $(p<0.05)$ for nearly all sampling locations. Likewise, breathing and wig and their interactions with other variables were significant for nearly all locations.

At the middle range of velocities, the collars, lapels, and lower sternum produced large (e.g., 100\%) over-estimations for standing and large underestimations (e.g., 50\%) for sitting. Surprisingly, the nose deviation ranged from $60 \%$ to $155 \%$. The most reliable location was the neck followed by the forehead, but neither was consistently within $20 \%$ of the mouth. 


\section{Acknowledgements}

This project has been supported by the Industrial and Management Systems Engineering Department (IMSE) and the National Institute for Occupational Safety and Health (NIOSH) grant number (1RO1 OHO4081-01).

I would like to express my sincere gratitude to Dr. Steven Guffey, my dissertation advisor, for his patience, guidance, and his willingness to give his time and knowledge extensively during the full course of this research. This research owes much to his sound advice.

I am deeply indebted to Dr. Wafik Iskander for his generous support and valuable directions. His continuous encouragement was a major source of inspiration throughout my stay at West Virginia University. I would like to take this opportunity to extent my gratitude to Dr. Warren Myers, Dr. Christopher Coffey, and Dr. Michael McCawley for their advice and guidance and for serving on my committee.

I give special thanks to Mr. Jim Dalton for his valuable assistance and technical vision during the construction phase of this project. I would like to thank my fellow student researchers, Sumeeth, Santosh, Amit, and Ahmed for their help during this study.

Finally, I would like to express my love and gratitude to my parents for their unlimited patience, advice and support. They have had great impact in shaping my life and establishing my career. 


\section{Abbreviations}

BZ

CFD

Clo

$\mathrm{C}_{0}, \mathrm{C}_{1}, \mathrm{C}_{2}, \mathrm{C}_{3}$

$\mathrm{C}_{\text {c.chest }}$

$\mathrm{C}_{\text {l.lapel }}$

$\mathrm{C}_{\text {r.lapel }}$

$\mathrm{C}_{\text {neck }}$

$\mathrm{C}_{\text {l.collar }}$

$\mathrm{C}_{\text {r.collar }}$

$\mathrm{C}_{\text {mouth }}$

$\mathrm{C}_{\text {nose }}$

$\mathrm{C}_{\text {forehead }}$

$\mathrm{C}_{\text {inhaled }}$

$\mathrm{C}_{\text {upper.torso }}$

$\mathrm{C}_{\text {lower.torso }}$

fpm

LEL

$\mathrm{mV}$

mVS

$\mathrm{NIOSH}$

OSHA

ppm

$\operatorname{Re}$

$\mathrm{R}^{2}$

$\mathrm{V}$
Breathing Zone

Computational Fluid Dynamics

Unit of thermal insulation for clothing

Constants in Regression Models

Concentartion at center chest location, ppm

Concentartion at left lapel location, ppm

Concentartion at right lapel location, ppm

Concentartion at neck location, ppm

Concentartion at left collar location, ppm

Concentartion at right collar location, ppm

Concentartion at mouth location, ppm

Concentartion at nose location, ppm

Concentartion at forhead location, ppm

Average of $\mathrm{C}_{\text {nose }}$ and $\mathrm{C}_{\text {mouth }}$, ppm

Average of $\mathrm{C}_{\text {neck }}, \mathrm{C}_{\text {l.collar, }}$ and $\mathrm{C}_{\text {r.collar, }}$ ppm

Average of $\mathrm{C}_{\text {c.chest }}, \mathrm{C}_{\text {l.lapel }}$, and $\mathrm{C}_{\text {r.lapel, }}$ ppm

feet per min

Lower Explosive Limit

milli-volt

milli-volt second

National Institute for Occupational Safety and Health

Occupational Safety and Health Administartion

parts per million

Reynolds number

Coefficient of Correlation

wind tunnel velocity, fpm 


\section{Table of Contents}

ABSTRACT

ACKNOWLEDGEMENTS

ABBREVIATIONS

iv

TABLE OF CONTENTS

LIST OF TABLES

LIST OF FIGURES

1.1 Background

1.2 Problem Statement

1.3 Hypotheses Tested

1.4 Research Objectives

CHAPTER 2: LITERATURE REVIEW

2.1 Studies comparing gas and vapor concentrations at the breathing zone of human subjects and simple manikin

2.3 Research work studying airflow patterns, wake length and width, boundary layer separation and modeling of breathing zone concentration

2.4 Research work studying the effect of manikin breathing and heating 


\section{CHAPTER 3: RESEARCH DESIGN, METHODS, APPARATUS AND PROCEDURES}

$\begin{array}{ll}3.2 \text { Apparatus } & 16\end{array}$

3.2.1 Manikin 16

3.2.2 Wind tunnel 20

3.2.3 Temperature, humidity and barometric measurements 21

3.2.4 Gas and vapor sampling apparatus for wind tunnel studies $\quad 21$

3.2.5 System for Generation and dispersion of tracer gas mixtures 21

3.2.6 Gas and vapor analyses $\quad 22$

$\begin{array}{ll}3.3 \text { Procedures } & 22\end{array}$

3.3.1 Sampling system preparation prior to experiment runs 22

3.3.2 Setting up the tracer gas release system 23

3.3.3 Adjustment of fan speed and measurement of environmental conditions 23

3.3.4 Preparation of the manikin 24

3.3.5 Sampling procedures 26

3.3.6 Analysis of ethanol sampling bags 26

3.3.7 Calibration of Voyager GC 27

$\begin{array}{ll}\text { CHAPTER 4: RESULTS OF STUDY I } & 28\end{array}$

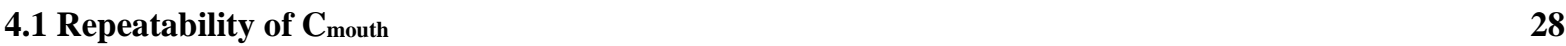

4.2 Effects of Independent Variables on all Sampling Locations 39

$\begin{array}{ll}4.2 .1 \text { Velocity } & 39\end{array}$

4.2.2 Heating 40

$\begin{array}{ll}4.2 .3 \text { Posture } & 40\end{array}$

4.3 Effects of Independent Variables on $C_{\text {inhaled }}, C_{\text {upper.torso, }}$ and $C_{\text {lower.torso }}$

4.4 Effects of Independent Variables on Ratio of Concentrations

CHAPTER 5: DISCUSSIONS OF STUDY I

5.1 Log-Transformation of Dependent Variables

5.2 Methods for Analysis of Variance (ANOVA)

5.3 Methods for Regression Analysis

5.4 Comparisons of individual Concentration Values and Ratios of Concentrations for all Sampling

Locations $\quad 62$ 
6.2 Effects of Independent Variables on all Sampling Locations 77

$\begin{array}{ll}6.2 .1 \text { Velocity } & 77\end{array}$

$\begin{array}{ll}\text { 6.2.2 Breathing } & 77\end{array}$

$\begin{array}{ll}6.2 .3 \mathrm{Wig} & 78\end{array}$

\begin{tabular}{l} 
6.2.4 Posture \\
\hline
\end{tabular}

6.3 Effects of Independent Variables on $C_{\text {inhaled }}, C_{\text {upper.torso, and } C_{\text {lower.torso }}} 86$

6.4 Effects of Independent Variables on Ratios of Concentrations 97

CHAPTER 7: DISCUSSIONS OF STUDY II 99

$\begin{array}{ll}\text { 7.1 Log-Transformation of Dependent Variables } & 100\end{array}$

$\begin{array}{ll}\text { 7.2 Methods for Analysis of Variance (ANOVA) } & 101\end{array}$

$\begin{array}{ll}\text { 7.3 Methods for Regression Analysis } & 103\end{array}$

7.4 Comparisons of Individual Concentration Values and Ratios of Concentrations for all Sampling Locations

CHAPTER 8: CONCLUSIONS AND RECOMMENDATIONS FOR BOTH STUDIES

$\begin{array}{ll}\text { 8.1 Specific Conclusions } & 115\end{array}$

8.1.1 Concentrations $\quad 115$

8.1.2 Ratios of Concentrations 116

$\begin{array}{ll}\text { 8.2 Recommendations for future work } & 116\end{array}$

$\begin{array}{lr}\text { 8.3 Caveats } & 117\end{array}$

$\begin{array}{ll}\text { REFERENCES } & 118\end{array}$

APPENDIX A: NORMAL PROBABILITY PLOTS (STUDY I) 123

APPENDIX B: REGRESSION ANALYSIS (STUDY I) 132 
APPENDIX C: NORMAL PROBABILITY PLOTS (STUDY II)

APPENDIX D: REGRESSION ANALYSIS (STUDY II)

APPENDIX E: SCATTER PLOTS OF LOG-TRANSFORMED CONCENTARTIONS (STUDY II)

APPENDIX F: INTERACTION PLOTS OF VELOCITY X HEATING (STUDY I) 184

APPENDIX G: LOW FLOW PUMPS CALIBRATION SHEET

APPENDIX H: AMBIENT CONDITIONS DURING SAMPLING

APPENDIX I: GC CALIBRATION CURVE AND STABILITY FOR ETHANOL

APPENDIX J: TESTING SAMPLING LINE LOSSES

APPENDIX K: COMPARISON OF ETHANOL AND ACETONE ADSORPTION IN TEDLAR AND TEFLON BAGS

APPENDIX L: COMPARISON OF ETHANOL AND ACETONE ADSORPTION IN TYGON AND TEFLON ${ }^{\mathrm{TM}}$ TUBINGS

APPENDIX M: CALIBRATION OF VOYAGER PORTABLE GAS CHROMATOGRAPH USING HEADSPACE VAPOR METHOD 


\section{List of Tables}

Table 3.1: Description of Surrogate Sites..................................................................15

Table 3.2: Levels for Independent Variables for Each Study ............................................16

Table 3.3: Anthropometric Data in mm for US Adults Aged 19-60 Years According to

(Gordon et al., 1989, cited in Kroemer and Grandjean, 1997)..................................17

Table 3.4: Metabolism, Respiration, Temperature, and Heart Rate as Indications of

Workload (Christensen, 1964, cited in Kroemer and Grandjean, 1997) ................19

Table 4.1: Average Concentrations (ppm) for Each Velocity Level and Manikin

Treatments

Table 4.2: Average Concentrations (ppm) for Each Velocity Level and Manikin

Treatment

Table 4.3: Ratios of Concentrations to $C_{\text {mouth }}$ for all Velocities and Manikin Treatments

Table 5.1: Coefficient of correlation (R2) for externally studentised residuals against normal scores for log-transformed individual concentrations and ratios of concentrations

Table 5.2: Completely Randomized Factorial Design of Experiments...........................54

Table 5.3: p-Values from ANOVAs for Log-Transformed Individual Concentrations .54

Table 5.4: p-Values from ANOVAs for Log-Transformed Ratios of Concentrations to

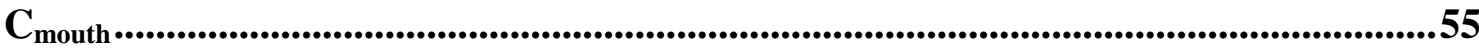

Table 5.5: p-Values from ANOVA's for Log-Transformed $C_{\text {inhaled, }} C_{\text {uppertorso, }}$ and

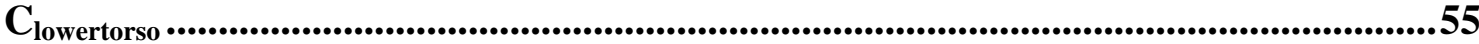

Table 5.6: Regression Coefficients for heated/standing manikin $(\mathbf{p}<0.001)$..................56

Table 5.7: Regression Coefficients for heated/seated manikin $(p<0.001)$......................56

Table 5.8: Regression Coefficients for unheated/standing manikin $(\mathbf{p}<0.001)$................57

Table 5.9: Regression Coefficients for unheated/seated manikin ( $p<0.001$ unless otherwise indicated).

Table 6.1a: Average Concentration Values (ppm) For Each Velocity Level and Manikin Treatment (Seated)

Table 6.1b: Average Concentration Values (ppm) For Each Velocity Level and Manikin Treatment (Standing)

Table 6.2a: Average Concentrations (ppm) at lower torso, upper torso, and inhaled (seated).

Table 6.2b: Average Concentrations (ppm) at lower torso, upper torso, and inhaled (standing)

Table 6.3a: Ratios of concentrations to $C_{\text {mouth }}$ for all velocities and manikin treatments (sitting).

Table 6.3b: Ratios of Concentrations to $C_{\text {mouth }}$ for all Velocities and Manikin Treatments (standing)

Table 7.1: Coefficient of correlation $\left(R^{2}\right)$ for externally studentised residuals against normal scores for log-transformed individual concentrations and ratios of concentrations 
Table 7.2: Completely Randomized Factorial Design of Experiments.

Table 7.3: p-Values from ANOVA's for Log-Transformed Individual Concentrations

Table 7.4: p-Values from ANOVA's for Log-Transformed Ratios of Concentrations to $\mathrm{C}_{\text {mouth }}$

Table 7.5: $p$-Values from ANOVA's for log-transformed $C_{\text {inhaled }}, C_{\text {uppertorso, }}$ and

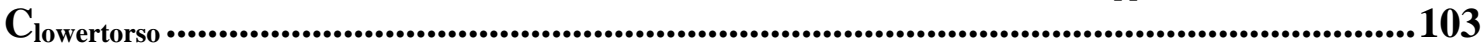

Table 7.6: Regression coefficients for seated/breathing/wig manikin $(p<0.001$ unless

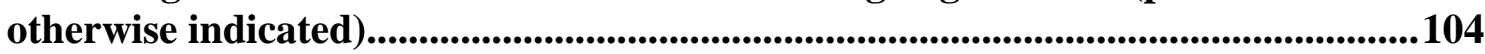

Table 7.7: Regression coefficients for seated/breathing/nowig manikin $(\mathbf{p}<0.001$ unless

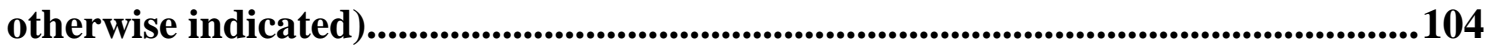

Table 7.8: Regression coefficients for standing/breathing/wig manikin ( $p<0.001$ unless

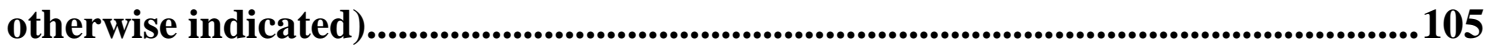

Table 7.9: Regression coefficients for standing/breathing/nowig manikin $(\mathbf{p}<0.001$ unless otherwise indicated)

Table 7.10: Percentage of $\mathbf{C}_{\text {mouth }}$ for surrogate sampling locations for heated, breathing, and clothed manikin .......................................................................................113

Table 7.11: Recommended best and acceptable surrogate sampling locations .............113 


\section{List of Figures}

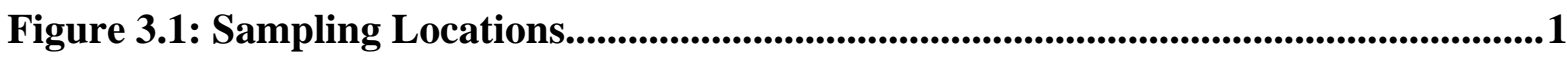

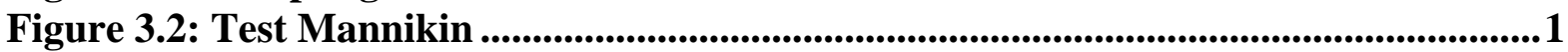

Figure 3.3: Wire used for heating ...................................................................................1

Figure 3.4: clothing and Hairstyle for seated manikin ......................................................1

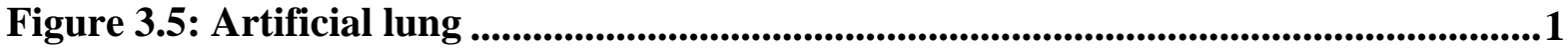

Figure 3.6: Schematic Flow Diagram for the Breathing Circuit.....................................19

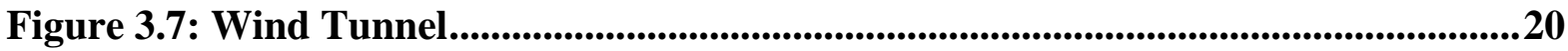

Figure 4.2-a: Scatter and mean plots of $C_{\text {mouth }}$ vs. velocity for all manikin treatments..30

Figure 4.2-b: Scatter and mean plots of $\log C_{\text {mouth }}$ vs. velocity for all manikin treatments

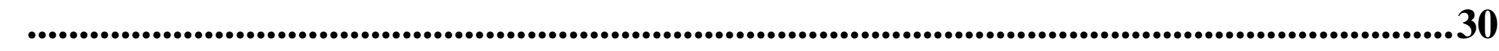

Figure 4.3-a: Scatter and mean plots of $\mathrm{C}_{\text {nose }}$ vs. velocity for all manikin treatments....31

Figure 4.3-b: Scatter and mean plots of $\log C_{\text {nose }}$ vs. velocity for all manikin treatments

Figure 4.4-a: Scatter and mean plots of $\mathrm{C}_{\mathrm{f} \text { orehead }} \mathrm{vs}$. velocity for all manikin treatments

Figure 4.4-b: Scatter and mean plots of $\log \mathrm{C}_{\text {forehead }}$ vs. velocity for all manikin treatments.

Figure 4.5-a: Scatter and mean plots of Cneck vs. velocity for all manikin treatments....33 Figure 4.5-b: Scatter and mean plots of $\log C_{\text {neck }}$ vs. velocity for all manikin treatments

Figure 4.6-a: Scatter and mean plots of $C_{\text {l.collar }}$ vs. velocity for all manikin treatments .34 Figure 4.6-b: Scatter and mean plots of log Cl.collar vs. velocity for all manikin treatments.

Figure 4.7-a: Scatter and mean plots of $\mathrm{C}_{\text {r.collar }}$ vs. velocity for all manikin treatments. 35 Figure 4.7-b: Scatter and mean plots of $\log \mathrm{C}_{\text {r.collar }}$ vs. velocity for all manikin treatments.....................................................................................................................35

Figure 4.8-a: Scatter and mean plots of $C_{c . c h e s t ~} v s$. velocity for all manikin treatments .36 Figure 4.8-b: Scatter and mean plots of $\log C_{c . c h e s t}$ vs. velocity for all manikin

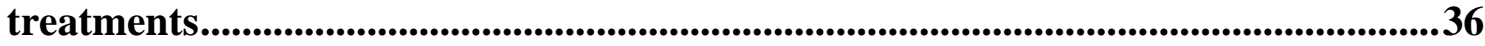

Figure 4.9-a: Scatter and mean plots of $C_{1 . l a p e l}$ vs. velocity for all manikin treatments ..37 Figure 4.9-b: Scatter and mean plots of $\log C_{l . l a p e l}$ vs. velocity for all manikin treatments

Figure 4.10-a: Scatter and mean plots of $C_{\text {r.lapel }}$ vs. velocity for all manikin treatments 38 Figure 4.10-b: Scatter and mean plots of log Cr.lapel vs. velocity for all manikin

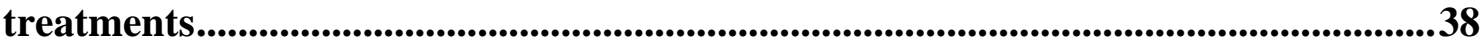

Figure 4.11: Mean concentration versus velocity for standing/heated manikin..............43 Figure 4.12: Mean concentration versus velocity for seated/heated manikin...................43 Figure 4.13: Mean concentration versus velocity for standing/unheated manikin .........44 
Figure 4.14: Mean concentration versus velocity for seated/unheated manikin ..............44

Figure 4.15: Scatter and mean plots of $C_{n o s e} / C_{\text {mouth }}$ vs. velocity for all manikin treatments

Figure 4.16: Scatter and mean plots of $\mathbf{C}_{\text {forehead }} / \mathbf{C}_{\text {mouth }}$ vs. velocity for all manikin treatments

Figure 4.17: Scatter and mean plots of $\mathbf{C}_{\text {neck }} / \mathbf{C}_{\text {mouth }}$ vs. velocity for all manikin treatments

Figure 4.18: Scatter and mean plots of $C_{l . c o l l a r} / C_{\text {mouth }}$ vs. velocity for all manikin treatments

Figure 4.19: Scatter and mean plots of $C_{r . c o l l a r} / C_{m o u t h}$ vs. velocity for all manikin treatments.

Figure 4.20: Scatter and mean plots of $C_{c . c h e s t} / C_{\text {mouth }}$ vs. velocity for all manikin treatments.

Figure 4.21: Scatter and mean plots of $C_{1 . l a p e l} / C_{\text {mouth }}$ vs. velocity for all manikin treatments

Figure 4.22: Scatter and mean plots of $C_{r . l a p e l} / C_{\text {mouth }}$ vs. velocity for all manikin treatments

Figure 5.1: Mean Concentration (ppm) versus velocity for standing/heated manikin ...58 Figure 5.2: Mean Concentration (ppm) versus velocity for seated/heated manikin .......58 Figure 5.3: Mean concentration (ppm) versus velocity for standing/unheated manikin 59 Figure 5.4: Mean concentration (ppm) versus velocity for seated/unheated manikin....59 Figure 5.5: Concentration ratio to $C_{\text {mouth }}$ versus velocity for standing/heated manikin 60 Figure 5.6: Concentration ratio to $C_{\text {mouth }}$ versus velocity for seated/heated manikin ....60 Figure 5.7: Concentration ratio to $C_{\text {mouth }}$ versus velocity for standing/unheated manikin

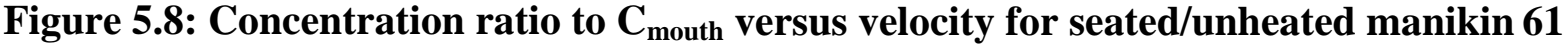
Figure 6.2-a: Scatter and mean plots of $\mathrm{C}_{\mathrm{m} \text { outh }} \mathrm{vs}$. velocity for all manikin treatments (seated).

Figure 6.2-b: Scatter and mean plots of $\mathrm{C}_{\mathrm{m}}$ outh vs. velocity for all manikin treatments (standing)

Figure 6.3-a: Scatter and mean plots of $\mathrm{C}_{\text {nose }}$ vs. velocity for all manikin treatment (seated).

Figure 6.3-b: Scatter and mean plots of $\mathrm{C}_{\text {nose }}$ vs. velocity for all manikin treatment (standing)

Figure 6.4-a: Scatter and mean plots of $\mathbf{C}_{\text {forehead }}$ vs. velocity for all manikin treatment (seated).

Figure 6.4-b: Scatter and mean plots of $\mathrm{C}_{\mathrm{forehead}} \mathrm{vs}$. velocity for all manikin treatment (standing)

Figure 6.5-a: Scatter and mean plots of $\mathrm{C}_{\text {neck }}$ vs. velocity for all manikin treatments (seated)

Figure 6.5-b: Scatter and mean plots of $C_{\text {neck }}$ vs. velocity for all manikin treatments (standing)

Figure 6.6-a: Scatter and mean plots of Cl.collar vs. velocity for all manikin treatment (seated) 
Figure 6.6-b: Scatter and mean plots of Cl.collar vs. velocity for all manikin treatment (standing)

Figure 6.7-a: Scatter and mean plots of $\mathrm{C}_{\text {r.collar }}$ vs. velocity for all manikin treatment (seated)

Figure 6.7-b: Scatter and mean plots of $\mathrm{C}_{\text {r.collar }}$ vs. velocity for all manikin treatment (standing)

Figure 6.8-a: Scatter and mean plots of $\mathbf{C}_{c . c h e s t}$ vs. velocity for all manikin treatment (seated)

Figure 6.8-b: Scatter and mean plots of $\mathbf{C}_{c . c h e s t}$ vs. velocity for all manikin treatment (Standing)

Figure 6.9-a: Scatter and mean plots of Cl.lapel vs. velocity for all manikin treatment (seated)

Figure 6.9-b: Scatter and mean plots of C..lapel vs. velocity for all manikin treatment (standing)

Figure 6.10-a: Scatter and mean plots of Cr.lapel vs. velocity for all manikin treatment (seated)

Figure 6.10-b: Scatter and mean plots of $C_{\text {r.lapel }}$ vs. velocity for all manikin treatment (standing)

Figure 6.11-a: Average BZ Concentration versus velocity for all treatments ..................82

Figure 6.11-b: Average BZ Concentration versus velocity for all treatment ..................82

Figure 6.12-a: Average BZ Concentration versus velocity for all treatment....................83

Figure 6.12-b: Mean BZ Concentration versus velocity for all treatment .........................83

Figure 6.13-a: Mean BZ Concentration versus velocity for all treatment ......................884

Figure 6.13-b: Mean BZ Concentration versus velocity for all treatment .......................84

Figure 6.14-a: Mean plot of $C_{\text {inhaled }}$ versus velocity for all manikin treatment...............85

Figure 6.14-b: Mean plot of $C_{\text {inhaled }}$ versus velocity for all manikin treatment ...............85

Figure 6.15-a: Scatter and mean plot of $\mathbf{C}_{\text {nose }} / \mathbf{C}_{\text {mouth }}$ vs. velocity for all manikin treatments (seated)

Figure 6.15-b: Scatter and mean plot of $C_{\text {nose }} / C_{\text {mouth }}$ vs. velocity for all manikin treatments (standing)

Figure 6.16-a: Scatter and mean plot of $\mathrm{C}_{\text {forehead }} / \mathrm{C}_{\text {mouth }}$ vs. velocity for all manikin treatments (seated)

Figure 6.16-b: Scatter and mean plot of $C_{\text {forehead }} / \mathbf{C}_{\text {mouth }}$ vs. velocity for all manikin treatments (standing)

Figure 6.17-a: Scatter and mean plot of $C_{n e c k} / C_{\text {mouth }}$ vs. velocity for all manikin treatments (seated)

Figure 6.17-b: Scatter and mean plot of $C_{n e c k} / C_{\text {mouth }}$ vs. velocity for all manikin treatments (standing)

Figure 6.18-a: Scatter and mean plot of $C_{\text {l.collar }} / \mathbf{C}_{\text {mouth }}$ vs. velocity for all manikin treatments (seated)

Figure 6.18-b: Scatter and mean plot of $\mathbf{C}_{\text {l.collar }} / \mathbf{C}_{\text {mouth }}$ vs. velocity for all manikin treatments (standing)

Figure 6.19-a: Scatter and mean plot of $\mathbf{C}_{\text {r.collar}} / \mathbf{C}_{\text {mouth }}$ vs. velocity for all manikin treatments (seated) 
Figure 19-b: Scatter and mean plot of $\mathbf{C}_{\text {r.collar }} / \mathbf{C}_{\text {mouth }}$ vs. velocity for all manikin treatments (standing)

Figure 6.20-a: Scatter and mean plot of $C_{c . c h e s t} / C_{\text {mouth }}$ vs. velocity for all manikin treatments (seated)

Figure 6.20-b: Scatter and mean plot of $\mathbf{C}_{c . c h e s t} / \mathbf{C}_{\text {mouth }}$ vs. velocity for all manikin treatments (standing)

Figure 6.21-a: Scatter and mean plot of $C_{1 . l a p e l} / C_{m o u t h}$ vs. velocity for all manikin treatments (seated)

Figure 6.21-b: Scatter and mean plot of $\mathbf{C}_{1 . \text { lapel }} / \mathbf{C}_{\text {mouth }}$ vs. velocity for all manikin treatments (standing)

Figure 6.22-a: Scatter and mean plot of $\mathrm{C}_{\text {r.lapel }} / \mathbf{C}_{\text {mouth }}$ vs. velocity for all manikin treatments (seated)

Figure 6.22-b: Scatter and mean plot of $\mathrm{C}_{\text {r.lapel }} / \mathrm{C}_{\text {mouth }}$ vs. velocity for all manikin treatments (standing)

Table 7.1: Coefficient of correlation $\left(\mathbf{R}^{2}\right)$ for externally studentised residuals against normal scores for log-transformed individual concentrations and ratios of concentrations

Figure 7.1: Mean concentration (ppm) versus velocity for seated/breathing/no wig manikin

Figure 7.2: Mean Concentration (ppm) versus velocity for standing/breathing/nowig manikin

Figure 7.3: Mean concentration (ppm) versus velocity for seated/breathing/wig manikin

Figure 7.4: Mean Concentration (ppm) versus velocity for standing/breathing/wig manikin

Figure 7.5: Concentration ratio to $C_{\text {mouth }}$ versus velocity for seated/breathing/no wig manikin

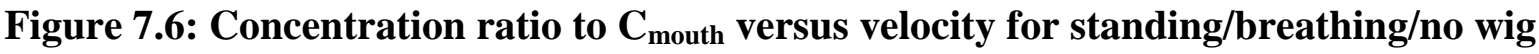
manikin

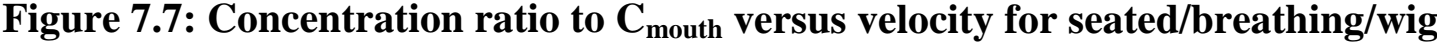
manikin

Figure 7.8: Concentration ratio to $C_{\text {mouth }}$ versus velocity for standing/breathing/wig manikin 


\section{Chapter 1: Introduction}

\subsection{Background}

Workers on the job are often exposed to airborne chemicals in levels that may be sufficient to affect their long-term health. Industrial hygienists sample their exposures and compare them to "safe" levels. In sampling these airborne chemicals, it is important that the sample fairly represent the inhaled concentration. For many years it was assumed that a sample taken anywhere in the so called "breathing zone" (BZ) would more or less equal the inhaled concentration. "The Occupational Safety and Health Administration (OSHA) considered the breathing zone to be a hemisphere forward of the shoulder with a radius of approximately 6-9 inches" (CFR, 1985). However, over time it became more and more apparent that there could be steep concentration gradients near sources. Hence, a sample taken at different locations in the supposed BZ near the body could give very different results.

By 1973, the volume accepted as representing the true BZ shrunk to be "within a foot of the head as well as the upper torso" (NIOSH, 1973). Presently the most popular sampling location is the lapels and collars (but sometimes on the sternum), perhaps due to their convenience when attaching filters and probe inlets.

In determining whether samples taken at a given location will have concentrations equal to inhaled concentrations, the "acid test" is to compare concentrations taken on human subjects at that location to samples simulanteously sampled near the mouths of the subjects. However, testing human subjects can be inconvenient and costly. Manikins are more convenient subjects than humans because humans must be treated with elaborate care to avoid harmful exposures and cannot be tested for long periods of time due to fatigue.

However, the convenience of manikins would be of dubious benefit if the results from manikin studies do not accurately predict results with humans. The only way to confirm that a simple manikin is behaving like humans is by comparing results from manikins to results from exposed humans under similar conditions. As will be discussed later, it is an open question whether manikins of any complexity are adequate surrogates for humans in modeling inhaled concentrations. Despite the substantial reliance on manikins in past studies, there are few published studies that even investigate whether manikins are reliable substitutes for humans in industrial hygiene sampling.

Manikins used in most previous experimental investigations were far from lifelike in many characteristics. Plausibly important characteristics include lifelike facial features such as hair, breathing, body temperature, anthropometrically-correct dimensions, posture, and body movement. As will be discussed, no study was found in which the manikin had all of these characteristics. If there were differences in results between such a simple manikin and a human, one could not determine whether the differences were due to these dissimilarities or to more subtle differences, such as facial features, hair style, etc. Manikins used in some previous works were just standing in uniform velocity fields with their hands straight down. In some studies, the source was placed in unrealistic locations. In the industrial work environment, the greatest exposures are likely where workers hold a source in their hands 
(Flynn and Shelton, 1990). In this research, the manikin held a source within its arms whether it was sitting or standing.

Physical as well as virtual modeling of human beings is a subject of growing interest for assessing, measuring and simulating personal exposure to contaminants in the workplace. As will be discussed later, manikins used in CFD simulations have been spheres, rectangles, sharp edged simplified shapes, or cylinder shaped models. The influence of manikin geometry on the flow pattern and contaminant dispersion at the breathing zone is still undergoing research (Brohus, 1997; Li et al., 2003; 2005). Issues which need careful consideration are those of the choice of anthropometric measures, plus the mechanical and geometrical representation of the human being (joints and body parts). Making such choices should depend on the intended use of the model. For instance, a manikin used to study air flow patterns and contaminant dispersion requires separated legs and separated arms to simulate a human being in a standing position while holding a source with his arms. Parameters that govern modeling of a human physically are simplicity, feasibility of the model, and the need to satisfy the purpose of research.

Anthropometric parameters such as height, width, and depth of the manikin parts are important for studying the proportions of physical or virtual manikins to human beings, while integral parameters such as surface area and body volume are important for studying the effects of convective and radiative heat loss from different body parts on air flow patterns and contaminant dispersion in breathing zones of workers.

It is plausible that, at a minimum, a manikin must be heated and must breathe because complicated interactions take place between inhalation and exhalation air flow, convective air flows due to body heat, thermal plumes and body posture in the breathing zone of a human being. For that reason, this study will determine the importance of heating, breathing, posture, and hair style.

\subsection{Problem Statement}

First problem: Industrial hygiene sampling for airborne exposures to workers is done by drawing air from probes located on the chests of workers. It is not proven that these samples accurately represent inhaled concentrations.

Second problem: Studies done on variations on concentrations near the human body have nearly all been done on manikins that do not breathe and are not heated. It is not proven that these manikins represent humans accurately. It is also not determined whether heating, breathing, postures, and hairstyles affect concentrations measured on manikins.

This study considers whether and how breathing, heating, hair style, and posture affect concentrations measured at several potential sampling locations on the head and torso of a manikin. Since the results will not be compared directly to a human, this study alone can not determine if any combination of treatments makes a manikin equivalent to humans for the purpose of exposure assessments. However, this study provides evidence that should be helpful in determining if these treatments are necessary to producing a faithful surrogate for humans. The logic is simple: if a treatment (e.g., breathing) makes no difference in the results for a manikin, then adding breathing to a non-breathing manikin probably is pointless whether or not the manikin is later shown to be equivalent to a human. On the other hand, if 
breathing does make a difference to a manikin, then it is reasonable to assume that human data would be more similar to the breathing manikin than to the non-breathing manikins since humans also breathe.

It is important to determine if the "improvements" intended to make manikins more lifelike are needed because making a manikin similar to a human can be costly, both in direct costs and in its effects on study size. For the latter, each improvement introduces another set of potentially important variables. For example, if heating is important, is it important to heat all body parts or is heating the upper torso sufficient? Are the results sensitive to small changes in body temperature? If a wig has substantial effects, then presumably wigs with different lengths and hairstyles could produce diverse effects. If so, then future studies would have to use a diverse array of manikins or treatments to manikins, increasing the size of the studies.

Hence, before acting on the assumption that breathing, heating, posture, and hair style must be part of the manikin, it is important to verify that each is important. If, for example, a breathing manikin gives results identical to an otherwise similar manikin that does not have breathing, then there is no point in incurring the costs of adding the simulated breathing. The same is true for heating. The direct costs of posture, wigs, and clothing are small, but the indirect costs could be substantial. If for example, a wig has strong effects, perhaps a different wig would have different strong effects. Hair would then be known to be a potent variable that must be considered in the diverse range of human hairstyles and lengths, increasing the size and cost of exposure studies using manikins. The same would be true for posture if it is important for two different positions.

Another independent variable for this study is air velocity, a crucial environmental condition that has proven important in other studies (Baldwin and Maynard, 1998; Guffey, et al 2001; Fletcher and Johnson, 1988; Fletcher and Johnson, 1996; Kim and Flynn, 1992; Kulmala et al, 1996; George et al, 1990; Flynn and Ljungqvist, 1995; Kim and Flynn, 1991a; Kim and Flynn, 1991b; Kim and Flynn, 1991; Flynn and Shelton, 1990; Flynn et al, 1995; Welling et al, 2000; Welling et al, 2001; Heist et al, 2003; Brohus, 1997; Brohus and Nielsen, 1994a; 1995; 1996b; Rodes et al, 1995; Bjorn and Nielsen, 1996a; 1996b). Five levels of velocity were tested because these studies generally have found the effects of velocity to be non-linear and because velocity could interact with other variables. For example, it is likely that the effects of heating a manikin would be quite different at low velocity ranges than at higher ones.

This study considers only two levels each of heating, breathing, posture, and hair style: 1) not present, and 2) in the middle of the range of likely human conditions. If the extremes for a treatment produce similar results, then it is reasonable to assume that the variable is not particularly important. If the differences are modest but significant, then, one, mid-range level may be sufficient. If the differences are substantial, more levels should be considered in future studies. Again, it is important to note that proving a heated breathing manikin with clothing and a wig produces results different from one without those features does not prove that either manikin is a reliable surrogate for a human. Only comparisons to results from humans can establish that. This is outside the scope of this study. 


\subsection{Hypotheses Tested}

The first hypothesis of this current research is that cross draft velocity, heating, breathing, posture, and hair style each affect the concentrations at each sampling location. The second hypothesis is that concentrations at other sampling locations differ from concentrations at the mouth and that the differences vary with velocity, heating, breathing, posture, and hair style.

This study cannot prove, for example, that a heated manikin is the same as a human, but it can demonstrate whether or not heating a manikin changes the concentrations measured on a manikin.

The dependent variables are concentrations sampled at mouth, nose, forehead, neck, both collars, both lapels, and center chest locations. The independent variables are specific human characteristics that are applied to the manikin at two levels each;

- Head and torso "skin" temperature (ambient vs. heated to $37^{\circ} \mathrm{C}$ )

- Posture (standing vs. sitting)

- Hair Style (2" long wig vs. bald)

- Breathing (simulated nose breathing vs. not breathing)

The first hypothesis for level of concentration, $\mathrm{C}$, can be stated for each location, i, as:

$\mathrm{H}_{\mathrm{o}}: \mathrm{C}_{\mathrm{i}}=$ constant

$\mathrm{H}_{1}: \mathrm{C}_{\mathrm{i}}=\mathrm{f}$ \{air velocity, body heat, breathing, posture, and hair style)

Where: $\mathrm{C}=$ concentartion

$\mathrm{i}=$ mouth, nose, forehead, neck, left collar, right collar, center chest, left lapel, right lapel.

The second hypothesis for the effect of location and the independent variables on the relative concentrations compared to the mouth can be stated as:

$\mathrm{H}_{\mathrm{o}}: \mathrm{C}_{\mathrm{i}} / \mathrm{C}_{\text {mouth }}=$ constant

$\mathrm{H}_{1}: \mathrm{C}_{\mathrm{i}} / \mathrm{C}_{\text {mouth }}=\mathrm{f}$ \{air velocity, body heat, breathing, posture, and hair style)

Where: $\mathrm{C}=$ concentration and $\mathrm{i}<>$ mouth

The significance of each independent variable and the interactive effects of independent variables were determined using ANOVA. In addition, all tests were replicated twice for each of five levels of cross draft velocities and at both of the two postures.

The following conditions were the same for all tests:

- Exposures tested in a large wind tunnel with relatively uniform flows

- Air flowed from the back of the manikin with the tracer gas source "held" in the manikin's hands at waist level.

- A single manikin was employed. It was stationary and its limbs did not move. 


\subsection{Research Objectives}

This study had the following objectives:

1. To experimentally investigate the effects of heating, breathing, posture, and hair style on concentrations at the mouth for an anthropometrically correct manikin.

2. To experimentally investigate the effects of heating, breathing, posture, and hair style on concentrations at other sampling locations and the ratios of concentrations to mouth for an anthropometrically correct manikin.

3. Use the results obtained from objective number 2 to determine the best surrogate sampling location that represent exposure at the mouth for the manikin.

4. To provide experimental results that can be used to validate the use of numerical simulations in exposure studies.

5. To provide experimental results that can be compared to human data to investigate the adequacy of a manikin as a surrogate subject to humans in exposure studies. 


\section{Chapter 2: Literature Review}

In personal exposure assessment, the concentration at the "breathing zone" is assumed to be equivalent to the concentration inhaled by a worker. Since sampling directly from the mouth or nose is considered uncomfortable, industrial hygienists have sampled elsewhere on the body in the belief that concentrations at those locations also were within the breathing zone. The boundary of the "breathing zone" has been defined by the National Institute for Occupational Safety and Health (NIOSH) as encompassing varying distances up to one meter (three feet) from the nose and mouth (NIOSH, 1973). The Occupational Safety and Health Administration (OSHA) considered the breathing zone to be a hemisphere forward of the shoulder with a radius of approximately 6-9 inches (CFR, 1985). Sampling at the collar or lapel is a common practice (NIOSH, 1973).

As will be discussed, there is no convincing proof in published literature that concentrations at the chest, collars, or lapels are representative of inhaled concentration. The limited research that has been done is discussed next.

\subsection{Studies comparing gas and vapor concentrations at the breathing zone of human subjects and simple manikin}

Fletcher and Johnson (1988) compared nose and lapel concentrations for a human subject and a manikin in an industrial environment. Sampling at the nose, left lapel, and right lapel, they found slight differences between samples at the lapel and the nose for a human subject seated at a table with a neutrally-buoyant source on the table. The manikin showed lower breathing zone concentration values than a human subject under the same conditions. When a denser than air source was substituted, they found that concentrations varied with sampling location with the concentration at the nose the lowest. Although Fletcher and Johnson used a anthropometric manikin, their manikin did not breathe nor was it heated. In addition, the experimental conditions were not defined clearly.

Welling et al. (2000) studied the dispersion of acetone from a low and moderate low "impulse" source in a uniform air stream flow. Concentrations were measured at 9 sampling locations (including nose level) infront of a human subject and unheated manikin. The effects of orientation and velocity of air flow, convection due to the human body, arm movement of a human being, and the type of source on the concentration gradients were studied. They tested the effects of facing, side, and back orientations to a cross-draft of $0.3 \mathrm{~m} / \mathrm{s}$. They found that concentrations were profoundly higher for the back orientation. They also tested the effects of arm movements and body heat for the back to flow orientation at $0.1,0.3$, and 0.5 $\mathrm{m} / \mathrm{s}$. They found that concentrations at the nose were higher for the human subject than the unheated manikin and were higher for arm movement than for a stationary human. However, neither of these results was statistically significant. 
According to Clark and Edholm (1985), the maximum air velocity induced by body heat at face level of a standing person is $0.3-0.5 \mathrm{~m} / \mathrm{s}$. They speculated that this convection flow would strengthen the upward reverse flow and the transportation of contaminant into the breathing zone. However, smoke tests showed that when a table was used and there was a gap between the body and the table, the vertical convection flow due to body heat transported uncontaminated air from below the table into the breathing zone, thereby diluting concentrations.

Guffey et al. (2001) used a manikin to study the effect of manikin orientation (back, side to, and facing), cross draft velocity $(10,22,47,80)$ and movement of manikin torso on three sampling locations within the breathing zone. The tracer gas used was undiluted $\mathrm{SF}_{6}$ at $0.1 \mathrm{l} / \mathrm{min}$. It was found that concentrations at the chest were 2.9 times the concentrations at the nose, with the ratio decreasing as wind tunnel velocity increased. They concluded that the ear was not a location to sample as there was a high variability in the ear concentrations as compared to the nose. Also, concentrations at all sample locations were 100-200 times higher for the back-to-flow orientation than for the side and facing orientations. Although the manikin used in their study was anthropometrically-scaled, it did not breathe nor was it heated. Also, the $\mathrm{SF}_{6}$ released was not neutrally buoyant, which could have had substantial effects on the results.

Malek et al. (1999) compared styrene samples taken at the nose, left lapel, right lapel, and chest of 21 workers who were spraying or rolling during boat building. They found that the average values at the nose ranged from $10 \%$ to $24 \%$ lower than samples taken at the lapels, with individual samples showing considerable variation. In addition, the ratio of nose to lapel concentrations varied by subject and by the task performed. They concluded that the variation in concentration within the breathing zone is affected by the distance between styrene source and the worker, the turbulent air flow in the breathing zone, "re-volatilization" of styrene from worker clothing and the average ventilation rate. They also found a clear correlation between concentrations measured at the chest and at the nose. However, Malek had his subjects wear bulky backpacks filled with sampling bags, thus potentially profoundly changing the air flow patterns near his subjects.

In a field study conducted by Martinelli et al. (1983), aerosol concentrations were measured simultaneously at the nose, lapel and forehead. They found considerable variability in concentrations at different sampling locations. However, the concentration at the lapel was higher than at the nose and forehead. They speculated that the discrepancies were due to resuspension of dust from clothing, the job performed, and individual work practice differences.

Cohen et al. (1982) measured exposures to styrene in a work place. They found that the concentration measured at the nose for an individual was about $76 \%$ of the level measured at the chest. However, Chatterjee et al (1969) investigated the lead concentrations in a lead acid electric accumulator (battery) factory by attaching two filter heads to the upper chest of the worker, one 5 inches below the other. The mean concentration obtained in the upper position was $22 \%$ less than the lower one.

In a study where beryllium was sampled in a workplace, Donaldson and Stringer (1980) observed that lapel samplers for beryllium gave results that are different from a composite of breathing zone and general area samples. Capodagali et al. (1980) conducted a 
field study on solvent sampling during a manual gluing operation in a shoe factory. Samples were collected with passive dosimeters placed at the right and left collars, mouth and nose, and at the forehead. They found that forehead concentrations were $25-80 \%$ lower than both collars.

Van Der Val et al (1984) in a field experiment for painters showed that right lapel concentrations on a right-handed painter were over $50 \%$ greater than their corresponding left lapel concentrations.

\subsection{Studies comparing the effects of source type, location and momentum}

Welling et al. (2000) studied the effect of source type (point or line source) and "momentum" 0.1 and $0.8 \mathrm{~m} / \mathrm{s}$ on the dispersion of acetone in the breathing zones of a human subject and an unheated manikin in a uniform air stream flow. The tracer gas used in their study was acetone. They found a 1\% higher concentration at the nose level with the line source than with the point source.

Kim and Flynn (1992) examined contaminant momentum, the presence of a flat plate downstream of the worker, the distance between contaminant source and the body, and the manikin's motion on concentrations at the mouth in a paint spray booth by using $\mathrm{SF}_{6}$ mixed with helium as a tracer gas. They found substantial reductions in mouth concentrations when the spray gun emitted contaminants with high momentum. Also, reductions of $30-50 \%$ in mouth concentrations were observed due to the effect of the distance from the source and worker's motion. They also developed mathematical relationships between concentrations at the mouth and contaminant source momentum. They used an unheated, non-breathing anthropometric manikins.

Kulmala et al. (1996) studied worker's exposure experimentally and numerically in the near-wake region of an unheated, non-breathing anthropometric manikin. The effect of contaminant source location on the worker's breathing zone concentration was examined by injecting almost neutrally buoyant $\mathrm{SF}_{6}$ (diluted to $2.8 \%$ with air) from 420 points in the wake region. The experiments were carried out using cross draft velocities of $0.25,0.375$, and 0.5 $\mathrm{m} / \mathrm{s}$. They found that the contaminant transport into the breathing zone depends strongly on the location of the release point. The airflow field was also determined numerically assuming a steady flow and using the standard k-e turbulence model. They also found that the mean recirculation length downstream from the manikin depended on free stream velocity and was 1.5 times the manikin width. They also observed that significant contaminant transport towards the breathing zone occurred only above the hip level.

George et al. (1990) tested a manikin (unheated, non breathing, half-sized) in a wind tunnel. They found that for the three cross-draft velocities tested $(0.51,0.76$, and $1.27 \mathrm{~m} / \mathrm{s})$, both the mouth and chest concentrations decreased with increasing velocity. For cases where the source was held in front of the manikin at waist height, concentrations were vastly lower than when the manikin faced upstream and sidestream than when it faced downstream. That suggests that worker exposures are dominated by the periods they face a downstream source unless the background concentration is very high. Finally, they found that the concentration at the mouth decreased exponentially with increasing horizontal distance from the manikin to 
the source. None of the findings gave a clue to the effects of sample location, source location, velocity, or cross-draft orientation on the ratio of mouth to lapel concentrations, but it is prudent to assume that all three variables could affect that ratio.

Flynn and George (1991) found greater exposure variability when the point source contaminant was located within the separated boundary layer than when the source was outside this region as one might expect. In another work George and Flynn (1990) studied the effect of source to manikin distance on concentration at the mouth location for a half-sized unheated manikin facing downstream. As the manikin source distance increased, a substantial reduction in $\mathrm{SF}_{6}$ concentration in breathing zone occurred especially as the source passed out of the separated region.

\subsection{Research work studying airflow patterns, wake length and width, boundary layer separation and modeling of breathing zone concentration}

Welling et al (2001) characterized the reverse flow zone created in front of a human being in a uniform flow using both experimental data and numerical simulation. Experiments were carried out by moving a point source of acetone vapor in front of the human subject and measuring the contaminant concentration at nose level in front of the subject. They found that the length of the reverse flow region was (0.9-1.4 m) with freestream velocities between 0.1 and $0.5 \mathrm{~m} / \mathrm{s}$ for a stationary human being. With the person moving his arms, the length of reverse flow fell to between $(0.5-1.2 \mathrm{~m})$ for the same velocities. In addition, numerical simulations were carried out to predict the length of reverse flow using the $k-\varepsilon$ turbulence model. Compared to experimental data, they found that the extent of the reverse flow region was predicted fairly well using numerical modeling.

Kim and Flynn (1991a) found the boundary layer separation to be an important factor in determining a worker's exposure to airborne contaminants. They developed a conceptual model to understand this phenomenon and to predict the average concentration in the reverse flow region downstream of a worker in a uniform freestream. Subsequently, the assumptions of this model were tested experimentally in wind tunnel studies. Based on these results, a revised model (Kim and Flynn, 1991b) was presented and validated using a tracer gas method. The revised model provided a reasonable estimate of the average concentration in the reverse flow region of the mannequin. Empirical models were presented that related both the average concentration in the reverse flow region and the mouth concentration to the body dimensions and the freestream air velocity.

Ojima (2003) investigated the reverse flow around a manikin's body produced by local exhaust ventilation when the contaminant source was located in the manikin's wake region using a clothed manikin. The exposure level and the contaminant leakage from the hoods in several conditions were measured by means of a smoke test and ethanol vapor used as a tracer gas. He found that the reverse flow could be visualized by the smoke in front of the standing manikin but could not be observed when the manikin was seated. Moreover, regardless of the hood type, the increase in the capture velocity was effective in decreasing 
exposure due to the reverse flow. The manikin used was unheated, non-breathing, and nonanthropometric but clothed.

Flynn and Ljungqvist (1995) studied wake effects on worker exposure and ventilation design using smoke visualization. They indicated the importance of flow visualization using smoke to detect and correct problems. Moreover, they pointed out that work practices are as important as ventilation design in controlling exposures. When sampling location and the source are in the wake zone, circulation patterns with the wake transports contaminant throughout its volume. If the source is in the hands and air is flowing from the back, then the face, lapel area, and hands were all within the wake zone. For flow from the side or front, none of these locations are in the wake. Thus, one would expect dramatically higher contaminant transport to the face and chest when the flow is from the back, as has been verified in other smoke visualization studies (Kim and Flynn, 1991a; 1991b; Guffey et al., 2001) that used a manikin holding a source in its hands.

Kim and Flynn (1991a) found that "chest" concentrations were approximately three times nose concentrations when the source was within the torso wake zone for unheated, non-breathing manikin. However, they were not measuring chest concentrations on the manikin, but rather at seven points on a plane in front of the manikin. In a smoke visualization study where vortex size was estimated, Kim and Flynn (1991b) found that the wake zone profile downstream of a manikin was not uniform. The wake zone was a much shorter distance downstream at the neck than at the hips. Furthermore, different air flow patterns prevailed in the head region than the chest region. Above the chest, a downwash over the top of the head was dominant, while for the chest to elbow region a combination of downwash and vortex shedding was important. Above the hip level the net airflow was directed upwards, while below the hip it was directed downwards.

Johnson et al. (1996) studied the air movement around a human and a manikin in a low speed flow field and suggested that a manikin selected for sampling studies should be heated, rounded shape, and clothed. However, Fletcher and Johnson (1996) and Homma and Yakiyama (1988) found no effect of breathing using a breathing and heated manikin placed in a uniform free stream while studying the flow field around the head and chest using laser Doppler anemometry. They found that exhalation breath did not break through the thermal boundary layer of the heated and breathing manikin they used.

Heist et al (2003) studied the effect of heating, breathing, and velocity on airflow patterns around a child-size manikin in a low-speed wind tunnel. They found that when the manikin was unheated the flow pattern on the downstream side of the manikin consisted of two slowly recirculating eddies. With the addition of body heat to the manikin (heated), the flow pattern downstream of the manikin changed to a rising vertical plume with velocities on the order of $0.1 \mathrm{~m} / \mathrm{s}$. This vertical plume was capable of transporting particulate matter into the breathing zone from near the floor. As the wind speed increased from 0.1 to $0.3 \mathrm{~m} / \mathrm{s}$, the vertical plume on the downstream side of the manikin was replaced by two recirculating eddies, a flow pattern similar to that with the unheated manikin. Although they used a childsize manikin, it was an anatomically correct physical model of human form, with movable joints and latex skin. The manikin tested was heated, breathed and was clothed.

Several studies have shown that natural convection due to body heat from humans can produce vertical velocities on the order of 0.1 to $0.25 \mathrm{~m} / \mathrm{s}$ in areas near the breathing zone. 
For instance, Melikov and Zhou measured profiles of vertical velocity as a function of the distance from the neck for a seated, clothed, heated, and anthropometric manikin. They found vertical velocities of $0.13 \mathrm{~m} / \mathrm{s}$ at $10 \mathrm{~mm}$ from the neck and $0.04 \mathrm{~m} / \mathrm{s}$ at $50 \mathrm{~mm}$ from the neck. They also introduced an "invading" flow from behind the manikin with velocities in the range form 0.1 to $0.3 \mathrm{~m} / \mathrm{s}$. This invading flow reduced the strength of the natural convection and thus the vertical velocity by one half.

The wind speeds experienced by people in indoor environments are important when investigating personal exposures. For example, Baldwin and Maynard (1998) reported that wind speeds in homes and offices are usually between 0.05 to $0.1 \mathrm{~m} / \mathrm{s}$. However, when industrial work environments were considered, the averaged wind speeds increased to 0.3 $\mathrm{m} / \mathrm{s}$. They also reported that average values of personal wind speed distributions were approximately $0.05 \mathrm{~m} / \mathrm{s}$ higher than measurements from static anemometers.

\subsection{Research work studying the effect of manikin breathing and heating}

Cermak et al (2002) studied the interactions between the free convection flow around a human body, the flow of respired air, personalized supply airflow, room airflow, and their effects on the quality of inhaled air using a two dimensional Particle Image Velocimeter (PIV). The manikin used to simulate human being was breathing, heated, clothed and wore a wig. The results showed that the personalized supply airflow was able to penetrate the free convection flow and reach directly the face of the manikin. A large velocity gradient was observed at the manikin's face with a maximum air velocity of $0.2 \mathrm{~m} / \mathrm{s}$.

Bjorn (2002) used Computational Fluid Dynamics (CFD) to simulate the effects of breathing in ventilated rooms. He found that CFD is capable of simulating the effects seen in physical experiments in a satisfactory manner. He tested the density of expired air at three combinations of exhalation temperature and mass flow rate $\left(28,35,35^{\circ} \mathrm{C}\right.$ and $3.77,3.77,2 \mathrm{x}$ $10^{-4} \mathrm{~kg} / \mathrm{s}$ ) and corrected the model to overcome inaccuracy regarding the density of the exhaled air based on exhalation temperature. He found that results were not sensitive to density variations. The interaction between the exhalation flow, other air flows generated by the human body, and the air flow patterns in displacement ventilated rooms have been investigated in other work by Bjørn and Nielsen (2002).

Bjørn and Nielsen (1996a) used CFD to investigate the effects of pulmonary ventilation rate, convective heat output, exhalation temperature, and cross sectional exhalation area on personal exposure. Experiments showed that exhalation from one person was able to penetrate the breathing zone of another person at a distance. In these experiments, two breathing thermal manikins were used: manikin no. 1 acted as contaminant source, breathing directly towards the face of manikin no.2. Tracer gas $\left(\mathrm{N}_{2} \mathrm{O}\right)$ was added to the exhalation, and manikin no. 2 was used for measuring personal exposure. Manikin no.1 exhaled through either its nose or mouth. Different distances between the two manikins were tested. Breathing was simulated by steady-state CFD with reasonably good results. The simulations showed that personal exposure was very sensitive to variations in the convective heat output (body heat) of both the exposed person and the exhaling person, the cross sectional area of nostrils, and the pulmonary rate of the exhaling person. They found that when exhalation air was heated, a substantial influence on buoyancy was seen. Exhalation 
did not follow the manikin's own convective airflow, however, it formed its own independent flow which penetrated the other manikin's breathing zone.

Bjørn and Nielsen (1996b) experimentally investigated in a displacement ventilated room. They found that exhalation from one person penetrated the breathing zone of another person placed nearby, thus leading to higher exposures. When two persons are placed close to each other, convective boundary layer flow interacted in such a way that the personal exposure to an ambient concentration field was altered. They used two breathing thermal manikins. The fresh air supply rate was $160 \mathrm{~m}^{3} / \mathrm{hr}$. For the set of experiments conducted they found that when the manikins were facing each other, interaction can take place. Horizontal distance and inclination are important parameters. If exhalation was directed towards the back, higher exposures do not occur. In the case of two persons standing close together, the exposure to ambient concentration was not altered.

Brohus (1997) presented personal exposure measurements by means of a breathing thermal manikin (BTM) developed at the Technical University of Denmark. The manikin was $1.7 \mathrm{~m}$ high anatomically correct female display manikin. The BTM wore tight-fitting clothes with an insulation value of 0.8 clo. Respiration was simulated by means of an artificial lung. Contaminant concentrations were measured at chest, front of the mouth, above the head, and in the inhaled air. For the manikin placed in a uniform flow field, he found considerable deviations from inhaled for concentrations measured in front of the head and above the head. However, concentrations measured at the chest had modest deviations from inhaled.

Divisions of the sensible heat loss from the body surface into convective and radiative heat transfer rates were developed based on experimental findings (Colin et al., 1967; Ichihara et al., 1997) using a thermal manikin. Yang et al. (2002) studied the influences of wind velocity, sensible heat loss, arranged furniture, and posture on local convective heat transfer coefficient (alpha). They concluded that the local convective heat transfer coefficient (alpha) was greatly influenced by wind velocity and slightly affectd by sensible heat loss. In addition, the value of (alpha) decreased as the manikin body approached the arranged furniture. This was clear at the feet, lower legs, thighs, hands, forearms, and upper arms of the manikin. In addition, the value of (alpha) for some parts such as the feet, lower legs, thighs and hands was affected by posture even when the sensible heat loss was constant.

Silva and Coelho (2002) studied local heat transfer coefficients for different body parts in a wind tunnel using a thermal naked manikin. Tests were performed at three flow orientations (front, side, and back), for two postures (seated and standing), and for the velocity range of 0 to $4 \mathrm{~m} / \mathrm{s}$. They concluded that peripheral parts of the body have higher heat losses than central parts. On the other hand, the head had the lowest convective heat transfer coefficient, probably due to the shielding effect of hair.

\subsection{Summary and Conclusions from the Review of Literature}

Literature relevant to this study was reviewed in Sections 2.1 to 2.4. Important variables considered in published studies included use of human, manikins, or simplier shapes, cross-draft velocity, body heat, breathing, posture and hair style. The only studies using human subjects were Malek et al. (1999), Martinelli et al. (1983), and Cohen et al. 
(1982). Malek found moderate differences between locations (e.g. roughly 20\%), while Cohen found that lapel samples do not represent actual inhalation exposure due to the resuspension of dust from clothing. Malek did not record cross-draft velocities or other environmental data, making comparisons to manikins difficult, while, Martinelli had his human subjects wore a large back pack during sampling that might have influenced the air flow patterns around workers.

Previous works on the flow and transport of aerosol around humans had used adult sized manikins (Rodes et al. 1995; Johnson et al. 1996; Melikov and Zhou 1996; Murakami et al. 1996; Brohus et al. 1997). Only Brohus (1997) and Heist (2003) used manikins that were clothed. None compared clothed to unclothed manikins. Only Fletcher and Johnson (1996) and Heist (2003) had manikins heated to simulate humans. They compared heated and non-heated manikins and concluded that heating changed the airflow patterns around the manikin and has substantial effect at low velocity ranges. Therefore, simulating body heat is important when the manikin is used as surrogate to human.

Studies considering the effect of body geometry on breathing zone concentrations (Brohus, 1997; Li et al., 2003; 2005) were not done experimentally, however, they were done numerically using CFD. For example, Li et al. (2005) found that rounded body shape (closest approximation to human body) resulted in much lower concentration levels than over simplified bodies. While, studies considered the use of a manikin holding a source in its hands (Guffey, et al 2001; Kim and Flynn, 1992; George et al, 1990; Welling et al, 2001) found dissimilar results when the source located within wake zone than outside the wake zone. Studies investigated the effects of cross draft velocities on air flow patterns around a worker (Fletcher and Johnson, 1996; Kim and Flynn, 1992; Kulmala et al, 1996; Welling et al, 2001; Heist et al, 2003) and found that recirculation length downstream the manikin (wake zone) depended on cross draft velocities and can be estimated using manikin dimensions. Therefore, velocity is important and is studied at different levels that are currently found in industrial environment.

Limited research had been conducted on the effect of movement (Ljungqvist, 1979; Guffey, 2001, Welling, 2000) on breathing zone concentrations of a manikin or human. It was concluded that movement tended to disperse contaminant more erratically and towards the mouth level. However, other study authors found no effect of movement on breathing zone concentrations. On the other hand, Fletcher and Johnson concluded that breathing did not break through the boundry layer developed by body heat, suggesting that breathing may not be important when simulating a human using a manikin. However, it diluted and caused dispersion of concentrations at the vicinity of mouth and interacted with the breathing zone of another close person. Therefore, simulating breathing is important for a manikin acting as a surrogate for humans.

Limited research was conducted for the effect of posture on sampling location in the breathing zone of manikin as studied by Brohus (1997). However, posture is important and had substantial effects on breathing zone concentrations and should be considered as part of the activities performed in work environments. No research has been conducted on the effect of hairstyle on breathing zone concentrations. However, Silvia and Coelho (2002) found that hair affected body heating and reduced heat loss from the head of the manikin. Therefore, attaching a wig to the manikin's head is an important feature in this study. 


\section{Chapter 3: Research Design, Methods, Apparatus and Procedures}

\subsection{Research Design and Methods}

The dependent variables for this study were: 1) concentrations measured simultaneously at several locations on the torso and head of a single, anthropometrically-correct manikin, and 2) the ratios of concentrations at other locations to the concentration measured at the mouth (see Figure 3.1). The sampling locations for the study are all either currently used in practice or could be used (see Table 1). Currently used positions are the left and right collar and the left and right lapels.

Sometimes sampling inlets are actually well below the collars and lapels, hence the selection of the center chest location. The forehead has been

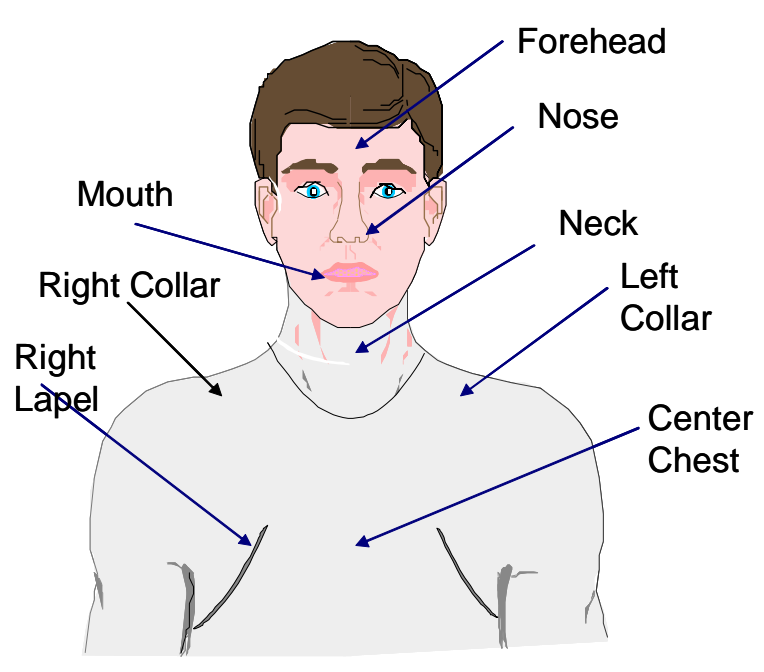

Figure 3.1: Sampling Locations proposed as a sampling location by Cohen et al. (1982). The mouth location represents true "inhaled" concentrations. The adjacent nose position would be expected to be nearly the same as the mouth but somewhat more convenient for sampling. Sampler positions in front of the ear and on top of the shoulder were studied and rejected by Guffey et al. (2001) as they found concentrations there to be both erratic and substantially $(\sim 70 \%)$ lower than samples collected at the mouth. 
Table 3.1: Description of Surrogate Sites

\begin{tabular}{lll}
\hline \multicolumn{1}{c}{ Anatomical Location } & Label & $\begin{array}{c}\text { Currently used } \\
\text { by IHs }\end{array}$ \\
\hline On the orbital midline $2 \mathrm{~cm}$ above the brow ridge & Forehead & No \\
$0.5 \mathrm{~cm}$ laterally from nasal orifice & Nose & No \\
At the mouth $3 \mathrm{~cm}$ from the right of the lip & Mouth & No \\
Sternoclavicular region & Neck & Sometimes \\
Right mid-clavicle & Right Collar & Often \\
Left mid-clavicle & Left Collar & Often \\
$4^{\text {th } \text { intercostal space on the right mid-clavicular line }}$ & Right lapel & Often \\
Mid point of left and right lapel & Center Chest & Often \\
$4^{\text {th } \text { intercostal space on the left mid-clavicular line }}$ & Left lapel & Often \\
\hline
\end{tabular}

The independent variables were binary (i.e., present or absent) for breathing, heating, posture, and wig as well as 5 levels of continuous variable, wind tunnel velocity. Two studies were conducted with each having full factorial designs. Some independent variables were common and others not (see Table 3.2). For the second study, the unheated condition was not used since heating was found to be important in Study I (see Results) and is more lifelike than non-heating. 
Table 3.2: Levels for Independent Variables for Each Study

\begin{tabular}{lll}
\hline \multicolumn{1}{c}{ Condition } & \multicolumn{1}{c}{ Study I } & \multicolumn{1}{c}{ Study II } \\
\hline \hline Cross Draft velocity (fpm) & $11,27,48,82,104$ & $11,27,48,82,104$ \\
Body Heat & unheated, heated & Heated \\
Hair Style & molded hair & molded hair, wig \\
Nose Breathing & no breathing & no breathing, breathing \\
Posture & Standing, seated & Standing, seated \\
\hline
\end{tabular}

There were two replications for each combination of independent variables. The significance of the independent variables and their interactions for each study were analyzed using Data desk (Odessa, NY) statistical software.

The fixed conditions of this study included the use of one anthropometrically-correct manikin wearing summer clothes. The manikin was stationary and none of its limbs were moved during a test. For all tests, the manikin's hands were placed on each side of the tracer gas source (a 9 inch pie-pan) in a manner intended to simulate light assembly work. The manikin was placed in the middle section of wind tunnel with its back oriented to the cross draft velocity (see Figure 3.5). Ambient temperatures could not be controlled tightly and varied somewhat $(72-77 \mathrm{~F})$.

Body posture (seated and standing) was included in this study for two main reasons: 1) postures are commonly found in work environments, and 2) the orientation of legs and arms to cross draft is perpendicular in the standing position and parallel in seated positions. Thus, it is plausible that body posture will affect air flow patterns around the manikin and hence change concentration gradients with in the breathing zone.

\subsection{Apparatus}

The apparatus consisted of the manikin and the features that were added to it, the sampling system, the tracer gas release system, the tracer gas concentrations measurement system, apparatus used to measure environmental conditions, and the wind tunnel and its related apparatus.

\subsubsection{Manikin}

The current manikin is a 66" high, anthropometrically scaled (including facial features and short hair) male with hollow cavities in the head, torso, legs and arms as shown in

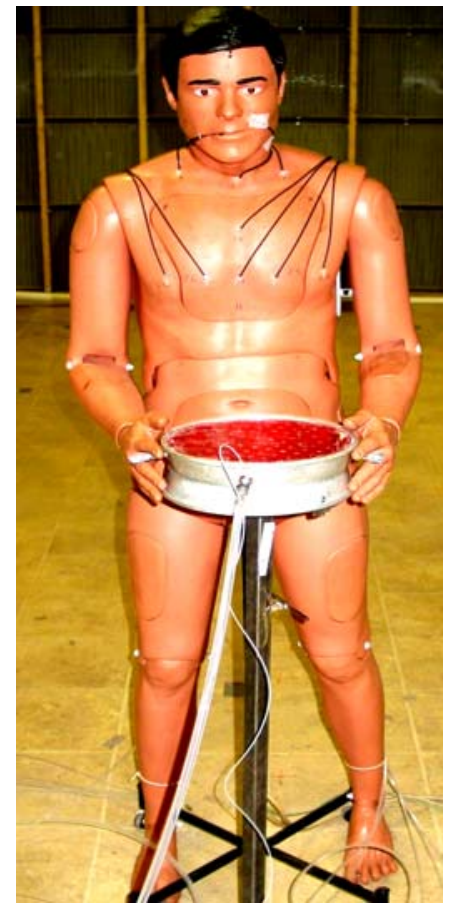

Figure 3.2: Test Mannikin 
Figure 3.2. It has a rubber skin that feels reasonably like real skin. The manikin has joints in shoulders, hips, and knees. This enables it to stand, sit and to move like on bicycle with the energy of movement supplied from outside. As shown in Table 3.3, the manikin dimensions match with $50^{\text {th }}$ percentile for women and $5^{\text {th }}$ percentile for men.

Table 3.3: Anthropometric Data in mm for US Adults Aged 19-60 Years According to (Gordon et al., 1989, cited in Kroemer and Grandjean, 1997)

\begin{tabular}{lcccc}
\hline & \multicolumn{3}{c}{ Women/Men } & Manikin \\
\hline Dimensions (mm) & 5 th & $50^{\text {th }}$ & 95 th & \\
\hline \hline Stature & $1528 / 1647$ & $1628 / 1755$ & $1737 / 1867$ & 1626 \\
Eye Height & $1415 / 1528$ & $1515 / 1633$ & $1621 / 1743$ & 1473 \\
Shoulder Height & $1241 / 1342$ & $1332 / 1442$ & $1432 / 1546$ & 1334 \\
Elbow Height & $926 / 995$ & $997 / 1072$ & $1074 / 1153$ & 1016 \\
Finger Tip Height & $531 / 591$ & $610 / 653$ & $670 / 716$ & 597 \\
Shoulder breadth & $333 / 367$ & $363 / 397$ & $391 / 426$ & 356 \\
(biacromial) & & & & 178 \\
Head Length & $170 / 179$ & $181 / 190$ & $191 / 201$ & \\
Head Breadth & $141 / 148$ & $151 / 158$ & $160 / 168$ & \\
& & & & \\
\hline
\end{tabular}


Heating the manikin head and torso skin to simulate body heat of humans was done by placing lengths of heated wires within the torso and the head and energized them with 90 watts of power to produce nearly uniform skin temperatures on the head and torso. By trial and error, we achieved the uniformity by: 1) adjusting the fraction of the wire in the head and in the torso, and 2) adding insulation at selected locations within the cavities. A picture of manikin chest with the heating wire on is shown in the following Figure 3.3. The average skin temperature for the manikin during experiments was ranged from 33 to $37^{\circ} \mathrm{C}$.

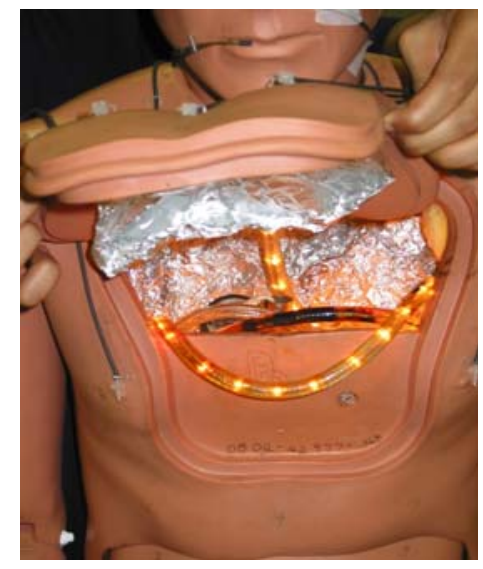

Figure 3.3: Wire used for heating
Clothing the manikin as shown in Figure 3.4 was done with loose-fitting pants and a summer weight shortsleeved shirt ("trim").

Clothing insulation assumed to be 1.0 clo. The manikin was either "bald" or wearing a wig with medium hair style of 2 inch long.

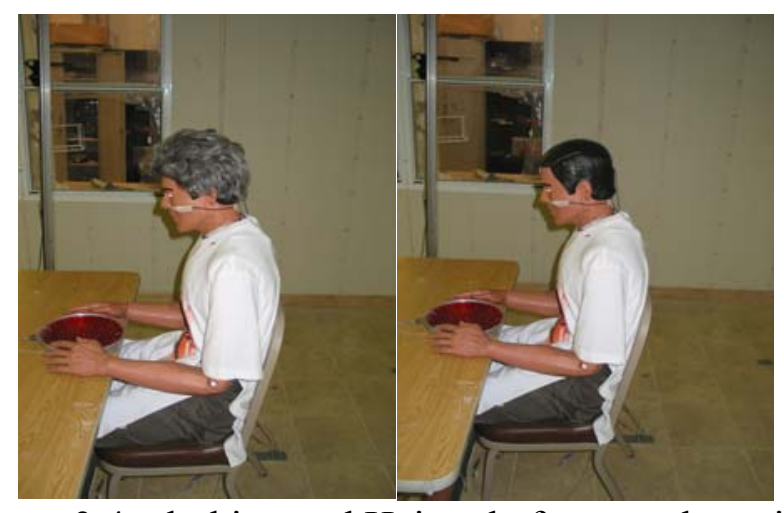

Figure 3.4: clothing and Hairstyle for seated manikin

Breathing by the manikin was simulated using an artificial lung as shown in Figure 3.5. The lung had a maximum volume of 1 liter and simulated the breathing of an average sedentary person performing light physical work. The adjusted breathing cycle consisted of inhalation (2.0s) and exhalation (2.0s). The frequency of exhaled/inhaled air for sedentary activity ranged $10-20$ per minute which gave a pulmonary ventilation rate of $10-20 \mathrm{lpm}$ (Christensen, 1964, cited in Kroemer and Grandjean, 1997). During experiments, pulmonary ventilation ranged from 16 to 18 lpm. While, Figure 3.6 illustrates a schematic diagram of the artificial lung and its breathing circuit. The lung breathing rate was adjusted by a lever. A compressed air piston assembly drew air in and expelled the same air through 1"

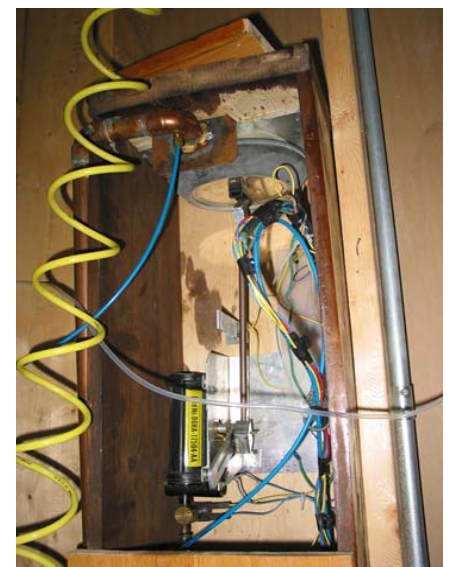

Figure 3.5: Artificial lung diameter Teflon ${ }^{\mathrm{TM}}$ tubing. The average exhaled breath temp was 96-98 F. As shown in Table 3.3, metabolism, respiration, heart rate and temperature varry as functions of work load (Christensen, 1964, cited in Kroemer and Grandjean, 1997). 
Table 3.4: Metabolism, Respiration, Temperature, and Heart Rate as Indications of Workload (Christensen, 1964, cited in Kroemer and Grandjean, 1997)

\begin{tabular}{lcccc}
\hline $\begin{array}{c}\text { Assessment of } \\
\text { work load }\end{array}$ & $\begin{array}{c}\text { oxygen } \\
\text { consumption } \\
\text { (liter/min) }\end{array}$ & $\begin{array}{c}\text { lung ventilation } \\
(\mathrm{lpm})\end{array}$ & Rectal Temp.C & $\begin{array}{c}\text { Heart rate } \\
\text { (pulse/min })\end{array}$ \\
\hline $\begin{array}{l}\text { Very low } \\
\text { (resting) } \\
\text { Low }\end{array}$ & $0.25-0.3$ & $6-7$ & 37.5 & $60-70$ \\
Moderate & $0.5-1.0$ & $11-20$ & 37.5 & $75-100$ \\
High & $1.0-1.5$ & $20-31$ & $37.5-38.0$ & $100-125$ \\
Very High & $1.5-2.0$ & $31-43$ & $38.0-38.5$ & $125-150$ \\
Extremely High & $2.4-4.0$ & $43-56$ & $38.5-39.0$ & $150-175$ \\
& & $60-100$ & over 39 & over 175 \\
\end{tabular}

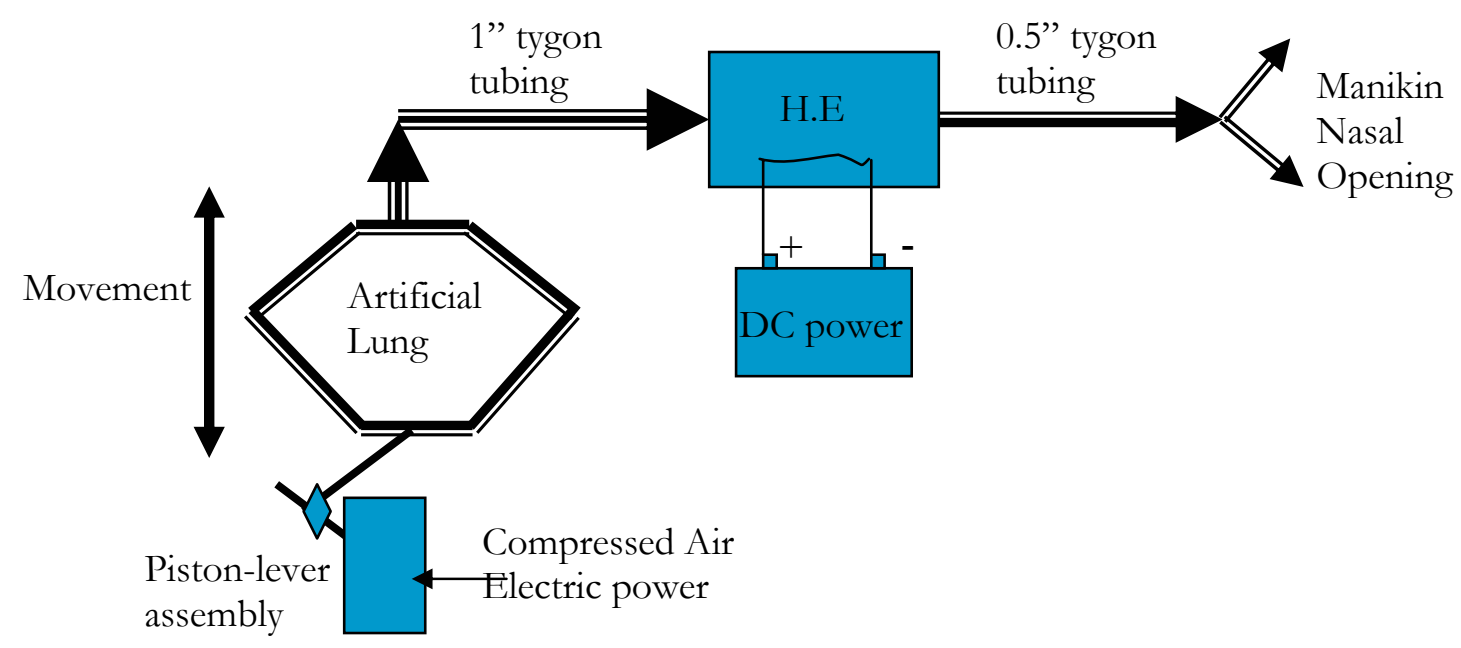

Figure 3.6: Schematic Flow Diagram for the Breathing Circuit 


\subsubsection{Wind tunnel}

The wind tunnel had no reducing section and was relatively short compared to its length as shown in Figure 3.7. The wind tunnel was equipped with upstream and downstream HEPA filters and downstream activated charcoal filter panels. The working section (between the HEPA filters) was $32 \mathrm{ft} \mathrm{long,} 12 \mathrm{ft}$ wide, and $9 \mathrm{ft}$ high. The manikin was tested at the middle of the wind tunnel, thus keeping a distance of nearly $4 \mathrm{ft}$ from each wall. The combined cross-section of the full sized tables with chairs and the manikin blocked less than $15 \%$ of the wind tunnel cross-section. Ethanol was removed by over $300 \mathrm{lbs}$ of activated charcoal before air exits wind tunnel cross section to the fan.
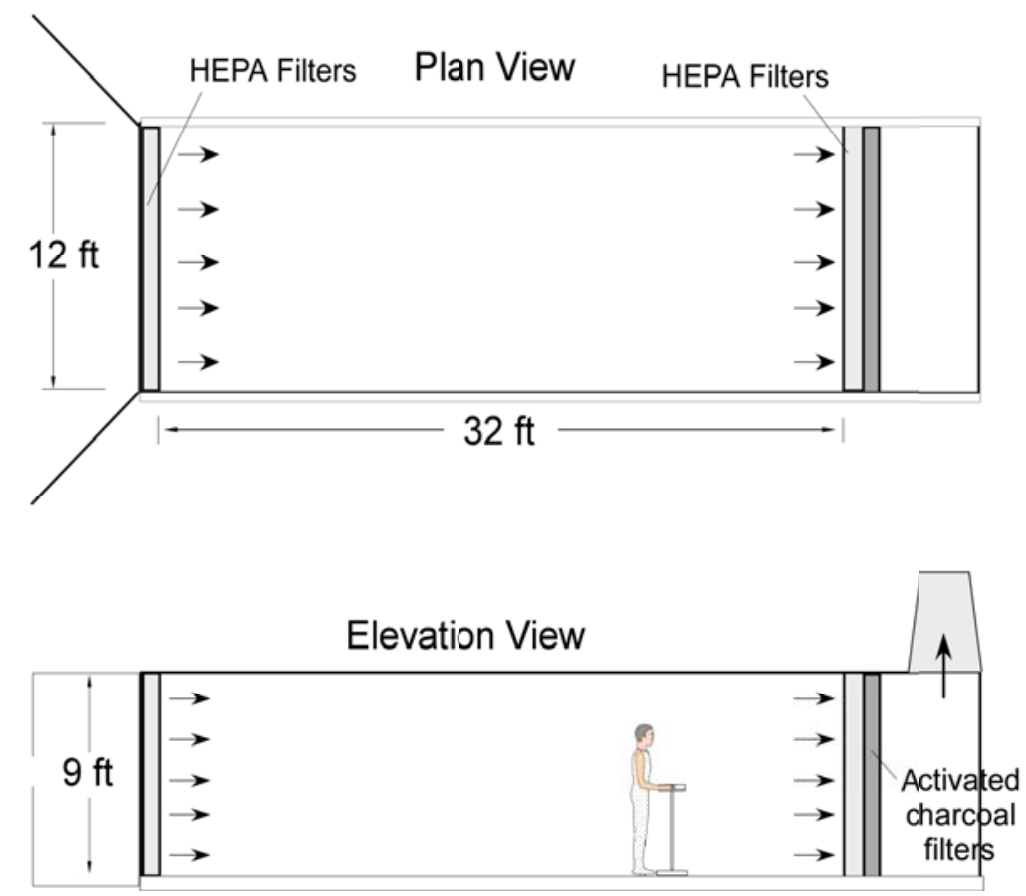

Figure 3.7: Wind Tunnel

To reduce thermal buoyancy effects due to different temperatures at the floor and ceiling, the floor of the building was covered by 0.75 " styrene foam insulating sheet, which was overlaid by $1 "$ plywood sheet and linoleum floor covering. Infrared thermometry had found temperatures in the air and at the walls, ceiling and floor to be within $2{ }^{\circ} \mathrm{C}$ winter and summer.

Repeated rounds of constant temperature anemometry (CTA) measurements taken at 6 " intervals vertically and 12 " intervals horizontally found a coefficient of variation of $10 \%$ for velocity along the axis of the wind tunnel. The turbulent intensity ranged up to $15-20 \%$ near the ceiling and was 3-5\% in the middle section where the manikin stands. The wind tunnel fan was controlled by a variable frequency drive allowing a range of wind tunnel velocities of 10 to $155 \mathrm{ft} / \mathrm{min}$. 


\subsubsection{Temperature, humidity and barometric measurements}

Temperatures of surfaces were measured with an infrared thermometer (Oakton, model number EW-35629 with accuracy of $\pm 1 \%$ or \pm 1 deg C and repeatability of $\pm 0.5 \%$ or \pm 1 deg $\mathrm{C}$ of full scale). Multiple points were measured on the manikin's head and torso and on the wind tunnel walls, ceiling, and floor. Air temperatures were measured with a calibrated dry bulb thermometer. Humidity was determined from a standard sling psychrometer, and barometric pressure was measured with a standard laboratory mercury barometer.

\subsubsection{Gas and vapor sampling apparatus for wind tunnel studies}

Samples were drawn from each sampling probe on the manikin in separate Teflon ${ }^{\mathrm{TM}}$ sampling lines. Each sampling line started with a $1 / 8$ " polypropylene probe pinned to the manikin's shirt or taped to the manikin face with tape. Each probe connected to roughly $4 \mathrm{ft}$ of $1 / 8$ " Teflon ${ }^{\mathrm{TM}}$ tubing, which ran over the shoulder to the small of the back. There each line connected to 0.25 " Teflon ${ }^{\mathrm{TM}}$ tubing, which run to the inlet port of a SKC Air-Check low-flow sampling pump and from the pump's outlet port to a $3 \mathrm{~L}$ Teflon ${ }^{\mathrm{TM}}$ sampling bag. The sampling pumps were calibrated with a BIOS International "Dry-Cal" (DCL-ML Rev 1.08) to a flow rate of $0.15 \mathrm{~L} / \mathrm{min}$.

All locations were sampled simultaneously for 22 minutes for each condition. After the first 7 minutes the bags were flushed with the same concentrations as that of correct exposure. Sampling then continued for 15 minutes. Within 2 hours, the concentration of ethanol and air mixture in each bag was analyzed using Voyager gas chromatograph with a photo ionization detector (PID). Before analysis, samples collected from the source were diluted until the expected level was about $50-60 \mathrm{ppm}$. The calibration of the PID sensor was verified every day of use by withdrawing ethanol head space air with a micro syringe and injecting it into a Teflon ${ }^{\mathrm{TM}}$ bag pre-filled with $2.4 \mathrm{~L}$ of clean air.

Leaks and other problems: Leaks and adsorption in the sampling pumps, tubing, and bags were measured by attaching bags filled with known concentrations of the tracer gases to a given sampling probe and drawing the air into sampling bags downstream of the sampling pumps. Losses of ethanol vapor to the plastic tubing and bags were reduced to about $5 \%$ by using Teflon ${ }^{\mathrm{TM}}$ lines and bags and by pre-treating the lines and bags for 7 minutes. This was done by the simple expedient of dumping the first 7 minutes of collected sample without flushing with clean air.

\subsubsection{System for Generation and dispersion of tracer gas mixtures}

Ethanol was injected by a Cole-Parmer syringe pump (74900 series) into a chamber through which $1 \mathrm{~L} / \mathrm{min}$ of nitrogen flowed. The ethanol dripped onto an electrical resistor energized by 10 watts of power from a regulated DC power source. The resistor was wrapped with aluminum foil to enhance evaporation, which appeared to be nearly instantaneous. The nitrogen flowrate was regulated and measured by an AALBORG mass flow meter (GFM171 flow range $0-1000 \mathrm{ml} / \mathrm{min}$ ). The mixture was carried by 0.25 inch Teflon ${ }^{\mathrm{TM}}$ tubing to a 9" diameter, 1" deep aluminum pie-pan that served as a contaminant source. An acrylic cover 
was glued "air-tight" to the pie-pan and drilled with 99 one-eigth inch diameter holes that were uniformly dispersed across the acrylic cover. The tracer gas mixture passed from the Teflon ${ }^{\mathrm{TM}}$ tubing to a connection fitted to the sides of the pie-pan and from there through the holes in the acrylic cover. The exit velocity through the $1 / 8$ " holes was less than $1 \mathrm{ft} / \mathrm{min}$. Extensive testing showed excellent repeatability (95\% withinin source concentrations). The sampling bags used for testing the high source concentrations were not used for exposure sampling. Each bag filled about 2L during sampling. After sampling, the bag contents were analyzed, then the bags were purged and flushed with clean air and held in readiness for reuse in the next day of sampling.

\subsubsection{Gas and vapor analyses}

Analysis of ethanol/air mixtures was performed using Photovac Voyager gas chromatograph (GC) equipped with a photo-ionization detector (PID), each calibrated using headspace techniques to create a known concentration in a Teflon ${ }^{\mathrm{TM}} \mathrm{bag}$.

\subsection{Procedures}

Procedures for exposure sampling are:

- $\quad$ Sampling system preparation prior to experiment runs

- $\quad$ Setting up the tracer gas release system

- Adjustment of fan speed and measurement of environmental conditions

- $\quad$ Preparation of the manikin

- $\quad$ Sampling procedures

- Analysis of ethanol sampling bags

- Calibration of Voyager Gas Chromatograph.

\subsubsection{Sampling system preparation prior to experiment runs}

1. Teflon ${ }^{\mathrm{TM}}$ bags required for sampling were purged by injecting 2 liters of ambient air into them using a 3 liter manual syringe pump.

2. The Teflon ${ }^{\mathrm{TM}}$ bags were then gently tapped to mix the clean air uniformly and left inside a laboratory hood for 5 minutes.

3. The Teflon ${ }^{\mathrm{TM}}$ bags were then tested for leaks by immersing them fully in a water bath and observing the escape of air bubbles, if any.

4. Inside the lab hood, the Teflon ${ }^{\mathrm{TM}}$ bags were manually rolled and pressed to empty them. 
5. Labels identifying sampling location, wind tunnel velocity and date and time of the run were stuck to each bag

6. Teflon ${ }^{\mathrm{TM}}$ bags were connected to the exhaust port of the sampling pumps.

7. Liquid ethanol was poured into a $125 \mathrm{ml}$ glass vial inside the lab hood.

8. Low flow pumps were calibrated prior to use.

9. The wind tunnel conditions (temperature, humidity, barometric pressure) were measured.

10. Connectors were mated to sampling pumps inlets and outlets, Teflon ${ }^{\mathrm{TM}}$ sampling bags, the sampling lines, and the mixing chamber

\subsubsection{Setting up the tracer gas release system}

1. Nitrogen was allowed to flow through 2-stage regulator to a rotameter followed by mass flowmeter. The Rotameter knob was adjusted until the mass flow meter read a nitrogen flow rate of $1 \mathrm{lpm}$.

2. The power supply to the aluminum foil wrapped resistor was adjusted to 6Volts and 1.5 Amperes.

3. A $10 \mathrm{ml}$ ethanol syringe was filled with liquid ethanol placed into the syringe pump. A tube attached to the end of the ethanol syringe was connected to the mixing chamber and adjusted such that the liquid ethanol droplets would directly fall on the aluminum wrapped foil resistor placed inside the mixing chamber.

4. The ethanol syringe pump flow rate was adjusted at $0.071 \mathrm{ml} / \mathrm{min}$. When mixed with $1 \mathrm{lpm}$ of $\mathrm{N}_{2}$, this produced a source concentration of $30,000 \mathrm{ppm}$. If $\mathrm{N}_{2}$ was replaced with air, that concentration would be equal to $80 \%$ of the lower explosive limit (LEL) for ethanol.

\subsubsection{Adjustment of fan speed and measurement of environmental conditions}

1. The wind tunnel velocity was set to the desired value by adjusting the fan controller to the predetermined RPM.

2. The ambient temperature and humidity inside and outside the wind tunnel were recorded.

3. The barometric pressure inside wind tunnel lab was recorded. 


\subsubsection{Preparation of the manikin}

The procedures varied slightly by posture and illustrated as follows:

\section{A. Unheated Standing}

1. Clothing (T-shirt and pants) were fit on the manikin chest, torso, and legs using Velcor ${ }^{\mathrm{TM}}$.

2. The manikin was placed in standing posture in the middle cross sectional area of the wind tunnel with its back oriented to the cross draft velocity. The source was placed over a source stand infront of the manikin within arm's reach.

3. Sampling lines and probes were pinned to the manikin's skin for chest and upper torso sampling locations. Probes on the face were placed with skin tape.

4. The $1 / 8$ " portion of the sampling lines were spread and taped along the back of the manikin in a uniform manner to present the least distortion to the airflow around and near the manikin.

5. The placement of the manikin in the middle section was verified by measuring the distances to the front and side walls of the wind tunnel using a measuring tape.

6. The distance from the floor level to each sampling locations were measured. The horizontal distance from the center of the source pan to the manikin's naval was measured. The source height was adjusted to be leveled with the manikin's naval.

7. The manikin was checked visually for any twists in chest or torso and was readjusted, if necessary, before sampling to ensure orthogonal orientation to cross drafts.

\section{B. Activate Heating}

1. The heating wire was cheked visually to ensure the uniform distribution inside the manikin's head and torso cavities and was readjusted, if necessary, before activating the heating wire.

2. The wire was activated by connecting the power cord to the power supply.

3. Two hours were allowed for electric heating to establish the desired manikin skin temperature $\left(33\right.$ to $\left.37^{\circ} \mathrm{C}\right)$.

4. The manikin skin temperature was recorded using the infrared thermometer which was pointed on each sampling location and to other locations marked at the back of the manikin.

5. The temperatures of the manikin, side walls, floor, source, and ceiling were measured and recorded in a spread sheet.

6. Pictures of the manikin (standing or sitting) inside the wind tunnel were taken using a digital camera. 
7. Then, wind tunnel doors were closed and the system was allowed to stabilize for 10 minutes, then sampling started.

8. Each day before sampling on the heated manikin, the heating wire (made of small tiny christmass bulbs) was checked visually for any burned bulbs. If so, the wire was replaced with brand new one.

\section{Sitting Posture}

1. Manikin stand was removed one day before sampling to change manikin posture from standing to sitting position.

2. The manikin was placed on a chair in the middle cross sectional area of the wind tunnel with its back oriented to cross draft velocity. The manikin was clothed with the same T-shirt and pants.

3. A table was placed in front of the manikin. The source pan was placed over the table with its edge leveled horizontally with the manikin naval.

4. Experiments were performed using the same procedures mentioned in the above sections A \& B.

\section{Attaching the wig}

5. Wig hair was combed by a brush

6. The wig was placed over the head of the manikin with its edge just $2 \mathrm{~mm}$ above the forehead sampling probe.

\section{E. Activating Breathing}

1. Manikin breathing was controlled from the outside of the wind tunnel.

2. The breathing circuit (breathing tubes and connectors) was checked visually.

3. To switch on breathing, compressed air supply was connected to the breathing machine which was mounted on the outside wall of the wind tunnel.

4. The power cord of the breathing machine was connected to the power supply.

5. When breathing was on, the piston lever assembly was pushing the diaphragm of the artificial pump. Green and red lamps (fixed on the board) were lit indicating inhalation and exhalation cycles.

6. The breathing machine pressure was adjusted to 9 psi. This was equal to a pulmonary ventilation of 15-20 lpm that was required to simulate breathing for a person in sedentary activity.

7. The breathing machine was left running for 10 minutes to stabilize the pulmonary rate.

8. A stop watch was used to record the number of breathing cycles per minute (frequency) which was found to be $17 / \mathrm{min}$ 
9. The exhaled breath temperature was measured and recorded at the nostrils of the manikin using mercury lab thermometer.

\subsubsection{Sampling procedures}

1. All sampling pumps were switched "ON"

2. A final visual check on manikin: holding source, centered position inside wind tunnel, any twist in arms or shoulder in seated or standing posture.

3. The wind tunnel doors and windows were sealed for leaks using plasters. The plasters were checked visually for being on place.

4. Heating was activated as mentioned in section B.

5. Breathing was activated as mentioned in section E.

6. The wig was attched as mentioned in section D.

7. There was a 5-minute period before starting the sampling pumps, to allow steady state of wind tunnel velocity and develop of background concentration in the wind tunnel.

8. Sampling bags were "opened" and then attached to the appropriate sampling lines, outside the wind tunnel.

9. The bags were allowed to be filled for a period of seven minutes.

10. At the end of 7 minutes, the bags were disconnected and emptied by means of a compressed air vacuum system. This was done to 'pre-treat' each sampling bag.

11. The Teflon ${ }^{\mathrm{TM}}$ bags were then re-attached to the pumps and allowed to fill for a period of 15 minutes. At the end of 15 minutes the Teflon ${ }^{\mathrm{TM}}$ bags were disconnected from the pumps, valves were closed. Bags were placed in a basket and taken to the GC analysis station.

\subsubsection{Analysis of ethanol sampling bags}

1. A clean air sample was run through the GC.

2. A sampled bag was selected in random and hooked to the GC inlet port.

3. The readings for the peak height $(\mathrm{mV})$, integrated peak area (mVS), and retention time $(\mathrm{sec})$ were displayed on screen.

4. Special observations, if any, were noted in the results.

5. The next bag was selected at random until all bags were analysed. 


\subsubsection{Calibration of Voyager GC}

1. The minimum and maximum values for the integrated area (mVS) were compared to a standard ppm value (known concentartion).

2. The ethanol bottle temperature in degrees Celsius was measured with a calibrated thermometer. The necessary headspace volume to achieve a desired calibration concentration "known value" was computed using this temperature. This was done for a minimum, maximum, and middle values.

3. For each of the 3 target levels, 2.4 liters of clean ambient air was injected in a Teflon ${ }^{\mathrm{TM}}$ sampling bag using the manual calibration syringe.

4. The exact amount of Ethanol vapor (saturated headspace) was drawn from the septa of the glass vial half-filled with ethanol. The vapor was injected into each of three different Teflon ${ }^{\mathrm{TM}}$ sampling bags and then the bags were closed.

5. The three Teflon ${ }^{\mathrm{TM}}$ sampling bags were then gently shaken for few times to ensure good mixing.

6. The bags were then kept in the lab hood for 5 minutes.

7. The bags were then opened and connected to the GC and the analysisstarted.

Depending on the pump time that was set in the GC the sample was drawn and a peak voltage $(\mathrm{mV})$, the integrated area $(\mathrm{mVS})$, and the retention time $(\mathrm{sec})$ were noted for each sample drawn.

8. A graph of the "known concentration" and the "mVS" obtained was plotted on a MS Excel spreadsheet.

9. A calibration curve of known concentrations ( $\mathrm{ppm})$ versus integrated peak area (mVS) was developed using linear regression.

10. The linear regression equation was used to compute sampling bag concentrations (ppm) for that day. 


\section{Chapter 4: Results of Study I}

For this study, the manikin was either sitting or standing and was either heated or not heated. It did not breathe or wear a wig, but it was clothed. This study was a complete factorial design which included 2 levels of posture, 2 levels of heating, and 5 levels of velocity. Each test condition was replicated twice in random order. Initial tests and replicates were always done on different days.

One goal of this study was to find the locations that act as the best surrogate for true inhaled concentrations. Another goal was to investigate the effects of posture, heating and velocity on concentrations measured at each location. As will be shown, all were highly significant. Although the manikin inhaled and exhaled through its nose in a realistic manner, its "lungs" did not absorb ethanol. Hence a sample taken at the mouth in the exhaled air stream should differ negligibly from a sample taken of inhaled breath alone. For that reason the concentrations at the mouth are treated here as the "gold standard" to which all others are compared. As will be shown, the concentrations fell into three groups with similar behavior: those at the face $\left(\mathrm{C}_{\text {mouth }}, \mathrm{C}_{\text {nose }}, \mathrm{C}_{\text {forehead }}\right)$, those at the shoulder area $\left(\mathrm{C}_{\text {neck }}, \mathrm{C}_{\text {l.collar }}, \mathrm{C}_{\text {r.collar }}\right)$, and those at the chest $\left(\mathrm{C}_{\text {c.chest }}, \mathrm{C}_{\text {l.lapel }}, \mathrm{C}_{\text {r.lapel }}\right)$.

\subsection{Repeatability of $\mathbf{C}_{\text {mouth }}$}

Two samples were taken simultaneously at the right edge of the mouth less than $1 \mathrm{~mm}$ apart. The coincident locations were intended to be redundant checks. Ideally, there should be no systematic differences between $\mathrm{C}_{\text {mouth }}$ and $\mathrm{C}_{\text {mouth }}$ regardless of the levels of other independent variables. Figure 4.1 plots $\mathrm{C}_{\text {mouth } 1}$ against $\mathrm{C}_{\text {mouth2 }}$ with all conditions included. Without accounting for velocity or any other independent variable, the two dependent variables were highly correlated $(\mathrm{R}-\mathrm{sq}=$

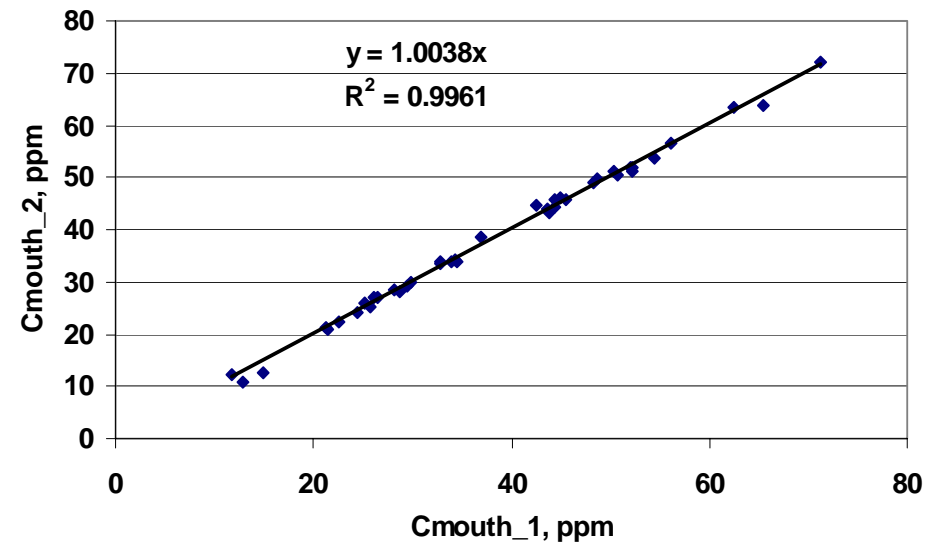

Figure 4.1: $\mathrm{C}_{\text {mouth1 }}$ versus $\mathrm{C}_{\text {mouth2 }}$ 0.996). The linear regression slope of 1.0038 and intercept of zero confirm the two are indistinguishable. Furthermore, ANOVA found no significant effects of any independent variable. These together suggest that the samples are measured correctly and thus that difference between other locations measured at the same time represent real deviations, not sampling or analytical error. Given the trivial differences between $\mathrm{C}_{\text {mouth1 }}$ and 


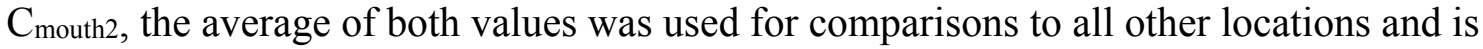
henceforth referred to as $\mathrm{C}_{\text {mouth. }}$.

As shown in Table 4.1, the average concentration values (ppm) varied with sampling location, velocity, heating, and posture where comparisons between concentrations must be matched to similar conditions. Figures 4.2 to 4.10 show the scatter and mean of concentrations and $\log$ transformed values with velocity for all sampling locations.

Table 4.1: Average Concentrations (ppm) for Each Velocity Level and Manikin Treatments

\begin{tabular}{|c|c|c|c|c|c|c|c|c|c|c|}
\hline Treatment & $\mathrm{V}, \mathrm{fpm}$ & $\mathrm{C}_{\text {c.chest }}$ & $\mathrm{C}_{\text {l.lapel }}$ & $\mathrm{C}_{\text {r.lapel }}$ & $\mathrm{C}_{\text {neck }}$ & $\mathrm{C}_{\text {l.collar }}$ & $\mathrm{C}_{\text {r.collar }}$ & $\mathrm{C}_{\text {mouth }}$ & $\mathrm{C}_{\text {nose }}$ & $\mathrm{C}_{\text {forehead }}$ \\
\hline \multirow{5}{*}{$\begin{array}{c}\text { Heated } \\
\text { Standing }\end{array}$} & 11 & 31.6 & 23.9 & 27.0 & 31.8 & 30.1 & 28.8 & 29.5 & 28.5 & 25.3 \\
\hline & 27 & 49.3 & 41.1 & 46.9 & 52.5 & 44.1 & 39.4 & 61.3 & 57.8 & 52.0 \\
\hline & 48 & 103.1 & 77.9 & 96.3 & 73.1 & 61.8 & 71.2 & 57.1 & 52.7 & 47.3 \\
\hline & 82 & 51.6 & 43.2 & 46.4 & 46.5 & 37.8 & 44.1 & 44.6 & 41.3 & 39.4 \\
\hline & 104 & 38.0 & 34.5 & 33.9 & 35.8 & 27.6 & 33.5 & 35.5 & 33.2 & 32.6 \\
\hline \multirow{5}{*}{$\begin{array}{l}\text { Heated } \\
\text { Seated }\end{array}$} & 11 & 18.6 & 15.6 & 14.4 & 15.0 & 16.3 & 17.4 & 12.8 & 10.1 & 7.8 \\
\hline & 27 & 22.6 & 21.9 & 20.4 & 21.3 & 21.3 & 20.3 & 22.7 & 21.5 & 14.9 \\
\hline & 48 & 32.0 & 31.0 & 29.5 & 43.0 & 37.2 & 38.3 & 48.5 & 50.5 & 37.1 \\
\hline & 82 & 23.6 & 21.1 & 18.3 & 20.6 & 20.7 & 20.0 & 29.6 & 31.0 & 26.2 \\
\hline & 104 & 18.4 & 16.2 & 15.3 & 16.1 & 17.0 & 15.3 & 21.9 & 21.8 & 18.9 \\
\hline \multirow{5}{*}{$\begin{array}{l}\text { Unheated } \\
\text { Standing }\end{array}$} & 11 & 116.5 & 135.3 & 83.9 & 68.5 & 70.2 & 63.9 & 62.9 & 66.8 & 42.2 \\
\hline & 27 & 79.2 & 92.4 & 73.5 & 41.7 & 44.4 & 44.0 & 42.1 & 36.6 & 27.6 \\
\hline & 48 & 67.3 & 76.2 & 54.1 & 40.0 & 43.2 & 40.6 & 33.4 & 29.8 & 30.1 \\
\hline & 82 & 52.0 & 49.5 & 48.1 & 35.3 & 36.9 & 34.2 & 30.0 & 27.3 & 19.5 \\
\hline & 104 & 31.8 & 42.5 & 28.5 & 21.8 & 22.3 & 22.9 & 21.2 & 17.8 & 15.6 \\
\hline \multirow{5}{*}{$\begin{array}{l}\text { Unheated } \\
\text { Seated }\end{array}$} & 11 & 41.8 & 51.7 & 42.6 & 56.4 & 61.2 & 53.2 & 58.8 & 58.2 & 52.7 \\
\hline & 27 & 30.0 & 33.0 & 30.7 & 44.5 & 43.3 & 38.8 & 51.0 & 53.2 & 46.0 \\
\hline & 48 & 22.9 & 26.1 & 23.2 & 39.8 & 39.3 & 35.6 & 47.4 & 51.5 & 44.6 \\
\hline & 82 & 20.2 & 22.8 & 22.7 & 34.6 & 33.9 & 32.5 & 38.8 & 38.9 & 33.6 \\
\hline & 104 & 15.7 & 19.6 & 17.7 & 32.8 & 30.8 & 24.7 & 34.3 & 34.4 & 31.3 \\
\hline
\end{tabular}




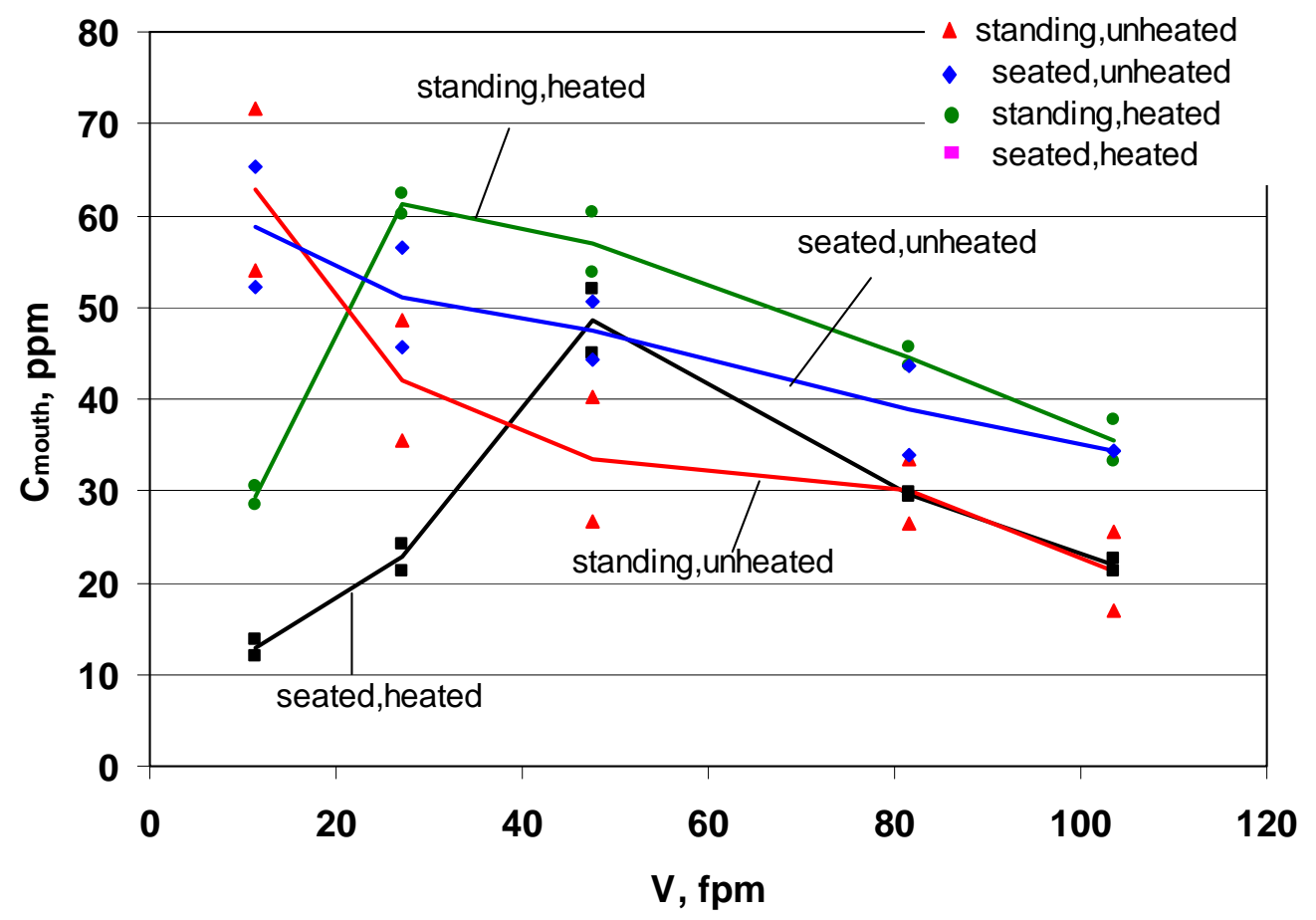

Figure 4.2-a: Scatter and mean plots of $\mathrm{C}_{\text {mouth }}$ Vs. velocity for all manikin treatments

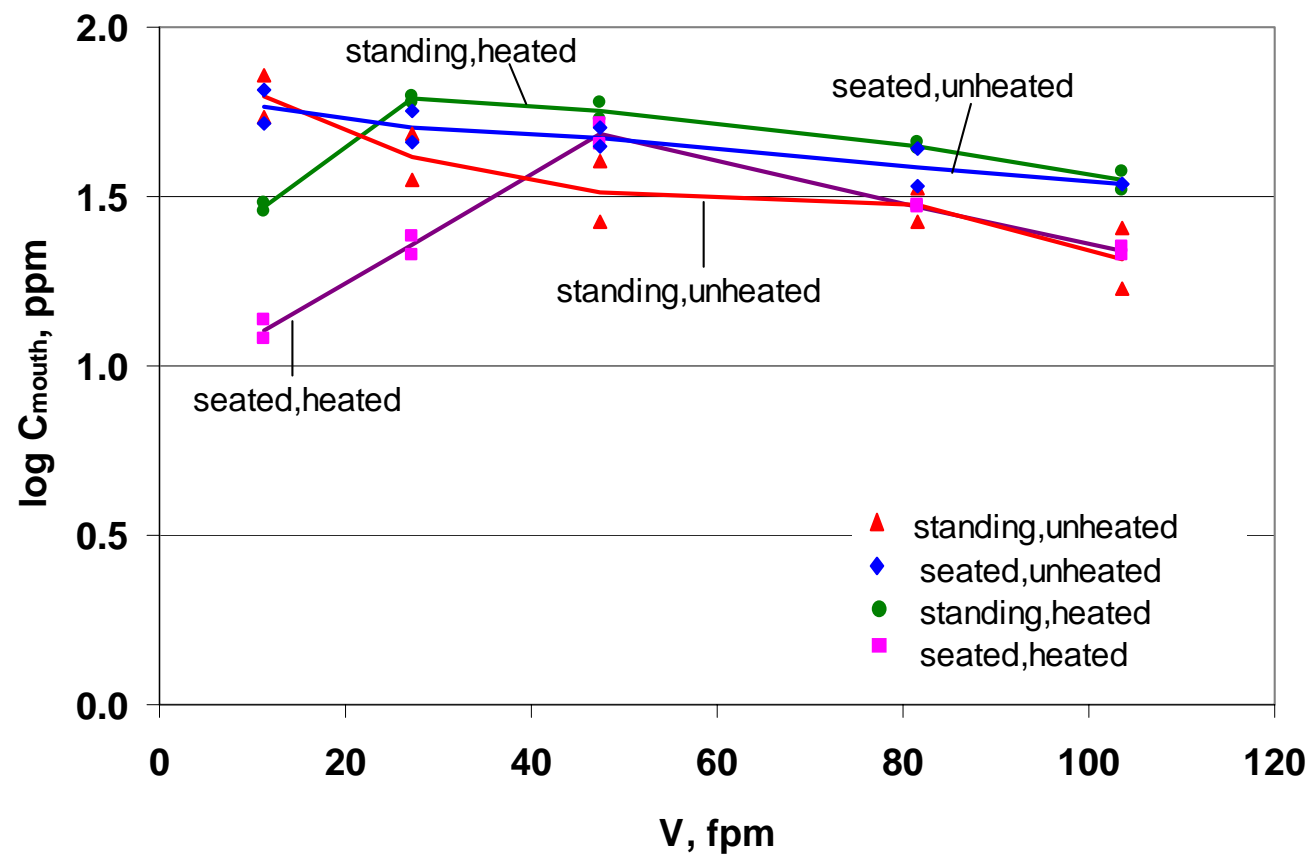

Figure 4.2-b: Scatter and mean plots of $\log \mathrm{C}_{\text {mouth }}$ vs. velocity for all manikin treatments 


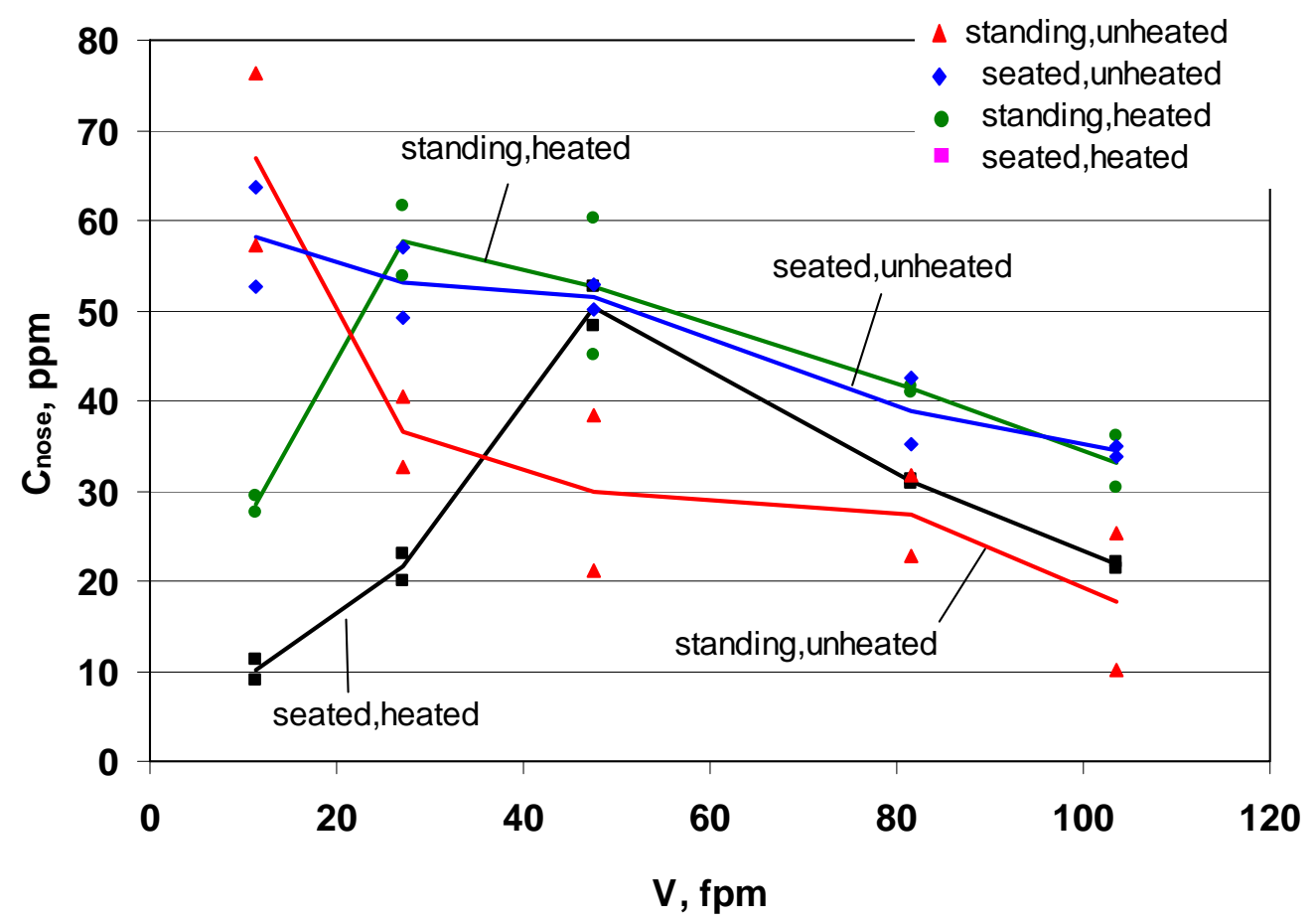

Figure 4.3-a: Scatter and mean plots of $\mathrm{C}_{\text {nose }}$ vs. velocity for all manikin treatments

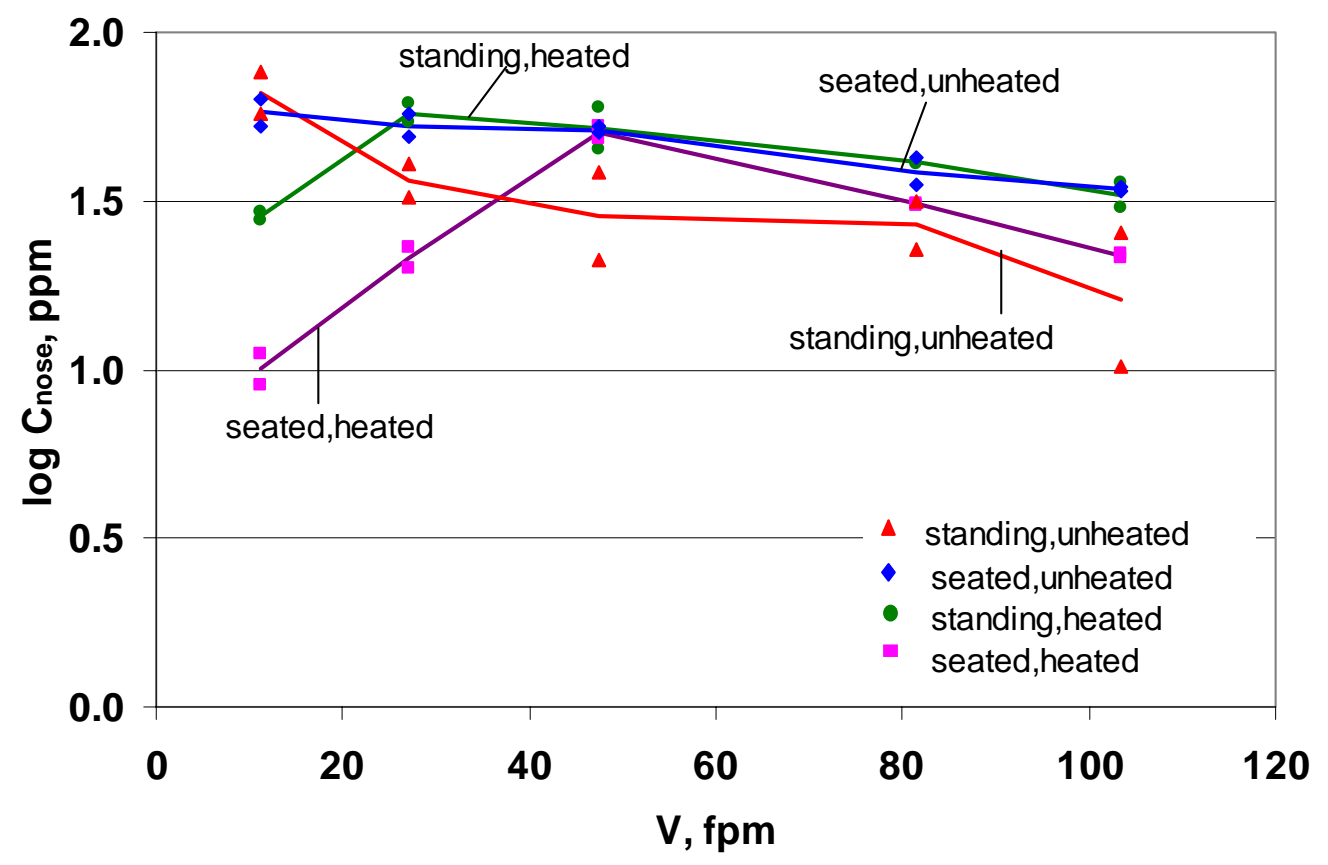

Figure 4.3-b: Scatter and mean plots of $\log \mathrm{C}_{\text {nose }}$ vs. velocity for all manikin treatments 


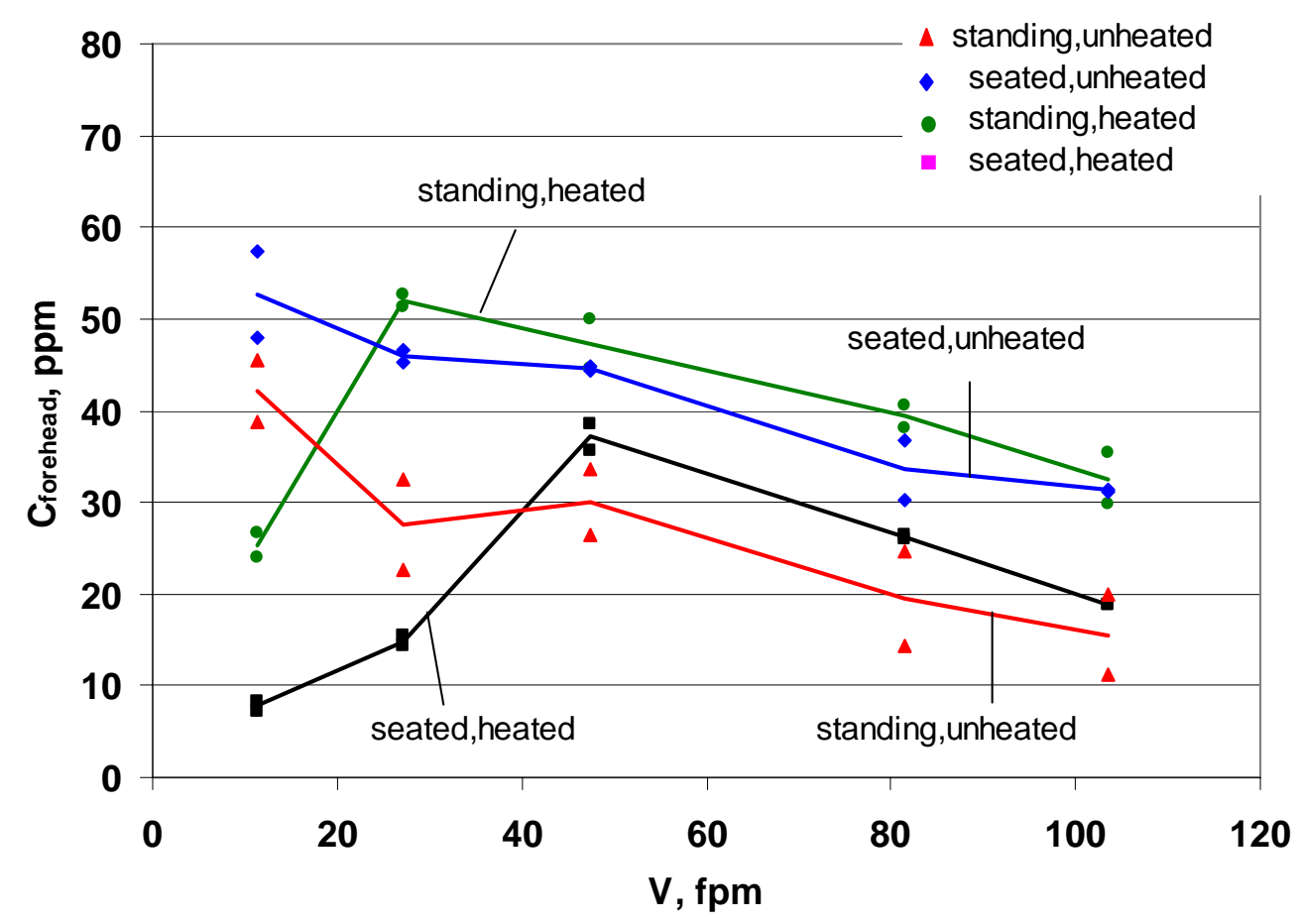

Figure 4.4-a: Scatter and mean plots of $\mathrm{C}_{\text {forehead }}$ vs. velocity for all manikin treatments

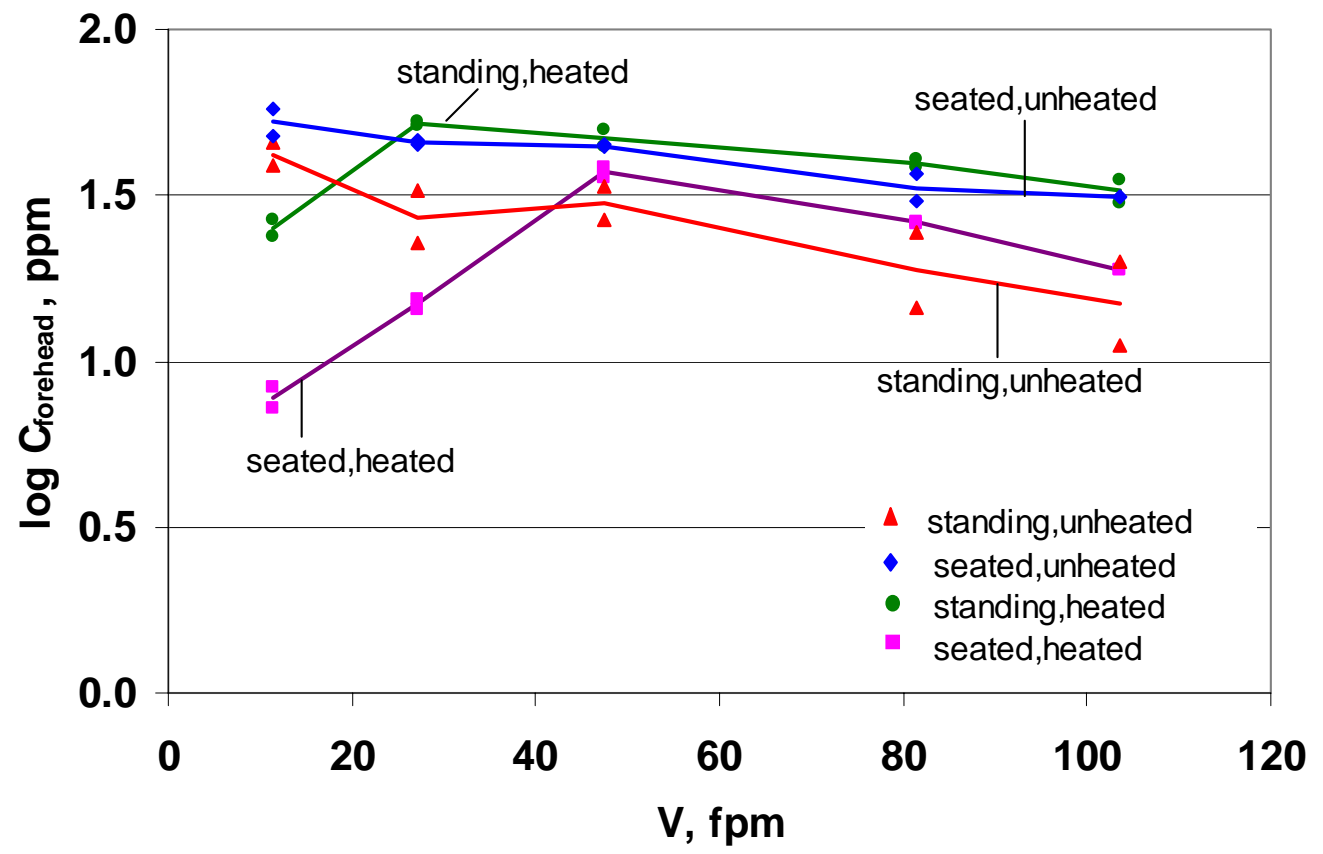

Figure 4.4-b: Scatter and mean plots of $\log \mathrm{C}_{\text {forehead }}$ vs. velocity for all manikin treatments 


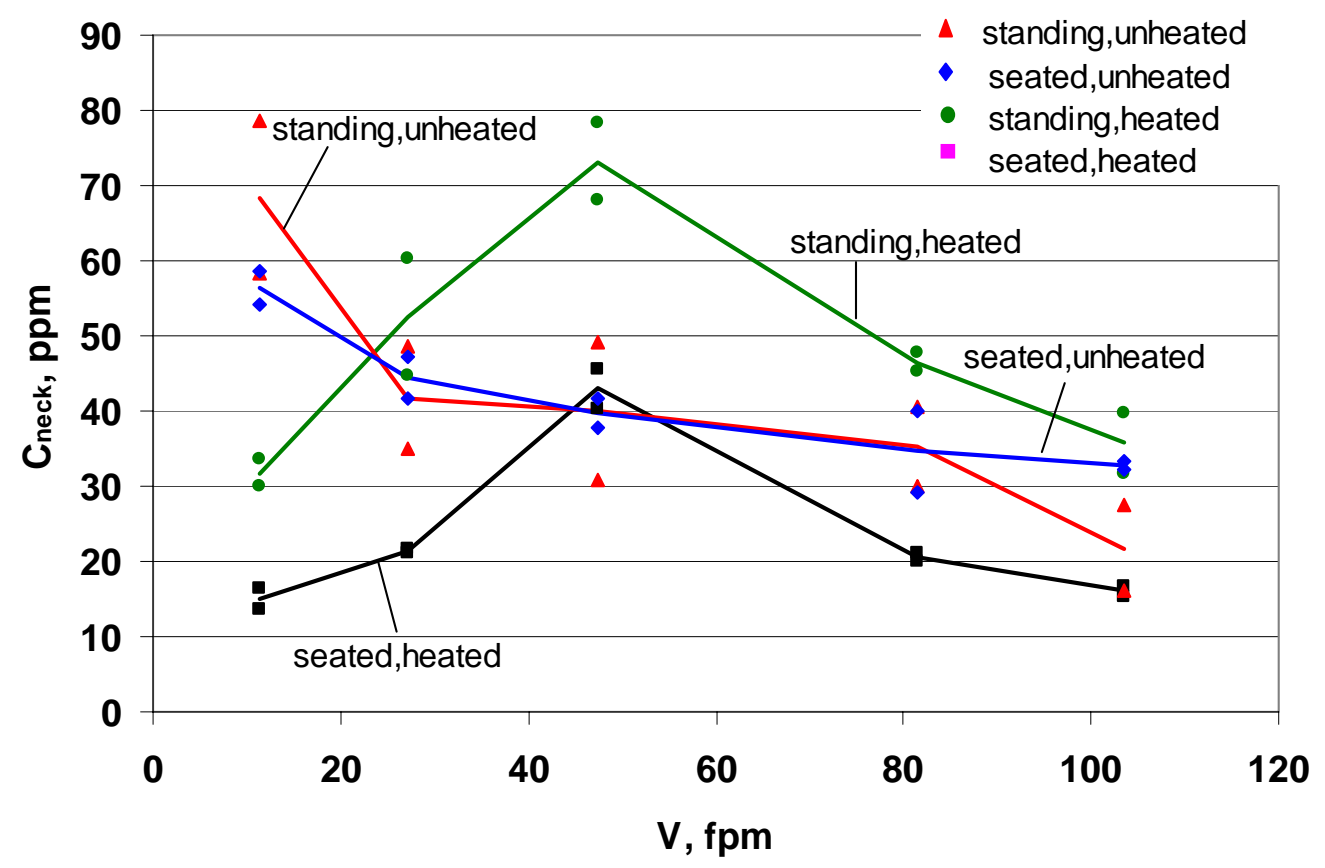

Figure 4.5-a: Scatter and mean plots of Cneck vs. velocity for all manikin treatments

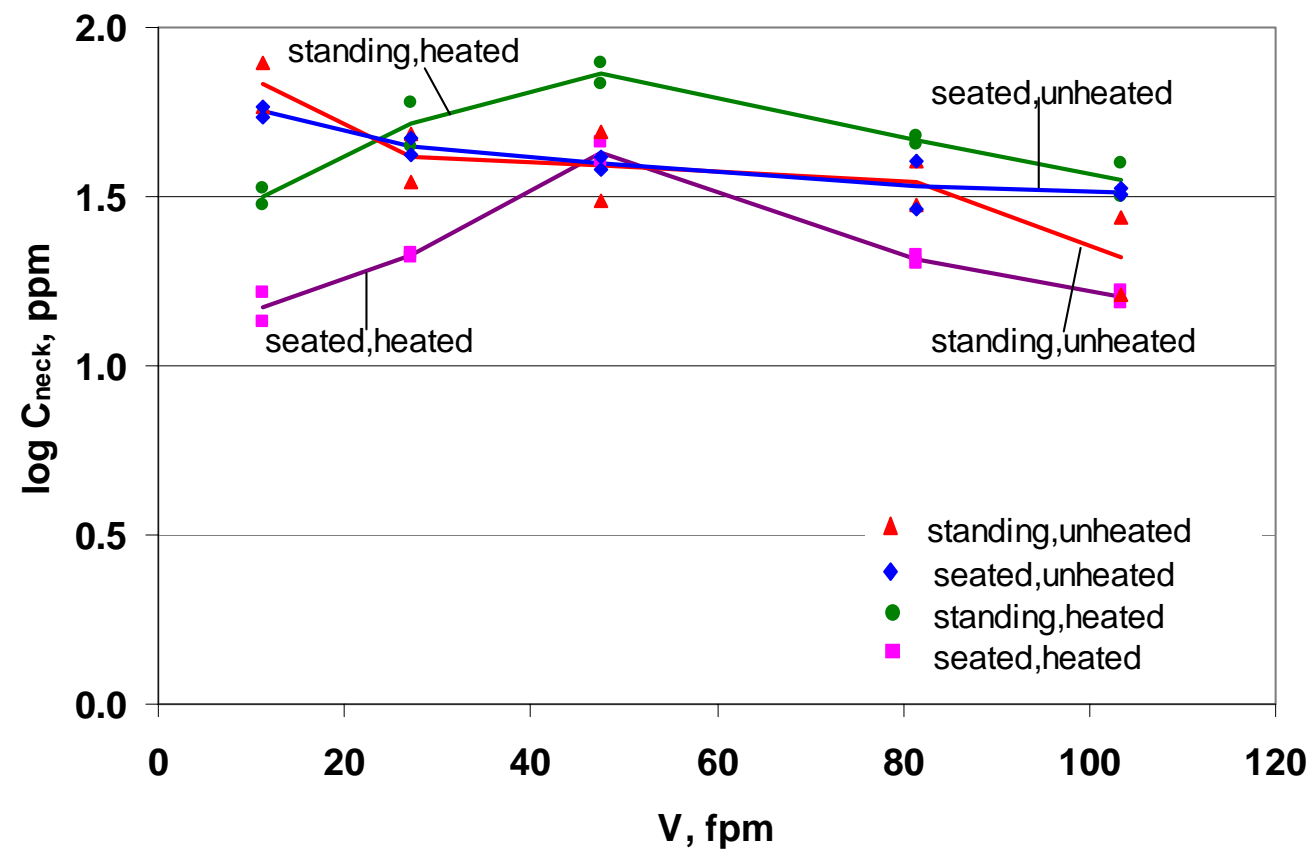

Figure 4.5-b: Scatter and mean plots of $\log \mathrm{C}_{\text {neck }}$ vs. velocity for all manikin treatments 


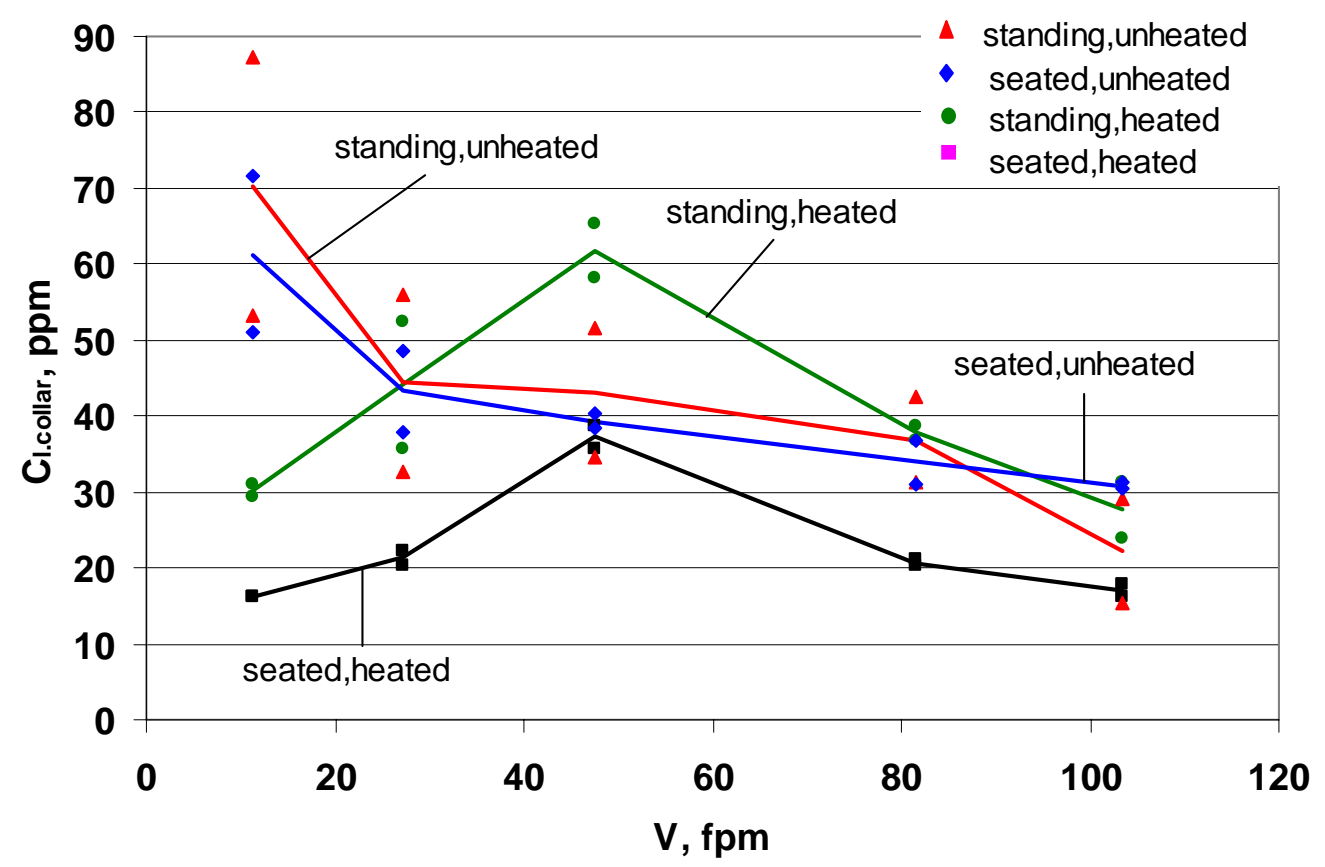

Figure 4.6-a: Scatter and mean plots of Cl.collar vs. velocity for all manikin treatments

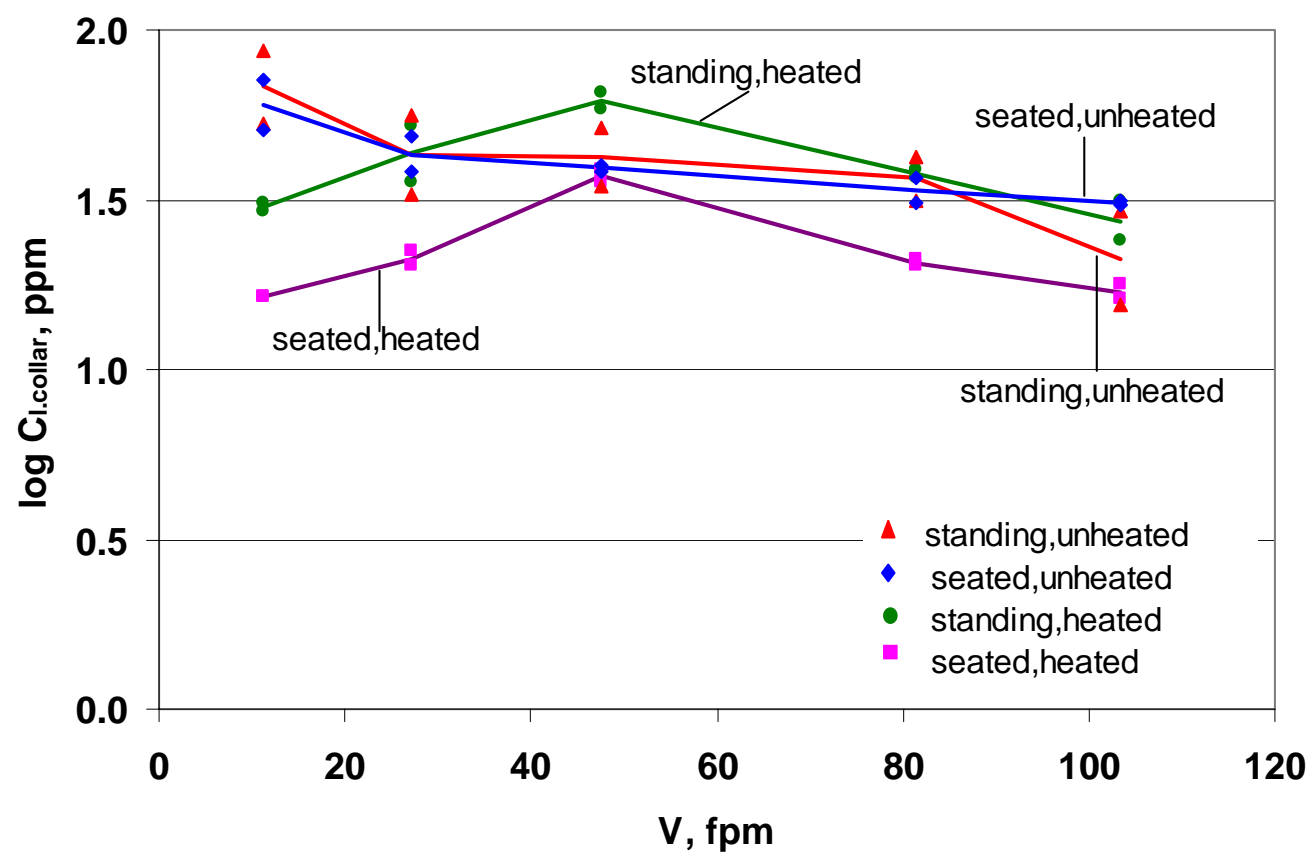

Figure 4.6-b: Scatter and mean plots of $\log \mathrm{C}_{\text {l.collar }}$ vs. velocity for all manikin treatments 


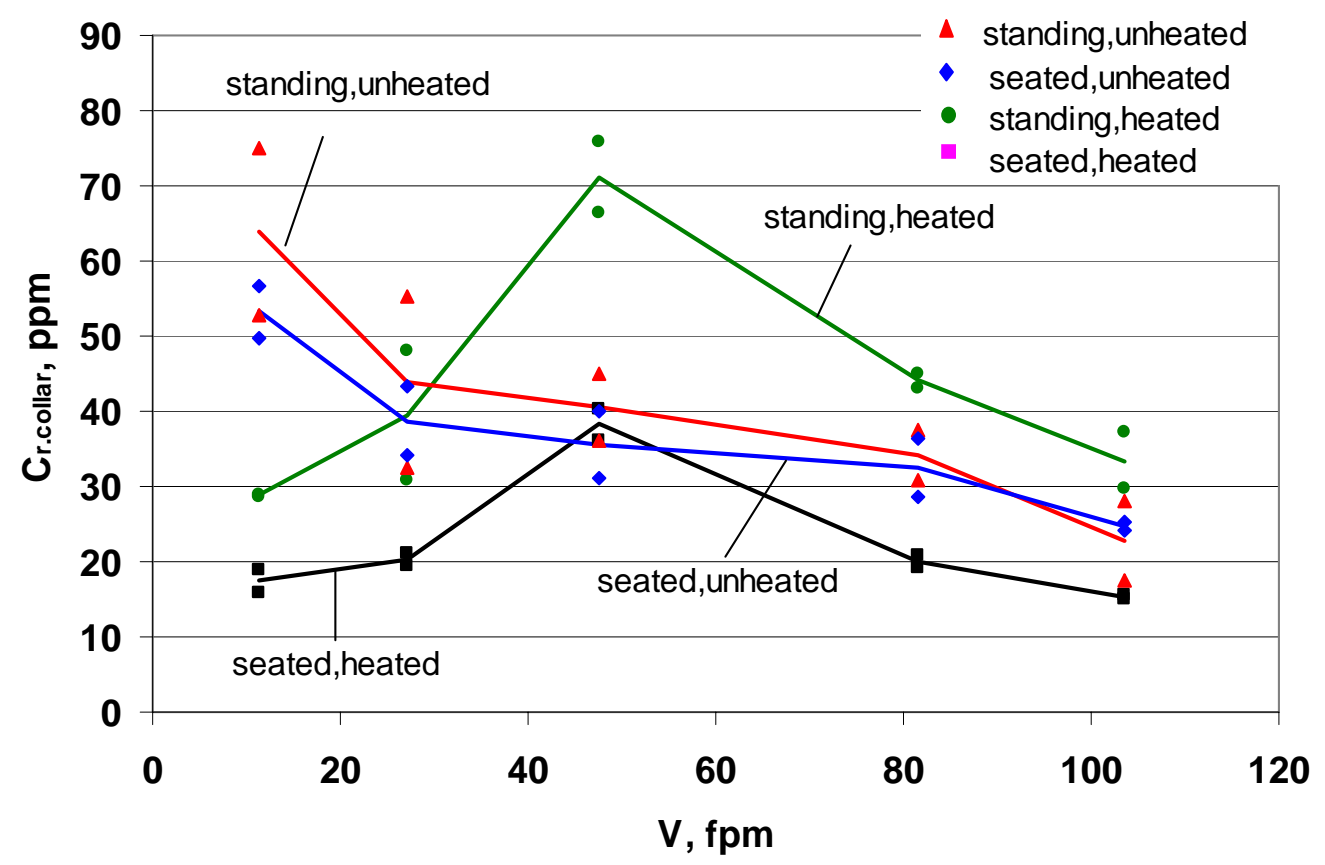

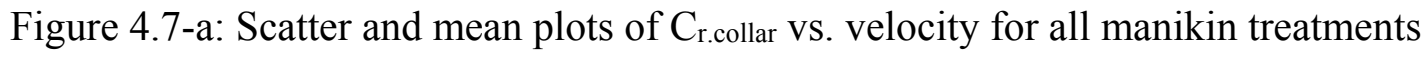

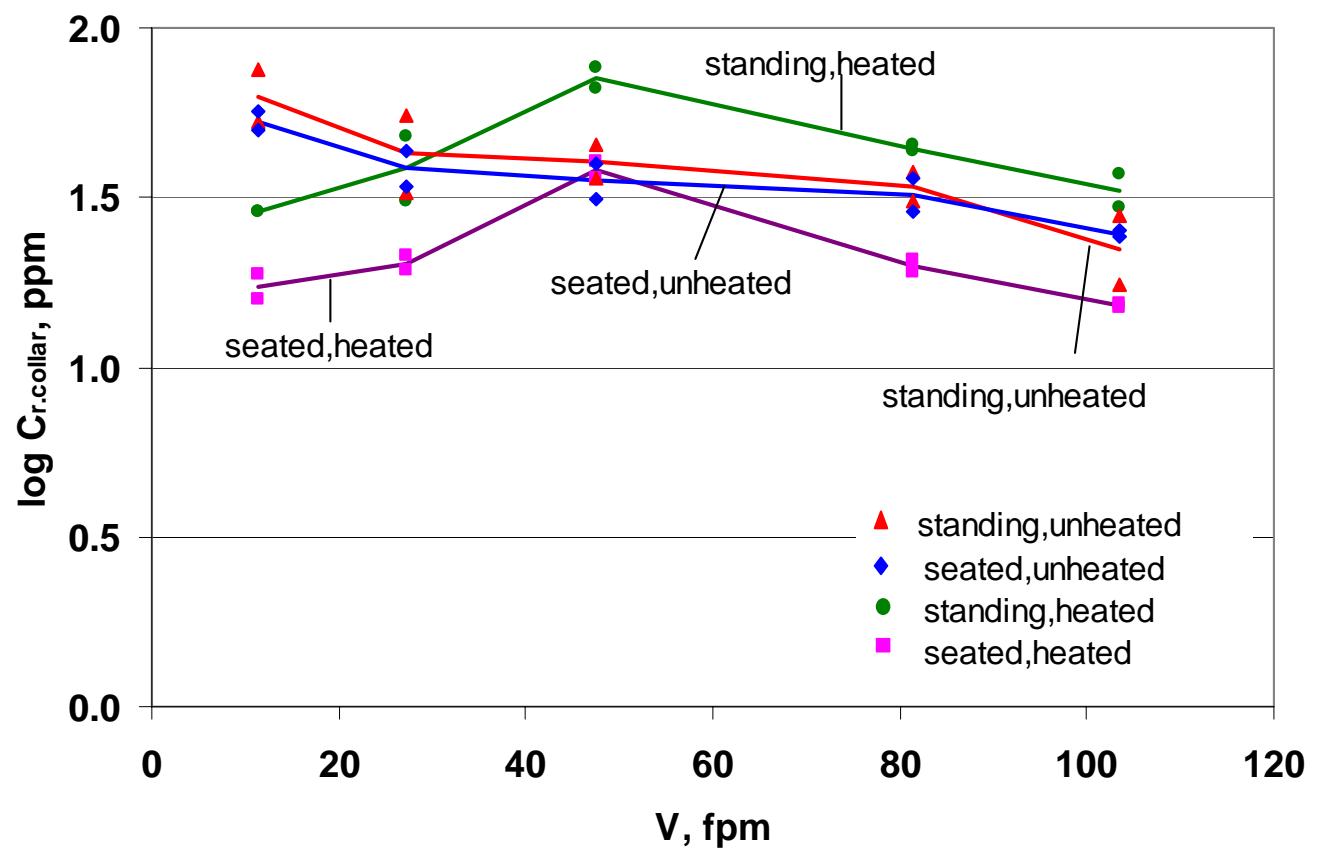

Figure 4.7-b: Scatter and mean plots of $\log \mathrm{C}_{\mathrm{r} . \mathrm{collar}}$ vs. velocity for all manikin treatments 


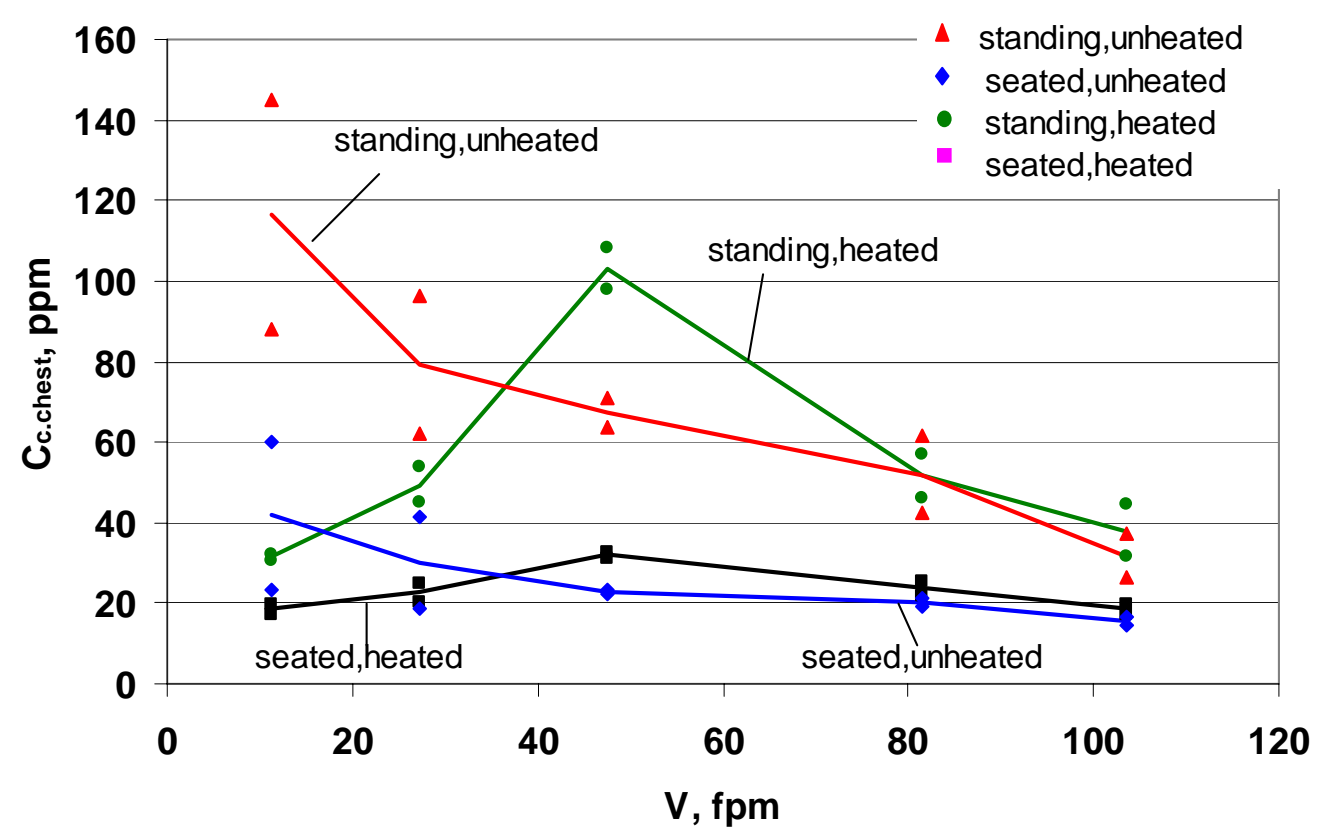

Figure 4.8-a: Scatter and mean plots of $\mathrm{C}_{\mathrm{c} . \text { chest }}$ vs. velocity for all manikin treatments

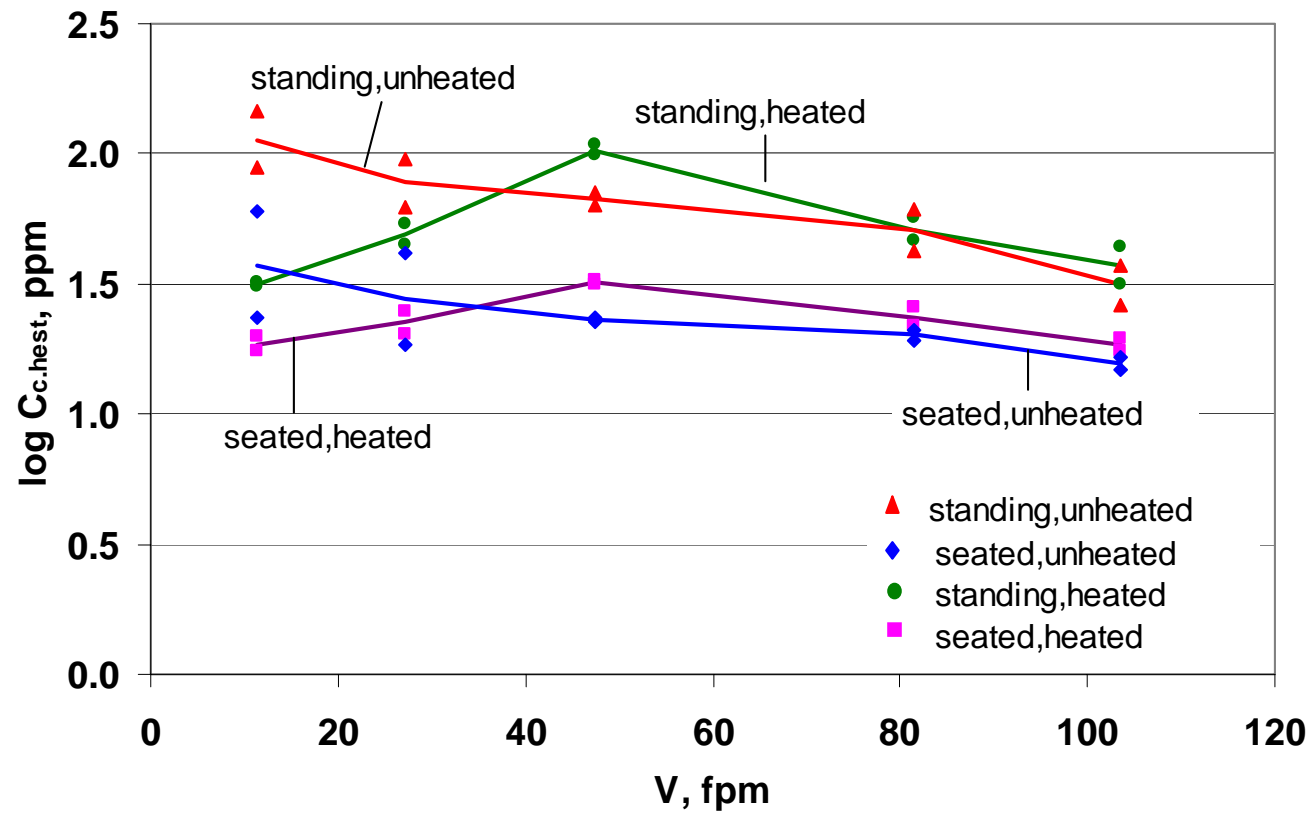

Figure 4.8-b: Scatter and mean plots of $\log \mathrm{C}_{\mathrm{c} . \text { chest }}$ vs. velocity for all manikin treatments 


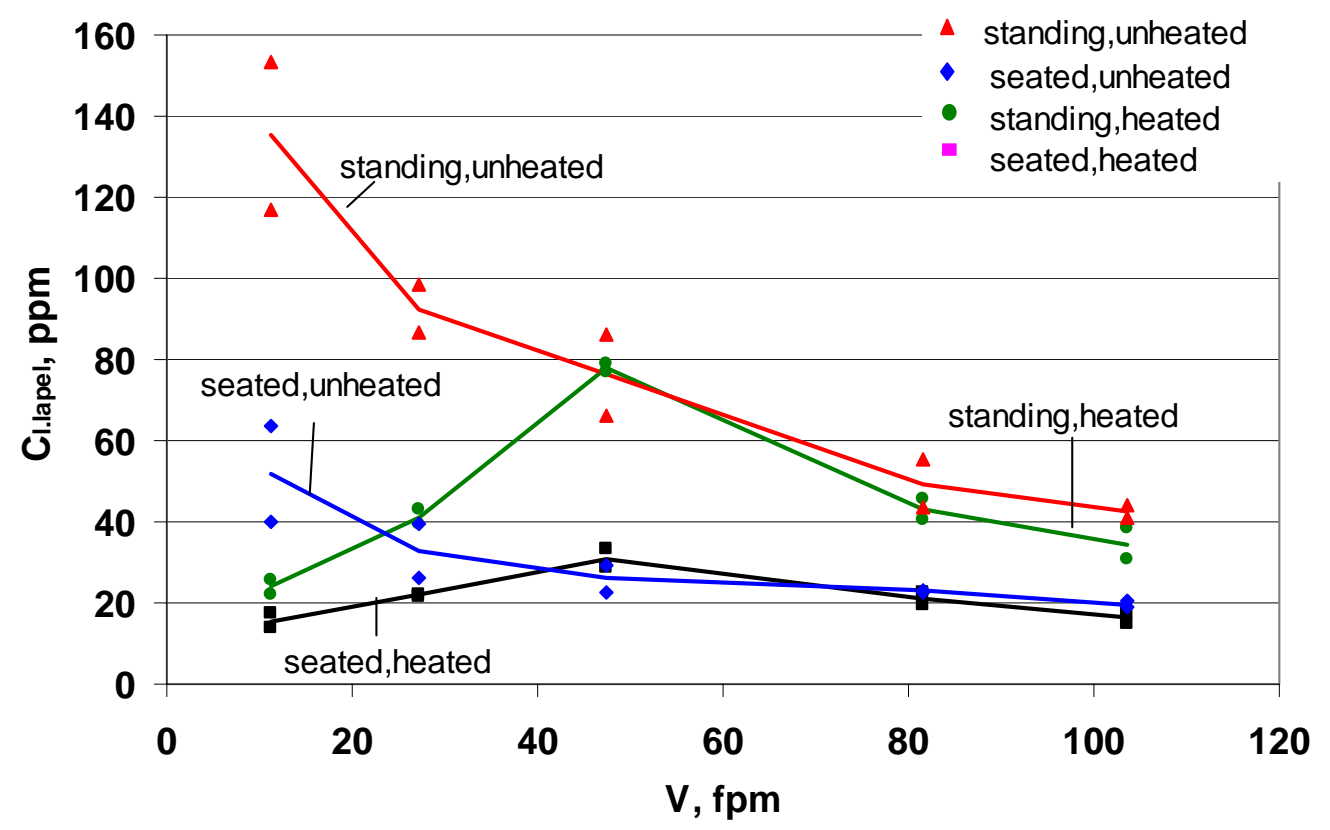

Figure 4.9-a: Scatter and mean plots of $\mathrm{C}_{1 . \text { lapel }}$ vs. velocity for all manikin treatments

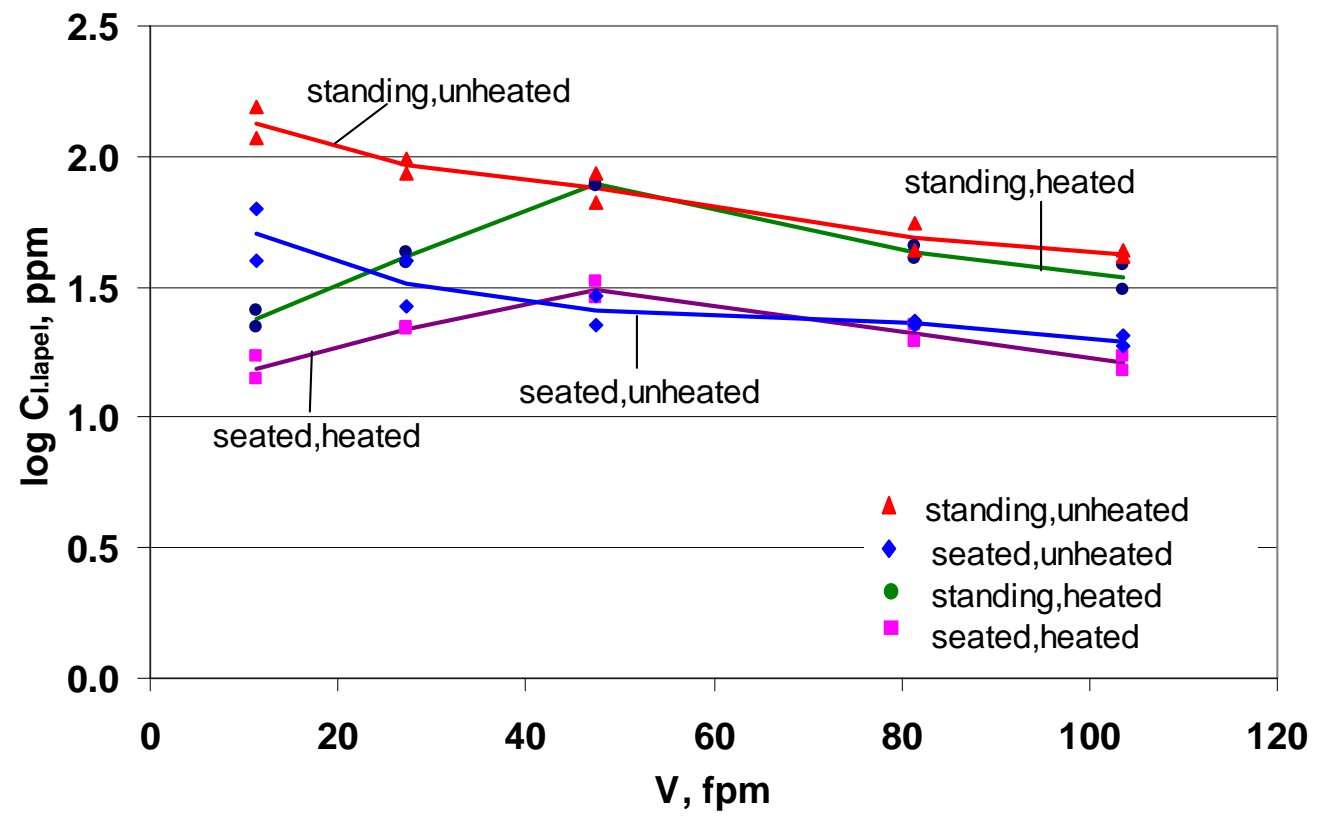

Figure 4.9-b: Scatter and mean plots of $\log \mathrm{C}_{1 . \text { lapel }}$ vs. velocity for all manikin treatments 


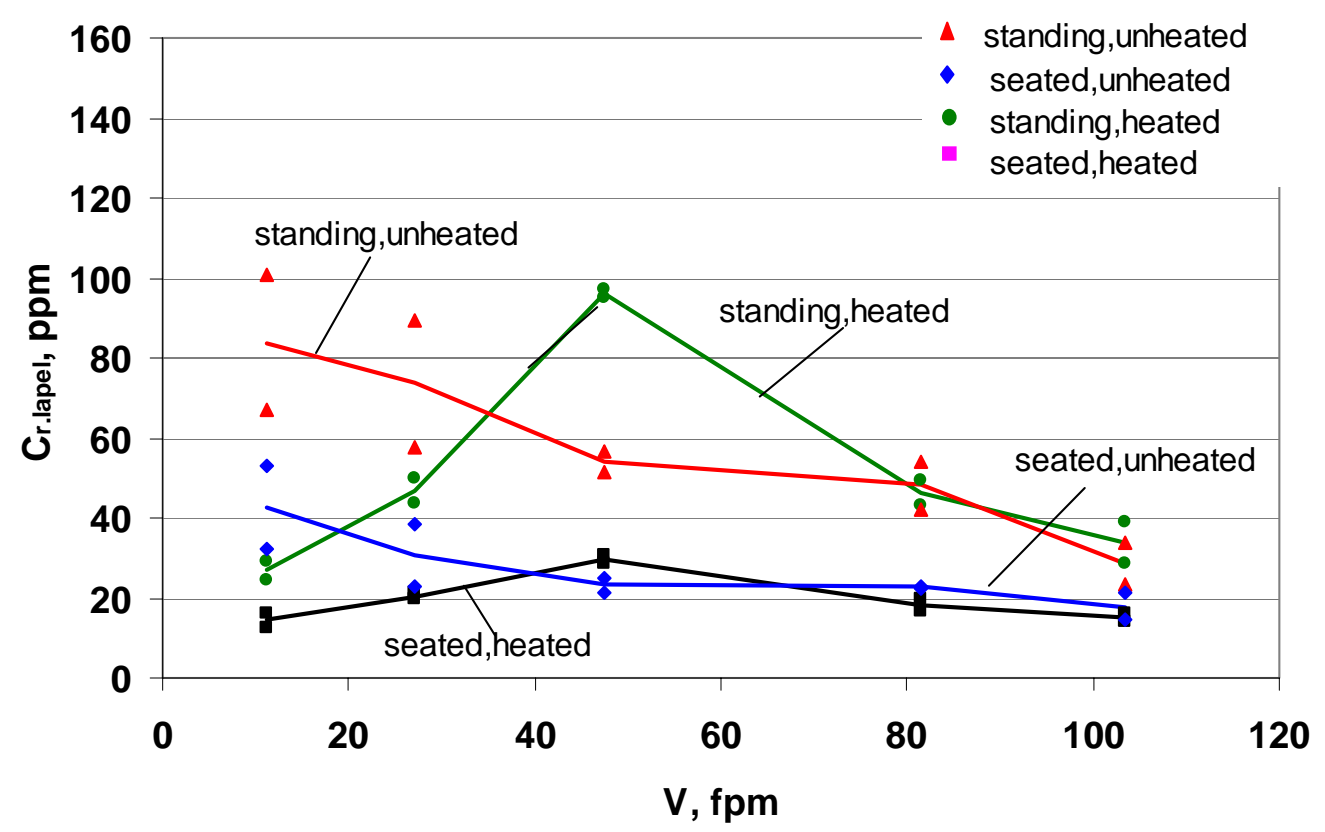

Figure 4.10-a: Scatter and mean plots of $\mathrm{C}_{\text {r.lapel }}$ vs. velocity for all manikin treatments

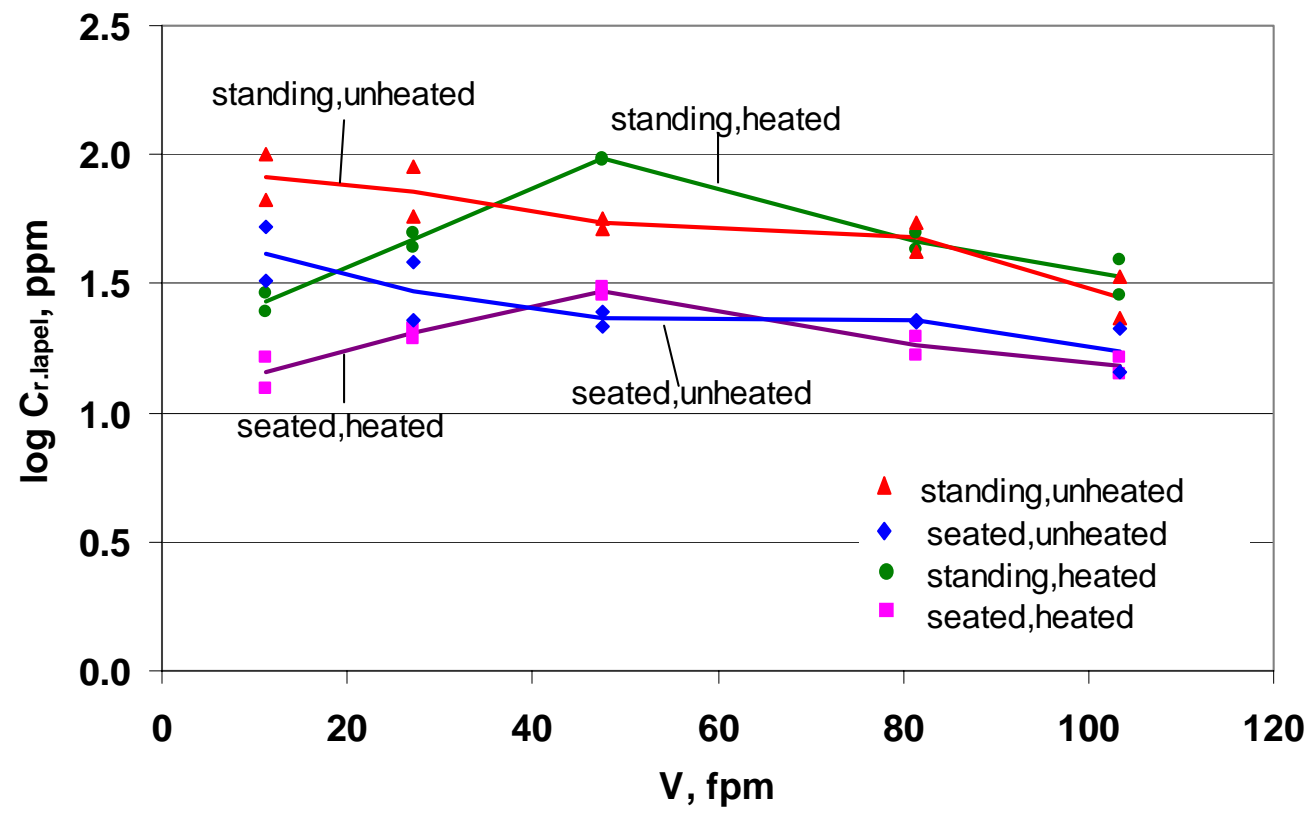

Figure 4.10-b: Scatter and mean plots of $\log \mathrm{C}_{\mathrm{r} \text {.lapel }}$ vs. velocity for all manikin treatments 


\subsection{Effects of Independent Variables on all Sampling Locations}

As listed in Table 4.1, values of concentrations measured at the face $\left(\mathrm{C}_{\text {mouth }}, \mathrm{C}_{\text {nose }}\right.$, $\left.\mathrm{C}_{\text {forehead }}\right)$, shoulder $\left(\mathrm{C}_{\text {neck }}, \mathrm{C}_{\text {l.collar }}, \mathrm{C}_{\text {r.collar }}\right)$, and chest $\left(\mathrm{C}_{\text {c.chest }}, \mathrm{C}_{\text {l.lapel }}, \mathrm{C}_{\text {r.lapel }}\right)$ varied with wind tunnel velocity, heating, and posture.

\subsubsection{Velocity}

As shown in Figures $4.2-4.10$, the effects of velocity on sampling locations appeared to be strikingly different for heated and unheated treatments but were similar for standing and seated postures. For unheated conditions, concentrations at all sampling locations fell more or less monotonically with increasing values of velocity. This behavior agrees with Flynn et al. (1991) and Kulmala (1996) results for their unheated manikins. These results disagree with Guffey and Flanagan (2001) whose concentrations increased monotonically with increasing velocity. However, it should be noted that the Reynolds numbers for this study $(\operatorname{Re}=1200-12000)$, Guffey and Flanagan $(\operatorname{Re}=1000-7200), \mathrm{Kim}$ and Flynn $(\mathrm{Re}=3419-17094)$, and Kulmala $(\mathrm{Re}=6300,9500$, and 12700$)$ were quite different, perhaps accounting for the differences in results between Guffey and Flanagan and the rest.

For the more lifelike conditions, a heated manikin, concentrations at all sampling locations varied in an inverted- $\mathrm{V}$ shape relationship with velocity for both sitting and standing postures (see Figures 4.2-4.10). $\mathrm{C}_{\text {mouth }}, \mathrm{C}_{\text {nose }}$, and $\mathrm{C}_{\text {forehead }}$, had the peak concentartions values at $27 \mathrm{fpm}$ for standing posture and at $48 \mathrm{fpm}$ for sitting (see Figures 4.2 - 4.4). However, concentrations at the shoulder, $\mathrm{C}_{\text {neck }}, \mathrm{C}_{\text {l.collar }}, \mathrm{C}_{\text {r.collar}}$, and the chest, $\mathrm{C}_{\text {c.chest }}, \mathrm{C}_{\text {l.lapel }}, \mathrm{C}_{\text {r.lapel }}$, had peak concentrations values at $48 \mathrm{fpm}$ only for both sitting and standing postures (see Figures 4.5 - 4.10). Those results agree with Brohus (1997), who employed a full-sized heated, breathing manikin wearing heavy clothing and wig. The velocity range in Brohus study was $0.05,0.15,0.3$, and $0.45 \mathrm{~m} / \mathrm{s}$, while, the Reynolds numbers were $(1000,3000,6000$, and 9000).

The effect of velocity on $\mathrm{C}_{\text {mouth }}, \mathrm{C}_{\text {nose }}$, and $\mathrm{C}_{\text {forehead, }}$, is shown in Table 4.1. For the heated manikin in a standing posture, $\mathrm{C}_{\text {mouth }}, \mathrm{C}_{\text {nose }}$, and $\mathrm{C}_{\text {forehead, }}$, doubled as velocity increased from 11 to $27 \mathrm{fpm}$ and decreased by half as velocity increased again from 27 to $104 \mathrm{fpm}$. On the other hand, for the seated posture, $\mathrm{C}_{\text {mouth }}, \mathrm{C}_{\text {nose }}$, and $\mathrm{C}_{\text {forehead }}$, increased four times as velocity increased from 11 to $48 \mathrm{fpm}$ and decreased by half as velocity increased from 48 to $104 \mathrm{fpm}$. The effect of velocity on $\mathrm{C}_{\text {mouth }}, \mathrm{C}_{\text {nose }}$, and $\mathrm{C}_{\text {forehead }}$, is substantial and the peak concentration values occurred at $27 \mathrm{fpm}$ for standing and at $48 \mathrm{fpm}$ for sitting posture. For unheated manikin, $\mathrm{C}_{\text {mouth }}, \mathrm{C}_{\text {nose }}$, and $\mathrm{C}_{\text {forehead }}$, declined monotonically with increasing velocities for both sitting and standing.

The effect of velocity on concentrations measured at the shoulder and chest levels is shown in Table 4.1. For the heated manikin, $\mathrm{C}_{\text {neck }}, \mathrm{C}_{\text {l.collar }}$, and $\mathrm{C}_{\text {r.collar}}$, doubled as velocity increased from 11 to $48 \mathrm{fpm}$ and decreased by half as velocity increased again from 48 to $104 \mathrm{fpm}$ for both sitting and standing postures. However, $\mathrm{C}_{\mathrm{c} . \mathrm{ches}}, \mathrm{C}_{1 . \text { lapel }}$, and $\mathrm{C}_{\text {r.lapel }}$ trippled for standing and doubled for sitting as velocity increased from 11 to $48 \mathrm{fpm}$ and decreased by one third its value as velocity increased again from 48 to $104 \mathrm{fpm}$ for standing and by one half for sitting. It is worth mentioning that, the effect of velocity on $\mathrm{C}_{\mathrm{neck}}, \mathrm{C}_{\text {l.collar }}, \mathrm{C}_{\mathrm{r} . \mathrm{collar}}$, and 
$\mathrm{C}_{\text {c.chest }}, \mathrm{C}_{1 . \text { lapel }}, \mathrm{C}_{\text {r.lapel }}$ is substantial and the peak concentration values occurred at 48 fpm only for both sitting and standing postures. Likewise concentrations at the face, for unheated manikin, concentrations at the shoulder and chest levels declined monotonically with increasing velocities for both sitting and standing.

\subsubsection{Heating}

As shown in Figures 4.2 - 4.10, the effects of heating on concentrations appeared to be strikingly different for heated and unheated conditions at different velocities. For standing posture, concentrations at the face, shoulder, and chest levels were substantially higher for unheated manikin than heated one, at the lower velocity ranges (11 and $27 \mathrm{fpm})$. On the other hand, for the higher velocities (27 to $104 \mathrm{fpm}$ ), concentrations at the face, shoulder, and chest were substantially higher for the heated manikin. Unlike standing, concentrations at all locations for the unheated manikin were considerably higher than the heated one at all velocities for the manikin in sitting posture. It is worth mentioning that minor differences in concentrations occurred only at $48 \mathrm{fpm}$ for some locations. For the unheated manikin, for both sitting and standing, concentrations at all locations had peak values at $11 \mathrm{fpm}$.

The effect of body heat on concentrations at the face, shoulder, and chest levels is shown in Table 4.1. At $11 \mathrm{fpm}$ and for the manikin in sitting or standing posture, $\mathrm{C}_{\text {mouth, }}$ $\mathrm{C}_{\text {nose }}$, and $\mathrm{C}_{\text {forehead, }}$ levels were $55 \%$ higher for unheated manikin than heated one. Likewise, for the same velocity, heating decreased $\mathrm{C}_{\text {neck }}, \mathrm{C}_{\text {l.collar }}, \mathrm{C}_{\mathrm{r} \text {.collar }}$ and $\mathrm{C}_{\text {c.chest }}, \mathrm{C}_{\text {l.lapel }}, \mathrm{C}_{\text {r.lapel }}$ levels by $54 \%$ and $57 \%$ for both sitting and standing postures.

Therefore, the effect of body heat on concentrations is substantial. Heating changes the airflow patterns around the manikin's head and torso. For the heated manikin, the results show that concentrations declined monotonically above $27 \mathrm{fpm}$ at the face and above $48 \mathrm{fpm}$ at shoulder and chest levels. In other words, as wind tunnel velocity increased, the relative importance of body heat decreased. These results agree with Heist et al. (2003), Fletcher and Johnson (1996), Brohus (1997), and Homma and Yakiyama (1988) who studied the effect of body heat on air flow patterns around a manikin in a uniform flow field and found that heating was also significant and had substantial effects at low speed wind environments. For these studies, wind velocities were ranged $0.05,0.15,0.3$, and $0.5 \mathrm{~m} / \mathrm{s}$.

\subsubsection{Posture}

The effect of posture was substantial for both the heated and unheated conditions and for all velocities. It is plausible that posture would affect concentrations because of the different orientation of arms and legs to cross draft. In the standing posture, the manikin arms and legs are perpendicular to the cross draft while in sitting posture the arms and legs are parallel to wind tunnel velocity. The arms and legs would affect air flow patterns around the manikin and hence concentration gradients in the breathing zone.

At the head, the effect of posture on $\mathrm{C}_{\text {mouth }}, \mathrm{C}_{\text {nose }}$, and $\mathrm{C}_{\text {forehead, }}$ is shown in Figures (4.2 - 4.4) and listed in Table 4.1. The effect of posture was neutralized with heating. Standing showed higher concentration levels than sitting for heated manikin while sitting showed higher concentration levels than standing for the unheated manikin for the entire velocity range. For example, at $48 \mathrm{fpm}, \mathrm{C}_{\text {mouth }}, \mathrm{C}_{\text {nose }}$, and $\mathrm{C}_{\text {forehead }}$ were higher for standing 
than sitting by $15 \%, 4 \%$, and $21 \%$ for the heated manikin while sitting was higher than standing for unheated. As velocity decreased to $27 \mathrm{fpm}$, concentrations were higher than sitting for the heated manikin and were lower for unheated.

The effect of posture on $\mathrm{C}_{\text {neck }}, \mathrm{C}_{\mathrm{l} \text {.collar }}$, and $\mathrm{C}_{\mathrm{r} \text {.collar }}$ is shown in Figures (4.5 - 4.7) and listed in Table 4.1. Standing showed higher concentration levels for $\mathrm{C}_{\text {neck }}, \mathrm{C}_{\text {l.collar, }}$, and $\mathrm{C}_{\text {r.collar }}$ than sitting for the heated manikin for the entire velocity range with peak concentrations at $48 \mathrm{fpm}$. For lifelike manikin, at $48 \mathrm{fpm}, \mathrm{C}_{\text {neck }}, \mathrm{C}_{\text {l.collar, }}$, and $\mathrm{C}_{\text {r.collar }}$ were approximately higher for standing by $46 \%$ than sitting. However, for unheated manikin, minor differences were found between sitting and standing for the entire velocity range.

Unlike concentrations at the shoulder, the effect of posture on $\mathrm{C}_{\text {c.chest }}, \mathrm{C}_{1 . \text { lapel, }}$, and $\mathrm{C}_{\text {r.lapel }}$ is shown in Figures $4.8-4.10$ and listed in Table 4.1. For the heated and unheated manikin, $\mathrm{C}_{\mathrm{c} . \text { chest }}, \mathrm{C}_{\text {l.lapel }}$, and $\mathrm{C}_{\mathrm{r} \text {.lapel }}$ were higher for standing than sitting for the entire velocity range with peak concentrations at $48 \mathrm{fpm}$ for heated manikin and at $11 \mathrm{fpm}$ for unheated. For example, at $48 \mathrm{fpm}, \mathrm{C}_{\text {c.chest }}, \mathrm{C}_{1 . \text { lapel, }}$, and $\mathrm{C}_{\text {r.lapel }}$ were approximately $65 \%$ higher for standing than sitting for both heated and unheated conditions.

Therefore, the effect of posture is substantial on concentrations at the head, shoulder, and chest. However, higher differences for standing and sitting were observed at chest locations may be refferd to the presence of the table down stream the manikin which was probably affecting the wake zone and air flow pattern. 
Table 4.2: Average Concentrations (ppm) for Each Velocity Level and Manikin Treatment

\begin{tabular}{cccccc}
\hline Treatment & $\mathrm{V}, \mathrm{fpm}$ & $\mathrm{C}_{\text {lower.torso }}$ & $\mathrm{C}_{\text {upper.torso }}$ & $\mathrm{C}_{\text {inhaled }}$ & $\mathrm{C}_{\text {forehead }}$ \\
\hline \hline & 11 & 27.5 & 30.2 & 29.0 & 25.3 \\
Heated & 27 & 45.8 & 45.3 & 59.5 & 52.0 \\
Standing & 48 & 92.4 & 68.7 & 52.7 & 47.3 \\
& 82 & 47.0 & 42.8 & 43.0 & 39.4 \\
\hline \hline & 104 & 35.5 & 32.3 & 34.3 & 32.6 \\
\hline Heated & & & & & \\
Seated & 11 & 16.2 & 16.2 & 11.5 & 7.8 \\
& 27 & 21.6 & 21.0 & 22.1 & 14.9 \\
& 82 & 30.8 & 39.5 & 49.5 & 37.1 \\
& 104 & 21.0 & 20.4 & 30.3 & 26.2 \\
Unheated & 16.6 & 16.1 & 21.8 & 18.9 \\
\hline Standing & 11 & 111.9 & 67.5 & 64.9 & 42.2 \\
& 27 & 81.7 & 43.4 & 39.3 & 27.6 \\
& 48 & 65.9 & 41.2 & 31.6 & 30.1 \\
& 104 & 49.9 & 35.5 & 28.6 & 19.5 \\
& 104 & 34.3 & 22.3 & 19.5 & 15.6 \\
\hline \hline
\end{tabular}




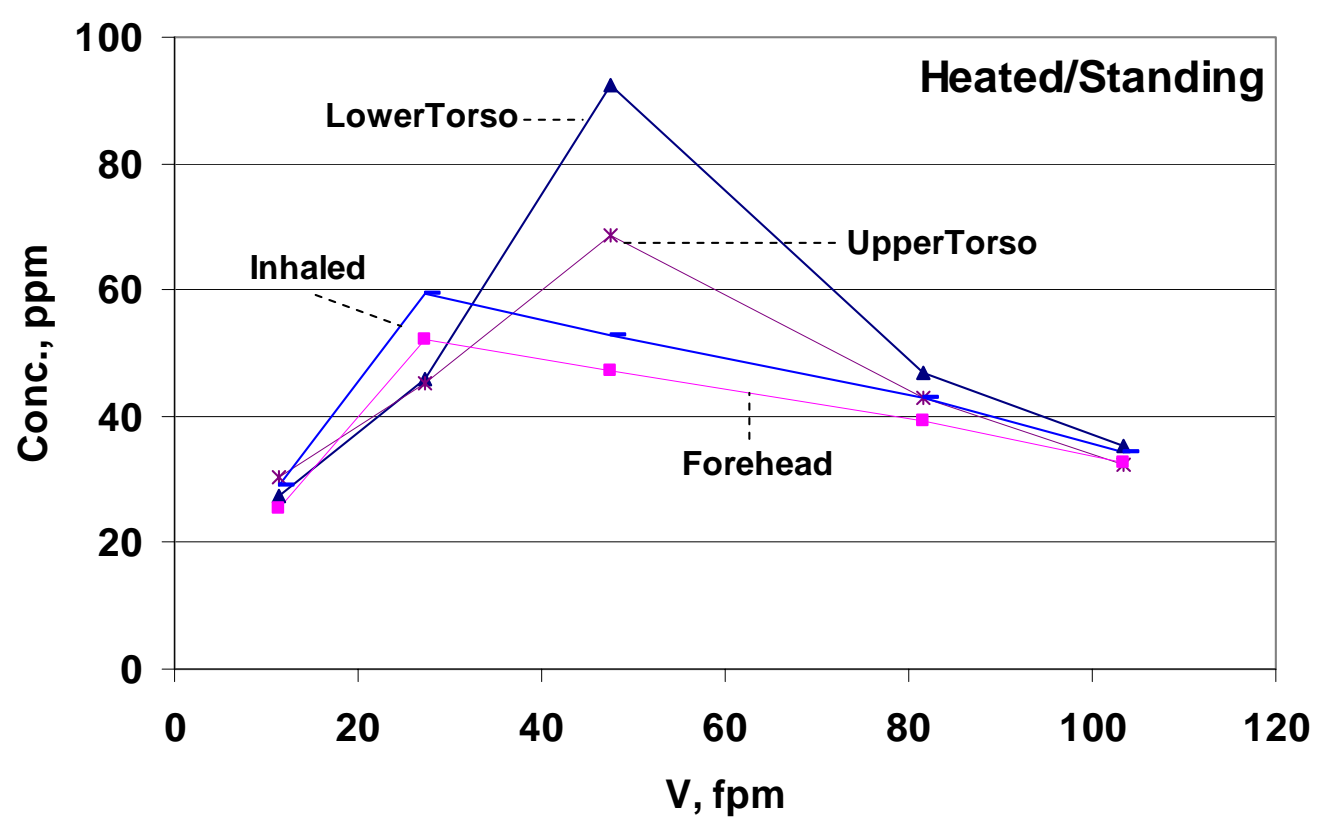

Figure 4.11: Mean concentration versus velocity for standing/heated manikin

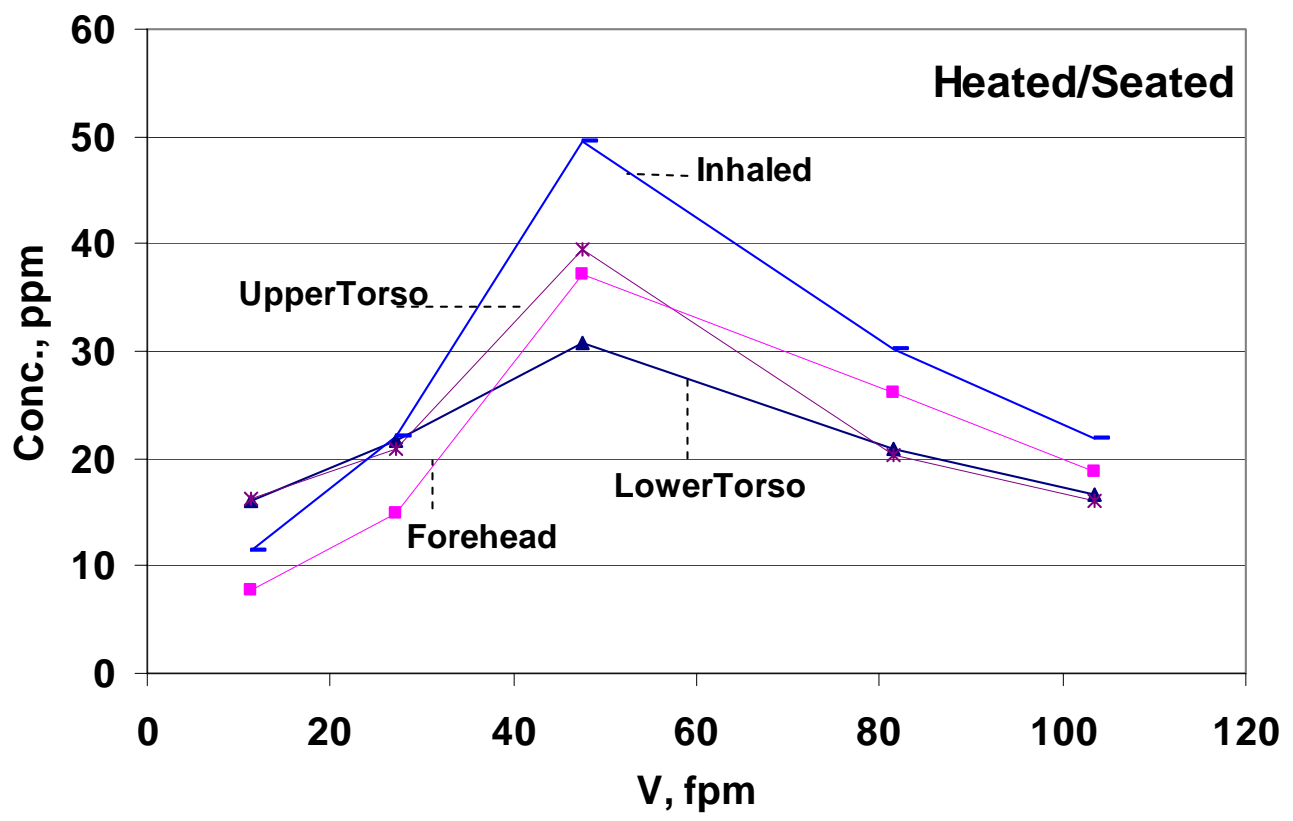

Figure 4.12: Mean concentration versus velocity for seated/heated manikin 


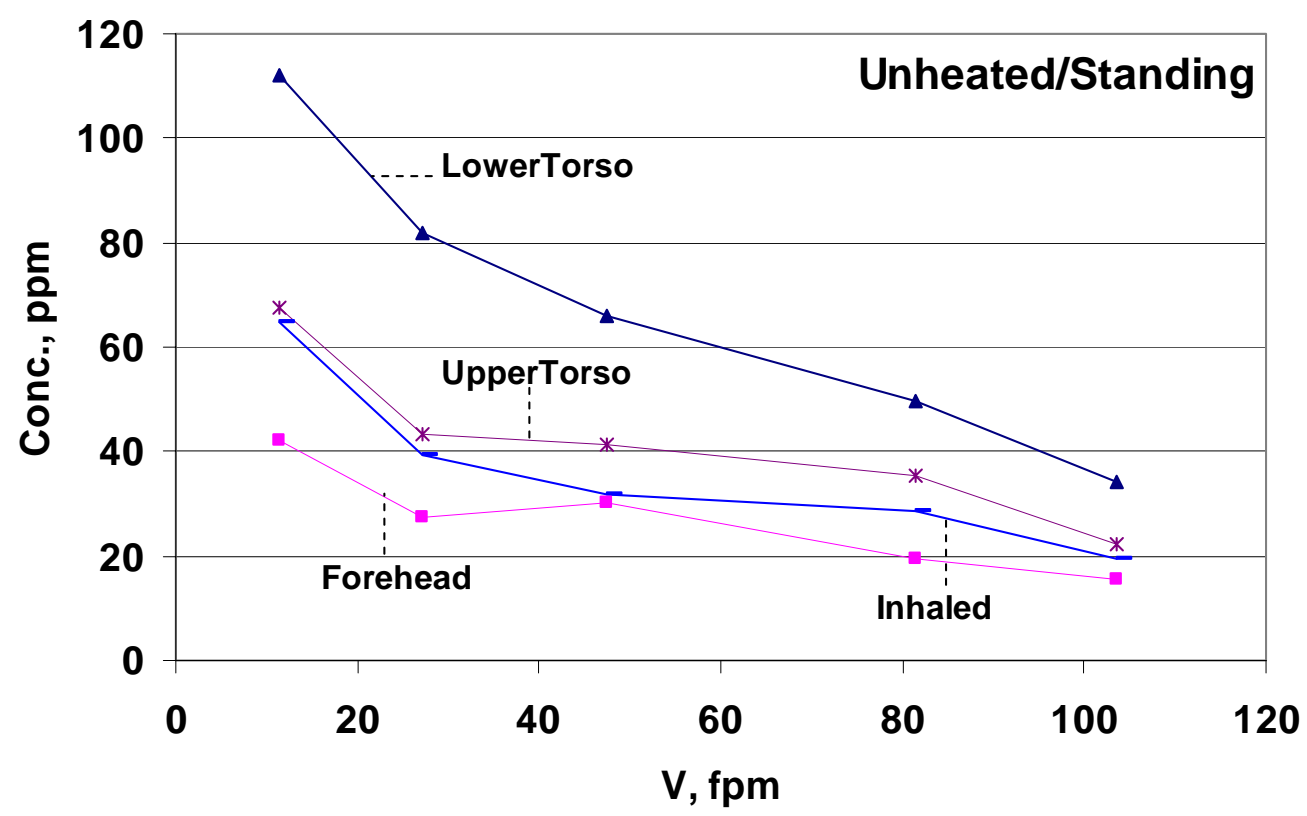

Figure 4.13: Mean concentration versus velocity for standing/unheated manikin

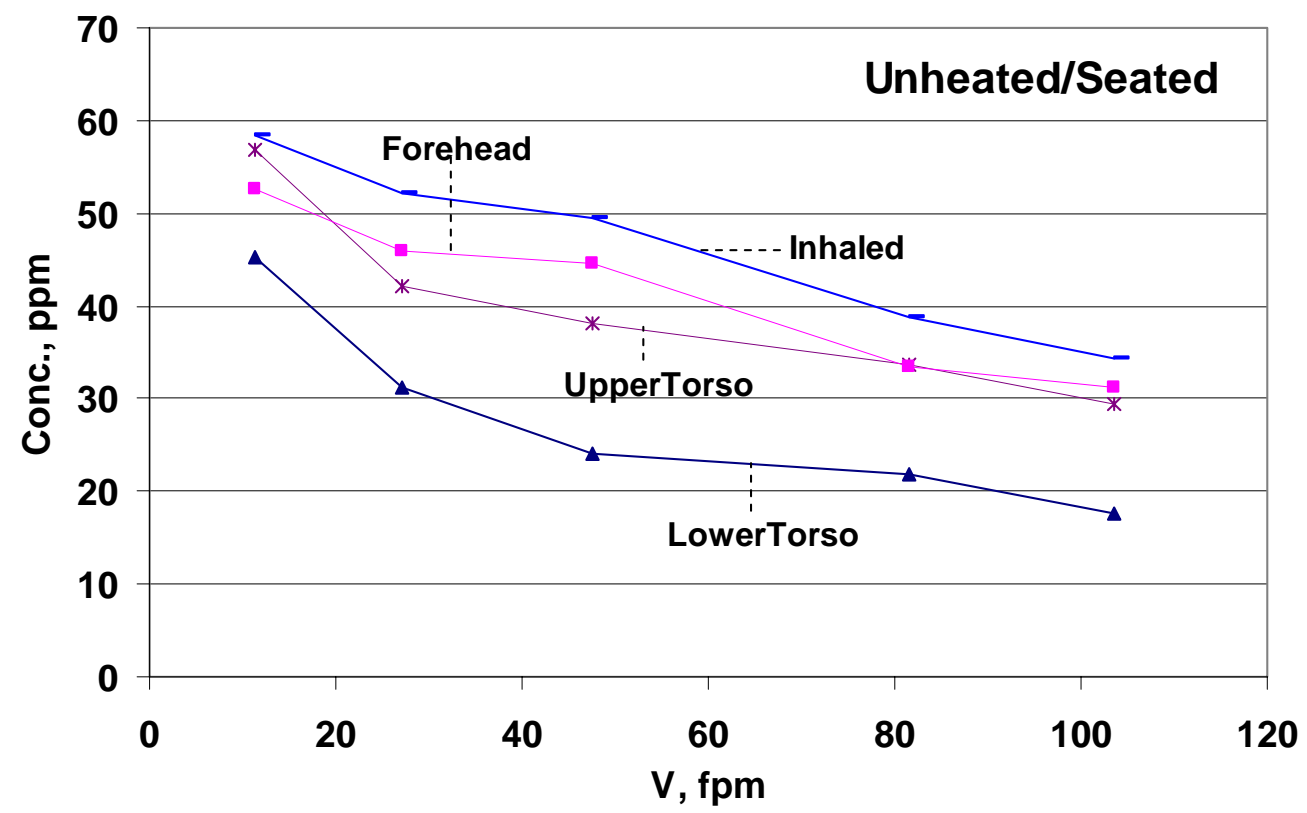

Figure 4.14: Mean concentration versus velocity for seated/unheated manikin 


\subsection{Effects of Independent Variables on $C_{\text {inhaled, }}, C_{\text {upper.torso, }}$ and $C_{\text {lower.torso }}$}

Since concentrations near the mouth behaved similarly, the average of $\mathrm{C}_{\text {mouth }}$ and $\mathrm{C}_{\text {nose }}$ were used to compute $\mathrm{C}_{\text {inhaled. }}$. Likewise, $\mathrm{C}_{\text {upper.torso }}$ is the average of $\mathrm{C}_{\text {neck }}$ and $\mathrm{C}_{\text {collars }}$ and $\mathrm{C}_{\text {lower.torso }}$ is the average of $\mathrm{C}_{\text {chest }}$ and $\mathrm{C}_{\text {lapels. }} . \mathrm{C}_{\text {forehead }}$ was the lowest concentration level compared to $\left(\mathrm{C}_{\text {mouth }}\right.$ and $\left.\mathrm{C}_{\text {nose }}\right)$ so it was not used to compute $\mathrm{C}_{\text {inhaled. }}$

Figures 4.11 to 4.14 show the effects of velocity, body heat and posture on $\mathrm{C}_{\text {inhaled, }}$, $\mathrm{C}_{\text {upper.torso, }}$ and $\mathrm{C}_{\text {lower.torso. }}$. For lifelike condition (heating), all three concentrations varied in an inverted- $\mathrm{V}$ shape with velocity for both sitting and standing. Peak concentration was measured for $\mathrm{C}_{\text {upper.torso }}$ and $\mathrm{C}_{\text {lower.torso }}$ at $48 \mathrm{fpm}$ for both postures. Peaks in $\mathrm{C}_{\text {inhaled }}$ were at 48 fpm for sitting and $27 \mathrm{fpm}$ for standing. The magnitudes of the peaks were about the same at a given location. However, the concentrations differed sharply by measurement locations. More importantly, the differences in concentrations were strongly affected by posture. For example, the lower torso concentrations were much higher than $C_{\text {inhaled }}$ for standing and lower for sitting (see Figures 4.11 and 4.12). Hence, whether a torso measurement exaggerated or underestimated the actual level depends on whether the manikin was sitting or standing.

Likewise patterns occurred for the unheated manikin. For example, the lower torso concentrations were much higher than inhaled for standing and lower for sitting for the entire velocity range (see Figures 4.13 and 4.14). 
Table 4.3: Ratios of Concentrations to $\mathrm{C}_{\text {mouth }}$ for all Velocities and Manikin Treatments

\begin{tabular}{|c|c|c|c|c|c|c|c|c|c|}
\hline Treatment & $\mathrm{V}, \mathrm{fpm}$ & $\mathrm{C}_{\text {c.chest }}$ & $\mathrm{C}_{1 . \text { lapel }}$ & $\mathrm{C}_{\text {r.lapel }}$ & $\mathrm{C}_{\text {neck }}$ & $\mathrm{C}_{\text {l.collar }}$ & $\mathrm{C}_{\text {r.collar }}$ & $\mathrm{C}_{\text {nose }}$ & $\mathrm{C}_{\text {forehead }}$ \\
\hline \multirow{5}{*}{$\begin{array}{l}\text { Heated } \\
\text { Standing }\end{array}$} & 11 & 1.07 & 0.81 & 0.91 & 1.08 & 1.02 & 0.98 & 0.97 & 0.86 \\
\hline & 27 & 0.80 & 0.67 & 0.76 & 0.86 & 0.72 & 0.64 & 0.94 & 0.85 \\
\hline & 48 & 1.95 & 1.48 & 1.83 & 1.39 & 1.18 & 1.36 & 1.01 & 0.90 \\
\hline & 82 & 1.15 & 0.97 & 1.04 & 1.04 & 0.85 & 0.99 & 0.93 & 0.88 \\
\hline & 104 & 1.06 & 0.97 & 0.95 & 1.01 & 0.78 & 0.94 & 0.94 & 0.92 \\
\hline \multirow{5}{*}{$\begin{array}{l}\text { Heated } \\
\text { Seated }\end{array}$} & 11 & 1.45 & 1.21 & 1.12 & 1.18 & 1.28 & 1.36 & 0.80 & 0.61 \\
\hline & 27 & 1.00 & 0.97 & 0.90 & 0.94 & 0.94 & 0.89 & 0.95 & 0.65 \\
\hline & 48 & 0.66 & 0.65 & 0.61 & 0.89 & 0.77 & 0.79 & 1.04 & 0.77 \\
\hline & 82 & 0.80 & 0.71 & 0.62 & 0.70 & 0.70 & 0.67 & 1.04 & 0.88 \\
\hline & 104 & 0.84 & 0.74 & 0.70 & 0.73 & 0.78 & 0.70 & 0.99 & 0.86 \\
\hline \multirow{5}{*}{$\begin{array}{l}\text { Unheated } \\
\text { Standing }\end{array}$} & 11 & 1.82 & 2.15 & 1.32 & 1.09 & 1.10 & 1.01 & 1.06 & 0.69 \\
\hline & 27 & 1.87 & 2.23 & 1.73 & 0.99 & 1.04 & 1.03 & 0.88 & 0.65 \\
\hline & 48 & 2.08 & 2.32 & 1.70 & 1.19 & 1.29 & 1.24 & 0.88 & 0.92 \\
\hline & 82 & 1.72 & 1.65 & 1.60 & 1.17 & 1.23 & 1.14 & 0.90 & 0.64 \\
\hline & 104 & 1.51 & 2.10 & 1.35 & 1.01 & 1.03 & 1.07 & 0.80 & 0.72 \\
\hline \multirow{5}{*}{$\begin{array}{c}\text { Unheated } \\
\text { Seated }\end{array}$} & 11 & 0.76 & 0.91 & 0.75 & 0.98 & 1.03 & 0.91 & 0.99 & 0.90 \\
\hline & 27 & 0.57 & 0.64 & 0.59 & 0.88 & 0.85 & 0.76 & 1.05 & 0.91 \\
\hline & 48 & 0.48 & 0.56 & 0.49 & 0.84 & 0.83 & 0.75 & 1.09 & 0.94 \\
\hline & 82 & 0.53 & 0.60 & 0.59 & 0.89 & 0.88 & 0.84 & 1.01 & 0.87 \\
\hline & 104 & 0.46 & 0.57 & 0.52 & 0.96 & 0.90 & 0.72 & 1.00 & 0.91 \\
\hline
\end{tabular}




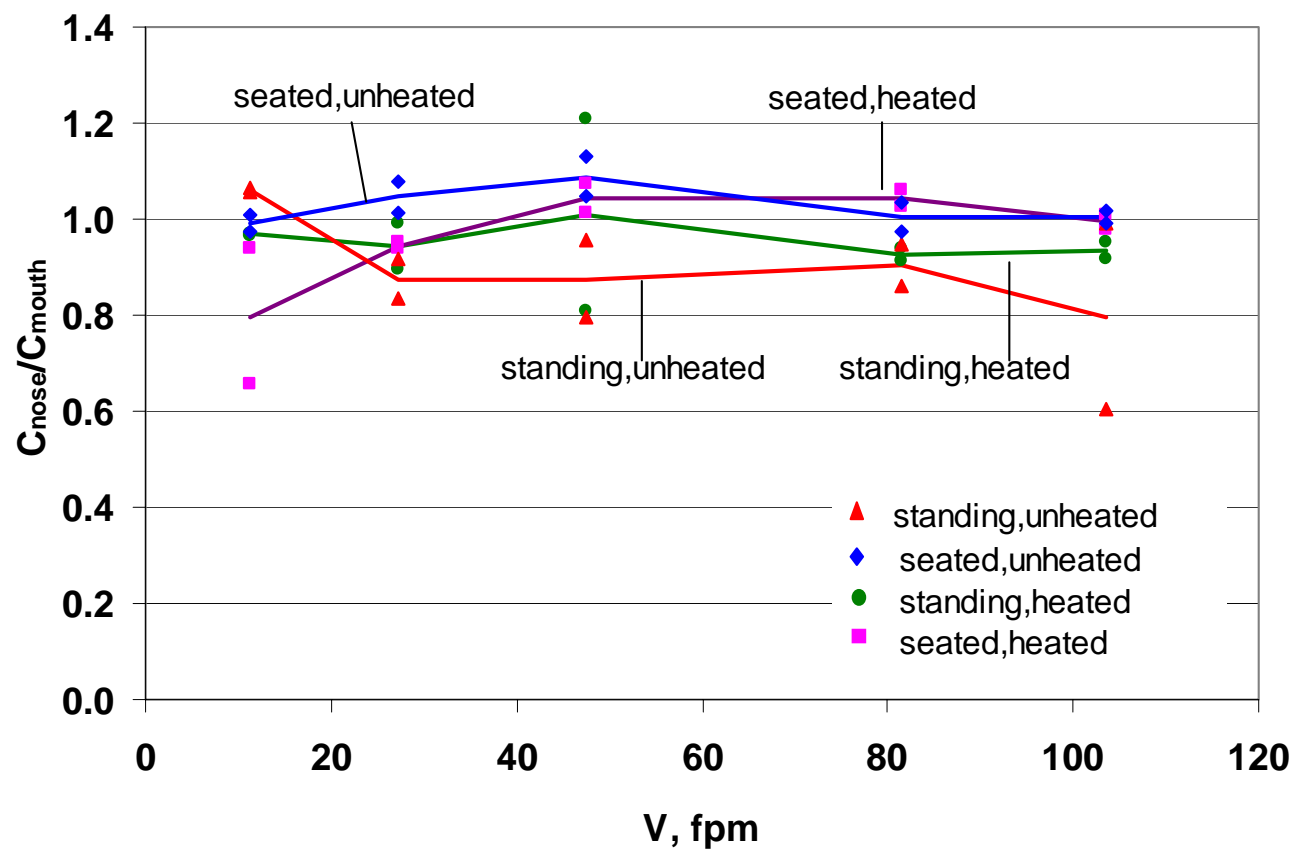

Figure 4.15: Scatter and mean plots of $\mathrm{C}_{\text {nose }} / \mathrm{C}_{\text {mouth }}$ vs. velocity for all manikin treatments

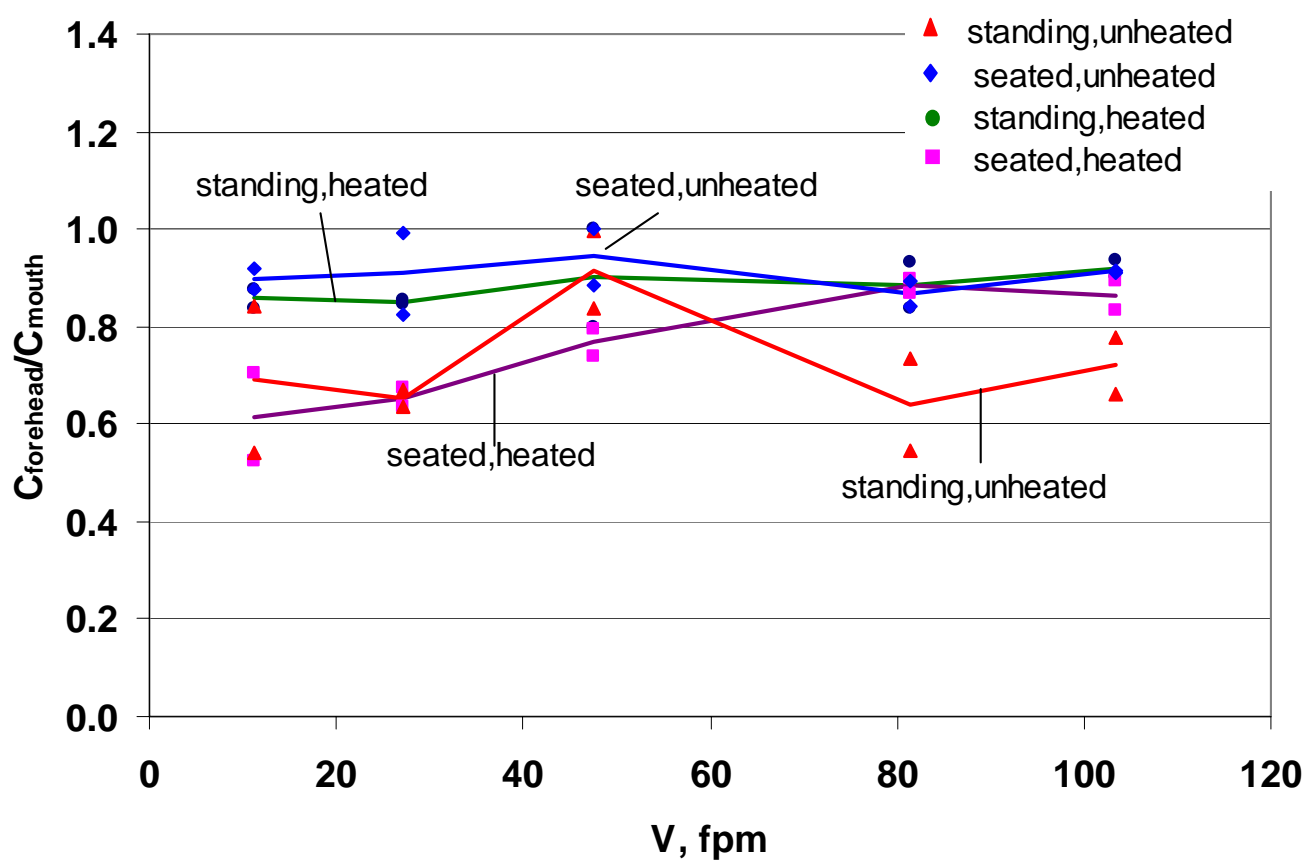

Figure 4.16: Scatter and mean plots of $\mathrm{C}_{\text {forehead }} / \mathrm{C}_{\text {mouth }}$ vs. velocity for all manikin treatments 


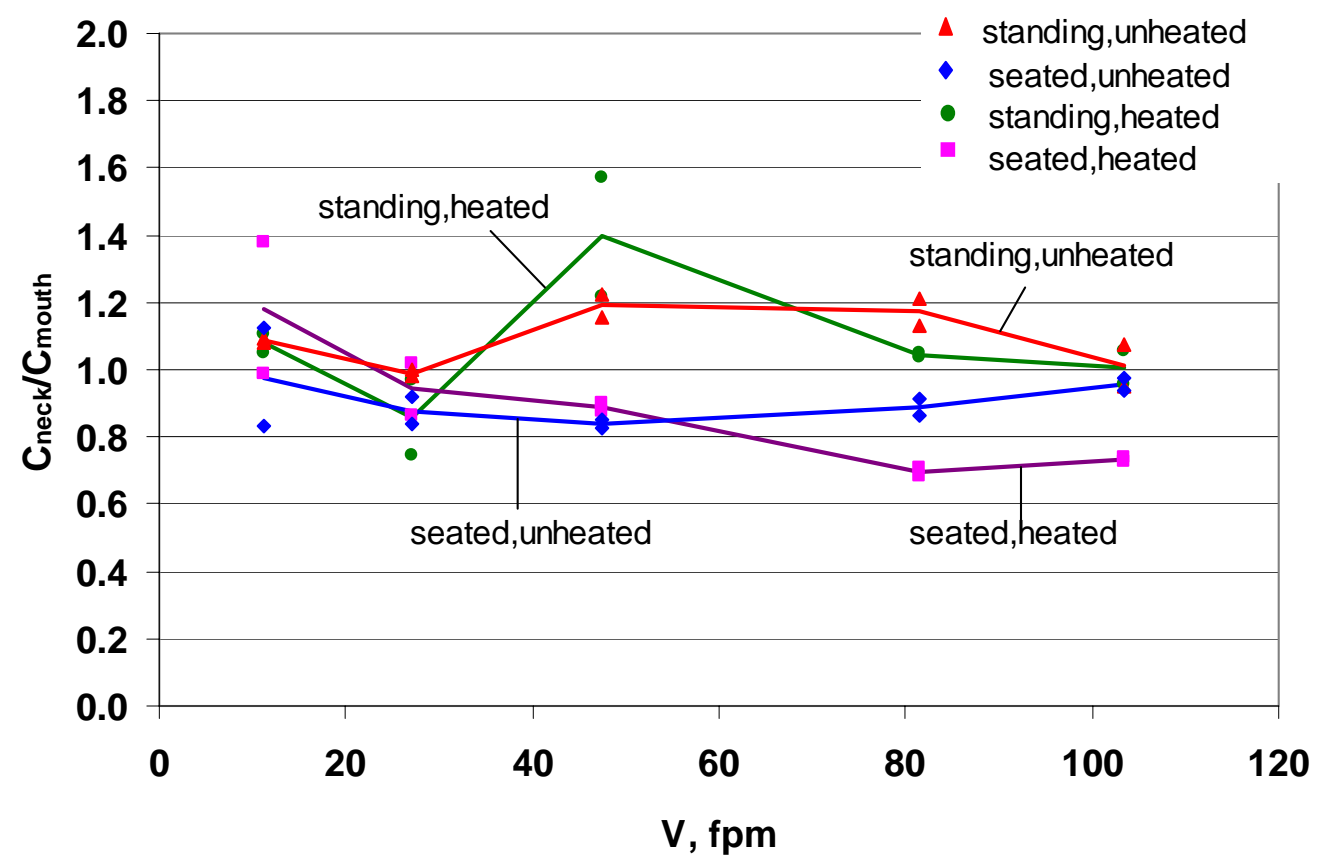

Figure 4.17: Scatter and mean plots of $\mathrm{C}_{\text {neck }} / \mathrm{C}_{\text {mouth }}$ vs. velocity for all manikin treatments

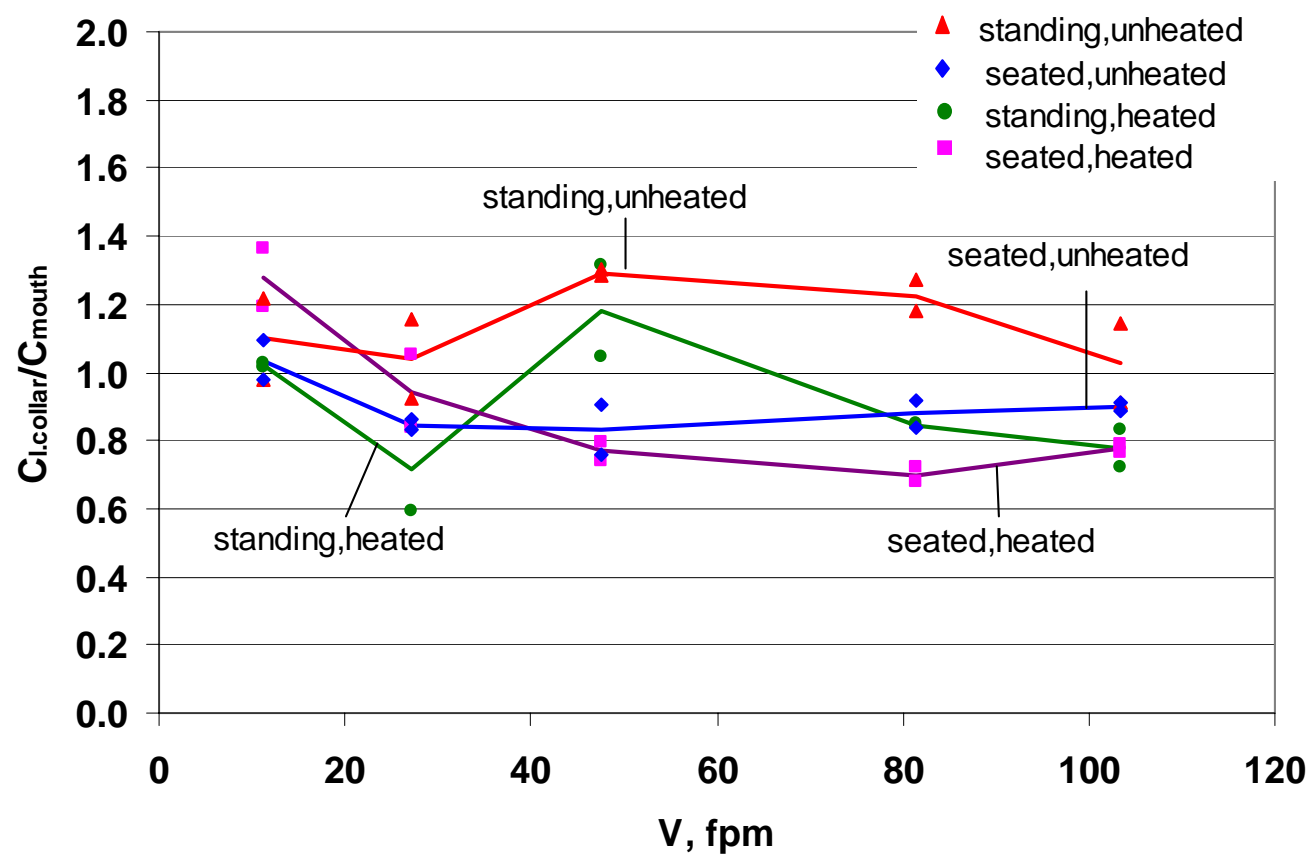

Figure 4.18: Scatter and mean plots of $\mathrm{C}_{\text {l.collar }} / \mathrm{C}_{\text {mouth }}$ vs. velocity for all manikin treatments 


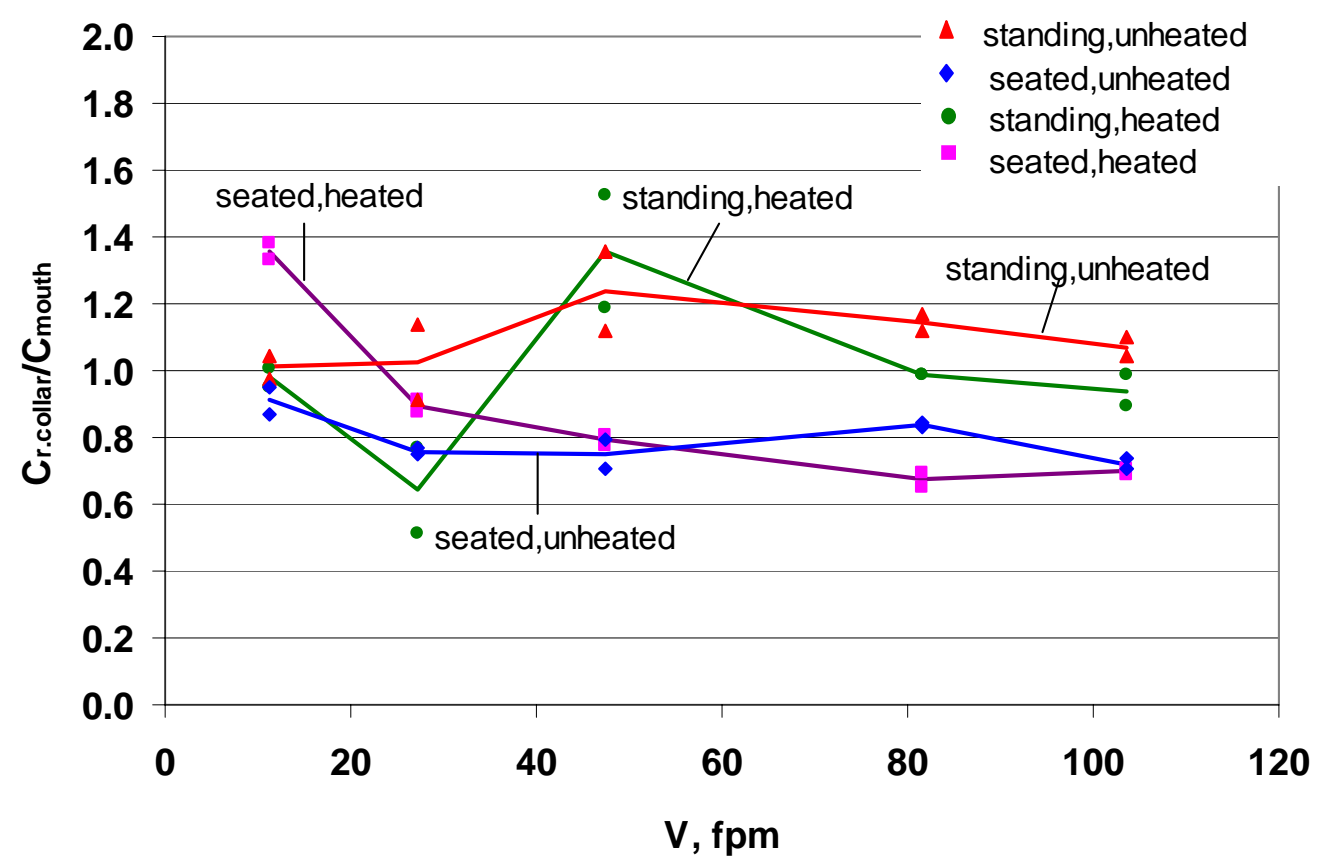

Figure 4.19: Scatter and mean plots of $\mathrm{C}_{\mathrm{r} . \text { collar }} / \mathrm{C}_{\text {mouth }}$ vs. velocity for all manikin treatments

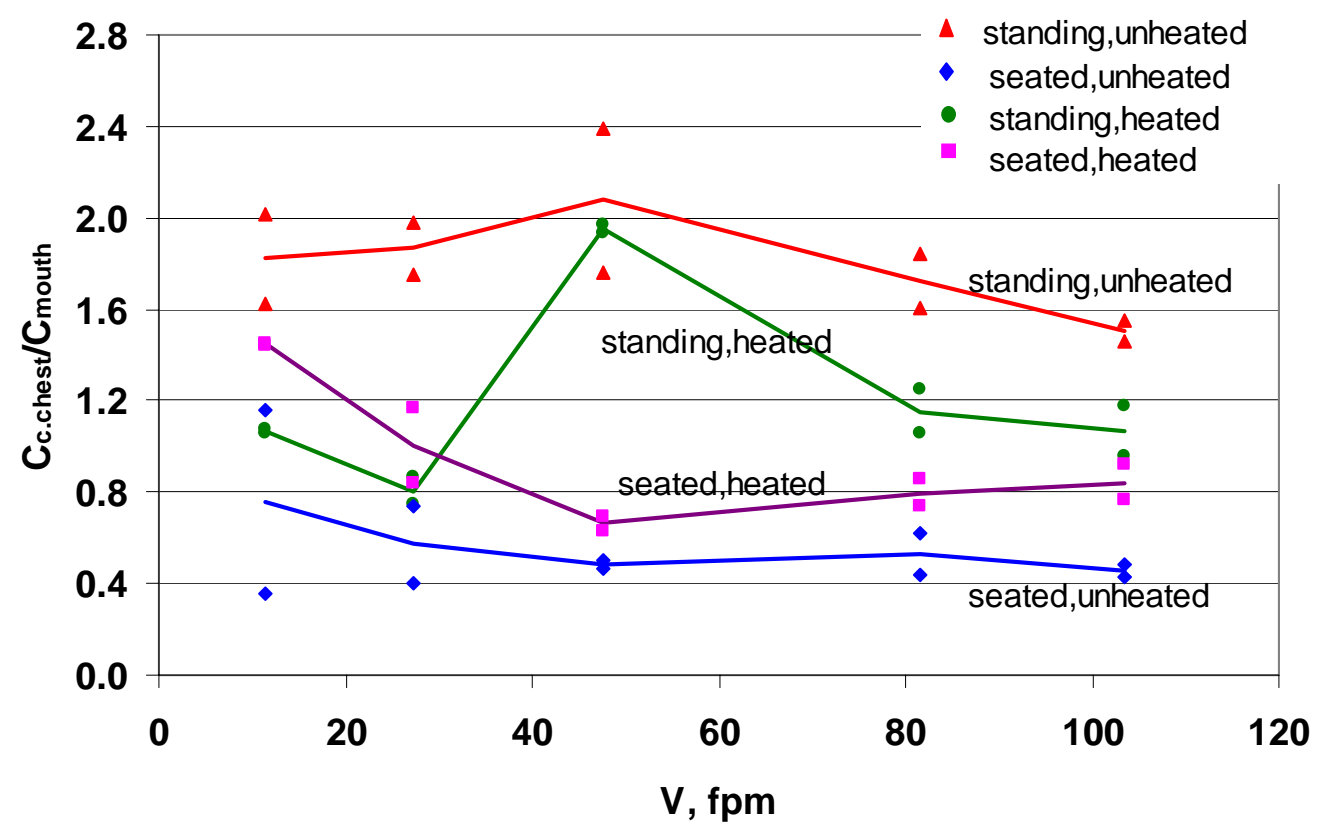

Figure 4.20: Scatter and mean plots of $\mathrm{C}_{\text {c.chest }} / \mathrm{C}_{\text {mouth }}$ vs. velocity for all manikin treatments 


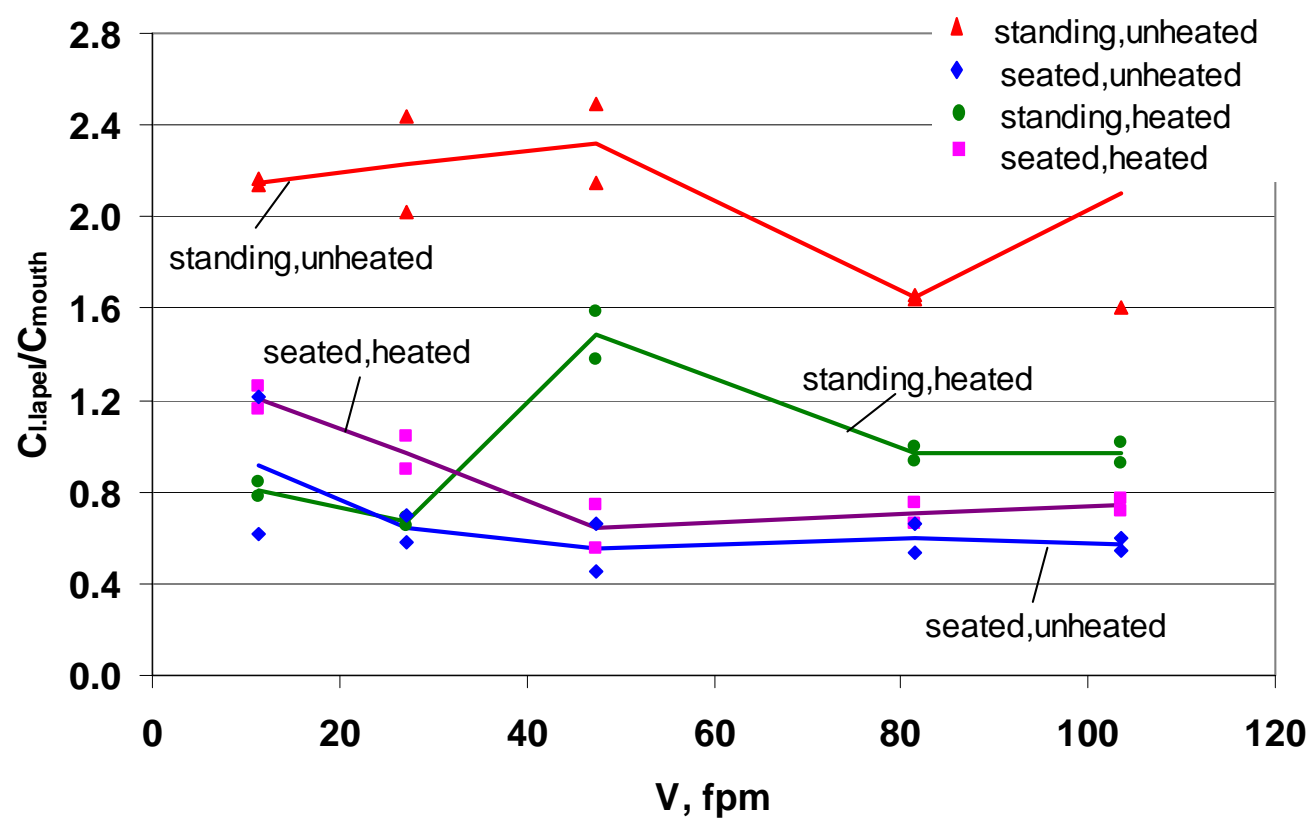

Figure 4.21: Scatter and mean plots of $\mathrm{Cl}_{1 . \text { lapel }} / \mathrm{C}_{\text {mouth }}$ vs. velocity for all manikin treatments

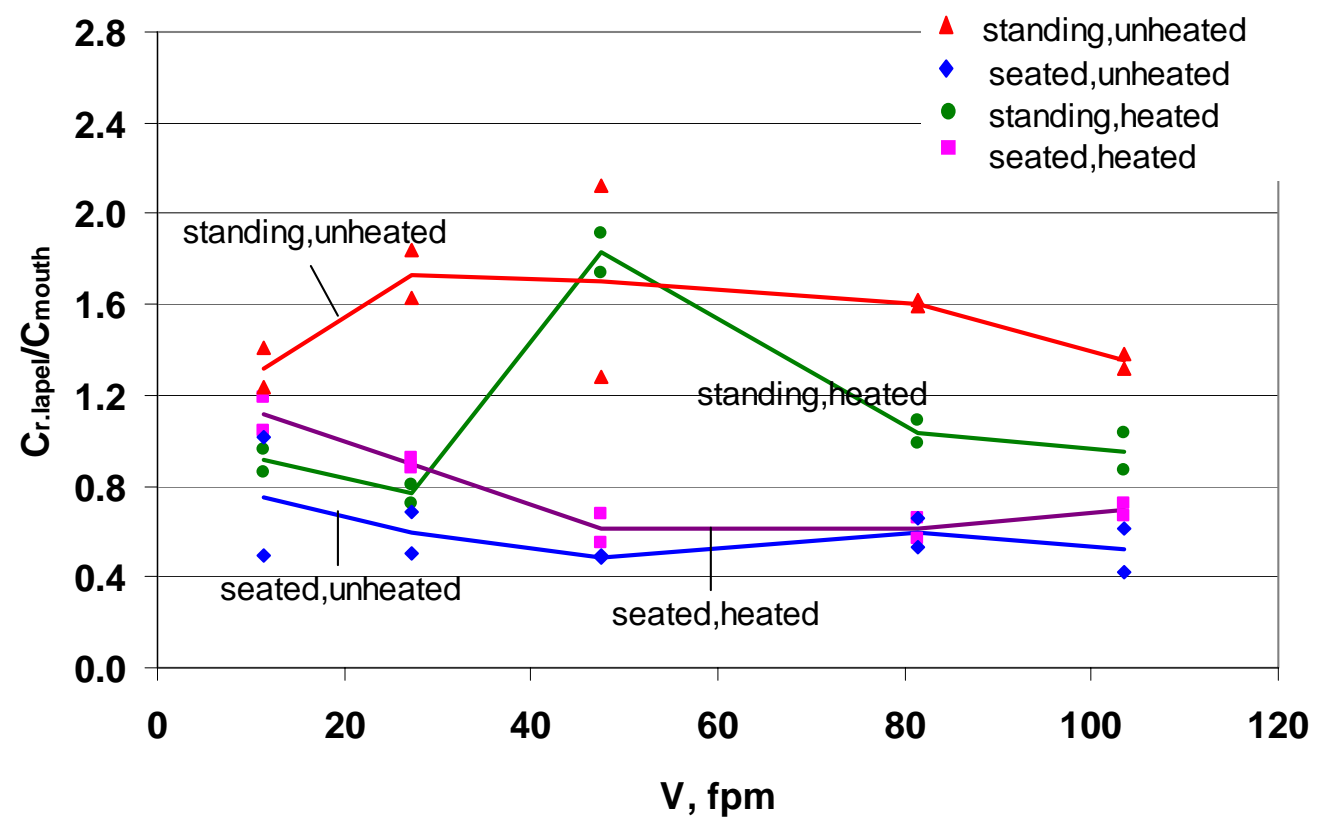

Figure 4.22: Scatter and mean plots of $\mathrm{C}_{\mathrm{r} \text {.lapel }} / \mathrm{C}_{\text {mouth }}$ vs. velocity for all manikin treatments 


\subsection{Effects of Independent Variables on Ratio of Concentrations}

The main purpose of this study was to investigate the agreement between lapels, collars, center chest, nose, neck, and forehead sampling locations to mouth location as assumed to be inhaled exposure. Concentration ratios to $\mathrm{C}_{\text {mouth }}$ for locations at the face $\left(\mathrm{C}_{\text {forehead }} / \mathrm{C}_{\text {mouth }}, \mathrm{C}_{\text {nose }} / \mathrm{C}_{\text {mouth }}\right)$, shoulder $\left(\mathrm{C}_{\text {l.collar }} / \mathrm{C}_{\text {mouth }}, \mathrm{C}_{\text {r.collar }} / \mathrm{C}_{\text {mouth }}, \mathrm{C}_{\text {neck }} / \mathrm{C}_{\text {mouth }}\right)$, and chest $\left(\mathrm{C}_{\text {r.lapel }} / \mathrm{C}_{\text {mouth }}, \mathrm{C}_{\text {c.chest }} / \mathrm{C}_{\text {mouth }}, \mathrm{C}_{\text {l.lapel }} / \mathrm{C}_{\text {mouth }}\right)$ varied wind tunnel velocity, heating, and posture.

The effect of velocity, heating, and posture on ratios of concentrations is shown in Figures 4.15 to 4.22 and is listed in Table 4.3. As shown in Figures 4.15-4.22, for the ratios of concentrations at the shoulder and chest levels, posture had an effect on the relationship with velocity than did heating. For example, sitting had similar patterns on ratios of concentrations at the shoulder and chest whether the manikin is heated or not. However, standing showed higher peak ratios for the effect of velocity than sitting. As discussed earlier in section 4.2, for a standing heated manikin, concentrations at the mouth had peak values occurred at $27 \mathrm{fpm}$, while, concentrations at the shoulder and chest levels had peak values occurred at $48 \mathrm{fpm}$. Therefore, the ratios of concentrations at the shoulder and chest levels for a standing heated manikin had two inverted-V peaks occurred at 27 and $48 \mathrm{fpm}$. The scatter in ratios of concentration was higher at the lower velocities than at higher velocities.

As shown in Table 4.3, for the heated manikin, the ratio of nose to mouth $\mathrm{C}_{\text {nose }} / \mathrm{C}_{\text {mouth }}$ was very close to unity for the entire velocity range and for both postures, except one value at $11 \mathrm{fpm}$ for sitting posture. The ratio of forehead to mouth $\mathrm{C}_{\text {forehead }} / \mathrm{C}_{\text {mouth }}$ was always lower than unity for the entire velocity range, but it approached unity (0.92) at highest velocity level. It is possible that $\mathrm{C}_{\text {forehead }}$ always underestimated mouth exposure due to the downwash patterns from the sides of the face and the top of head.

The effect of posture, velocity and heating on ratios of concentrations at the shoulder is shown in Figures 4.17 - 4.19. For lifelike conditions, $\mathrm{C}_{\text {neck }} / \mathrm{C}_{\text {mouth }}, \mathrm{C}_{\text {l.collar }} / \mathrm{C}_{\text {mouth }}$, and $\mathrm{C}_{\mathrm{r} \text {.collar }} / \mathrm{C}_{\text {mouth }}$, had two inverted-V peaks with velocity at 27 and $48 \mathrm{fpm}$ for standing and a declined flattened-U relationship with velocity for sitting. As listed in Table $4.3, \mathrm{C}_{\text {neck }} / \mathrm{C}_{\text {mouth }}$, $\mathrm{C}_{\text {l.collar }} / \mathrm{C}_{\text {mouth }}$, and $\mathrm{C}_{\text {r.collar }} / \mathrm{C}_{\text {mouth }}$, were around (1.02) at $11 \mathrm{fpm}$ for standing posture, and were around (0.94) at $27 \mathrm{fpm}$ for sitting.

The effect of posture, velocity and heating on ratios of concentrations at the chest is shown in Figures 4.20-4.22. For lifelike conditions, heated manikin, ratios of concentrations at center chest, left lapel, and right lapel to mouth had two inverted-V peaks with velocity at 27 and $48 \mathrm{fpm}$ for standing posture and a declined flattened-U relationship with velocity for

sitting. As listed in Table $4.3, \mathrm{C}_{\text {c.chest }} / \mathrm{C}_{\text {mouth }}, \mathrm{C}_{\text {l.lapel }} / \mathrm{C}_{\text {mouth }}$ and $\mathrm{C}_{\mathrm{r} \text {.lapel }} / \mathrm{C}_{\text {mouth }}$ had values ranged (0.9-1.2) at the lower velocity levels for both sitting and standing. At $48 \mathrm{fpm}$, concentrations at the chest overestimated mouth concentrations by 1.75 for standing, and underestimated mouth concentrations by 0.65 for sitting. 


\section{Chapter 5: Discussions of Study I}

Data Desk (Data Description Inc. Ithaca, NY) software was used to do statistical analysis of results. The independent variables for this study were five levels of velocity (11, $27,48,82$, and $104 \mathrm{fpm}$ ), two levels of heating (unheated, heated) and two levels of posture (standing, seated). The dependent variables were concentrations at each sampling location and ratio of concentrations. As results were quite variable, log transformation of concentration values and ratio of concentrations were used.

Dependent variables were log-transformed to produce residuals that were normally distributed (see Section 5.1). Using log ratio of concentration allowed analysis of the differences in logs of two dependent values, removing "small denominator" problems associated with actual ratios: $\log \left\{\mathrm{C}_{\text {neck }} / \mathrm{C}_{\text {mouth }}\right\}=\left\{\log \mathrm{C}_{\text {neck }}-\log \mathrm{C}_{\text {mouth }}\right\}$

\subsection{Log-Transformation of Dependent Variables}

Critical value for coefficient of correlation between ordered residuals and expected values under normality when distribution of error term is normal was found to be equal $(\mathrm{r}=$ 0.972 ) for a sample of size $n=40$, and level of significance alpha $=0.05$ (Neter et al. 1996). Table 5.1 listed the coefficient of correlation for externally studentized residuals versus nscores (computed using DataDesk software) for log-transformed dependent variables (concentrations and ratios of concentrations for each sampling location).

As shown in Table 5.1, log transformed individual concentration and ratio of concentartions showed reasonable degree of normality for all sampling locations, except for $\log \mathrm{C}_{\text {nose }}, \log \left\{\mathrm{C}_{\text {nose }} / \mathrm{C}_{\text {mouth }}\right\}$, Log $\left\{\mathrm{C}_{\mathrm{r} . \text { collar }} / \mathrm{C}_{\text {mouth }}\right\}$, and $\log \left\{\mathrm{C}_{\mathrm{c} . \text { chest }} / \mathrm{C}_{\text {mouth }}\right\}$. Although correlation coefficients varied for each dependent variable, there was no substantial departure from linearity. However, as shown in Figures A.2, A.10, A.14, and A.15, the non-normality is due to 1 or 2 points. Normal probability plots for log-transformed concentrations and logtransformed ratios of concentrations are shown in Appendix A. 
Table 5.1: Coefficient of correlation (R2) for externally studentised residuals against normal scores for log-transformed individual concentrations and ratios of concentrations

\begin{tabular}{lclc}
\hline Individual Concentrations & $\mathrm{R}^{2}$ & Ratios of Concentrations & $\mathrm{R}^{2}$ \\
\hline \hline $\log \mathrm{C}_{\text {mouth }}$ & 0.99 & $\log \left\{\mathrm{C}_{\text {nose }} / \mathrm{C}_{\text {mouth }}\right\}$ & 0.93 \\
$\log \mathrm{C}_{\text {nose }}$ & 0.95 & $\log \left\{\mathrm{C}_{\text {forehead }} / \mathrm{C}_{\text {mouth }}\right\}$ & 0.97 \\
$\log \mathrm{C}_{\text {forehead }}$ & 0.99 & $\log \left\{\mathrm{C}_{\text {neck }} / \mathrm{C}_{\text {mouth }}\right\}$ & 0.99 \\
$\log \mathrm{C}_{\text {neck }}$ & 0.98 & $\log \left\{\mathrm{C}_{\text {l.collar }} / \mathrm{C}_{\text {mouth }}\right\}$ & 0.96 \\
$\log \mathrm{C}_{\text {l.collar }}$ & 0.99 & $\log \left\{\mathrm{C}_{\text {r.collar }} / \mathrm{C}_{\text {mouth }}\right\}$ & 0.95 \\
$\log \mathrm{C}_{\text {r.collar }}$ & 0.99 & $\log \left\{\mathrm{C}_{\text {c.chest }} / \mathrm{C}_{\text {mouth }}\right\}$ & 0.92 \\
$\log \mathrm{C}_{\text {c.chest }}$ & 0.96 & $\log \left\{\mathrm{C}_{\text {l.lapel }} / \mathrm{C}_{\text {mouth }}\right\}$ & 0.98 \\
$\log \mathrm{C}_{\text {l.lapel }}$ & 0.99 & $\log \left\{\mathrm{C}_{\text {r.lapel }} / \mathrm{C}_{\text {mouth }}\right\}$ & 0.97 \\
$\log \mathrm{C}_{\text {r.lapel }}$ & 0.99 & & \\
$\log \mathrm{C}_{\text {inhaled }}$ & 0.98 & & \\
$\log \mathrm{C}_{\text {uppertorso }}$ & 0.98 & & \\
$\log \mathrm{C}_{\text {lowertorso }}$ & 0.97 & & \\
\hline & \multicolumn{2}{|}{$\mathrm{R}_{\text {critical }}=0.972$} &
\end{tabular}

\subsection{Methods for Analysis of Variance (ANOVA)}

The independent variables for this study were five levels of velocity $(11,27,48,82$, and $104 \mathrm{fpm}$ ), two levels of heating (unheated, heated) and two levels of posture (standing, seated). The dependent variables were concentrations at each sampling location and ratios of concentrations. The design is a completely randomized factorial design with two replications for each treatment combination, see Table 5.2. The linear statistical model used for the analysis of variance is illustrated by the following equation:

$\mathrm{Y}_{\mathrm{ijk}}=\mu+\tau_{\mathrm{i}}+\beta_{\mathrm{j}}+\gamma_{\mathrm{k}}+(\tau \beta)_{\mathrm{ij}}+(\tau \gamma)_{\mathrm{ik}}+(\beta \gamma)_{\mathrm{jk}}+(\tau \beta \gamma)_{\mathrm{ijk}}+\varepsilon_{\mathrm{ijkl}}$

Where $\mathrm{i}=1,2,3,4,5 ; \mathrm{j}=1,2 ; \mathrm{k}=1,2 ; 1=1,2 ;$ and $\tau_{\mathrm{i}}, \beta_{\mathrm{j}}, \gamma_{\mathrm{k}}$, represent the effects of wind tunnel velocity, manikin heating and posture, while $(\tau \beta)_{\mathrm{ij}},(\tau \gamma)_{\mathrm{ik}},(\beta \gamma)_{\mathrm{jk}},(\tau \beta \gamma)_{\mathrm{ijk}}$ represent the interaction of velocity, heating and posture. $\varepsilon_{\mathrm{ijkl}}$ represents the random error. 
Table 5.2: Completely Randomized Factorial Design of Experiments

\begin{tabular}{ccccccc}
\hline \multirow{5}{*}{ Heated } & & \multicolumn{5}{c}{ Velocity, fpm } \\
\cline { 3 - 7 } & & 11 & 27 & 48 & 82 & 104 \\
\multirow{3}{*}{ Unheated } & Seated & ++ & ++ & ++ & ++ & ++ \\
& Standing & ++ & ++ & ++ & ++ & ++ \\
& Seated & ++ & ++ & ++ & ++ & ++ \\
& Standing & ++ & ++ & ++ & ++ & ++ \\
\hline
\end{tabular}

Analysis of variance was performed on log-transformed dependent variables (concentrations and ratios of concentrations for all sampling locations) for the effects of the independent variables (velocity, heating and posture) and their interaction. The outline for ANOVA table was obtained from (Montgomery, D., 1997). For the fixed effects model, test statistics for each independent variable and interaction was developed by dividing the corresponding mean square for the variable or interaction by the mean square error. All of these $\mathrm{F}$ tests were one tail tests. The number of degrees of freedom for any factor is the number of levels of the factor minus one, the number of degrees of freedom for an interaction is the product of the number of degrees of freedom associated with the individual components of the interaction (Montgomery, D, 1997). All tests were done at 95\% confidence level $(\alpha=0.05)$. Data Desk software was used to compute ANOVA and the results of the F-tests were summarized as p-values.

Table 5.3 and 5.4 list the p-values for log-transformed individual concentrations and ratios of concentrations for all sampling locations. Table 5.5 shows p-values for log transformed concentrations for $\mathrm{C}_{\text {inhaled }}, \mathrm{C}_{\text {uppertorso }}$, and $\mathrm{C}_{\text {lowertorso }}$.

Table 5.3: p-Values from ANOVAs for Log-Transformed Individual Concentrations

\begin{tabular}{lcccccccccc}
\hline Source & $\mathrm{df}$ & $\mathrm{C}_{\text {mouth }}$ & $\mathrm{C}_{\text {nose }}$ & $\mathrm{C}_{\text {forehead }}$ & $\mathrm{C}_{\text {neck }}$ & $\mathrm{C}_{\text {l.collar }}$ & $\mathrm{C}_{\text {r.collar }}$ & $\mathrm{C}_{\text {c.chest }}$ & $\mathrm{C}_{\text {l.lapel }}$ & $\mathrm{C}_{\text {r.lapel }}$ \\
\hline Const & 1 & 0.001 & 0.001 & 0.001 & 0.001 & 0.001 & 0.001 & 0.001 & 0.001 & 0.001 \\
Velocity & 4 & 0.001 & 0.001 & 0.001 & 0.001 & 0.001 & 0.001 & 0.001 & 0.001 & 0.001 \\
Heating & 1 & 0.001 & 0.01 & 0.001 & 0.001 & 0.001 & 0.001 & 0.09 & 0.001 & 0.001 \\
Posture & 1 & 0.001 & 0.24 & 0.07 & 0.001 & 0.001 & 0.001 & 0.001 & 0.001 & 0.001 \\
VelocityxHeating & 4 & 0.001 & 0.001 & 0.001 & 0.001 & 0.001 & 0.001 & 0.001 & 0.001 & 0.001 \\
VelocityxPosture & 4 & 0.001 & 0.001 & 0.01 & 0.44 & 0.47 & 0.99 & 0.54 & 0.34 & 0.26 \\
HeatingxPosture & 1 & 0.001 & 0.001 & 0.001 & 0.001 & 0.001 & 0.001 & 0.27 & 0.02 & 0.24 \\
\hline
\end{tabular}


Table 5.4: p-Values from ANOVAs for Log-Transformed Ratios of Concentrations to $\mathrm{C}_{\text {mouth }}$

\begin{tabular}{lccccccccc}
\hline Source & $\mathrm{df}$ & $\mathrm{C}_{\text {nose }}$ & $\mathrm{C}_{\text {forehead }}$ & $\mathrm{C}_{\text {neck }}$ & $\mathrm{C}_{\text {l.collar }}$ & $\mathrm{C}_{\text {r.collar }}$ & $\mathrm{C}_{\text {c.chest }}$ & $\mathrm{C}_{\text {l.lapel }}$ & $\mathrm{C}_{\text {r.lapel }}$ \\
\hline Const & 1 & 0.02 & 0.001 & 0.15 & 0.001 & 0.001 & 0.92 & 0.89 & 0.01 \\
Velocity & 4 & 0.75 & 0.07 & 0.01 & 0.001 & 0.001 & 0.25 & 0.15 & 0.36 \\
Heating & 1 & 0.94 & 0.80 & 0.35 & 0.001 & 0.41 & 0.48 & 0.001 & 0.52 \\
Posture & 1 & 0.06 & 0.33 & 0.001 & 0.001 & 0.001 & 0.001 & 0.001 & 0.001 \\
VelocityxHeating & 4 & 0.26 & 0.13 & 0.05 & 0.04 & 0.03 & 0.79 & 0.72 & 0.34 \\
VelocityxPosture & 4 & 0.10 & 0.39 & 0.001 & 0.001 & 0.001 & 0.02 & 0.001 & 0.001 \\
HeatingxPosture & 1 & 0.08 & 0.001 & 0.86 & 0.01 & 0.01 & 0.001 & 0.001 & 0.001 \\
\hline
\end{tabular}

Table 5.5: p-Values from ANOVA's for Log-Transformed $\mathbf{C}_{\text {inhaled }}, \mathbf{C}_{\text {uppertorso }}$, and $\mathbf{C}_{\text {lowertorso }}$

\begin{tabular}{lcccc}
\hline Source & $\mathrm{df}$ & $\mathrm{C}_{\text {inhaled }}$ & $\mathrm{C}_{\text {uppertorso }}$ & $\mathrm{C}_{\text {lowertorso }}$ \\
\hline Const & 1 & 0.001 & 0.001 & 0.001 \\
Velocity & 4 & 0.001 & 0.001 & 0.001 \\
Heating & 1 & 0.001 & 0.001 & 0.001 \\
Posture & 1 & 0.04 & 0.001 & 0.001 \\
VelocityxHeating & 4 & 0.001 & 0.001 & 0.001 \\
VelocityxPosture & 4 & 0.001 & 0.72 & 0.33 \\
HeatingxPosture & 1 & 0.001 & 0.001 & 0.41 \\
\hline
\end{tabular}

\subsection{Methods for Regression Analysis}

Regression analysis was performed on log transformed concentrations for each sampling location with wind tunnel velocity for each manikin treatment. Manikin treatments were divided into four groups: heated/standing, heated/seated, unheated/standing, and unheated/seated. For unheated conditions, linear regression was applied to fit the data with velocity for both standing and seated manikin. For heated conditions, a second velocity term was added to the regression model to correct for the inverted V-shape peak for both seated and standing conditions.

For unheated conditions, the regression model for concentration at the mouth, $\mathrm{C}_{\text {mouth, }}$ is:

$$
\log C_{\text {mouth }}=\beta_{0}+\beta_{1} V_{1}
$$

For heated conditions, the regression model for $\mathrm{C}_{\text {mouth }}$ is:

$$
\log C_{\text {mouth }}=\beta_{0}+\beta_{1} V_{1}+\beta_{2} V_{2}
$$

In case the peak concentration occurred at $48 \mathrm{fpm}$, then, $\left\{\mathrm{V}_{2}=\left(\mathrm{V}_{1}-48\right) \mathrm{x}\right\}$

Where: $\mathrm{x}=0$ if $\mathrm{V}_{1} \leq 48$ and $\mathrm{x}=1$ if $\mathrm{V}_{1}>48$

In case the peak concentration occurred at $27 \mathrm{fpm}$, then $\left\{\mathrm{V}_{2}=\left(\mathrm{V}_{1}-27\right) \mathrm{x}\right\}$ 
Where: $\mathrm{x}=0$ if $\mathrm{V}_{1} \leq 27$ and $\mathrm{x}=1$ if $\mathrm{V}_{1}>27$. Concentrations at each sampling location were fitted using the same model applied on $\log \mathrm{C}_{\text {mouth }}$.

Tables 5.6 to 5.9 summarize adjusted R-square, regression coefficients, and p-Values obtained from regression analysis for each sampling location and manikin treatment. Detailed regression results are shown in appendix B.

Table 5.6: Regression Coefficients for heated/standing manikin $(\mathrm{p}<0.001)$

\begin{tabular}{lccccc}
\hline & Adj_R $^{2}(\%)$ & $\mathrm{C}_{0}$ & $\mathrm{C}_{1}$ & $\mathrm{C}_{2}$ & $\mathrm{C}_{3}$ \\
\hline \hline Log $\mathrm{C}_{\text {mouth }}$ & 95.3 & 1.24 & 0.02 & -0.02 & \\
$\log \mathrm{C}_{\text {nose }}$ & 87.5 & 1.23 & 0.02 & -0.02 & \\
$\log \mathrm{C}_{\text {forehead }}$ & 94 & 1.17 & 0.02 & -0.02 & \\
$\log \mathrm{C}_{\text {neck }}$ & 85 & 1.41 & 0.01 & & -0.02 \\
$\log \mathrm{C}_{\text {l.collar }}$ & 83.2 & 1.39 & 0.01 & & -0.01 \\
$\log \mathrm{C}_{\text {r.collar }}$ & 82.3 & 1.32 & 0.01 & & -0.02 \\
$\log \mathrm{C}_{\text {c.chest }}$ & 91.3 & 1.33 & 0.01 & & -0.02 \\
$\log \mathrm{C}_{\text {1.lapel }}$ & 95.1 & 1.23 & 0.01 & & -0.02 \\
$\log \mathrm{C}_{\text {r.lapel }}$ & 93.8 & 1.26 & 0.02 & & -0.02 \\
\hline
\end{tabular}

Table 5.7: Regression Coefficients for heated/seated manikin $(\mathrm{p}<0.001)$

\begin{tabular}{lcccc}
\hline & Adj_R $^{2}(\%)$ & $\mathrm{C}_{0}$ & $\mathrm{C}_{1}$ & $\mathrm{C}_{3}$ \\
\hline \hline Log $\mathrm{C}_{\text {mouth }}$ & 97.9 & 0.93 & 0.02 & -0.02 \\
Log $\mathrm{C}_{\text {nose }}$ & 98 & 0.79 & 0.02 & -0.03 \\
Log $\mathrm{C}_{\text {forehead }}$ & 98.8 & 0.67 & 0.02 & -0.02 \\
$\log \mathrm{C}_{\text {neck }}$ & 93.8 & 1.02 & 0.01 & -0.02 \\
$\log \mathrm{C}_{\text {l.collar }}$ & 94.5 & 1.09 & 0.01 & -0.02 \\
$\log \mathrm{C}_{\text {r.collar }}$ & 89.5 & 1.10 & 0.01 & -0.02 \\
$\log \mathrm{C}_{\text {c.chest }}$ & 84.8 & 1.18 & 0.01 & -0.01 \\
$\log \mathrm{C}_{\text {l.lapel }}$ & 89 & 1.10 & 0.01 & -0.01 \\
$\log \mathrm{C}_{\text {r.lapel }}$ & 86.7 & 1.07 & 0.01 & -0.01 \\
\hline
\end{tabular}


Table 5.8: Regression Coefficients for unheated/standing manikin $(\mathrm{p}<0.001)$

\begin{tabular}{lccc}
\hline & Adj_R $^{2}(\%)$ & $\mathrm{C}_{0}$ & $\mathrm{C}_{1}$ \\
\hline \hline Log $\mathrm{C}_{\text {mouth }}$ & 71.3 & 1.78 & -0.004 \\
$\log \mathrm{C}_{\text {nose }}$ & 59.9 & 1.79 & -0.005 \\
Log $\mathrm{C}_{\text {forehead }}$ & 65.6 & 1.64 & -0.004 \\
$\log \mathrm{C}_{\text {neck }}$ & 62 & 1.82 & -0.004 \\
$\log \mathrm{C}_{\text {l.collar }}$ & 54.7 & 1.84 & -0.004 \\
$\log \mathrm{C}_{\text {r.collar }}$ & 64.5 & 1.80 & -0.004 \\
$\log \mathrm{C}_{\text {c.chest }}$ & 77.3 & 2.08 & -0.005 \\
$\log \mathrm{C}_{\text {l.lapel }}$ & 90.1 & 2.14 & -0.005 \\
$\log \mathrm{C}_{\text {r.lapel }}$ & 74.5 & 1.98 & -0.005 \\
\hline
\end{tabular}

Table 5.9: Regression Coefficients for unheated/seated manikin $(\mathrm{p}<0.001$ unless otherwise indicated)

\begin{tabular}{lccc}
\hline & $\mathrm{Adj}_{\mathrm{C}} \mathrm{R}^{2}(\%)$ & $\mathrm{C}_{0}$ & $\mathrm{C}_{1}$ \\
\hline \hline Log $\mathrm{C}_{\text {mouth }}$ & 77.2 & 1.79 & -0.002 \\
$\log \mathrm{C}_{\text {nose }}$ & 84.4 & 1.80 & -0.003 \\
Log $\mathrm{C}_{\text {forehead }}$ & 87.5 & 1.74 & -0.002 \\
$\log \mathrm{C}_{\text {neck }}$ & 74.2 & 1.74 & -0.002 \\
$\log \mathrm{C}_{\text {l.collar }}$ & 69.7 & 1.76 & -0.003 \\
$\log \mathrm{C}_{\text {r.collar }}$ & 74.3 & 1.71 & -0.003 \\
$\log \mathrm{C}_{\text {c.chest }}$ & 42.5 & 1.57 & -0.004 \\
$\log \mathrm{C}_{\text {l.lapel }}$ & 67.2 & 1.67 & -0.004 \\
$\log \mathrm{C}_{\text {r.lapel }}$ & 56.8 & 1.60 & -0.003 \\
\hline & \multicolumn{1}{c}{$\mathrm{p}<0.05$} & &
\end{tabular}




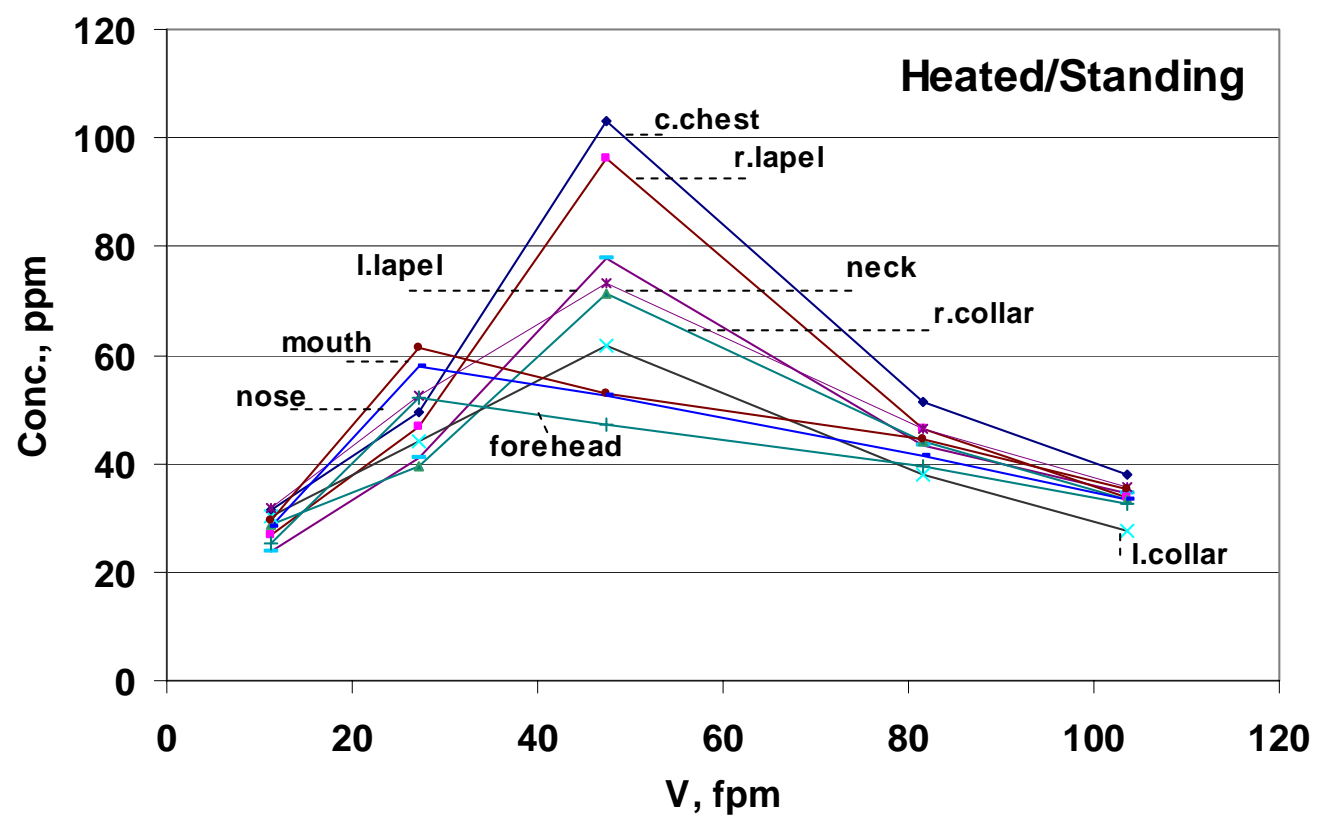

Figure 5.1: Mean Concentration (ppm) versus velocity for standing/heated manikin

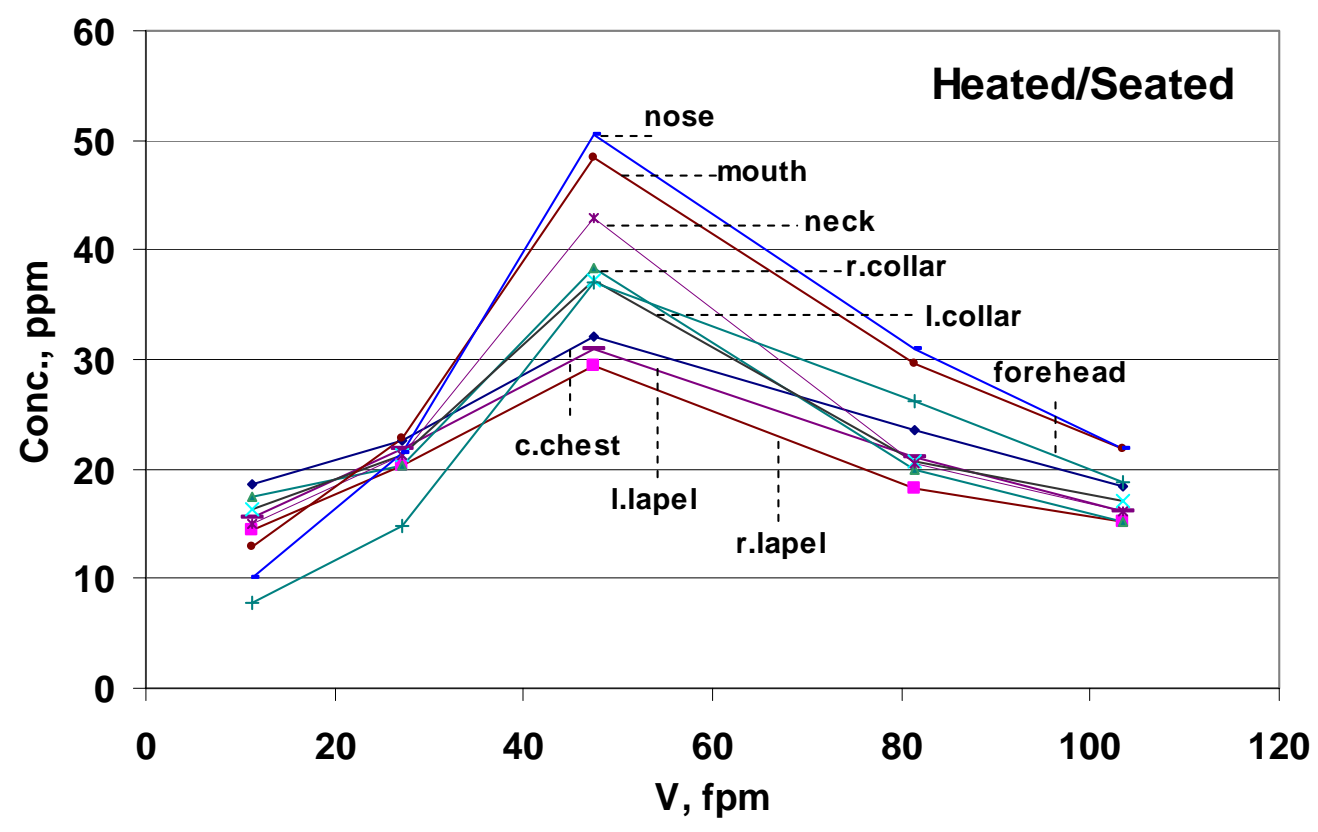

Figure 5.2: Mean Concentration (ppm) versus velocity for seated/heated manikin 


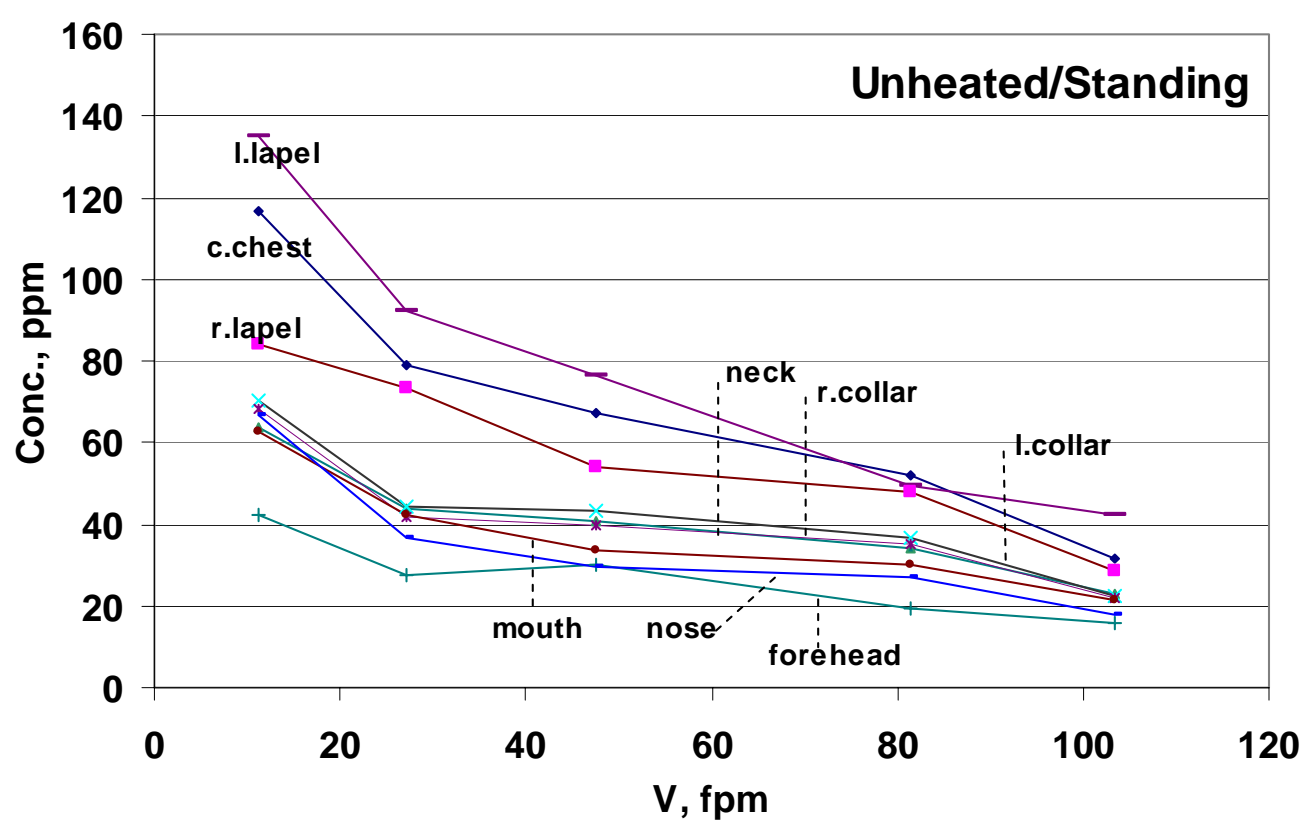

Figure 5.3: Mean concentration ( $\mathrm{ppm}$ ) versus velocity for standing/unheated manikin

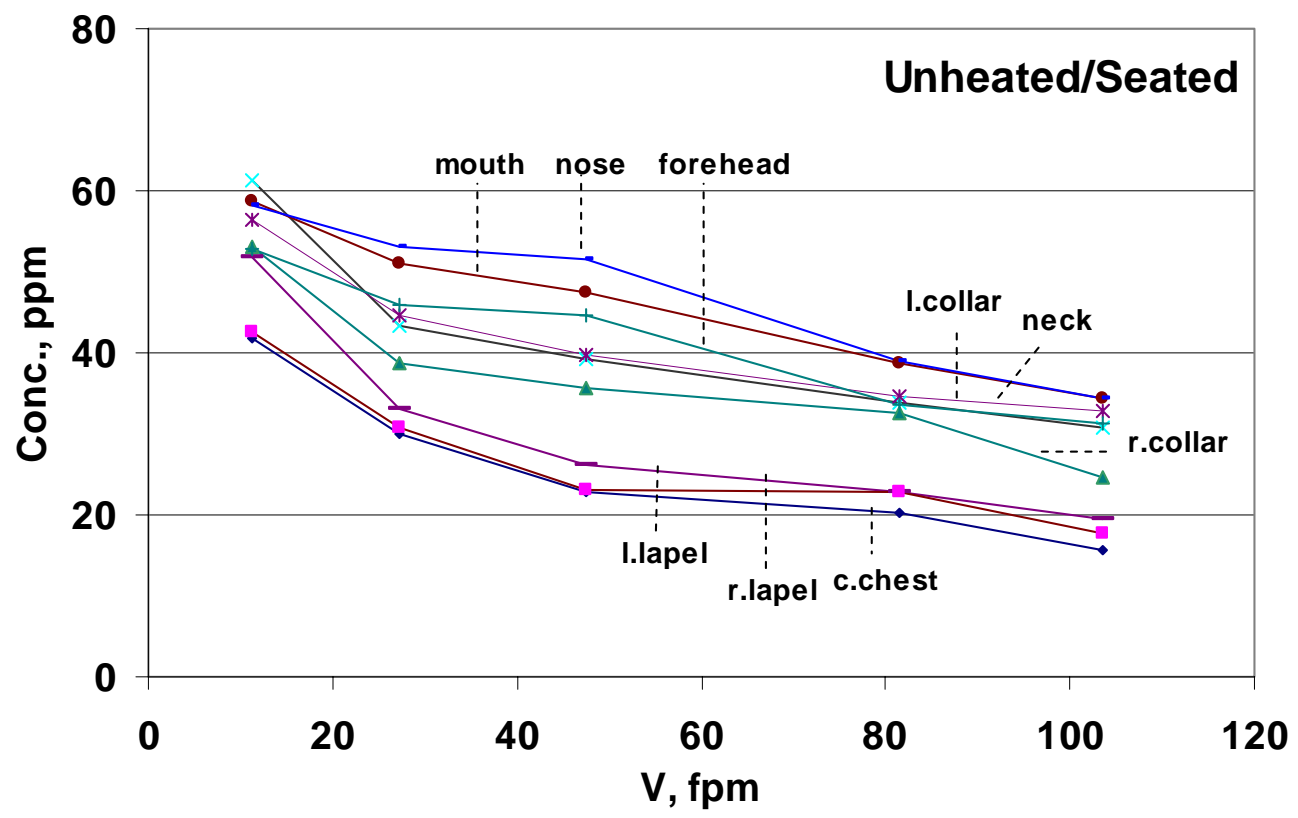

Figure 5.4: Mean concentration ( $\mathrm{ppm}$ ) versus velocity for seated/unheated manikin 


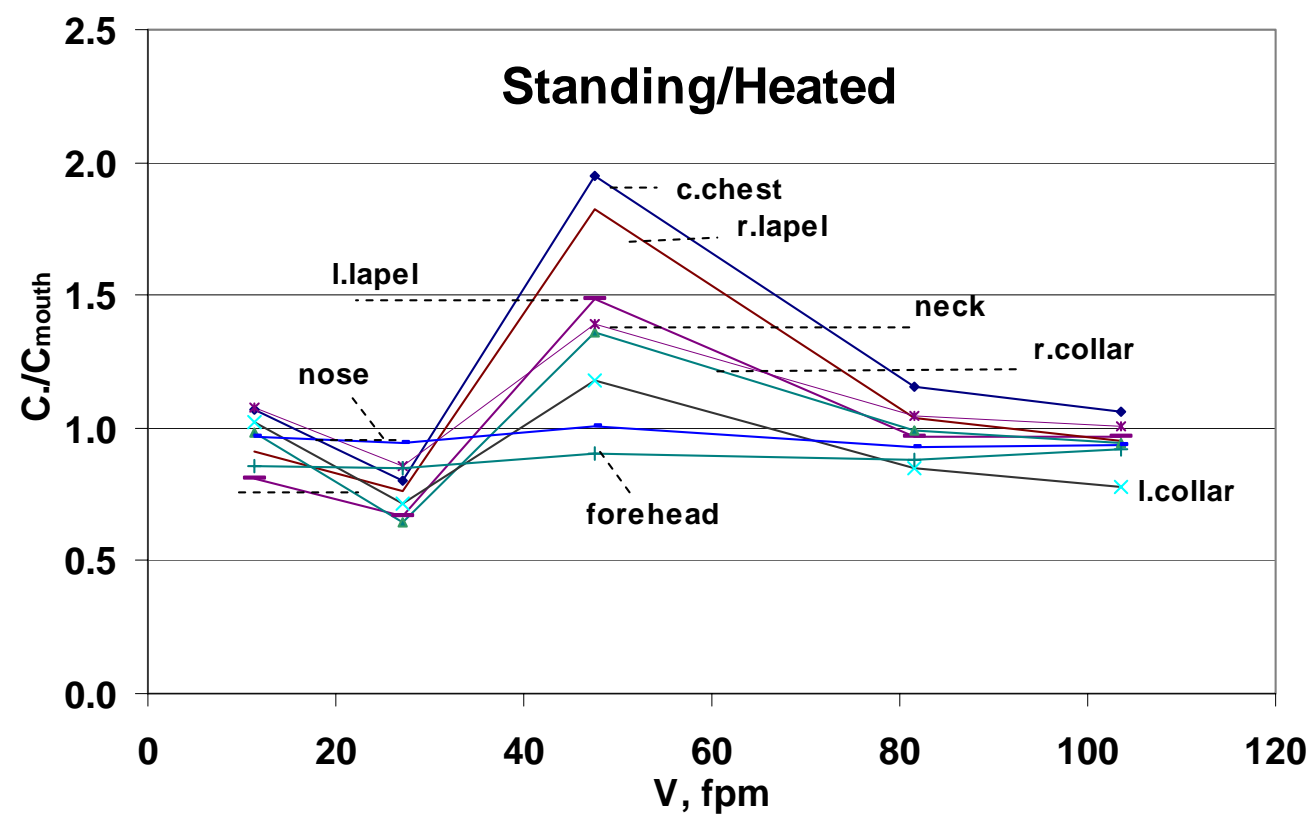

Figure 5.5: Concentration ratio to $\mathrm{C}_{\text {mouth }}$ versus velocity for standing/heated manikin

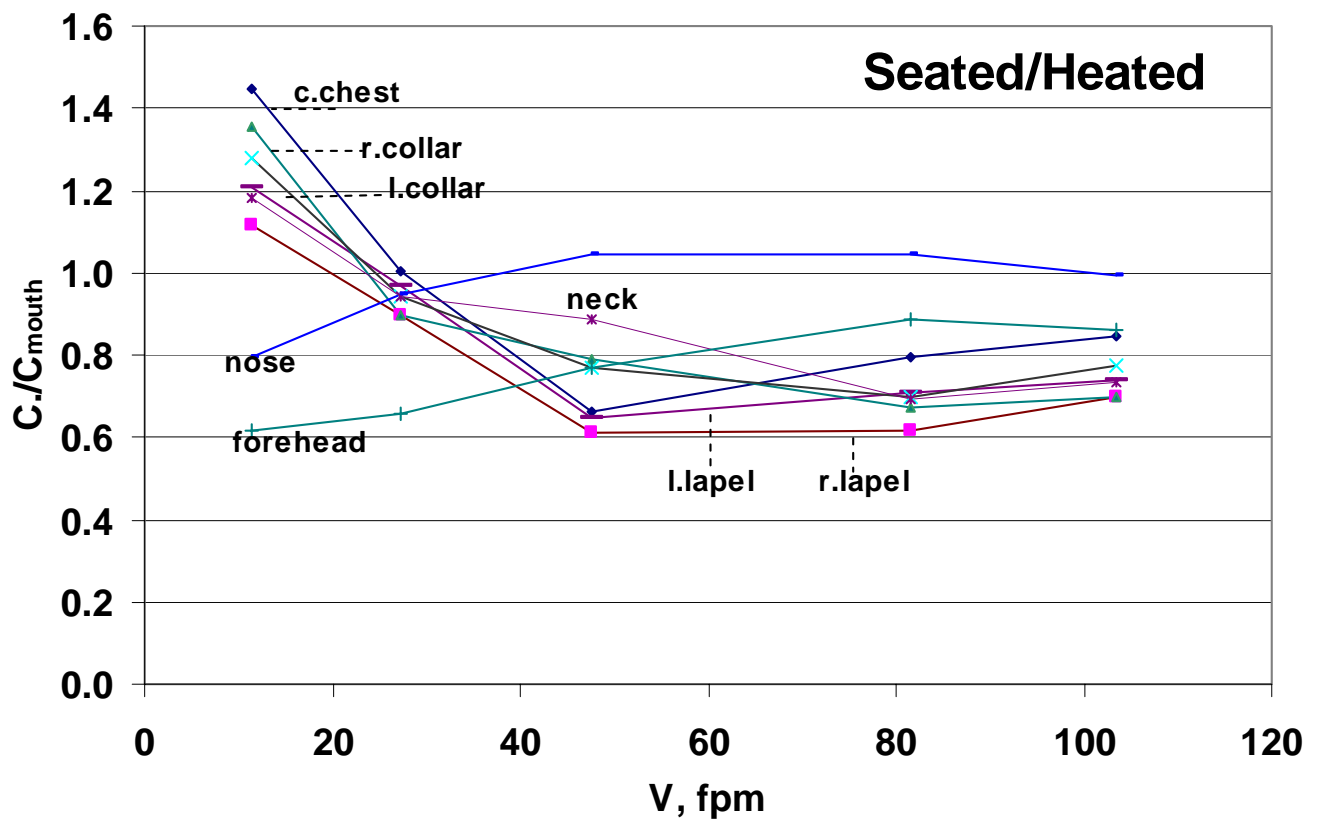

Figure 5.6: Concentration ratio to $\mathrm{C}_{\text {mouth }}$ versus velocity for seated/heated manikin 


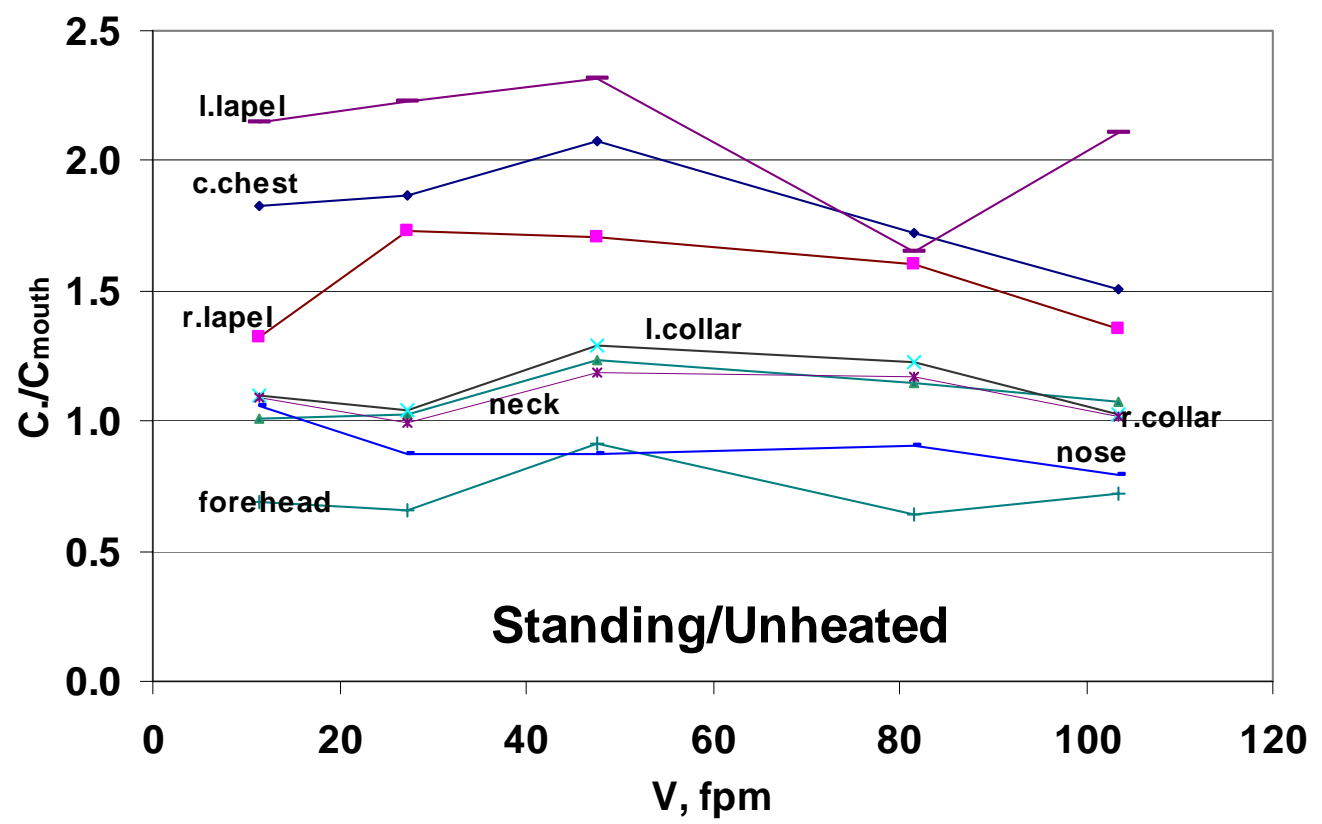

Figure 5.7: Concentration ratio to $\mathrm{C}_{\text {mouth }}$ versus velocity for standing/unheated manikin

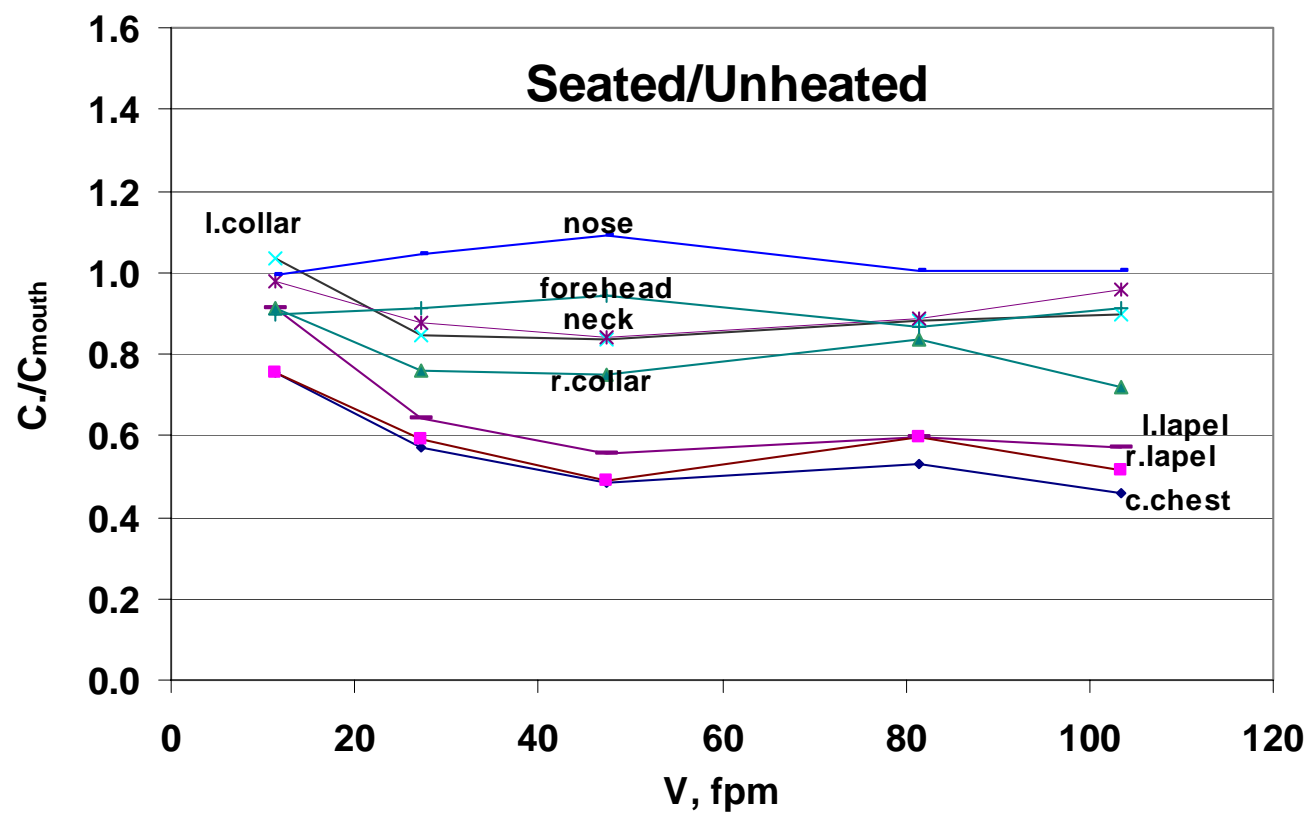

Figure 5.8: Concentration ratio to $\mathrm{C}_{\text {mouth }}$ versus velocity for seated/unheated manikin 


\subsection{Comparisons of individual Concentration Values and Ratios of Concentrations for all Sampling Locations}

As shown in Figures 5.1-5.4, the effects of wind tunnel velocity on all locations appeared to be strikingly different for heated and unheated treatments but were similar for standing and sitting postures. For unheated conditions, concentrations at all sampling locations fell more or less monotonically with increasing values of velocity. This behavior agrees with Flynn et al. (1991) and Kulmala (1996), who tested only unheated manikins. Concentrations did not increase monotonically with increasing velocity as found by Guffey and Flanagan (2001). However, it should be noted that the Reynolds numbers for this study $(\operatorname{Re}=1200-12000)$, Guffey and Flanagan $(\mathrm{Re}=1000-7200)$, Kim and Flynn $(\mathrm{Re}=3419$ $17094)$, and Kulmala $(\mathrm{Re}=6300,9500,12700)$ were quite different, perhaps accounting for the differences in results between Guffey and Flanagan and the rest.

For lifelike conditions, heated manikin, concentrations varied in an inverted-V shape relationship with velocity for both sitting and standing. $\mathrm{C}_{\text {mouth }}, \mathrm{C}_{\text {nose }}$, and $\mathrm{C}_{\text {forehead }}$ had peak values at $27 \mathrm{fpm}$ for standing and $48 \mathrm{fpm}$ for sitting. However, concentrations at the shoulder, $\mathrm{C}_{\text {neck }}, \mathrm{C}_{\text {l.collar }}$, and $\mathrm{C}_{\text {r.collar }}$, and chest, $\mathrm{C}_{\text {c.chest }}, \mathrm{C}_{\text {l.lapel }}$, and $\mathrm{C}_{\text {r.lapel }}$ had peak values at 48 fpm only for both postures. As listed in Table 4.1, for standing manikin, heating increased concentration levels at the mouth and nose locations for the entire velocity range, except at $11 \mathrm{fpm}$. For the same locations, the heated manikin had substantially lower concentrations for sitting at all velocities. These results were strongly supported by the analysis of variance (ANOVA) as shown in Table 5.3. The effect of velocity and heating were significant for logtransformed concentrations at all locations $(\mathrm{p}<0.001)$. In addition, the interaction of velocity and heating was also significant $(\mathrm{p}<0.001)$. These results agree with Heist et al. (2003), Fletcher and Johnson (1996), Brohus (1997), and Homma and Yakiyama (1988) who studied the effect of body heat on air flow patterns around a manikin in a uniform flow field and found that heating was also significant and had substantial effects at low speed wind environments. For these studies, wind velocities were ranged $0.05,0.15,0.3$, and $0.5 \mathrm{~m} / \mathrm{s}$.

For the heated manikin, the effect of posture (sitting/standing) was quite significant on sampling locations. Sitting reduced concentration levels at chest and shoulder locations (see Figures 5.1-5.4 and Table 4.1). The reductions were statistically significant $(\mathrm{p}<0.001)$ for $\log$ transformed concentrations. The effect of posture on $\log \mathrm{C}_{\text {mouth }}$ was statistically significant $(\mathrm{p}<0.001)$ but not significant for $\log \mathrm{C}_{\text {nose }}$ and $\log \mathrm{C}_{\text {forehead. }}$. The interaction of velocity and posture was not significant $(p>0.26)$ for concentrations at the shoulder and chest, but, was significant for $\mathrm{C}_{\text {nose }}, \mathrm{C}_{\text {mouth }}$, and $\mathrm{C}_{\text {forehead. }}$. Also, the interaction of velocity and posture was significant at face $(\mathrm{p}<0.01)$. This is because concentrations at the face had peak values at $27 \mathrm{fpm}$ for standing and $48 \mathrm{fpm}$ for sitting.

The interaction of posture and heating was very significant for locations at the face and shoulder $(\mathrm{p}<0.001)$, but not significant for chest locations. This is illustrated in Figures 5.1-5.4. For the heated and unheated conditions, $C_{\text {c.chest }}, C_{\text {l.lapel }}$, and $C_{\text {r.lapel }}$, had the highest values for standing, but, the lowest values for sitting, for all velocities.

Compared to individual locations, $\mathrm{C}_{\text {inhaled }}, \mathrm{C}_{\text {upper.torso }}$, and $\mathrm{C}_{\text {lower.torso }}$ showed similar patterns with velocity, heating and posture, but, concentration levels were slightly different (see Tables 4.1 and 4.2). Analysis of Variance (ANOVA) for log transformed concentrations 
is shown in Table 5.5. Velocity, heating, and posture had a statistically significant effect $(p<0.001)$ on $C_{\text {inhaled }}, C_{\text {upper.torso, }}$, and $C_{\text {lower.torso. }}$. Likewise, the interaction of velocity and heating had same significance. The interactions of velocity and posture and heating and posture on the three levels had similar significance when compared to concentrations at individual locations.

As shown in Figures 5.5-5.8, unlike individual concentrations, the effect of velocity on ratios of concentration appeared to be different for heated and unheated conditions and for standing and seated postures. The ratio of nose to mouth $\mathrm{C}_{\text {nose }} / \mathrm{C}_{\text {mouth }}$ varied very closely to unity for all treatment combinations and did not show any specific patterns. This was strongly supported by the analysis of variance (ANOVA), shown in Table 5.4. The effects of velocity, heating, and posture and their interactions velocity $\mathrm{x}$ heating, velocity $\mathrm{x}$ posture, and heating $\mathrm{x}$ posture, on $\log \left\{\mathrm{C}_{\text {nose }} / \mathrm{C}_{\text {mouth }}\right\}$ were statistically barely insignificant $(\mathrm{p}>0.06)$. $\mathrm{C}_{\text {nose }}$ was located adjacent to the distal end of the nose on the left side, very closely to $\mathrm{C}_{\text {mouth. }}$.

The effect of independent variables and their interactions on $\log \left\{\mathrm{C}_{\text {forehead }} / \mathrm{C}_{\text {mouth }}\right\}$ was also statistically insignificant, except for the interaction of heating $\mathrm{x}$ posture $(\mathrm{p}<0.001)$. $\mathrm{C}_{\text {forehead }}$ consistently underestimated mouth exposure for the effect of independent variables. This is because of the downwash airflows coming from the sides of the face and the top of head. Since, the bias of $\mathrm{C}_{\text {forehead }} / \mathrm{C}_{\text {mouth }}$ was consistent, a mathematical relationship could be developed to estimate mouth concentrations using the forehead.

As listed in Table 5.4, the effect of posture on log-transformed ratios of concentrations at the chest was statistically significant $(\mathrm{p}<0.001) . \mathrm{C}_{\mathrm{c} . \text { chest }} / \mathrm{C}_{\text {mouth }}, \mathrm{C}_{1 . \text { lapel }} / \mathrm{C}_{\text {mouth }}$, and $\mathrm{C}_{\mathrm{r} \text {.lapel }} / \mathrm{C}_{\text {mouth }}$ varied with posture. Concentartions at chest locations overestimated mouth for standing and underestimated mouth concentrations for sitting (see Figures 5.5-5.8). The ratio $\mathrm{C}_{\text {c.chest }} / \mathrm{C}_{\text {mouth }}$ was approximately 2.1 for the unheated standing manikin and 1.95 for heated manikin. This agrees with (Malek et al, 1999) and (Welling et al, 2000) who tested human subjects and agrees also with (Guffey, et al., 2001), (Kim and Flynn, 1992) and (Kulmala et al., 1996) who tested unheated manikins and found that concentrations at the chest were higher than concentrations at vicinity of mouth (e.g. nose). For the unheated standing manikin, the ratio $\mathrm{C}_{\mathrm{c} . \text { chest }} / \mathrm{C}_{\text {mouth }}$ was 2.1 for this study and 2.9 for (Guffey, et al., 2001). The differences agree qualitatively and disagre quantitively, because the manikin used in this study was anthropometrically correct, while, the one used in (Guffey et al., 2001) was $60 \%$ smaller.

As listed in Table 5.4, ANOVA, the effect of velocity, posture, and the interaction of velocity and posture was statistically significant $(\mathrm{p}<0.01)$ on $\log$ transformed ratios of concentrations at shoulder level. Although heating was not significant for ratios of concentrations at the neck and the right collar, the interaction of velocity and heating was slightly significant $(\mathrm{p}<=0.05)$ for both ratios. It is worth mentioning that there are differences in statistical significance for the ratios of three sampling locations. This could be related to the fact that samplers at the shoulder level were in contact with clothing for both collars while neck sampler was in contact with manikin skin. Also, both collars had downwashed air flows coming from above the shoulder level and washing both of them. This is not the case for the neck location.

Tables 5.6 to 5.9 listed regression coefficients, p-values and adjusted R-squared for $\log$ transformed concentrations for each sampling location. Log transformed concentartions 
were regressed versus wind tunnel velocity for each manikin treatment. For unheated conditions (seated and standing), wind tunnel velocity was highly significant $(\mathrm{p}<=0.009)$ for all sampling locations, except for Log Cc.chest that had significane at $(p=0.024)$ for unheated/seated. The concentrations at all sampling locations decreases as wind tunnel velocity with increases (see tables 5.8 and 5.9). This was observed by the negative sign for velocity coefficient $\left(C_{1}\right)$. Velocity coefficient $\left(C_{1}\right)$ ranged from $(-0.002$ to -0.005$)$ for both seated and standing. The regression constant $\left(\mathrm{C}_{0}\right)$ varied substantially from sampling location to another and from seated to standing. For example, $\left(\mathrm{C}_{0}\right)$ ranged from $1.64-2.14$ for standing and from $1.60-1.80$ for seated. Regression coefficient $\left(\mathrm{C}_{0}\right)$ values at chest level were higher than mouth level for standing and lower for seated. Adjusted R-squared $\left(\mathrm{R}^{2}\right)$ ranged $60 \%-80 \%$ for both seated and standing for most sampling locations. This indicated that about $60 \%$ of the data can be represented by these regression models.

For heated manikin conditions, wind tunnel velocity was highly significant $(\mathrm{p}<0.0001)$ for all sampling locations for both seated and standing. Velocity coefficients $\left(\mathrm{C}_{1}\right)$ and $\left(\mathrm{C}_{2}\right)$ ranged from $(0.01$ to 0.02$)$ and from $(-0.01$ to -0.02$)$ respectively for both seated and standing. Velocity coefficient $\left(\mathrm{C}_{1}\right)$ was lower than $\left(\mathrm{C}_{2}\right)$ for all sampling locations (see tables 5.6 and 5.7). The regression constant $\left(\mathrm{C}_{0}\right)$ varied substantially from sampling location to another and from seated to standing. For example, $\left(\mathrm{C}_{0}\right)$ ranged from $1.17-1.39$ for standing and from $0.67-1.18$ for seated. Regression coefficient $\left(\mathrm{C}_{0}\right)$ values at chest level were higher than mouth level for seated and were almost same for standing, except for $\log \mathrm{C}_{\text {c.chest }}(1.33)$. Adjusted R-squared $\left(\mathrm{R}^{2}\right)$ ranged in the $80 \%-90 \%$ for both seated and standing for most sampling locations. This indicated that about $90 \%$ of the data can be represented by these regression models. In conclusion, adjusted $\mathrm{R}$-squared $\left(\mathrm{R}^{2}\right)$ for heated conditions were higher than unheated. Regression coefficient $\left(\mathrm{C}_{0}\right)$ values varied from seated to standing and from heated to unheated for all sampling locations. 


\section{Chapter 6: Results of Study II}

For this study, the manikin was either sitting or standing, breathing or not breathing and wearing a wig or bald. The manikin was heated and clothed throughout the whole study. This study was a complete factorial design with each condition including replicates (2) tested in random order. Initial tests and replicates were always done on different days.

As in Study I, one primary goal was to find the locations that act as the best surrogates for true inhaled concentrations. Concentrations measured at the mouth were assumed to equal "inhaled" volume. The secondary goal was to determine whether breathing, hair style, posture, and velocity affected concentrations measured on the manikin. Although the manikin inhaled and exhaled through its nose in a realistic manner, its "lungs" did not absorb ethanol. Hence a sample taken at the mouth in the exhaled air stream should differ negligibly from a sample taken of inhaled breath alone. As will be shown, the concentrations fell into three groups with similar behavior: those at the face $\left(\mathrm{C}_{\text {mouth }}, \mathrm{C}_{\text {nose }}, \mathrm{C}_{\text {forehead }}\right)$, the shoulder $\left(\mathrm{C}_{\text {neck }}, \mathrm{C}_{\text {l.collar }}, \mathrm{C}_{\mathrm{r} \text {.collar }}\right)$, and the chest $\left(\mathrm{C}_{\mathrm{c} \text {.chest }}, \mathrm{C}_{\text {l.lapel }}, \mathrm{C}_{\mathrm{r} . \text { lapel }}\right)$.

\subsection{Repeatability of $\mathbf{C}_{\text {mouth }}$}

Two samples were taken simultaneously at the right edge of the mouth less than $1 \mathrm{~mm}$ apart. The coincident locations were intended to be redundant checks. Ideally, there should be no systematic differences between $\mathrm{C}_{\text {mouth }}$ and $\mathrm{C}_{\text {mouth }_{2}}$ regardless of the levels of other independent variables. As shown in Figure 6.1, $\mathrm{C}_{\text {mouth1 } 1}$ and $\mathrm{C}_{\text {mouth2 }}$ are highly correlated $(\mathrm{R}-\mathrm{sq}=0.99)$ even when no independent variables are included in the regression model. The linear regression slope of 0.996 and intercept of zero confirm the

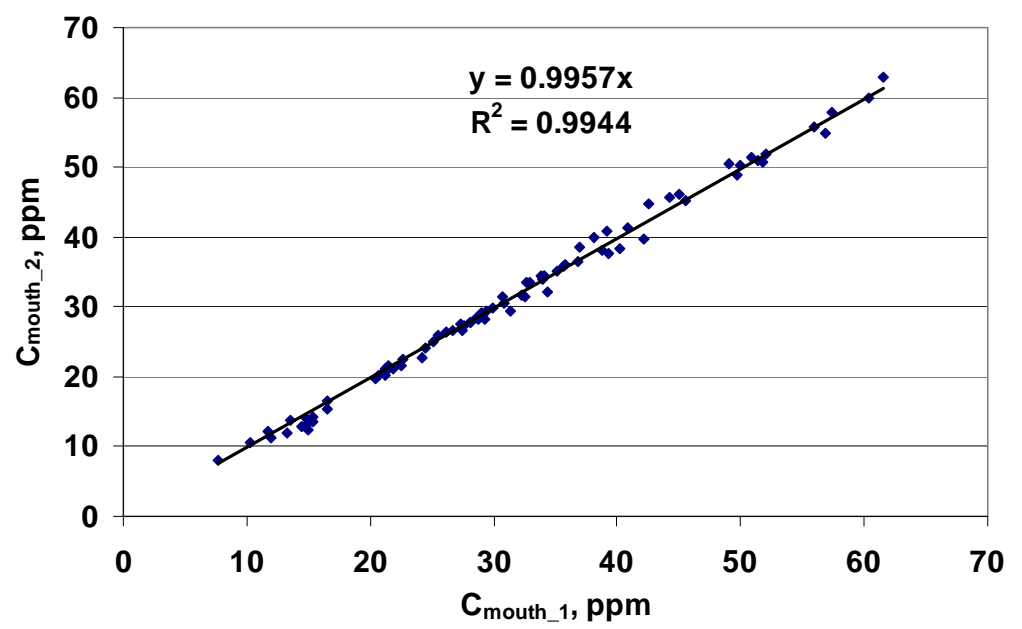

Figure 6.1: $\mathrm{C}_{\text {mouth }_{1}}$ versus $\mathrm{C}_{\text {mouth }_{2}}$ two are indistinguishable.

Furthermore, ANOVA found no significant effects of any independent variable. These together suggest that the sampling procedures are highly repeatable and that differences between other locations measured at the same time represent real deviations at those times, not sampling errors. Given the trivial differences between $\mathrm{C}_{\text {mouth1 }}$ and $\mathrm{C}_{\text {mouth2 }}$, the 
average of both values was used for comparisons to all other locations and is henceforth referred to as $\mathrm{C}_{\text {mouth. }}$.

As shown in Tables 6.1 a and 6.1b and Figures 6.2 to 6.10, the average concentration values varied with sampling location, velocity, breathing, wig, and posture. Hence, comparisons between concentrations must be matched to similar conditions. Appendix C shows scatter and mean plots for log transformed concentrations with velocity for all sampling locations.

Table 6.1a: Average Concentration Values (ppm) For Each Velocity Level and Manikin Treatment (Seated)

\begin{tabular}{|c|c|c|c|c|c|c|c|c|c|c|}
\hline Treatment & V,fpm & $\mathrm{C}_{\text {c.chest }}$ & $\mathrm{C}_{\text {l.lapel }}$ & $\mathrm{C}_{\text {r.lapel }}$ & $\mathrm{C}_{\text {neck }}$ & $\mathrm{C}_{\text {l.collar }}$ & $\mathrm{C}_{\text {r.collar }}$ & $\mathrm{C}_{\text {mouth }}$ & $\mathrm{C}_{\text {nose }}$ & $\mathrm{C}_{\text {forehead }}$ \\
\hline \multirow{5}{*}{$\begin{array}{c}\text { Seated } \\
\text { NoBreathing } \\
\text { NoWig }\end{array}$} & 11 & 18.6 & 15.6 & 14.4 & 15.0 & 16.3 & 17.4 & 12.8 & 10.1 & 7.8 \\
\hline & 27 & 22.6 & 21.9 & 20.4 & 21.3 & 21.3 & 20.3 & 22.7 & 21.5 & 14.9 \\
\hline & 48 & 32.0 & 31.0 & 29.5 & 43.0 & 37.2 & 38.3 & 48.5 & 50.5 & 37.1 \\
\hline & 82 & 23.6 & 21.1 & 18.3 & 20.6 & 20.7 & 20.0 & 29.6 & 31.0 & 26.2 \\
\hline & 104 & 18.4 & 16.2 & 15.3 & 16.1 & 17.0 & 15.3 & 21.9 & 21.8 & 18.9 \\
\hline \multirow{5}{*}{$\begin{array}{l}\text { Seated } \\
\text { Breathing } \\
\text { NoWig }\end{array}$} & 11 & 12.8 & 9.2 & 10.8 & 15.7 & 15.6 & 12.1 & 15.9 & 13.3 & 9.3 \\
\hline & 27 & 18.3 & 17.9 & 15.2 & 33.7 & 26.7 & 24.5 & 34.9 & 35.0 & 25.9 \\
\hline & 48 & 21.2 & 23.0 & 21.9 & 36.7 & 34.7 & 36.8 & 48.3 & 46.8 & 44.3 \\
\hline & 82 & 17.4 & 14.1 & 18.0 & 28.9 & 29.5 & 25.9 & 31.5 & 34.1 & 28.1 \\
\hline & 104 & 16.3 & 12.7 & 12.9 & 25.0 & 28.0 & 21.9 & 26.6 & 28.4 & 21.9 \\
\hline \multirow{5}{*}{$\begin{array}{c}\text { Seated } \\
\text { NoBreathing } \\
\text { Wig }\end{array}$} & 11 & 9.8 & 7.3 & 7.2 & 28.3 & 23.5 & 31.9 & 18.6 & 15.9 & 12.8 \\
\hline & 27 & 14.1 & 13.1 & 13.5 & 44.1 & 26.6 & 41.3 & 53.5 & 48.9 & 45.9 \\
\hline & 48 & 19.7 & 18.6 & 20.4 & 37.4 & 25.8 & 33.4 & 44.3 & 43.0 & 42.1 \\
\hline & 82 & 13.2 & 11.2 & 11.5 & 29.0 & 22.9 & 29.2 & 33.7 & 32.2 & 32.8 \\
\hline & 104 & 10.0 & 10.7 & 9.3 & 25.0 & 21.4 & 24.3 & 31.3 & 28.9 & 27.6 \\
\hline \multirow{5}{*}{$\begin{array}{l}\text { Seated } \\
\text { Breathing } \\
\text { Wig }\end{array}$} & 11 & 8.6 & 6.4 & 6.6 & 12.4 & 7.0 & 13.6 & 10.7 & 6.1 & 6.6 \\
\hline & 27 & 15.5 & 13.4 & 12.5 & 19.9 & 18.0 & 17.1 & 24.6 & 26.0 & 26.8 \\
\hline & 48 & 18.8 & 16.9 & 16.2 & 27.9 & 25.9 & 22.1 & 32.0 & 35.6 & 38.7 \\
\hline & 82 & 14.8 & 12.6 & 10.1 & 24.6 & 24.0 & 23.4 & 27.7 & 30.0 & 28.6 \\
\hline & 104 & 7.6 & 9.5 & 7.8 & 23.0 & 22.2 & 21.3 & 26.5 & 27.7 & 24.2 \\
\hline
\end{tabular}


Table 6.1b: Average Concentration Values (ppm) For Each Velocity Level and Manikin Treatment (Standing)

\begin{tabular}{|c|c|c|c|c|c|c|c|c|c|c|}
\hline Treatment & V,fpm & $\mathrm{C}_{\text {c.chest }}$ & $\mathrm{C}_{\text {l.lapel }}$ & $\mathrm{C}_{\text {r.lapel }}$ & $\mathrm{C}_{\text {neck }}$ & $\mathrm{C}_{\text {l.collar }}$ & $\mathrm{C}_{\text {r.collar }}$ & $\mathrm{C}_{\text {mouth }}$ & $\mathrm{C}_{\text {nose }}$ & $\mathrm{C}_{\text {forehead }}$ \\
\hline \multirow{5}{*}{$\begin{array}{c}\text { Standing } \\
\text { NoBreathing } \\
\text { NoWig }\end{array}$} & 11 & 31.6 & 23.9 & 27.0 & 31.8 & 30.1 & 28.8 & 29.5 & 28.5 & 25.3 \\
\hline & 27 & 49.3 & 41.1 & 46.9 & 52.5 & 44.1 & 39.4 & 61.3 & 57.8 & 52.0 \\
\hline & 48 & 103.1 & 77.9 & 96.3 & 73.1 & 61.8 & 71.2 & 57.1 & 52.7 & 47.3 \\
\hline & 82 & 51.6 & 43.2 & 46.4 & 46.5 & 37.8 & 44.1 & 44.6 & 41.3 & 39.4 \\
\hline & 104 & 38.0 & 34.5 & 33.9 & 35.8 & 27.6 & 33.5 & 35.5 & 33.2 & 32.6 \\
\hline \multirow{5}{*}{$\begin{array}{l}\text { Standing } \\
\text { Breathing } \\
\text { NoWig }\end{array}$} & 11 & 25.9 & 12.9 & 17.3 & 25.0 & 25.9 & 18.8 & 20.3 & 21.4 & 18.6 \\
\hline & 27 & 29.6 & 17.1 & 19.9 & 41.1 & 34.8 & 25.6 & 40.1 & 42.4 & 36.8 \\
\hline & 48 & 62.3 & 38.5 & 53.5 & 49.5 & 44.1 & 42.0 & 38.5 & 39.1 & 31.9 \\
\hline & 82 & 37.5 & 25.2 & 29.9 & 32.4 & 32.9 & 28.1 & 30.1 & 31.6 & 29.0 \\
\hline & 104 & 30.1 & 23.5 & 22.3 & 26.2 & 28.4 & 21.6 & 25.1 & 28.4 & 25.4 \\
\hline \multirow{5}{*}{$\begin{array}{c}\text { Standing } \\
\text { NoBreathing } \\
\text { Wig }\end{array}$} & 11 & 53.5 & 35.1 & 38.3 & 41.3 & 44.4 & 36.7 & 30.3 & 29.2 & 27.1 \\
\hline & 27 & 59.6 & 44.9 & 52.0 & 54.1 & 50.7 & 57.7 & 41.2 & 38.2 & 32.1 \\
\hline & 48 & 65.3 & 54.2 & 68.0 & 61.6 & 55.0 & 59.0 & 54.3 & 51.5 & 44.7 \\
\hline & 82 & 37.5 & 28.6 & 33.3 & 39.0 & 31.0 & 38.6 & 39.6 & 36.2 & 36.8 \\
\hline & 104 & 36.4 & 25.9 & 34.5 & 30.0 & 22.7 & 34.1 & 34.1 & 29.7 & 30.3 \\
\hline \multirow{5}{*}{$\begin{array}{l}\text { Standing } \\
\text { Breathing } \\
\text { Wig }\end{array}$} & 11 & 28.4 & 9.3 & 10.6 & 27.5 & 19.9 & 12.3 & 16.9 & 20.1 & 16.8 \\
\hline & 27 & 27.4 & 12.5 & 18.7 & 36.7 & 29.3 & 21.8 & 38.8 & 37.3 & 30.8 \\
\hline & 48 & 38.2 & 23.3 & 22.3 & 32.5 & 25.3 & 18.1 & 26.7 & 35.7 & 28.6 \\
\hline & 82 & 32.9 & 18.5 & 18.7 & 25.5 & 21.3 & 17.0 & 21.3 & 31.0 & 23.0 \\
\hline & 104 & 31.3 & 16.5 & 15.0 & 23.3 & 18.4 & 13.6 & 19.9 & 30.6 & 24.3 \\
\hline
\end{tabular}




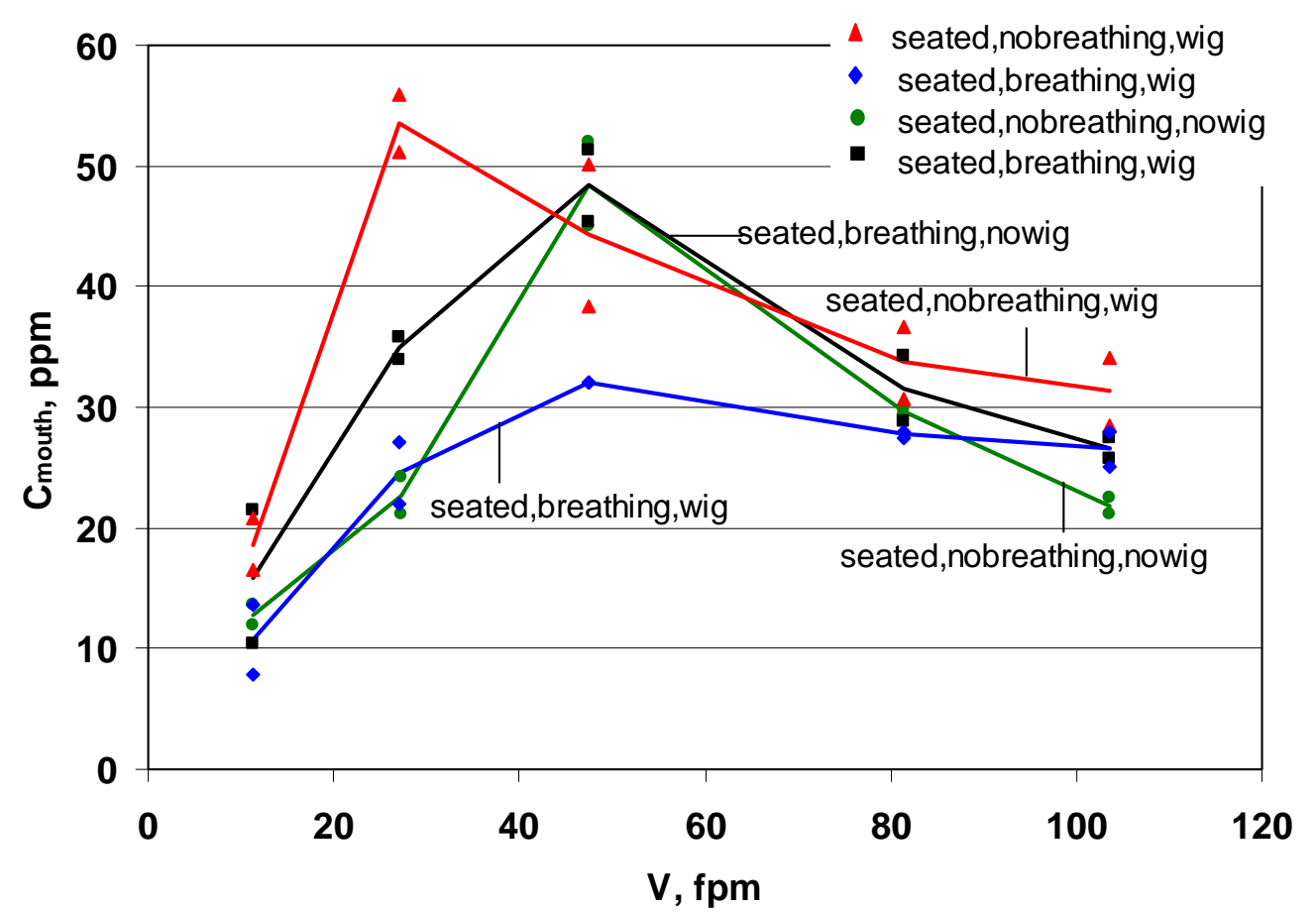

Figure 6.2-a: Scatter and mean plots of $\mathrm{C}_{\mathrm{m}}$ outh vs. velocity for all manikin treatments (seated)

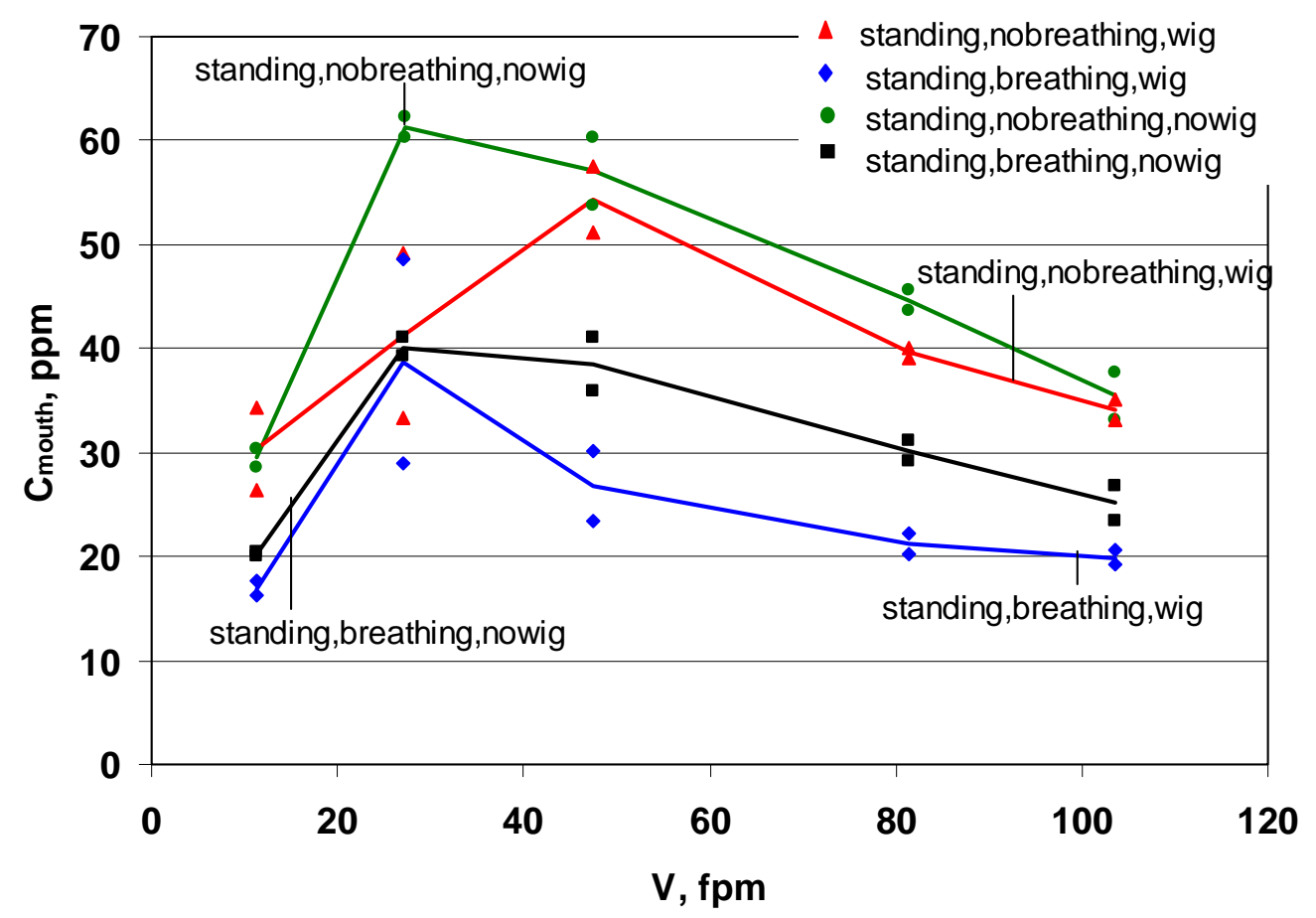

Figure 6.2-b: Scatter and mean plots of $\mathrm{C}_{\mathrm{m}}$ outh vs. velocity for all manikin treatments (standing) 


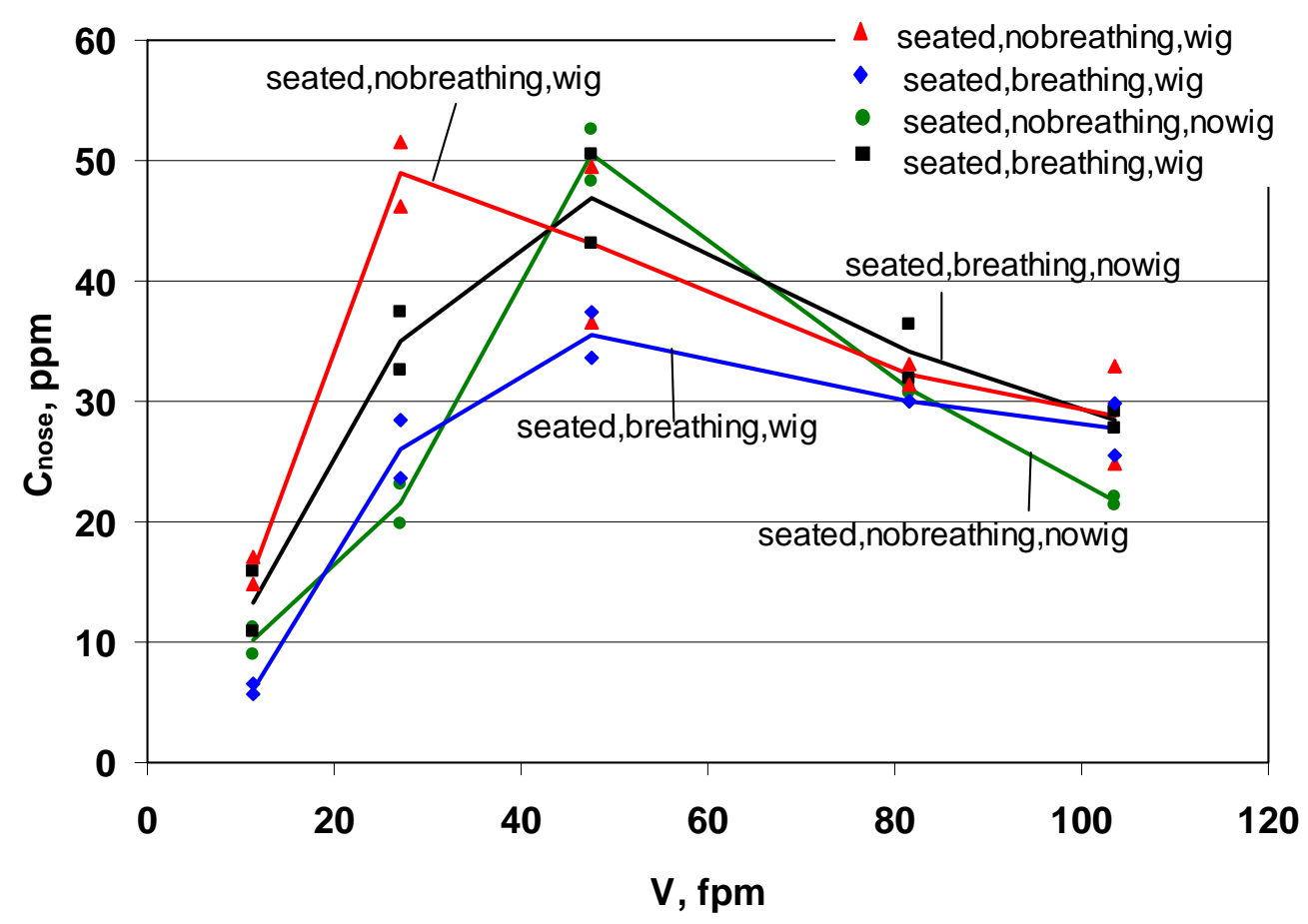

Figure 6.3-a: Scatter and mean plots of $\mathrm{C}_{\text {nose }}$ vs. velocity for all manikin treatment (seated)

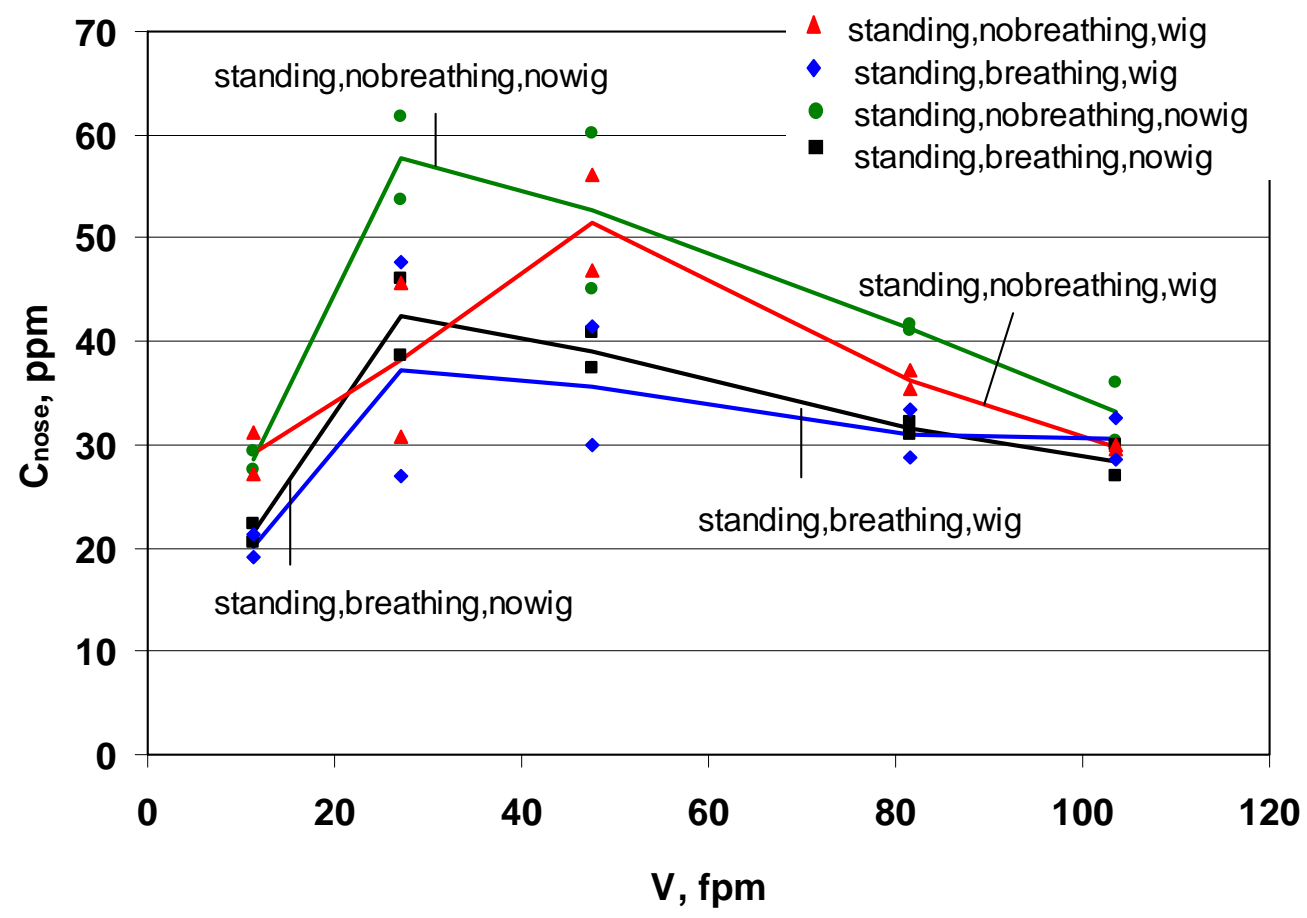

Figure 6.3-b: Scatter and mean plots of $\mathrm{C}_{\text {nose }}$ vs. velocity for all manikin treatment (standing) 


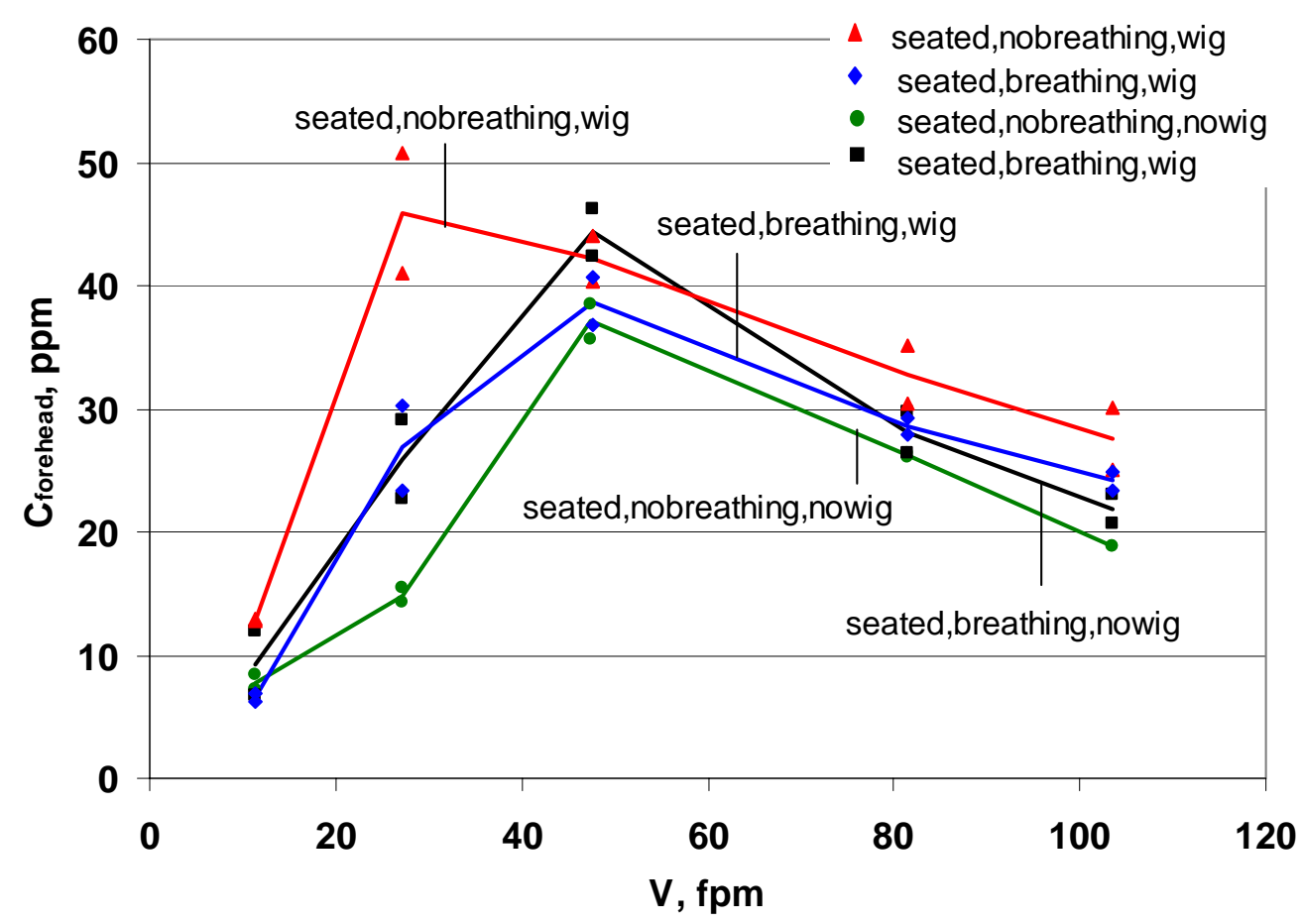

Figure 6.4-a: Scatter and mean plots of $\mathrm{C}_{\text {forehead }}$ vs. velocity for all manikin treatment (seated)

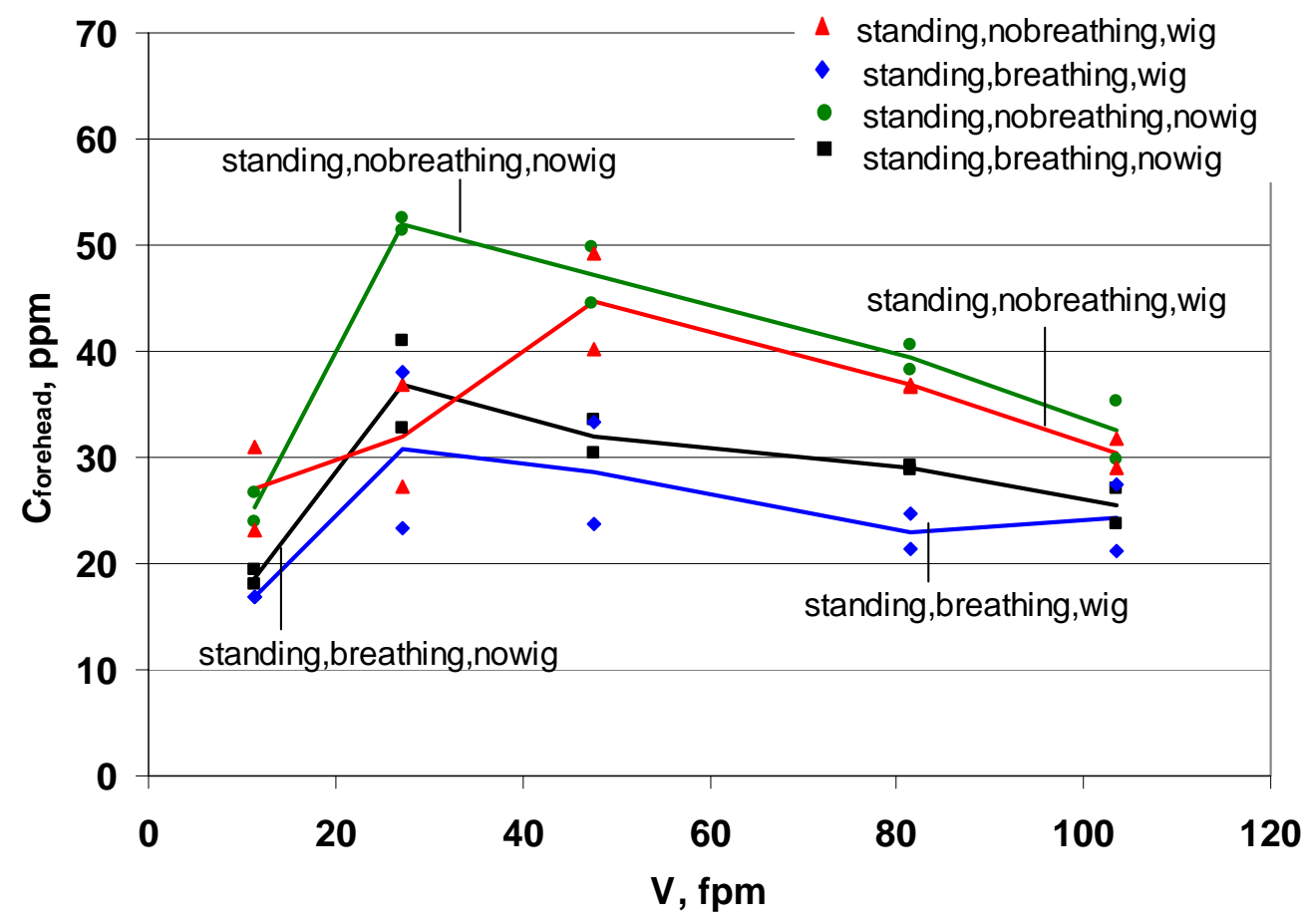

Figure 6.4-b: Scatter and mean plots of $\mathrm{C}_{\text {forehead }}$ vs. velocity for all manikin treatment (standing) 


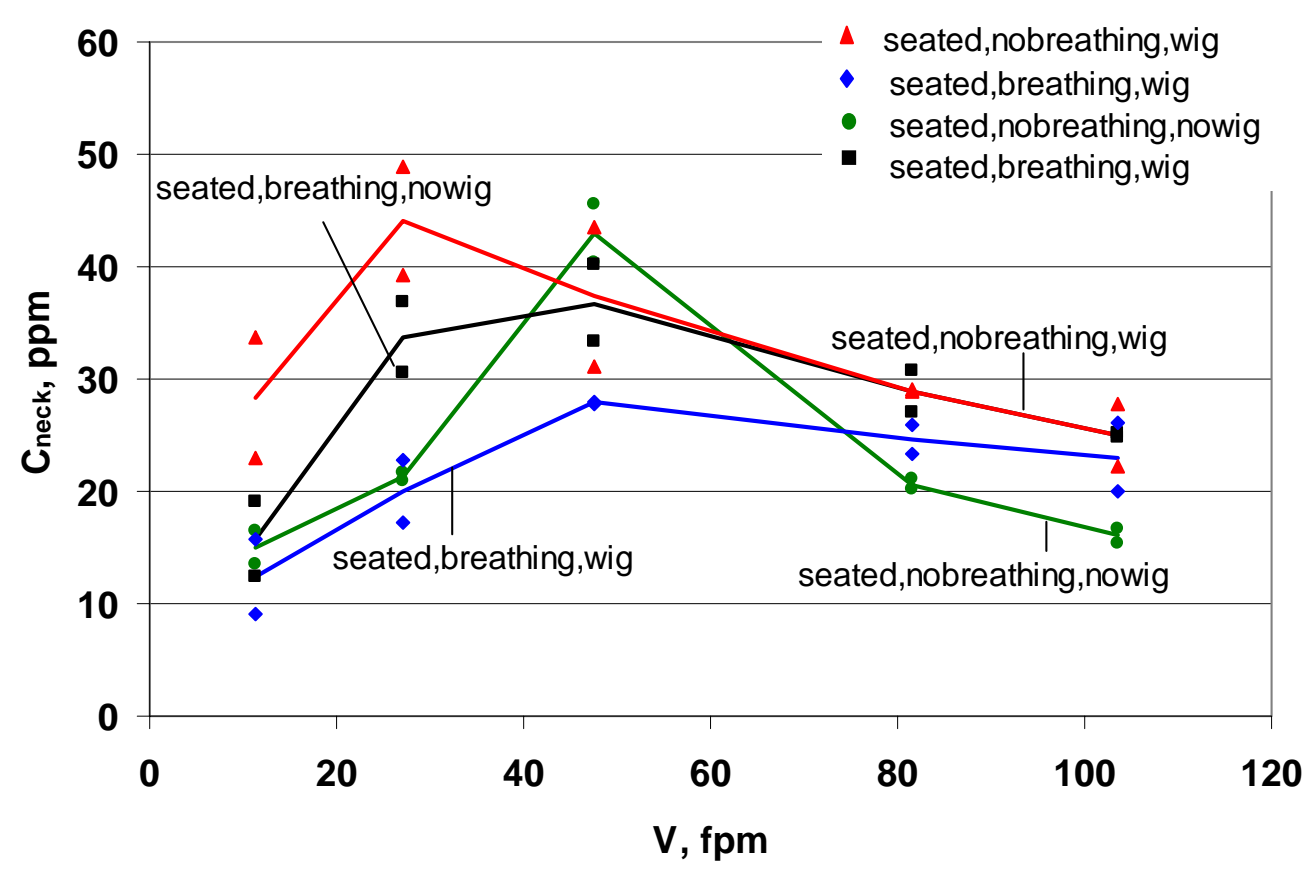

Figure 6.5-a: Scatter and mean plots of $\mathrm{C}_{\text {neck }}$ vs. velocity for all manikin treatments (seated)

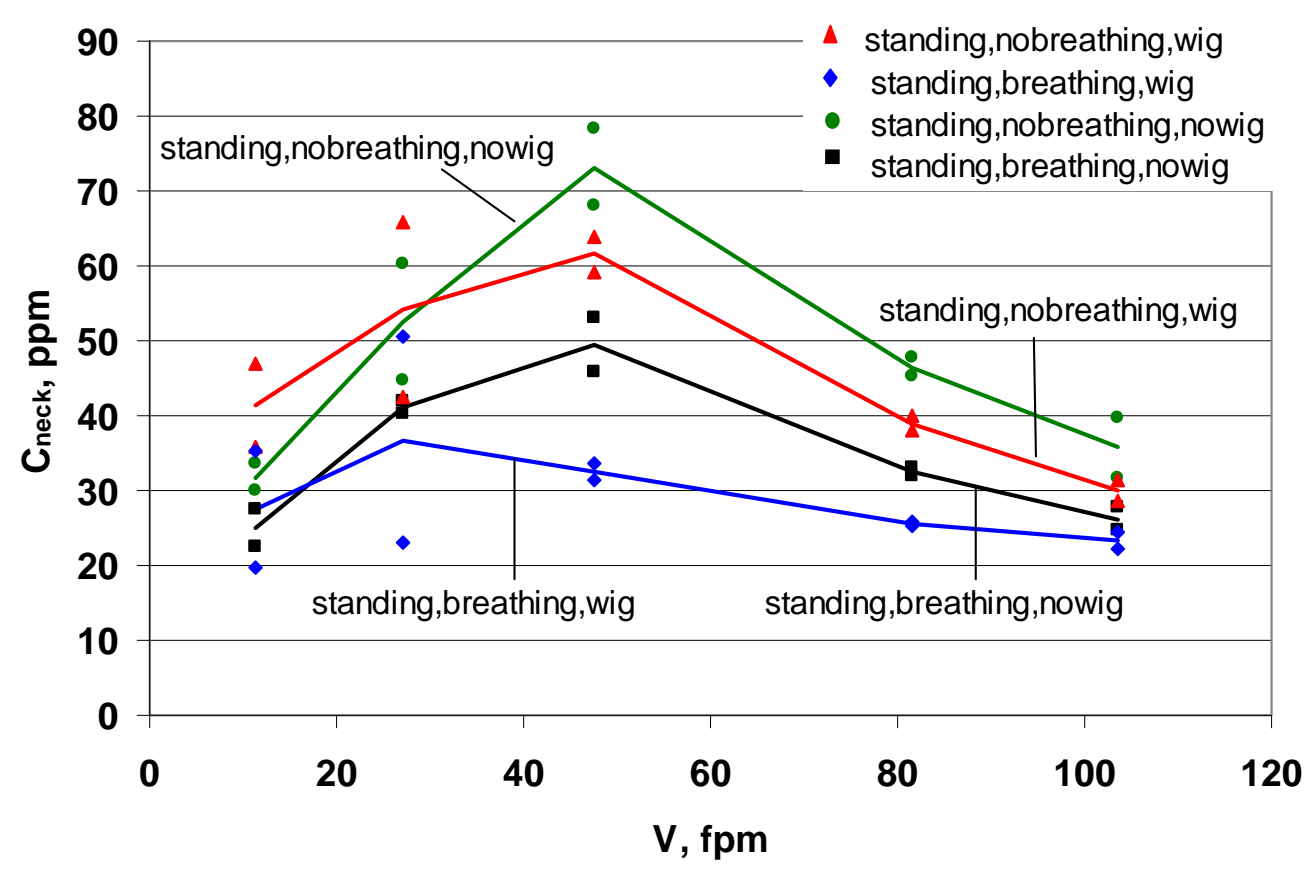

Figure 6.5-b: Scatter and mean plots of $\mathrm{C}_{\text {neck }}$ vs. velocity for all manikin treatments (standing) 


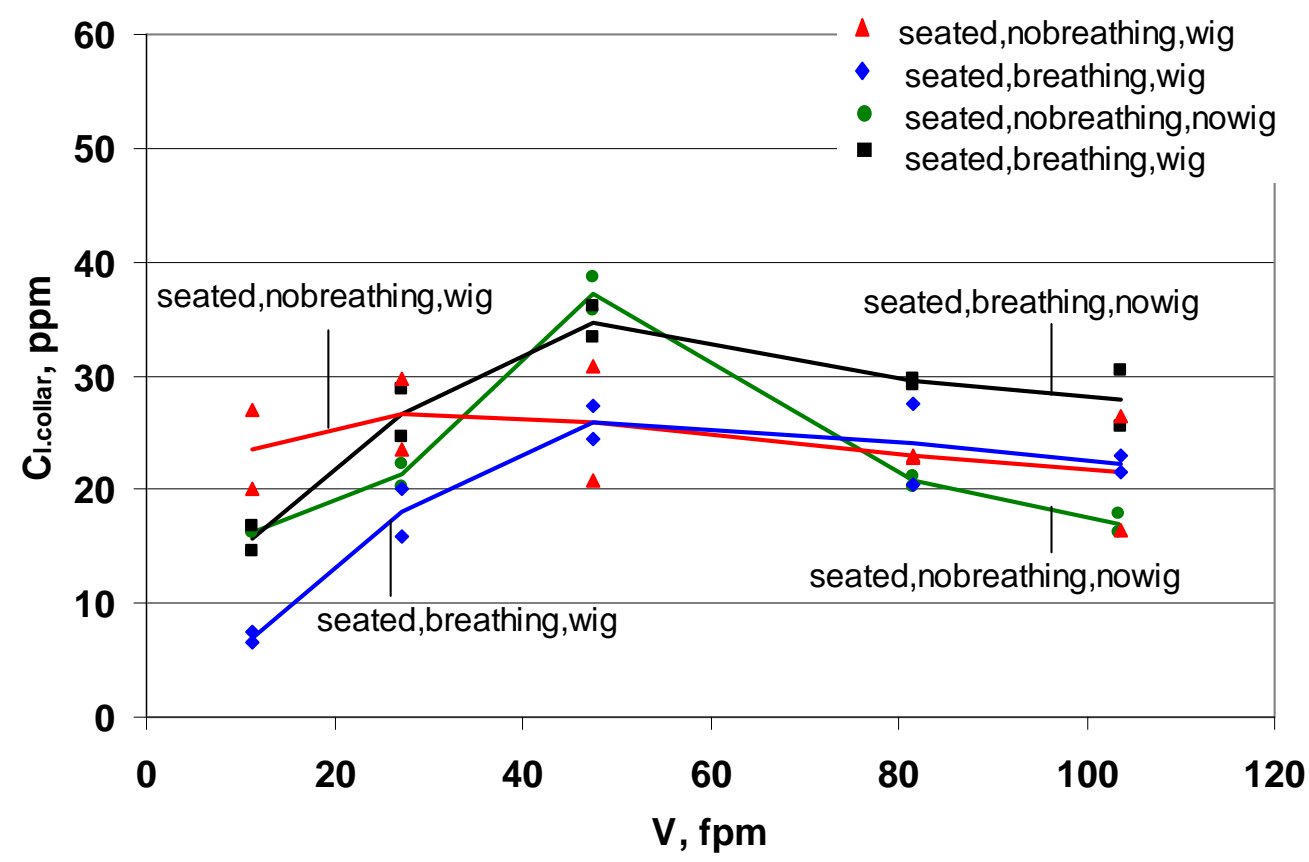

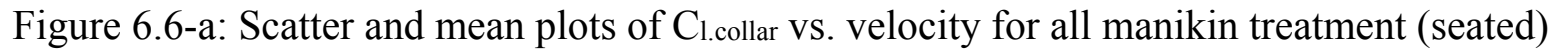

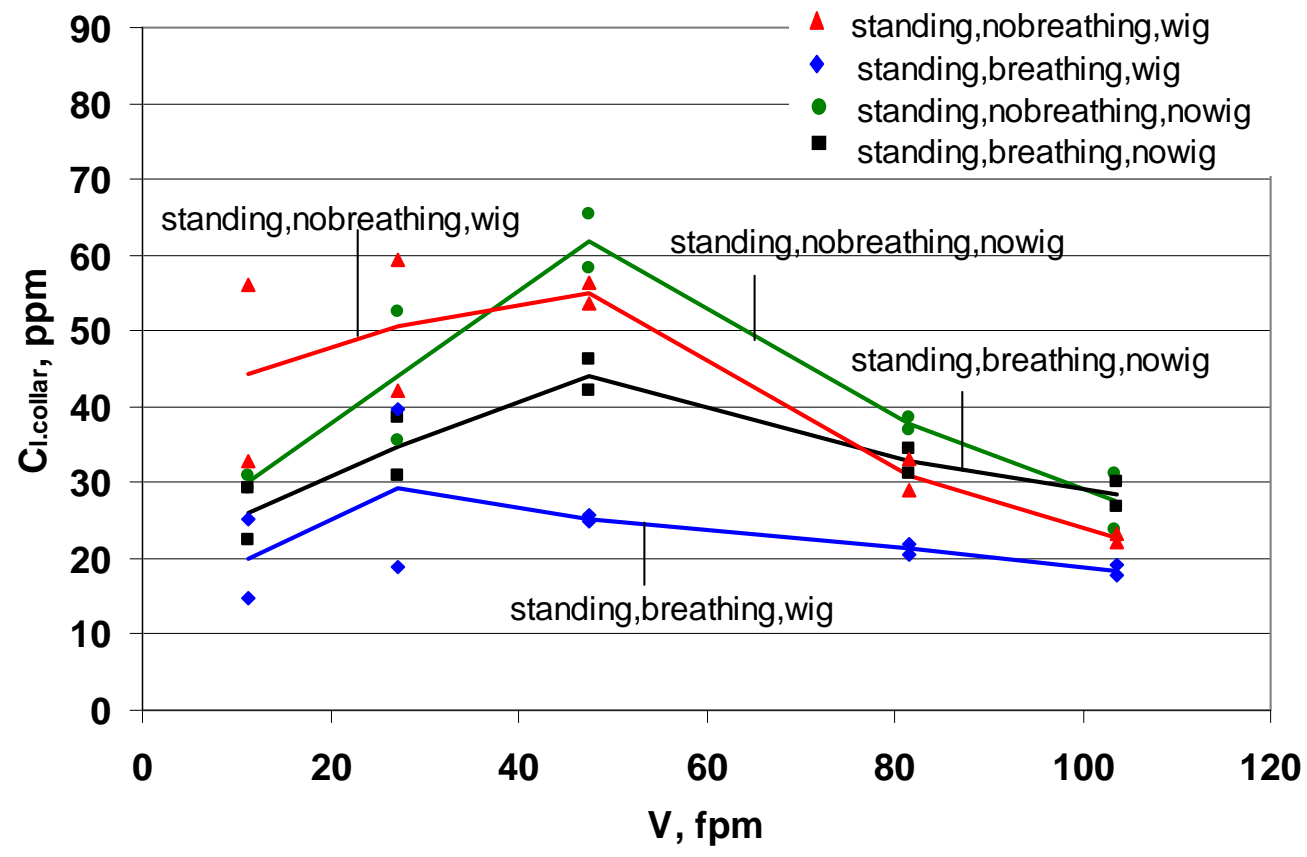

Figure 6.6-b: Scatter and mean plots of Cl.collar vs. velocity for all manikin treatment (standing) 


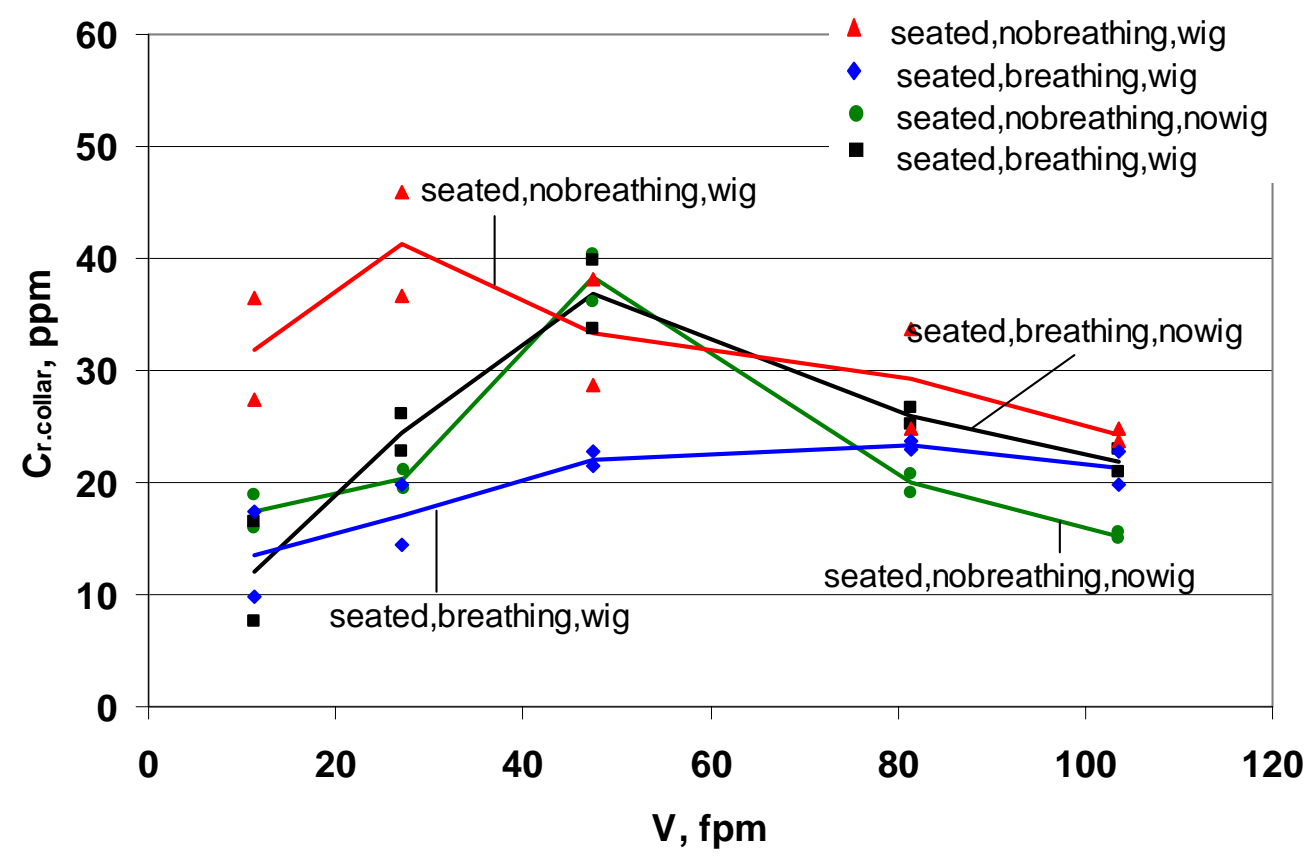

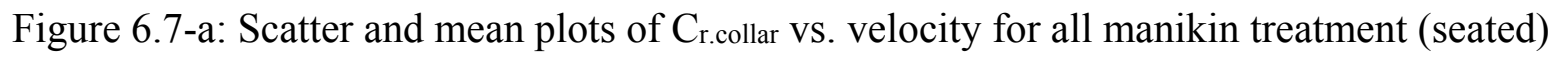

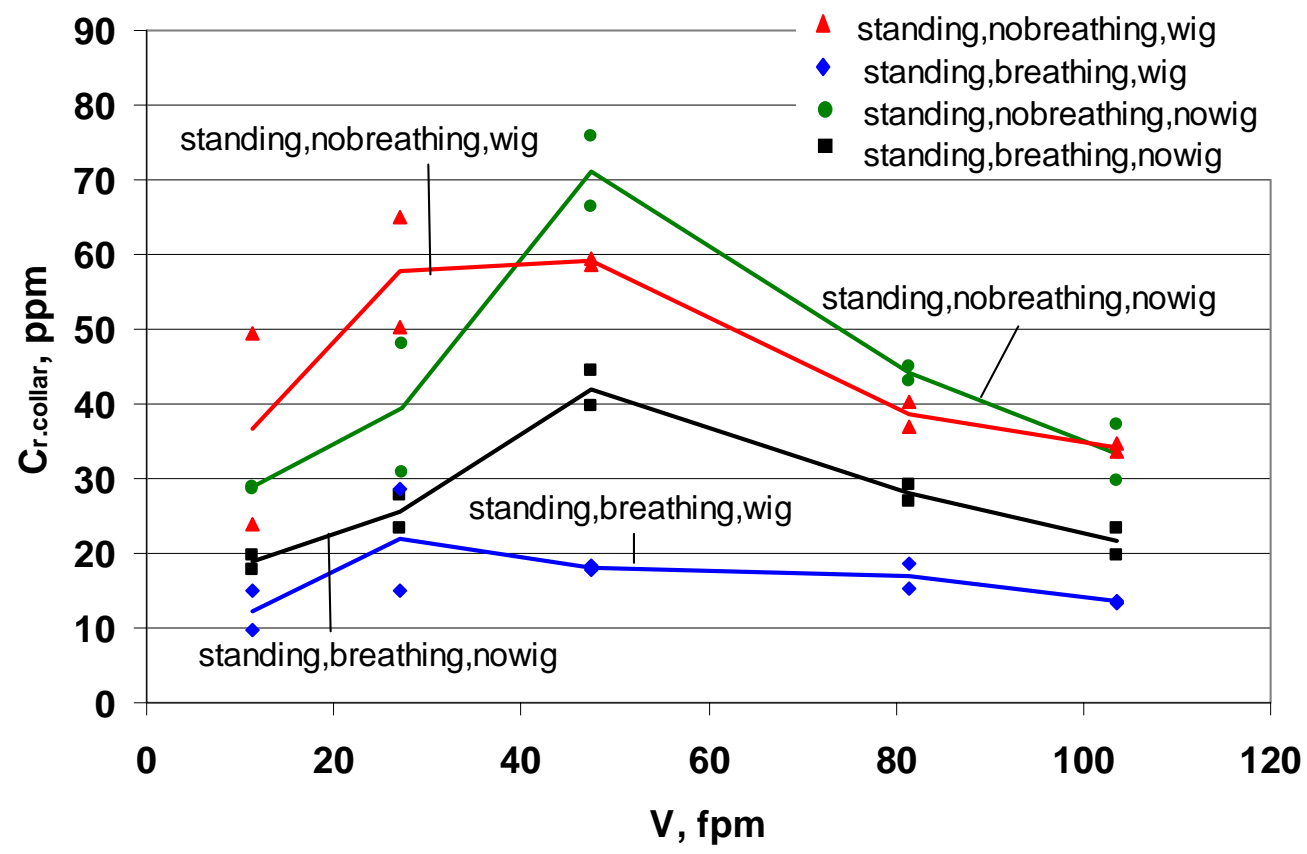

Figure 6.7-b: Scatter and mean plots of $\mathrm{C}_{\mathrm{r} . \text {.collar }} \mathrm{vs.}$. velocity for all manikin treatment (standing) 


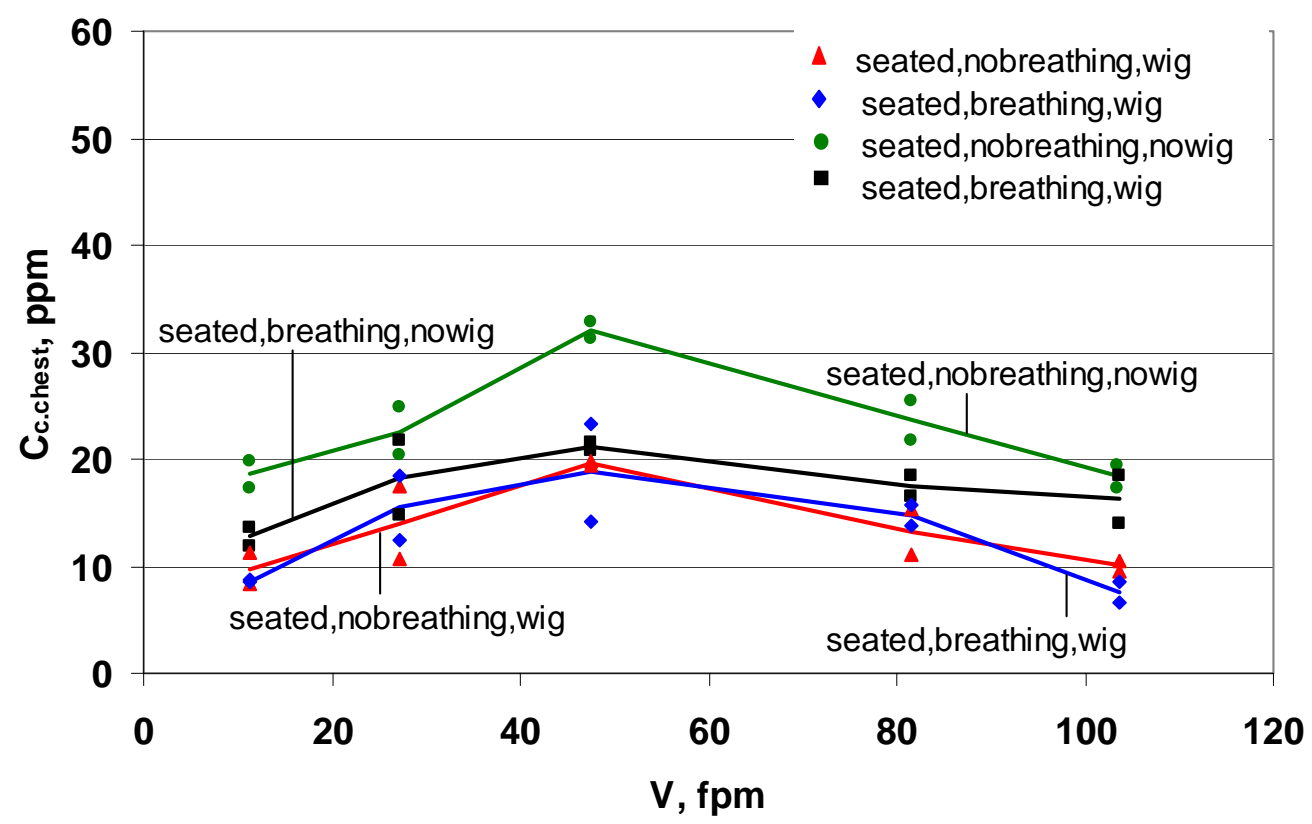

Figure 6.8-a: Scatter and mean plots of $\mathrm{C}_{\text {c.chest }}$ vs. velocity for all manikin treatment (seated)

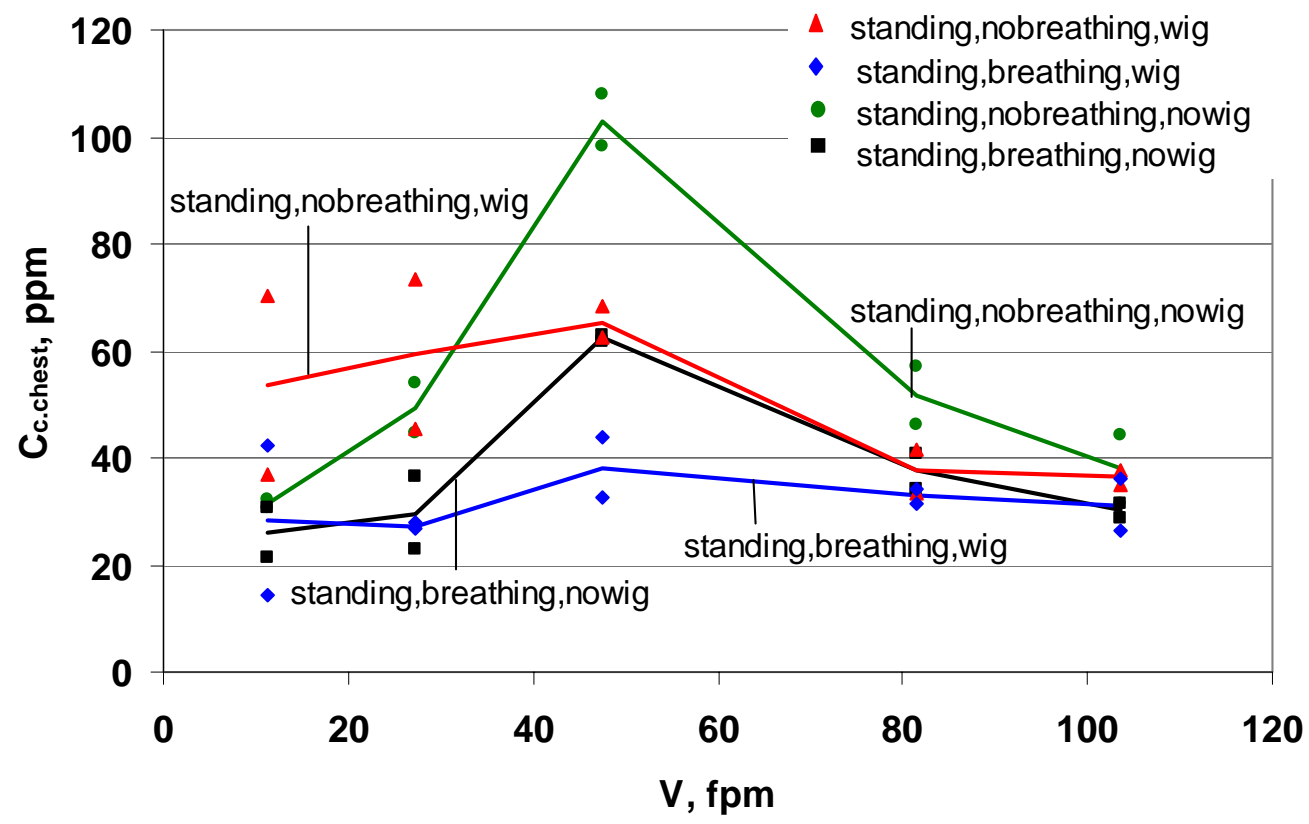

Figure 6.8-b: Scatter and mean plots of $\mathrm{C}_{\mathrm{c} . \text { chest }}$ vs. velocity for all manikin treatment (Standing) 


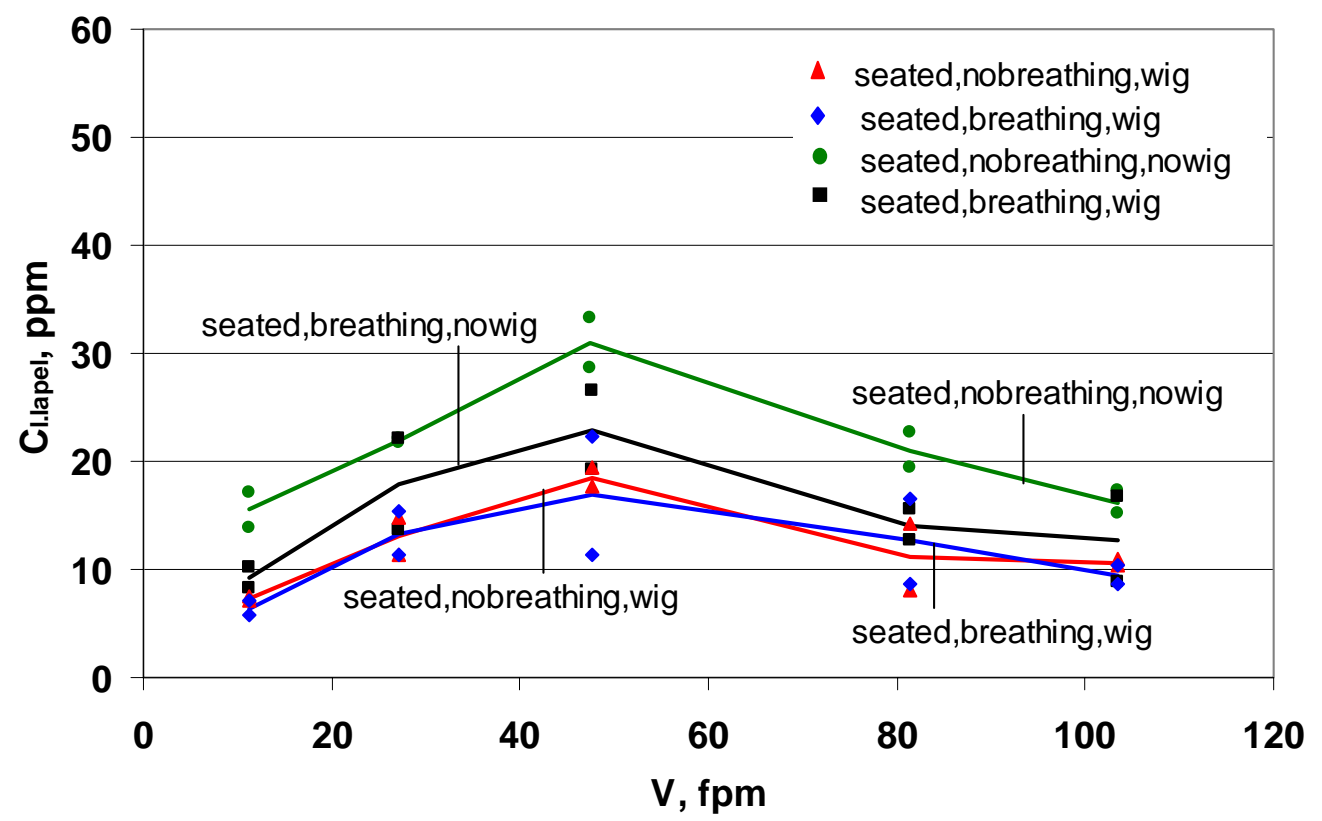

Figure 6.9-a: Scatter and mean plots of C1.lapel vs. velocity for all manikin treatment (seated)

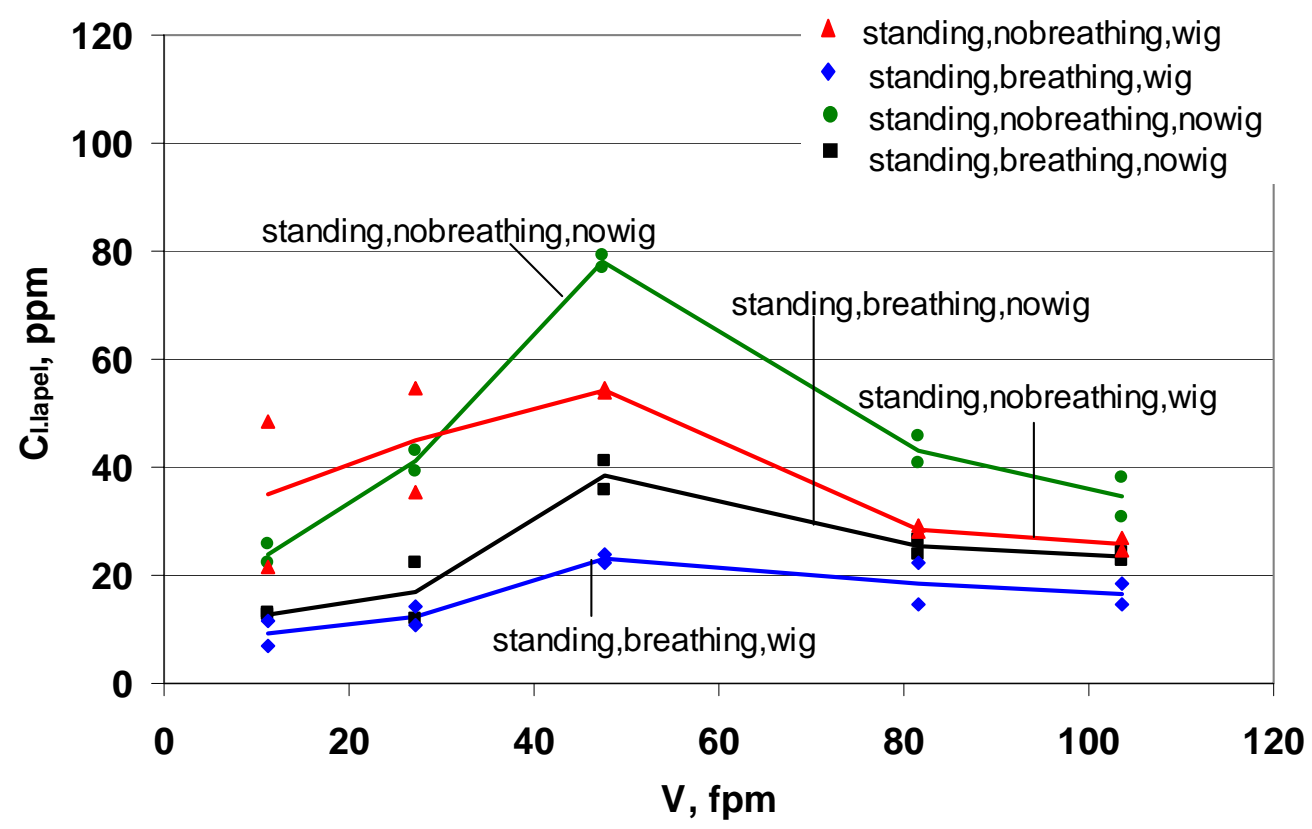

Figure 6.9-b: Scatter and mean plots of $\mathrm{C}_{1.1 \mathrm{lapel}} \mathrm{vs.}$. velocity for all manikin treatment (standing) 


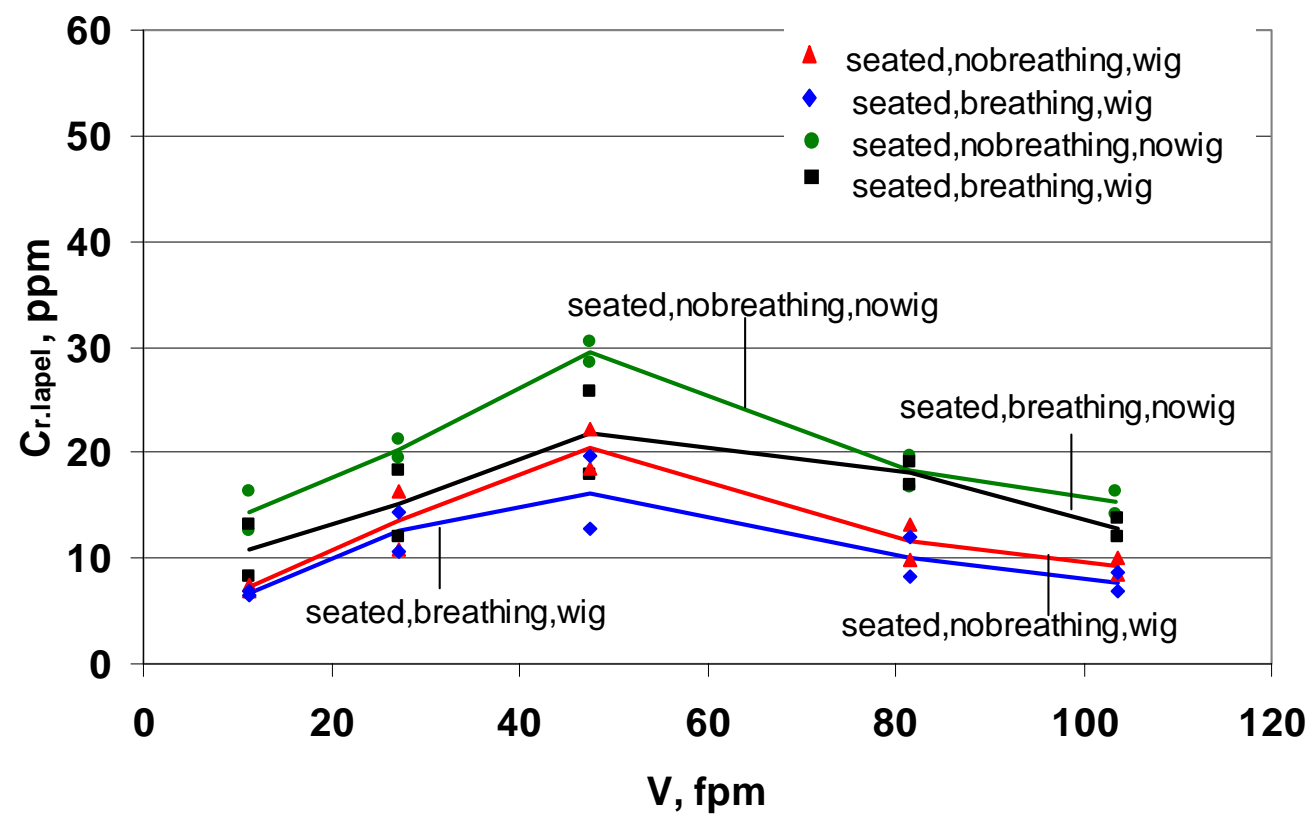

Figure 6.10-a: Scatter and mean plots of $\mathrm{C}_{\text {r.lapel }}$ vs. velocity for all manikin treatment (seated)

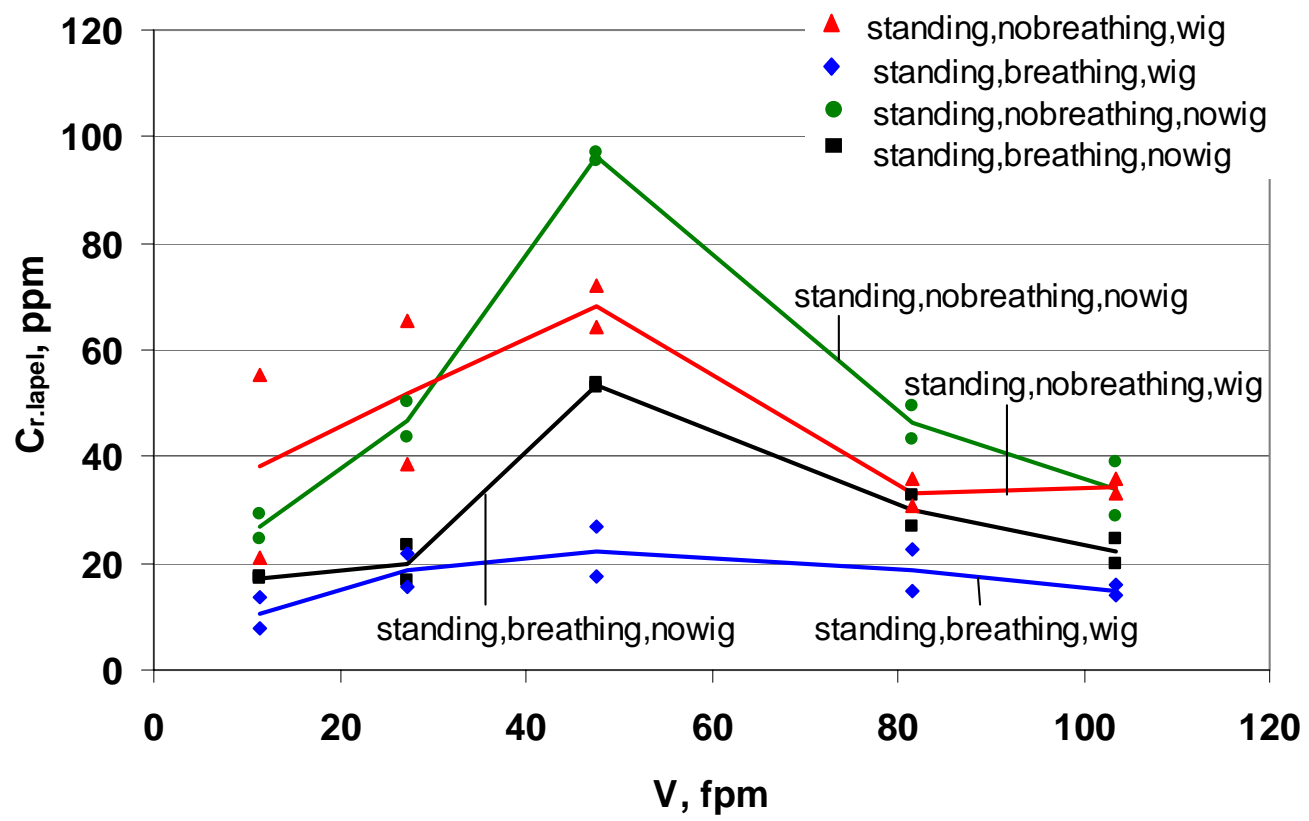

Figure 6.10-b: Scatter and mean plots of $\mathrm{C}_{\text {r.lapel }}$ vs. velocity for all manikin treatment (standing) 


\subsection{Effects of Independent Variables on all Sampling Locations}

As listed in Tables 6.1a and 6.1b, concentration values of sampling locations at the face $\left(\mathrm{C}_{\text {mouth }}, \mathrm{C}_{\text {forehead }}, \mathrm{C}_{\text {nose }}\right)$, at the shoulder $\left(\mathrm{C}_{\text {neck }}, \mathrm{C}_{\text {l.collar }}, \mathrm{C}_{\mathrm{r} \text {.collar }}\right)$, and chest $\left(\mathrm{C}_{\text {c.chest }}, \mathrm{C}_{\text {l.lapel }}\right.$, $\mathrm{C}_{\text {r.lapel }}$ ) varied with different combinations of wind tunnel velocity, breathing, wig and posture. Generally, sampling locations were grouped based on two criteria: 1) similar patterns with velocity, breathing, wig and posture and 2) similar concentration levels. The following illustrates the effects of breathing, wig, posture and velocity on sampling locations.

\subsubsection{Velocity}

As shown in Figures 6.2 to 6.10, the effects of velocity appeared to be similar from one sampling location to another within each group for any given treatment combinations. As was true for a heated manikin in Study I, concentrations varied in an inverted-V shape relationship with velocity. Peak concentration levels occurred at either 27 or $48 \mathrm{fpm}$ for all treatment combinations. These results agree with Study I of this work and with Brohus (1997), who studied the effect of heating on concentrations using full-sized, heated, breathing manikin wearing heavy clothing and wig at similar velocities.

The effect of velocity on concentrations at the face is shown in Figures 6.2 to 6.4. For breathing, with or without a wig, $\mathrm{C}_{\text {mouth }}, \mathrm{C}_{\text {nose }}$, and $\mathrm{C}_{\text {forehead }}$ had peak values at $27 \mathrm{fpm}$ for the standing manikin and $48 \mathrm{fpm}$ for sitting. However, for the effect of wig only, $\mathrm{C}_{\text {mouth }}, \mathrm{C}_{\text {nose }}$, and $\mathrm{C}_{\text {forehead }}$ had peak values at $48 \mathrm{fpm}$ for standing and $27 \mathrm{fpm}$ for sitting posture. As shown in Tables $6.1 \mathrm{a}$ and $6.1 \mathrm{~b}$, the difference in the means of various treatments was substantial at the low and middle velocities, but minor at the highest level (104 fpm).

The effect of velocity on concentrations at the shoulder is shown in Figures 6.5 to 6.7 . For lifelike conditions, with or without a wig, $C_{\text {neck }}, C_{\text {l.collar, }}$, and $C_{\text {r.collar }}$ had flat peaks at 27 and $48 \mathrm{fpm}$ for both sitting and standing postures. However, for the effect of wig only, $\mathrm{C}_{\text {neck, }}$, $\mathrm{C}_{\text {l.collar, }}$ and $\mathrm{C}_{\text {r.collar }}$ had peak concentrations at $27 \mathrm{fpm}$ for sitting and $48 \mathrm{fpm}$ for standing. As shown in Tables 6.1a and 6.1b, the difference in the means of various treatments was substantial at $48 \mathrm{fpm}$ for standing and moderate at $27 \mathrm{fpm}$ for sitting.

The effect of velocity on concentrations at chest level is shown in Figures 6.8 to 6.10. $\mathrm{C}_{\text {c.chest }}, \mathrm{C}_{\text {l.lapel}}$, and $\mathrm{C}_{\text {r.lapel }}$ had peak values at $48 \mathrm{fpm}$ for both sitting and standing. The peaks were wider for sitting than standing. As shown in Tables $6.1 \mathrm{a}$ and $6.1 \mathrm{~b}$, for lifelike conditions, the difference in the means of various treatments for the three locations was modest at all velocities for sitting and was substantial at $48 \mathrm{fpm}$ for standing.

\subsubsection{Breathing}

As shown in Figures 6.2 to 6.10 , the effects of breathing on sampling locations appeared to be substantial for all sampling locations, and for both sitting and standing manikin. For a breathing manikin, with or without a wig, concentrations at all sampling locations varied in an inverted-V shape relationship with velocity. The peak concentrations varied with posture and wig. Breathing reduced concentrations for all sampling locations. 
The effect of breathing was greater for locations at the face and shoulder for the manikin wearing a wig for both postures.

As will be discussed later, the effect of breathing was substantial for all sampling locations. In addition, these findings agree with Heist et al. (2003), Fletcher and Johnson (1996), and Wood and Birkett (1979) who tested the effect of breathing for chid-size manikin and for adult sized manikin standing in a low speed flow field $(0.1-0.5 \mathrm{~m} / \mathrm{s})$. Heist et al. (2003) found that breathing affected air flow patterns around the manikin in the vicinity of the mouth and nose, while, Wood and Birkett (1979) found that breathing action had little effect on a personal sampler located on manikin's lapel. In addition, Fletcher and Johnson (1996) found that breathing was confined to thermal boundry layer and did not influence the general flow field.

The effect of breathing, for the manikin wearing a wig, on concentrations at the face is shown in Figures 6.2 to 6.4. Breathing changed the peak location for $\mathrm{C}_{\text {mouth }}, \mathrm{C}_{\text {nose }}$, and $\mathrm{C}_{\text {forehead }}$ from $27 \mathrm{fpm}$ to $48 \mathrm{fpm}$ for sitting and from $48 \mathrm{fpm}$ to $27 \mathrm{fpm}$ for standing. As shown in Tables 6.1 a and $6.1 \mathrm{~b}$, at $48 \mathrm{fpm}, \mathrm{C}_{\text {mouth }}, \mathrm{C}_{\text {nose }}$, and $\mathrm{C}_{\text {forehead }}$ concentration values for breathing and wig conditions were 51\% lower for standing manikin and 54\% lower for sitting than the no breathing and wig conditions.

The effect of breathing, for the manikin wearing a wig, on concentrations at the shoulder level is shown in Figures 6.5 to 6.7. Likewise, Breathing changed the peak locations for $\mathrm{C}_{\text {neck }}, \mathrm{C}_{\text {l.collar}}$, and $\mathrm{C}_{\mathrm{r} \text {.collar }}$ in similar patterns as concentrations at the face. As shown in Tables 6.1 a and $6.1 \mathrm{~b}$, at $48 \mathrm{fpm}, \mathrm{C}_{\text {neck }}, \mathrm{C}_{\text {l.collar }}$, and $\mathrm{C}_{\text {r.collar }}$ concentration values for breathing and wig conditions were $47 \%$ lower for standing manikin and $25 \%$ lower for sitting than the no breathing and wig conditions.

Unlike concentrations at the face and shoulder levels, the effect of breathing, for the manikin wearing a wig, on concentrations at the chest level is shown in Figures 6.8 to 6.10. Breathing had greater effect on $\mathrm{C}_{\text {c.chest }}, \mathrm{C}_{\text {l.lapel }}$, and $\mathrm{C}_{\text {r.lapel }}$ for the low and middle velocity levels $(11-48 \mathrm{fpm})$ for standing. However, the effect of breathing on concentrations at the chest was minor at all velocities and for sitting posture. As shown in Tables 6.1a and 6.1b, at $48 \mathrm{fpm}, \mathrm{C}_{\text {c.chest }}, \mathrm{C}_{\text {l.lapel }}$, and $\mathrm{C}_{\text {r.lapel }}$ concentration values for breathing and wig conditions were $42 \%$ lower than the no breathing and wig for standing manikin.

\subsubsection{Wig}

As shown in Figures 6.2 to 6.10, the effects of wig on sampling locations appeared to be strikingly different with or without the effect of breathing and for both for the entire velocity range. For lifelike conditions (breathing), the wig had substantial and higher effects on concentrations measured at the face and the shoulder levels than concentrations measured at the chest for sitting posture at all velocities. Interestingly, the effect of the wig varied modestly with velocity at all sampling locations for standing manikin. As will be shown later, the wig reduced concentration levels, but with the peak location varied with velocity for all sampling locations.

The effect of wig on concentrations at the face is shown in Figures 6.2 to $6.4 . \mathrm{C}_{\text {mouth }}$, $\mathrm{C}_{\text {nose }}$, and $\mathrm{C}_{\text {forehead }}$ had an inverted-V peak concentration values at $27 \mathrm{fpm}$ for standing 
manikin and $48 \mathrm{fpm}$ for sitting, for lifelike conditions. However, for the effect of wig only, the location of the peak changed to $48 \mathrm{fpm}$ for standing and $27 \mathrm{fpm}$ for sitting. As shown in Tables 6.1 a and 6.1b, at $27 \mathrm{fpm}$ and for a breathing standing manikin, $\mathrm{C}_{\text {mouth }}, \mathrm{C}_{\text {nose }}$, and $\mathrm{C}_{\text {forehead }}$ concentration values for wearing a wig were $3 \%$ lower than bald conditions. On the other hand, at $48 \mathrm{fpm}$, for a breathing sitting manikin, $\mathrm{C}_{\text {mouth }}, \mathrm{C}_{\text {nose }}$, and $\mathrm{C}_{\text {forehead }}$ concentration values for wearing a wig were $34 \%$ lower than bald conditions.

The effect of wig on concentrations at the shoulder is shown in Figures 6.5 to 6.7. $\mathrm{C}_{\text {neck }}, \mathrm{C}_{\text {l.collar, and }} \mathrm{C}_{\text {r.collar }}$ had peaks occured at $48 \mathrm{fpm}$ for sitting and $27 \mathrm{fpm}$ for standing, for lifelike conditions. However, for the effect of wig only, the location of the peak changed to $48 \mathrm{fpm}$ for standing and $27 \mathrm{fpm}$ for sitting. As shown in Tables 6.1a and 6.1b, at $48 \mathrm{fpm}$, for a breathing standing manikin, $\mathrm{C}_{\text {neck }}, \mathrm{C}_{\text {l.collar, }}$ and $\mathrm{C}_{\text {r.collar }}$ concentration values for wearing a wig were $34 \%$ lower than bald conditions. On the other hand, at $48 \mathrm{fpm}$, for a breathing sitting manikin, $C_{\text {neck }}, C_{\text {l.collar }}$, and $C_{\text {r.collar }}$ concentration values for wearing a wig were $24 \%$ lower than bald conditions.

The effect of wig on concentrations at the chest is shown in Figures 6.8 to 6.10. $\mathrm{C}_{\text {c.chest }}, \mathrm{C}_{1 . \text { lapel }}$, and $\mathrm{C}_{\text {r.lapel }}$ had peaks occured at $48 \mathrm{fpm}$ for various treatment combinations. However, peaks were flatter for chest concentrations than shoulder and face concentrations. As shown in Tables $6.1 \mathrm{a}$ and $6.1 \mathrm{~b}$, at $48 \mathrm{fpm}$, for a breathing standing manikin, $\mathrm{C}_{\text {c.chest }}$, $\mathrm{C}_{1 . \text { lapel }}$, and $\mathrm{C}_{\mathrm{r} \text {.lapel }}$ concentration values for wearing a wig were $39 \%$ lower than bald conditions. On the other hand, at $48 \mathrm{fpm}$, for a breathing sitting manikin, $\mathrm{C}_{\mathrm{c} . \text { chest }}, \mathrm{C}_{1 . \text { lapel }}$, and $\mathrm{C}_{\text {r.lapel }}$ concentration values for wearing a wig were $12 \%$ lower than bald conditions.

\subsubsection{Posture}

The effect of posture was substantial for the effects of velocity, breathing, and hair style. It is plausible that posture would affect concentrations because of the different orientation of arms and legs to cross draft. In the standing posture, the manikin arms and legs are perpendicular to the cross draft while in sitting posture the arms and legs are parallel to wind tunnel velocity. The arms and legs would affect air flow patterns around the manikin and hence concentration gradients in the breathing zone.

For instance, for sitting, concentrations at the face $\mathrm{C}_{\text {mouth }}, \mathrm{C}_{\text {nose }}$, and $\mathrm{C}_{\text {forehead, }}$, had peak concentrations occurred at $48 \mathrm{fpm}$ for lifelike conditions and at $27 \mathrm{fpm}$ for the effect of wig only. For standing, the peak for each treatment combination shifted to the other's locations (see Figures 6.2 to 6.4). Similarly, concentrations at the shoulder level, $\mathrm{C}_{\text {neck }}, \mathrm{C}_{\text {l.collar, }}$ and $\mathrm{C}_{\text {r.collar }}$ had peak occurred in similar pattern to concentrations at the face. Unlike sitting, concentartions at shoulder level peaked at $48 \mathrm{fpm}$ and at $27 \mathrm{fpm}$ for various treatments for standing as shown in Figures 6.5 to 6.7. Concentartions at chest level, $\mathrm{C}_{\text {c.chest }}, \mathrm{C}_{1 . \text { lapel }}$, and $\mathrm{C}_{\text {r.lapel }}$ peaked at $48 \mathrm{fpm}$ for both postures and for all treatments (see Figures 6.8 to 6.10). As will be discussed later on, the effect of posture was statistically significant for all sampling locations. 
Table 6.2a: Average Concentrations (ppm) at lower torso, upper torso, and inhaled (seated)

\begin{tabular}{|c|c|c|c|c|c|}
\hline Treatment & $\mathrm{V}, \mathrm{fpm}$ & $\mathrm{C}_{\text {lower.torso }}$ & $\mathrm{C}_{\text {upper.torso }}$ & $\mathrm{C}_{\text {inhaled }}$ & $\mathrm{C}_{\text {forehead }}$ \\
\hline \multirow{5}{*}{$\begin{array}{c}\text { Seated } \\
\text { NoBreathing } \\
\text { NoWig }\end{array}$} & 11 & 16.2 & 16.2 & 11.5 & 7.8 \\
\hline & 27 & 21.6 & 21.0 & 22.1 & 14.9 \\
\hline & 48 & 30.8 & 39.5 & 49.5 & 37.1 \\
\hline & 82 & 21.0 & 20.4 & 30.3 & 26.2 \\
\hline & 104 & 16.6 & 16.1 & 21.8 & 18.9 \\
\hline \multirow{5}{*}{$\begin{array}{l}\text { Seated } \\
\text { Breathing } \\
\text { NoWig }\end{array}$} & 11 & 10.9 & 14.5 & 14.6 & 9.3 \\
\hline & 27 & 17.1 & 28.3 & 34.9 & 25.9 \\
\hline & 48 & 22.0 & 36.1 & 47.6 & 44.3 \\
\hline & 82 & 16.5 & 28.1 & 32.8 & 28.1 \\
\hline & 104 & 14.0 & 25.0 & 27.5 & 21.9 \\
\hline \multirow{5}{*}{$\begin{array}{c}\text { Seated } \\
\text { NoBreathing } \\
\text { Wig }\end{array}$} & 11 & 8.1 & 27.9 & 17.3 & 12.8 \\
\hline & 27 & 13.5 & 37.3 & 51.2 & 45.9 \\
\hline & 48 & 19.5 & 32.2 & 43.7 & 42.1 \\
\hline & 82 & 11.9 & 27.0 & 33.0 & 32.8 \\
\hline & 104 & 10.0 & 23.6 & 30.1 & 27.6 \\
\hline \multirow{5}{*}{$\begin{array}{c}\text { Seated } \\
\text { Breathing } \\
\text { Wig }\end{array}$} & 11 & 7.2 & 11.0 & 8.4 & 6.6 \\
\hline & 27 & 13.8 & 18.3 & 25.3 & 26.8 \\
\hline & 48 & 17.3 & 25.3 & 33.8 & 38.7 \\
\hline & 82 & 12.5 & 24.0 & 28.9 & 28.6 \\
\hline & 104 & 8.3 & 22.2 & 27.1 & 24.2 \\
\hline
\end{tabular}


Table 6.2b: Average Concentrations (ppm) at lower torso, upper torso, and inhaled (standing)

\begin{tabular}{cccccc}
\hline Treatment & V,fpm & C lower.torso & $\mathrm{C}_{\text {upper.torso }}$ & $\mathrm{C}_{\text {inhaled }}$ & $\mathrm{C}_{\text {forehead }}$ \\
\hline \hline & & & & & \\
Standing & 11 & 27.5 & 30.2 & 29.0 & 25.3 \\
NoBreathing & 27 & 45.8 & 45.3 & 59.5 & 52.0 \\
NoWig & 48 & 92.4 & 68.7 & 54.9 & 47.3 \\
& 82 & 47.0 & 42.8 & 43.0 & 39.4 \\
& 104 & 35.5 & 32.3 & 34.3 & 32.6 \\
\hline \hline Standing & 11 & 18.7 & 23.2 & 20.9 & 18.6 \\
Breathing & 27 & 22.2 & 33.8 & 41.2 & 36.8 \\
NoWig & 48 & 51.5 & 45.2 & 38.8 & 31.9 \\
& 82 & 30.9 & 31.1 & 30.8 & 29.0 \\
& 104 & 25.3 & 25.4 & 26.7 & 25.4 \\
\hline \hline Standing & 11 & & & & \\
NoBreathing & 27 & 42.3 & 40.8 & 29.7 & 27.1 \\
Wig & 48 & 52.1 & 54.2 & 39.7 & 32.1 \\
Breathing & 27 & 62.5 & 58.6 & 52.9 & 44.7 \\
Wig & 48 & 32.1 & 36.2 & 37.9 & 36.8 \\
& 82 & 27.9 & 25.3 & 31.2 & 28.6 \\
& 104 & 32.3 & 29.0 & 31.9 & 30.3 \\
\hline \hline
\end{tabular}




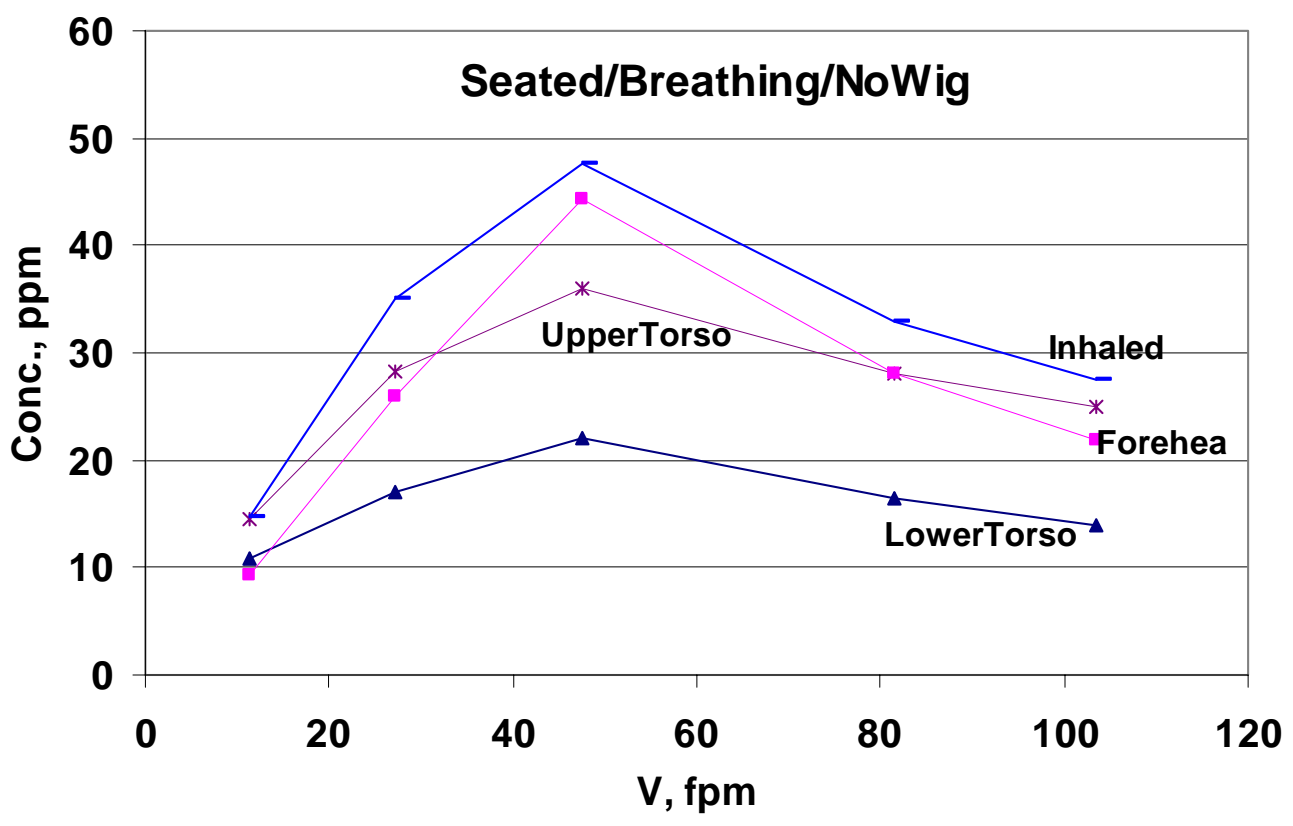

Figure 6.11-a: Average BZ Concentration versus velocity for all treatments

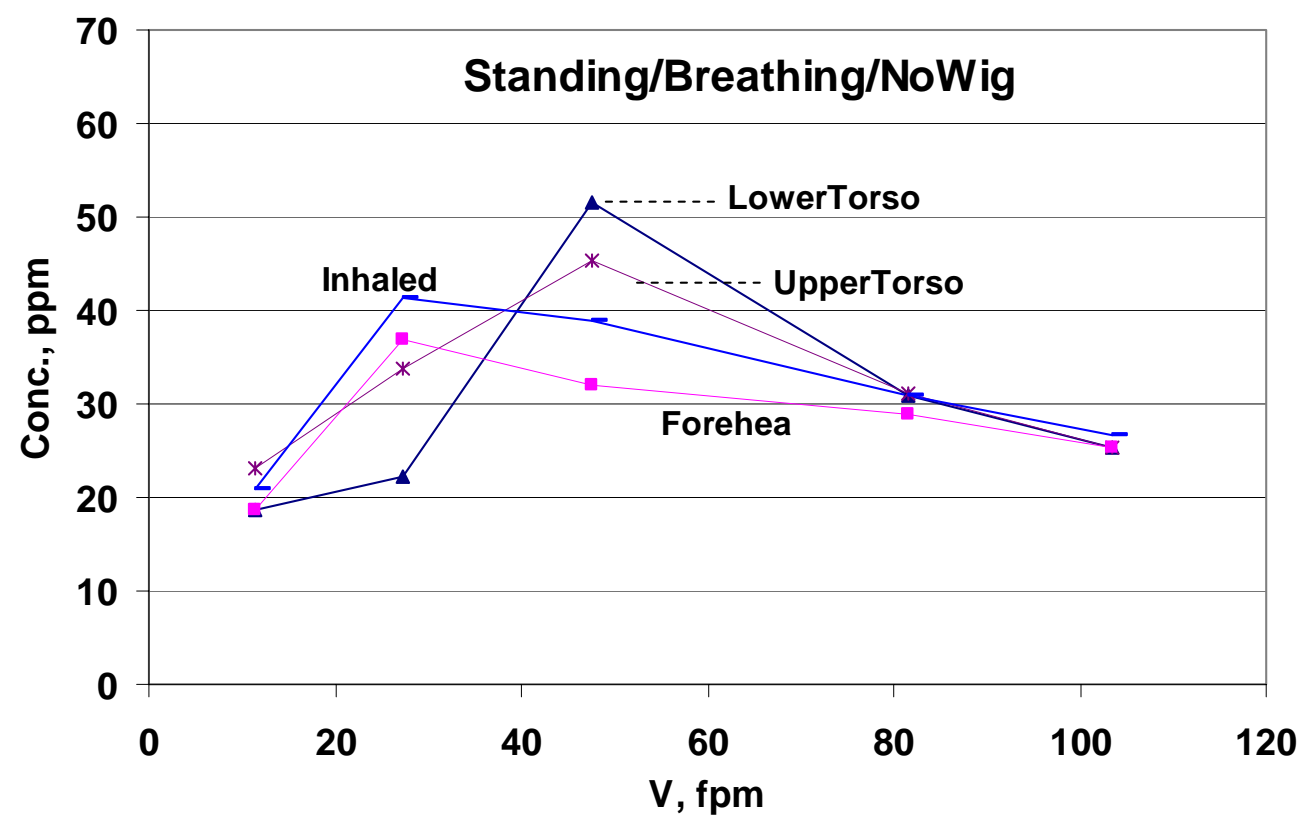

Figure 6.11-b: Average BZ Concentration versus velocity for all treatment 


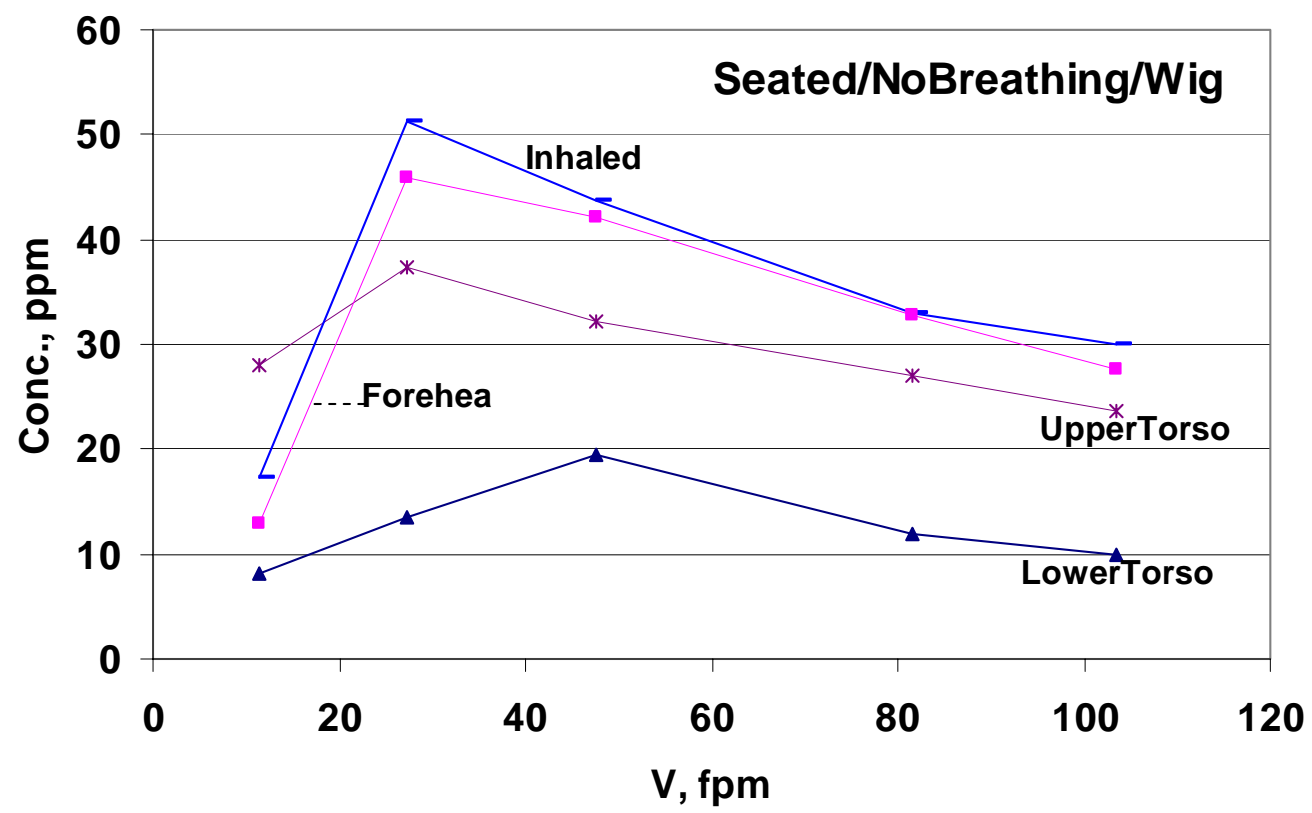

Figure 6.12-a: Average BZ Concentration versus velocity for all treatment

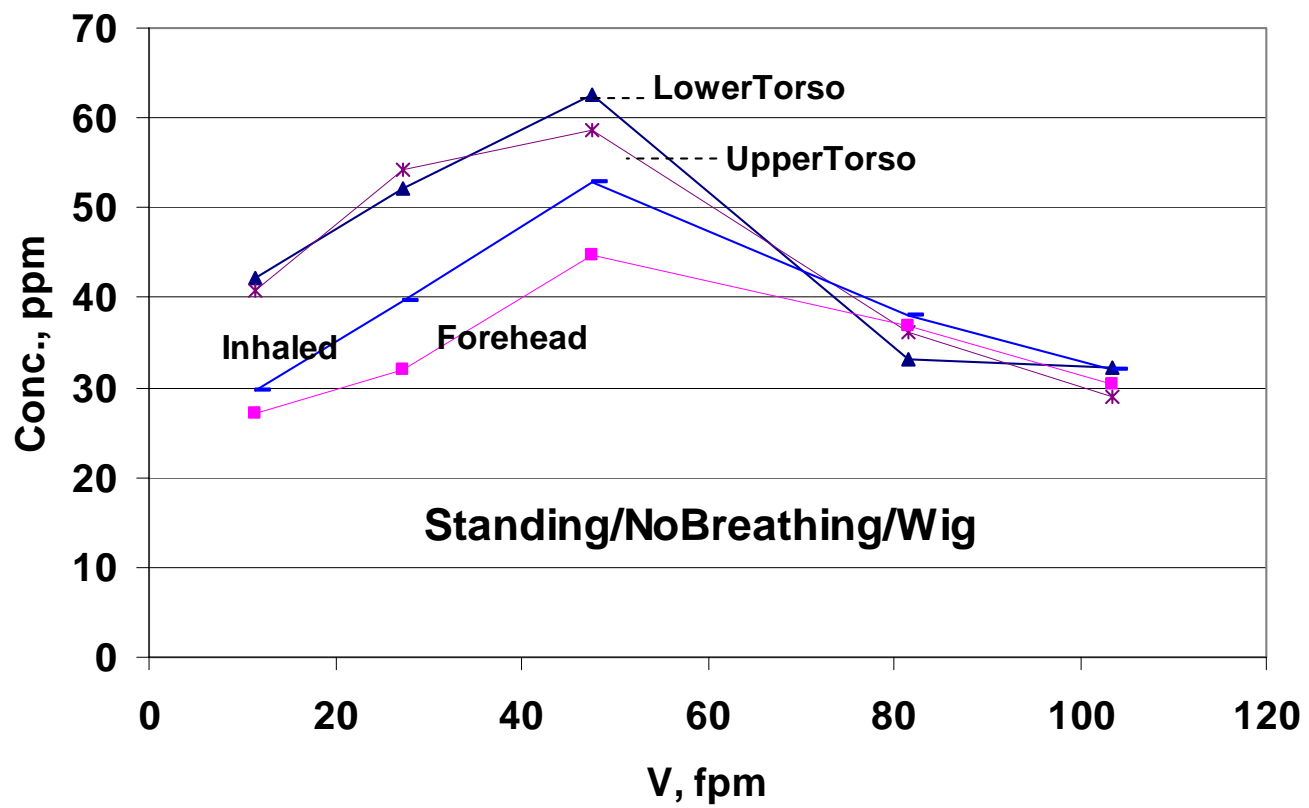

Figure 6.12-b: Mean BZ Concentration versus velocity for all treatment 


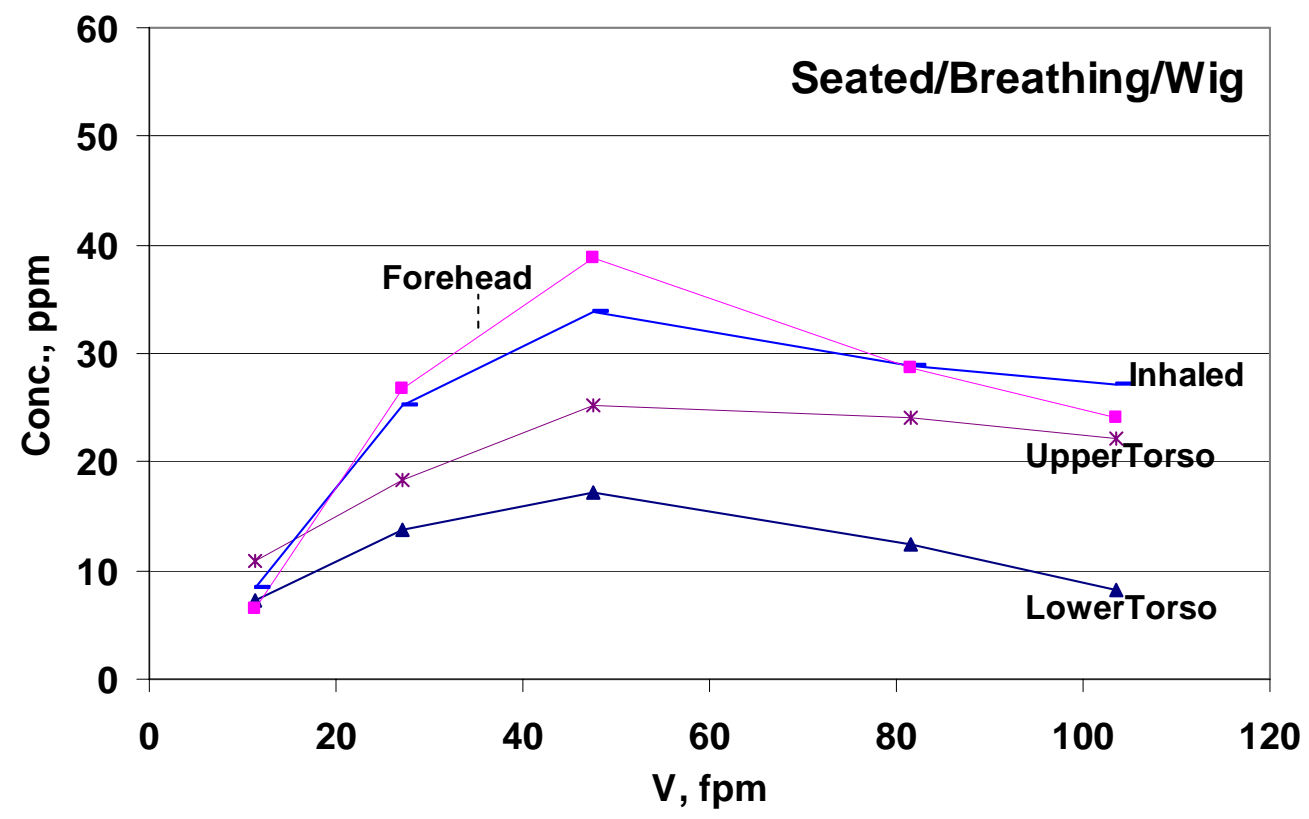

Figure 6.13-a: Mean BZ Concentration versus velocity for all treatment

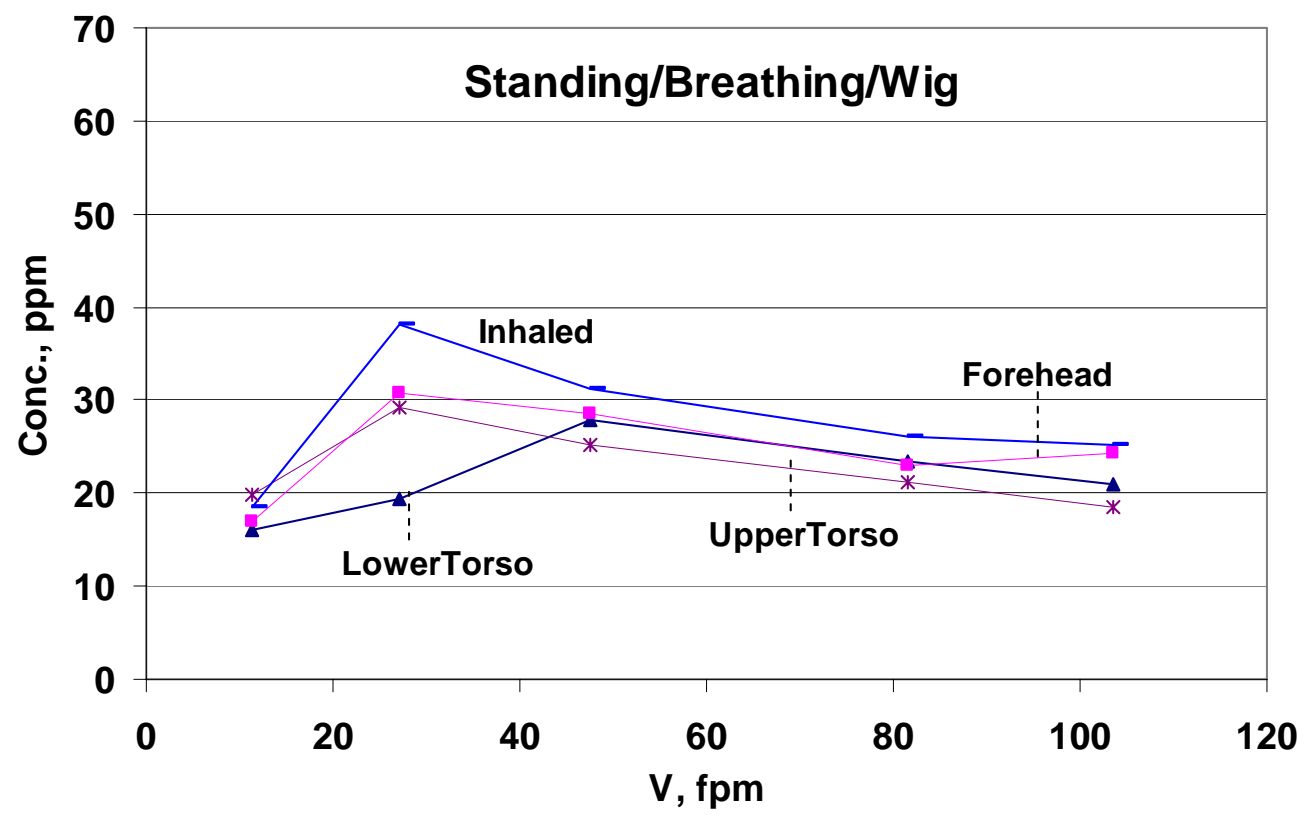

Figure 6.13-b: Mean BZ Concentration versus velocity for all treatment 


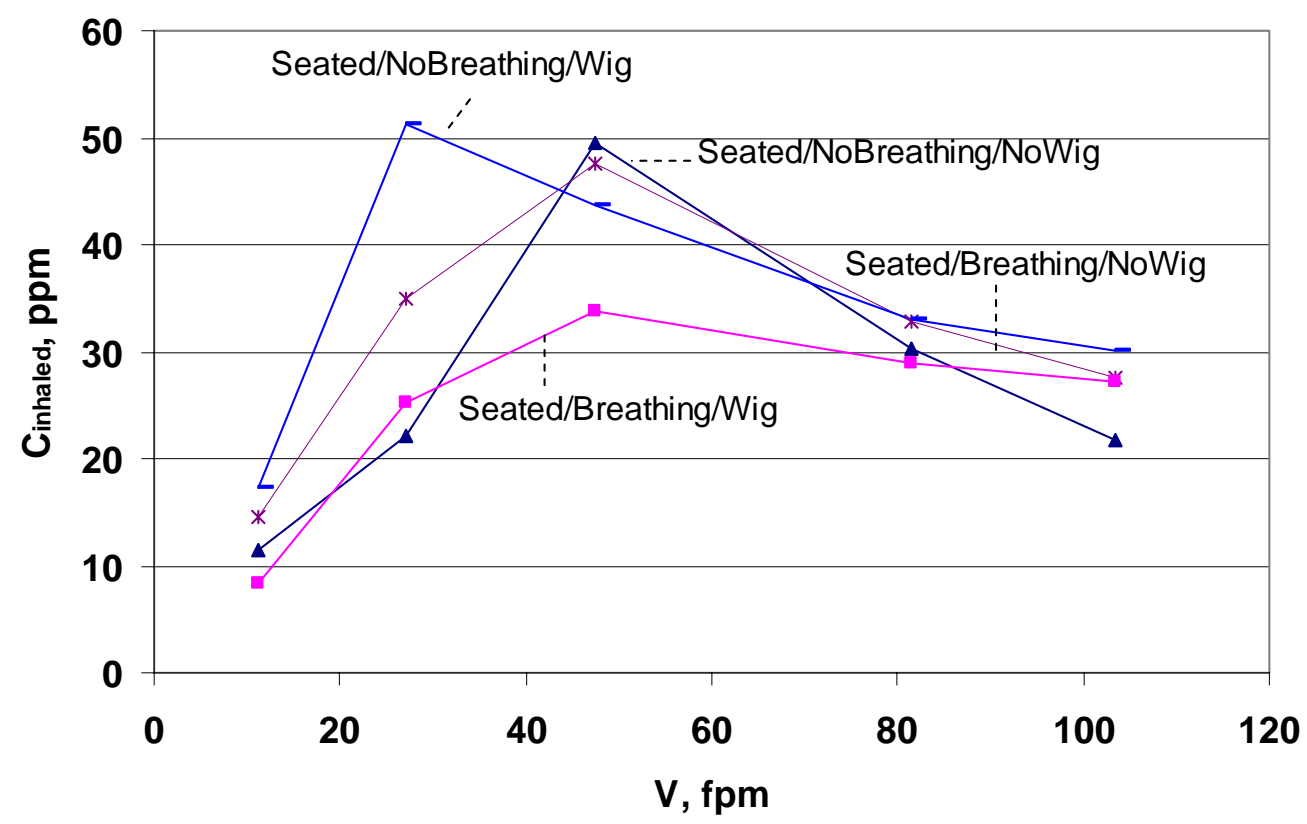

Figure 6.14-a: Mean plot of $\mathrm{C}_{\text {inhaled }}$ versus velocity for all manikin treatment

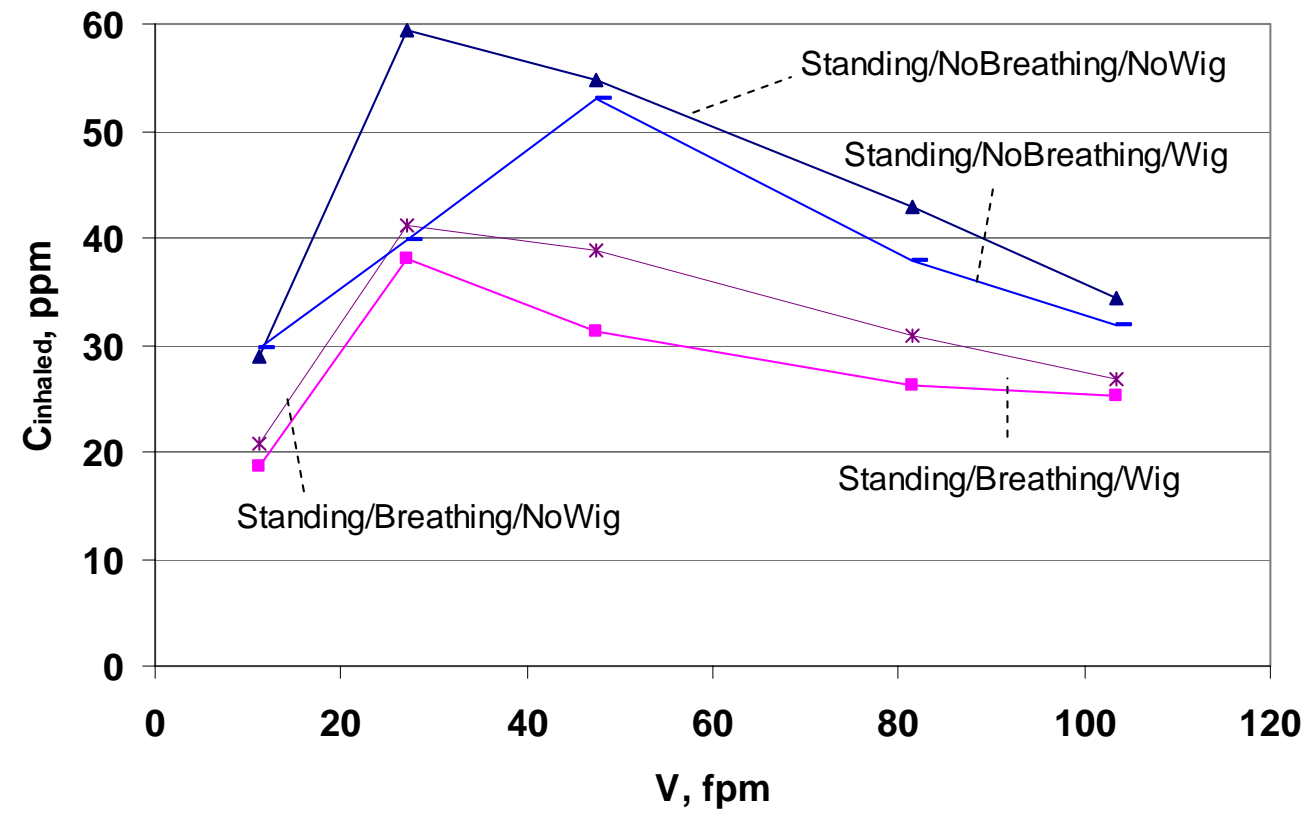

Figure 6.14-b: Mean plot of $\mathrm{C}_{\text {inhaled }}$ versus velocity for all manikin treatment 


\subsection{Effects of Independent Variables on $C_{\text {inhaled }}, C_{\text {upper.torsos }}$ and $C_{\text {lower.torso }}$}

Since concentrations near the mouth behaved similarly, the average of $\mathrm{C}_{\text {mouth }}$ and $\mathrm{C}_{\text {nose }}$ were used to compute $\mathrm{C}_{\text {inhaled }}$. Likewise, $\mathrm{C}_{\text {uptorso }}$ is the average of $\mathrm{C}_{\text {neck }}$ and the two collars and $\mathrm{C}_{\text {lowtorso }}$ is the average of $\mathrm{C}_{\text {chest }}$ and the two lapels. $\mathrm{C}_{\text {forehead }}$ was the lowest concentration level compared to $\left(\mathrm{C}_{\text {mouth }}\right.$ and $\left.\mathrm{C}_{\text {nose }}\right)$ so it was not used to compute $\mathrm{C}_{\text {inhaled }}$.

Figures 6.11 to 6.14 show the effects of velocity, breathing, wig, and posture on $\mathrm{C}_{\text {inhaled }}, \mathrm{C}_{\text {uppertorso }}$, and $\mathrm{C}_{\text {lowertorso }}$. For the the most realistic conditions, breathing and wig, all three concentrations varied in an inverted-V shape with velocity for both sitting and standing. The location of the peak was different for sitting (48 fpm) and standing ( $27 \mathrm{fpm})$, but the magnitudes of the peaks were about the same at a given location. However, the concentrations differed sharply by measurement locations. More importantly, the differences in concentrations were strongly affected by posture. For example, the lower chest concentrations were much higher than $\mathrm{C}_{\text {inhaled }}$ for standing and lower for sitting (see Figures $6.11 \mathrm{a} \& \mathrm{~b})$. Hence, whether a torso measurement exaggerated or underestimated the actual level depends on whether the manikin was sitting or standing.

As shown in Tables 6.2a and 6.2b, for lifelike conditions, at peak velocities, the effect of breathing and wig on $\mathrm{C}_{\text {inhaled }}$ was substantial, $32 \%$ reduction for sitting. On the other hand, the effect of breathing only on $\mathrm{C}_{\text {inhaled }}$ was substantial, $31 \%$ reduction in concentrations for standing. Similarlly, the effect of breathing and wig on $\mathrm{C}_{\text {upper.torso }}$ substantially reduced concentration levels by $36 \%$ for sitting and $44 \%$ for standing. 
Table 6.3a: Ratios of concentrations to $\mathrm{C}_{\text {mouth }}$ for all velocities and manikin treatments (sitting)

\begin{tabular}{|c|c|c|c|c|c|c|c|c|c|}
\hline Treatment & V,fpm & $\mathrm{C}_{\text {c.chest }}$ & $\mathrm{C}_{\text {l.lapel }}$ & $\mathrm{C}_{\text {r.lapel }}$ & $\mathrm{C}_{\text {neck }}$ & $\mathrm{C}_{\text {l.collar }}$ & $\mathrm{C}_{\text {r.collar }}$ & $\mathrm{C}_{\text {nose }}$ & $\mathrm{C}_{\text {forehead }}$ \\
\hline \multirow{5}{*}{$\begin{array}{c}\text { Seated } \\
\text { NoBreathing } \\
\text { NoWig }\end{array}$} & 11 & 1.45 & 1.21 & 1.12 & 1.18 & 1.28 & 1.36 & 0.80 & 0.61 \\
\hline & 27 & 1.00 & 0.97 & 0.90 & 0.94 & 0.94 & 0.89 & 0.95 & 0.65 \\
\hline & 48 & 0.66 & 0.65 & 0.61 & 0.89 & 0.77 & 0.79 & 1.04 & 0.77 \\
\hline & 82 & 0.80 & 0.71 & 0.62 & 0.70 & 0.70 & 0.67 & 1.04 & 0.88 \\
\hline & 104 & 0.84 & 0.74 & 0.70 & 0.73 & 0.78 & 0.70 & 0.99 & 0.86 \\
\hline \multirow{5}{*}{$\begin{array}{l}\text { Seated } \\
\text { Breathing } \\
\text { NoWig }\end{array}$} & 11 & 0.89 & 0.64 & 0.71 & 1.04 & 1.09 & 0.75 & 0.89 & 0.60 \\
\hline & 27 & 0.53 & 0.52 & 0.44 & 0.97 & 0.76 & 0.70 & 1.00 & 0.74 \\
\hline & 48 & 0.44 & 0.48 & 0.46 & 0.76 & 0.72 & 0.77 & 0.97 & 0.92 \\
\hline & 82 & 0.55 & 0.45 & 0.57 & 0.92 & 0.95 & 0.83 & 1.09 & 0.90 \\
\hline & 104 & 0.61 & 0.48 & 0.48 & 0.94 & 1.06 & 0.82 & 1.07 & 0.83 \\
\hline \multirow{5}{*}{$\begin{array}{c}\text { Seated } \\
\text { NoBreathing } \\
\text { Wig }\end{array}$} & 11 & 0.52 & 0.40 & 0.39 & 1.51 & 1.26 & 1.71 & 0.86 & 0.70 \\
\hline & 27 & 0.26 & 0.24 & 0.25 & 0.82 & 0.50 & 0.77 & 0.91 & 0.86 \\
\hline & 48 & 0.45 & 0.43 & 0.46 & 0.84 & 0.58 & 0.75 & 0.97 & 0.96 \\
\hline & 82 & 0.40 & 0.34 & 0.35 & 0.87 & 0.69 & 0.86 & 0.96 & 0.98 \\
\hline & 104 & 0.32 & 0.34 & 0.30 & 0.80 & 0.68 & 0.78 & 0.94 & 0.88 \\
\hline \multirow{5}{*}{$\begin{array}{l}\text { Seated } \\
\text { Breathing } \\
\text { Wig }\end{array}$} & 11 & 0.87 & 0.63 & 0.67 & 1.15 & 0.69 & 1.26 & 0.60 & 0.65 \\
\hline & 27 & 0.65 & 0.56 & 0.52 & 0.81 & 0.75 & 0.69 & 1.06 & 1.09 \\
\hline & 48 & 0.59 & 0.53 & 0.51 & 0.87 & 0.81 & 0.69 & 1.11 & 1.21 \\
\hline & 82 & 0.53 & 0.46 & 0.36 & 0.89 & 0.87 & 0.84 & 1.08 & 1.03 \\
\hline & 104 & 0.29 & 0.36 & 0.30 & 0.86 & 0.84 & 0.80 & 1.04 & 0.91 \\
\hline
\end{tabular}


Table 6.3b: Ratios of Concentrations to $\mathrm{C}_{\text {mouth }}$ for all Velocities and Manikin Treatments (standing)

\begin{tabular}{|c|c|c|c|c|c|c|c|c|c|}
\hline Treatment & $\mathrm{V}, \mathrm{fpm}$ & $\mathrm{C}_{\text {c.chest }}$ & $\mathrm{C}_{\text {l.lapel }}$ & $\mathrm{C}_{\text {r.lapel }}$ & $\mathrm{C}_{\text {neck }}$ & $\mathrm{C}_{\text {l.collar }}$ & $\mathrm{C}_{\text {r.collar }}$ & $\mathrm{C}_{\text {nose }}$ & $\mathrm{C}_{\text {forehead }}$ \\
\hline \multirow{5}{*}{$\begin{array}{c}\text { Standing } \\
\text { NoBreathing } \\
\text { NoWig }\end{array}$} & 11 & 1.07 & 0.81 & 0.91 & 1.08 & 1.02 & 0.98 & 0.97 & 0.86 \\
\hline & 27 & 0.80 & 0.67 & 0.76 & 0.86 & 0.72 & 0.64 & 0.94 & 0.85 \\
\hline & 48 & 1.81 & 1.37 & 1.69 & 1.29 & 1.09 & 1.26 & 0.93 & 0.83 \\
\hline & 82 & 1.15 & 0.97 & 1.04 & 1.04 & 0.85 & 0.99 & 0.93 & 0.88 \\
\hline & 104 & 1.06 & 0.97 & 0.95 & 1.01 & 0.78 & 0.94 & 0.94 & 0.92 \\
\hline \multirow{5}{*}{$\begin{array}{l}\text { Standing } \\
\text { Breathing } \\
\text { NoWig }\end{array}$} & 11 & 1.28 & 0.63 & 0.85 & 1.23 & 1.28 & 0.93 & 1.06 & 0.92 \\
\hline & 27 & 0.74 & 0.43 & 0.50 & 1.03 & 0.87 & 0.64 & 1.06 & 0.92 \\
\hline & 48 & 1.63 & 1.00 & 1.40 & 1.29 & 1.15 & 1.09 & 1.02 & 0.83 \\
\hline & 82 & 1.24 & 0.84 & 0.99 & 1.08 & 1.09 & 0.93 & 1.05 & 0.96 \\
\hline & 104 & 1.20 & 0.94 & 0.89 & 1.05 & 1.13 & 0.86 & 1.13 & 1.01 \\
\hline \multirow{5}{*}{$\begin{array}{c}\text { Standing } \\
\text { NoBreathing } \\
\text { Wig }\end{array}$} & 11 & 1.72 & 1.12 & 1.21 & 1.36 & 1.44 & 1.18 & 0.97 & 0.89 \\
\hline & 27 & 1.43 & 1.08 & 1.24 & 1.31 & 1.23 & 1.42 & 0.93 & 0.78 \\
\hline & 48 & 1.21 & 1.00 & 1.26 & 1.14 & 1.01 & 1.09 & 0.95 & 0.82 \\
\hline & 82 & 0.95 & 0.72 & 0.84 & 0.98 & 0.78 & 0.97 & 0.92 & 0.93 \\
\hline & 104 & 1.07 & 0.76 & 1.01 & 0.88 & 0.67 & 1.00 & 0.87 & 0.89 \\
\hline \multirow{5}{*}{$\begin{array}{l}\text { Standing } \\
\text { Breathing } \\
\text { Wig }\end{array}$} & 11 & 1.71 & 0.55 & 0.64 & 1.64 & 1.19 & 0.73 & 1.19 & 0.99 \\
\hline & 27 & 0.75 & 0.36 & 0.49 & 0.92 & 0.73 & 0.55 & 0.96 & 0.80 \\
\hline & 48 & 1.48 & 0.88 & 0.82 & 1.23 & 0.96 & 0.69 & 1.33 & 1.06 \\
\hline & 82 & 1.55 & 0.88 & 0.87 & 1.20 & 1.00 & 0.80 & 1.47 & 1.08 \\
\hline & 104 & 1.56 & 0.83 & 0.75 & 1.17 & 0.93 & 0.68 & 1.54 & 1.22 \\
\hline
\end{tabular}




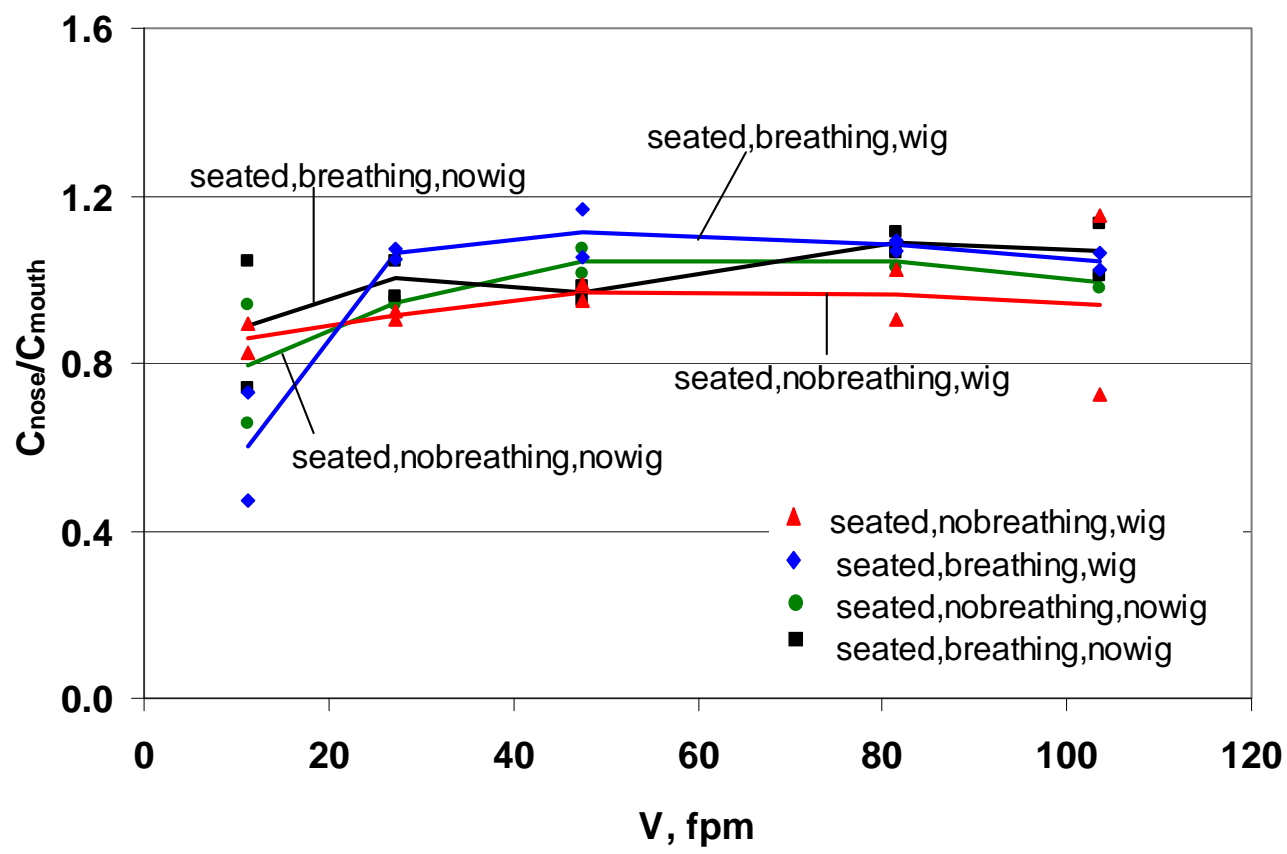

Figure 6.15-a: Scatter and mean plot of $\mathrm{C}_{\text {nose }} / \mathrm{C}_{\text {mouth }}$ vs. velocity for all manikin treatments (seated)

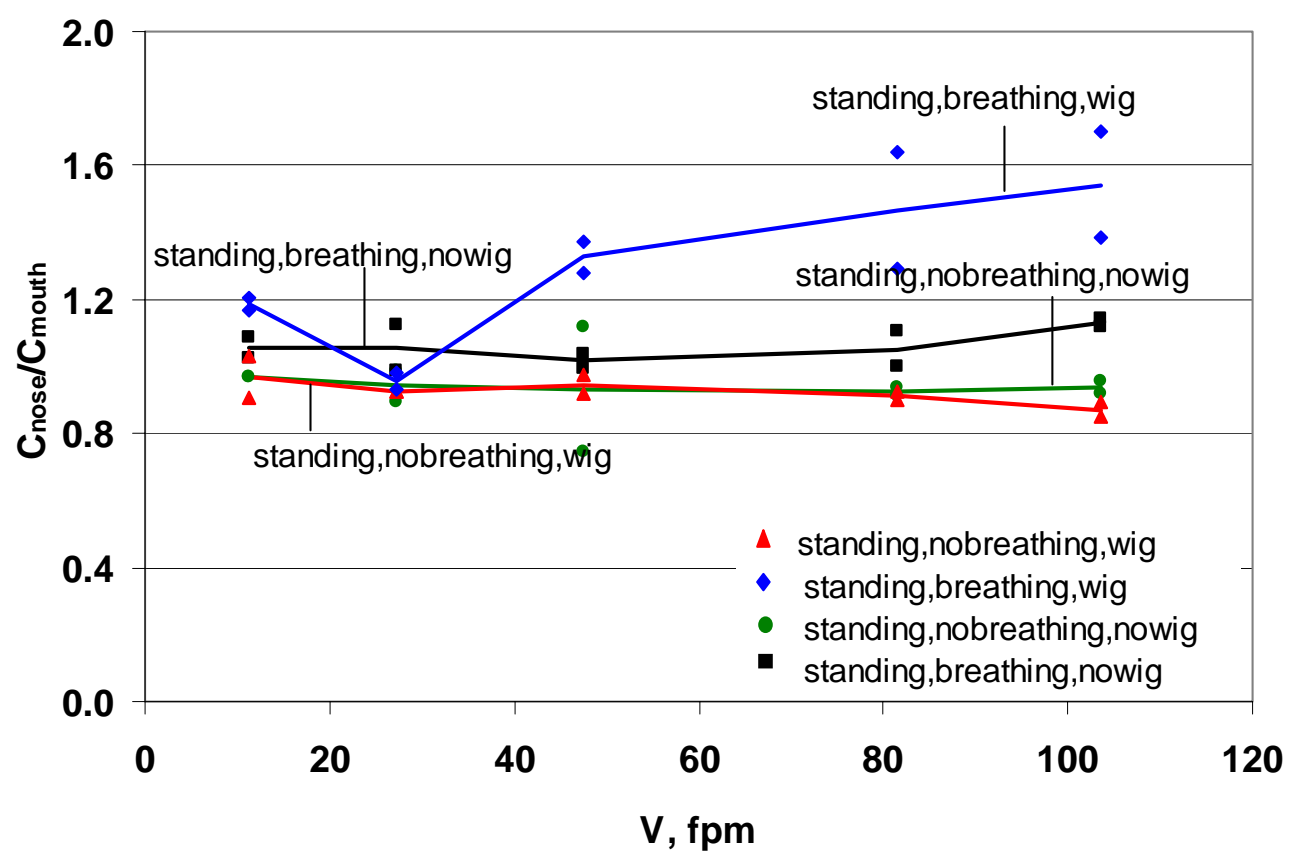

Figure 6.15-b: Scatter and mean plot of $\mathrm{C}_{\text {nose }} / \mathrm{C}_{\text {mouth }}$ vs. velocity for all manikin treatments (standing) 


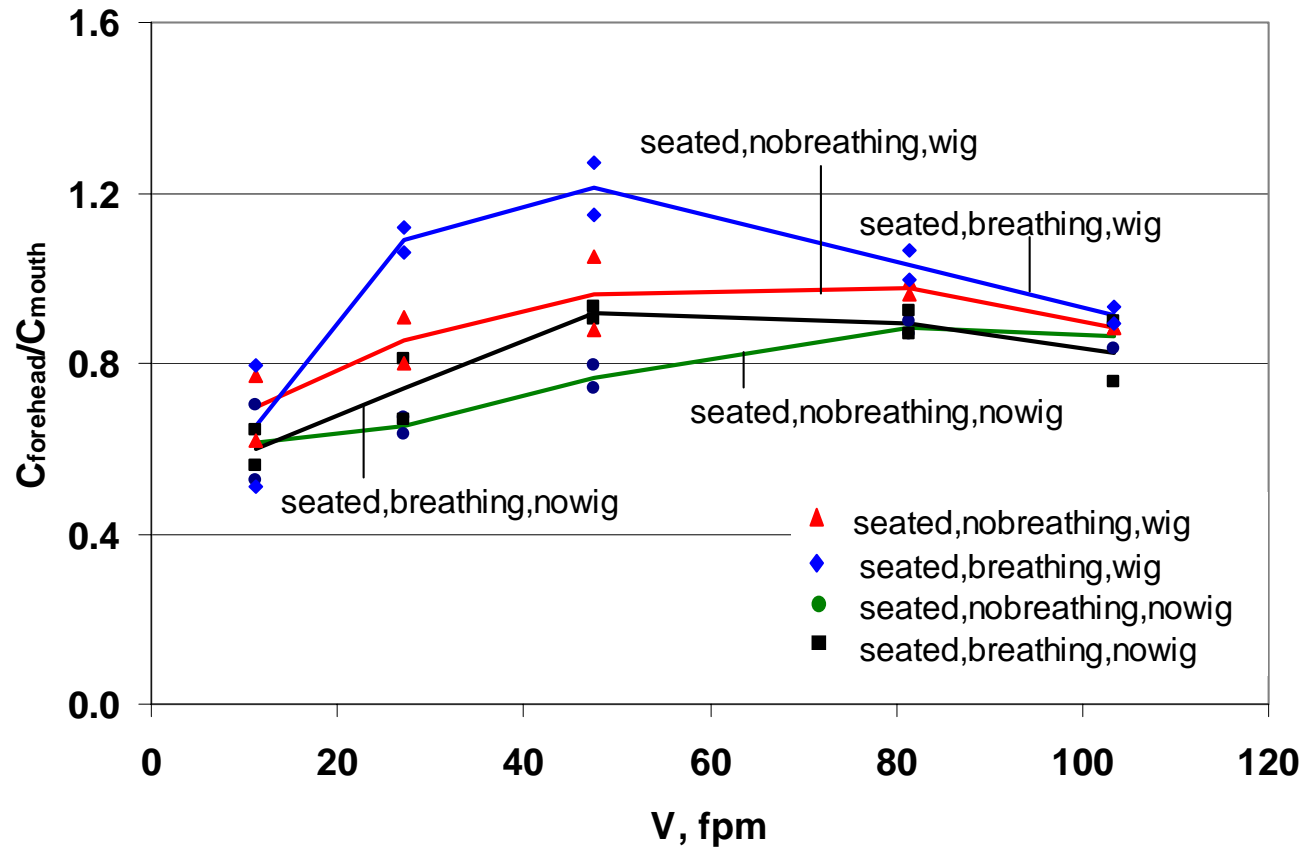

Figure 6.16-a: Scatter and mean plot of $\mathrm{C}_{\text {forehead }} / \mathrm{C}_{\text {mouth }}$ vs. velocity for all manikin treatments (seated)

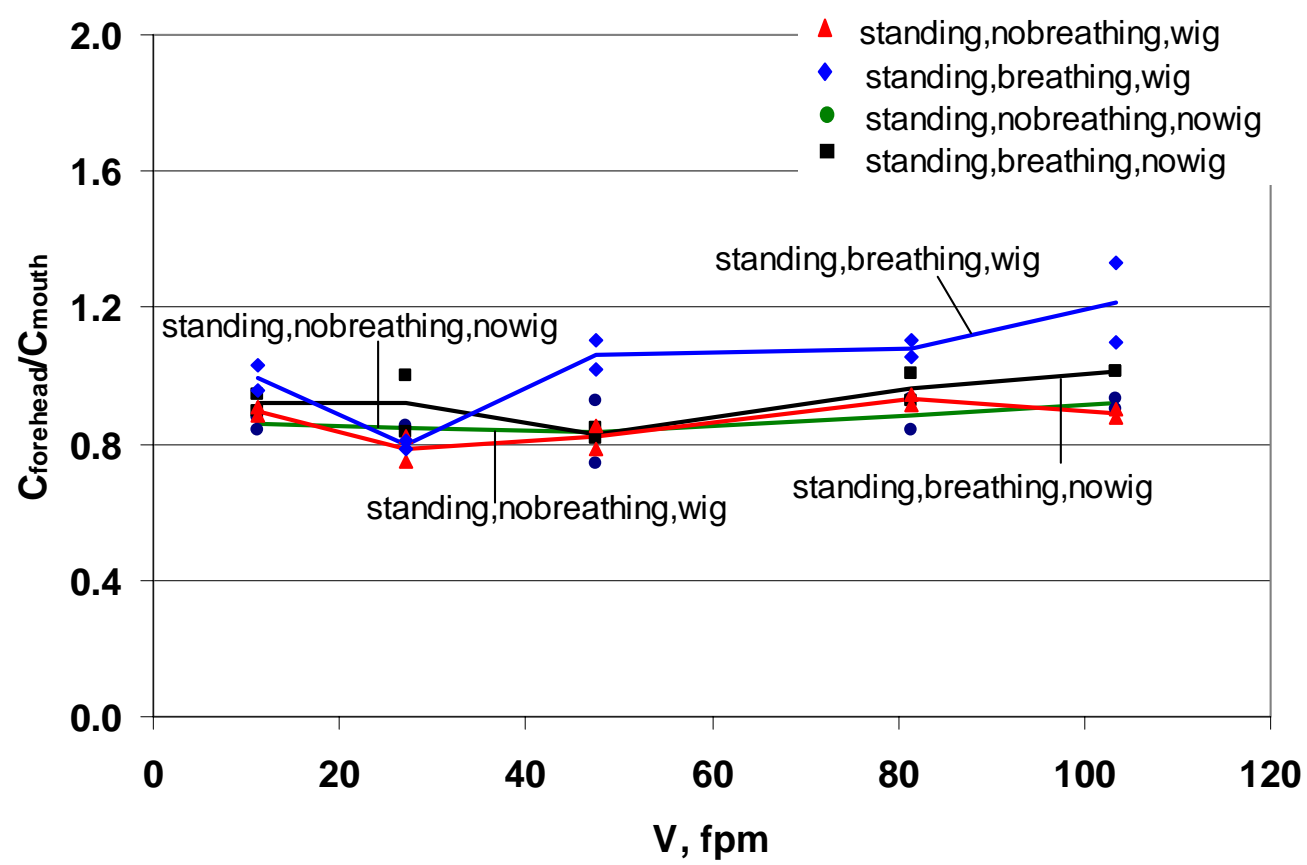

Figure 6.16-b: Scatter and mean plot of $\mathrm{C}_{\text {forehead }} / \mathrm{C}_{\text {mouth }}$ vs. velocity for all manikin treatments (standing) 


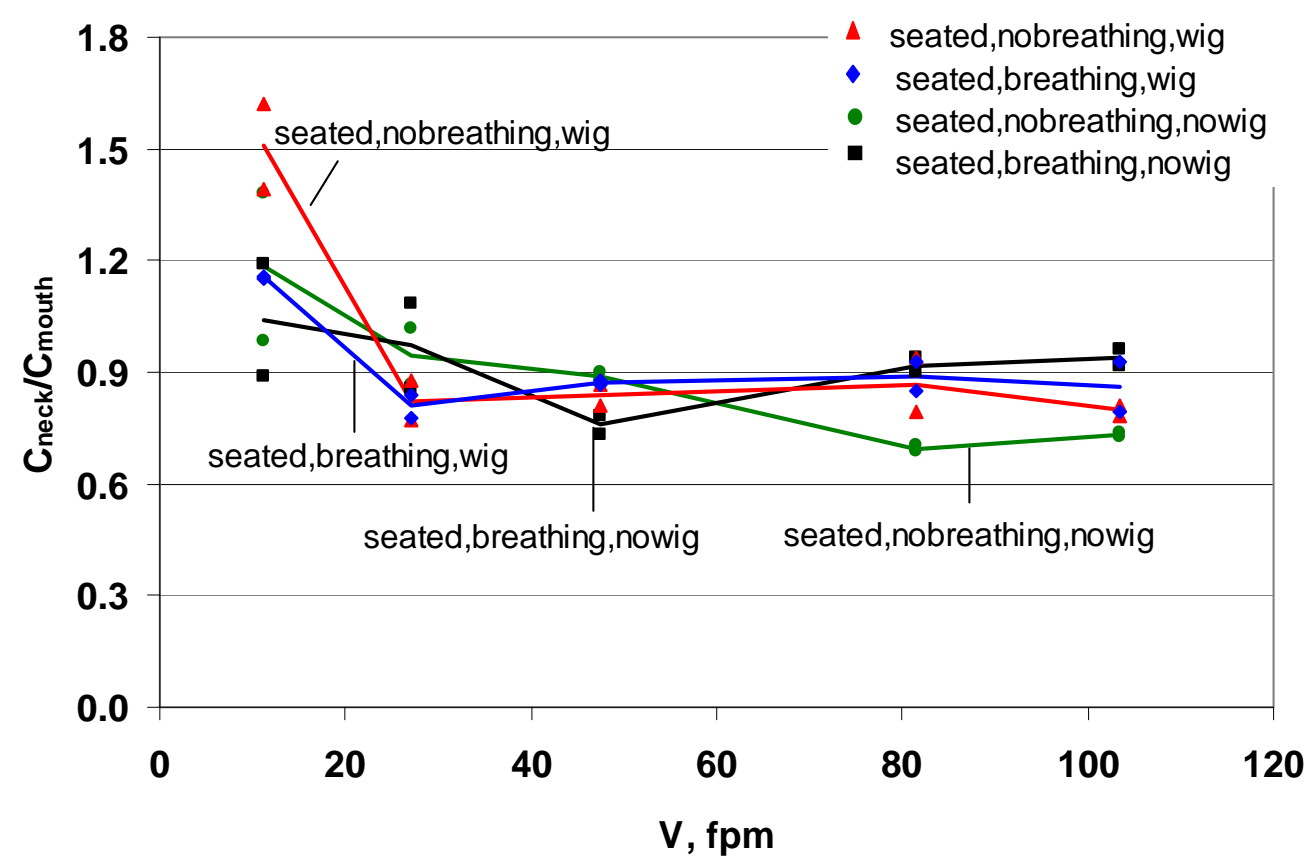

Figure 6.17-a: Scatter and mean plot of $\mathrm{C}_{\text {neck }} / \mathrm{C}_{\text {mouth }}$ vs. velocity for all manikin treatments (seated)

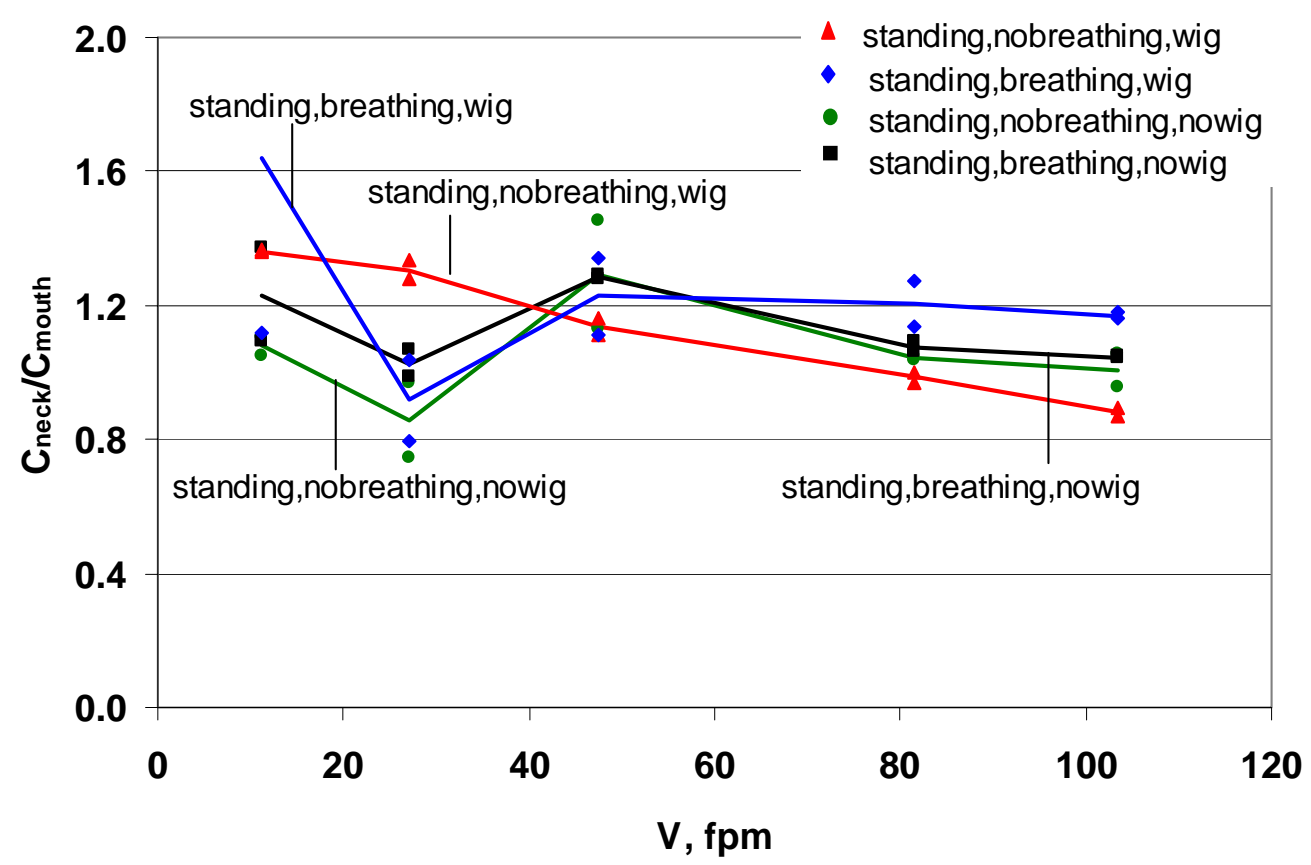

Figure 6.17-b: Scatter and mean plot of $\mathrm{C}_{\text {neck }} / \mathrm{C}_{\text {mouth }}$ vs. velocity for all manikin treatments (standing) 


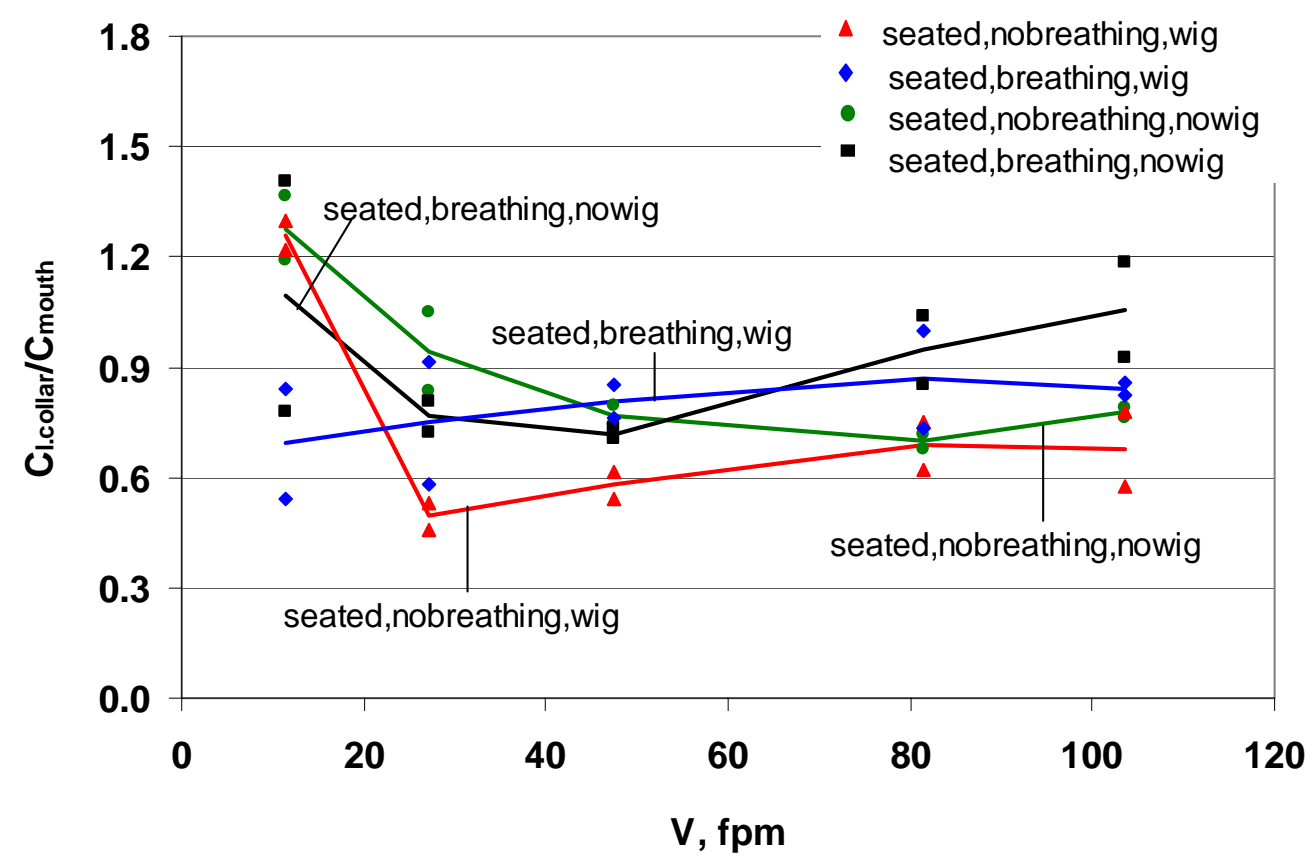

Figure 6.18-a: Scatter and mean plot of $\mathrm{C}_{1 . \text { collar }} / \mathrm{C}_{\text {mouth }}$ vs. velocity for all manikin treatments (seated)

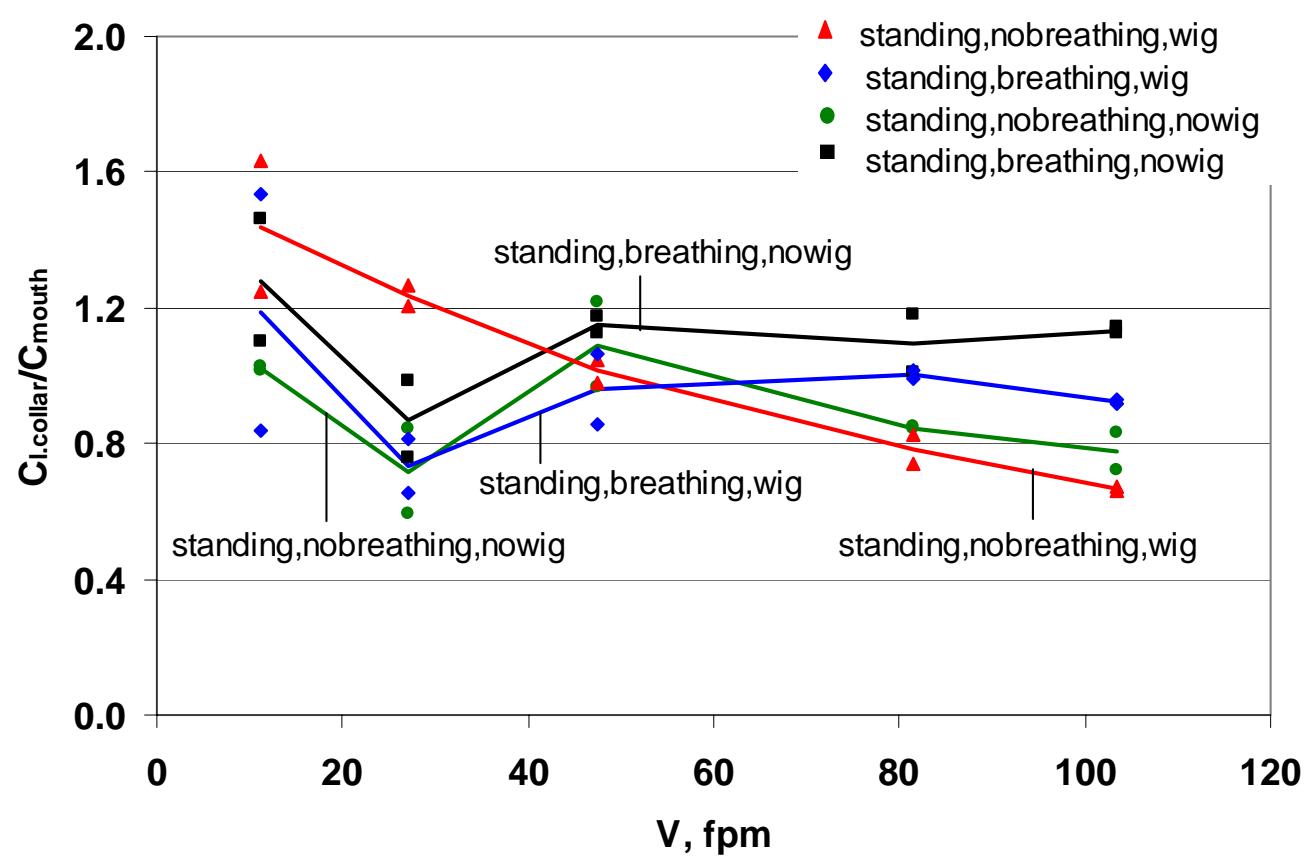

Figure 6.18-b: Scatter and mean plot of $\mathrm{Cl}_{\text {l.collar }} / \mathrm{C}_{\text {mouth }}$ vs. velocity for all manikin treatments (standing) 


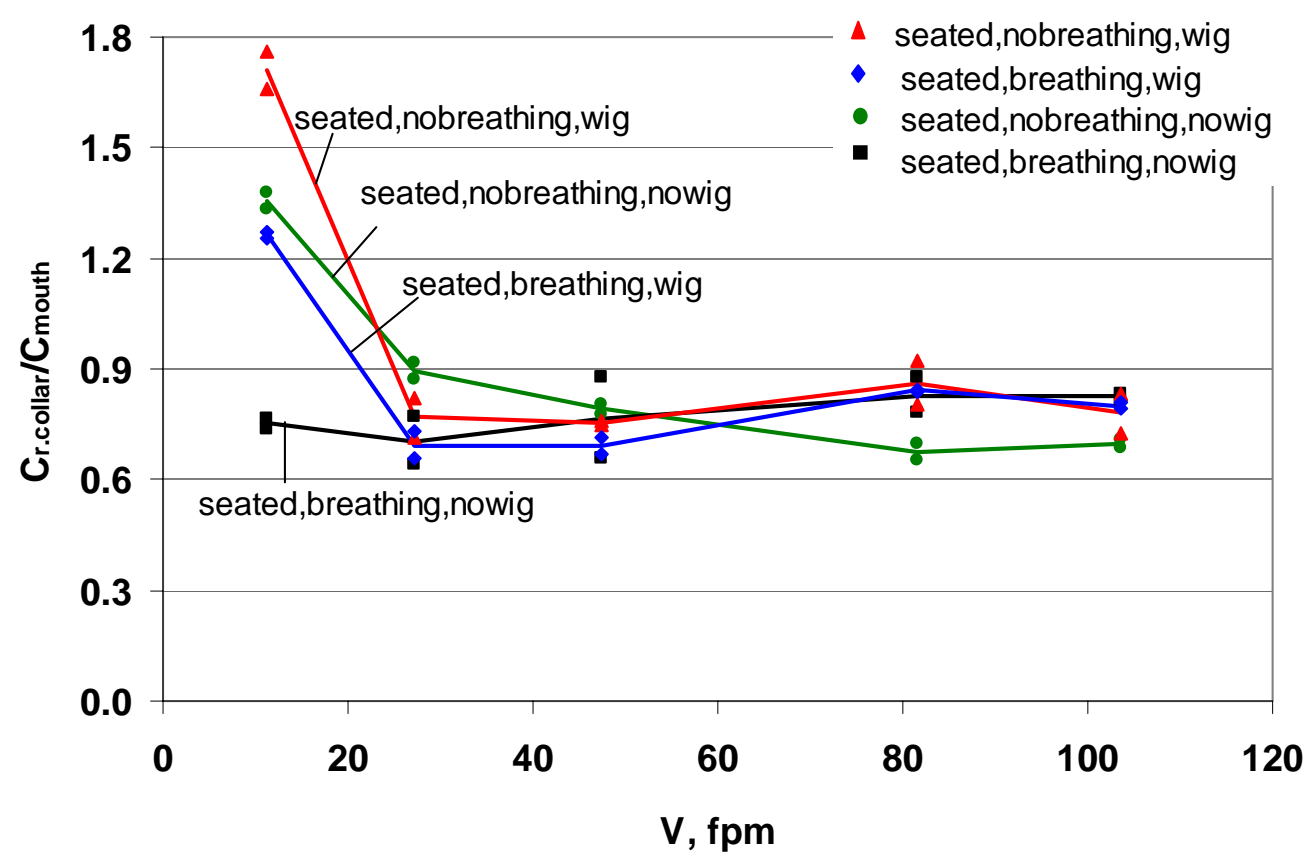

Figure 6.19-a: Scatter and mean plot of $\mathrm{C}_{\mathrm{r} . c o l l a r} / \mathrm{C}_{\text {mouth }}$ vs. velocity for all manikin treatments (seated)

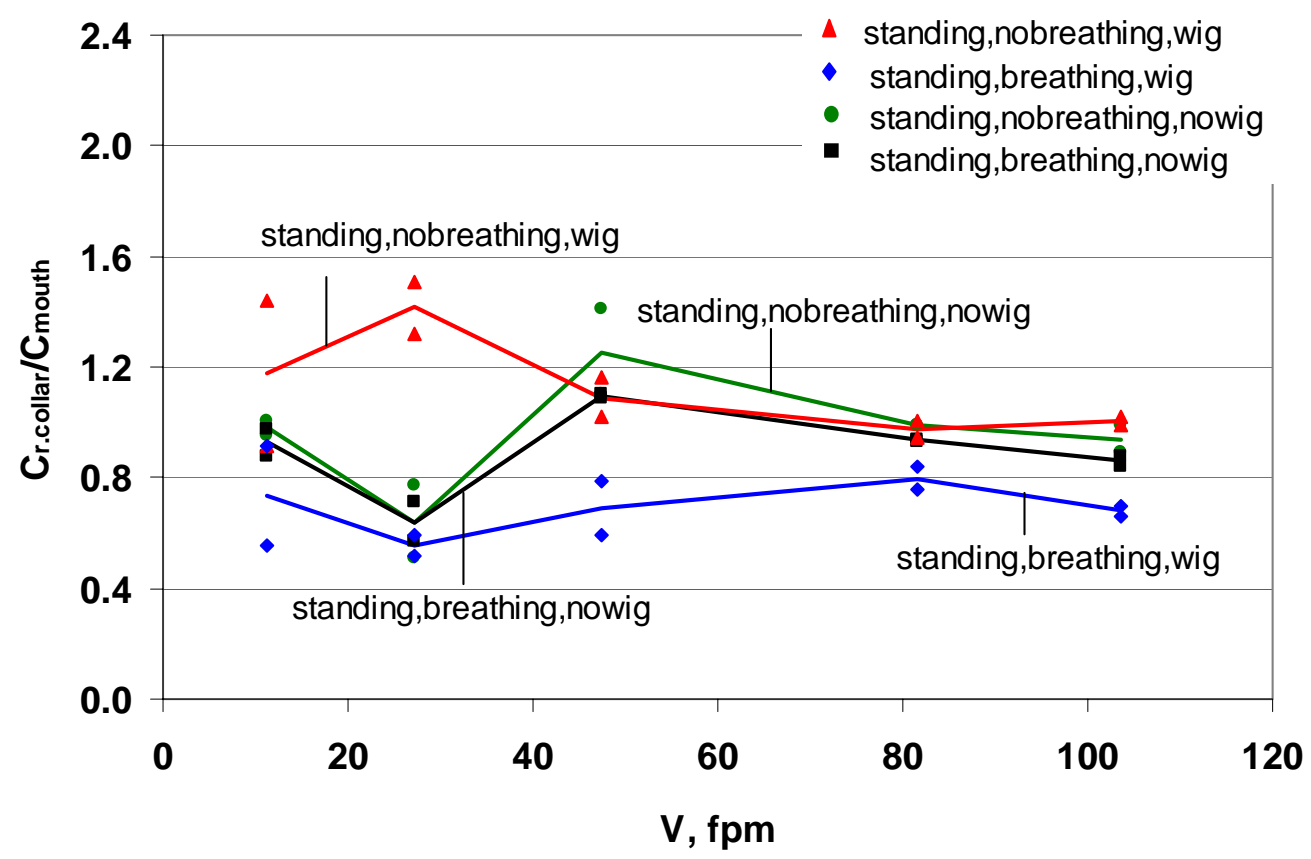

Figure 19-b: Scatter and mean plot of $\mathrm{C}_{\mathrm{r} . \text { collar }} / \mathrm{C}_{\text {mouth }}$ vs. velocity for all manikin treatments (standing) 


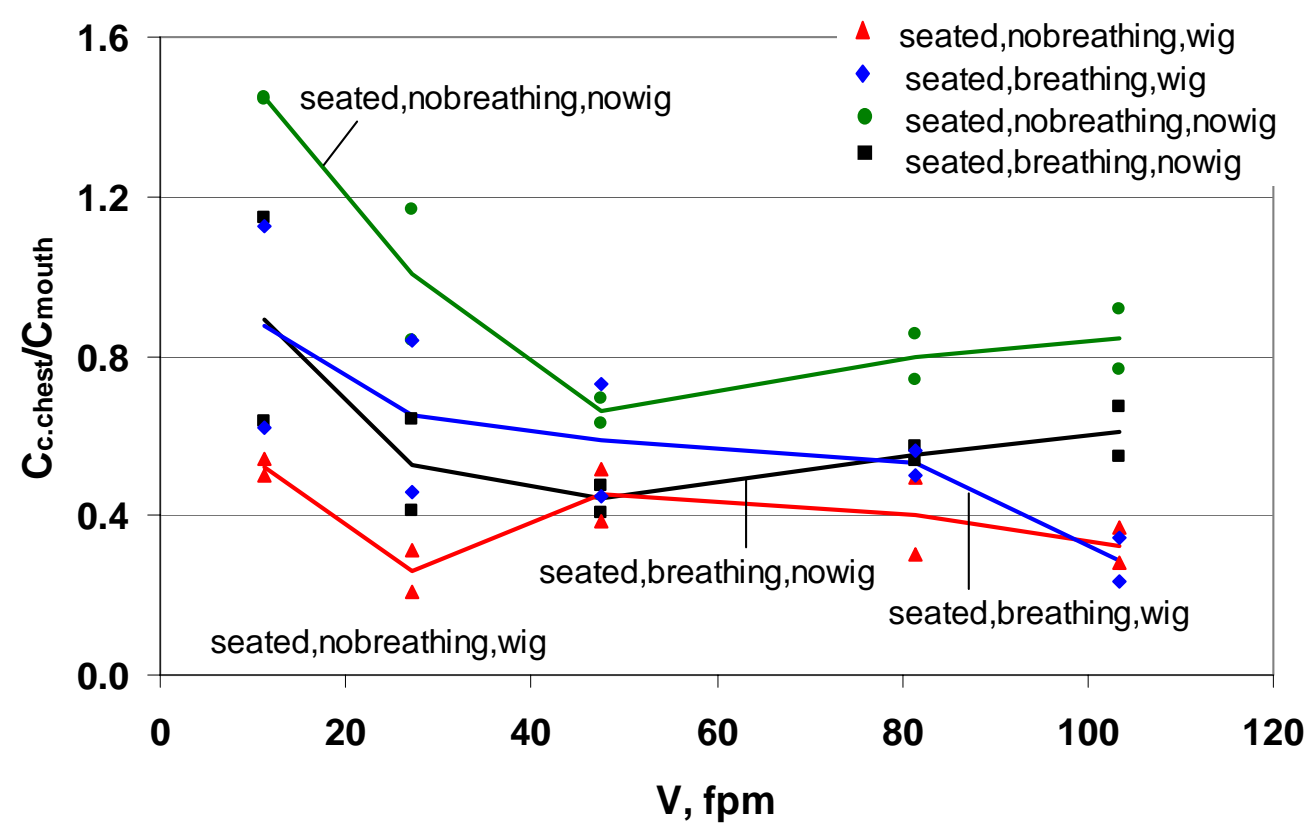

Figure 6.20-a: Scatter and mean plot of $\mathrm{C}_{\text {c.chest }} / \mathrm{C}_{\text {mouth }}$ vs. velocity for all manikin treatments (seated)

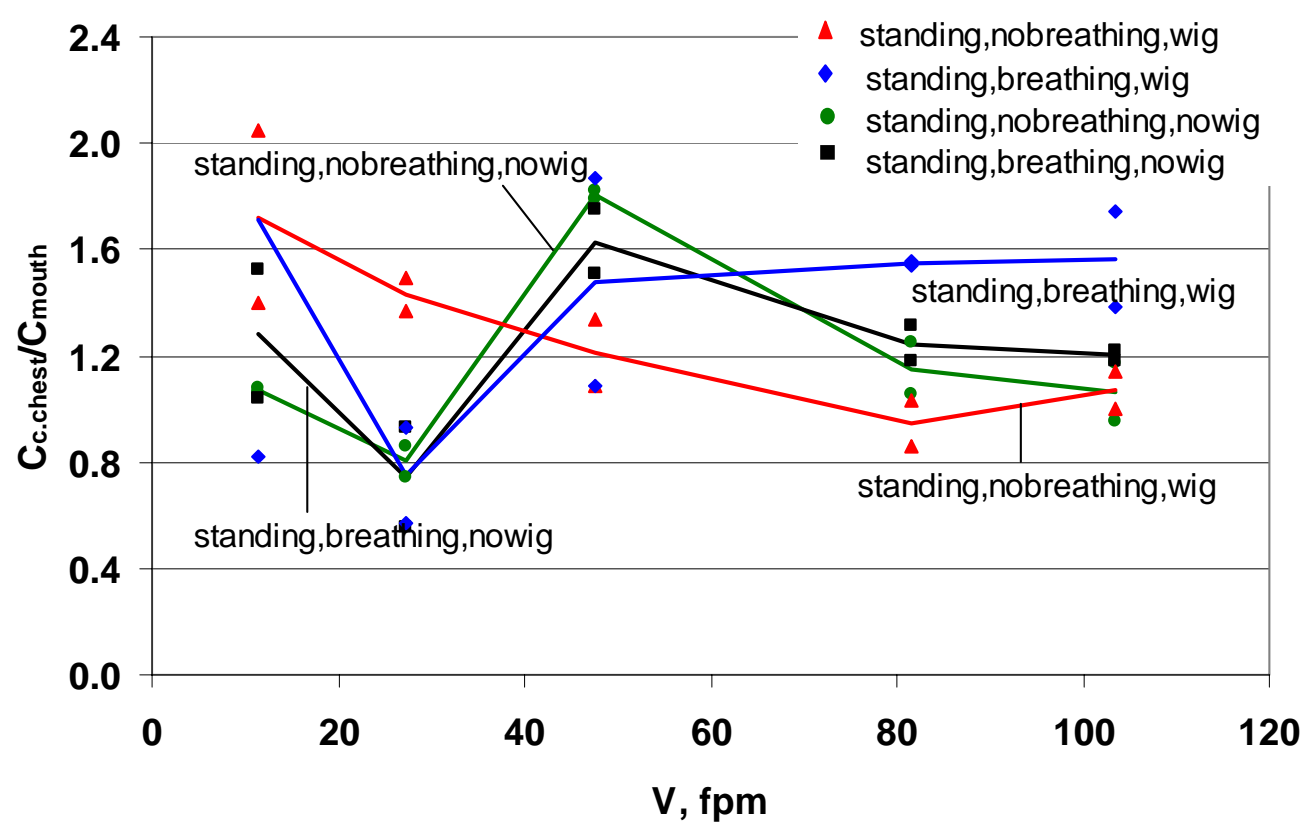

Figure 6.20-b: Scatter and mean plot of $\mathrm{C}_{\text {c.chest }} / \mathrm{C}_{\text {mouth }}$ vs. velocity for all manikin treatments (standing) 


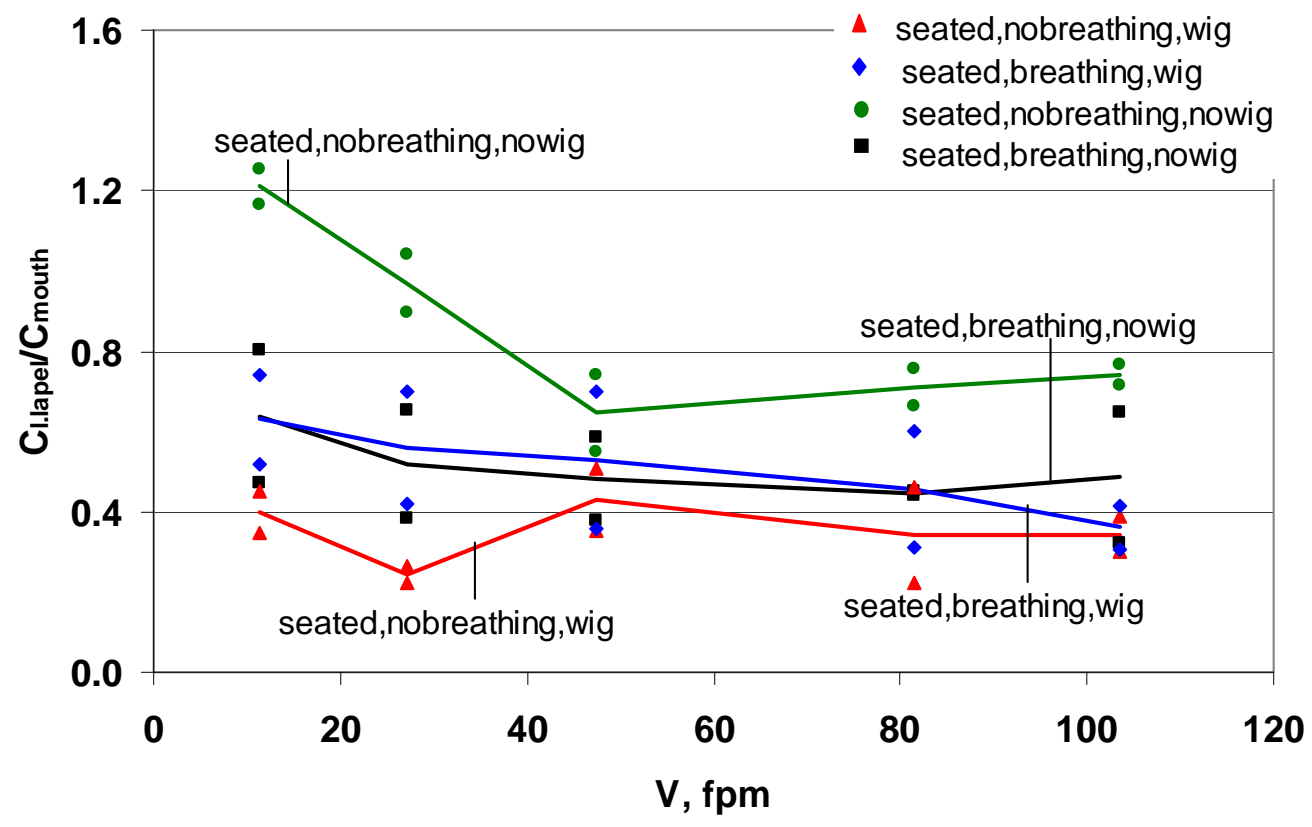

Figure 6.21-a: Scatter and mean plot of $\mathrm{C}_{1.1 \text { lapel }} / \mathrm{C}_{\text {mouth }}$ vs. velocity for all manikin treatments (seated)

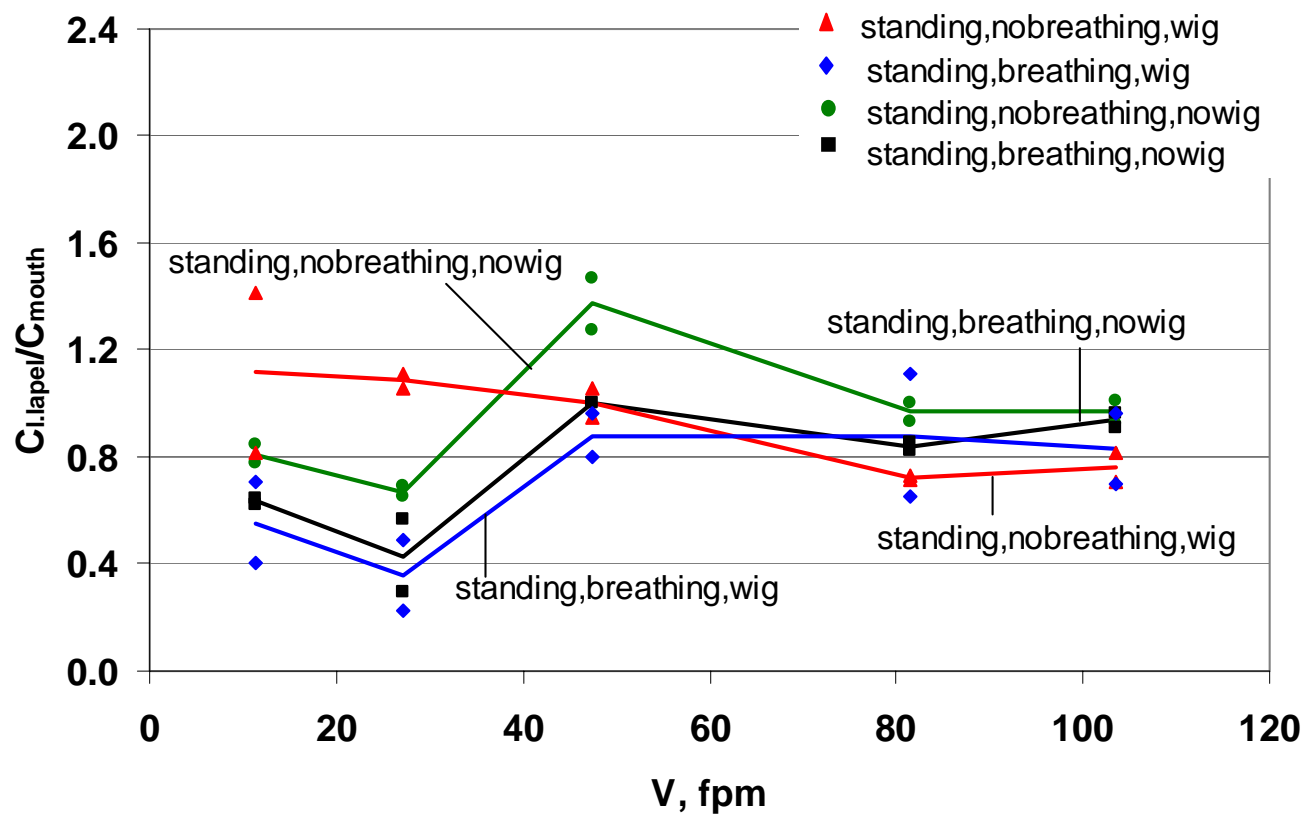

Figure 6.21-b: Scatter and mean plot of $\mathrm{C}_{1 . \text { lapel }} / \mathrm{C}_{\text {mouth }}$ vs. velocity for all manikin treatments (standing) 


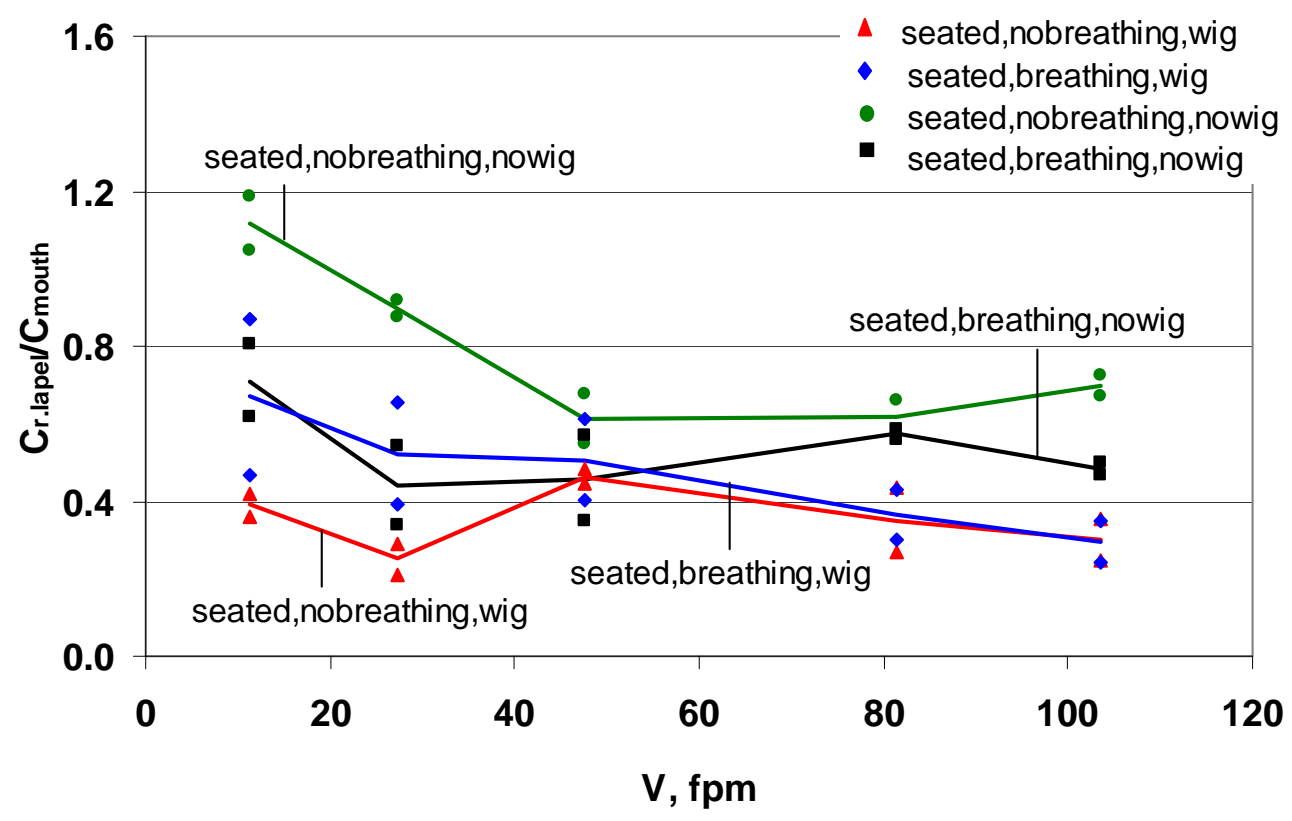

Figure 6.22-a: Scatter and mean plot of $\mathrm{C}_{\text {r.lapel }} / \mathrm{C}_{\text {mouth }}$ vs. velocity for all manikin treatments (seated)

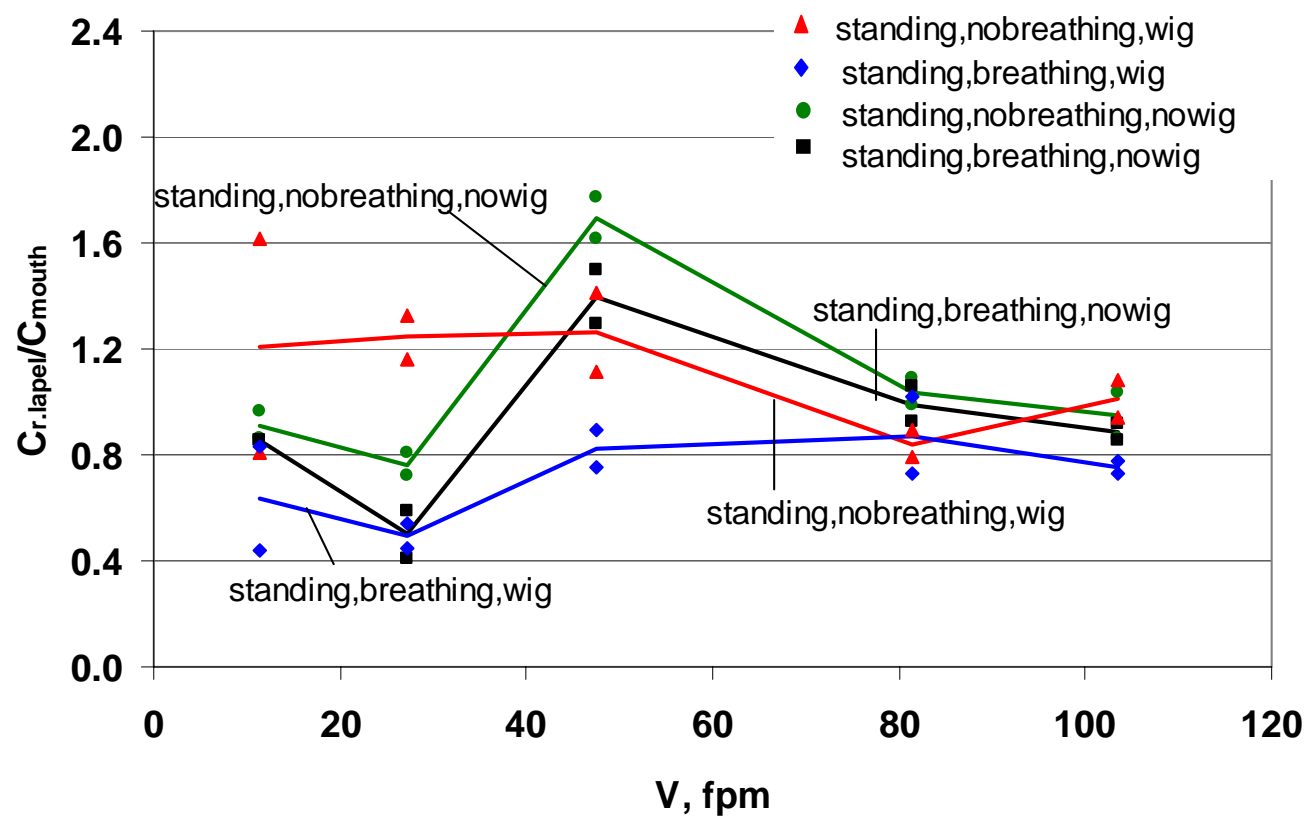

Figure 6.22-b: Scatter and mean plot of $\mathrm{C}_{\mathrm{r} . \text { lapel }} / \mathrm{C}_{\text {mouth }}$ vs. velocity for all manikin treatments (standing) 


\subsection{Effects of Independent Variables on Ratios of Concentrations}

As stated previously, we assume that concentrations measured near the mouth, $\mathrm{C}_{\text {mouth }}$, are the "true" values. Thus, the differences between values measured at other locations and $\mathrm{C}_{\text {mouth }}$ are "errors" attributable to other sampling location. The second goal of this study was to investigate whether the measured concentrations varied with sampling location, and if they did differ, how their ratios varied with velocity, posture, breathing, and hair style.

The results are presented in terms of ratios rather than differences since the relative error is more useful to know than the absolute error, which would vary with every exposure condition. The ideal ratio between the $\mathrm{C}_{\text {mouth }}$ and concentrations at other locations is unity. $\mathrm{A}$ ratio less than unity represents underestimation and greater than unity represents overestimation.

The results are shown in Figures 6.15 to 6.22 and Tables $6.3 \mathrm{a}$ and $6.3 \mathrm{~b}$. The effects of velocity on ratio of concentration appeared to be quite different for breathing and wig treatments and for standing and sitting postures. The scatter in ratios of concentration was higher at lower velocities. In addition, some locations had greater scatter than others.

As listed in Tables 6.3a and 6.3b, for lifelike (breathing and wig) conditions, the ratios of nose to mouth, $\mathrm{C}_{\text {nose }} / \mathrm{C}_{\text {mouth }}$, and forehead to mouth, $\mathrm{C}_{\text {forehead }} / \mathrm{C}_{\text {mouth }}$, had a V-peak occurred at $27 \mathrm{fpm}$ for standing and a flattened inverted-V peak at $48 \mathrm{fpm}$ for sitting. However, for the effect of wig only, the wig has greater effect on $\mathrm{C}_{\text {nose }} / \mathrm{C}_{\text {mouth }}$ ratio at higher velocity ranges for standing. For the effect of breathing and wig, the ratio of forehead to mouth $\mathrm{C}_{\text {forehead }} / \mathrm{C}_{\text {mouth }}$ was closer to unity $(0.91-1.22)$ for higher velocity ranges for both sitting and standing. As shown in Figures 6.16a and 6.16b, breathing had greater effect on $\mathrm{C}_{\text {forehead }} / \mathrm{C}_{\text {mouth }}$ for sitting than standing. This is because that breathing reduced mouth concentrations while the wig decreased $\mathrm{C}_{\text {forehead }}$ concentration levels. It is worth mentioning that when neither breathing nor wig was present (Study I), $\mathrm{C}_{\text {forehead }}$ always underestimated mouth exposure.

For lifelike (breathing) conditions, concentration ratios of neck to mouth, $\mathrm{C}_{\text {neck }} / \mathrm{C}_{\text {mouth }}$, left collar to mouth, $\mathrm{C}_{\text {l.collar }} / \mathrm{C}_{\text {mouth }}$, and right collar to mouth, $\mathrm{C}_{\mathrm{r} \text {.collar }} / \mathrm{C}_{\text {mouth }}$, have similar patterns with velocity but different for sitting and standing (see Figures 6.20 to 6.22). $\mathrm{C}_{\text {neck }} / \mathrm{C}_{\text {mouth }}, \mathrm{C}_{\text {l.collar }} / \mathrm{C}_{\text {mouth }}$, and $\mathrm{C}_{\text {r.collar }} / \mathrm{C}_{\text {mouth }}$, had flattened $\mathrm{V}$-shape with the peak concentrations occurred at $48 \mathrm{fpm}$ for sitting and had two other peaks ( $\mathrm{V}$ and inverted-V) at 27 and $48 \mathrm{fpm}$ for standing. On the other hand, for breathing and wig conditions, $\mathrm{C}_{\text {neck }} / \mathrm{C}_{\text {mouth }}$, $\mathrm{C}_{\text {l.collar }} / \mathrm{C}_{\text {mouth }}$, and $\mathrm{C}_{\text {r.collar }} / \mathrm{C}_{\text {mouth }}$, had flattened $\mathrm{V}$ shape with velocity at $27 \mathrm{fpm}$ for both sitting and standing. This relation ship was slightly different for the $\mathrm{C}_{1 \text {.collar }} / \mathrm{C}_{\text {mouth }}$ due to the variability at $27 \mathrm{fpm}$ for this location.

As listed in Tables 6.3a and 6.3b, for standing, $\mathrm{C}_{\text {neck }} / \mathrm{C}_{\text {mouth }}$ over estimated mouth concentrations, while, $\mathrm{C}_{\text {r.collar }} / \mathrm{C}_{\text {mouth }}$ underestimated mouth concentrations. $\mathrm{C}_{\text {l.collar }} / \mathrm{C}_{\text {mouth }}$ was a mix of both. On the other hand, for sitting, concentrations at neck, left collar, and right collar underestimated mouth concentrations for lifelike conditions. In conclusion, ratio of concentrations at shoulder level varied from location to another and from sitting to standing with tendency to underestimate mouth concnetrations. 
For lifelike (breathing and wig) conditions, ratios of concentration for center chest $\mathrm{C}_{\text {c.chest }} / \mathrm{C}_{\text {mouth }}$, left lapel $\mathrm{C}_{1 . \text { lapel }} / \mathrm{C}_{\text {mouth }}$, and right lapel $\mathrm{C}_{\text {r.lapel }} / \mathrm{C}_{\text {mouth }}$, have similar patterns with velocity. However, the pattern is very different for sitting and standing (see Figures 6.20 to 6.22). $\mathrm{C}_{\text {c.chest }} / \mathrm{C}_{\text {mouth }}, \mathrm{C}_{1 . \text { lapel }} / \mathrm{C}_{\text {mouth }} \mathrm{C}_{\text {r.lapel }} / \mathrm{C}_{\text {mouth }}$, varied monotonically with velocity for sitting, while, two peaks occurred at 27 and $48 \mathrm{fpm}$ for standing. Similar patterns occurred for the effect of breathing and bold conditions.

As listed in Tables 6.3a and 6.3b, concentrations at center chest, left lapel, and right lapel underestimated mouth concentrations for all velocities for sitting posture. However, for lifelike conditions and for standing, $\mathrm{C}_{\text {l.lapel }} / \mathrm{C}_{\text {mouth }}$ and $\mathrm{C}_{\text {r.lapel }} / \mathrm{C}_{\text {mouth }}$ under estimated mouth concentrations, while, $\mathrm{C}_{\mathrm{c} \text {.chest }} / \mathrm{C}_{\text {mouth }}$ had values overestimated mouth concentrations (1.2-1.6) for all velocities. Althouhg left and right lapels underestimated mouth concentartions, the ratios were closer to one (0.85-0.99) at higher velocities than lower ones. In conclusion, ratios of concentration at chest level were more variable (wider range) for sitting than standing and tended to underestimate mouth exposures.

For lifelike conditions, concentration ratios varied from one location to another with the effect of independent variables. For example, it was found that nose and forehead concentration levels were closer to mouth levels with tendency to overestimate exposures at higher velocities. However, concentration ratios at chest levels (center chest, left and right lapel) underestimated mouth exposures while concentrations at neck, left and right collar were a mix of both of them. 


\section{Chapter 7: Discussions of Study II}

One major goal of both Study I and Study II was to determine if other sampling locations experience the same concentrations as the mouth (the "gold standard"). If not, it is of interest to know how the independent variables affect the differences. A secondary purpose was to determine what lifelike features are necessary for a manikin to be a representative surrogate for a human being for exposure sampling. Since human data were not taken for comparisons, the assumption here is that if different levels of a variable produce different results for the manikin, then the most "lifelike" conditions should be used in subsequent manikin testing. If a variable proved important in testing and if more than one level is lifelike (e.g. bald or hair), then each level should be tested in future studies.

Study I established that body heat was important. Since all humans are heated by metabolic activity, it is pointless to futher consider unheated manikins. For that reason, the manikin was heated for all test conditions in Study II. Study I also established that manikin posture was important and that cross-draft velocity was important. Since humans may sit or stand at work and the cross-draft velocities at the work station may differ, then manikins should be tested both sitting and standing and at a range of cross-draft velocities. This was done for Study II.

Study II introduced two additional variables: breathing and hair style. If breathing is important, then manikins in future tests should be tested while breathing. If results for the manikin are affected by whether it is wearing a wig or not, then since some humans have hair and some do not, manikins should be tested both with hair and without.

Data Desk (Data Description Inc. Ithaca, NY) software was used to do statistical analysis of results. The independent variables for this study were five levels of velocity (11, 27, 48, 82, and $104 \mathrm{fpm}$ ), two levels of breathing (breathing, nobreathing), two levels of hair style (bald, wig), and two levels of posture (seated, standing). The dependent variables were concentrations at each sampling location and the ratios of concentrations.

As stated previously, the results (see Figures 6.2 to 6.10) appeared to show that breathing and hair style were important as were the interactions of breathing and hair with other independent variables. As is shown in the following sections, breathing, hair style, posture, and velocity and many of their interactions were statistically significant.

Tables 7.3 to 7.5 list the p-values from ANOVA for both log-transformed concentrations and ratios of concentrations for the effect of independent variables and their interactions. Using non-transformed dependent values had little effect on the p-values (not shown). 
Table 7.1: Coefficient of correlation $\left(\mathrm{R}^{2}\right)$ for externally studentised residuals against normal scores for log-transformed individual concentrations and ratios of concentrations

\begin{tabular}{lclc}
\hline Concentrations & $\mathrm{R}^{2}$ & Ratios of Concentrations & $\mathrm{R}^{2}$ \\
\hline \hline $\log \mathrm{C}_{\text {mouth }}$ & 0.972 & $\log \left\{\mathrm{C}_{\text {nose }} / \mathrm{C}_{\text {mouth }}\right\}$ & 0.963 \\
$\log \mathrm{C}_{\text {nose }}$ & 0.977 & $\log \left\{\mathrm{C}_{\text {forehead }} / \mathrm{C}_{\text {mouth }}\right\}$ & 0.973 \\
$\log \mathrm{C}_{\text {forehead }}$ & 0.974 & $\log \left\{\mathrm{C}_{\text {neck }} / \mathrm{C}_{\text {mouth }}\right\}$ & 0.96 \\
$\log \mathrm{C}_{\text {neck }}$ & 0.983 & $\log \left\{\mathrm{C}_{\text {l.collar }} / \mathrm{C}_{\text {mouth }}\right\}$ & 0.986 \\
$\log \mathrm{C}_{\text {l.collar }}$ & 0.988 & $\log \left\{\mathrm{C}_{\text {r.collar }} / \mathrm{C}_{\text {mouth }}\right\}$ & 0.98 \\
$\log \mathrm{C}_{\text {r.collar }}$ & 0.97 & $\log \left\{\mathrm{C}_{\text {c.chest }} / \mathrm{C}_{\text {mouth }}\right\}$ & 0.987 \\
$\log \mathrm{C}_{\text {c.chest }}$ & 0.969 & $\log \left\{\mathrm{C}_{\text {l.lapel }} / \mathrm{C}_{\text {mouth }}\right\}$ & 0.997 \\
$\log \mathrm{C}_{\text {l.lapel }}$ & 0.991 & $\log \left\{\mathrm{C}_{\text {r.lapel }} / \mathrm{C}_{\text {mouth }}\right\}$ & 0.994 \\
$\log \mathrm{C}_{\text {r.lapel }}$ & 0.984 & & \\
$\log \mathrm{C}_{\text {inhaled }}$ & 0.971 & & \\
$\log \mathrm{C}_{\text {uppertorso }}$ & 0.977 & & \\
$\log \mathrm{C}_{\text {lowertorso }}$ & 0.966 & & \\
& & \multirow{2}{*}{$\mathrm{R}_{\text {critical }}^{2}=0.985$} & \\
\hline
\end{tabular}

\subsection{Log-Transformation of Dependent Variables}

Dependent variables were log-transformed to produce residuals that were normally distributed. Using log ratio of concentration allowed analysis of the differences in logs of two dependent values, removing the potential for "small denominator" problems associated with actual ratios:

$$
\log \left\{\mathrm{C}_{\text {neck }} / \mathrm{C}_{\text {mouth }}\right\}=\left\{\log \mathrm{C}_{\text {neck }}-\log \mathrm{C}_{\text {mouth }}\right\}
$$

The coefficient of correlation $\left(\mathrm{R}^{2}\right)$ values for externally studentised residuals against normal scores were compared to the "critical coefficient of correlation" of 0.985 for sample size $n=80$ (Neter et al., 1996). As shown in Table 7.1, $\mathrm{R}^{2}$ for log-transformed concentrations and ratios of concentartions showed reasonable degree of normality for most sampling locations. Although correlation coefficients varied for each dependent variable, there was no substantial departure from linearity. This was illustrated by the normal probability plots shown in Appendix C. 


\subsection{Methods for Analysis of Variance (ANOVA)}

The independent variables for this study were five levels of velocity $(11,27,48,82$, and $104 \mathrm{fpm}$ ), two levels of breathing (breathing, nobreathing), two levels of hair style (bold, wig), and two levels of posture (seated, standing). The dependent variables were concentrations at each sampling location and ratio of concentrations. As shown in Table 7.2, the design was completely randomized factorial design with two replications for each treatment. Experiments were done on randomized order. The linear statistical model used for the analysis of variance is illustrated by the following equation:

$\mathrm{Y}_{\mathrm{ijklm}}=\mu+\tau_{\mathrm{i}}+\beta_{\mathrm{j}}+\gamma_{\mathrm{k}}+\lambda_{1}+(\tau \beta)_{\mathrm{ij}}+(\tau \gamma)_{\mathrm{ik}}+(\tau \lambda)_{\mathrm{il}}+(\beta \gamma)_{\mathrm{jk}}+(\beta \lambda)_{\mathrm{j} 1}+(\gamma \lambda)_{\mathrm{kl}}+(\tau \beta \gamma)_{\mathrm{ijk}}+(\tau \beta \lambda)_{\mathrm{ijl}}$

$+(\tau \gamma \lambda)_{\mathrm{ikl}}+(\beta \gamma \lambda)_{\mathrm{jkl}}+(\tau \beta \gamma \lambda)_{\mathrm{ijkl}}+\varepsilon_{\mathrm{ijklm}}$

Where $\mathrm{i}=1,2,3,4,5 ; \mathrm{j}=1,2 ; \mathrm{k}=1,2 ; 1=1,2 ; \mathrm{m}=1,2$ and $\tau_{\mathrm{i}}, \beta_{\mathrm{j}}, \gamma_{\mathrm{k}}, \lambda_{1}$ represent the effects of wind tunnel velocity, breathing, wig and posture, while $(\tau \beta)_{\mathrm{ij}},(\tau \gamma)_{\mathrm{ik}},(\tau \lambda)_{\mathrm{il}}$, $(\beta \gamma)_{\mathrm{jk}},(\beta \lambda)_{\mathrm{jl}},(\gamma \lambda)_{\mathrm{kl}},(\tau \beta \gamma)_{\mathrm{ijk}},(\tau \beta \lambda)_{\mathrm{ijl}},(\tau \gamma \lambda)_{\mathrm{ikl}},(\beta \gamma \lambda)_{\mathrm{jkl}},(\tau \beta \gamma \lambda)_{\mathrm{ijkl}}$ represent the interaction terms of velocity, breathing, wig and posture. $\varepsilon_{\mathrm{ijklm}}$ represents the random error.

Table 7.2: Completely Randomized Factorial Design of Experiments

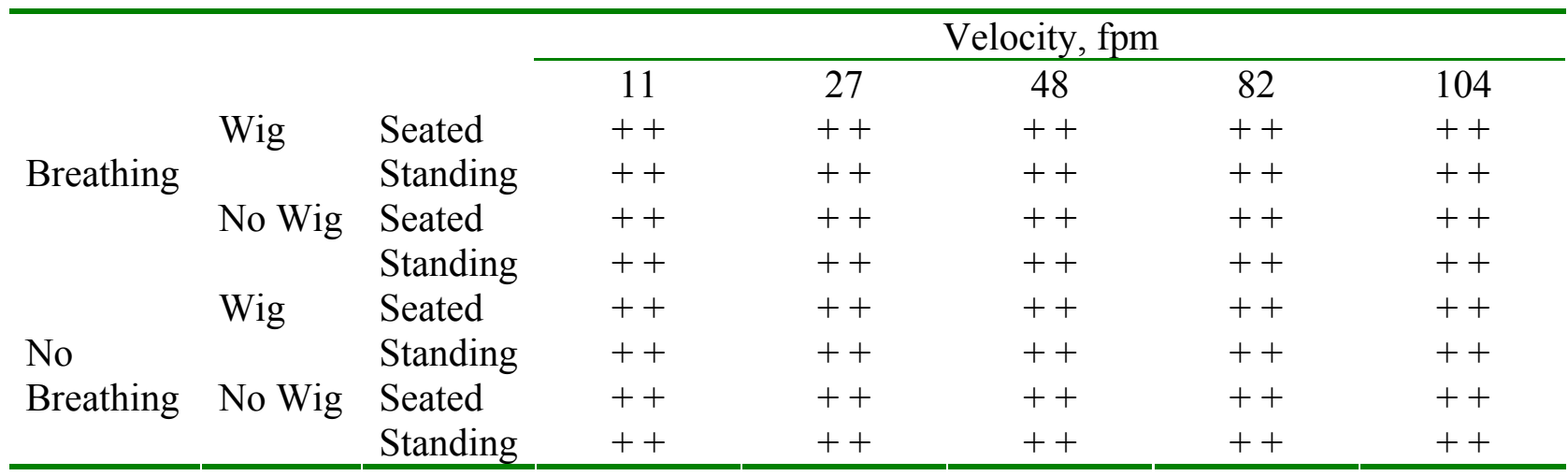

Analysis of variance was computed for log-transformed dependent variables (concentrations and ratio of concentrations) for the effect of independent variables (velocity, breathing, hair style, and posture) and their interactions. The outline for ANOVA for fixed effects model was obtained from (Montgomery, D., 1997). For the fixed effects model, test statistics for each independent variable and interaction was developed by dividing the corresponding mean square for the variable or interaction by the mean square error. The number of degrees of freedom for any factor is the number of levels of the factor minus one, the number of degrees of freedom for an interaction is the product of the number of degrees of freedom associated with the individual components of the interaction (Montgomery, D., 1997). All tests were done at $95 \%$ confidence level $(\alpha=0.05)$. Data Desk software was used to perform ANOVA and the results of performing F-tests were summarized as p-values.

Tables 7.3 and 7.4 listed the p-values from ANOVA for log transformed individual concentrations and ratio of concentrations for all sampling locations. While Table 7.5 shows $\mathrm{p}$-values form ANOVA for $\log$ transformed individual concentrations for $\mathrm{C}_{\text {inhaled }}, \mathrm{C}_{\text {uppertorso, }}$, and $\mathrm{C}_{\text {lowertorso. }}$ 
Table 7.3: $\mathrm{p}$-Values from ANOVA's for Log-Transformed Individual Concentrations

\begin{tabular}{lcccccccccc}
\hline Source & $\mathrm{df}$ & $\mathrm{C}_{\text {mouth }}$ & $\mathrm{C}_{\text {nose }}$ & $\mathrm{C}_{\text {forehead }}$ & $\mathrm{C}_{\text {neck }}$ & $\mathrm{C}_{\text {l.collar }}$ & $\mathrm{C}_{\text {r.collar }}$ & $\mathrm{C}_{\text {c.chest }}$ & $\mathrm{C}_{\text {l.lapel }}$ & $\mathrm{C}_{\text {r.lapel }}$ \\
\hline \hline Const & 1 & 0.001 & 0.001 & 0.001 & 0.001 & 0.001 & 0.001 & 0.001 & 0.001 & 0.001 \\
Velocity & 4 & 0.001 & 0.001 & 0.001 & 0.001 & 0.001 & 0.001 & 0.001 & 0.001 & 0.001 \\
Breathing & 1 & 0.001 & 0.001 & 0.001 & 0.001 & 0.001 & 0.001 & 0.001 & 0.001 & 0.001 \\
Wig & 1 & 0.07 & 0.16 & 0.29 & 0.56 & 0.001 & 0.24 & 0.001 & 0.001 & 0.001 \\
Posture & 1 & 0.001 & 0.001 & 0.001 & 0.001 & 0.001 & 0.001 & 0.001 & 0.001 & 0.001 \\
VelocityxBreathing & 4 & 0.66 & 0.02 & 0.25 & 0.08 & 0.00 & 0.02 & 0.48 & 0.15 & 0.33 \\
VelocityxWig & 4 & 0.26 & 0.49 & 0.53 & 0.04 & 0.25 & 0.00 & 0.34 & 0.80 & 0.22 \\
VelocityxPosture & 4 & 0.001 & 0.001 & 0.001 & 0.11 & 0.001 & 0.84 & 0.52 & 0.35 & 0.78 \\
BreathingxWig & 1 & 0.001 & 0.001 & 0.001 & 0.001 & 0.001 & 0.001 & 0.50 & 0.74 & 0.10 \\
BreathingxPosture & 1 & 0.001 & 0.05 & 0.001 & 0.001 & 0.001 & 0.001 & 0.02 & 0.001 & 0.001 \\
WigxPosture & 1 & 0.01 & 0.22 & 0.001 & 0.04 & 0.53 & 0.001 & 0.001 & 0.09 & 0.07 \\
VelocityxBreathingxWig & 4 & 0.85 & 0.02 & 0.38 & 0.21 & 0.05 & 0.59 & 0.66 & 0.72 & 0.83 \\
VelocityxBreathingxPosture & 4 & 0.51 & 0.80 & 0.54 & 0.23 & 0.08 & 0.09 & 0.41 & 0.16 & 0.85 \\
VelocityxWigxPosture & 4 & 0.25 & 0.01 & 0.001 & 0.76 & 0.18 & 0.42 & 0.03 & 0.37 & 0.16 \\
BreathingxWigxPosture & 1 & 0.01 & 0.001 & 0.001 & 0.001 & 0.53 & 0.90 & 0.09 & 0.01 & 0.02 \\
\hline
\end{tabular}

Table 7.4: $\mathrm{p}$-Values from ANOVA's for Log-Transformed Ratios of Concentrations to $\mathrm{C}_{\text {mouth }}$

\begin{tabular}{lccccccccc}
\hline Source & $\mathrm{df}$ & $\mathrm{C}_{\text {nose }}$ & $\mathrm{C}_{\text {forehead }}$ & $\mathrm{C}_{\text {neck }}$ & $\mathrm{C}_{\text {l.collar }}$ & $\mathrm{C}_{\text {r.collar }}$ & $\mathrm{C}_{\text {c.chest }}$ & $\mathrm{C}_{\text {l.lapel }}$ & $\mathrm{C}_{\text {r.lapel }}$ \\
\hline \hline Const & 1 & 0.86 & 0.001 & 0.63 & 0.001 & 0.001 & 0.001 & 0.001 & 0.001 \\
Velocity & 4 & 0.001 & 0.001 & 0.001 & 0.001 & 0.001 & 0.001 & 0.03 & 0.001 \\
Breathing & 1 & 0.001 & 0.001 & 0.15 & 0.06 & 0.00 & 0.92 & 0.001 & 0.001 \\
Wig & 1 & 0.39 & 0.001 & 0.10 & 0.02 & 0.48 & 0.001 & 0.001 & 0.001 \\
Posture & 1 & 0.001 & 0.001 & 0.001 & 0.001 & 0.09 & 0.001 & 0.001 & 0.001 \\
VelocityxBreathing & 4 & 0.07 & 0.23 & 0.08 & 0.001 & 0.001 & 0.75 & 0.41 & 0.37 \\
VelocityxWig & 4 & 0.46 & 0.42 & 0.08 & 0.86 & 0.01 & 0.72 & 0.97 & 0.70 \\
VelocityxPosture & 4 & 0.001 & 0.001 & 0.02 & 0.12 & 0.001 & 0.01 & 0.001 & 0.001 \\
BreathingxWig & 1 & 0.09 & 0.08 & 0.41 & 0.26 & 0.001 & 0.001 & 0.001 & 0.08 \\
BreathingxPosture & 1 & 0.001 & 0.28 & 0.32 & 0.83 & 0.001 & 0.49 & 0.09 & 0.02 \\
WigxPosture & 1 & 0.02 & 0.001 & 0.58 & 0.05 & 0.05 & 0.001 & 0.001 & 0.001 \\
VelocityxBreathingxWig & 4 & 0.07 & 0.64 & 0.22 & 0.27 & 0.50 & 0.93 & 0.98 & 0.67 \\
VelocityxBreathingxPosture & 4 & 0.34 & 0.05 & 0.19 & 0.12 & 0.07 & 0.15 & 0.05 & 0.23 \\
VelocityxWigxPosture & 4 & 0.44 & 0.01 & 0.17 & 0.10 & 0.001 & 0.02 & 0.29 & 0.01 \\
BreathingxWigxPosture & 1 & 0.06 & 0.51 & 0.56 & 0.03 & 0.001 & 0.001 & 0.001 & 0.001 \\
\hline
\end{tabular}


Table 7.5: p-Values from ANOVA's for log-transformed $\mathbf{C}_{\text {inhaled, }}, \mathbf{C}_{\text {uppertorso, }}$, and $\mathbf{C}_{\text {lowertorso }}$

\begin{tabular}{lcccc}
\hline Source & $\mathrm{df}$ & $\mathrm{C}_{\text {inhaled }}$ & $\mathrm{C}_{\text {upper.torso }}$ & $\mathrm{C}_{\text {lower.torso }}$ \\
\hline \hline Const & 1 & 0.00 & 0.00 & 0.00 \\
Velocity & 4 & 0.00 & 0.00 & 0.00 \\
Breathing & 1 & 0.00 & 0.00 & 0.00 \\
Wig & 1 & 0.11 & 0.06 & 0.00 \\
Posture & 1 & 0.00 & 0.00 & 0.00 \\
VelocityxBreathing & 4 & 0.20 & 0.00 & 0.20 \\
VelocityxPosture & 4 & 0.00 & 0.06 & 0.49 \\
VelocityxWig & 4 & 0.32 & 0.01 & 0.35 \\
BreathingxWig & 1 & 0.00 & 0.00 & 0.98 \\
BreathingxPosture & 1 & 0.00 & 0.00 & 0.00 \\
WigxPosture & 1 & 0.04 & 0.02 & 0.00 \\
VelocityxBreathingxWig & 4 & 0.25 & 0.29 & 0.77 \\
VelocityxBreathingxPosture & 4 & 0.74 & 0.10 & 0.34 \\
VelocityxWigxPosture & 4 & 0.06 & 0.62 & 0.06 \\
BreathingxWigxPosture & 1 & 0.00 & 0.12 & 0.02 \\
\hline
\end{tabular}

\subsection{Methods for Regression Analysis}

Regression analysis was performed on log transformed concentrations for each sampling location (dependent variable) with wind tunnel velocity (independent variable) for each treatment combination. Treatments were divided into four groups which are:

breathing/nowig/standing, breathing/nowig/seated, breathing/wig/standing, and breathing/wig/seated. For all treatments, linear regression was applied to fit the data with velocity for both standing and seated manikin conditions. A second velocity term was added to the regression model to model the inverted $\mathrm{V}$-shape peak for both seated and standing conditions.

For example, the regression model for $\log \mathrm{C}_{\text {mouth }}$ was:

$$
\log C_{\text {mouth }}=\beta_{0}+\beta_{1} V_{1}+\beta_{2} V_{2}
$$

In cases where the peak occurred at $48 \mathrm{fpm}$, then

$$
\left\{\mathrm{V}_{2}=\left(\mathrm{V}_{1}-48\right) \mathrm{x}\right\} \text {, where } \mathrm{x}=0 \text { if } \mathrm{V}_{1} \leq 48 \text { and } \mathrm{x}=1 \text { if } \mathrm{V}_{1}>48
$$

In cases where the peak occurred at $27 \mathrm{fpm}$, then

$$
\left\{\mathrm{V}_{2}=\left(\mathrm{V}_{1}-27\right) \mathrm{x}\right\} \text {, where } \mathrm{x}=0 \text { if } \mathrm{V}_{1} \leq 27 \text { and } \mathrm{x}=1 \text { if } \mathrm{V}_{1}>27
$$

Concentrations at all sampling locations were fitted using the same steps applied on log $\mathrm{C}_{\text {mouth }}$. Tables 7.6 to 7.9 summarized regression models results (adjusted Rsq, coefficients, 
and p-values) for all sampling locations. Detailed analysis and results are presented in Appendix D.

Table 7.6: Regression coefficients for seated/breathing/wig manikin ( $p<0.001$ unless otherwise indicated)

\begin{tabular}{|c|c|c|c|c|}
\hline & Adj_R $R^{2}(\%)$ & $\mathrm{C}_{0}$ & $\mathrm{C}_{1}$ & $\mathrm{C}_{2}$ \\
\hline Log $C_{\text {mouth }}$ & 74 & 0.926 & 0.0130 & -0.0154 \\
\hline Log $\mathrm{C}_{\text {nose }}$ & 79.6 & 0.667 & 0.0202 & -0.024 \\
\hline $\log C_{\text {forehead }}$ & 80.8 & 0.691 & 0.0203 & -0.0255 \\
\hline $\log C_{\text {neck }}$ & 69.6 & 0.985 & 0.0099 & -0.0119 \\
\hline $\log C_{\text {l.collar }}$ & 85.6 & 0.732 & 0.015 & -0.0173 \\
\hline $\log C_{\text {r.collar }}$ & 56.4 & 1.045 & $0.0065^{2}$ & $-0.0068^{1}$ \\
\hline Log $C_{\text {c.chest }}$ & 61.2 & 0.859 & $0.0097^{2}$ & -0.0167 \\
\hline Log $C_{1 . l a p e l}$ & 44.4 & 0.7363 & $0.0107^{2}$ & $-0.0155^{2}$ \\
\hline Log $C_{\text {r.lapel }}$ & 66.7 & 0.7453 & 0.0101 & -0.0163 \\
\hline
\end{tabular}

Table 7.7: Regression coefficients for seated/breathing/nowig manikin ( $p<0.001$ unless otherwise indicated)

\begin{tabular}{|c|c|c|c|c|}
\hline & Adj_R ${ }^{2}(\%)$ & $\mathrm{C}_{0}$ & $\mathrm{C}_{1}$ & $\mathrm{C}_{2}$ \\
\hline $\log C_{\text {mouth }}$ & 67.3 & 1.079 & 0.0134 & -0.0189 \\
\hline $\log C_{\text {nose }}$ & 76.9 & 1.022 & 0.015 & -0.0195 \\
\hline $\log C_{\text {forehead }}$ & 82.9 & 0.797 & 0.0187 & -0.025 \\
\hline $\log C_{\text {neck }}$ & 57.1 & 1.14 & 0.01 & -0.014 \\
\hline Log $C_{\text {l.collar }}$ & 85.2 & 1.12 & 0.01 & -0.011 \\
\hline Log $C_{\text {r.collar }}$ & 70.3 & 0.937 & 0.014 & -0.0184 \\
\hline Log $C_{\text {c.chest }}$ & 51.3 & 1.06 & $0.006^{2}$ & $-0.008^{2}$ \\
\hline Log $C_{1 . \text { lapel }}$ & 51.5 & 0.891 & $0.0101^{2}$ & $-0.0158^{2}$ \\
\hline Log $C_{\text {r.lapel }}$ & 57 & 0.921 & $0.01^{2}$ & $-0.013^{2}$ \\
\hline
\end{tabular}


Table 7.8: Regression coefficients for standing/breathing/wig manikin $(\mathrm{p}<0.001$ unless otherwise indicated)

\begin{tabular}{|c|c|c|c|c|c|}
\hline & $\mathrm{Adj}_{2} \mathrm{R}^{2}(\%)$ & $\mathrm{C}_{0}$ & $\mathrm{C}_{1}$ & $\mathrm{C}_{2}$ & $\mathrm{C}_{3}$ \\
\hline $\log C_{\text {mouth }}$ & 69.2 & 1.01 & 0.019 & -0.023 & \\
\hline $\log C_{\text {nose }}$ & 53.7 & 1.123 & $0.016^{2}$ & $-0.017^{2}$ & \\
\hline $\log C_{\text {forehead }}$ & 51.4 & 1.05 & $0.0155^{2}$ & $-0.017^{2}$ & \\
\hline $\log C_{\text {neck }}$ & 9.2 & 1.33 & $0.0075^{1}$ & $-0.01^{1}$ & \\
\hline $\log C_{\text {l.collar }}$ & 17.5 & 1.168 & $0.010^{1}$ & $-0.012^{1}$ & \\
\hline Log $C_{\text {r.collar }}$ & 39.1 & 0.912 & 0.0149 & -0.017 & \\
\hline Log $C_{\text {c.chest }}$ & 0.8 & 1.32 & $0.005^{1}$ & & $-0.007^{1}$ \\
\hline $\log C_{\text {l.lapel }}$ & 71.9 & 0.81 & 0.011 & & -0.014 \\
\hline $\log C_{\text {r.lapel }}$ & 41.8 & 0.952 & $0.0089^{2}$ & & $-0.0123^{1}$ \\
\hline
\end{tabular}

Table 7.9: Regression coefficients for standing/breathing/nowig manikin $(\mathrm{p}<0.001$ unless otherwise indicated)

\begin{tabular}{|c|c|c|c|c|c|}
\hline & $\mathrm{Adj}_{2} \mathrm{R}^{2}(\%)$ & $\mathrm{C}_{0}$ & $\mathrm{C}_{1}$ & $\mathrm{C}_{2}$ & $\mathrm{C}_{3}$ \\
\hline $\log C_{\text {mouth }}$ & 94.4 & 1.085 & 0.0196 & -0.022 & \\
\hline $\log C_{\text {nose }}$ & 93.7 & 1.12 & 0.0188 & -0.021 & \\
\hline $\log C_{\text {forehead }}$ & 89.7 & 1.067 & 0.0179 & -0.0198 & \\
\hline $\log C_{\text {neck }}$ & 82.4 & 1.34 & 0.00786 & & -0.0133 \\
\hline $\log C_{\text {l.collar }}$ & 75.2 & 1.35 & 0.006 & & -0.01 \\
\hline $\log C_{\text {r.collar }}$ & 92.4 & 1.155 & 0.0098 & & -0.0148 \\
\hline Log $C_{\text {c.chest }}$ & 67.9 & 1.24 & 0.011 & & -0.016 \\
\hline $\log C_{1 . l a p e l}$ & 76.7 & 0.924 & 0.0131 & & -0.0165 \\
\hline Log $C_{\text {r.lapel }}$ & 79.2 & 1.02 & 0.014 & & -0.02 \\
\hline
\end{tabular}




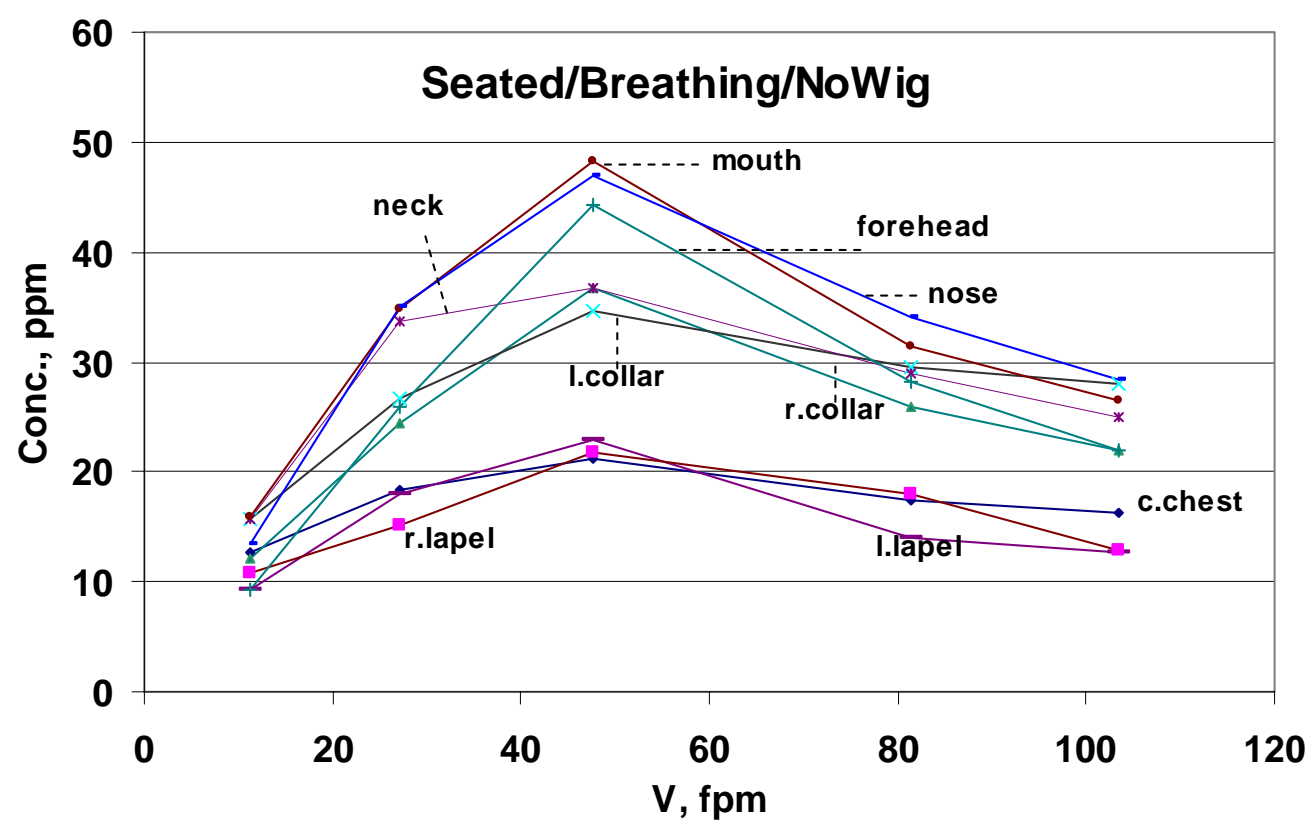

Figure 7.1: Mean concentration (ppm) versus velocity for seated/breathing/no wig manikin

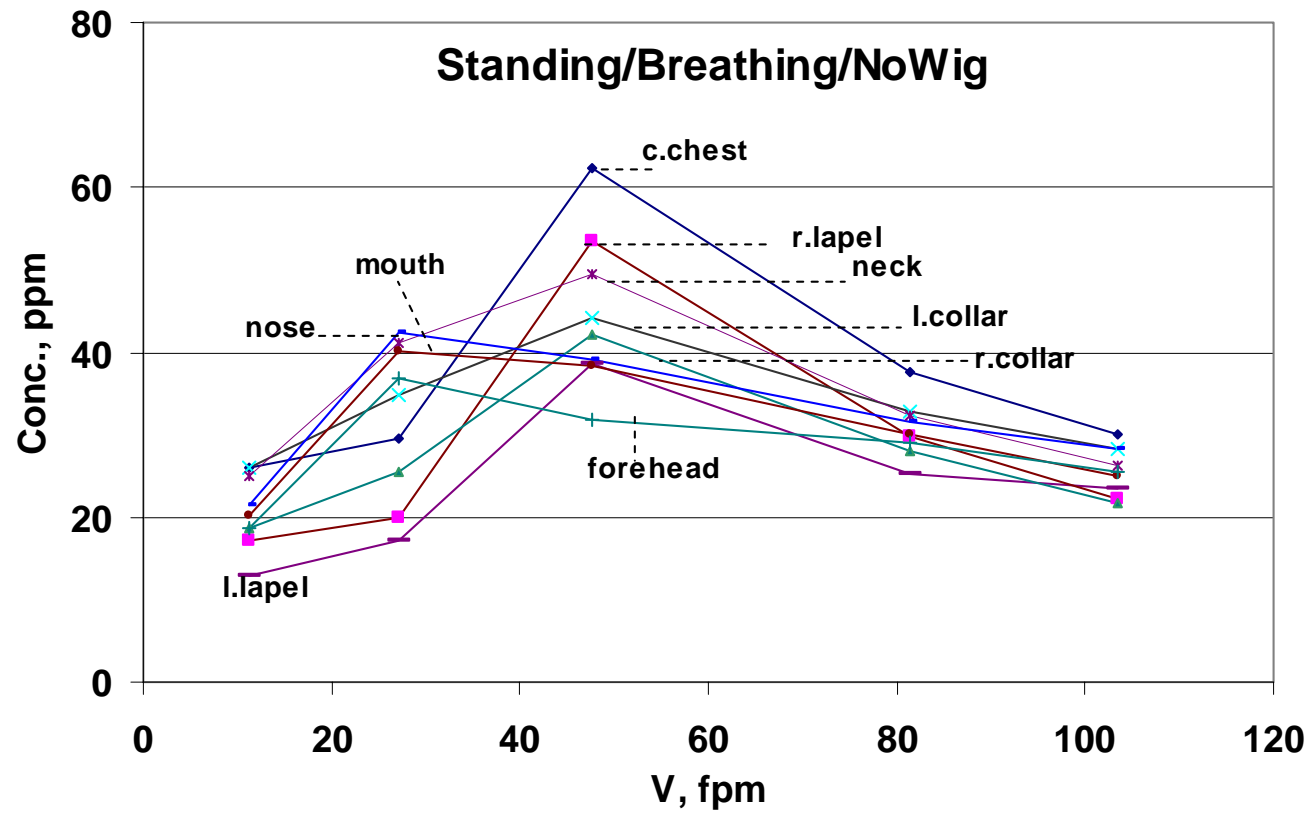

Figure 7.2: Mean Concentration (ppm) versus velocity for standing/breathing/nowig manikin 


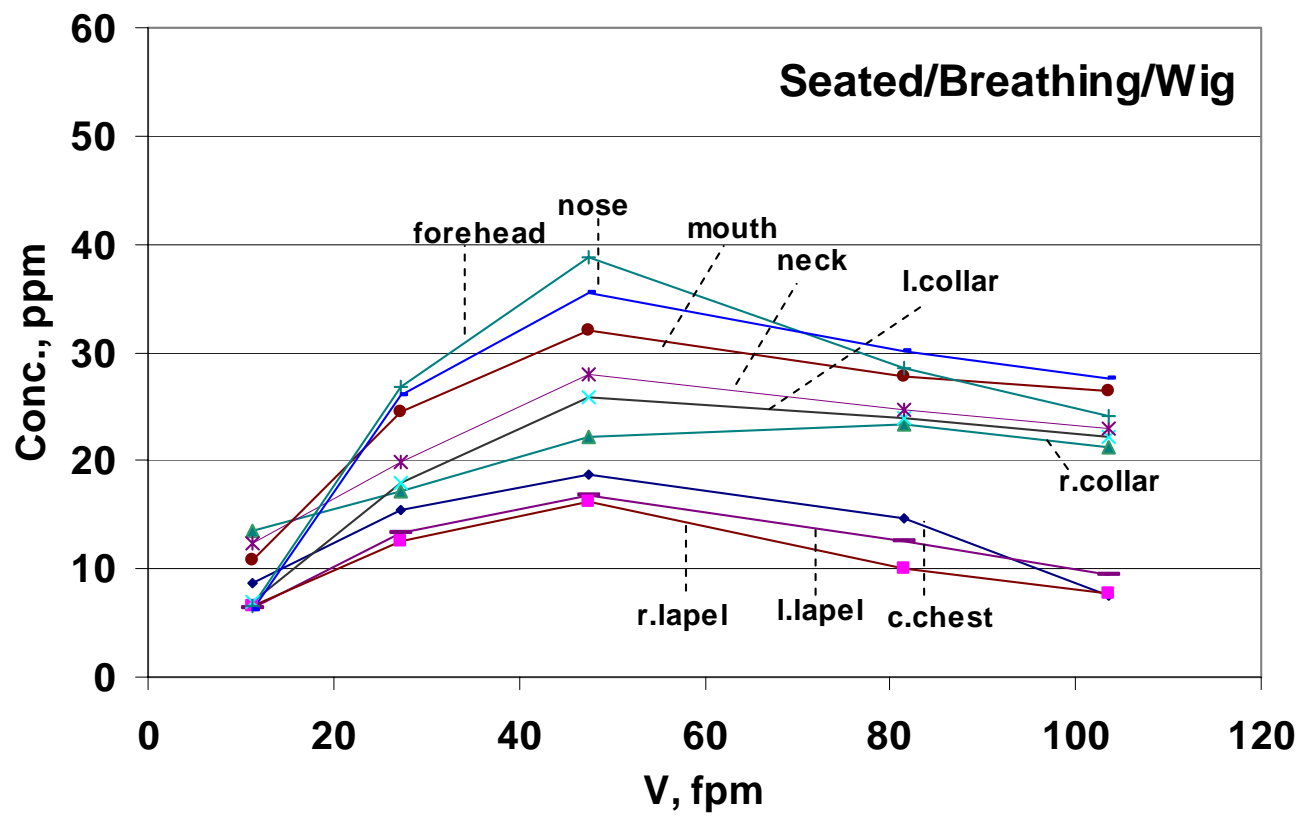

Figure 7.3: Mean concentration ( $\mathrm{ppm}$ ) versus velocity for seated/breathing/wig manikin

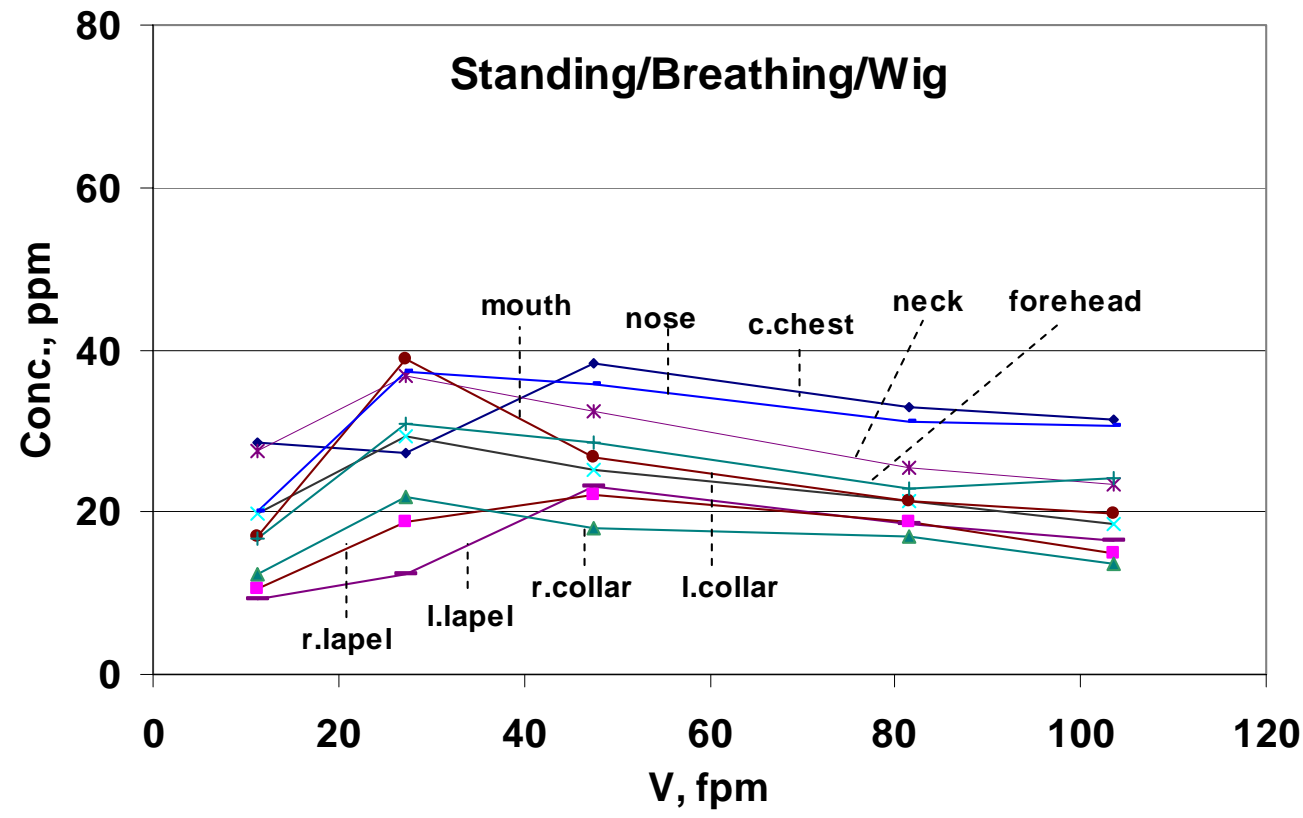

Figure 7.4: Mean Concentration (ppm) versus velocity for standing/breathing/wig manikin 


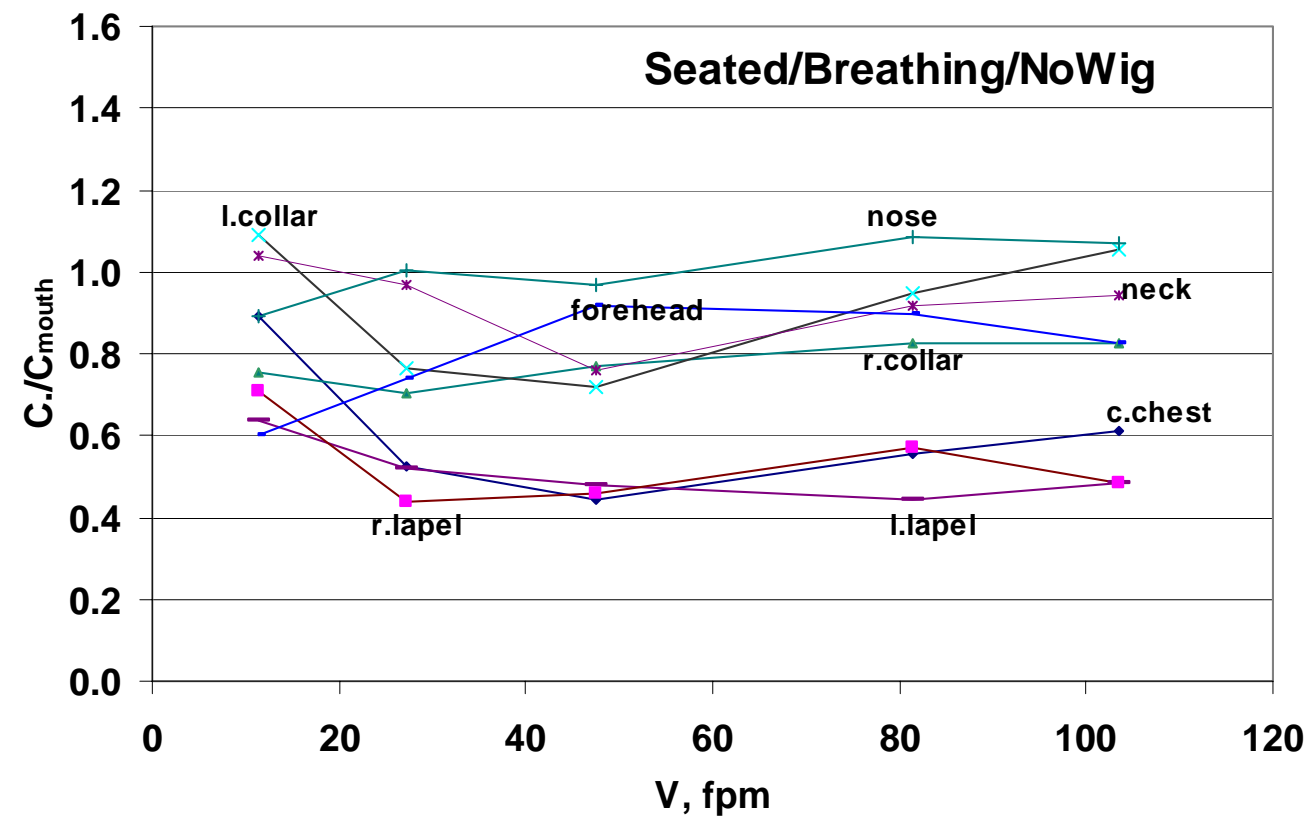

Figure 7.5: Concentration ratio to $\mathrm{C}_{\text {mouth }}$ versus velocity for seated/breathing/no wig manikin

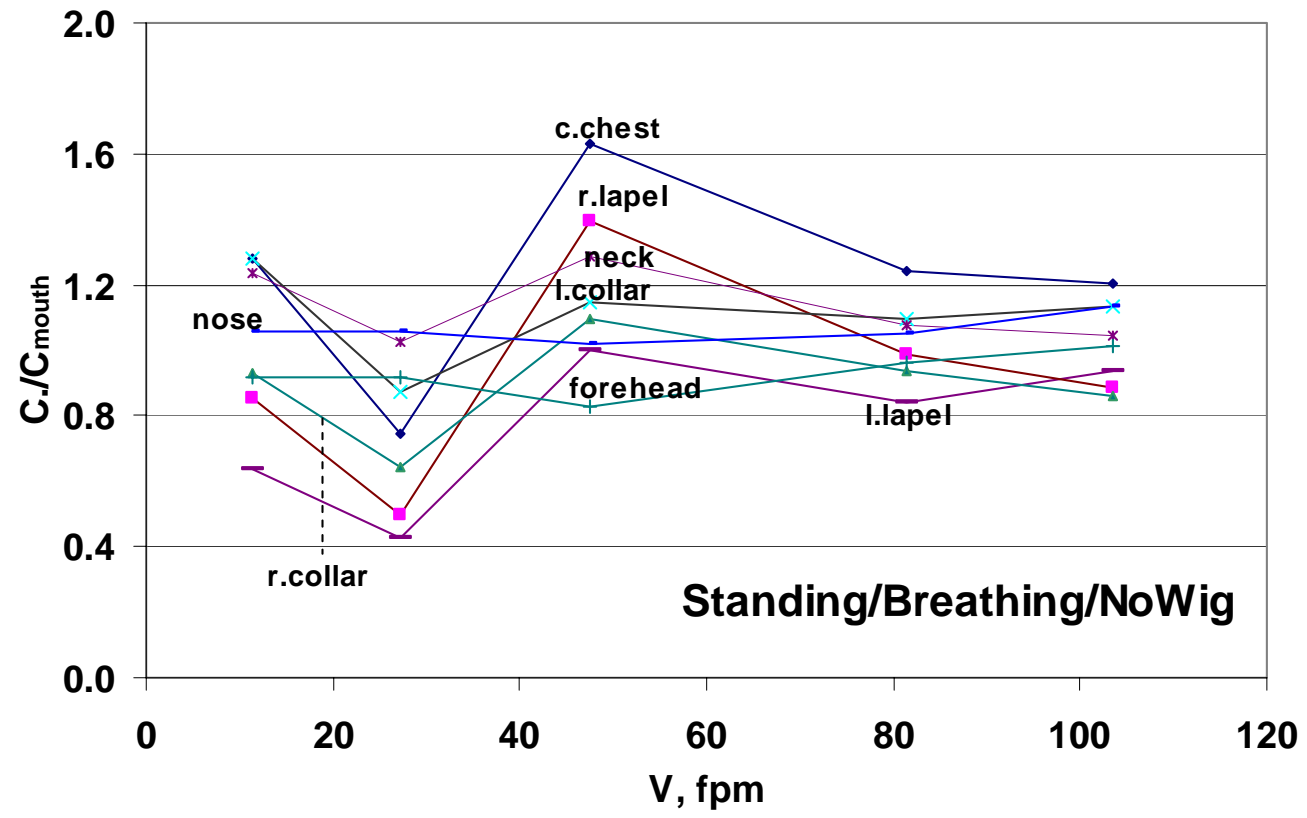

Figure 7.6: Concentration ratio to $\mathrm{C}_{\text {mouth }}$ versus velocity for standing/breathing/no wig manikin 


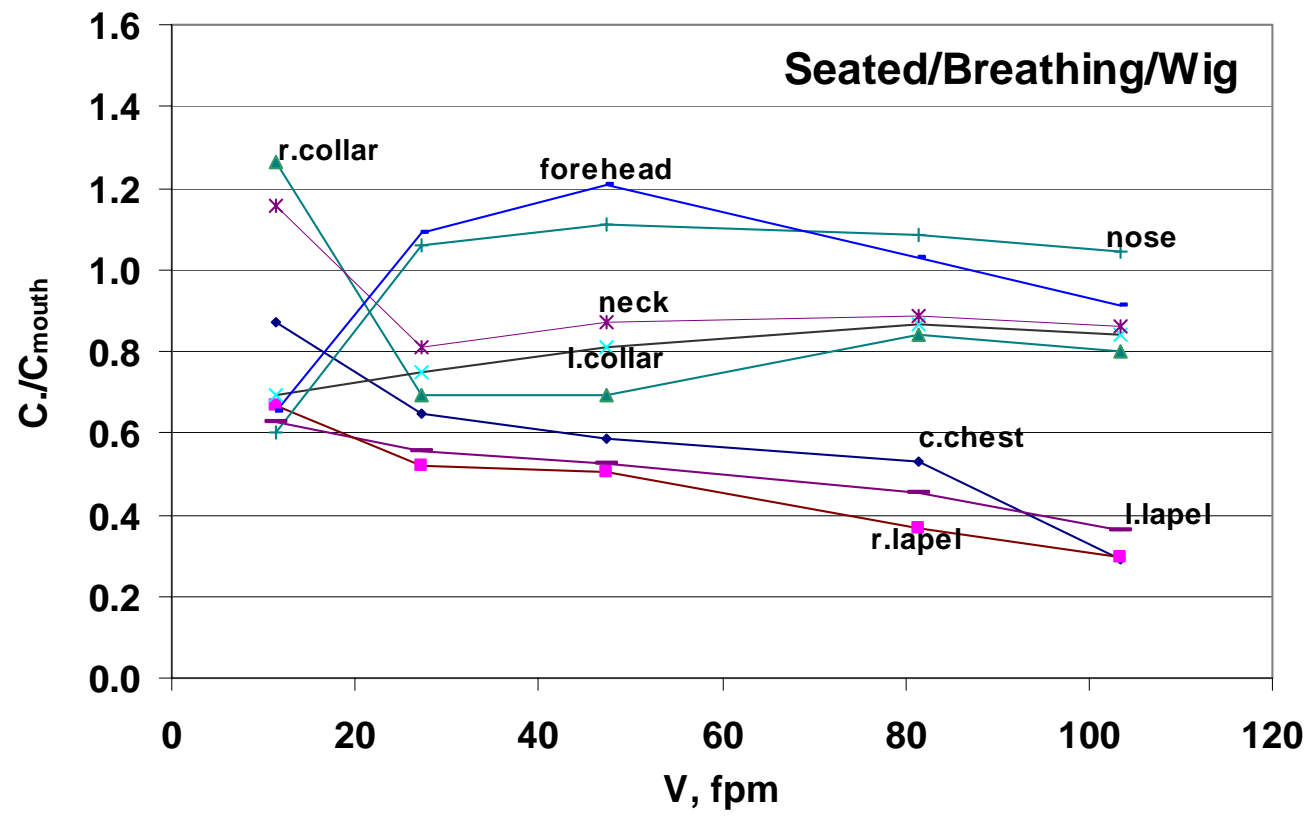

Figure 7.7: Concentration ratio to $\mathrm{C}_{\text {mouth }}$ versus velocity for seated/breathing/wig manikin

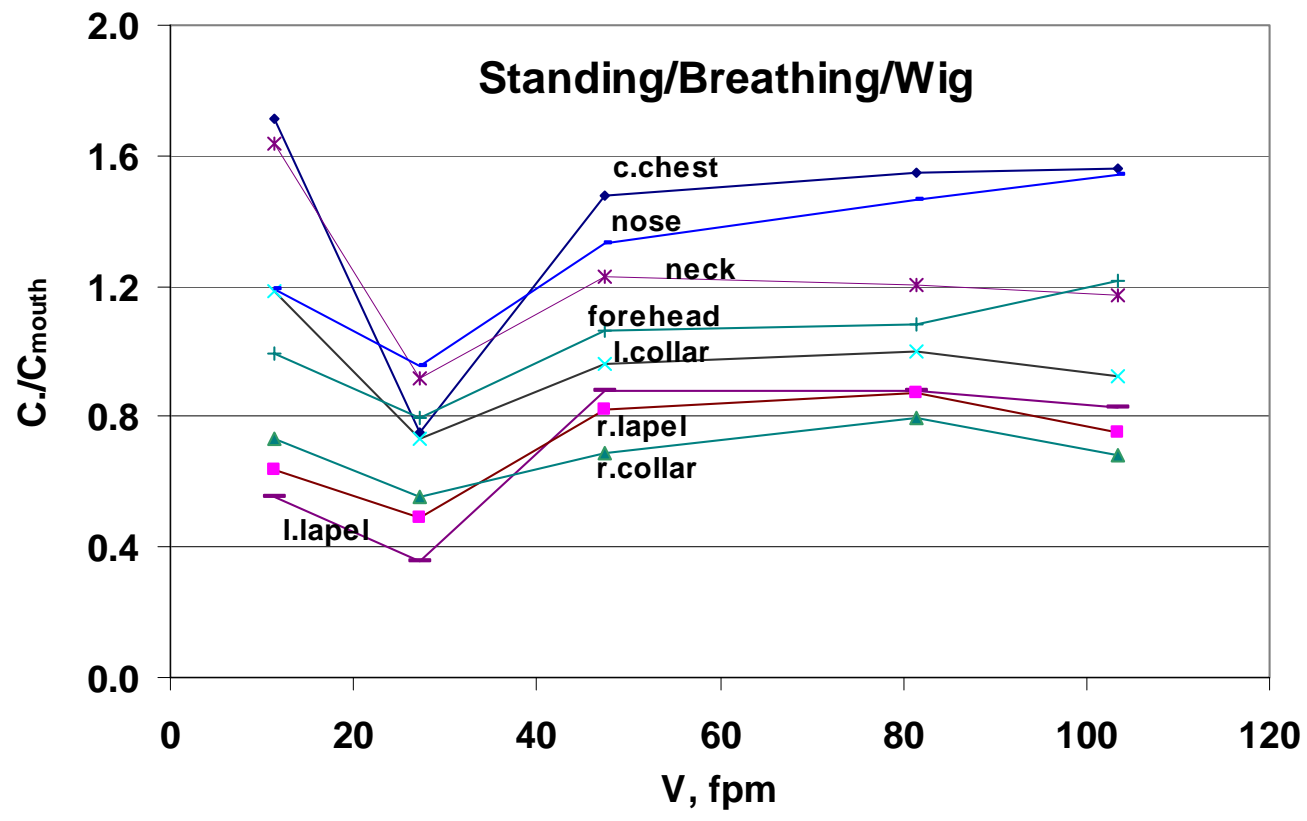

Figure 7.8: Concentration ratio to $\mathrm{C}_{\text {mouth }}$ versus velocity for standing/breathing/wig manikin 


\subsection{Comparisons of Individual Concentration Values and Ratios of Concentrations for all Sampling Locations}

The effects of velocity, breathing, hair style and posture on concentrations at all sampling locations is shown in Figures 7.1 to 7.4. Concentrations at all sampling locations and for all manikin treatments, varied in an inverted-V shape relationship with wind tunnel velocity. Peak concentration levels occurred at velocity range of 27 to $48 \mathrm{fpm}$. As velocity increases, concentrations at different locations increase to a peak value ( 2 to 3 times its original levels), then decrease as velocity continue increasing to maximum level. Likewise, for lifelike conditions, breathing substantially reduced concentration levels for sitting and significantly reduced concentration levels at all sampling locations for standing. These results were strongly supported by the analysis of variance (ANOVA) shown in Table 7.3. The effects of velocity and breathing were statistically significant for all sampling locations $(p<0.001)$. The interaction of velocity and breathing was not significant for locations at mouth, forehead, neck and chest ( $\mathrm{p}>0.08$ ). This is because nose breathing diluted (reduced) concentrations at both collars more than the neck, while, one effect of breathing to be larger at low velocities than higher ones.

These results agree with Heist et al (2003), Fletcher and Johnson (1996), and Wood and Birkett (1979) who tested respectively the effect of breathing for chid size manikin, window type manikin, and for adult size manikin standing in a low speed flow field $(0.1-$ $0.5 \mathrm{~m} / \mathrm{s}$ ). Heist et al (2003) found that breathing affected air flow patterns around the manikin in the vicinity of the mouth and nose, while, Wood and Birkett (1979) found that breathing action had little effect on a personal sampler located on manikin's lapel. Fletcher and Johnson (1996) found that breathing effects were confined to thermal boundry layer and did not influence the general flow field. Apparently, all of them tested the effect of breathing on air flow patterns around manikin.

As shown in Figures 7.1 to 7.4 and listed in Table 7.3, the effect of posture (sitting/standing) was statistically significant for all sampling locations. For breathing conditions, sitting reduced concentration levels for all sampling locations at the chest and shoulder level. Conversely, standing reduced concentration levels for sampling locations at mouth, nose and forehead. The reductions were statistically significant $(\mathrm{p}<0.001)$. However, the interaction of velocity and posture was statistically significant $(p<0.001)$ for concentrations at the face but not significant for concentrations at the shoulder and chest $(\mathrm{p}>0.35)$. This concentration levels at the face had peak values at $27 \mathrm{fpm}$ for standing and 48 fpm for sitting. It was plausible that posture would affect sampling locations because of the orientation of arms and legs to wind tunnel velocity. In standing posture, the manikin arms and legs were perpendicular to wind tunnel velocity, while, in sitting, the arms and legs were parallel to wind tunnel velocity. Another point worth mentioning, the presence of a table in front of the manikin in sitting posture would have affected air flow patterns around the manikin's face and torso.

As shown in Figures 7.1 to 7.4, the effects of wig on sampling locations appeared to be strikingly different for different conditions for both sitting and standing. For lifelike conditions, the wig did not affect air flow patterns around the face and torso for sitting 
posture, but it reduced concentration levels slightly at the face. The effect of wig in standing posture was quite different. The wig tended to decrease concentrations for sampling locations at chest level, while, slightly affected concentrations at the face level. For both sitting and standing, attaching the wig on manikin's head did not only flatten the peaks (occurred at 27 and $48 \mathrm{fpm}$ ) but also changed the level of the peaks for all sampling locations. This was strongly supported by the ANOVA values listed in Table 7.3. The effect of wig was not significant for concentrations at the mouth, nose, forhead, neck and both collars ( $p>0.1)$. It was statistically significant for center chest and both lapels $(p<0.001)$.

It was plausible that putting the wig on manikin's head will affect the convective air flow developed above the head which should be affecting concentrations levels at the face more than the chest. It is worth mentioning that the interactions of wig and posture and wig and breathing both were statistically significant for mouth and forehead locations $(p<0.001)$. The interaction of wig and velocity was not significant $(\mathrm{p}>0.5)$. Interestingly, the three way interactions of velocity/wig/breathing, velocity/breathing/posture, velocity/wig/posture, and breathing/wig/posture, were not significant for nearly all sampling locations.

Compared to individual concentration levels, average values for $\mathrm{C}_{\text {inhaled }}, \mathrm{C}_{\text {upper.torso, }}$, and $\mathrm{C}_{\text {lower.torso }}$ showed similar patterns with independent variables (velocity, breathing, wig, and posture). However, concentration levels were slightly different. On the other hand, as shown in Table 7.5, ANOVA for $\log$ transformed $\mathrm{C}_{\text {inhaled }}, \mathrm{C}_{\text {upper.torso }}$, and $\mathrm{C}_{\text {lower.torso }}$ showed significance for the effect of velocity, breathing and posture $(p<0.001)$, similarly, the effect of wig was statistically significanrt for locations at lower torso. The interaction of breathing and wig was statistically significant for inhaled and upper torso locations $(p<0.001)$ and was insignificant for lower torso $(\mathrm{p}>0.98)$. However, the three way interactions of velocity wig breathing, velocity breathing posture, and velocity wig posture, were statistically insignificant ( $\mathrm{p}>0.1)$ for all sampling locations, while, the three way interaction of breathing/wig/posture was statistically significant $(\mathrm{p}<0.02)$.

On contrary to individual concentrations, the effects of independent variables on ratios of concentrations appeared to be strikingly different for all sampling locations as shown in Figures 7.5 to 7.8. The effect of velocity on ratio of concentration appeared to be different for lifelike conditions and for standing and seated postures for all sampling locations. Ratios of concentrations followed similar patterns for standing where peaks occurred at $27 \mathrm{fpm}$ (V-shape) and $48 \mathrm{fpm}$ (inverted-V), however, patterns were different for sitting. For lifelike conditions, breathing significantly affected ratios of concentrations at the lower and higher velocity ranges for sititng.

Concentration ratios for locations at chest and both lapels were significant for sitting. This was strongly supported by the analysis of variance (ANOVA), shown in table 7.4. The effects of velocity and posture on log transformed ratios of concentrations were statistically significant $(\mathrm{p}<0.001)$. However, the effect of breathing was statistically significant for ratios of concentrations for all locations $(\mathrm{p}<0.001)$, escept for neck and center chest did not show significance $(\mathrm{p}>0.9)$. The wig has no significant effect on the artio $\mathrm{C}_{\text {nose }} / \mathrm{C}_{\text {mouth }}(\mathrm{p}>0.3)$, however, the effect of wig on ratios of concentration at forehead, center chest and both lapels were statistically significant $(\mathrm{p}<0.001)$.

As listed in Table 7.4, the interactions of velocity and breathing and velocity and wig insignificantly affected log transformed ratios of concentrations at chest level ( $p>0.4)$. However, the interactions of velocity and posture, breathing and posture, and breathing and 
wig were statistically significant $(\mathrm{p}<0.001)$. This was illustrated in Figures 7.5-7.8, ratios of concentrations for $\mathrm{C}_{\text {c.chest }} / \mathrm{C}_{\text {mouth }}, \mathrm{C}_{\text {l.lapel }} / \mathrm{C}_{\text {mouth }} \mathrm{C}_{\text {r.lapel }} / \mathrm{C}_{\text {mouth }}$ varied with posture (higher than unity for standing and lower than unity for seated) for lifelike conditions (with and without wig). For example, for lifelike conditions, the ratios of $\mathrm{C}_{\text {c.chest }} / \mathrm{C}_{\text {mouth }}, \mathrm{C}_{\text {l.lapel }} / \mathrm{C}_{\text {mouth }}$, and $\mathrm{C}_{\text {r.lapel }} / \mathrm{C}_{\text {mouth }}$ were approximately equal to $1.63,1.0$, and 1.40 for standing, and were equal to $0.65,0.56$, and 0.52 for sitting. This agrees with (Malek et al, 1996) and (Welling et al, 2000) who tested human subjects and agrees also with (Guffey, et al., 2001), (Kim and Flynn, 1992), and (Kulmala et al., 1996) who tested unheated standing manikins. They found that concentrations at the chest were higher than concentrations at the vicinity of mouth. However, these results strongly disagree (for standing) and agree (for sitting) with (Brohus, 1997) who found that concentrations at the chest were underestimating mouth exposures for both sitting and standing. (Brohus, 1997) studied ratios of concentrations by using a breathing themal manikin, wearing heavy clothing and a wig, and the manikin was sitting and standing in low speed wind environment. For breathing conditions, the ratio $\mathrm{C}_{\text {c.chest }} / \mathrm{C}_{\text {mouth }}$ was 1.63 for this study while 2.9 for (Guffey et al., 2001). The difference agrees qualitatively and disagrees quantitively because the manikin used (anthropometrically correct breathing thermal manikin wearing a wig) was different than (Guffey et al., 2001).

Tables 7.6 to 7.9 list regression coefficients, p-values and adjusted R-squared for logtransformed concentrations for each sampling location. Log-transformed concentartions were regressed versus wind tunnel velocity for each manikin treatment. For breathing conditions (sitting), wind tunnel velocity was significant $(\mathrm{p}<0.01)$ for all sampling locations for wig conditions and was highly significant $(\mathrm{p}<0.001)$ for bald conditions. The concentrations at all sampling locations increased to a peak value as wind tunnel velocity increased and decreased as velocity continued increasing (see Tables 7.6 and 7.7). This $\mathrm{V}-$ shape is confirmed by the positive sign for velocity coefficient $\left(\mathrm{C}_{1}\right)$ and the negative sign for velocity coefficient $\left(C_{2}\right)$. Both coefficients were statistically significant $(p<0.05)$ for nearly all treatment combinations. The regression constant $\left(\mathrm{C}_{0}\right)$ varied substantially from sampling location to another and from wig to no wig conditions. For example, $\left(\mathrm{C}_{0}\right)$ ranged from $0.67-$ 1.05 for wig and from $0.8-1.14$ for bald. Regression coefficient $\left(\mathrm{C}_{0}\right)$ values at chest level were higher than mouth level for wig and lower for bald. Adjusted R-squared $\left(\mathrm{R}^{2}\right)$ ranged in the $60 \%-80 \%$ for both wig and bold for most sampling locations, except $44 \%$ for left lapel. This indicated that about $70 \%$ of the data can be represented by these regression models.

For lifelike conditions (standing), velocity was highly significant $(\mathrm{p}<0.001)$ for all sampling locations for bald conditions, and it was significant $(\mathrm{p}<0.01)$ for most locations. The V-shape model was not significant for neck, left collar and center chest locations for wig conditions. Concentrations increased to a peak value as velocity increased, then decreased as velocity continued increasing (see Tables 7.8 and 7.9). This was illustrated by the positive sign for velocity coefficient $\left(C_{1}\right)$ and the negative sign for velocity coefficient $\left(C_{2}\right)$ or $\left(C_{3}\right)$. The regression constant $\left(\mathrm{C}_{0}\right)$ varied substantially from sampling location to another and from wig to no wig conditions. For example, $\left(\mathrm{C}_{0}\right)$ ranged from $0.8-1.33$ for wig and from $0.92-$ 1.35 for bold. Regression coefficient $\left(\mathrm{C}_{0}\right)$ values at chest level were higher than mouth level for wig and lower for bald. Adjusted R-squared ranged in the $70 \%-90 \%$ for bald conditions and from $40 \%-60 \%$ for wig. This indicated that about $80 \%$ of the variation in the data can be represented by these regression models for standing breathing bald manikin while $50 \%$ of variation can be represented for standing breathing wearing wig manikin. 
Table 7.10: Percentage of $\mathrm{C}_{\text {mouth }}$ for surrogate sampling locations for heated, breathing, and clothed manikin

\begin{tabular}{cccccccccc}
\hline Posture & V,fpm & $\begin{array}{c}\text { Center } \\
\text { Chest }\end{array}$ & Left Lapel & $\begin{array}{c}\text { Right } \\
\text { Lapel }\end{array}$ & Neck & $\begin{array}{c}\text { Left } \\
\text { Collar }\end{array}$ & $\begin{array}{c}\text { Right } \\
\text { Collar }\end{array}$ & Nose & Forehead \\
\hline \hline Sitting, only & Low & $44-89$ & $48-64$ & $46-71$ & $81-115$ & $69-109$ & $69-126$ & $60-111$ & $60-121$ \\
& High & $29-61$ & $36-48$ & $30-48$ & $86-94$ & $84-106$ & $80-84$ & $104-109$ & $83-103$ \\
Standing, only & Low & $75-171$ & $36-100$ & $50-140$ & $92-164$ & $73-128$ & $55-109$ & $96-133$ & $80-99$ \\
& High & $120-155$ & $84-94$ & $75-99$ & $105-120$ & $93-113$ & $68-93$ & $105-154$ & $96-122$ \\
Posture & Low & $44-171$ & $36-100$ & $46-140$ & $81-164$ & $69-128$ & $55-126$ & $60-133$ & $60-121$ \\
unknown & High & $29-155$ & $36-94$ & $30-99$ & $86-120$ & $84-113$ & $68-93$ & $105-154$ & $83-122$ \\
Sitting, only & Unknown & $29-89$ & $36-64$ & $30-71$ & $81-115$ & $69-109$ & $69-126$ & $60-111$ & $60-121$ \\
Standing, only & Unknown & $75-171$ & $36-100$ & $50-140$ & $92-164$ & $73-128$ & $55-109$ & $96-154$ & $80-122$ \\
Posture & Unknown & $29-171$ & $36-100$ & $30-140$ & $81-164$ & $69-128$ & $55-126$ & $60-154$ & $60-122$ \\
unknown & & & & & & & & & \\
\end{tabular}

Table 7.11: Recommended best and acceptable surrogate sampling locations

\begin{tabular}{lllrl}
\hline \multicolumn{1}{c}{ Posture } & Velocity Level & Best Location & Range (\%) & *Acceptable Location (s) \\
\hline \hline Sitting, only & Low & Neck & $81-115$ & Neck \\
& High & Nose & $104-109$ & Nose, Neck, Forehead \\
Standing, only & Low & Forehead & $80-99$ & Forehead \\
& High & Neck & $105-120$ & Neck, Forehead \\
Posture unknown & Low & Neck & $81-164$ & None \\
& High & Neck & $86-120$ & Neck, Forehead \\
Sitting, only & Unknown & Neck & $81-115$ & Neck \\
Standing, only & Unknown & Forehead & $80-122$ & Forehead \\
Posture unknown & Unknown & Neck & $81-164$ & None \\
\hline
\end{tabular}

* “Acceptable Range" = 80\%-125\%

\subsection{Recommended Surrogate Sampling Locations}

One of the two goals in these two studies was to determine which sampling location was an adequate surrogate for the mouth. To better illustrate the fitness of each location, Table 7.10 lists the range of deviations from $\mathrm{C}_{\text {mouth }}$ for each location for "low" velocities and "high" velocities separately for sitting and standing. The division in the velocity range assumes that cross-draft velocities in walk in booths typically range between $80 \mathrm{ft} / \mathrm{min}$ and about $120 \mathrm{ft} / \mathrm{min}$ and that range can be estimated from the results found for 80 and 104 
$\mathrm{ft} / \mathrm{min}$. Likewise, it is assumed that cross-draft velocities outside of booths typically range from $10 \mathrm{ft} / \mathrm{min}$ to around $70 \mathrm{ft} / \mathrm{min}$ and the range of errors for those conditions can be estimated from the results for 11,27 , and $48 \mathrm{ft} / \mathrm{min}$. The differences between sitting and standing, low and high velocities were so extreme that if both postures and velocities were combined together the range of deviations would have been more extreme. Table 7.10 lists the range of deviations from $\mathrm{C}_{\text {mouth }}$ for each location for both postures (sitting/standing) and velocities (low/high) combined together.

As can be seen in Table 7.10, the left and right lapels are highly inconsistent with each other, as are the left and right collars. Since one cannot know in advance whether the left or the right side will be higher for a given manikin (or worker), the total range of both the left and right should be used in estimating errors for either side. This range is so broad as to be useless. Note also that some studies (Malek et al., 1999) have shown that measured exposures are higher on the dominant side of a worker but did not determine which side more accurately represented inhalation. For that reason, it is recommended here that samples should no longer be taken at the collars or lapels unless and until further studies validate their fidelity to inhaled concentrations.

Likewise, the center chest shows very high overestimations for standing and great underestimations for sitting. For that reason, the center chest area should be avoided, if possible. Surprisingly, although the nose location was usually the most accurate, the neck was more accurate for the standing posture at high velocities and for sitting at low velocities. When both velocities were combined, the most accurate locations were the neck for sitting and the forehead for standing. However, when both postures and velocities were combined, all locations were highly underestimating and overestimating mouth concentrations, but the neck was the least of them to underestimate exposures.

Using the ranges in Table 7.10 as a basis for decision-making, the "best" locations for sampling and the "adequate" locations are shown in Table 7.11. Note that a single range covers both bald and not-bald. They were aggregated on the basis that suggesting different sampling locations for those with hair and those without would be altogether too confusing (and would induce humorous observations that might not always be welcomed). Likewise, sitting and standing were combined together (posture unknown) on the basis that allow workers to do minor changes in posture while performing the task. In judging "best" locations, an underestimation was considered more harmful than an overestimation. As a result, the "best" locations fell within $90-120 \%$ except for the forehead, for which the best range was $80-99 \%$. As illustrated in Table 7.11, a location was deemed "acceptable" if its range for a given condition fell within the range of $80 \%$ to $125 \%$. Thus, the neck followed by the forehead was recommended surrogate locations to mouth for nearly all treatment combinations. 


\section{Chapter 8: \\ Conclusions and Recommendations for Both Studies}

The main purpose of this work was to investigate the effects of velocity, heating, breathing, hair style and posture on concentrations at several locations on a manikin to determine whether: 1) concentrations at other locations were substantially equal to those measured at the mouth, and 2) concentrations or ratios of concentrations were different if the manikin was heated or not heated and breathing or not breathing.

In summary, the results indicated that no alternate sampling location closely matches the mouth under all conditions tested and that breathing and heating were important variables.

\subsection{Specific Conclusions}

Conclusions can be drawn from these two studies both for the levels of concentrations and the relative levels of concentrations at different locations. These results have strong implications for previous studies and for current sampling practices.

\subsubsection{Concentrations}

- Posture, wind tunnel velocity, breathing, and body heat all had statistically significant effects on log-transformed concentrations for all sampling locations. Hair style had statistically significant effects at the lower chest but not on the face or shoulder level.

- The effect of heating was substantial at low velocity ranges (11 to $48 \mathrm{fpm}$ ) and modest at higher velocities (48 to $104 \mathrm{fpm}$ ).

- The interaction of velocity and heating had a statistically significant effect on concentrations at each sampling location. For heated conditions, concentrations varied with an inverted-V relationship with wind tunnel velocity. For unheated conditions, concentrations declined monotonically with wind tunnel velocity.

- The interaction of breathing and wig was statistically significant on concentrations at the face and upper torso. For the breathing-heated conditions, the effect of wig was substantial on concentrations at the face for both sitting and standing postures.

- The interaction of velocity and posture had a statistically significant effect on log transformed concentrations only at the face.

- The interaction of posture and heating had statistically significant effects on logtransformed concentrations at the face and shoulder levels. 


\subsubsection{Ratios of Concentrations}

- Velocity and posture had a statistically significant effect on ratios of concentrations for all sampling locations.

- Heating did not have a statistically significant effect on ratios of concentrations for most sampling locations. Likewise, breathing and wig had statistical significance on some ratios and not for others.

- The wig was not statistically significant for the ratios of concentrations at forehead. The interaction of wig and posture had a statistical significance at this location.

- Concentrations at the mouth were always higher for standing than sitting.

- Concentrations measured at the chest and shoulder levels were higher than mouth concentrations for standing posture and were lower than mouth concentrations for sitting.

- Concentrations measured at the forehead location were always lower than concentrations measured at the mouth for both sitting and standing.

- Center chest, both lapels, and both collars sampling locations are not good surrogates to estimate actual inhalation exposure.

- Nose, Neck and Forehead sampling locations are the best surrogate locations to estimate actual inhalation exposure.

Finally, adding breathing, heating, and hair to the manikin is important. All had substantial effects and statistical significance on concentrations at the mouth. These results raised questions about the adequacy of manikin as a surrogate to humans in sampling and the need to collect human data for comparisons. Also, these results raised questions about the unvalidity of unheated, non breathing, and unclothed manikin data in modeling inhalation exposures. In addition, the effect of hair was substantial on concentrations at the mouth and should be considered for more research at different levels (i.e. longer hair that reach the collars). However, sensitivity of these results to posture suggests that even minor changes in posture can have substantial effects. Finally, these results recommended the nose to be considered the best sampling location, followed by the neck, and then by the forehead.

\subsection{Recommendations for future work}

This research was developed to investigate the effects of velocity, heating, breathing, hair style and posture on concentrations at the mouth and ratios of concentrations in the breathing zone of a manikin. As the results of this study are considered important for laboratory research as well as for industrial hygiene practices, further investigations to be conducted for the effects of these variables at higher levels and the addition of new variables that are plausible to be important. 
It is highly recommended to sample at the neck, forehead, and nose locations as surrogates to sampling at the mouth for a breathing, heated, clothed, wearing a wig manikin. Advanced sampling methods should be used to practically employ the nose in sampling.

It is also recommended to study the effects of mouth breathing and higher breathing rates that are required for moderate and heavy activities. In addition, realistic worker movements that include arms, legs and torso, hair with different length, and the interactions of these factors with breathing may have substantial effects on inhaled concentrations. Also, in any industrial environment, workers wear glasses, helmets, caps, and googles. These variables may have an effect on inhaled concentartions for workers.

\subsection{Caveats}

1. Only one manikin was used and its arms and legs were not heated that might have an effect on results

2. Sensitivity of the results to posture suggests that even minor changes in posture can have substantial effects

3. More levels of hair style to be studied (e.g.hair length that can go down to the collars)

4. Only nose breathing was used. However, mouth breathing could possibly change the results

5. The effect of movement was not studied and could be an important variable

6. The results of this research are not yet compared to humans 


\section{References}

Baldwin, P.E.J., and Maynard, A.D. (1998). A Survey of WindSpeeds in Indoor Workplaces, Ann. Occup. Hyg. 42:303-313.

Bjørn, E. (2002). Dispersal of Exhaled Air in Stratified Surroundings-CFD Studies, proc. of the 8th conference on air distribution in rooms. ROOMVENT 2002, Copenhagen, Denemark, Vol. 1

Bjørn, E., and Nielsen, P.V. (2002). Dispersal of Exhaled Air in Displacement Ventilated Rooms, Indoor Air journal, Blackwell-Munksgaard 2002. (In Press)

Bjørn, E. and Nielsen, P.V. (2002). CFD Simulations of Contaminant Transport Between Two Breathing Persons, proc. of the 8th conference on air distribution in rooms, ROOMVENT 2002, Copenhagen, Denemark, Vol. 1

Bjørn, E., and Nielsen, P.V. (1996). Exposure due to Interacting Air Flows between Persons. Proc. ROOMVENT '96, 5th Int. Conf. on Air Distribution in Rooms, Yokohama, Japan. Vol.1, pp.107-114.

Brohus, H., and Nielsen, P.V. (1996). "CFD Models of Persons Evaluated by Full-Scale Wind Channel Experiments." Proc. ROOMVENT '96, 5th Int. Conf. on Air Distribution in Rooms, Yokohama, Japan. Vol.2. pp 137-144.

Brohus, H. and Nielsen, P. V. (1996). Personal exposure in displacement ventilated rooms. Indoor Air: 6, 157-167.

Bjørn, E., and Nielsen, P.V., (1996): Exposure Due To Interacting Air Flows Between Two Persons: Proceedings Of Proceedings Of Roomvent '96, 5th international Conference On Air Distribution In Rooms, Yokohama, Japan, Vol.1, Pp. 107 - 114, 1996.

Brohus, H., (1997). Measurement Of Personal Exposure Using A Breathing Thermal Manikin, Proceedings Of Ventilation '97, The 5th International Symposium On Ventilation For Contaminant Control, Global Developments In Industrial Ventilation, Ottawa, Canada, Vol. 2, P. 781-791

Cermak, R., Holsøe, J., Meyer, K.E., Melikov, A.K. (2002). PIV Measurements at the Breathing Zone with Personalized Ventilation, proc. of the $8^{\text {th }}$ conference on air distribution in rooms, ROOMVENT 2002, Copenhagen, Denemark, Vol. 1

Colin, J., Houdas, Y. (1967). Experimental Determination of Coefficient of Heat Exchanges by Convection of Human Body, Journal of Applied Physiology $22: 31$

Clark, R. and Edholm, O.G. (1985): Man and His Thermal Environment. Edward Arnold Ltd, London.

Carlton, GN and Flynn, M.R (1997). A model to estimate worker exposure to spray paint mist: Appl. Occup. Environ. Hyg. 12(5):375382-39 
Cohen, B.S., Harley, N.H., Lippman, M. (1984). Bias in Air Sampling Techniques Used to Measure Inhalation Exposure. Am Ind Hyg.Assoc.J.44: 187-192

Chatterjee, B.B., Williams, M.K., Walford, J., and King, E. (1969). The Location of Personal Samplers Filter Heads. Am.Ind Hyg.Assoc.J.30: 643-645

Cermak, R., Majer, M., Melikov, A.K. (2002), Improved quality of inhaled air with personalized ventilation. In: Proceedings of Indoor Air 2002, Monterey, pp. 10541059.

Donaldson, H.M. and Stringer, W.T (1980). Beryllium Sampling Methods. Am. Ind. Hyg.Assoc.J.41: 85-90

Flynn, M.R., Chen, M.M., Kim, T.H. and Muthedath, P. (1995). Computational Simulation of Worker Exposure using a Particle Trajectory Method: Ann. Occup. Hyg. Vol. 39, pp. 277-289.

Flynn, M.R., and George, D.K. (1991). Aerodynamics and Exposure Variability. Applied Occupational and Environmental Hygiene. 6:36-39

Flynn, M.R., and Ljungqvist, B. (1995). A Review of Wake Effects On a Workers Exposure. Ann.Occup.Hyg. 39: 211-221

Fletcher, B., and Johnson, A.E. (1989). Comparison of Personal and Area Concentration Measurements, and the Use of a Mannikin In Sampling. In Ventilation'88, edited by J.H.Vincent. New York: Pergamon Press, pp.161-167.

Guffey, S.E., Flanagan, M.E., Van Belle, G. (2001). Air Sampling at the Chest and Ear as Representative of the Breathing Zone. Am Ind Hyg.Assoc.J.62: 416-427

George, D. K., Flynn, M. R., Goodman, R. (1990). The Impact of Boundary Layer Separation on Local Exhaust Design and Worker Exposure. App. Occup. Environ. Hyg. 5(8):501-509

Heist, D.K., Eisner, A.D., Mitchell, W., and Wiener, R. (2003). Airflow around a Child-

Size Manikin in a Low-Speed Wind Environment, Aerosol Science and Technology 37: 303-314.

Holmer, I., Nilsson, H., Havenith, G., and Parsons, K. (1999). Clothing Convective Heat Exchange Proposal for Improved Prediction in Standards and Models Ann. occup. Hyg., Vol. 43, No. 5, pp. 329-337

Ichihara, M., Saitou, M., Nishimura, M. and Tanabe, S. (1997). Measurement of Convective and Radiative Heat Transfer Coefficients of Standing and Sitting Human Body Using Thermal Manikin, J. Archit. Plann. Environ. Eng., AIJ, No.501, 45-51

Johnson, A.E., Fletcher, B., Saunders, C.J. (1996).Air Movement Around a Worker in a Low-Speed Flow Field. Ann.Occup.Hyg. 40: 57-64

Kaczmarczyk J, Zeng Q., Melikov A., Fanger PO, (2002a). The effect of personalized ventilation system on air quality prediction, SBS symptoms, and occupant's performance. In: Proceedings of Indoor Air 2002, Monterey, pp. 1042-1047. 
Kaczmarczyk J, Zeng Q., Melikov A., Fanger PO, (2002). Individual control and people's preferences in experiments with Personalized Ventilation System. In: Proceedings of Roomvent 2002, pp. 57-60.

Kim, T. and Flynn, M. R. (1991a). Modeling a Worker's Exposure from a Hand-Held Source in a Uniform Freestream. Am. Ind. Hyg. Assoc. J. 52(11) : 458-463

Kim, T. and Flynn, M.R. (1991b). Airflow Pattern Around a Worker in a Uniform Freestream. Am. Ind. Hyg. Assoc. J. 52 (7): 287-296

Kim, T. and Flynn, M.R. (1991): A Revised Model to Predict the Average Concentration in the Reverse Flow Region Downstream of a Worker in a uniform Freestream. Ventilation 1991, ASHRAE

Kim, T. and Flynn, M.R. (1992). The Effect of Contaminant Source Momentum on a Workers Breathing Zone Concentration in a Uniform Freestream. Am Ind Hyg.Assoc.J.53: 757-766

Kulmala, I., Saamanen, A., Enbom, S. (1996). The Effect of Contaminant Source Location on Worker Exposure in the Near-Wake Region. Ann.Occup.Hyg. 40: 511- 523

Kroemer, K.H.E., and Grandjean, E. (1997). Fitting The Task To The Human. Fifth Edition. Taylor and Francis.

Ljungqvist, B. (1979). Some Observations on Interactions Between Air Movement and the Dispersion of Pollution (Swedish Council for Building Research Document D8:1979). Stockholm, Sweden: Swedish Council for Building Research

Li, J., Yavuz, I., Celik, I., and Guffey, S.E. (2005). A Numerical Study of Worker Exposure to a Gaseous Contaminant: Variations on Body Shape and Scalar Transport Model. Journal of Occupational and Environmental Hygiene, 2:323-334.

Lotens, W. A. (1993). Heat transfer from humans wearing clothing. Doctoral dissertation, Delft University of Technology, February 1993, Delft.

Lotens, W. A. and Havenith, G. (1991). Calculation of clothing insulation and vapour resistance. Ergonomics 34, 233-254.

Malek, R.F., Daisy, J.M., Cohen, B.S (1996). Breathing Zone Concentrations Variations in the Reinforced Plastic Industry; Field measurements in a Boat Manufacturing Plant. Appl.Occup.Environ.Hyg. 14(11): 777-784

Martinelli, C.A., Harley, N.H., Cohen, B.S. (1983). Monitoring Real-time Aerosol Distribution in the Breathing Zone. Am Ind Hyg.Assoc.J.44: 280-285

Montgomery, D.C. (1997). Design and Analysis of Experiments. New York: John Wiley and sons.

Melikov, A., and Zhou, G. (1996). Air Movement at the Neck of the Human Body. In Proceedings, $7^{\text {th }}$ International Conference on Indoor Air Quality and Climate: Indoor Air '96, edited by S. Yoshizawa et al., International Society of Indoor Air Quality and Climate, Nagoya, Japan, 1:209-214. 
Melikov, A.K., Pitchurov, G., Naydenov, K., Langkilde, G. (2002). Field study on occupant comfort and office thermal environment in rooms with displacement ventilation, in preparation for submission to HVAC\&R Research Journal.

Melikov, A., Cermak, R., Mayer, M., (2001). Personalized ventilation: evaluation of different air terminal devices, Proceedings of CLMA 2000, Napoli, Paper 524.

Melikov A, Kaczmarczyk J, Cygan L. (2000a). Indoor Air Quality Assessment by A Breathing Thermal Manikin, Proceedings of ROOMVENT'2000, vol(1), Reading, UK.

Melikov A, Kaczmarczyk J, Cygan L. (2000). A Breathing Thermal Manikin for indoor air quality assessment, in preparation for submission to Indoor AirJournal.

Murakami, S., Kato, S., and Zeng, J. (1996). CFD Analysis of Thermal Environment around Human Body. In Proceedings, $7^{\text {th }}$ International Conference on Indoor Air Quality and Climate: Indoor Air '96, edited by S. Yoshizawa et al., International Society of Indoor Air Quality and Climate, Nagoya, Japan, 2:479-484.

McCullough, E. A., Jones, B. W. and Huck, P. E. J. (1985) A comprehensive database for estimating cloth ing insulation. ASHRAE Trans. 91, 29-47.

McCullough, E. A., Jones, B. W. and Tamura, T. (1989). A database for determining the evaporative resistance of clothing. ASHRAE Trans. 95, 316-328.

Naydenov, K., Pitchurov, G., Melikov, A., Langkilde, G. (2002). Performance of Displacement Ventilation in practice. In: Proceedings of ROOMVENT02, pp. 483486.

Neter, J., Kutner, M.H., Nachtsheim, C.J., and Wasserman, W. (1996). Applied Linear Regression Models. Richard D. Irwin, Inc.

National Institute of Occupational Safety and Health (NIOSH). The Industrial Environment - Its Evaluation and Control. Washington, DC: US Government

Printing Office, 1973.

OSHA Technical Manual: CPL2-2.20B, Chapter 1, Personal Sampling for Air Contaminants. OSHA, Cincinnati, OH, 1985.

Ojima, J. (2003). Evaluation of the Reverse Flow Around a Worker's Body Produced by a Local Exhaust Hood. Sangyo EiseigakuZasshi. Jul 45(4):125-32

Pitchurov, G., Naidenov, K., Melikov, A.K., Langkilde, G. ( 2002). Field survey of Occupants Thermal Comfort in Rooms with Displacement Ventilation. In: Proceedings of ROOMVENT02, pp. 479-482.

Parsons, K. C, Havenith, G., Holmer, I., Nilsson, H., and Malchaire, J. (1999). The Effects of Wind and Human Movement on the Heat and Vapour Transfer Properties of clothing Ann. occup. Hyg., Vol. 43, No. 5, pp. 347-352.

Rodes, C.E., Kamens, R.M., and Wiener, R.W. (1995). Experimental Considerations for the Study of Contaminant Dispersion Near the Body, Am. Ind. Hyg. Assoc. 56:535-545.

Rodes, C.E., Kamens, R.M., Wiener, R.W. (1995). Experimental Consideration for the Study of Contaminant Dispersion near the Body Am Ind Hyg.Assoc.J.56: 535-545. 
Silva, M.C.G. and Coelho, J.A. (2002). Convection Coefficients For The Human Body Parts Determined With a Thermal Mannequin, proc. of the 8th conference on air distribution in rooms, ROOMVENT 2002, Copenhagen, Denemark, Vol. 2

Tanabe, S., Arens, E.A., Bauman, F.S., Zhang, H. and Madsen, T.L. (1994). Evaluating Thermal Environments by Using a Thermal Manikin with Controlled Skin Surface Temperature, ASHRAE Transactions, 3739, Vol.100, Part 1, pp.39-48.

Van Der Wal, J.F., Moerkerken, A. (1984). The Performance of Passive Diffusion Monitors for organic Vapours for Personal Sampling of Painters. Ann.Occup.Hyg. 28: 39-47.

Welling I, Andersson IM, Rosen G, Raisanen J, Mielo T, Marttinen K, Niemela R. (2000). Contaminant dispersion in the vicinity of a worker in a uniform velocity field. Ann Occup Hyg. May: 44(3):219-25.

Welling I, Andersson IM, Rosen G, Raisanen J, Mielo T, Marttinen K, Niemela R. (2001). Extent of the Reverse Flow Wake Region Produced by a Body in a Uniform Flow Field: Appl. Occup. Environ. Hyg. Vol 16 (9):900-904.

Yang, J.H., Kato, S., Hayashi, T., Murakami, S. (2002). Measurement of Local Convective Heat Transfer Coefficients of the Human Body in Outdoor and Indoor Environments, proceedings of the 8th conference on air distribution in rooms, ROOMVENT 2002, Copenhagen, Denemark.

Zeng, Q., Kaczmarczyk, J., Melikov, A., Fanger, P.O. (2002): Design ranges for acceptable air temperature and flow rate for Personalized Ventilation System, in preparation for submission to HVAC\&R Research. 


\section{Appendix A: Normal Probability Plots (STUDY I)}

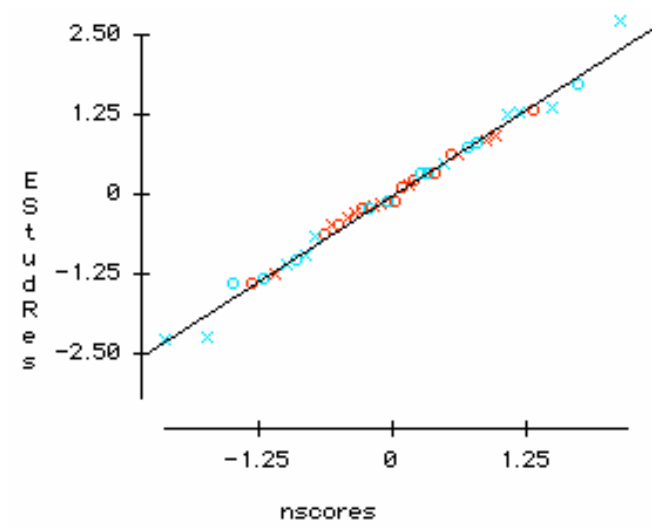

Figure A.1: Normal probability plot of E-StudRes Vs nscores $\log \mathrm{C}_{\text {mouth }}$

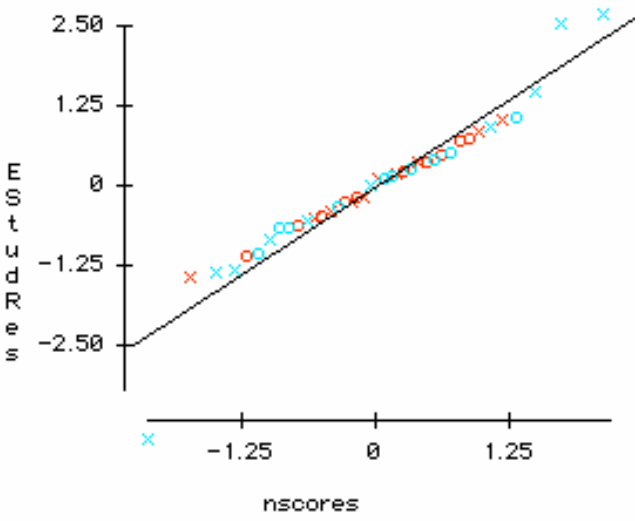

Figure A.2: Normal probability plot of E-StudRes Vs nscores $\log \mathrm{C}_{\text {nose }}$

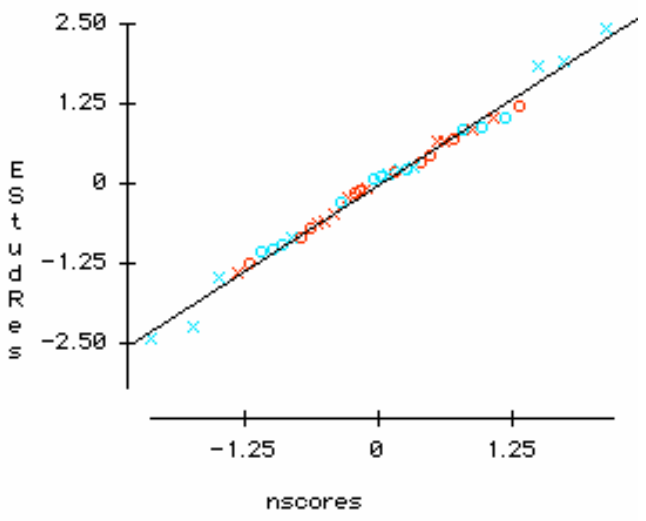

Figure A.3: Normal probability plot of E-StudRes Vs nscores $\log \mathrm{C}_{\text {forehead }}$ 


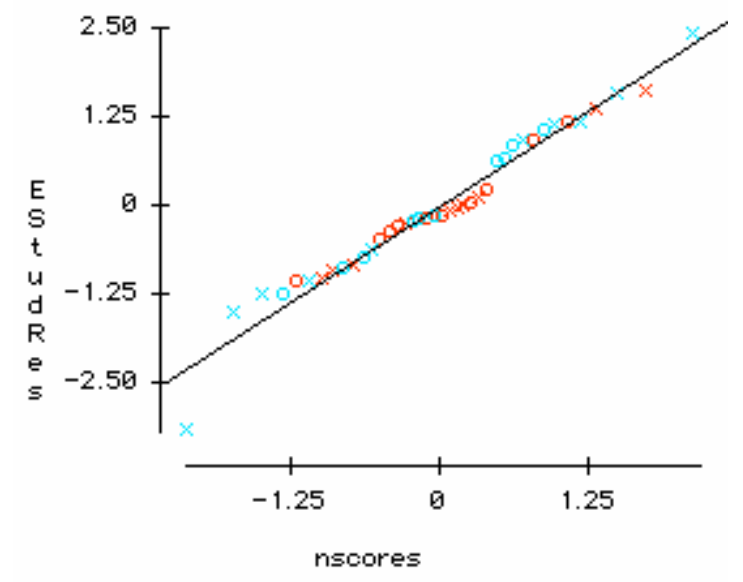

Figure A.4: Normal probability plot of E-StudRes Vs nscores $\log C_{\text {neck }}$

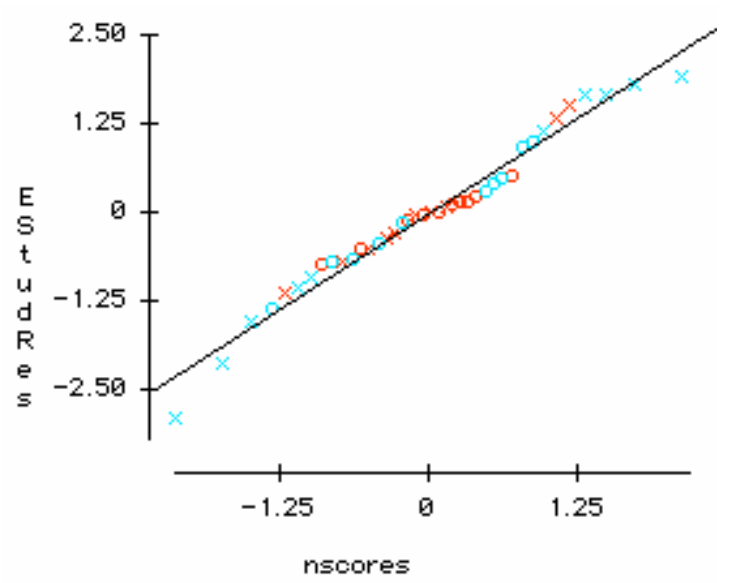

Figure A.5: Normal probability plot of E-StudRes Vs nscores $\log \mathrm{C}_{\text {l.collar }}$

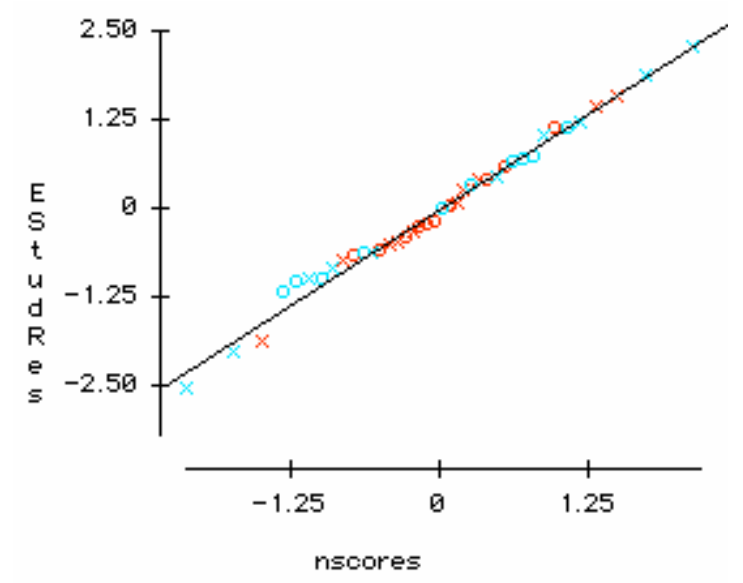

Figure A.6: Normal probability plot of E-StudRes Vs nscores $\log \mathrm{C}_{\text {r.collar }}$ 


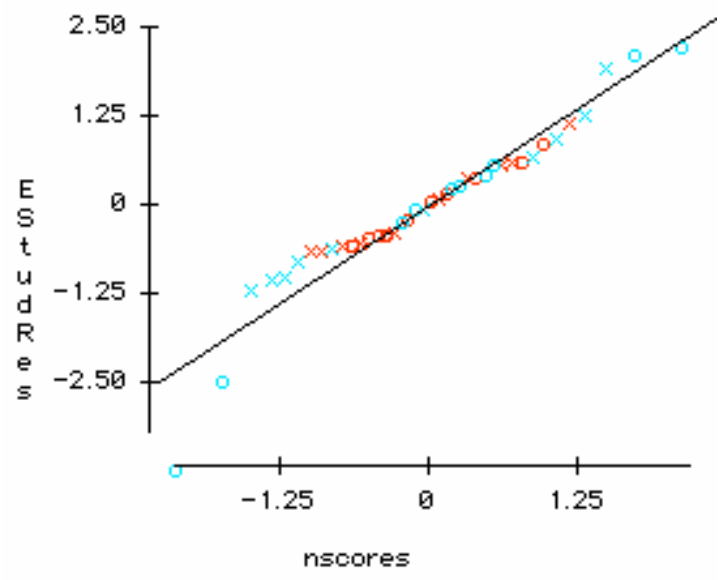

Figure A.7: Normal probability plot of E-StudRes Vs nscores $\log \mathrm{C}_{\text {c.chest }}$

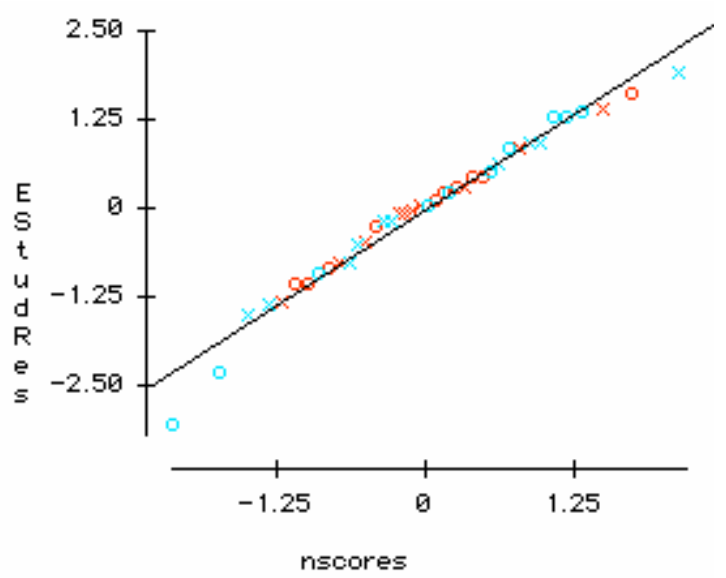

Figure A.8: Normal probability plot of E-StudRes Vs nscores $\log \mathrm{C}_{1 . \text { lapel }}$

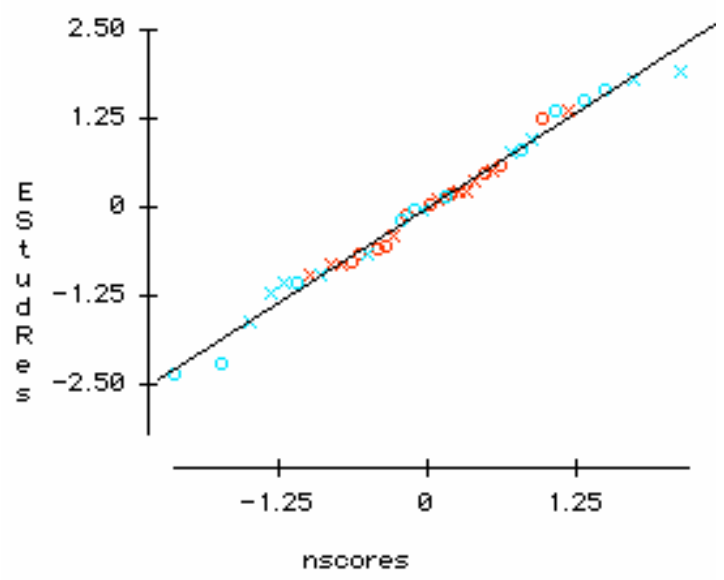

Figure A.9: Normal probability plot of E-StudRes Vs nscores $\log C_{\text {r.lapel }}$ 


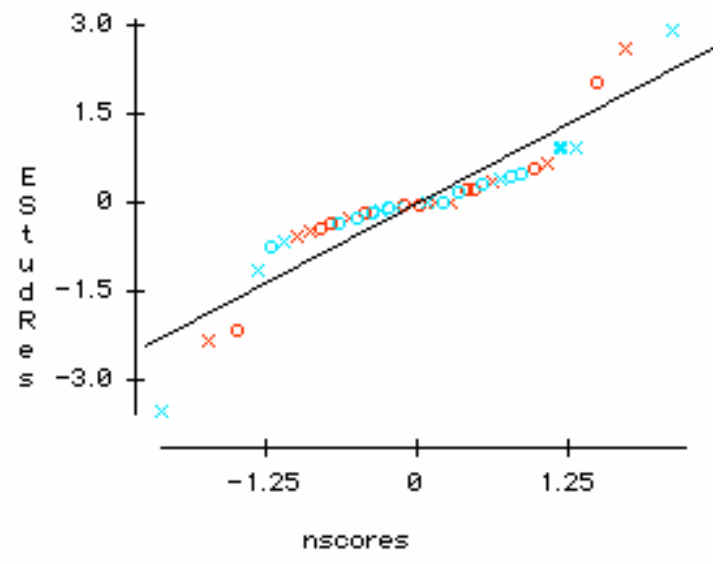

Figure A.10: Normal probability plot of E-StudRes Vs nscores for $\log \left\{\mathrm{C}_{\text {nose }} / \mathrm{C}_{\text {mouth }}\right\}$

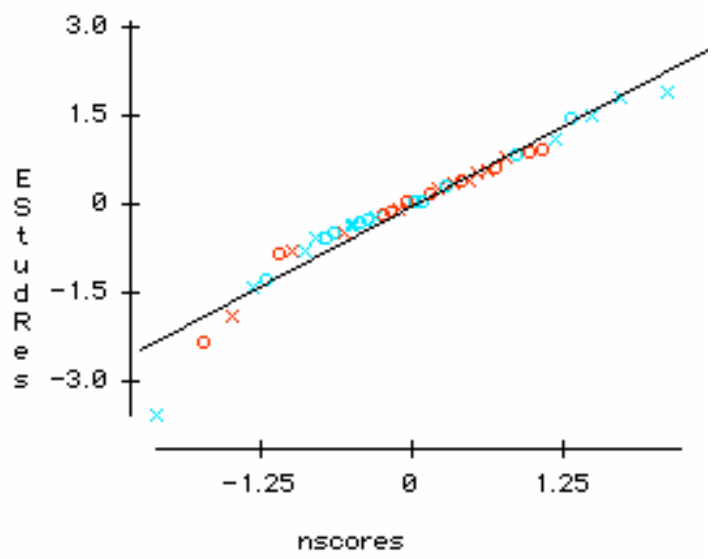

Figure A.11: Normal probability plot of E-StudRes Vs nscores for $\log \left\{\mathrm{C}_{\text {forehead }} / \mathrm{C}_{\text {mouth }}\right\}$ 


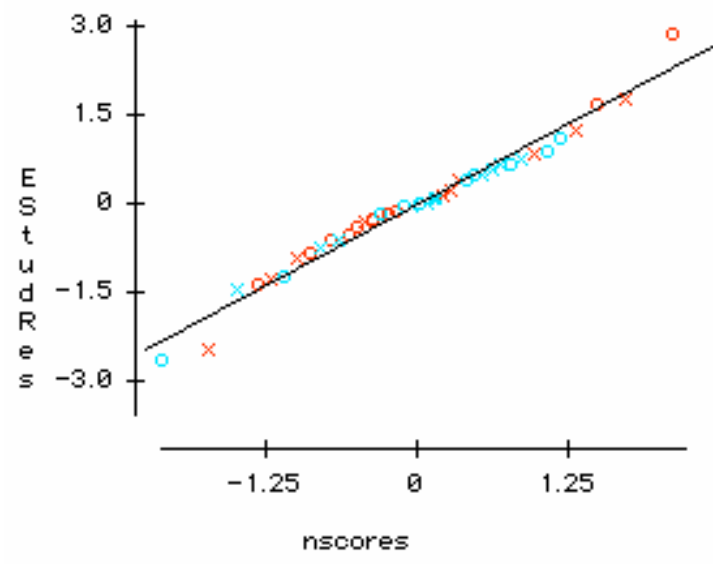

Figure A.12: Normal probability plot of E-StudRes Vs nscores for $\log \left\{\mathrm{C}_{\text {neck }} / \mathrm{C}_{\text {mouth }}\right\}$

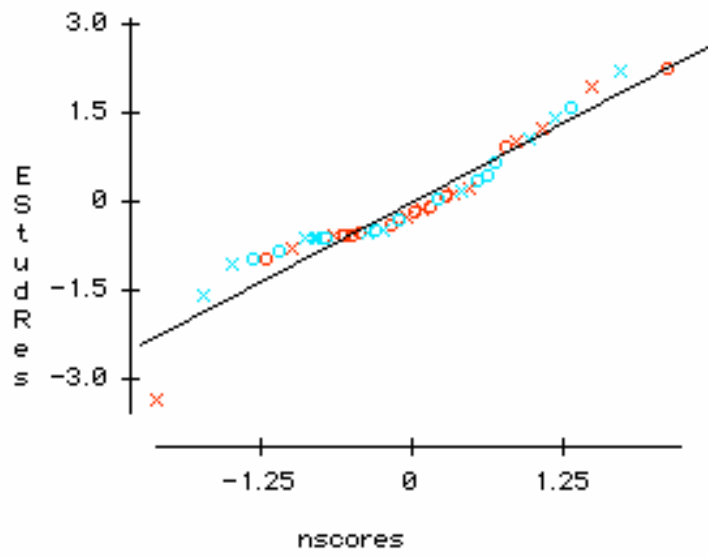

Figure A.13: Normal probability plot of E-StudRes Vs nscores $\log \left\{\mathrm{C}_{\mathrm{l} . \text { collar }} / \mathrm{C}_{\mathrm{mouth}}\right\}$

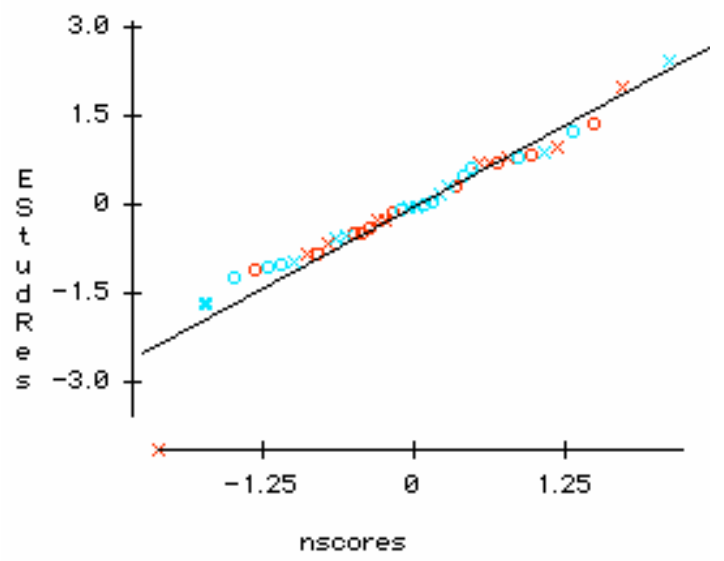

Figure A.14: Normal probability plot of E-StudRes Vs nscores $\log \left\{\mathrm{C}_{\text {r.collar }} / \mathrm{C}_{\text {mouth }}\right\}$ 


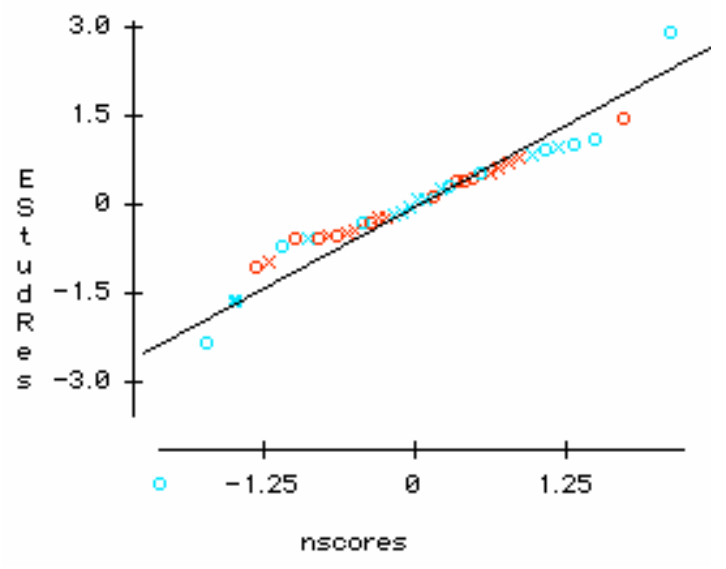

Figure A.15: Normal probability plot of E-StudRes Vs nscores for $\log \left\{\mathrm{C}_{\text {c.chest }} / \mathrm{C}_{\text {mouth }}\right\}$

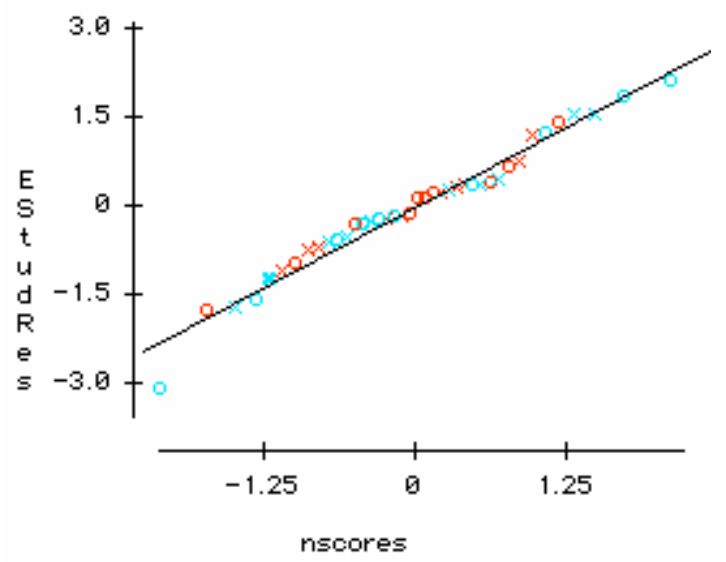

Figure A.16: Normal probability plot of E-StudRes Vs nscores for $\log \left\{\mathrm{C}_{\text {l.lapel }} / \mathrm{C}_{\mathrm{mouth}}\right\}$

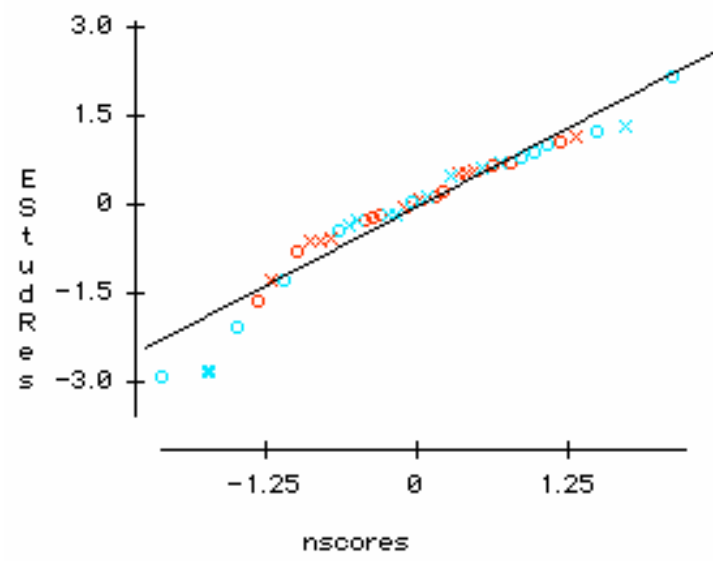

Figure A.17: Normal probability plot of E-StudRes Vs nscores for $\log \left\{\mathrm{C}_{\text {r.lapel }} / \mathrm{C}_{\text {mouth }}\right\}$ 


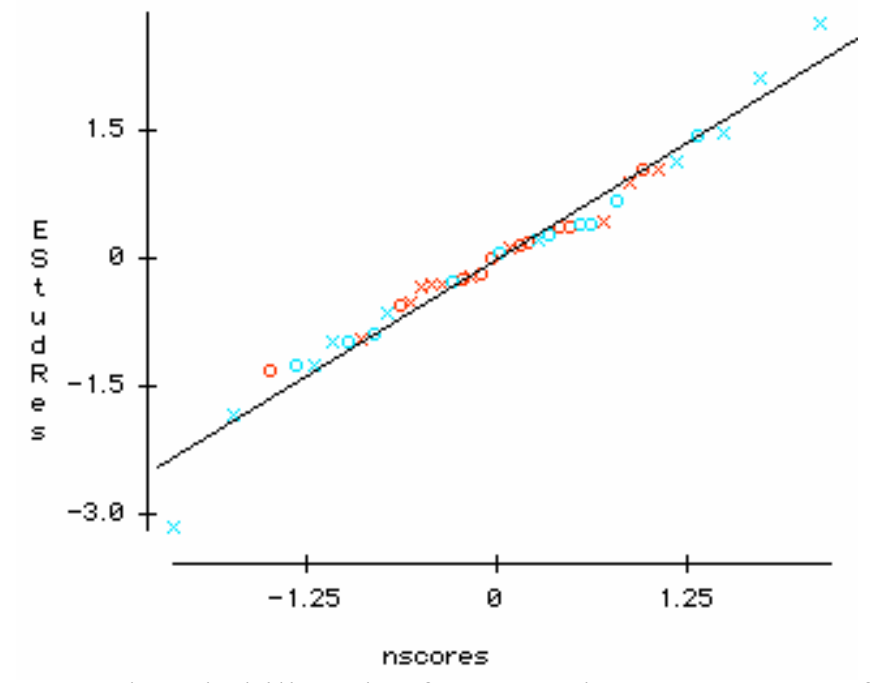

Figure A.18: Normal probability plot for E-StudRes Vs nscores for $\log C_{\text {inhaled }}$

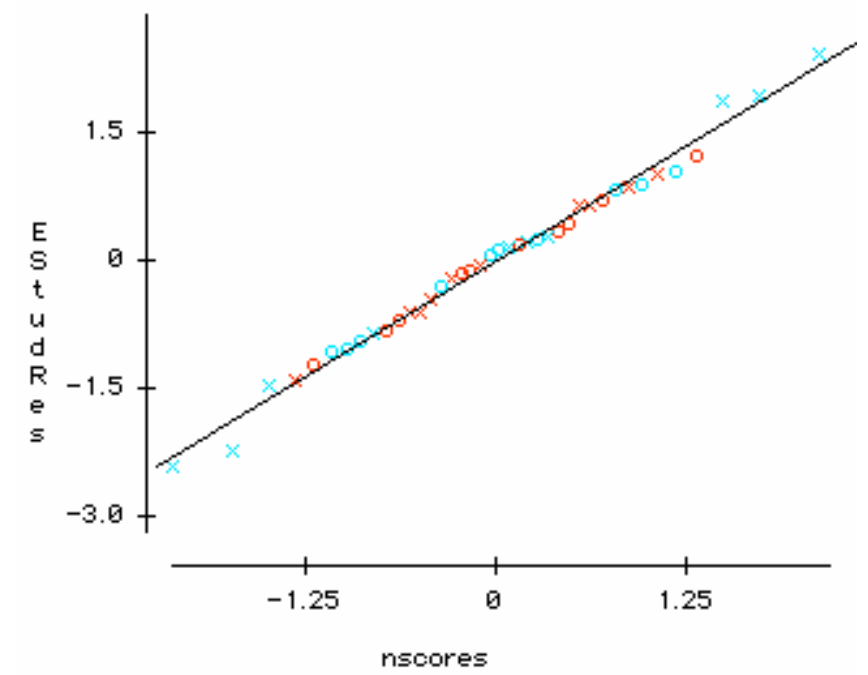

Figure A.19: Normal probability plot for E-StudRes Vs nscores for $\log \mathrm{C}_{\text {forehead }}$ 


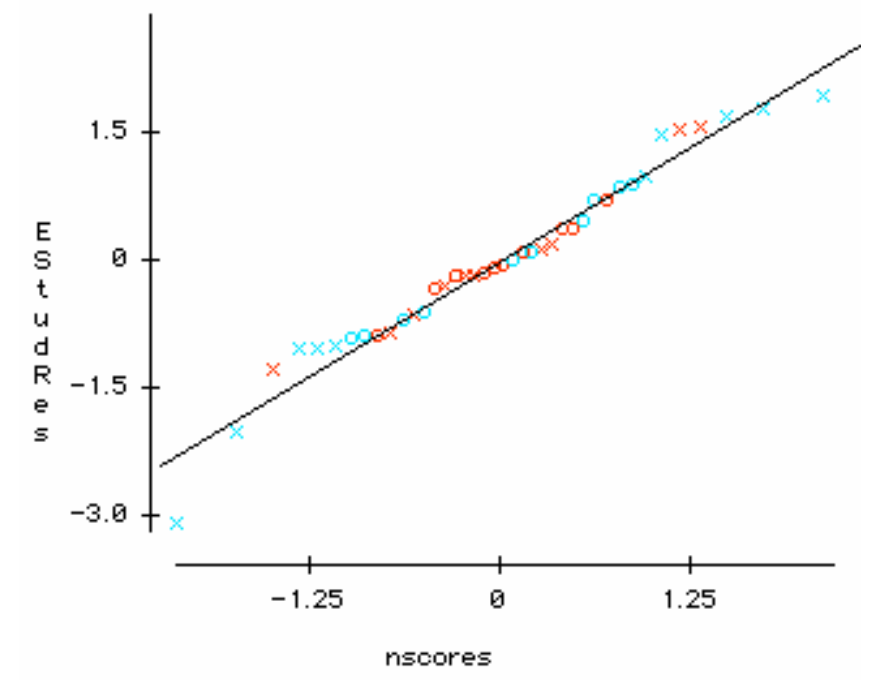

Figure A.20: Normal probability plot for E-StudRes Vs nscores for $\log \mathrm{C}_{\text {uppertorso }}$

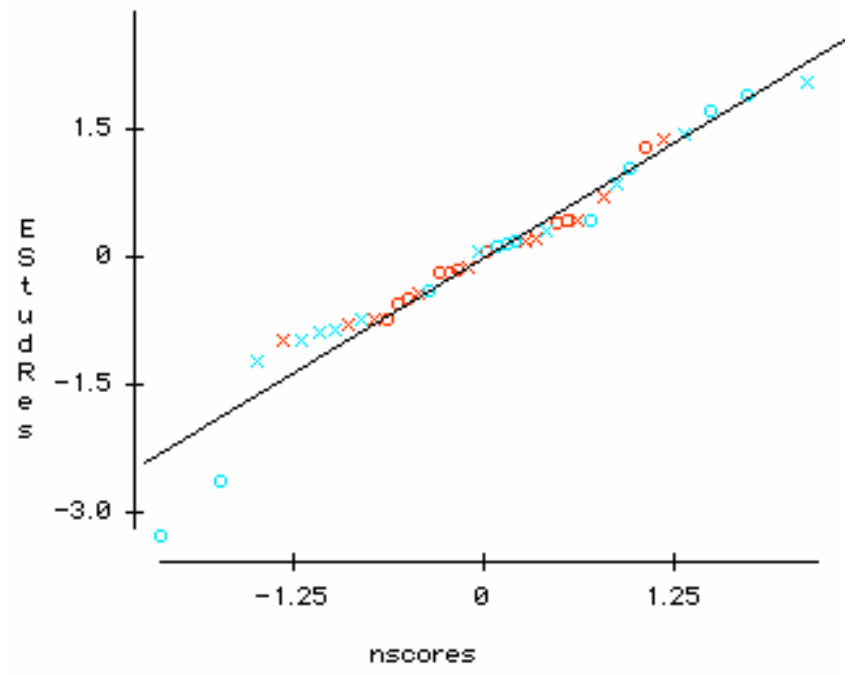

Figure A.21: Normal probability plot for E-StudRes Vs nscores for $\log \mathrm{C}_{\text {lowertorso }}$ 


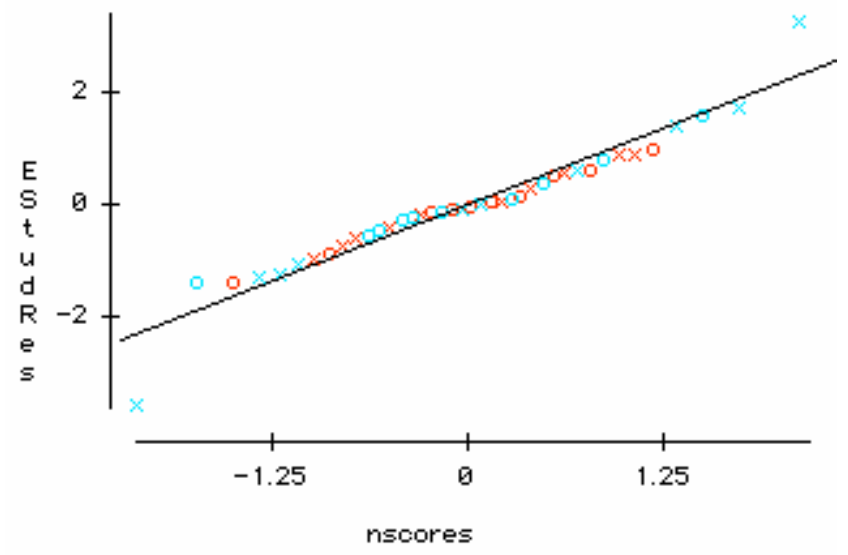

Figure A.22: Normal probability plot for E-StudRes Vs nscores for $\mathrm{C}_{\text {forehead }} / \mathrm{C}_{\text {inhaled }}$

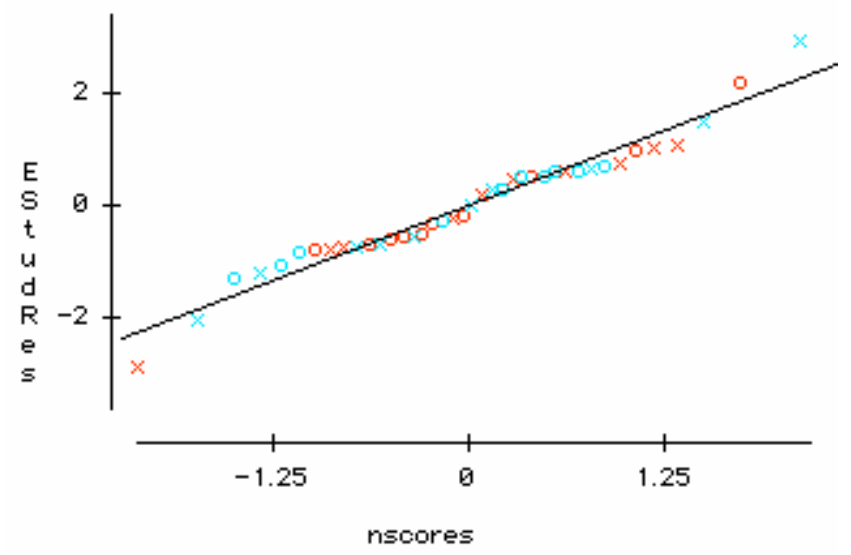

Figure A.23: Normal probability plot for E-StudRes Vs nscores for $\mathrm{C}_{\text {uppertorso }} / \mathrm{C}_{\text {inhaled }}$

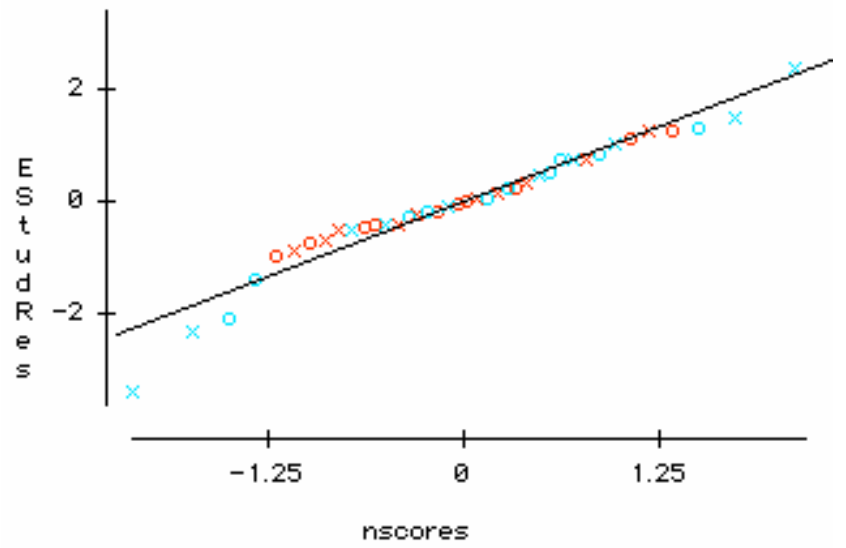

Figure A.24: Normal probability plot for E-StudRes Vs nscores for $\mathrm{C}_{\text {lowertorso }} / \mathrm{C}_{\text {inhaled }}$ 


\section{Appendix B: Regression analysis (STUDY I)}

Table B.1: Regression of $\log \mathrm{C}_{\text {mouth }}$ with velocity for heated/standing manikin

$\begin{aligned} & \text { Dependent variable is: log } \mathbf{C}_{\text {mouth }} \\
& \text { R squared = 96.4\% R squared (adjusted) }=95.3 \% \\
& \mathrm{~s}=0.02654 \text { with } 10-3=7 \text { degrees of freedom }\end{aligned}$
\begin{tabular}{l|l|l|l|l|}
\hline Source & Sum of Squares & df & Mean Square & F-ratio \\
\hline Regression & 0.130221 & 2 & 0.0651105 & 92.4 \\
\hline Residual & 0.00493132 & 7 & 0.000704474 & \\
\hline Variable & Coefficient & s.e. of Coeff & t-ratio & prob \\
\hline Constant & 1.24067 & 0.03395 & 36.5 & 0.0001 \\
\hline V1 & 0.0201971 & 0.001527 & 13.2 & 0.0001 \\
\hline V2 & -0.0231016 & 0.001703 & -13.6 & 0.0001 \\
\hline
\end{tabular}

Table B.2: Regression of $\log \mathrm{C}_{\text {nose }}$ with velocity for heated/standing manikin

\begin{tabular}{|c|c|c|c|c|}
\hline \multicolumn{5}{|c|}{$\begin{array}{l}\text { Dependent variable is: } \quad \log \mathbf{C}_{\text {nose }} \\
R \text { squared }=90.3 \% \quad \text { R squared (adjusted) }=87.5 \% \\
S=0.04488 \text { with } 10-3=7 \text { degrees of freedom }\end{array}$} \\
\hline Source & Sum of Squares & $\mathrm{df}$ & Mean Square & F-ratio \\
\hline Regression & 0.131374 & 2 & 0.0656871 & 32.6 \\
\hline Residual & 0.0141 & 7 & 0.00201429 & \\
\hline Variable & Coefficient & s.e. of Coeff & t-ratio & prob \\
\hline Constant & 1.22874 & 0.05741 & 21.4 & 0.0001 \\
\hline $\mathrm{V} 1$ & 0.0200044 & 0.002582 & 7.75 & 0.0001 \\
\hline V2 & -0.0230844 & 0.00288 & -8.01 & 0.0001 \\
\hline
\end{tabular}


Table B.3: Regression of $\log \mathrm{C}_{\text {forehead }}$ with velocity for heated/standing manikin

\begin{tabular}{|c|c|c|c|c|}
\hline \multicolumn{5}{|c|}{$\begin{array}{l}\text { Dependent variable is: } \quad \log \mathbf{C}_{\text {forehead }} \\
\mathrm{R} \text { squared }=95.3 \% \quad \mathrm{R} \text { squared (adjusted) }=94.0 \% \\
\mathrm{~s}=0.02982 \text { with } 10-3=7 \text { degrees of freedom }\end{array}$} \\
\hline Source & Sum of Squares & $\mathrm{df}$ & Mean Square & F-ratio \\
\hline Regression & 0.127004 & 2 & 0.063502 & 71.4 \\
\hline Residual & 0.00622431 & 7 & 0.000889187 & \\
\hline Variable & Coefficient & s.e. of Coeff & t-ratio & prob \\
\hline Constant & 1.17238 & 0.03814 & 30.7 & 0.0001 \\
\hline V1 & 0.0202985 & 0.001716 & 11.8 & 0.0001 \\
\hline $\mathrm{V} 2$ & -0.0228675 & 0.001914 & -11.9 & 0.0001 \\
\hline
\end{tabular}

Table B.4: Regression of $\log \mathrm{C}_{\text {neck }}$ with velocity for heated/standing manikin

\begin{tabular}{|c|c|c|c|c|}
\hline \multicolumn{5}{|c|}{$\begin{array}{l}\text { Dependent variable is: } \quad \log \mathbf{C}_{\text {neck }} \\
\mathrm{R} \text { squared }=88.3 \% \quad \mathrm{R} \text { squared (adjusted) }=85.0 \% \\
\mathrm{~s}=0.05466 \text { with } 10-3=7 \text { degrees of freedom }\end{array}$} \\
\hline Source & Sum of Squares & df & Mean Square & F-ratio \\
\hline Regression & 0.158143 & 2 & 0.0790714 & 26.5 \\
\hline Residual & 0.0209141 & 7 & 0.00298773 & \\
\hline Variable & Coefficient & s.e. of Coeff & t-ratio & prob \\
\hline Constant & 1.41235 & 0.04823 & 29.3 & 0.0001 \\
\hline V1 & 0.0097612 & 0.001464 & 6.67 & 0.0003 \\
\hline V3 & -0.0156532 & 0.002155 & -7.26 & 0.0002 \\
\hline
\end{tabular}


Table B.5: Regression of $\log \mathrm{C}_{\text {l.collar }}$ with velocity for heated/standing manikin

\begin{tabular}{|c|c|c|c|c|}
\hline \multicolumn{5}{|c|}{$\begin{array}{l}\text { Dependent variable is: } \quad \log \mathbf{C}_{\text {l.collar }} \\
\mathrm{R} \text { squared }=86.9 \% \quad \mathrm{R} \text { squared (adjusted) }=83.2 \% \\
\mathrm{~s}=0.05783 \text { with } 10-3=7 \text { degrees of freedom }\end{array}$} \\
\hline Source & Sum of Squares & $\mathrm{df}$ & Mean Square & F-ratio \\
\hline Regression & 0.155511 & 2 & 0.0777556 & 23.2 \\
\hline Residual & 0.0234107 & 7 & 0.00334439 & \\
\hline Variable & Coefficient & s.e. of Coeff & t-ratio & prob \\
\hline Constant & 1.38928 & 0.05103 & 27.2 & 0.0001 \\
\hline V1 & 0.00856335 & 0.001549 & 5.53 & 0.0009 \\
\hline V3 & -0.0149805 & 0.00228 & -6.57 & 0.0003 \\
\hline
\end{tabular}

Table B.6: Regression of $\log C_{\text {r.collar }}$ with velocity for heated/standing manikin

\begin{tabular}{|c|c|c|c|c|}
\hline \multicolumn{5}{|c|}{$\begin{array}{l}\text { Dependent variable is: } \quad \log \mathbf{C}_{\text {r.collar }} \\
\text { R squared }=86.3 \% \quad \text { R squared (adjusted) }=82.3 \% \\
\mathrm{~s}=0.06365 \text { with } 10-3=7 \text { degrees of freedom }\end{array}$} \\
\hline Source & Sum of Squares & $\mathrm{df}$ & Mean Square & F-ratio \\
\hline Regression & 0.178011 & 2 & 0.0890054 & 22 \\
\hline Residual & 0.0283574 & 7 & 0.00405106 & \\
\hline Variable & Coefficient & s.e. of Coeff & t-ratio & prob \\
\hline Constant & 1.31881 & 0.05616 & 23.5 & 0.0001 \\
\hline V1 & 0.0109136 & 0.001705 & 6.4 & 0.0004 \\
\hline V3 & -0.0165646 & 0.002509 & -6.6 & 0.0003 \\
\hline
\end{tabular}


Table B.7: Regression of $\log \mathrm{C}_{\text {c.chest }}$ with velocity for heated/standing manikin

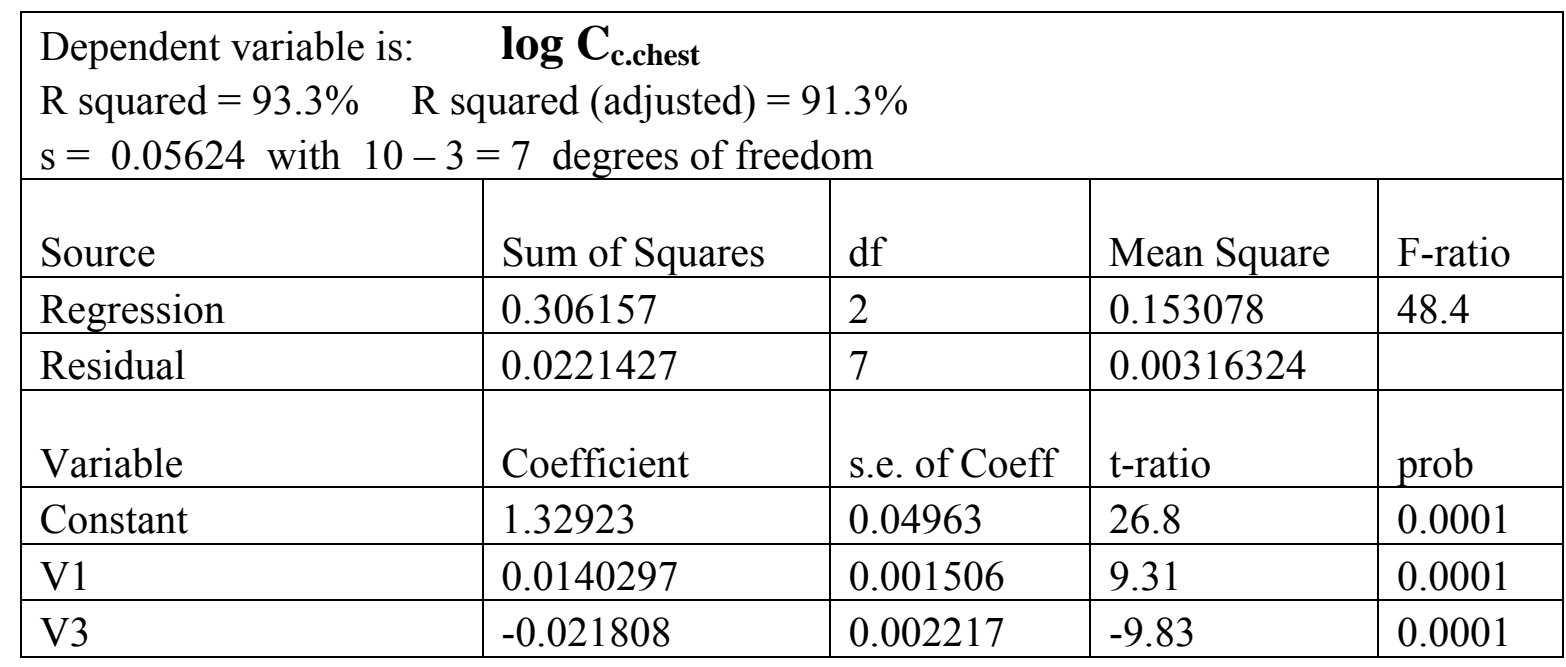

Table B.8: Regression of $\log \mathrm{C}_{1 . \text { lapel }}$ with velocity for heated/standing manikin

\begin{tabular}{|c|c|c|c|c|}
\hline \multicolumn{5}{|c|}{$\begin{array}{l}\text { Dependent variable is: } \quad \log \mathbf{C}_{\mathbf{l} . \text { lapel }} \\
\mathrm{R} \text { squared }=96.2 \% \quad \mathrm{R} \text { squared (adjusted) }=95.1 \% \\
\mathrm{~s}=0.03975 \text { with } 10-3=7 \text { degrees of freedom }\end{array}$} \\
\hline Source & Sum of Squares & $\mathrm{df}$ & Mean Square & F-ratio \\
\hline Regression & 0.27772 & 2 & 0.13886 & 87.9 \\
\hline Residual & 0.0110615 & 7 & 0.00158022 & \\
\hline Variable & Coefficient & s.e. of Coeff & t-ratio & prob \\
\hline Constant & 1.22523 & 0.03508 & 34.9 & 0.0001 \\
\hline V1 & 0.0138989 & 0.001065 & 13.1 & 0.0001 \\
\hline V3 & -0.020445 & 0.001567 & -13 & 0.0001 \\
\hline
\end{tabular}


Table B.9: Regression of $\log \mathrm{C}_{\mathrm{r} . \text { lapel }}$ with velocity for heated/standing manikin

\begin{tabular}{|c|c|c|c|c|}
\hline \multicolumn{5}{|c|}{$\begin{array}{l}\text { Dependent variable is: } \quad \log \mathbf{C}_{\text {r.lapel }} \\
\mathrm{R} \text { squared }=95.2 \% \quad \mathrm{R} \text { squared (adjusted) }=93.8 \% \\
\mathrm{~s}=0.05034 \text { with } 10-3=7 \text { degrees of freedom }\end{array}$} \\
\hline Source & Sum of Squares & $\mathrm{df}$ & Mean Square & F-ratio \\
\hline Regression & 0.3502 & 2 & 0.1751 & 69.1 \\
\hline Residual & 0.0177366 & 7 & 0.00253381 & \\
\hline Variable & Coefficient & s.e. of Coeff & t-ratio & prob \\
\hline Constant & 1.25978 & 0.04441 & 28.4 & 0.0001 \\
\hline V1 & 0.0150258 & 0.001348 & 11.1 & 0.0001 \\
\hline V3 & -0.0233212 & 0.001985 & -11.8 & 0.0001 \\
\hline
\end{tabular}

Table B.10: Regression of $\log \mathrm{C}_{\text {mouth }}$ with velocity for heated/seated manikin

\begin{tabular}{|c|c|c|c|c|}
\hline \multicolumn{5}{|c|}{$\begin{array}{l}\text { Dependent variable is: } \log \mathbf{C}_{\text {mouth }} \\
\text { R squared }=98.4 \% \quad \text { R squared (adjusted) }=97.9 \% \\
\mathrm{~s}=0.02889 \text { with } 10-3=7 \text { degrees of freedom }\end{array}$} \\
\hline Source & Sum of Squares & df & Mean Square & F-ratio \\
\hline Regression & 0.353319 & 2 & 0.17666 & 212 \\
\hline Residual & 0.00584368 & 7 & 0.000834811 & \\
\hline Variable & Coefficient & s.e. of Coeff & t-ratio & prob \\
\hline Constant & 0.926224 & 0.02549 & 36.3 & 0.0001 \\
\hline V1 & 0.0159198 & 0.0007739 & 20.6 & 0.0001 \\
\hline $\mathrm{V} 3$ & -0.0220513 & 0.001139 & -19.4 & 0.0001 \\
\hline
\end{tabular}


Table B.11: Regression of $\log \mathrm{C}_{\text {nose }}$ with velocity for heated/seated manikin

\begin{tabular}{|c|c|c|c|c|}
\hline \multicolumn{5}{|c|}{$\begin{array}{l}\text { Dependent variable is: } \log \mathbf{C}_{\text {nose }} \\
\mathrm{R} \text { squared }=98.5 \% \quad \text { R squared (adjusted) }=98.0 \% \\
\mathrm{~S}=0.03404 \text { with } 10-3=7 \text { degrees of freedom }\end{array}$} \\
\hline Source & Sum of Squares & df & Mean Square & F-ratio \\
\hline Regression & 0.525785 & 2 & 0.262892 & 227 \\
\hline Residual & 0.00811289 & 7 & 0.00115898 & \\
\hline Variable & Coefficient & s.e. of Coeff & t-ratio & prob \\
\hline Constant & 0.790686 & 0.03004 & 26.3 & 0.0001 \\
\hline V1 & 0.0193638 & 0.0009118 & 21.2 & 0.0001 \\
\hline $\mathrm{V} 3$ & -0.0259728 & 0.001342 & -19.4 & 0.0001 \\
\hline
\end{tabular}

Table B.12: Regression of $\log \mathrm{C}_{\text {forehead }}$ with velocity for heated/seated manikin

\begin{tabular}{|c|c|c|c|c|}
\hline \multicolumn{5}{|c|}{$\begin{array}{l}\text { Dependent variable is: } \log \mathbf{C}_{\text {forehead }} \\
\mathrm{R} \text { squared }=99.1 \% \quad \text { R squared (adjusted) }=98.8 \% \\
\mathrm{~s}=0.0264 \text { with } 10-3=7 \text { degrees of freedom }\end{array}$} \\
\hline Source & Sum of Squares & $\mathrm{df}$ & Mean Square & F-ratio \\
\hline Regression & 0.528113 & 2 & 0.264056 & 379 \\
\hline Residual & 0.00487976 & 7 & 0.000697109 & \\
\hline Variable & Coefficient & s.e. of Coeff & t-ratio & prob \\
\hline Constant & 0.66846 & 0.0233 & 28.7 & 0.0001 \\
\hline V1 & 0.0189959 & 0.0007072 & 26.9 & 0.0001 \\
\hline $\mathrm{V} 3$ & -0.0240586 & 0.001041 & -23.1 & 0.0001 \\
\hline
\end{tabular}


Table B.13: Regression of $\log C_{\text {neck }}$ with velocity for heated/seated manikin

\begin{tabular}{|c|c|c|c|c|}
\hline \multicolumn{5}{|c|}{$\begin{array}{l}\text { Dependent variable is: } \log \mathbf{C}_{\text {neck }} \\
\mathrm{R} \text { squared }=95.2 \% \quad \text { R squared (adjusted) }=93.8 \% \\
\mathrm{~s}=0.04295 \text { with } 10-3=7 \text { degrees of freedom }\end{array}$} \\
\hline Source & Sum of Squares & df & Mean Square & F-ratio \\
\hline Regression & 0.256856 & 2 & 0.128428 & 69.6 \\
\hline Residual & 0.0129105 & 7 & 0.00184435 & \\
\hline Variable & Coefficient & s.e. of Coeff & t-ratio & prob \\
\hline Constant & 1.01887 & 0.03789 & 26.9 & 0.0001 \\
\hline V1 & 0.0123745 & 0.00115 & 10.8 & 0.0001 \\
\hline V3 & -0.0199341 & 0.001693 & -11.8 & 0.0001 \\
\hline
\end{tabular}

Table B.14: Regression of $\log C_{1 . \text { collar }}$ with velocity for heated/seated manikin

\begin{tabular}{|c|c|c|c|c|}
\hline \multicolumn{5}{|c|}{$\begin{array}{l}\text { Dependent variable is: } \log \mathbf{C}_{\mathbf{l} . \text { collar }} \\
\mathrm{R} \text { squared }=95.7 \% \quad \text { R squared (adjusted) }=94.5 \% \\
\mathrm{~S}=0.03184 \text { with } 10-3=7 \text { degrees of freedom }\end{array}$} \\
\hline Source & Sum of Squares & df & Mean Square & F-ratio \\
\hline Regression & 0.15884 & 2 & 0.0794198 & 78.4 \\
\hline Residual & 0.00709557 & 7 & 0.00101365 & \\
\hline Variable & Coefficient & s.e. of Coeff & t-ratio & prob \\
\hline Constant & 1.08939 & 0.02809 & 38.8 & 0.0001 \\
\hline $\mathrm{V} 1$ & 0.00966195 & 0.0008527 & 11.3 & 0.0001 \\
\hline V3 & -0.0156571 & 0.001255 & -12.5 & 0.0001 \\
\hline
\end{tabular}


Table B.15: Regression of $\log \mathrm{C}_{\text {r.collar }}$ with velocity for heated/seated manikin

\begin{tabular}{|c|c|c|c|c|}
\hline \multicolumn{5}{|c|}{$\begin{array}{l}\text { Dependent variable is: } \log \mathbf{C}_{\mathbf{r} . c o l l a r} \\
\mathrm{R} \text { squared }=91.9 \% \quad \text { R squared (adjusted) }=89.5 \% \\
\mathrm{~S}=0.0476 \text { with } 10-3=7 \text { degrees of freedom }\end{array}$} \\
\hline Source & Sum of Squares & df & Mean Square & F-ratio \\
\hline Regression & 0.179169 & 2 & 0.0895846 & 39.5 \\
\hline Residual & 0.0158605 & 7 & 0.00226579 & \\
\hline Variable & Coefficient & s.e. of Coeff & t-ratio & prob \\
\hline Constant & 1.10274 & 0.042 & 26.3 & 0.0001 \\
\hline V1 & 0.00944431 & 0.001275 & 7.41 & 0.0001 \\
\hline V3 & -0.0162421 & 0.001877 & -8.65 & 0.0001 \\
\hline
\end{tabular}

Table B.16: Regression of $\log \mathrm{C}_{\mathrm{c} . \text { chest }}$ with velocity for heated/seated manikin

\begin{tabular}{|c|c|c|c|c|}
\hline \multicolumn{5}{|c|}{$\begin{array}{l}\text { Dependent variable is: } \mathbf{L o g} \mathbf{C}_{\text {c.chest }} \\
\mathrm{R} \text { squared }=88.2 \% \quad \mathrm{R} \text { squared (adjusted) }=84.8 \% \\
\mathrm{~S}=0.03836 \text { with } 10-3=7 \text { degrees of freedom }\end{array}$} \\
\hline Source & Sum of Squares & df & Mean Square & F-ratio \\
\hline Regression & 0.0769717 & 2 & 0.0384858 & 26.2 \\
\hline Residual & 0.0103013 & 7 & 0.00147161 & \\
\hline Variable & Coefficient & s.e. of Coeff & t-ratio & prob \\
\hline Constant & 1.18256 & 0.03385 & 34.9 & 0.0001 \\
\hline V1 & 0.00675036 & 0.001027 & 6.57 & 0.0003 \\
\hline V3 & -0.0109062 & 0.001512 & -7.21 & 0.0002 \\
\hline
\end{tabular}


Table B.17: Regression of $\log \mathrm{C}_{1 . \text { lapel }}$ with velocity for heated/seated manikin

\begin{tabular}{|c|c|c|c|c|}
\hline \multicolumn{5}{|c|}{$\begin{array}{l}\text { Dependent variable is: } \mathbf{L o g} \mathbf{C}_{\mathbf{l}} \text { lapel } \\
\mathrm{R} \text { squared }=91.5 \% \quad \text { R squared (adjusted) }=89.0 \% \\
\mathrm{~s}=0.03926 \text { with } 10-3=7 \text { degrees of freedom }\end{array}$} \\
\hline Source & Sum of Squares & $\mathrm{df}$ & Mean Square & F-ratio \\
\hline Regression & 0.115769 & 2 & 0.0578844 & 37.6 \\
\hline Residual & 0.0107883 & 7 & 0.00154118 & \\
\hline Variable & Coefficient & s.e. of Coeff & t-ratio & prob \\
\hline \begin{tabular}{|l|} 
Constant \\
\end{tabular} & 1.10313 & 0.03464 & 31.8 & 0.0001 \\
\hline V1 & 0.00825538 & 0.001051 & 7.85 & 0.0001 \\
\hline V3 & -0.0133688 & 0.001548 & -8.64 & 0.0001 \\
\hline
\end{tabular}

Table B.18: Regression of $\log \mathrm{C}_{\text {r.lapel }}$ with velocity for heated/seated manikin

\begin{tabular}{|c|c|c|c|c|}
\hline \multicolumn{5}{|c|}{$\begin{array}{l}\text { Dependent variable is: } \log \mathbf{C}_{\text {r.lapel }} \\
\mathrm{R} \text { squared }=89.7 \% \quad \text { R squared (adjusted) }=86.7 \% \\
\mathrm{~s}=0.04488 \text { with } 10-3=7 \text { degrees of freedom }\end{array}$} \\
\hline Source & Sum of Squares & $\mathrm{df}$ & Mean Square & F-ratio \\
\hline Regression & 0.122516 & 2 & 0.0612581 & 30.4 \\
\hline Residual & 0.0140991 & 7 & 0.00201416 & \\
\hline Variable & Coefficient & s.e. of Coeff & t-ratio & prob \\
\hline Constant & 1.06684 & 0.0396 & 26.9 & 0.0001 \\
\hline V1 & 0.00840008 & 0.001202 & 6.99 & 0.0002 \\
\hline V3 & -0.0137233 & 0.001769 & -7.76 & 0.0001 \\
\hline
\end{tabular}


Table B.19: Regression of $\log \mathrm{C}_{\text {mouth }}$ with velocity for unheated/standing manikin

\begin{tabular}{|c|c|c|c|c|}
\hline \multicolumn{5}{|c|}{$\begin{array}{l}\text { Dependent variable is: } \quad \mathbf{L o g} \mathbf{C}_{\text {mouth }} \\
\mathrm{R} \text { squared }=74.5 \% \quad \mathrm{R} \text { squared (adjusted) }=71.3 \% \\
\mathrm{~s}=0.09853 \text { with } 10-2=8 \text { degrees of freedom }\end{array}$} \\
\hline Source & Sum of Squares & $\mathrm{df}$ & Mean Square & F-ratio \\
\hline Regression & 0.226672 & 1 & 0.226672 & 23.4 \\
\hline Residual & 0.0776586 & 8 & 0.00970733 & \\
\hline Variable & Coefficient & s.e. of Coeff & t-ratio & prob \\
\hline Constant & 1.78393 & 0.05859 & 30.4 & 0.0001 \\
\hline $\mathrm{V} 1$ & -0.00442427 & 0.0009156 & -4.83 & 0.0013 \\
\hline
\end{tabular}

Table B.20: Regression of $\log \mathrm{C}_{\text {nose }}$ with velocity for unheated/standing manikin

\begin{tabular}{|c|c|c|c|c|}
\hline \multicolumn{5}{|c|}{$\begin{array}{l}\text { Dependent variable is: } \mathbf{L o g} \mathbf{C}_{\text {nose }} \\
\mathrm{R} \text { squared }=64.3 \% \quad \mathrm{R} \text { squared (adjusted) }=59.9 \% \\
\mathrm{~s}=0.1542 \text { with } 10-2=8 \text { degrees of freedom }\end{array}$} \\
\hline Source & Sum of Squares & $\mathrm{df}$ & Mean Square & F-ratio \\
\hline Regression & 0.342614 & 1 & 0.342614 & 14.4 \\
\hline Residual & 0.190105 & 8 & 0.0237631 & \\
\hline Variable & Coefficient & s.e. of Coeff & t-ratio & prob \\
\hline Constant & 1.78907 & 0.09168 & 19.5 & 0.0001 \\
\hline V1 & -0.00543933 & 0.001432 & -3.8 & 0.0053 \\
\hline
\end{tabular}


Table B.21: Regression of $\log \mathrm{C}_{\text {forehead }}$ with velocity for unheated/standing manikin

\begin{tabular}{|c|c|c|c|c|}
\hline \multicolumn{5}{|c|}{$\begin{array}{l}\text { Dependent variable is: } \quad \mathbf{L o g} \mathbf{C}_{\text {forehead }} \\
\mathrm{R} \text { squared }=69.4 \% \quad \text { R squared (adjusted) }=65.5 \% \\
\mathrm{~s}=0.1116 \text { with } 10-2=8 \text { degrees of freedom }\end{array}$} \\
\hline Source & Sum of Squares & $\mathrm{df}$ & Mean Square & F-ratio \\
\hline Regression & 0.225612 & 1 & 0.225612 & 18.1 \\
\hline Residual & 0.0996396 & 8 & 0.012455 & \\
\hline Variable & Coefficient & s.e. of Coeff & t-ratio & prob \\
\hline Constant & 1.63535 & 0.06637 & 24.6 & 0.0001 \\
\hline $\mathrm{V} 1$ & -0.00441392 & 0.001037 & -4.26 & 0.0028 \\
\hline
\end{tabular}

Table B.22: Regression of $\log \mathrm{C}_{\text {neck }}$ with velocity for unheated/standing manikin

\begin{tabular}{|c|c|c|c|c|}
\hline \multicolumn{5}{|c|}{$\begin{array}{l}\text { Dependent variable is: } \quad \mathbf{L o g} \mathbf{C}_{\text {neck }} \\
\mathrm{R} \text { squared }=66.2 \% \quad \mathrm{R} \text { squared (adjusted) }=62.0 \% \\
\mathrm{~s}=0.1194 \text { with } 10-2=8 \text { degrees of freedom }\end{array}$} \\
\hline Source & Sum of Squares & df & Mean Square & F-ratio \\
\hline Regression & 0.223599 & 1 & 0.223599 & 15.7 \\
\hline Residual & 0.11414 & 8 & 0.0142675 & \\
\hline Variable & Coefficient & s.e. of Coeff & t-ratio & prob \\
\hline Constant & 1.81827 & 0.07104 & 25.6 & 0.0001 \\
\hline V1 & -0.00439417 & 0.00111 & -3.96 & 0.0042 \\
\hline
\end{tabular}


Table B.23: Regression of $\log \mathrm{C}_{\text {l.collar }}$ with velocity for unheated/standing manikin

\begin{tabular}{|c|c|c|c|c|}
\hline \multicolumn{5}{|c|}{$\begin{array}{l}\text { Dependent variable is: } \quad \mathbf{L o g} \mathbf{C}_{\mathbf{l} . \text { collar }} \\
\mathrm{R} \text { squared }=59.8 \% \quad \text { R squared (adjusted) }=54.7 \% \\
\mathrm{~s}=0.1377 \text { with } 10-2=8 \text { degrees of freedom }\end{array}$} \\
\hline Source & Sum of Squares & df & Mean Square & F-ratio \\
\hline Regression & 0.225428 & 1 & 0.225428 & 11.9 \\
\hline Residual & 0.151724 & 8 & 0.0189655 & \\
\hline Variable & Coefficient & s.e. of Coeff & t-ratio & prob \\
\hline Constant & 1.83503 & 0.0819 & 22.4 & 0.0001 \\
\hline V1 & -0.00441211 & 0.00128 & -3.45 & 0.0087 \\
\hline
\end{tabular}

Table B.24: Regression of $\log \mathrm{C}_{\text {r.collar }}$ with velocity for unheated/standing manikin

\begin{tabular}{|c|c|c|c|c|}
\hline \multicolumn{5}{|c|}{$\begin{array}{l}\text { Dependent variable is: } \quad \log \mathbf{C}_{\mathbf{r} . c o l l a r} \\
\mathrm{R} \text { squared }=68.5 \% \quad \mathrm{R} \text { squared (adjusted) }=64.5 \% \\
\mathrm{~S}=0.1053 \text { with } 10-2=8 \text { degrees of freedom }\end{array}$} \\
\hline Source & Sum of Squares & df & Mean Square & F-ratio \\
\hline Regression & 0.192807 & 1 & 0.192807 & 17.4 \\
\hline Residual & 0.0887156 & 8 & 0.0110895 & \\
\hline Variable & Coefficient & s.e. of Coeff & t-ratio & prob \\
\hline Constant & 1.8033 & 0.06263 & 28.8 & 0.0001 \\
\hline V1 & -0.00408041 & 0.0009786 & -4.17 & 0.0031 \\
\hline
\end{tabular}


Table B.25: Regression of $\log \mathrm{C}_{\text {c.chest }}$ with velocity for unheated/standing manikin

\begin{tabular}{|c|c|c|c|c|}
\hline \multicolumn{5}{|c|}{$\begin{array}{l}\text { Dependent variable is: } \quad \mathbf{L o g} \mathbf{C}_{\text {c.chest }} \\
\mathrm{R} \text { squared }=79.8 \% \quad \text { R squared (adjusted) }=77.3 \% \\
\mathrm{~S}=0.1022 \text { with } 10-2=8 \text { degrees of freedom }\end{array}$} \\
\hline Source & Sum of Squares & df & Mean Square & F-ratio \\
\hline Regression & 0.330325 & 1 & 0.330325 & 31.6 \\
\hline Residual & 0.0834979 & 8 & 0.0104372 & \\
\hline Variable & Coefficient & s.e. of Coeff & t-ratio & prob \\
\hline Constant & 2.08414 & 0.06076 & 34.3 & 0.0001 \\
\hline V1 & -0.00534089 & 0.0009494 & -5.63 & 0.0005 \\
\hline
\end{tabular}

Table B.26: Regression of $\log \mathrm{C}_{1.1 \mathrm{lapel}}$ with velocity for unheated/standing manikin

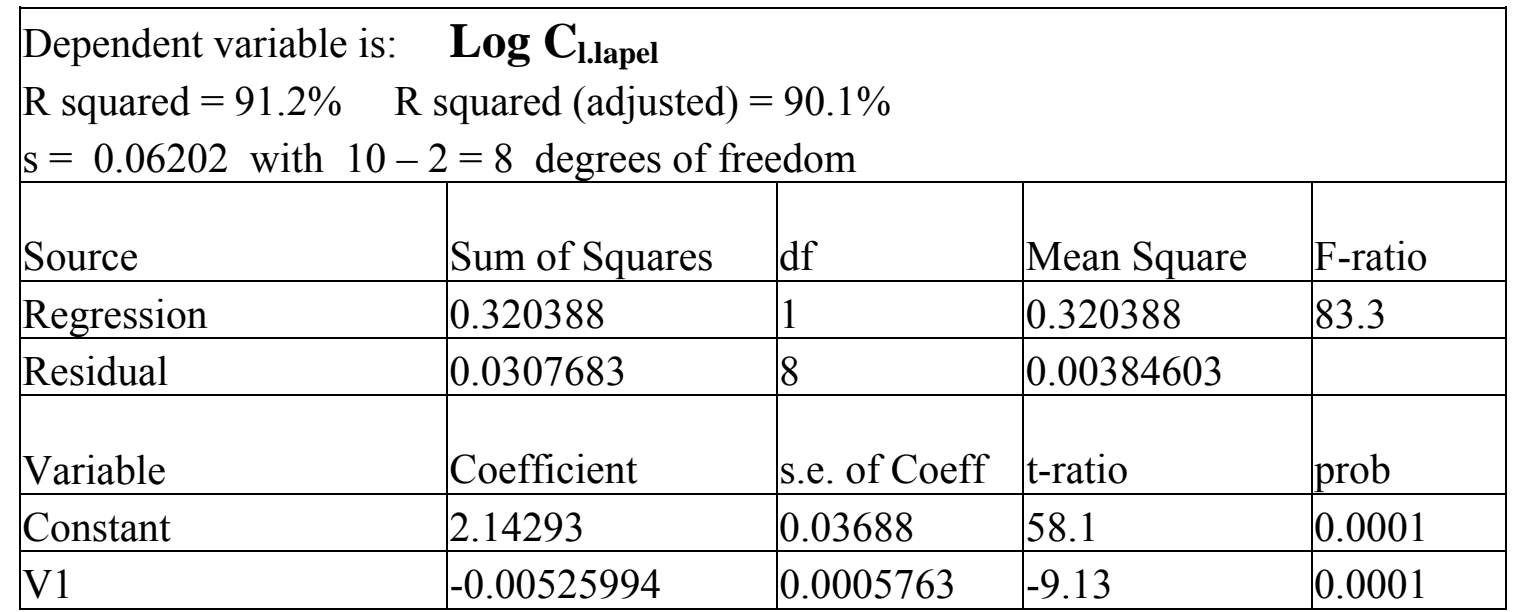


Table B.27: Regression of $\log \mathrm{C}_{\text {r.lapel }}$ with velocity for unheated/standing manikin

\begin{tabular}{|c|c|c|c|c|}
\hline \multicolumn{5}{|c|}{$\begin{array}{l}\text { Dependent variable is: } \quad \log \mathbf{C}_{\text {r.lapel }} \\
\text { R squared }=77.3 \% \quad \text { R squared (adjusted) }=74.5 \% \\
S=0.09473 \text { with } 10-2=8 \text { degrees of freedom }\end{array}$} \\
\hline Source & Sum of Squares & df & Mean Square & F-ratio \\
\hline Regression & 0.244719 & 1 & 0.244719 & 27.3 \\
\hline Residual & 0.0717858 & 8 & 0.00897323 & \\
\hline Variable & Coefficient & s.e. of Coeff & t-ratio & prob \\
\hline Constant & 1.97548 & 0.05634 & 35.1 & 0.0001 \\
\hline V1 & -0.00459702 & 0.0008803 & -5.22 & 0.0008 \\
\hline
\end{tabular}

Table B.28: Regression of $\log \mathrm{C}_{\text {mouth }}$ with velocity for unheated/seated manikin

\begin{tabular}{|l}
$\begin{array}{l}\text { Dependent variable is: } \log \mathbf{C}_{\text {mouth }} \\
\text { R squared }=79.7 \% \quad \text { R squared (adjusted) }=77.2 \% \\
\text { s=0.04667 with } 10-2=8 \text { degrees of freedom }\end{array}$ \\
\begin{tabular}{l|l|l|l|l|} 
Source & Sum of Squares & df & Mean Square & F-ratio \\
\hline Regression & 0.0684879 & 1 & 0.0684879 & 31.4 \\
\hline Residual & 0.0174233 & 8 & 0.00217791 & \\
\hline & & & & \\
Variable & Coefficient & s.e. of Coeff & t-ratio & prob \\
\hline Constant & 1.78534 & 0.02775 & 64.3 & 0.0001 \\
\hline V1 & -0.00243192 & 0.0004337 & -5.61 & 0.0005 \\
\hline
\end{tabular}
\end{tabular}


Table B.29: Regression of $\log \mathrm{C}_{\text {nose }}$ with velocity for unheated/seated manikin

\begin{tabular}{|c|c|c|c|c|}
\hline \multicolumn{5}{|c|}{$\begin{array}{l}\text { Dependent variable is: } \quad \log \mathbf{C}_{\text {nose }} \\
\mathrm{R} \text { squared }=86.1 \% \quad \text { R squared (adjusted) }=84.4 \% \\
\mathrm{~s}=0.03837 \text { with } 10-2=8 \text { degrees of freedom }\end{array}$} \\
\hline Source & Sum of Squares & $\mathrm{df}$ & Mean Square & F-ratio \\
\hline Regression & 0.0731574 & 1 & 0.0731574 & 49.7 \\
\hline Residual & 0.0117799 & 8 & 0.00147248 & \\
\hline Variable & Coefficient & s.e. of Coeff & t-ratio & prob \\
\hline Constant & 1.80071 & 0.02282 & 78.9 & 0.0001 \\
\hline V1 & -0.00251346 & 0.0003566 & -7.05 & 0.0001 \\
\hline
\end{tabular}

Table B.30: Regression of $\log \mathrm{C}_{\text {forehead }}$ with velocity for unheated/seated manikin

\begin{tabular}{|c|c|c|c|c|}
\hline \multicolumn{5}{|c|}{$\begin{array}{l}\text { Dependent variable is: } \quad \log \mathbf{C}_{\text {forehead }} \\
\mathrm{R} \text { squared }=88.9 \% \quad \text { R squared (adjusted) }=87.5 \% \\
\mathrm{~s}=0.03342 \text { with } 10-2=8 \text { degrees of freedom }\end{array}$} \\
\hline Source & Sum of Squares & df & Mean Square & F-ratio \\
\hline Regression & 0.0715594 & 1 & 0.0715594 & 64.1 \\
\hline Residual & 0.00893511 & 8 & 0.00111689 & \\
\hline Variable & Coefficient & s.e. of Coeff & t-ratio & prob \\
\hline Constant & 1.7448 & 0.01988 & 87.8 & 0.0001 \\
\hline V1 & -0.00248586 & 0.0003106 & -8 & 0.0001 \\
\hline
\end{tabular}


Table B.31: Regression of $\log \mathrm{C}_{\text {neck }}$ with velocity for unheated/seated manikin

\begin{tabular}{|c|c|c|c|c|}
\hline \multicolumn{5}{|c|}{$\begin{array}{l}\text { Dependent variable is: } \quad \log \mathbf{C}_{\text {neck }} \\
\mathrm{R} \text { squared }=77.0 \% \quad \mathrm{R} \text { squared (adjusted) }=74.2 \% \\
\mathrm{~s}=0.04931 \text { with } 10-2=8 \text { degrees of freedom }\end{array}$} \\
\hline Source & Sum of Squares & $\mathrm{df}$ & Mean Square & F-ratio \\
\hline Regression & 0.0652639 & 1 & 0.0652639 & 26.8 \\
\hline Residual & 0.0194529 & 8 & 0.00243162 & \\
\hline Variable & Coefficient & s.e. of Coeff & t-ratio & prob \\
\hline Constant & 1.73791 & 0.02933 & 59.3 & 0.0001 \\
\hline V1 & -0.00237399 & 0.0004582 & -5.18 & 0.0008 \\
\hline
\end{tabular}

Table B.32: Regression of $\log \mathrm{C}_{\text {l.collar }}$ with velocity for unheated/seated manikin

\begin{tabular}{|c|c|c|c|c|}
\hline \multicolumn{5}{|c|}{$\begin{array}{l}\text { Dependent variable is: } \quad \log \mathbf{C}_{\mathbf{l} \text {.collar }} \\
\mathrm{R} \text { squared }=73.1 \% \quad \text { R squared (adjusted) }=69.7 \% \\
\mathrm{~s}=0.06395 \text { with } 10-2=8 \text { degrees of freedom }\end{array}$} \\
\hline Source & Sum of Squares & df & Mean Square & F-ratio \\
\hline Regression & 0.0887879 & 1 & 0.0887879 & 21.7 \\
\hline Residual & 0.0327211 & 8 & 0.00409014 & \\
\hline Variable & Coefficient & s.e. of Coeff & t-ratio & prob \\
\hline Constant & 1.75503 & 0.03803 & 46.1 & 0.0001 \\
\hline V1 & -0.00276898 & 0.0005943 & -4.66 & 0.0016 \\
\hline
\end{tabular}


Table B.33: Regression of $\log \mathrm{C}_{\mathrm{r} . \mathrm{collar}}$ with velocity for unheated/seated manikin

\begin{tabular}{|c|c|c|c|c|}
\hline \multicolumn{5}{|c|}{$\begin{array}{l}\text { Dependent variable is: } \quad \log \mathbf{C}_{\text {r.collar }} \\
\mathrm{R} \text { squared }=77.2 \% \quad \mathrm{R} \text { squared (adjusted) }=74.3 \% \\
\mathrm{~S}=0.06216 \text { with } 10-2=8 \text { degrees of freedom }\end{array}$} \\
\hline Source & Sum of Squares & df & Mean Square & F-ratio \\
\hline Regression & 0.104498 & 1 & 0.104498 & 27 \\
\hline Residual & 0.0309157 & 8 & 0.00386446 & \\
\hline Variable & Coefficient & s.e. of Coeff & t-ratio & prob \\
\hline Constant & 1.71447 & 0.03697 & 46.4 & 0.0001 \\
\hline V1 & -0.00300398 & 0.0005777 & -5.2 & 0.0008 \\
\hline
\end{tabular}

Table B.34: Regression of $\log \mathrm{C}_{\text {c.chest }}$ with velocity for unheated/seated manikin

\begin{tabular}{|c|c|c|c|c|}
\hline \multicolumn{5}{|c|}{$\begin{array}{l}\text { Dependent variable is: } \quad \log \mathbf{C}_{\text {c.chest }} \\
\mathrm{R} \text { squared }=48.9 \% \quad \mathrm{R} \text { squared (adjusted) }=42.5 \% \\
\mathrm{~s}=0.1417 \text { with } 10-2=8 \text { degrees of freedom }\end{array}$} \\
\hline Source & Sum of Squares & df & Mean Square & F-ratio \\
\hline Regression & 0.153716 & 1 & 0.153716 & 7.66 \\
\hline Residual & 0.160534 & 8 & 0.0200667 & \\
\hline Variable & Coefficient & s.e. of Coeff & t-ratio & prob \\
\hline Constant & 1.57182 & 0.08424 & 18.7 & 0.0001 \\
\hline V1 & -0.00364336 & 0.001316 & -2.77 & 0.0244 \\
\hline
\end{tabular}


Table B.35: Regression of $\log \mathrm{C}_{1 . \text { lapel }}$ with velocity for unheated/seated manikin

\begin{tabular}{|c|c|c|c|c|}
\hline \multicolumn{5}{|c|}{$\begin{array}{l}\text { Dependent variable is: } \quad \log \mathrm{C}_{\text {l.lapel }} \\
\mathrm{R} \text { squared }=70.8 \% \quad \mathrm{R} \text { squared (adjusted) }=67.2 \% \\
\mathrm{~s}=0.09484 \text { with } 10-2=8 \text { degrees of freedom }\end{array}$} \\
\hline Source & Sum of Squares & df & Mean Square & F-ratio \\
\hline Regression & 0.174647 & 1 & 0.174647 & 19.4 \\
\hline Residual & 0.071953 & 8 & 0.00899413 & \\
\hline Variable & Coefficient & s.e. of Coeff & t-ratio & prob \\
\hline Constant & 1.6652 & 0.0564 & 29.5 & 0.0001 \\
\hline V1 & -0.0038835 & 0.0008813 & -4.41 & 0.0023 \\
\hline
\end{tabular}

Table B.36: Regression of $\log \mathrm{C}_{\text {r.lapel }}$ with velocity for unheated/seated manikin

\begin{tabular}{|c|c|c|c|c|}
\hline \multicolumn{5}{|c|}{$\begin{array}{l}\text { Dependent variable is: } \quad \log \mathbf{C}_{\text {r.lapel }} \\
\mathrm{R} \text { squared }=61.6 \% \quad \mathrm{R} \text { squared (adjusted) }=56.8 \% \\
\mathrm{~s}=0.1041 \text { with } 10-2=8 \text { degrees of freedom }\end{array}$} \\
\hline Source & Sum of Squares & df & Mean Square & F-ratio \\
\hline Regression & 0.139108 & 1 & 0.139108 & 12.8 \\
\hline Residual & 0.0867237 & 8 & 0.0108405 & \\
\hline Variable & Coefficient & s.e. of Coeff & t-ratio & prob \\
\hline Constant & 1.59734 & 0.06192 & 25.8 & 0.0001 \\
\hline V1 & -0.00346592 & 0.0009675 & -3.58 & 0.0072 \\
\hline
\end{tabular}




\section{Appendix C: Normal Probability Plots (STUDY II)}

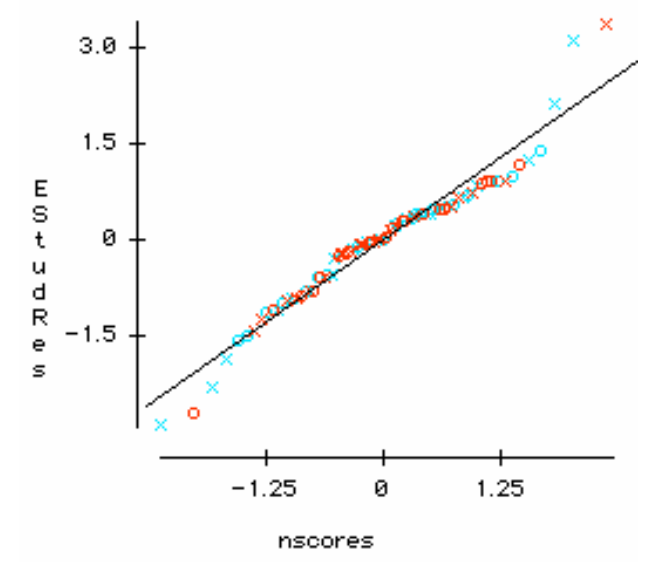

Figure C.1: Normal probability plot of E-StudRes Vs nscores $\log \mathrm{C}_{\text {mouth }}$

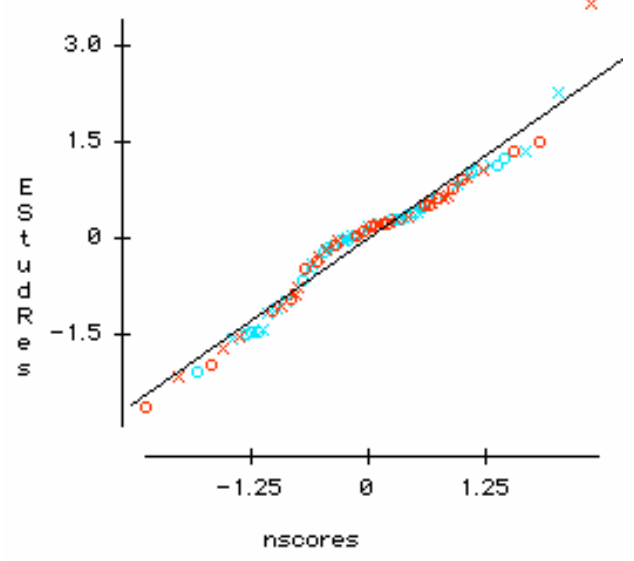

Figure C.2: Normal probability plot of E-StudRes Vs nscores $\log \mathrm{C}_{\text {nose }}$

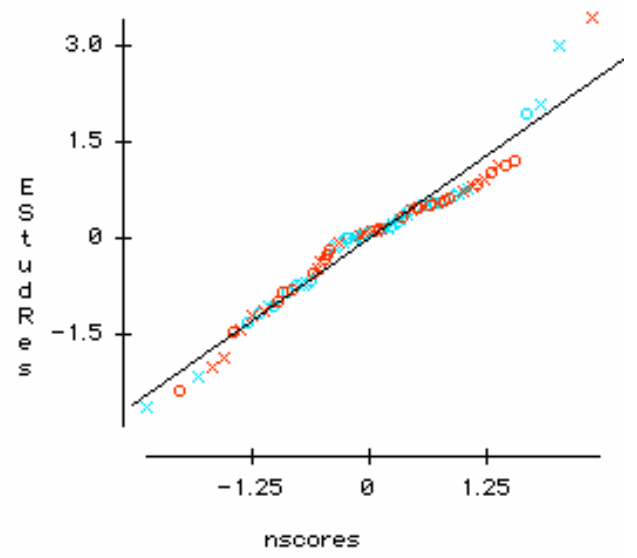

Figure C.3: Normal probability plot of E-StudRes Vs nscores $\log \mathrm{C}_{\text {forehead }}$ 


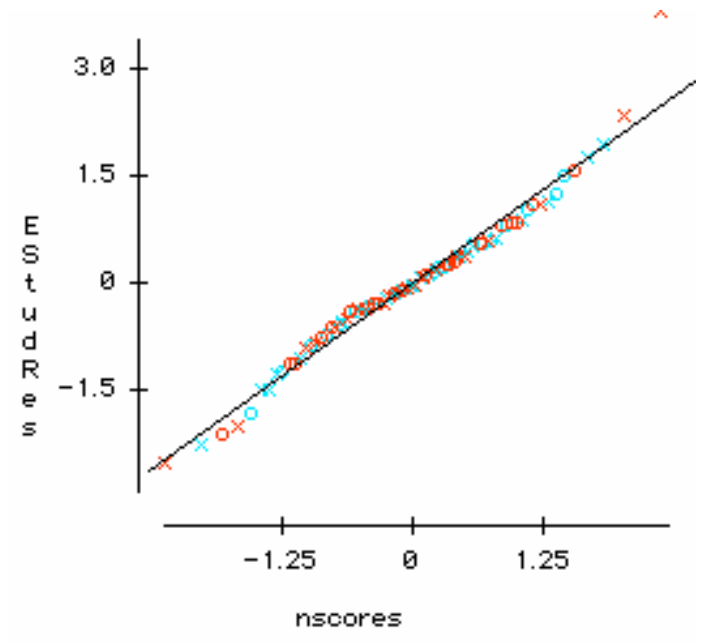

Figure C.4: Normal probability plot of E-StudRes Vs nscores $\log \mathrm{C}_{\text {neck }}$

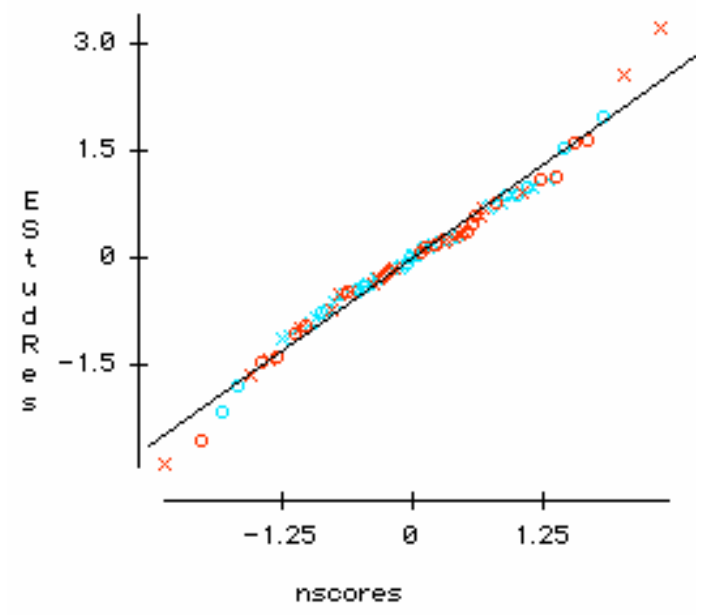

Figure C.5: Normal probability plot of E-StudRes Vs nscores $\log \mathrm{C}_{1 . \text { collar }}$

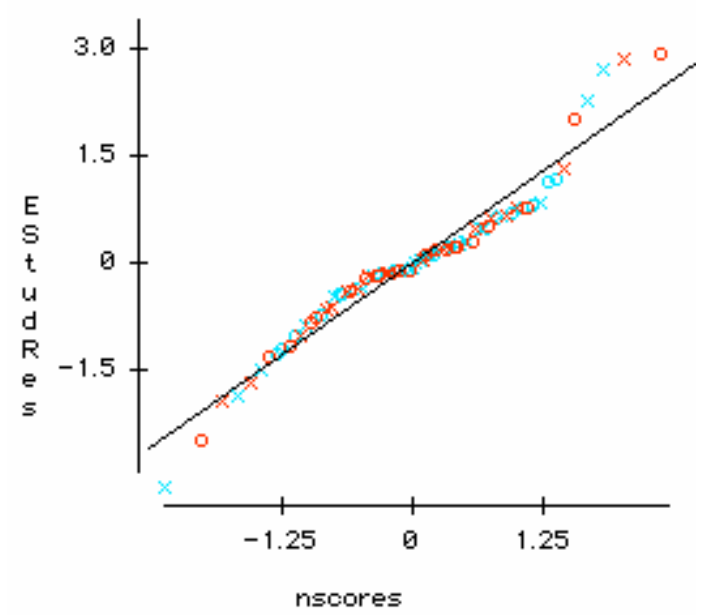

Figure C.6: Normal probability plot of E-StudRes Vs nscores $\log \mathrm{C}_{\mathrm{r} \text {.collar }}$ 


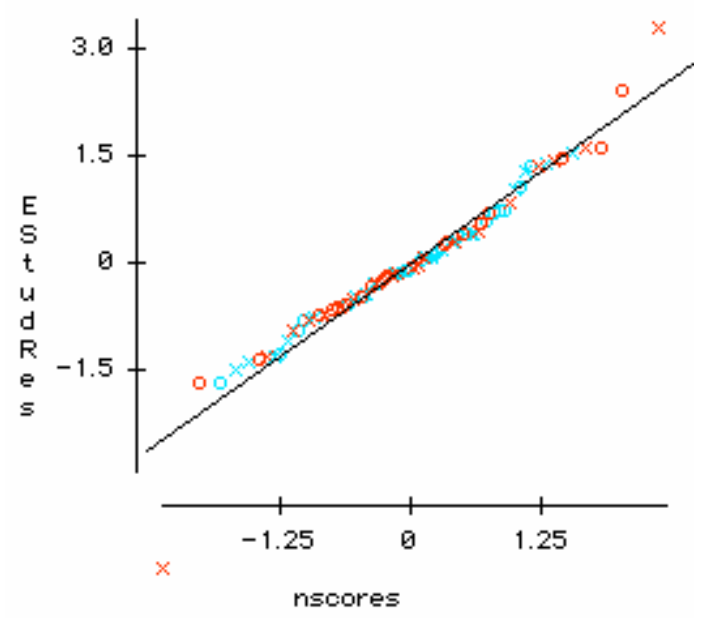

Figure C.7: Normal probability plot of E-StudRes Vs nscores $\log \mathrm{C}_{\text {c.chest }}$

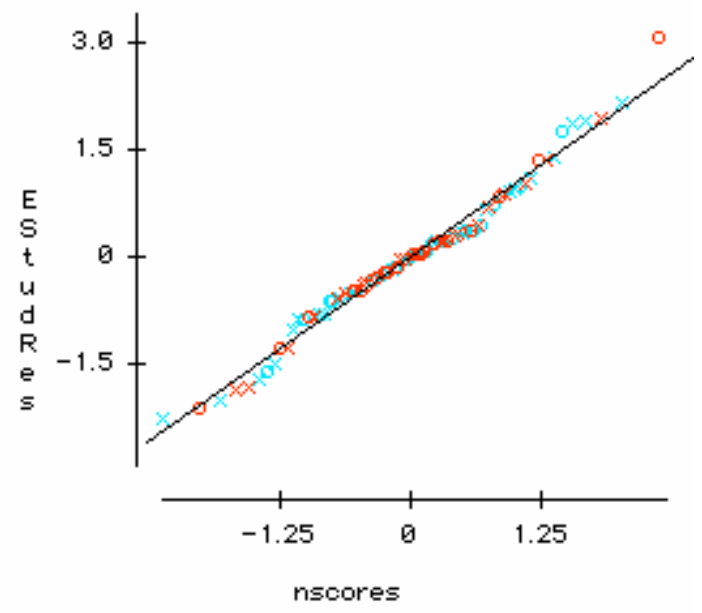

Figure C.8: Normal probability plot of E-StudRes Vs nscores $\log \mathrm{C}_{1 . \text { lapel }}$

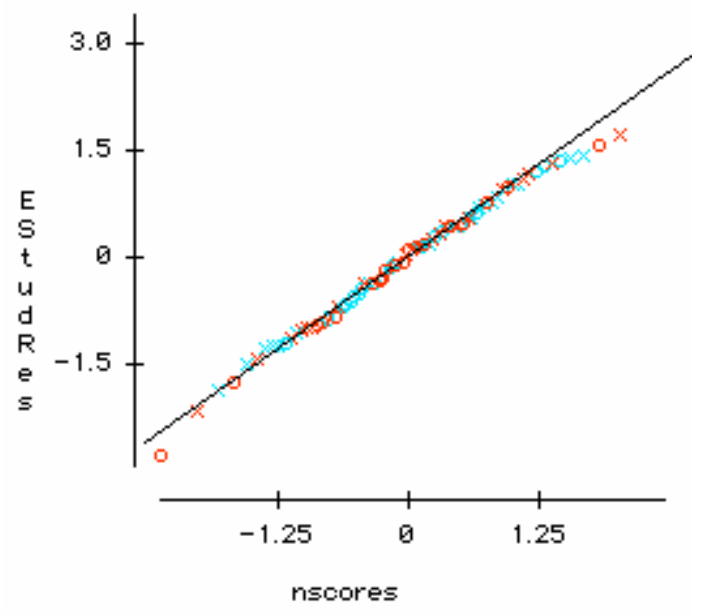

Figure C.9: Normal probability plot of E-StudRes Vs nscores $\log \mathrm{C}_{\text {r.lapel }}$ 


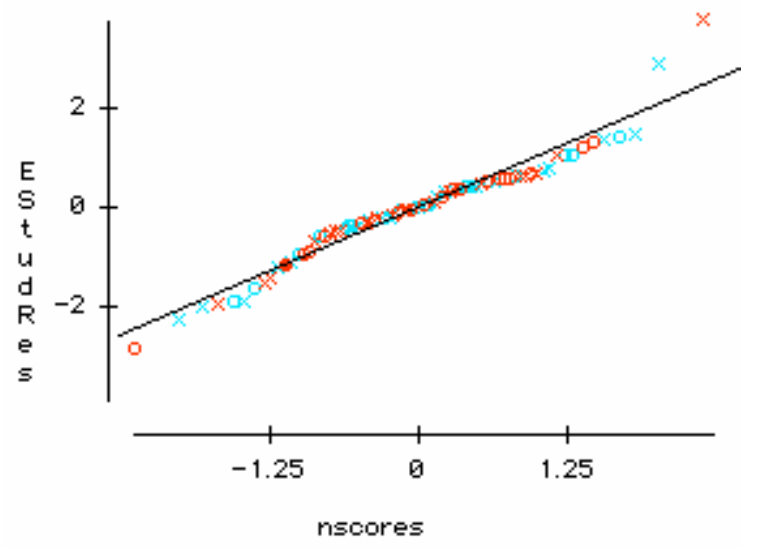

Figure C.10: Normal probability plot of E-StudRes Vs nscores $\log C_{\text {inhaled }}$

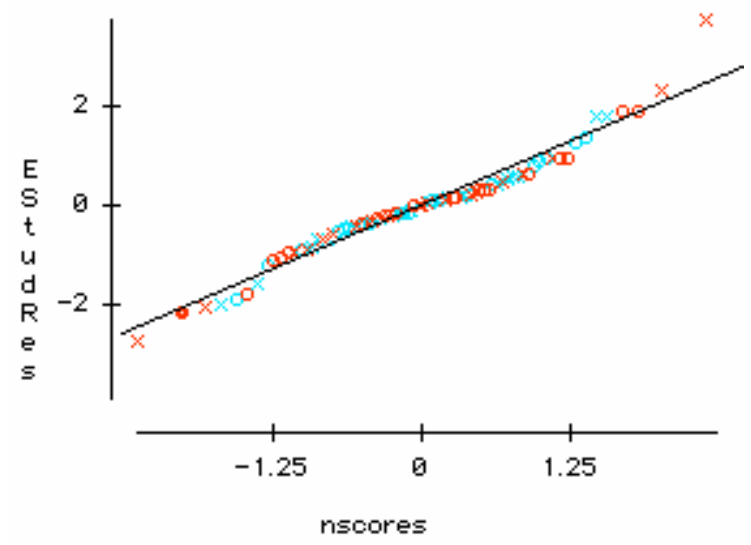

Figure C.11: Normal probability plot of E-StudRes Vs nscores $\log \mathrm{C}_{\text {upper.torso }}$

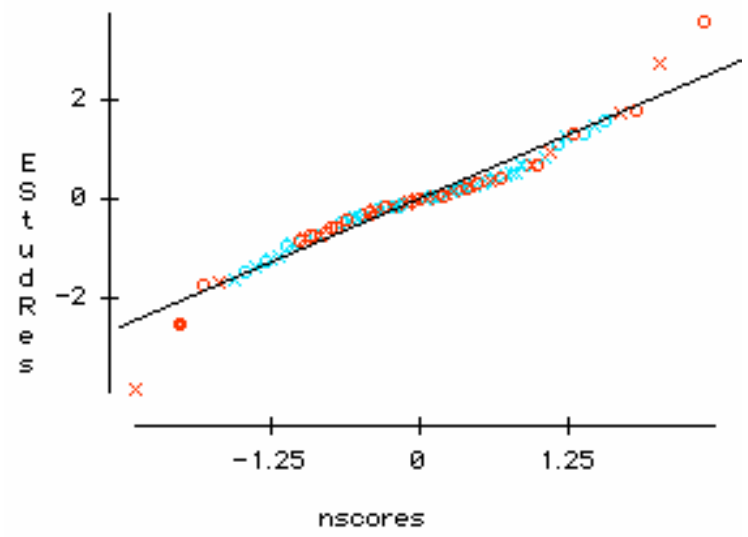

Figure C.12: Normal probability plot of E-StudRes Vs nscores $\log \mathrm{C}_{\text {lower.torso }}$ 


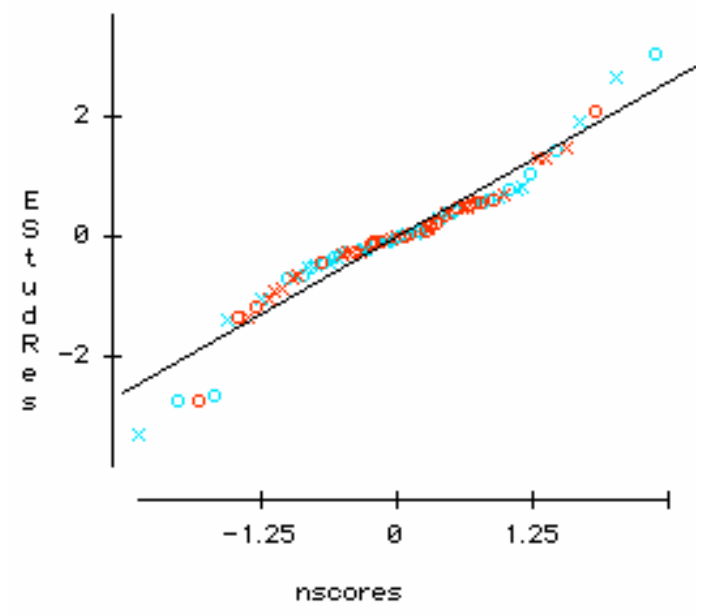

Figure C.13: Normal probability plot of E-StudRes Vs nscores for $\log \left\{\mathrm{C}_{\text {nose }} / \mathrm{C}_{\text {mouth }}\right\}$

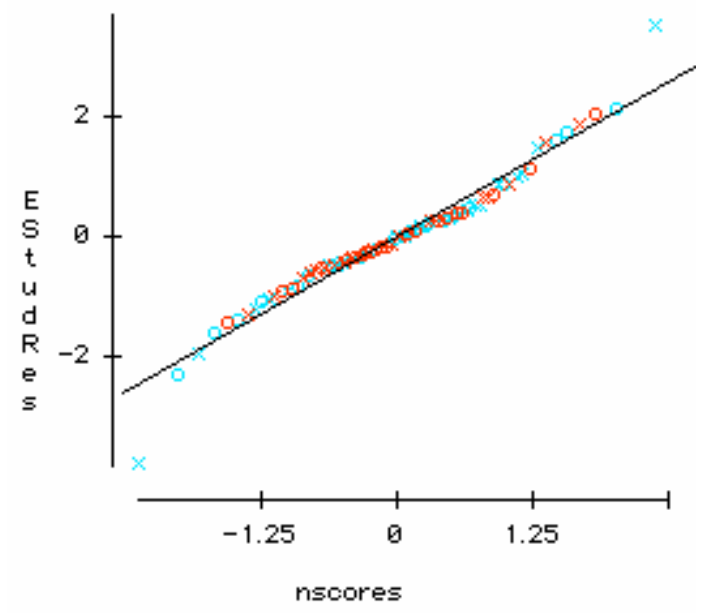

Figure C.14: Normal probability plot of E-StudRes Vs nscores for $\log \left\{\mathrm{C}_{\text {forehead }} / \mathrm{C}_{\text {mouth }}\right\}$ 


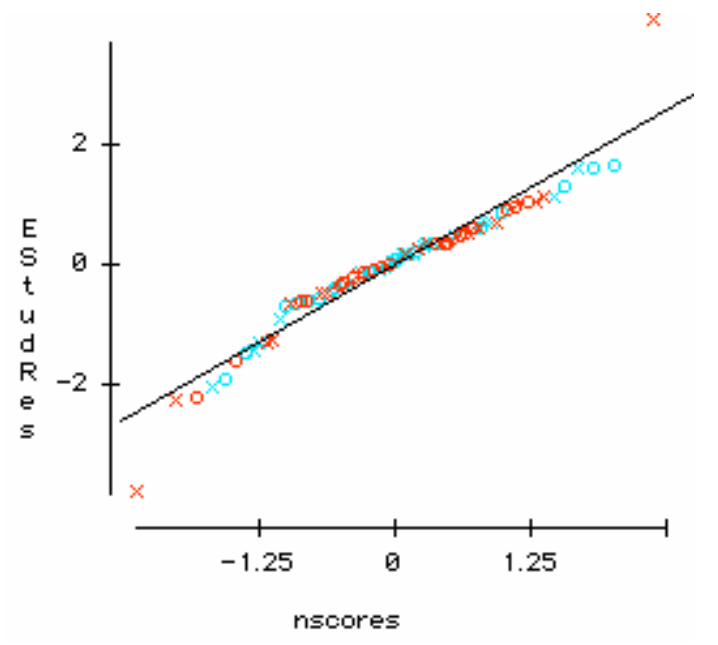

Figure C.15: Normal probability plot of E-StudRes Vs nscores for $\log \left\{\mathrm{C}_{\text {neck }} / \mathrm{C}_{\text {mouth }}\right\}$

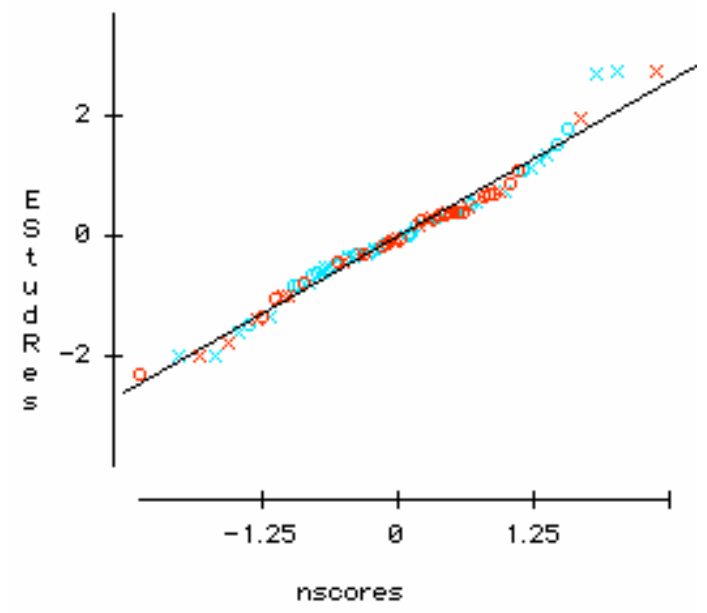

Figure C.16: Normal probability plot of E-StudRes Vs nscores $\log \left\{\mathrm{C}_{\text {l.collar }} / \mathrm{C}_{\text {mouth }}\right\}$

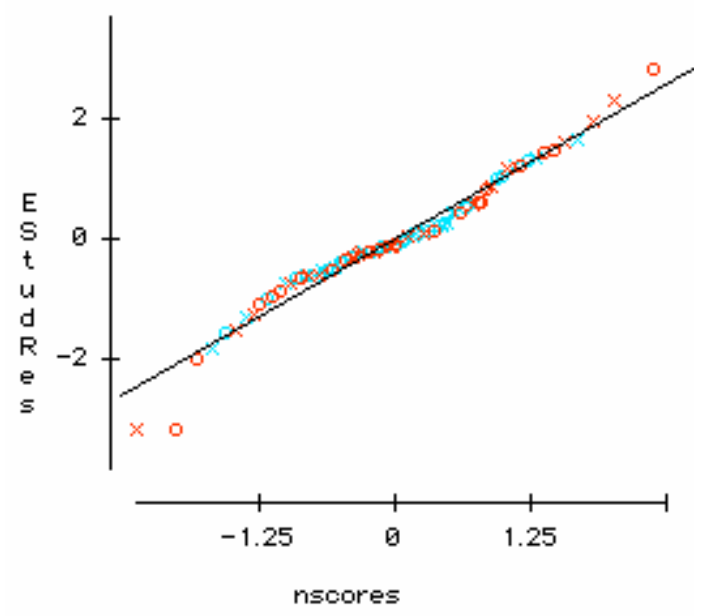

Figure C.17: Normal probability plot of E-StudRes Vs nscores $\log \left\{\mathrm{C}_{\mathrm{r} . \text { collar }} / \mathrm{C}_{\text {mouth }}\right\}$ 


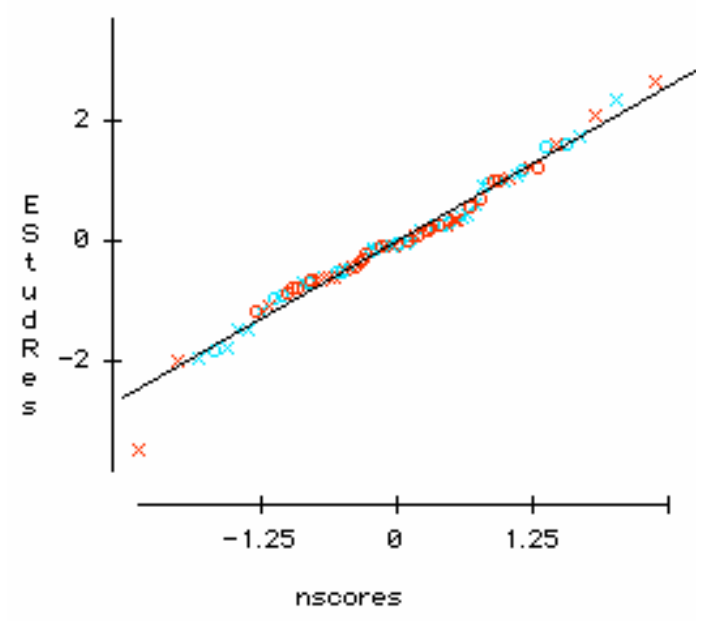

Figure C.18: Normal probability plot of E-StudRes Vs nscores for $\log \left\{\mathrm{C}_{\mathrm{c} . \text { chest }} / \mathrm{C}_{\text {mouth }}\right\}$

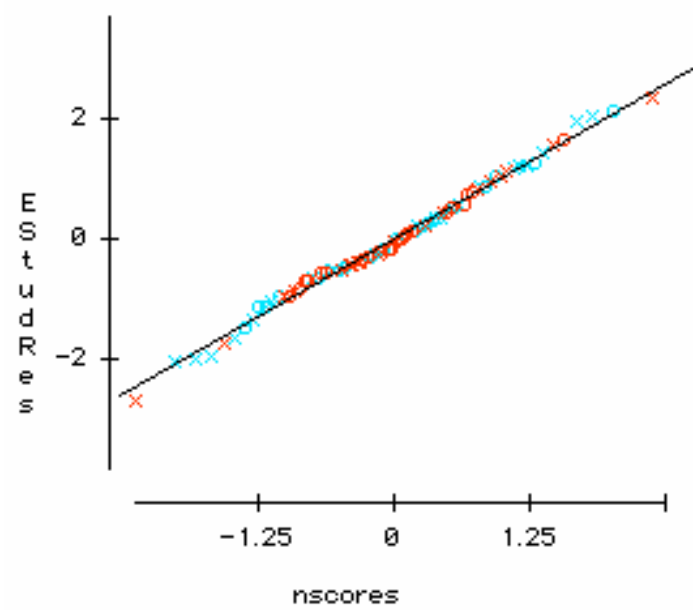

Figure C.19: Normal probability plot of E-StudRes Vs nscores for $\log \left\{\mathrm{C}_{1 . \text { lapel }} / \mathrm{C}_{\text {mouth }}\right\}$

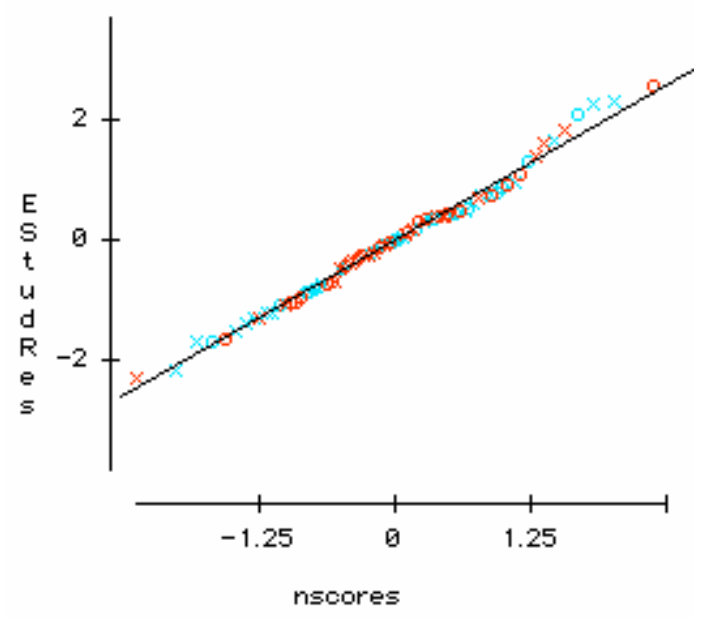

Figure C.20: Normal probability plot of E-StudRes Vs nscores for $\log \left\{\mathrm{C}_{\text {r.lapel }} / \mathrm{C}_{\text {mouth }}\right\}$ 


\section{Appendix D: Regression analysis (Study II)}

Table D.1: Regression of $\log \mathrm{C}_{\text {mouth }}$ with velocity for manikin: seated/breathing/wig

\begin{tabular}{|c|c|c|c|c|}
\hline \multicolumn{5}{|c|}{$\begin{array}{l}\text { R squared }=79.8 \% \quad \text { R squared (adjusted) }=74.0 \% \\
s=0.09913 \text { with } 10-3=7 \text { degrees of freedom }\end{array}$} \\
\hline Source & Sum of Squares & $\mathrm{df}$ & Mean Square & F-ratio \\
\hline Regression & 0.271665 & 2 & 0.135832 & 13.8 \\
\hline Residual & 0.0687872 & 7 & 0.00982674 & \\
\hline Variable & Coefficient & s.e. of Coeff & t-ratio & prob \\
\hline Constant & 0.9260 & 0.0 & 10.60 & 0.0001 \\
\hline Velocity & 0.01302 & 0.0 & 4.90 & 0.0017 \\
\hline $\mathrm{V}(47.5)$ & $-0.0154 \mathrm{C}$ & 0.0 & -3.94 & 0.0056 \\
\hline
\end{tabular}

Table D.2: Regression of $\log \mathrm{C}_{\text {mouth }}$ with velocity for manikin: seated/breathing/nowig

\begin{tabular}{|c|c|c|c|c|}
\hline \multicolumn{5}{|c|}{$\begin{array}{l}R \text { squared }=74.6 \% \quad R \text { squared (adjusted) }=67.3 \% \\
s=0.1104 \text { with } 10-3=7 \text { degrees of freedom }\end{array}$} \\
\hline Source & Sum of Squares & df & Mean Square & F-ratio \\
\hline Regression & 0.250691 & 2 & 0.125346 & 10.3 \\
\hline Residual & 0.0853449 & 7 & 0.0121921 & \\
\hline Variable & Coefficient & s.e. of Coeff & t-ratio & prob \\
\hline Constant & 1.07924 & 0.09743 & 11.1 & 0.0001 \\
\hline Velocity & 0.013384 & 0.002957 & 4.53 & 0.0027 \\
\hline$V(47.5)$ & -0.0189073 & 0.004353 & -4.34 & 0.0034 \\
\hline
\end{tabular}


Table D.3: Regression of $\log \mathrm{C}_{\text {nose }}$ with velocity for manikin: seated/breathing/wig

\begin{tabular}{|c|c|c|c|c|}
\hline \multicolumn{5}{|c|}{$\begin{array}{l}\text { R squared }=84.1 \% \quad \mathrm{R} \text { squared (adjusted) }=79.6 \% \\
\mathrm{~s}=0.1332 \text { with } 10-3=7 \text { degrees of freedom }\end{array}$} \\
\hline Source & Sum of Squares & $\mathrm{df}$ & Mean Square & F-ratio \\
\hline Regression & 0.65864 & 2 & 0.32932 & 18.6 \\
\hline Residual & 0.124123 & 7 & 0.0177318 & \\
\hline Variable & Coefficient & s.e. of Coeff & t-ratio & prob \\
\hline Constant & 0.666865 & 0.1175 & 5.68 & 0.0008 \\
\hline Velocity & 0.0202057 & 0.003567 & 5.67 & 0.0008 \\
\hline $\mathrm{V}(47.5)$ & -0.0238034 & 0.00525 & -4.53 & 0.0027 \\
\hline
\end{tabular}

Table D.4: Regression of $\log \mathrm{C}_{\text {nose }}$ with velocity for manikin: seated/breathing/nowig

\begin{tabular}{|c|c|c|c|c|}
\hline \multicolumn{5}{|c|}{$\begin{array}{l}\mathrm{R} \text { squared }=82.1 \% \quad \mathrm{R} \text { squared (adjusted) }=76.9 \% \\
\mathrm{~s}=0.09686 \text { with } 10-3=7 \text { degrees of freedom }\end{array}$} \\
\hline Source & $\begin{array}{l}\text { Sum of } \\
\text { Squares }\end{array}$ & $\mathrm{df}$ & $\begin{array}{c}\text { Mean } \\
\text { Square }\end{array}$ & F-ratio \\
\hline Regression & 0.300519 & 2 & 0.15026 & 16 \\
\hline Residual & 0.0656669 & 7 & 0.00938099 & \\
\hline Variable & Coefficient & s.e. of Coeff & t-ratio & prob \\
\hline Constant & 1.02156 & 0.08546 & 12 & ${ }^{2} 0.0001$ \\
\hline Velocity & 0.0146232 & 0.002594 & 5.64 & 0.0008 \\
\hline $\mathrm{V}(47.5)$ & -0.0195143 & 0.003819 & -5.11 & 0.0014 \\
\hline
\end{tabular}


Table D.5: Regression of $\log \mathrm{C}_{\text {forehead }}$ with velocity for manikin: seated/breathing/wig

\begin{tabular}{|c|c|c|c|c|}
\hline \multicolumn{5}{|c|}{$\begin{array}{l}\mathrm{R} \text { squared }=85.1 \% \quad \mathrm{R} \text { squared (adjusted) }=80.8 \% \\
\mathrm{~s}=0.1238 \text { with } 10-3=7 \text { degrees of freedom }\end{array}$} \\
\hline Source & Sum of Squares & df & Mean Square & F-ratio \\
\hline Regression & 0.612237 & 2 & 0.306119 & 20 \\
\hline Residual & 0.10727 & 7 & 0.0153243 & \\
\hline Variable & Coefficient & s.e. of Coeff & t-ratio & prob \\
\hline Constant & 0.690685 & 0.1092 & 6.32 & 0.0004 \\
\hline Velocity & 0.0203378 & 0.003316 & 6.13 & 0.0005 \\
\hline$V(47.5)$ & -0.0254958 & 0.004881 & -5.22 & 0.0012 \\
\hline
\end{tabular}

Table D.6: Regression of $\log \mathrm{C}_{\text {forehead }}$ with velocity for manikin: seated/breathing/nowig

\begin{tabular}{|c|c|c|c|c|}
\hline \multicolumn{5}{|c|}{$\begin{array}{l}\text { R squared }=86.7 \% \quad \text { R squared (adjusted) }=82.9 \% \\
s=0.1036 \text { with } 10-3=7 \text { degrees of freedom }\end{array}$} \\
\hline Source & Sum of Squares & df & Mean Square & F-ratio \\
\hline Regression & 0.489343 & 2 & 0.244672 & 22.8 \\
\hline Residual & 0.0751695 & 7 & 0.0107385 & \\
\hline Variable & Coefficient & s.e. of Coeff & t-ratio & prob \\
\hline Constant & 0.796805 & 0.09143 & 8.71 & ${ }^{2} 0.0001$ \\
\hline Velocity & 0.0186788 & 0.002776 & 6.73 & 0.0003 \\
\hline$V(47.5)$ & -0.0250411 & 0.004086 & -6.13 & 0.0005 \\
\hline
\end{tabular}


Table D.7: Regression of $\log \mathrm{C}_{\text {neck }}$ with velocity for manikin: seated/breathing/wig

\begin{tabular}{|c|c|c|c|c|}
\hline \multicolumn{5}{|c|}{$\begin{array}{l}\text { R squared }=76.3 \% \quad \text { R squared (adjusted) }=69.6 \% \\
\mathrm{~s}=0.08393 \text { with } 10-3=7 \text { degrees of freedom }\end{array}$} \\
\hline Source & Sum of Squares & $\mathrm{df}$ & Mean Square & F-ratio \\
\hline Regression & 0.158911 & 2 & 0.0794553 & 11.3 \\
\hline Residual & 0.049306 & 7 & 0.00704372 & \\
\hline Variable & Coefficient & s.e. of Coeff & t-ratio & prob \\
\hline Constant & 0.985173 & 0.07405 & 13.3 & ${ }^{2} 0.0001$ \\
\hline Velocity & 0.00999715 & 0.002248 & 4.45 & 0.003 \\
\hline $\mathrm{V}(47.5)$ & -0.0118875 & 0.003309 & -3.59 & 0.0088 \\
\hline
\end{tabular}

Table D.8: Regression of $\log \mathrm{C}_{\text {neck }}$ with velocity for manikin: seated/breathing/nowig

\begin{tabular}{|c|c|c|c|c|}
\hline \multicolumn{5}{|c|}{$\begin{array}{l}\text { R squared }=66.6 \% \quad \text { R squared (adjusted) }=57.1 \% \\
s=0.09849 \text { with } 10-3=7 \text { degrees of freedom }\end{array}$} \\
\hline Source & Sum of Squares & df & Mean Square & F-ratio \\
\hline Regression & 0.135493 & 2 & 0.0677467 & 6.98 \\
\hline Residual & 0.0679009 & 7 & 0.00970013 & \\
\hline Variable & Coefficient & s.e. of Coeff & t-ratio & prob \\
\hline Constant & 1.14032 & 0.0869 & 13.1 & ${ }^{2} 0.0001$ \\
\hline Velocity & 0.0098536 & 0.002638 & 3.74 & 0.0073 \\
\hline $\mathrm{V}(47.5)$ & -0.0137693 & 0.003883 & -3.55 & 0.0094 \\
\hline
\end{tabular}


Table D.9: Regression of $\log \mathrm{C}_{\text {l.collar }}$ with velocity for manikin: seated/breathing/wig

\begin{tabular}{|c|c|c|c|c|}
\hline \multicolumn{5}{|c|}{$\begin{array}{l}\text { R squared }=88.8 \% \quad \text { R squared (adjusted) }=85.6 \% \\
\mathrm{~s}=0.08478 \text { with } 10-3=7 \text { degrees of freedom }\end{array}$} \\
\hline Source & Sum of Squares & $\mathrm{df}$ & Mean Square & F-ratio \\
\hline Regression & 0.397641 & 2 & 0.19882 & 27.7 \\
\hline Residual & 0.0503148 & 7 & 0.00718783 & \\
\hline Variable & Coefficient & s.e. of Coeff & t-ratio & prob \\
\hline Constant & 0.732032 & 0.07481 & 9.79 & ${ }^{2} 0.0001$ \\
\hline Velocity & 0.0152127 & 0.002271 & 6.7 & 0.0003 \\
\hline $\mathrm{V}(47.5)$ & -0.0172557 & 0.003343 & -5.16 & 0.0013 \\
\hline
\end{tabular}

Table D.10: Regression of $\log \mathrm{C}_{\text {l.collar }}$ with velocity for manikin: seated/breathing/nowig

\begin{tabular}{|c|c|c|c|c|}
\hline \multicolumn{5}{|c|}{$\begin{array}{l}\text { R squared }=88.5 \% \quad \text { R squared (adjusted) }=85.2 \% \\
\mathrm{~s}=0.0489 \text { with } 10-3=7 \text { degrees of freedom }\end{array}$} \\
\hline Source & Sum of Squares & df & Mean Square & F-ratio \\
\hline Regression & 0.128381 & 2 & 0.0641903 & 26.8 \\
\hline Residual & 0.0167373 & 7 & 0.00239104 & \\
\hline Variable & Coefficient & s.e. of Coeff & t-ratio & prob \\
\hline Constant & 1.11973 & 0.04315 & 26 & ${ }^{2} 0.0001$ \\
\hline Velocity & 0.00922976 & 0.00131 & 7.05 & 0.0002 \\
\hline $\mathrm{V}(47.5)$ & -0.0114004 & 0.001928 & -5.91 & 0.0006 \\
\hline
\end{tabular}


Table D.11: Regression of $\log \mathrm{C}_{\text {r.collar }}$ with velocity for manikin: seated/breathing/wig

\begin{tabular}{|c|c|c|c|c|}
\hline \multicolumn{5}{|c|}{$\begin{array}{l}R \text { squared }=66.1 \% \quad R \text { squared (adjusted) }=56.4 \% \\
s=0.07914 \text { with } 10-3=7 \text { degrees of freedom }\end{array}$} \\
\hline Source & Sum of Squares & $\mathrm{df}$ & Mean Square & F-ratio \\
\hline Regression & 0.0855934 & 2 & 0.0427967 & 6.83 \\
\hline Residual & 0.0438443 & 7 & 0.00626347 & \\
\hline Variable & Coefficient & s.e. of Coeff & t-ratio & prob \\
\hline Constant & 1.04503 & 0.06983 & 15 & ${ }^{2} 0.0001$ \\
\hline Velocity & 0.0065308 & 0.00212 & 3.08 & 0.0178 \\
\hline $\mathrm{V}(47.5)$ & -0.00680494 & 0.00312 & -2.18 & 0.0656 \\
\hline
\end{tabular}

Table D.12: Regression of $\log \mathrm{C}_{\mathrm{r} . \text { collar }}$ with velocity for manikin: seated/breathing/nowig

\begin{tabular}{|c|c|c|c|c|}
\hline \multicolumn{5}{|c|}{$\begin{array}{l}R \text { squared }=76.9 \% \quad R \text { squared (adjusted) }=70.3 \% \\
s=0.1069 \text { with } 10-3=7 \text { degrees of freedom }\end{array}$} \\
\hline Source & Sum of Squares & $\mathrm{df}$ & Mean Square & F-ratio \\
\hline Regression & 0.266024 & 2 & 0.133012 & 11.6 \\
\hline Residual & 0.0800506 & 7 & 0.0114358 & \\
\hline Variable & Coefficient & s.e. of Coeff & t-ratio & prob \\
\hline Constant & 0.936705 & 0.09436 & 9.93 & ${ }^{2} 0.0001$ \\
\hline Velocity & 0.0137706 & 0.002864 & 4.81 & 0.0019 \\
\hline $\mathrm{V}(47.5)$ & -0.018451 & 0.004216 & -4.38 & 0.0032 \\
\hline
\end{tabular}


Table D.13: Regression of $\log \mathrm{C}_{\text {c.chest }}$ with velocity for manikin: seated/breathing/wig

\begin{tabular}{|c|c|c|c|c|}
\hline \multicolumn{5}{|c|}{$\begin{array}{l}\mathrm{R} \text { squared }=69.8 \% \quad \mathrm{R} \text { squared (adjusted) }=61.2 \% \\
\mathrm{~s}=0.1087 \text { with } 10-3=7 \text { degrees of freedom }\end{array}$} \\
\hline Source & Sum of Squares & $\mathrm{df}$ & Mean Square & F-ratio \\
\hline Regression & 0.191114 & 2 & 0.0955569 & 8.08 \\
\hline Residual & 0.0827494 & 7 & 0.0118213 & \\
\hline Variable & Coefficient & s.e. of Coeff & t-ratio & prob \\
\hline Constant & 0.859174 & 0.09593 & 8.96 & 0.0001 \\
\hline Velocity & 0.00971092 & 0.002912 & 3.33 & 0.0125 \\
\hline$V(47.5)$ & -0.0167482 & 0.004287 & -3.91 & 0.0058 \\
\hline
\end{tabular}

Table D.14: Regression of $\log \mathrm{C}_{\text {c.chest }}$ with velocity for manikin: seated/breathing/nowig

\begin{tabular}{|c|c|c|c|c|}
\hline \multicolumn{5}{|c|}{$\begin{array}{l}\text { R squared }=62.1 \% \quad \text { R squared (adjusted) }=51.3 \% \\
\mathrm{~s}=0.06443 \text { with } 10-3=7 \text { degrees of freedom }\end{array}$} \\
\hline Source & Sum of Squares & df & Mean Square & F-ratio \\
\hline Regression & 0.0475813 & 2 & 0.0237907 & 5.73 \\
\hline Residual & 0.0290583 & 7 & 0.00415118 & \\
\hline Variable & Coefficient & s.e. of Coeff & t-ratio & prob \\
\hline Constant & 1.05979 & 0.05685 & 18.6 & ${ }^{2} 0.0001$ \\
\hline Velocity & 0.00582321 & 0.001726 & 3.37 & 0.0118 \\
\hline $\mathrm{V}(47.5)$ & -0.00828101 & 0.00254 & -3.26 & 0.0139 \\
\hline
\end{tabular}


Table D.15: Regression of $\log C_{1.1 a p e l}$ with velocity for manikin: seated/breathing/wig

\begin{tabular}{|c|c|c|c|c|}
\hline \multicolumn{5}{|c|}{$\begin{array}{l}\mathrm{R} \text { squared }=56.7 \% \quad \mathrm{R} \text { squared (adjusted) }=44.4 \% \\
\mathrm{~s}=0.1327 \text { with } 10-3=7 \text { degrees of freedom }\end{array}$} \\
\hline Source & Sum of Squares & $\mathrm{df}$ & Mean Square & F-ratio \\
\hline Regression & 0.161585 & 2 & 0.0807925 & 4.59 \\
\hline Residual & 0.123282 & 7 & 0.0176117 & \\
\hline Variable & Coefficient & s.e. of Coeff & t-ratio & prob \\
\hline Constant & 0.736273 & 0.1171 & 6.29 & 0.0004 \\
\hline Velocity & 0.0106708 & 0.003554 & 3 & 0.0199 \\
\hline $\mathrm{V}(47.5)$ & -0.0154635 & 0.005232 & -2.96 & 0.0212 \\
\hline
\end{tabular}

Table D.16: Regression of $\log \mathrm{C}_{1 . \text { lapel }}$ with velocity for manikin: seated/breathing/nowig

\begin{tabular}{|c|c|c|c|c|}
\hline \multicolumn{5}{|c|}{$\begin{aligned} & \mathrm{R} \text { squared }=62.3 \% \quad \mathrm{R} \text { squared (adjusted) }=51.5 \% \\
\mathrm{~s}= & 0.1176 \text { with } 10-3=7 \text { degrees of freedom }\end{aligned}$} \\
\hline Source & Sum of Squares & $\mathrm{df}$ & Mean Square & F-ratio \\
\hline Regression & 0.159863 & 2 & 0.0799313 & 5.78 \\
\hline Residual & 0.09678 & 7 & 0.0138257 & \\
\hline Variable & Coefficient & s.e. of Coeff & t-ratio & prob \\
\hline Constant & 0.890844 & 0.1037 & 8.59 & ${ }^{2} 0.0001$ \\
\hline Velocity & 0.0101553 & 0.003149 & 3.22 & 0.0146 \\
\hline $\mathrm{V}(47.5)$ & -0.0157563 & 0.004636 & -3.4 & 0.0115 \\
\hline
\end{tabular}


Table D.17: Regression of $\log \mathrm{C}_{\mathrm{r} \text {.lapel }}$ with velocity for manikin: seated/breathing/wig

\begin{tabular}{|c|c|c|c|c|}
\hline \multicolumn{5}{|c|}{$\begin{array}{c}\text { R squared }=74.1 \% \quad \text { R squared (adjusted) }=66.7 \% \\
\mathrm{~s}=0.09278 \text { with } 10-3=7 \text { degrees of freedom }\end{array}$} \\
\hline Source & Sum of Squares & df & Mean Square & F-ratio \\
\hline Regression & 0.172508 & 2 & 0.0862542 & 10 \\
\hline Residual & 0.0602606 & 7 & 0.00860866 & \\
\hline Variable & Coefficient & s.e. of Coeff & t-ratio & prob \\
\hline Constant & 0.745296 & 0.08187 & 9.1 & ${ }^{2} 0.0001$ \\
\hline Velocity & 0.0101072 & 0.002485 & 4.07 & 0.0048 \\
\hline $\mathrm{V}(47.5)$ & -0.0163276 & 0.003658 & -4.46 & 0.0029 \\
\hline
\end{tabular}

Table D.18: Regression of $\log \mathrm{C}_{\text {r.lapel }}$ with velocity for manikin: seated/breathing/nowig

\begin{tabular}{|c|c|c|c|c|}
\hline \multicolumn{5}{|c|}{$\begin{array}{l}\text { R squared }=66.6 \% \quad \text { R squared (adjusted) }=57.0 \% \\
s=0.09068 \text { with } 10-3=7 \text { degrees of freedom }\end{array}$} \\
\hline Source & Sum of Squares & $\mathrm{df}$ & Mean Square & F-ratio \\
\hline Regression & 0.114644 & 2 & 0.0573222 & 6.97 \\
\hline Residual & 0.0575584 & 7 & 0.00822263 & \\
\hline Variable & Coefficient & s.e. of Coeff & t-ratio & prob \\
\hline Constant & 0.920569 & 0.08001 & 11.5 & ${ }^{2} 0.0001$ \\
\hline Velocity & 0.00902303 & 0.002429 & 3.72 & 0.0075 \\
\hline $\mathrm{V}(47.5)$ & -0.0129217 & 0.003575 & -3.61 & 0.0086 \\
\hline
\end{tabular}


Table D.19: Regression of $\log \mathrm{C}_{\text {mouth }}$ with velocity for manikin: standing/breathing/wig

\begin{tabular}{|c|c|c|c|c|}
\hline \multicolumn{5}{|c|}{$\begin{array}{l}\text { R squared }=76.0 \% \quad \text { R squared (adjusted) }=69.2 \% \\
\mathrm{~s}=0.07753 \text { with } 10-3=7 \text { degrees of freedom }\end{array}$} \\
\hline Source & Sum of Squares & $\mathrm{df}$ & Mean Square & F-ratio \\
\hline Regression & 0.13344 & 2 & 0.0667198 & 11.1 \\
\hline Residual & 0.0420772 & 7 & 0.00601103 & \\
\hline Variable & Coefficient & s.e. of Coeff & t-ratio & prob \\
\hline Constant & 1.01025 & 0.09897 & 10.2 & ${ }^{2} 0.0001$ \\
\hline Velocity & 0.0193454 & 0.004439 & 4.36 & 0.0033 \\
\hline $\mathrm{V}(27.2)$ & -0.0227952 & 0.004966 & -4.59 & 0.0025 \\
\hline
\end{tabular}

Table D.20: Regression of $\log \mathrm{C}_{\text {mouth }}$ with velocity for manikin: standing/breathing/nowig

\begin{tabular}{|c|c|c|c|c|}
\hline \multicolumn{5}{|c|}{$\begin{array}{l}\text { R squared }=95.6 \% \quad \text { R squared (adjusted) }=94.4 \% \\
\mathrm{~s}=0.02827 \text { with } 10-3=7 \text { degrees of freedom }\end{array}$} \\
\hline Source & Sum of Squares & $\mathrm{df}$ & Mean Square & F-ratio \\
\hline Regression & 0.122243 & 2 & 0.0611214 & 76.5 \\
\hline Residual & 0.00559296 & 7 & 0.000798994 & \\
\hline Variable & Coefficient & s.e. of Coeff & t-ratio & prob \\
\hline Constant & 1.08565 & 0.03608 & 30.1 & ${ }^{2} 0.0001$ \\
\hline Velocity & 0.0196304 & 0.001619 & 12.1 & ${ }^{2} 0.0001$ \\
\hline $\mathrm{V}(27.2)$ & -0.0223795 & 0.00181 & -12.4 & ${ }^{2} 0.0001$ \\
\hline
\end{tabular}


Table D.21: Regression of $\log \mathrm{C}_{\text {nose }}$ with velocity for manikin: standing/breathing/wig

\begin{tabular}{|c|c|c|c|c|}
\hline \multicolumn{5}{|c|}{$\begin{array}{l}\text { R squared }=64.0 \% \quad \text { R squared (adjusted) }=53.7 \% \\
\mathrm{~s}=0.08102 \text { with } 10-3=7 \text { degrees of freedom }\end{array}$} \\
\hline Source & Sum of Squares & df & Mean Square & F-ratio \\
\hline Regression & 0.0816907 & 2 & 0.0408453 & 6.22 \\
\hline Residual & 0.0459542 & 7 & 0.00656488 & \\
\hline Variable & Coefficient & s.e. of Coeff & t-ratio & prob \\
\hline Constant & 1.12297 & 0.1034 & 10.9 & ${ }^{2} 0.0001$ \\
\hline Velocity & 0.0159921 & 0.00464 & 3.45 & 0.0107 \\
\hline $\mathrm{V}(27.2)$ & -0.0170188 & 0.005189 & -3.28 & 0.0135 \\
\hline
\end{tabular}

Table D.22: Regression of $\log \mathrm{C}_{\text {nose }}$ with velocity for manikin: standing/breathing/nowig

\begin{tabular}{|c|c|c|c|c|}
\hline \multicolumn{5}{|c|}{$\begin{array}{l}\text { R squared }=95.1 \% \quad \text { R squared (adjusted) }=93.7 \% \\
\mathrm{~s}=0.02852 \text { with } 10-3=7 \text { degrees of freedom }\end{array}$} \\
\hline Source & Sum of Squares & df & Mean Square & F-ratio \\
\hline Regression & 0.109796 & 2 & 0.054898 & 67.5 \\
\hline Residual & 0.00569248 & 7 & 0.000813211 & \\
\hline Variable & Coefficient & s.e. of Coeff & t-ratio & prob \\
\hline Constant & 1.11808 & 0.0364 & 30.7 & ${ }^{2} 0.0001$ \\
\hline Velocity & 0.0188499 & 0.001633 & 11.5 & ${ }^{2} 0.0001$ \\
\hline $\mathrm{V}(27.2)$ & -0.0211971 & 0.001826 & -11.6 & ${ }^{2} 0.0001$ \\
\hline
\end{tabular}


Table D.23: Regression of $\log \mathrm{C}_{\text {forehead }}$ with velocity for manikin: standing/breathing/wig

\begin{tabular}{|c|c|c|c|c|}
\hline \multicolumn{5}{|c|}{$\begin{array}{l}\mathrm{R} \text { squared }=62.2 \% \quad \mathrm{R} \text { squared (adjusted) }=51.4 \% \\
\mathrm{~s}=0.0798 \text { with } 10-3=7 \text { degrees of freedom }\end{array}$} \\
\hline Source & Sum of Squares & df & Mean Square & F-ratio \\
\hline Regression & 0.0732558 & 2 & 0.0366279 & 5.75 \\
\hline Residual & 0.0445718 & 7 & 0.0063674 & \\
\hline Variable & Coefficient & s.e. of Coeff & t-ratio & prob \\
\hline Constant & 1.05046 & 0.1019 & 10.3 & ${ }^{2} 0.0001$ \\
\hline Velocity & 0.0154738 & 0.004569 & 3.39 & 0.0117 \\
\hline $\mathrm{V}(27.2)$ & -0.0169205 & 0.005111 & -3.31 & 0.0129 \\
\hline
\end{tabular}

Table D.24: Regression of $\log \mathrm{C}_{\text {forehead }}$ with velocity for manikin: standing/breathing/nowig

\begin{tabular}{|c|c|c|c|c|}
\hline \multicolumn{5}{|c|}{$\begin{array}{l}\text { R squared }=92.0 \% \quad \text { R squared (adjusted) }=89.7 \% \\
\mathrm{~s}=0.03506 \text { with } 10-3=7 \text { degrees of freedom }\end{array}$} \\
\hline Source & Sum of Squares & $\mathrm{df}$ & Mean Square & F-ratio \\
\hline Regression & 0.0985265 & 2 & 0.0492632 & 40.1 \\
\hline Residual & 0.00860322 & 7 & 0.00122903 & \\
\hline Variable & Coefficient & s.e. of Coeff & t-ratio & prob \\
\hline Constant & 1.06735 & 0.04475 & 23.9 & ${ }^{2} 0.0001$ \\
\hline Velocity & 0.01797 & 0.002007 & 8.95 & ${ }^{2} 0.0001$ \\
\hline $\mathrm{V}(27.2)$ & -0.0198989 & 0.002245 & -8.86 & ${ }^{2} 0.0001$ \\
\hline
\end{tabular}


Table D.25: Regression of $\log \mathrm{C}_{\text {neck }}$ with velocity for manikin: standing/breathing/wig

\begin{tabular}{|c|c|c|c|c|}
\hline \multicolumn{5}{|c|}{$\begin{array}{l}\mathrm{R} \text { squared }=29.4 \% \quad \mathrm{R} \text { squared (adjusted) }=9.2 \% \\
\mathrm{~s}=0.1152 \text { with } 10-3=7 \text { degrees of freedom }\end{array}$} \\
\hline Source & Sum of Squares & $\mathrm{df}$ & Mean Square & F-ratio \\
\hline Regression & 0.0386641 & 2 & 0.0193321 & 1.46 \\
\hline Residual & 0.092845 & 7 & 0.0132636 & \\
\hline Variable & Coefficient & s.e. of Coeff & t-ratio & prob \\
\hline Constant & 1.3348 & 0.147 & 9.08 & ${ }^{2} 0.0001$ \\
\hline Velocity & 0.00758424 & 0.006595 & 1.15 & 0.2879 \\
\hline $\mathrm{V}(27.2)$ & -0.00988118 & 0.007376 & -1.34 & 0.2222 \\
\hline
\end{tabular}

Table D.26: Regression of $\log \mathrm{C}_{\text {neck }}$ with velocity for manikin: standing/breathing/nowig

\begin{tabular}{|c|c|c|c|c|}
\hline \multicolumn{5}{|c|}{$\begin{array}{l}\mathrm{R} \text { squared }=86.3 \% \quad \mathrm{R} \text { squared (adjusted) }=82.4 \% \\
\mathrm{~s}=0.05174 \text { with } 10-3=7 \text { degrees of freedom }\end{array}$} \\
\hline Source & Sum of Squares & $\mathrm{df}$ & Mean Square & F-ratio \\
\hline Regression & 0.118534 & 2 & 0.0592671 & 22.1 \\
\hline Residual & 0.0187407 & 7 & 0.00267724 & \\
\hline Variable & Coefficient & s.e. of Coeff & t-ratio & prob \\
\hline Constant & 1.33979 & 0.04565 & 29.3 & ${ }^{2} 0.0001$ \\
\hline Velocity & 0.00785745 & 0.001386 & 5.67 & 0.0008 \\
\hline $\mathrm{V}(47.5)$ & -0.013313 & 0.00204 & -6.53 & 0.0003 \\
\hline
\end{tabular}


Table D.27: Regression of $\log \mathrm{C}_{\text {l.collar }}$ with velocity for manikin: standing/breathing/wig

\begin{tabular}{|c|c|c|c|c|}
\hline \multicolumn{5}{|c|}{$\begin{array}{l}\text { R squared }=35.8 \% \quad \mathrm{R} \text { squared (adjusted) }=17.5 \% \\
\mathrm{~s}=0.1065 \text { with } 10-3=7 \text { degrees of freedom }\end{array}$} \\
\hline Source & Sum of Squares & $\mathrm{df}$ & Mean Square & F-ratio \\
\hline Regression & 0.0442633 & 2 & 0.0221317 & 1.95 \\
\hline Residual & 0.0793286 & 7 & 0.0113327 & \\
\hline Variable & Coefficient & s.e. of Coeff & t-ratio & prob \\
\hline Constant & 1.16861 & 0.1359 & 8.6 & ${ }^{2} 0.0001$ \\
\hline Velocity & 0.0100901 & 0.006096 & 1.66 & 0.1418 \\
\hline $\mathrm{V}(27.2)$ & -0.0123311 & 0.006818 & -1.81 & 0.1135 \\
\hline
\end{tabular}

Table D.28: Regression of $\log \mathrm{C}_{\text {l.collar }}$ with velocity for manikin: standing/breathing/nowig

\begin{tabular}{|c|c|c|c|c|}
\hline \multicolumn{5}{|c|}{$\begin{array}{l}\text { R squared }=80.7 \% \quad \text { R squared (adjusted) }=75.2 \% \\
\mathrm{~s}=0.04657 \text { with } 10-3=7 \text { degrees of freedom }\end{array}$} \\
\hline Source & Sum of Squares & $\mathrm{df}$ & Mean Square & F-ratio \\
\hline Regression & 0.0634214 & 2 & 0.0317107 & 14.6 \\
\hline Residual & 0.0151826 & 7 & 0.00216894 & \\
\hline Variable & Coefficient & s.e. of Coeff & t-ratio & prob \\
\hline Constant & 1.34821 & 0.04109 & 32.8 & ${ }^{2} 0.0001$ \\
\hline Velocity & 0.00632308 & 0.001247 & 5.07 & 0.0014 \\
\hline $\mathrm{V}(47.5)$ & -0.00992914 & 0.001836 & -5.41 & 0.001 \\
\hline
\end{tabular}


Table D.29: Regression of $\log \mathrm{C}_{\text {r.collar }}$ with velocity for manikin: standing/breathing/wig

\begin{tabular}{|c|c|c|c|c|}
\hline \multicolumn{5}{|c|}{$\begin{array}{c}\text { R squared }=52.7 \% \quad \text { R squared (adjusted) }=39.1 \\
\mathrm{~s}=0.0955 \text { with } 10-3=7 \text { degrees of freedom }\end{array}$} \\
\hline Source & Sum of Squares & $\mathrm{df}$ & Mean Square & F-ratio \\
\hline Regression & 0.0710298 & 2 & 0.0355149 & 3.89 \\
\hline Residual & 0.0638364 & 7 & 0.00911948 & \\
\hline Variable & Coefficient & s.e. of Coeff & t-ratio & prob \\
\hline Constant & 0.912152 & 0.1219 & 7.48 & 0.0001 \\
\hline Velocity & 0.0148519 & 0.005468 & 2.72 & 0.0299 \\
\hline $\mathrm{V}(27.2)$ & -0.0170288 & 0.006116 & -2.78 & 0.0271 \\
\hline
\end{tabular}

Table D.30: Regression of $\log \mathrm{C}_{\mathrm{r} . c o l l a r}$ with velocity for manikin: standing/breathing/nowig

\begin{tabular}{|c|c|c|c|c|}
\hline \multicolumn{5}{|c|}{$\begin{array}{l}\mathrm{R} \text { squared }=94.1 \% \quad \mathrm{R} \text { squared (adjusted) }=92.4 \% \\
\mathrm{~s}=0.03569 \text { with } 10-3=7 \text { degrees of freedom }\end{array}$} \\
\hline Source & Sum of Squares & $\mathrm{df}$ & Mean Square & F-ratio \\
\hline Regression & 0.142454 & 2 & 0.0712268 & 55.9 \\
\hline Residual & 0.00891509 & 7 & 0.00127358 & \\
\hline Variable & Coefficient & s.e. of Coeff & t-ratio & prob \\
\hline Constant & 1.15477 & 0.03149 & 36.7 & ${ }^{2} 0.0001$ \\
\hline Velocity & 0.00975459 & 0.0009558 & 10.2 & ${ }^{2} 0.0001$ \\
\hline $\mathrm{V}(47.5)$ & -0.0148224 & 0.001407 & -10.5 & ${ }^{2} 0.0001$ \\
\hline
\end{tabular}


Table D.31: Regression of $\log \mathrm{C}_{\mathrm{c} . \text { chest }}$ with velocity for manikin: standing/breathing/wig

\begin{tabular}{|c|c|c|c|c|}
\hline \multicolumn{5}{|c|}{$\begin{array}{c}\text { R squared }=22.8 \% \quad \mathrm{R} \text { squared (adjusted) }=0.8 \% \\
\mathrm{~s}=0.1363 \text { with } 10-3=7 \text { degrees of freedom }\end{array}$} \\
\hline Source & Sum of Squares & $\mathrm{df}$ & Mean Square & F-ratio \\
\hline Regression & 0.03848 & 2 & 0.01924 & 1.04 \\
\hline Residual & 0.13009 & 7 & 0.0185843 & \\
\hline Variable & Coefficient & s.e. of Coeff & t-ratio & prob \\
\hline Constant & 1.32194 & 0.1203 & 11 & ${ }^{2} 0.0001$ \\
\hline Velocity & 0.00513472 & 0.003651 & 1.41 & 0.2024 \\
\hline $\mathrm{V}(47.5)$ & -0.00652061 & 0.005375 & -1.21 & 0.2644 \\
\hline
\end{tabular}

Table D.32: Regression of $\log \mathrm{C}_{\mathrm{c} . \text { chest }}$ with velocity for manikin: standing/breathing/nowig

\begin{tabular}{|c|c|c|c|c|}
\hline \multicolumn{5}{|c|}{$\begin{array}{l}\text { R squared }=75.0 \% \quad \text { R squared (adjusted) }=67.9 \% \\
\mathrm{~s}=0.08963 \text { with } 10-3=7 \text { degrees of freedom }\end{array}$} \\
\hline Source & Sum of Squares & df & Mean Square & F-ratio \\
\hline Regression & 0.168904 & 2 & 0.0844522 & 10.5 \\
\hline Residual & 0.0562377 & 7 & 0.00803396 & \\
\hline Variable & Coefficient & s.e. of Coeff & t-ratio & prob \\
\hline Constant & 1.24121 & 0.07909 & 15.7 & ${ }^{2} 0.0001$ \\
\hline Velocity & 0.0108483 & 0.002401 & 4.52 & 0.0027 \\
\hline $\mathrm{V}(47.5)$ & -0.0159301 & 0.003534 & -4.51 & 0.0028 \\
\hline
\end{tabular}


Table D.33: Regression of $\log \mathrm{C}_{1 . \text { lapel }}$ with velocity for manikin: standing/breathing/wig

\begin{tabular}{|c|c|c|c|c|}
\hline \multicolumn{5}{|c|}{$\begin{array}{l}\text { R squared }=78.2 \% \quad R \text { squared (adjusted) }=71.9 \% \\
\mathrm{~s}=0.08843 \text { with } 10-3=7 \text { degrees of freedom }\end{array}$} \\
\hline Source & Sum of Squares & $\mathrm{df}$ & Mean Square & F-ratio \\
\hline Regression & 0.196017 & 2 & 0.0980087 & 12.5 \\
\hline Residual & 0.0547423 & 7 & 0.00782033 & \\
\hline Variable & Coefficient & s.e. of Coeff & t-ratio & prob \\
\hline Constant & 0.812384 & 0.07803 & 10.4 & ${ }^{2} 0.0001$ \\
\hline Velocity & 0.011341 & 0.002369 & 4.79 & 0.002 \\
\hline $\mathrm{V}(47.5)$ & -0.0138885 & 0.003487 & -3.98 & 0.0053 \\
\hline
\end{tabular}

Table D.34: Regression of $\log C_{1 . l a p e l}$ with velocity for manikin: standing/breathing/nowig

\begin{tabular}{|c|c|c|c|c|}
\hline \multicolumn{5}{|c|}{$\begin{array}{l}R \text { squared }=81.9 \% \quad R \text { squared (adjusted) }=76.7 \% \\
s=0.08923 \text { with } 10-3=7 \text { degrees of freedom }\end{array}$} \\
\hline Source & Sum of Squares & $\mathrm{df}$ & Mean Square & F-ratio \\
\hline Regression & 0.251594 & 2 & 0.125797 & 15.8 \\
\hline Residual & 0.0557322 & 7 & 0.00796174 & \\
\hline Variable & Coefficient & s.e. of Coeff & t-ratio & prob \\
\hline Constant & 0.923621 & 0.07873 & 11.7 & ${ }^{2} 0.0001$ \\
\hline Velocity & 0.0130832 & 0.00239 & 5.47 & 0.0009 \\
\hline $\mathrm{V}(47.5)$ & -0.016504 & 0.003518 & -4.69 & 0.0022 \\
\hline
\end{tabular}


Table D.35: Regression of $\log \mathrm{C}_{\text {r.lapel }}$ with velocity for manikin: standing/breathing/wig

\begin{tabular}{|c|c|c|c|c|}
\hline \multicolumn{5}{|c|}{$\begin{array}{l}\mathrm{R} \text { squared }=54.7 \% \quad \mathrm{R} \text { squared (adjusted) }=41.8 \% \\
\mathrm{~s}=0.1138 \text { with } 10-3=7 \text { degrees of freedom }\end{array}$} \\
\hline Source & Sum of Squares & df & Mean Square & F-ratio \\
\hline Regression & 0.109606 & 2 & 0.054803 & 4.23 \\
\hline Residual & 0.0906277 & 7 & 0.0129468 & \\
\hline Variable & Coefficient & s.e. of Coeff & t-ratio & prob \\
\hline Constant & 0.951848 & 0.1004 & 9.48 & ${ }^{2} 0.0001$ \\
\hline Velocity & 0.00886592 & 0.003048 & 2.91 & 0.0227 \\
\hline $\mathrm{V}(47.5)$ & -0.0123175 & 0.004486 & -2.75 & 0.0287 \\
\hline
\end{tabular}

Table D.36: Regression of $\log \mathrm{C}_{\mathrm{r} \text {.lapel }}$ with velocity for manikin: standing/breathing/nowig

\begin{tabular}{|c|c|c|c|c|}
\hline \multicolumn{5}{|c|}{$\begin{array}{l}\text { R squared }=83.8 \% \quad \text { R squared (adjusted) }=79.2 \% \\
\mathrm{~s}=0.08658 \text { with } 10-3=7 \text { degrees of freedom }\end{array}$} \\
\hline Source & Sum of Squares & $\mathrm{df}$ & Mean Square & F-ratio \\
\hline Regression & 0.27211 & 2 & 0.136055 & 18.2 \\
\hline Residual & 0.0524689 & 7 & 0.00749556 & \\
\hline Variable & Coefficient & s.e. of Coeff & t-ratio & prob \\
\hline Constant & 1.02039 & 0.07639 & 13.4 & ${ }^{2} 0.0001$ \\
\hline Velocity & 0.013902 & 0.002319 & 6 & 0.0005 \\
\hline $\mathrm{V}(47.5)$ & -0.0199039 & 0.003413 & -5.83 & 0.0006 \\
\hline
\end{tabular}




\section{Appendix E: Scatter plots of log- transformed concentartions (Study II)}

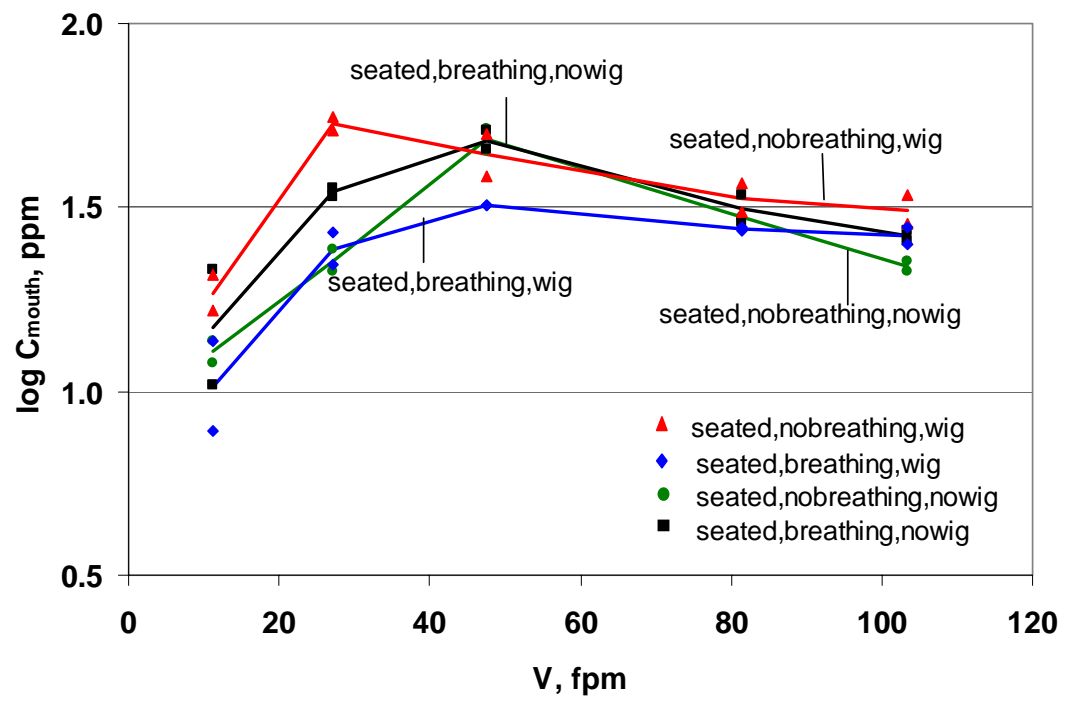

Figure E.1a: Scatter and mean plot of $\log \mathrm{C}_{\text {mouth }}$ vs. velocity for all manikin treatment

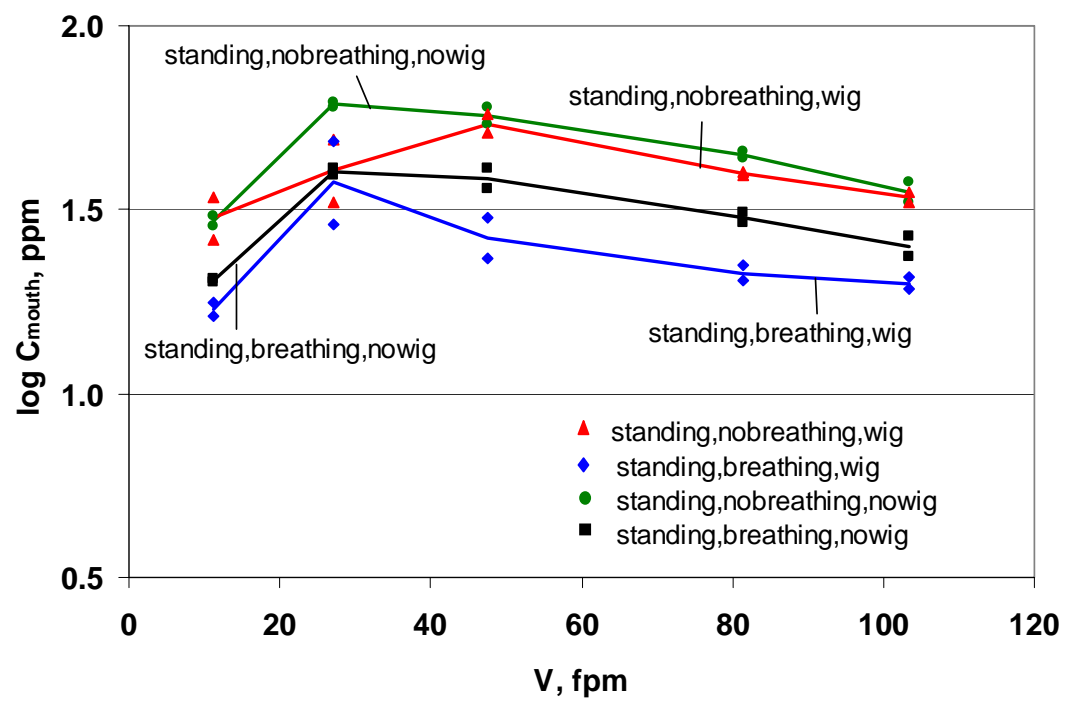

Figure E.1b: Scatter and mean plot of $\log \mathrm{C}_{\text {mouth }}$ vs. velocity for all manikin treatment 


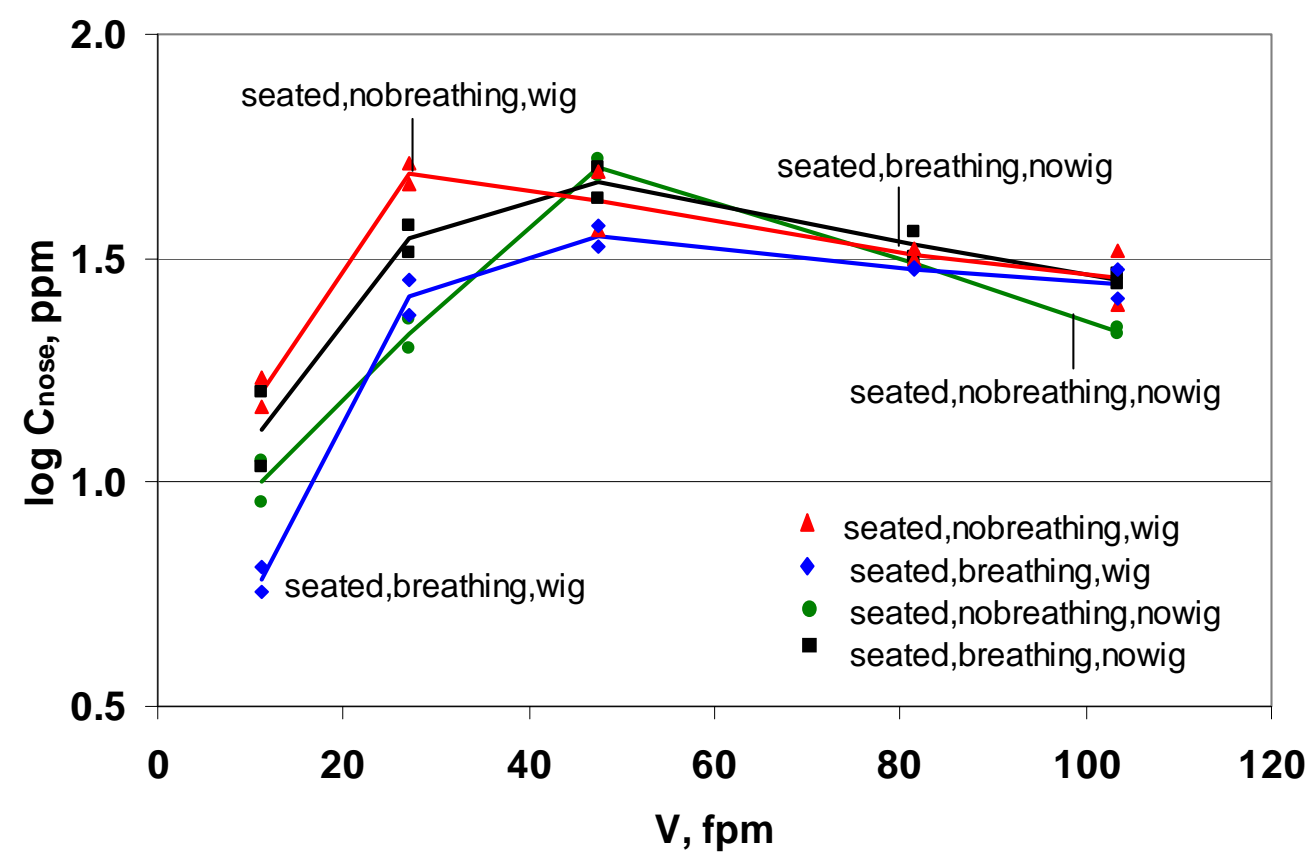

Figure E.2a: Scatter and mean plot of $\log \mathrm{C}_{\text {nose }}$ vs. velocity for all manikin treatment

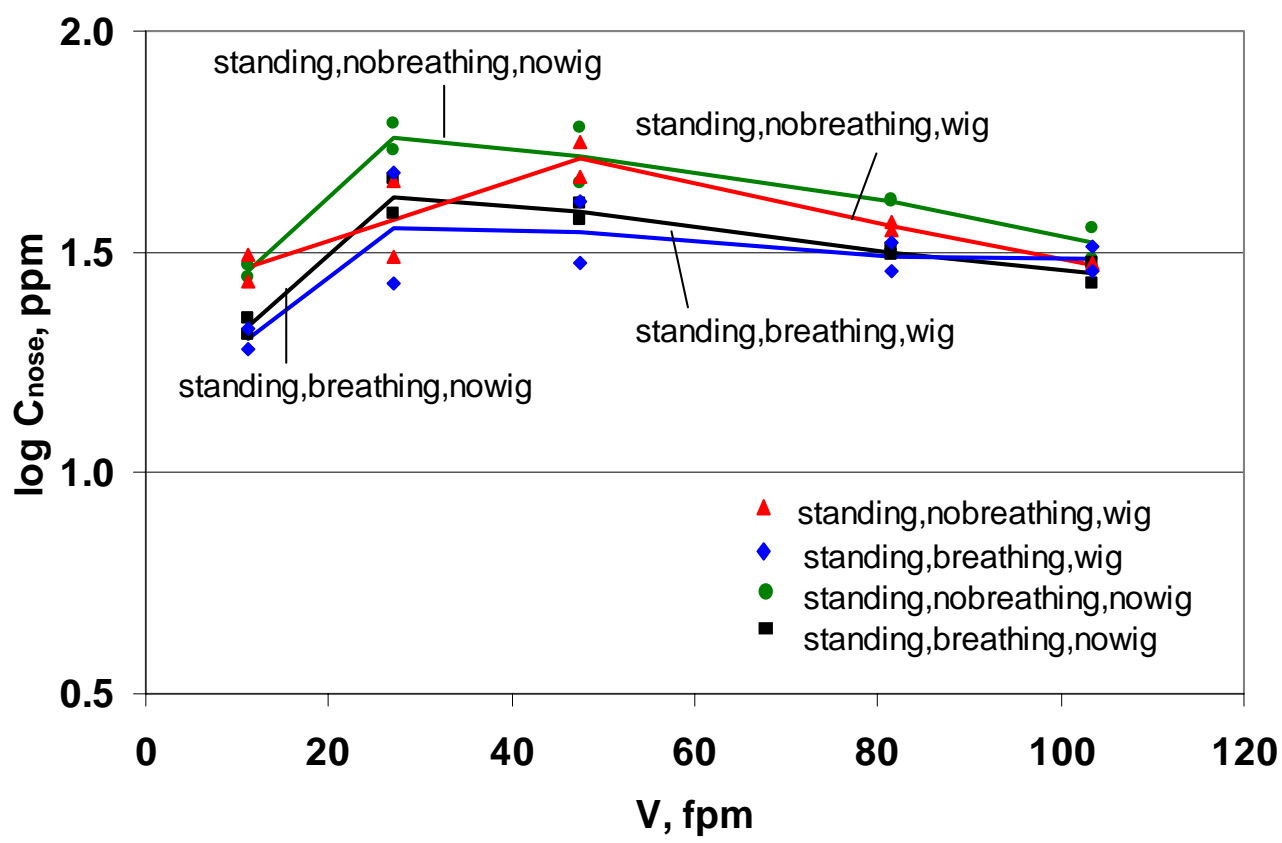

Figure E.2b: Scatter and mean plot of $\log$ Cnose $_{\text {vs. velocity for all manikin treatment }}$ 


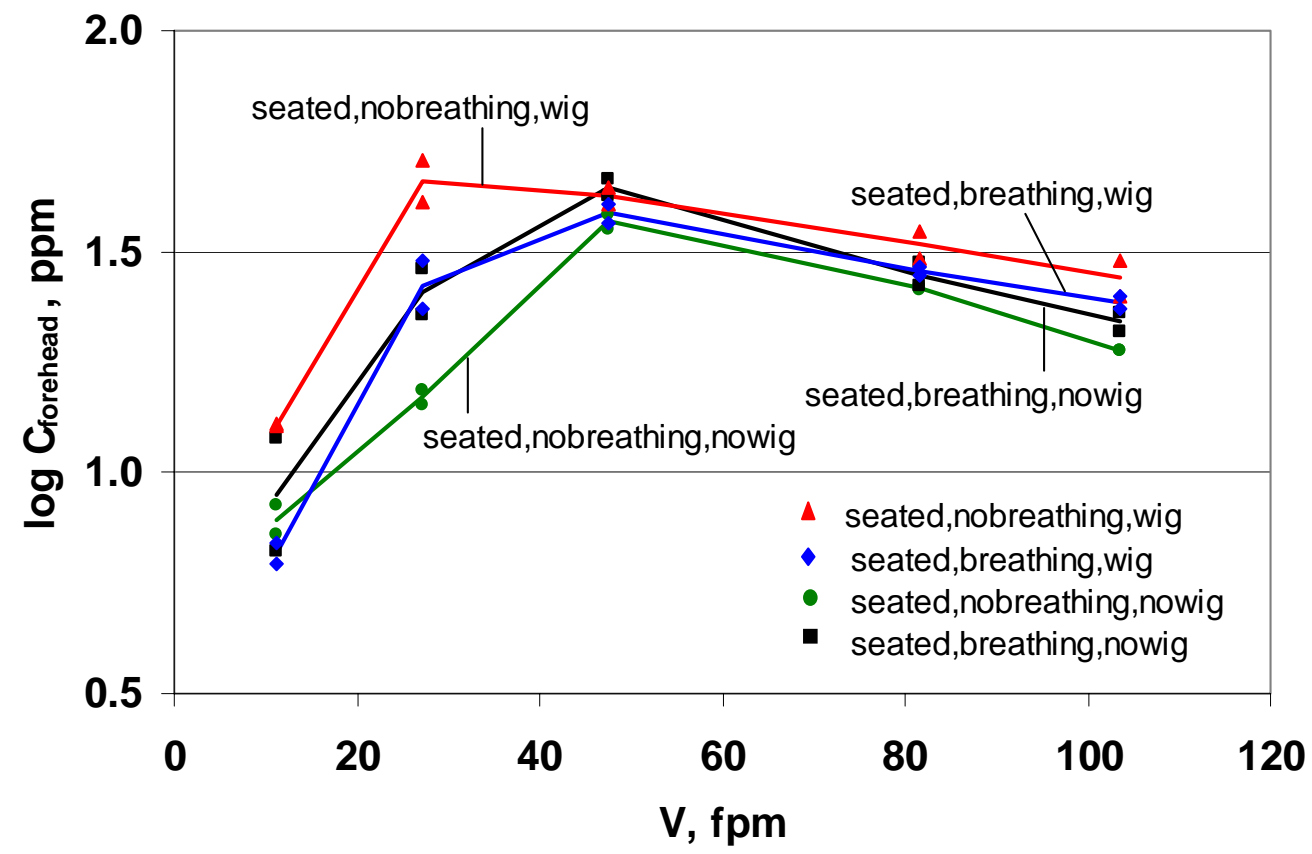

Figure E.3a: Scatter and mean plot of $\log \mathrm{C}_{\text {forehead }}$ vs. velocity for all manikin treatment

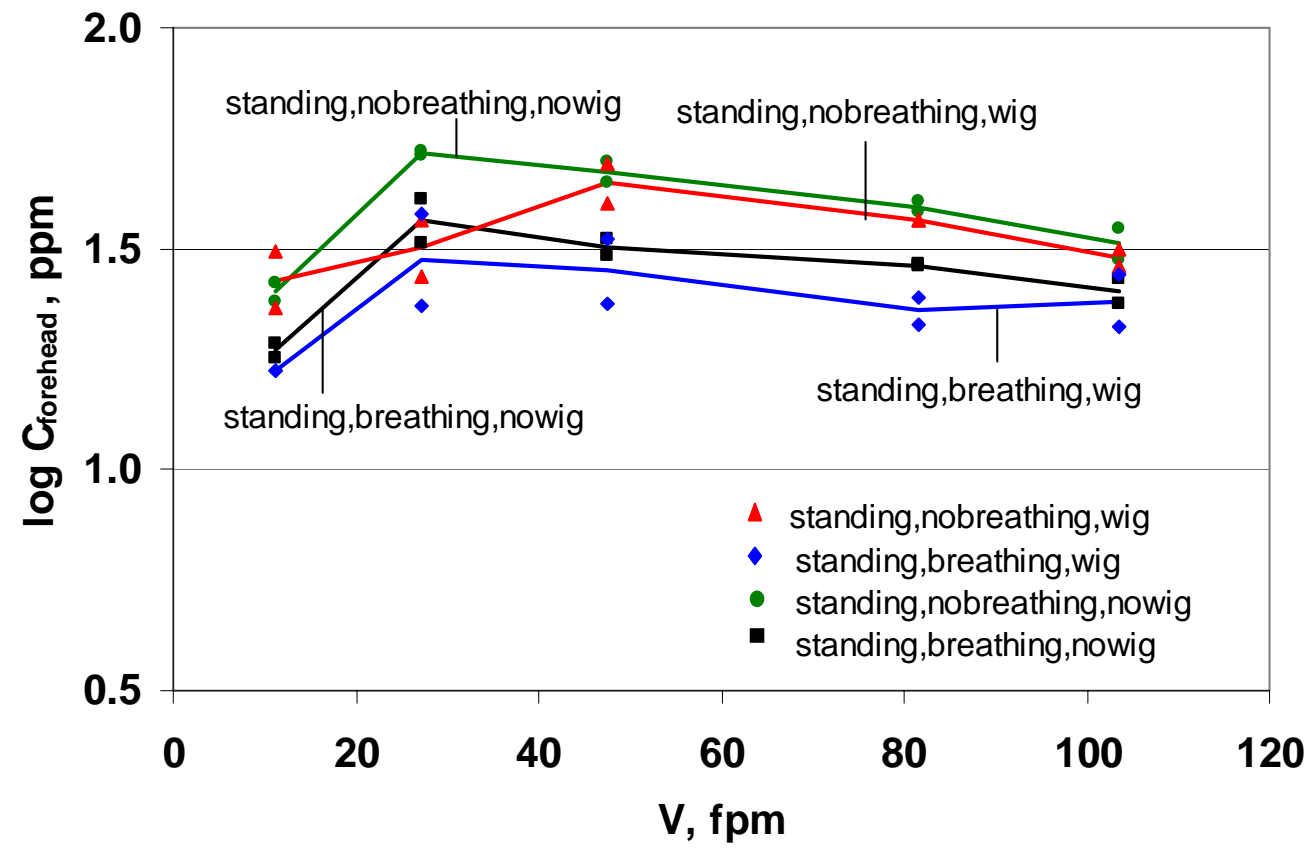

Figure E.3b: Scatter and mean plot of $\log \mathrm{C}_{\text {forehead }}$ vs. velocity for all manikin treatment 


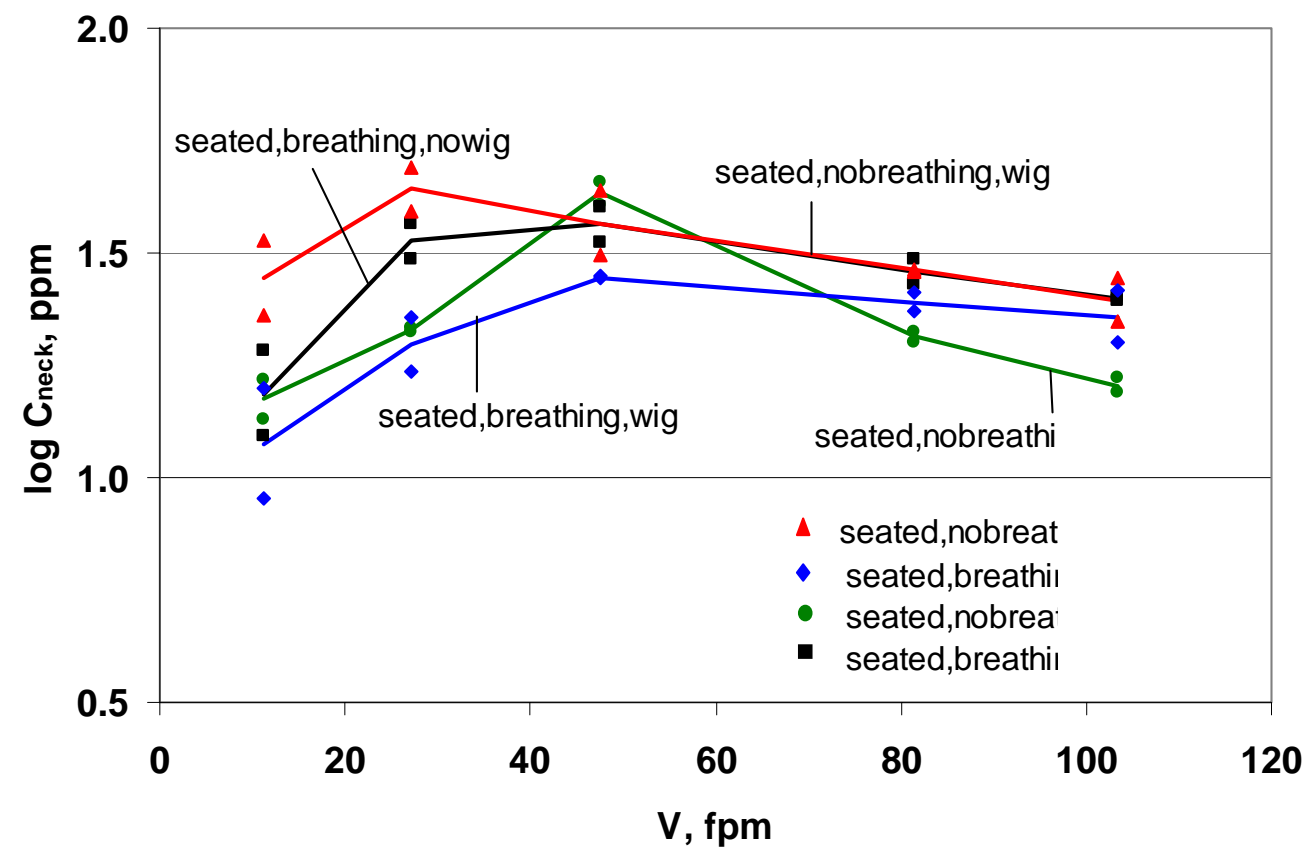

Figure E.4a: Scatter and mean plot of $\log \mathrm{C}_{\text {neck }}$ vs. velocity for all manikin treatments

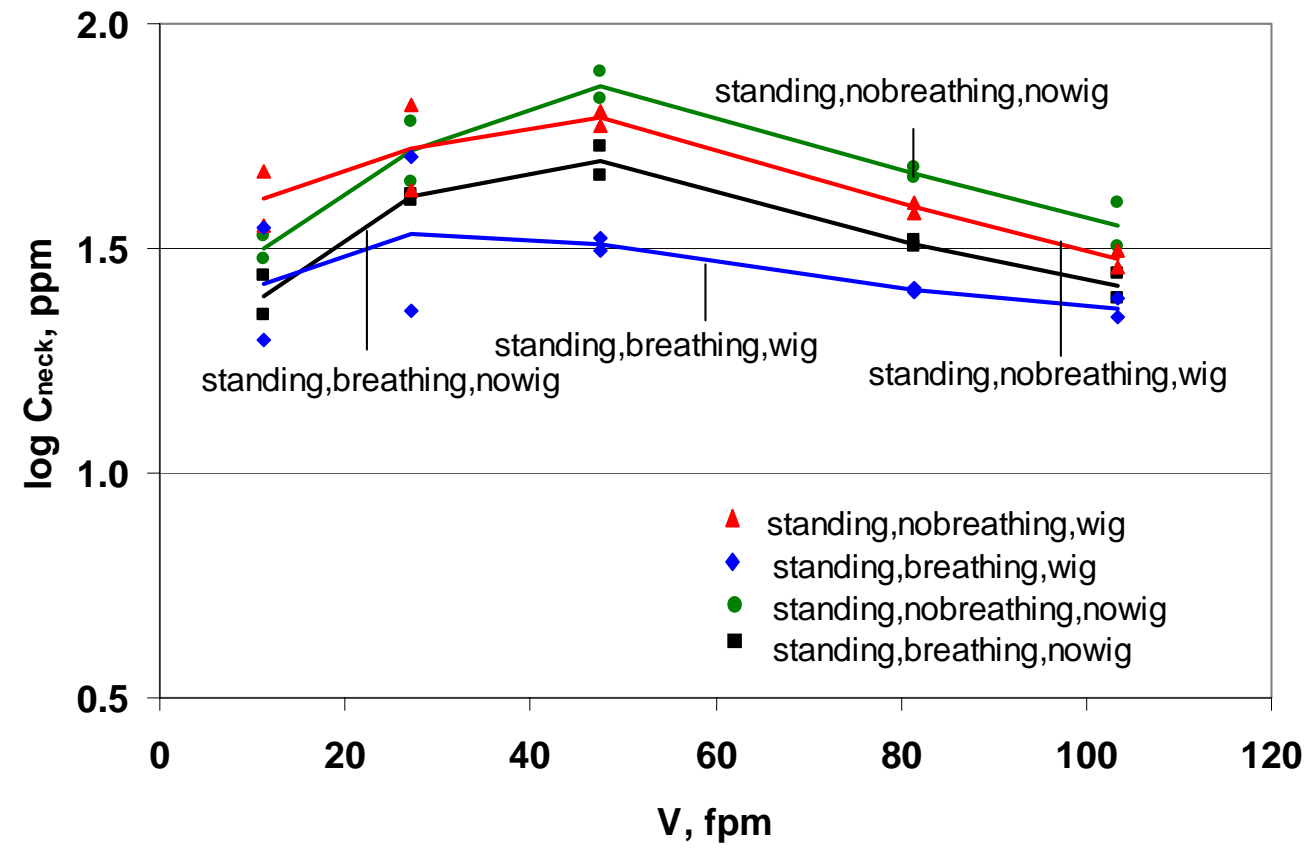

Figure E.4b: Scatter and mean plot of $\log \mathrm{C}_{\text {neck }}$ vs. velocity for all manikin treatments 


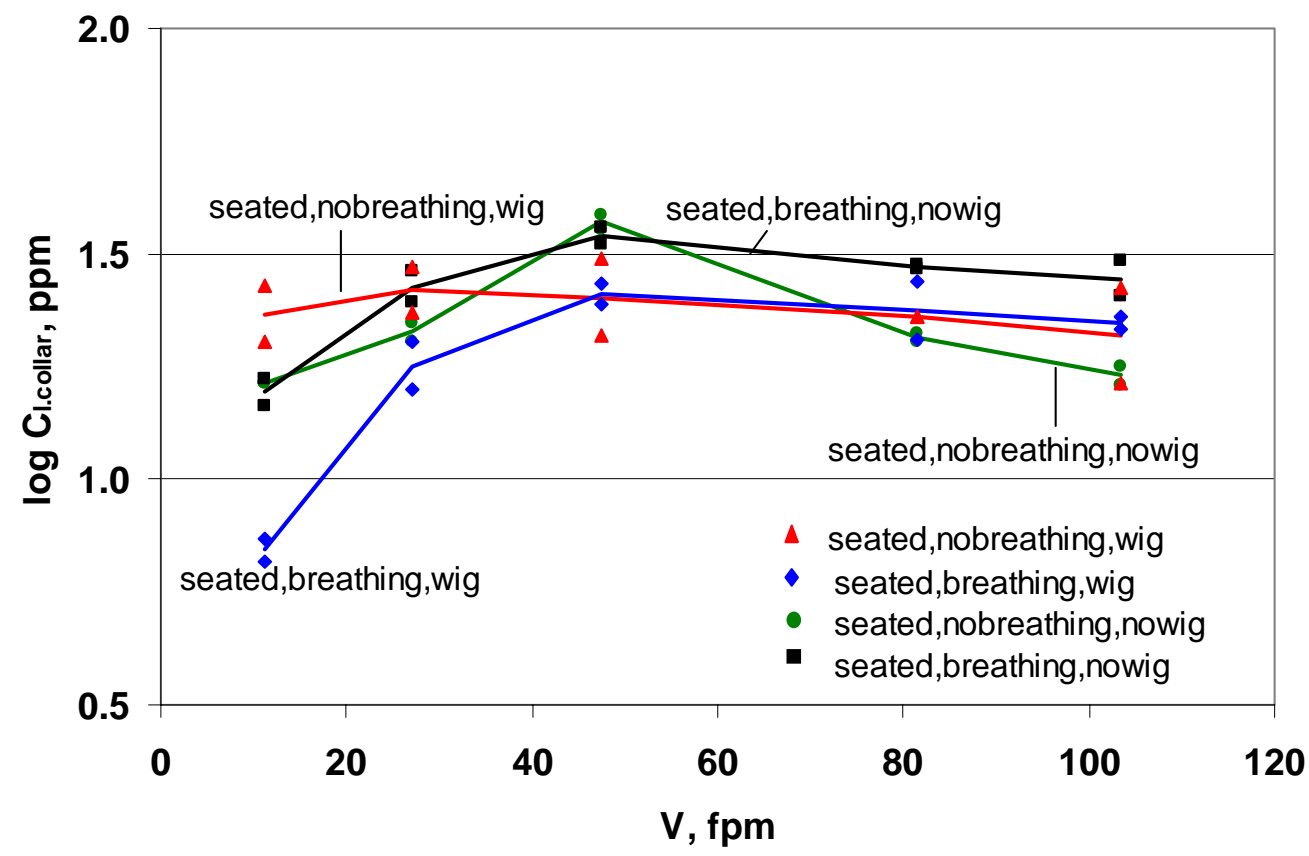

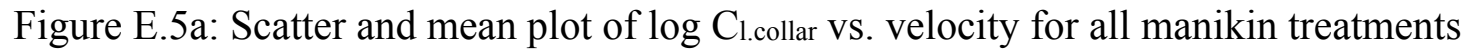

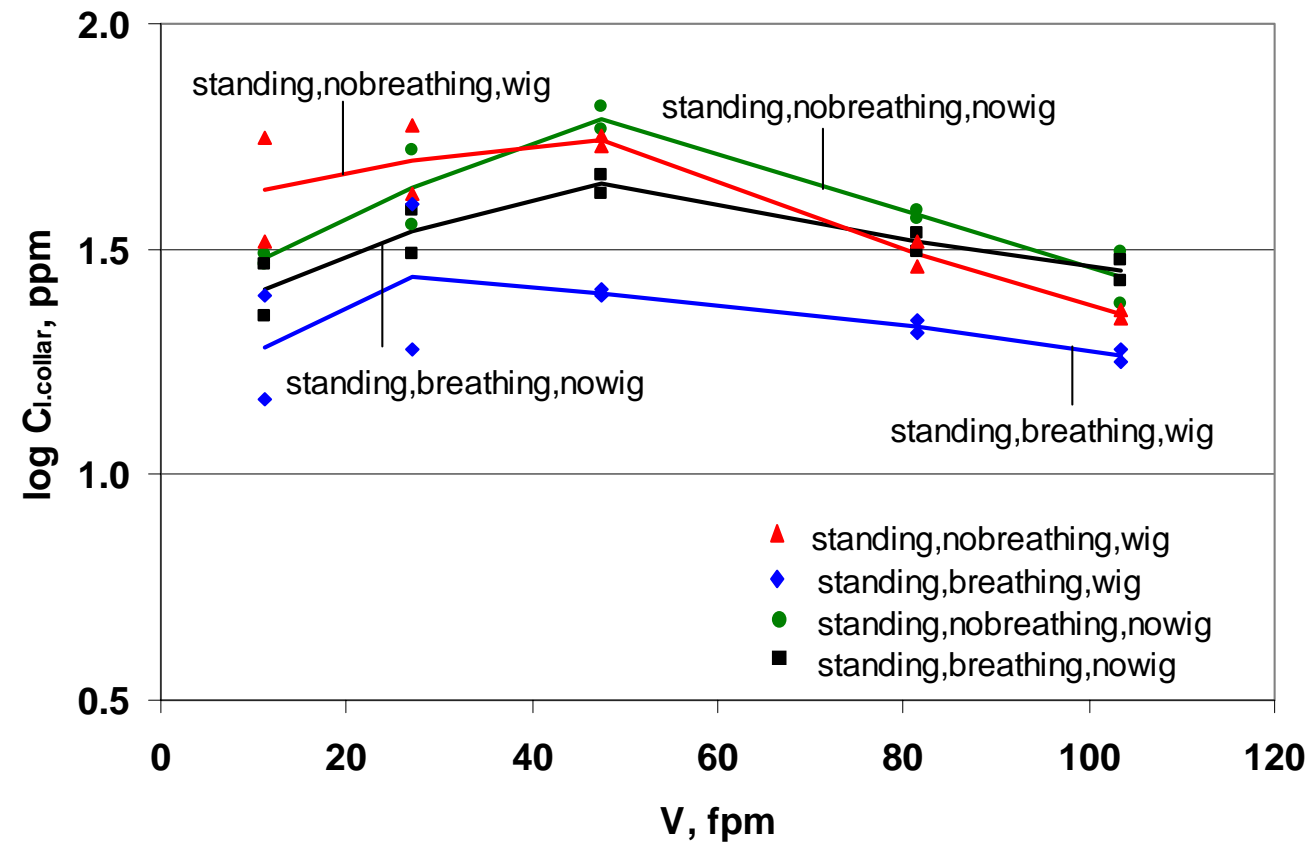

Figure E.5b: Scatter and mean plot of log Cl.collar vs. velocity for all manikin treatments 


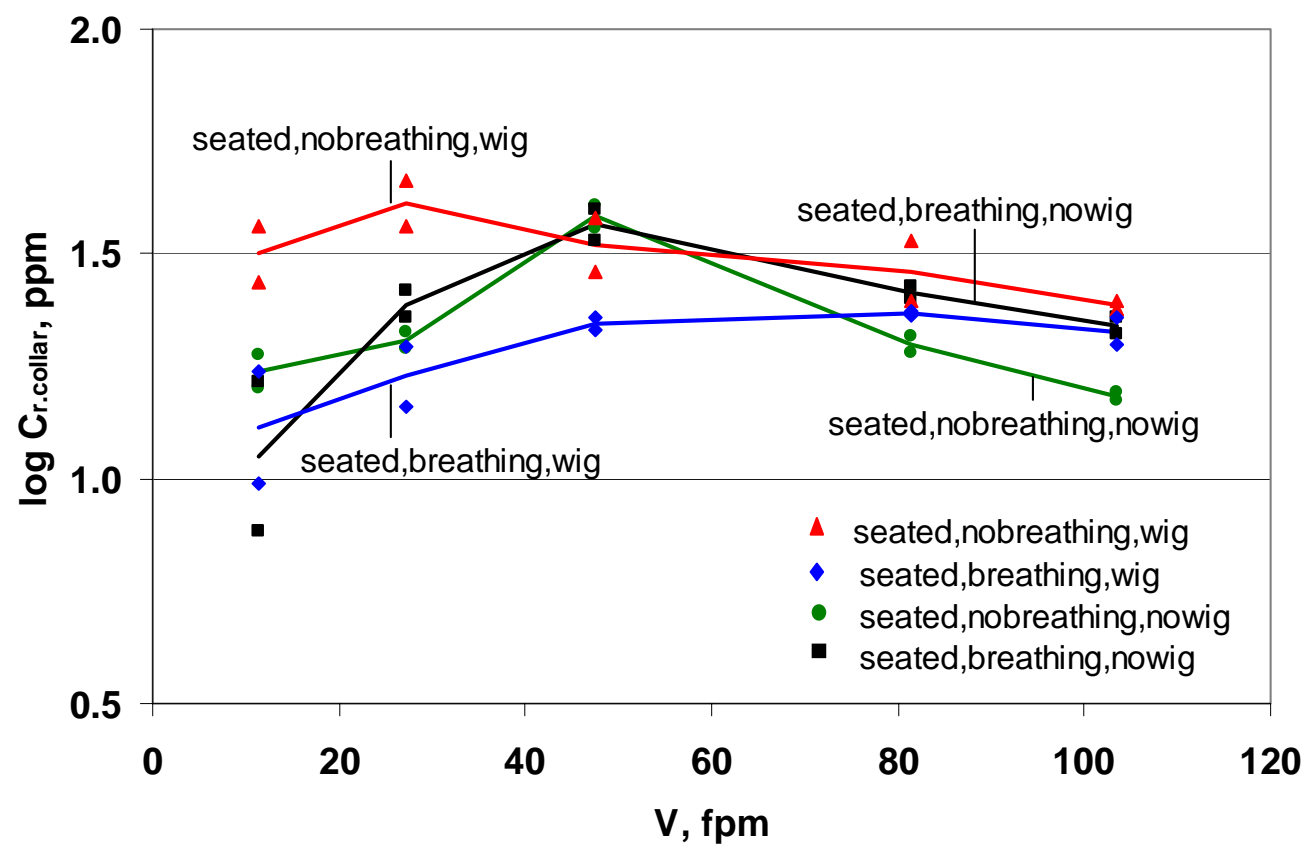

Figure E.6a: Scatter and mean plot of $\log \mathrm{C}_{\mathrm{r} . \mathrm{collar}} \mathrm{vs.}$. velocity for all manikin treatment

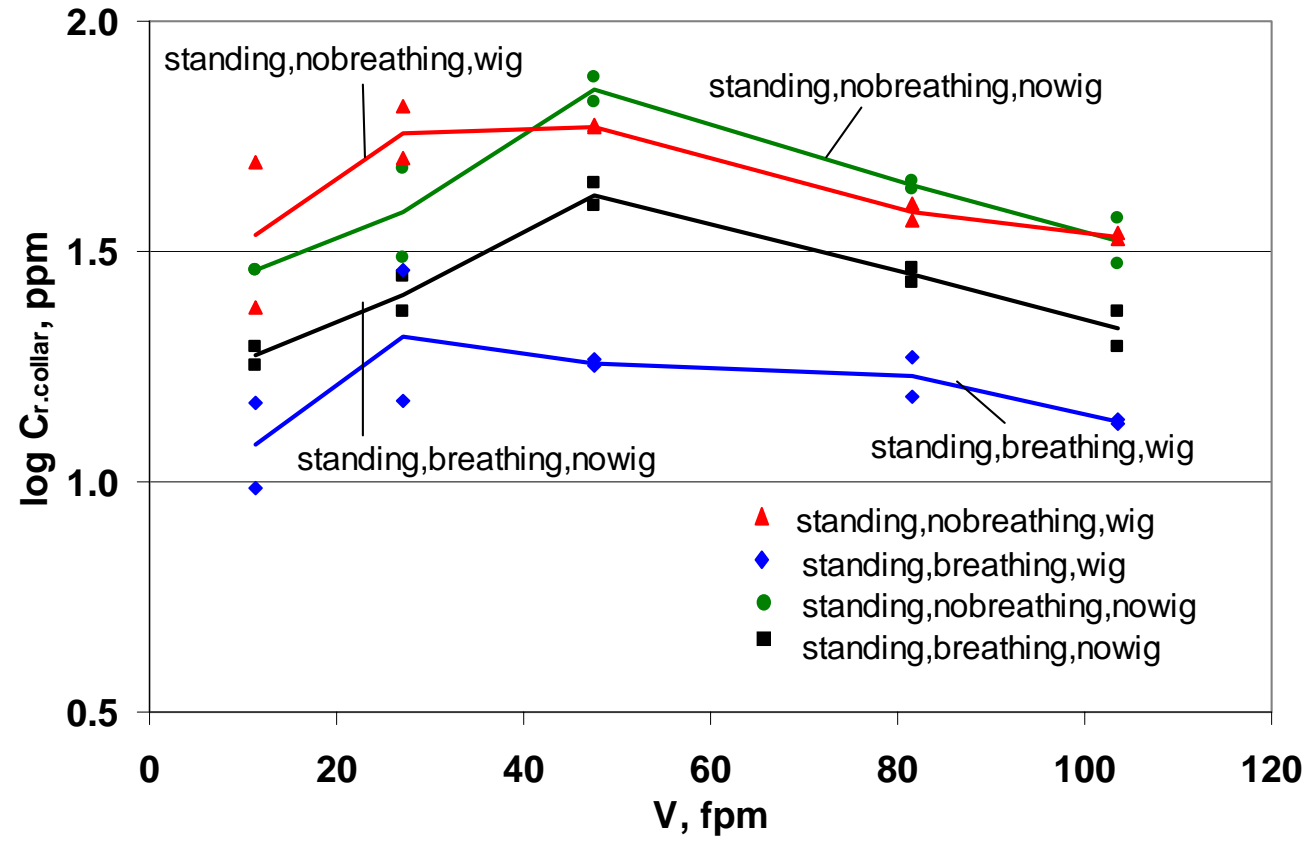

Figure E.6b: Scatter and mean plot of $\log \mathrm{C}_{\mathrm{r} . c o l l a r}$ vs. velocity for all manikin treatment 


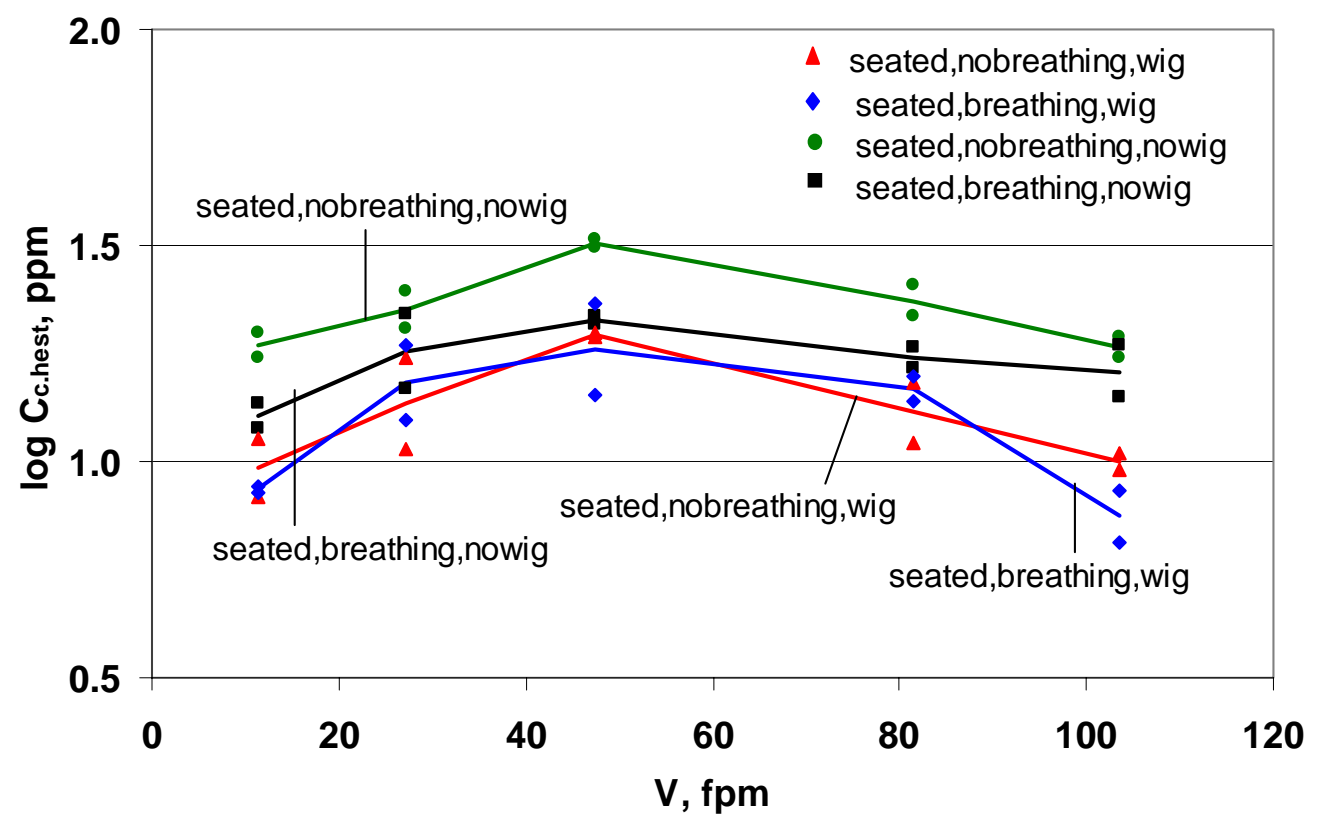

Figure E.7a: Scatter and mean plot of $\log \mathrm{C}_{\mathrm{c} . \text { chest }} \mathrm{vs.}$. velocity for all manikin treatment

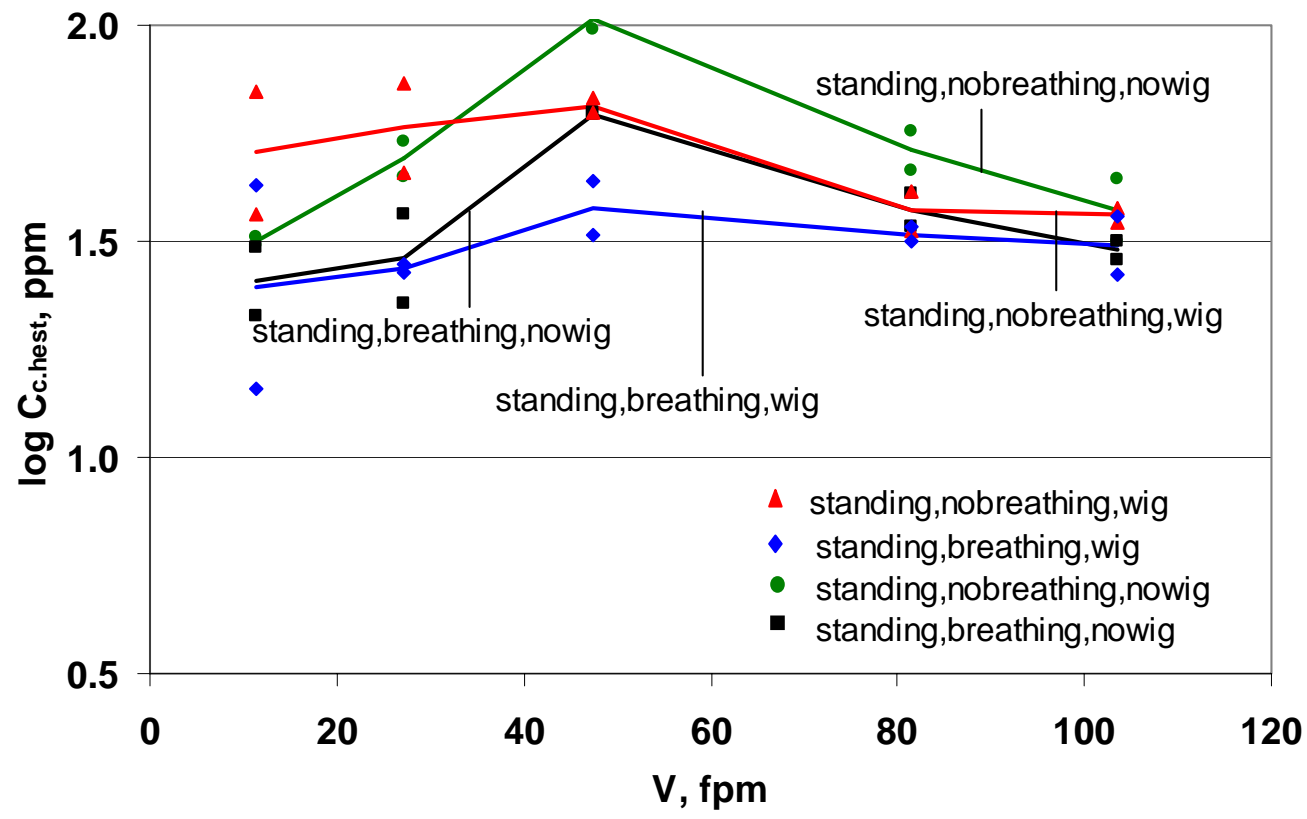

Figure E.7b: Scatter and mean plot of $\log \mathrm{C}_{\mathrm{c} . \text { chest }} \mathrm{vs.}$. velocity for all manikin treatment 


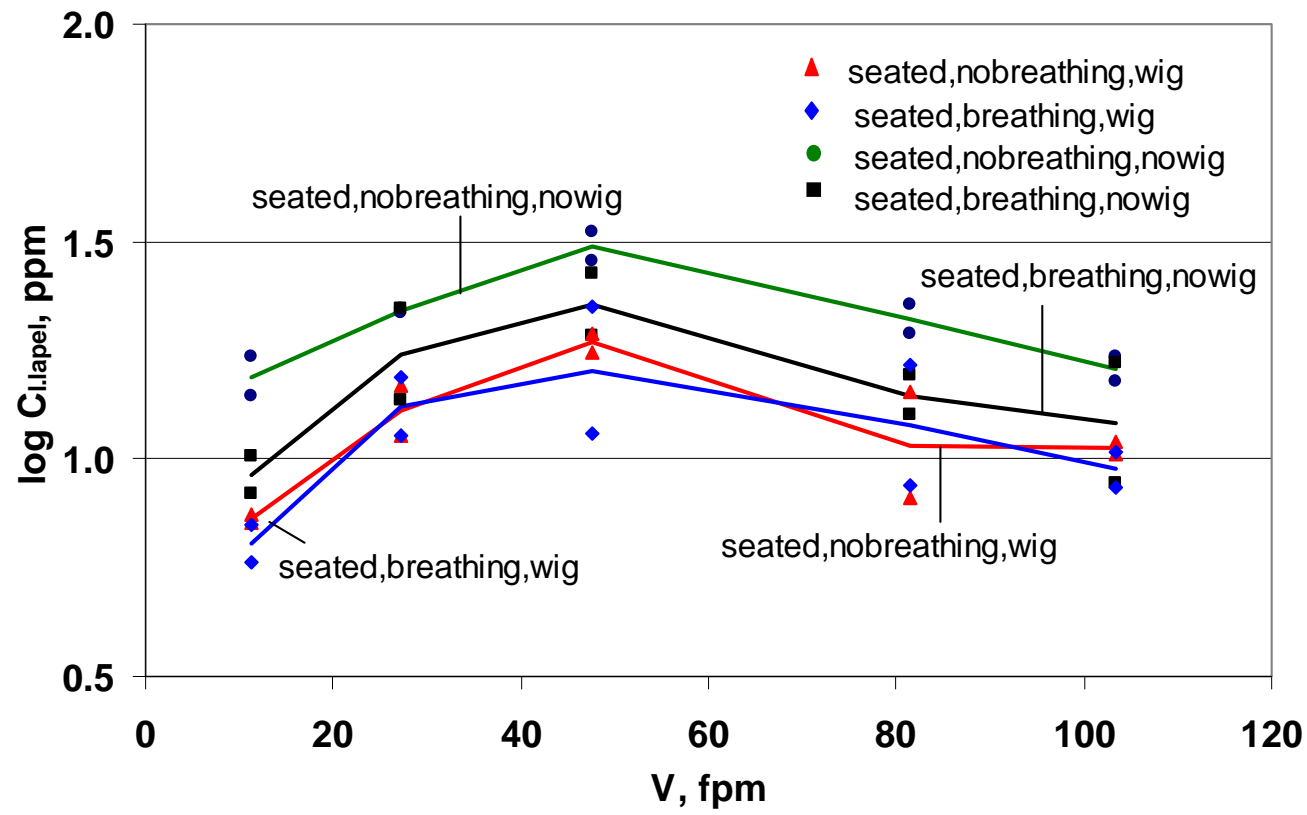

Figure E.8a: Scatter and mean plot of $\log \mathrm{C}_{1 . l a p e l}$ vs. velocity for all manikin treatment

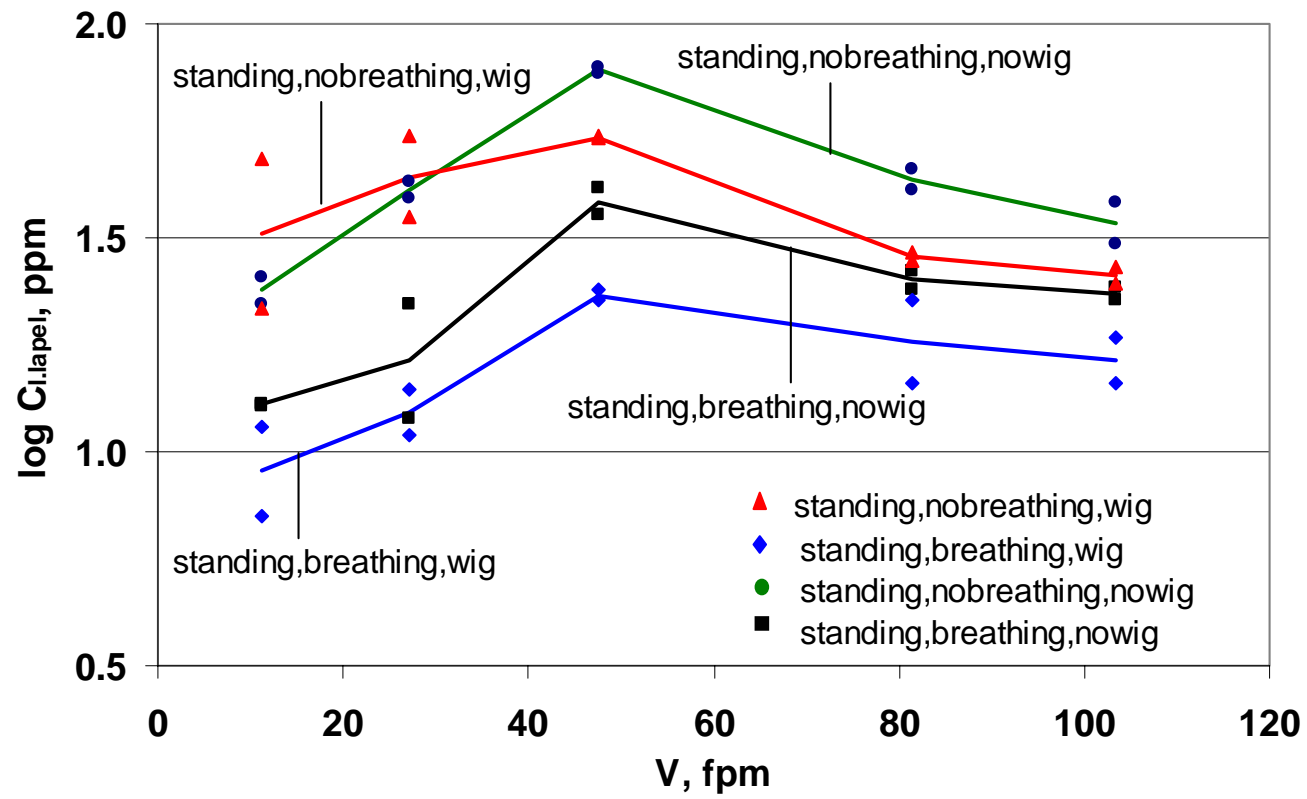

Figure E.8b: Scatter and mean plot of $\log$ Cl.lapel vs. velocity for all manikin treatment 


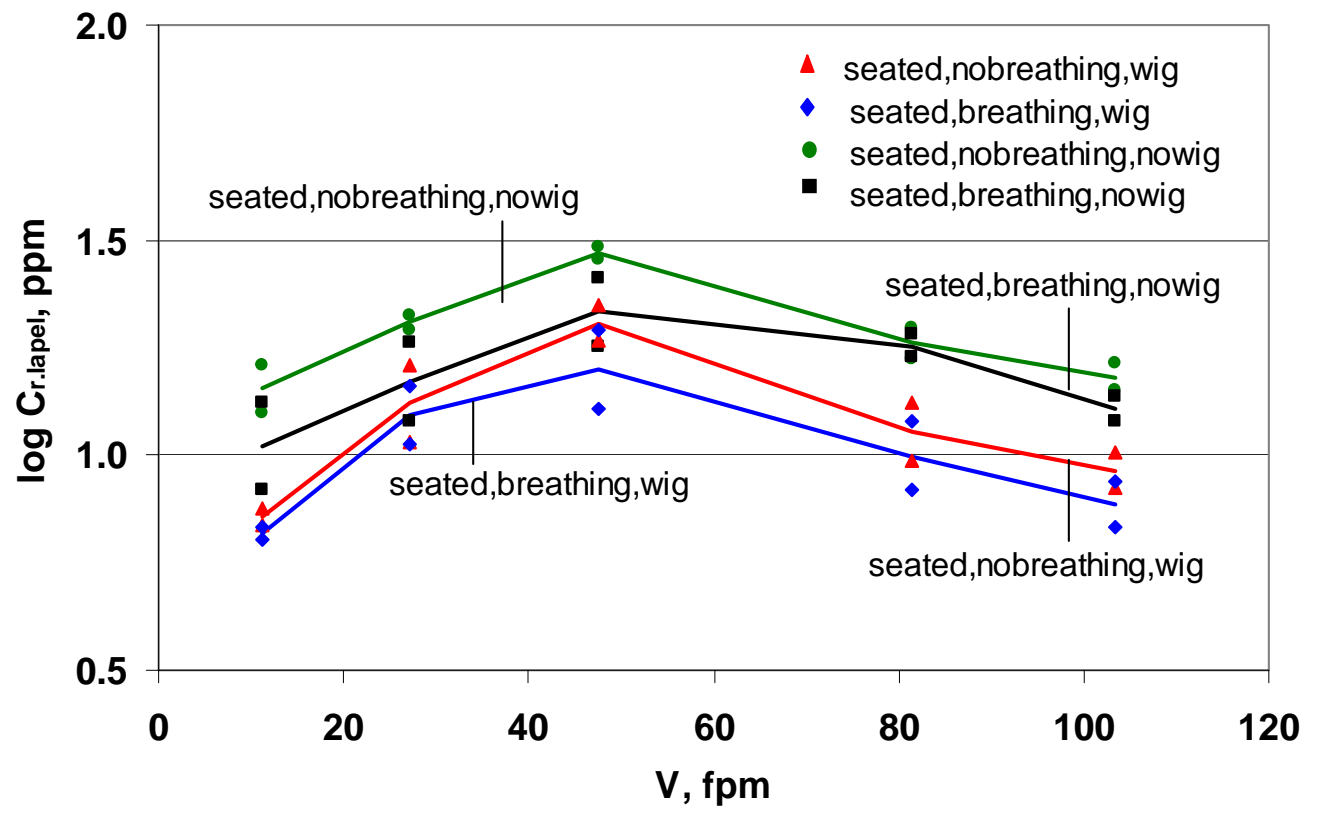

Figure E.9a: Scatter and mean plot of $\log \mathrm{C}_{\text {r.lapel }}$ vs. velocity for all manikin treatment

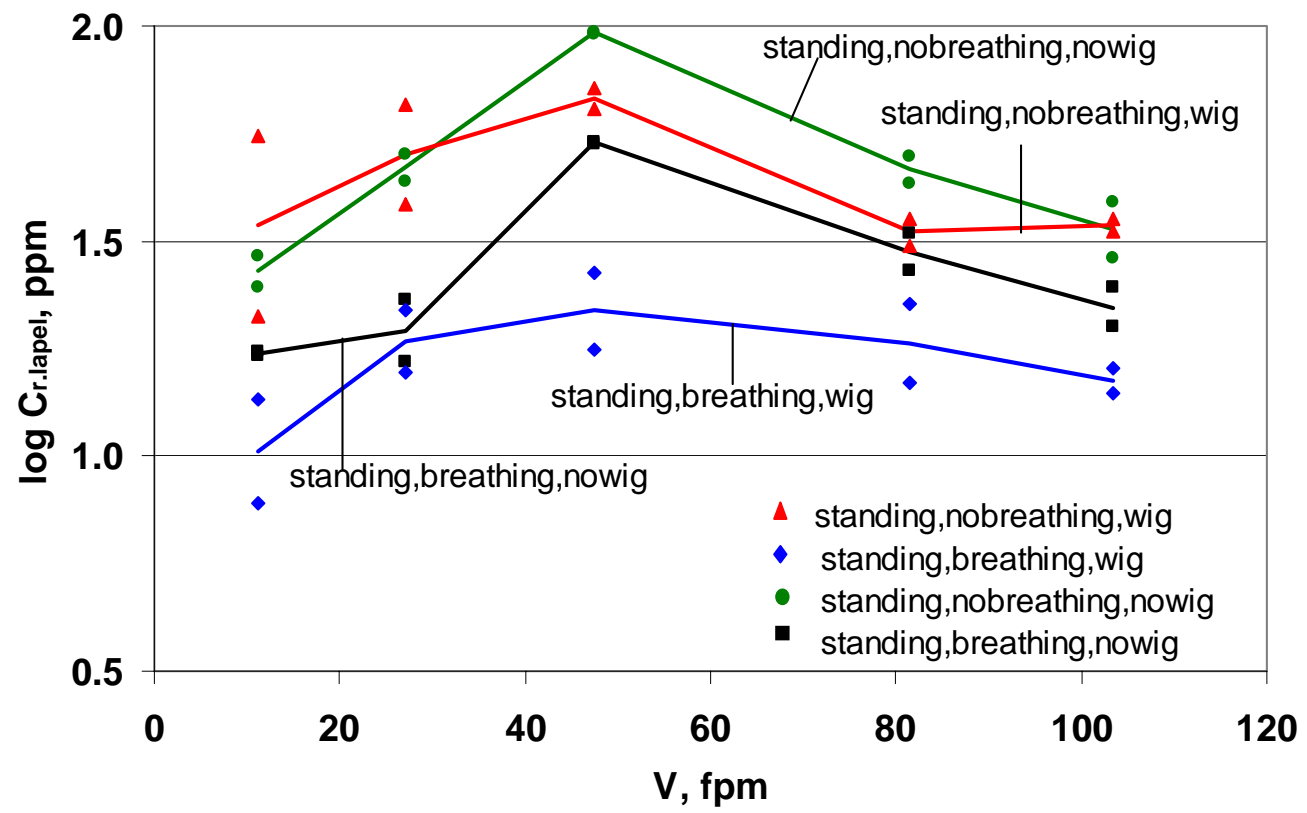

Figure E.9b: Scatter and mean plot of $\log \mathrm{C}_{\text {r.lapel }}$ vs. velocity for all manikin treatment 


\section{Appendix F: Interaction Plots of Velocity $x$ Heating (Study I)}

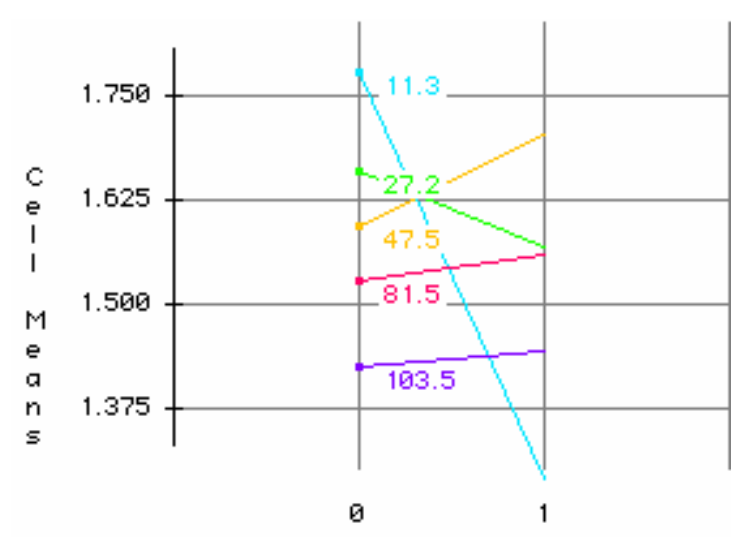

Factor

Figure F.1: Interaction plot of velocity $\mathrm{x}$ heating for $\log \mathrm{C}_{\mathrm{mouth}}$

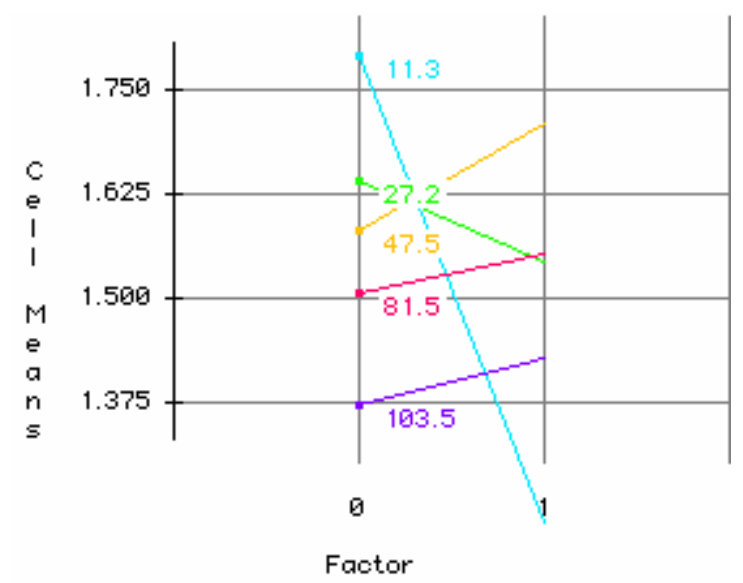

Figure F.2: Interaction plot of velocity $\mathrm{x}$ heating for $\log \mathrm{C}_{\text {nose }}$ 


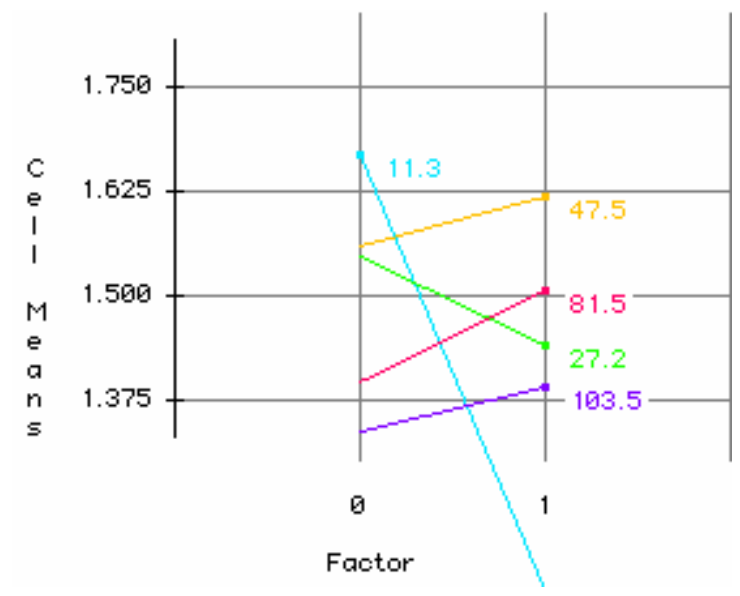

Figure F.3: Interaction plot of velocity $\mathrm{x}$ heating for $\log \mathrm{C}_{\text {forehead }}$

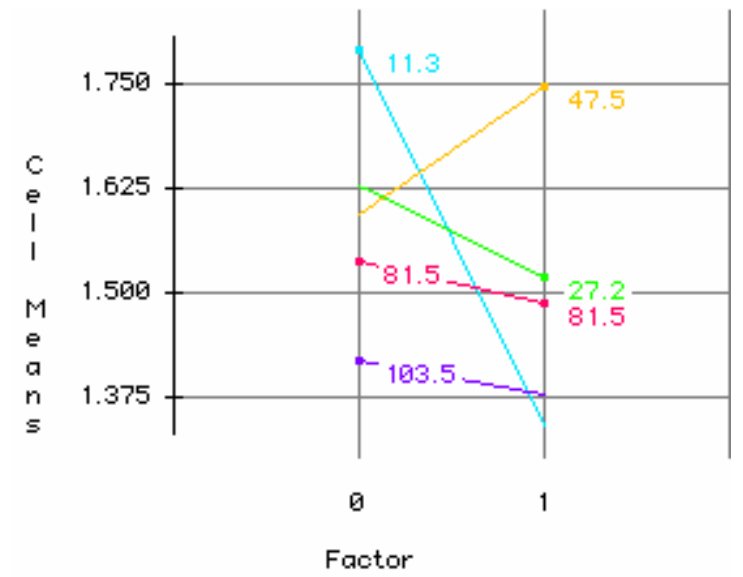

Figure F.4: Interaction plot of velocity $\mathrm{x}$ heating for $\log \mathrm{C}_{\text {neck }}$

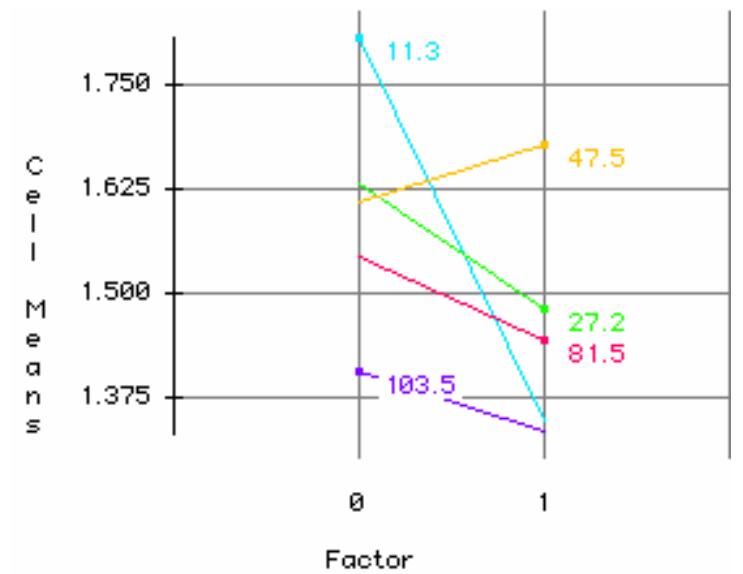

Figure F.5: Interaction plot of velocity $\mathrm{x}$ heating for $\log \mathrm{C}_{1 . \text { collar }}$ 


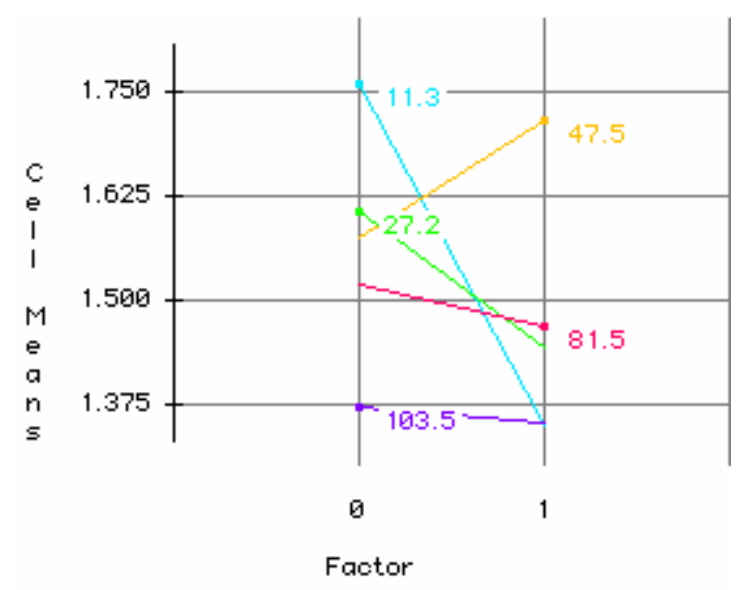

Figure F.6: Interaction plot of velocity x heating for $\log \mathrm{C}_{\text {r.collar }}$

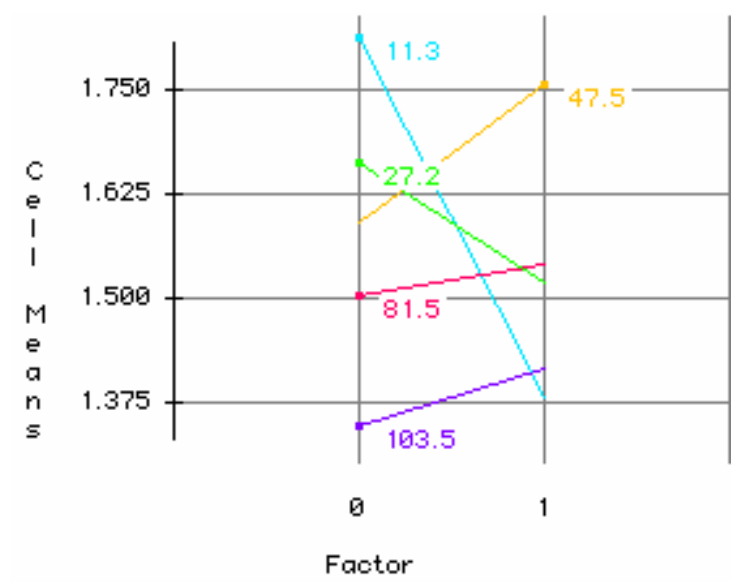

Figure F.7: Interaction plot of velocity $\mathrm{x}$ heating for $\log \mathrm{C}_{\mathrm{c} . \text { chest }}$

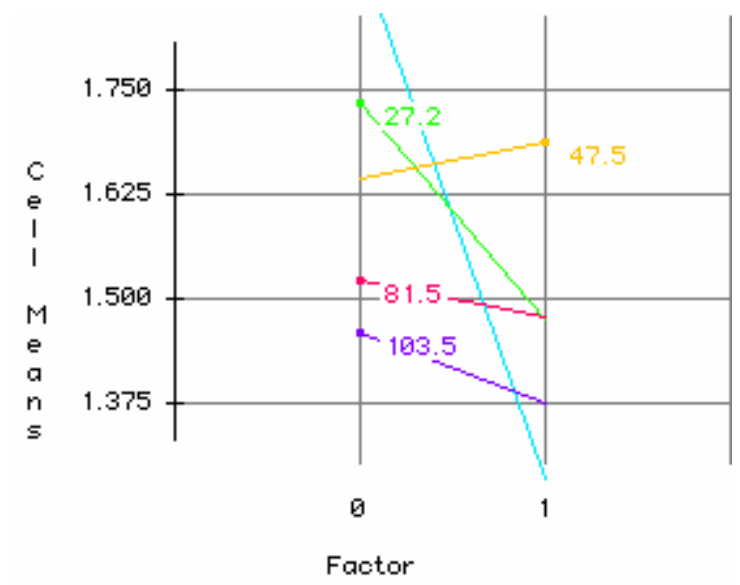

Figure F.8: Interaction plot of velocity $\mathrm{x}$ heating for $\log \mathrm{C}_{1 . \text { lapel }}$ 


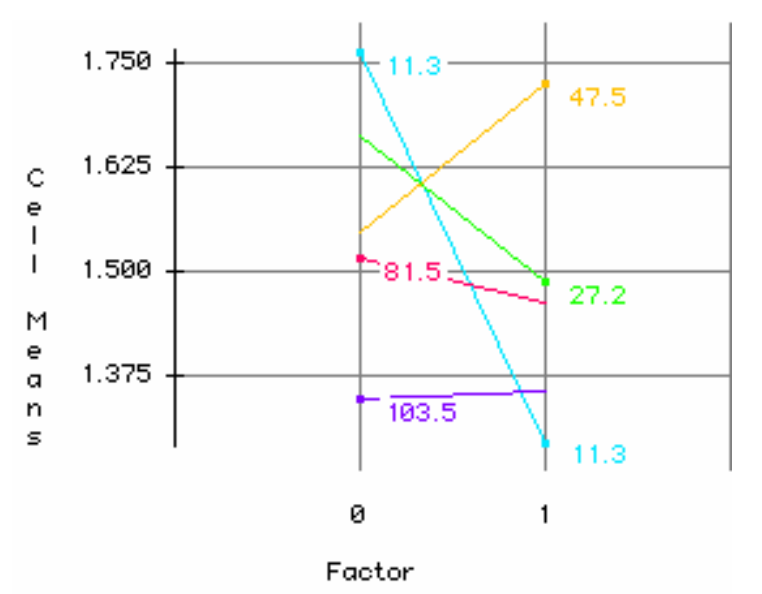

Figure F.9: Interaction plot of velocity $\mathrm{x}$ heating for $\log \mathrm{C}_{\mathrm{r} \text {.lapel }}$

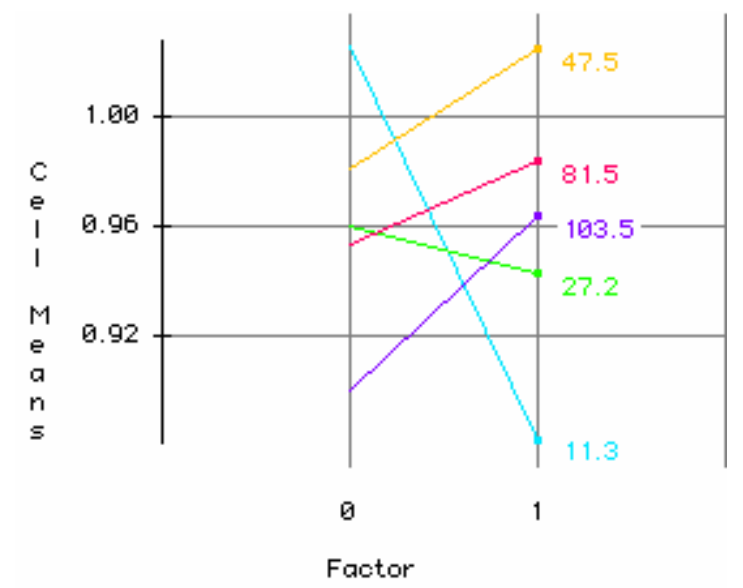

Figure F.10: Interaction plot of velocity $\mathrm{x}$ heating for $\mathrm{C}_{\text {nose }} / \mathrm{C}_{\text {mouth }}$

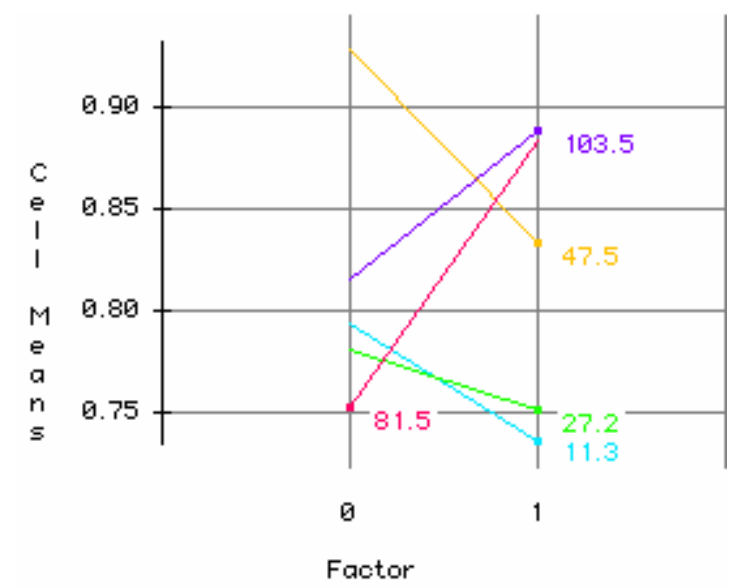

Figure F.11: Interaction plot of velocity $\mathrm{x}$ heating for $\mathrm{C}_{\text {forehead }} / \mathrm{C}_{\text {mouth }}$ 


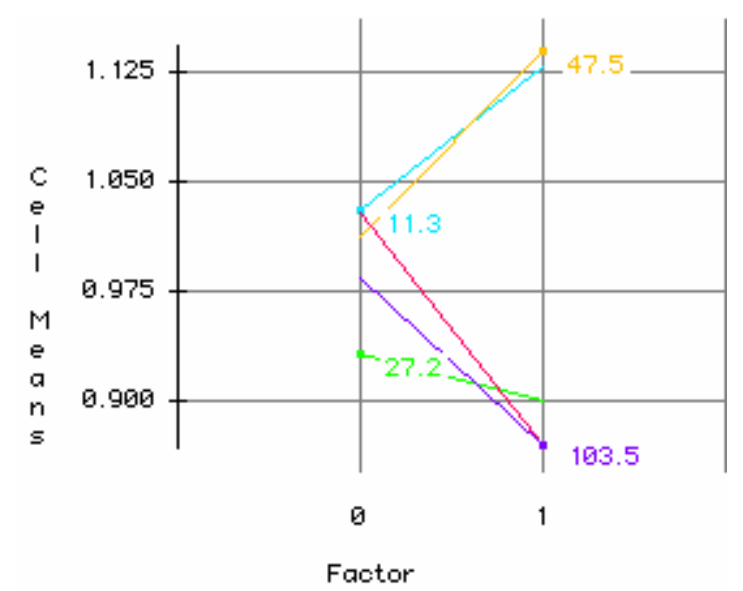

Figure F.12: Interaction plot of velocity $\mathrm{x}$ heating for $\mathrm{C}_{\text {neck }} / \mathrm{C}_{\text {mouth }}$

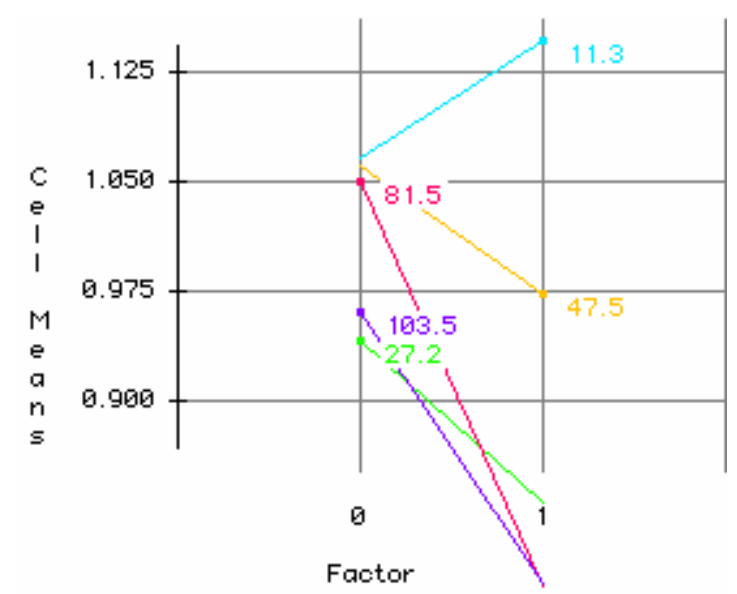

Figure F.13: Interaction plot of velocity $\mathrm{x}$ heating for $\mathrm{C}_{\text {l.collar }} / \mathrm{C}_{\text {mouth }}$

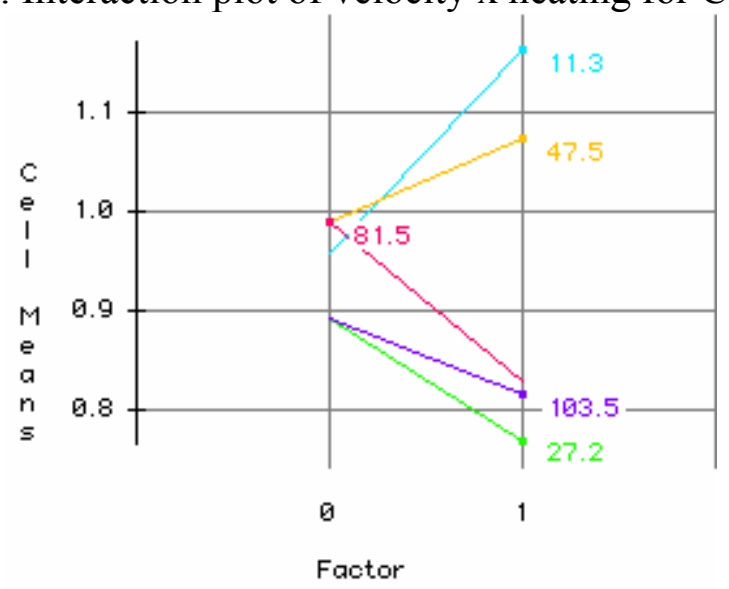

Figure F.14: Interaction plot of velocity $\mathrm{x}$ heating for $\mathrm{C}_{\mathrm{r} \text {.collar }} / \mathrm{C}_{\text {mouth }}$ 


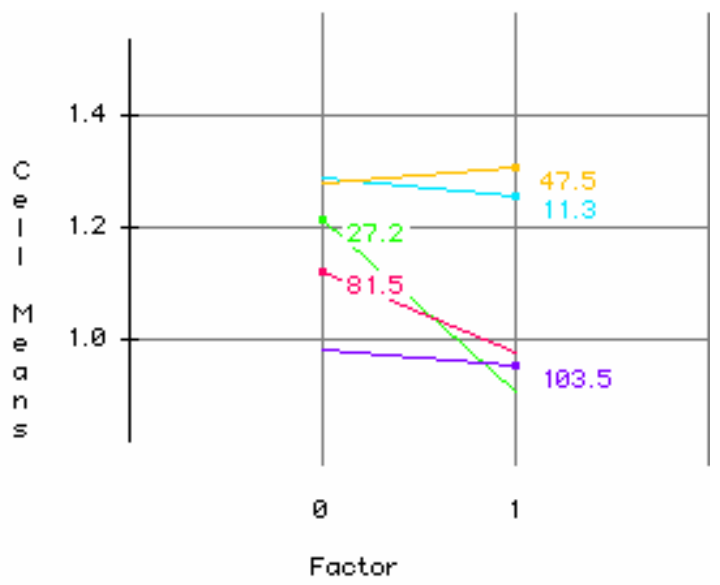

Figure F.15: Interaction plot of velocity $\mathrm{x}$ heating for $\mathrm{C}_{\text {c.chest }} / \mathrm{C}_{\text {mouth }}$

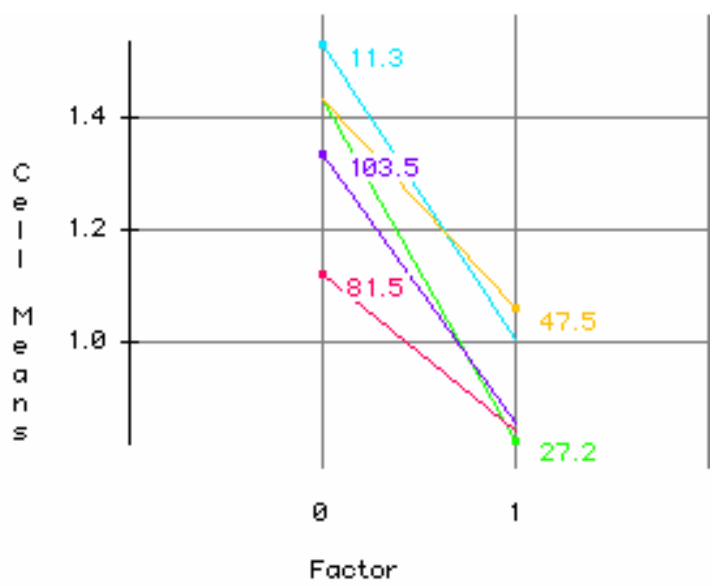

Figure F.16: Interaction plot of velocity $\mathrm{x}$ heating for $\mathrm{C}_{1 . \text { lapel }} / \mathrm{C}_{\text {mouth }}$

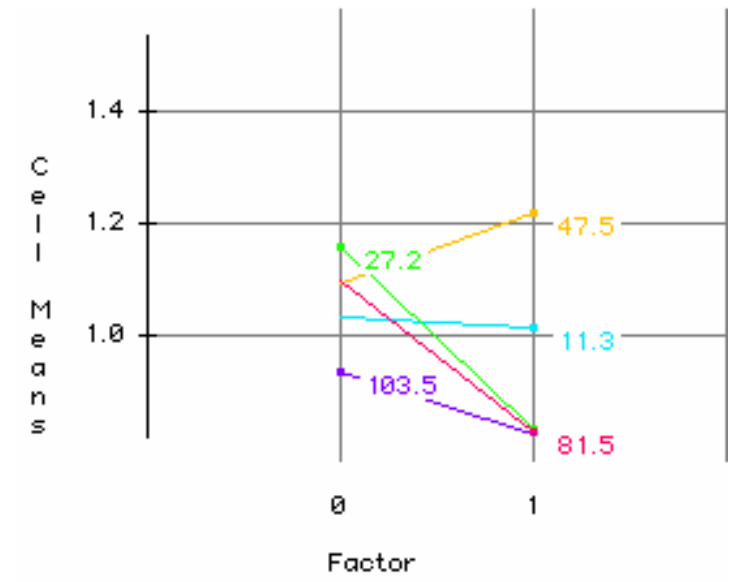

Figure F.17: Interaction plot of velocity $\mathrm{x}$ heating for $\mathrm{C}_{\mathrm{r} . \text { lapel }} / \mathrm{C}_{\text {mouth }}$ 


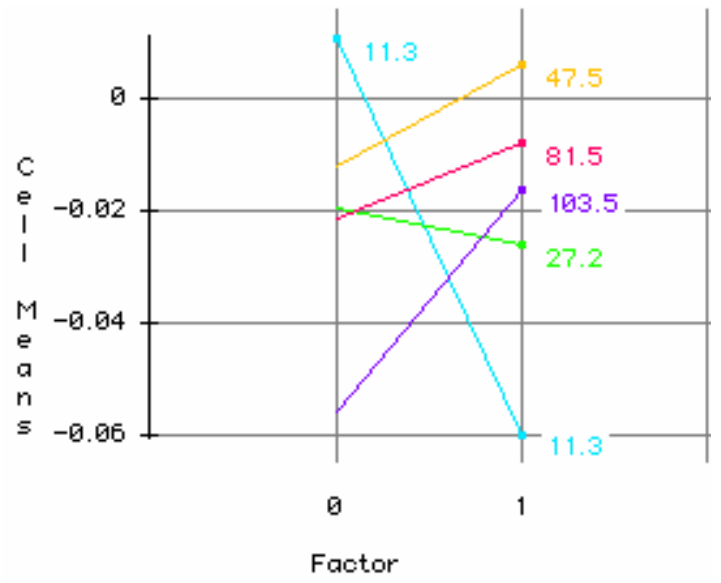

Figure F.18: Interaction plot of velocity $\mathrm{x}$ heating for $\log \left\{\mathrm{C}_{\text {nose }} / \mathrm{C}_{\text {mouth }}\right\}$

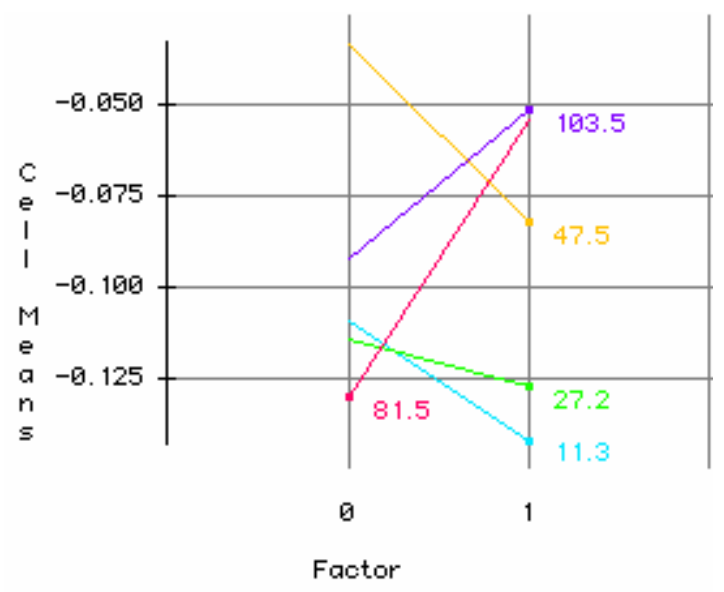

Figure F.19: Interaction plot of velocity $\mathrm{x}$ heating for $\log \left\{\mathrm{C}_{\text {forehead }} / \mathrm{C}_{\text {mouth }}\right\}$ 


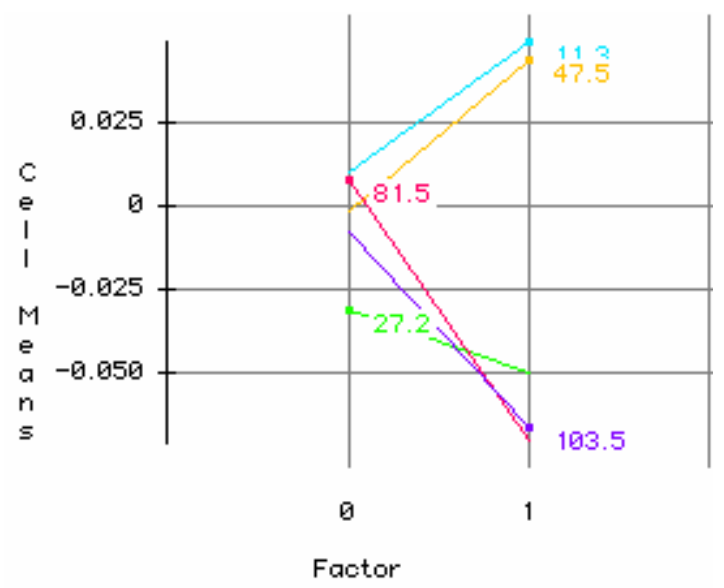

Figure F.20: Interaction plot of velocity $\mathrm{x}$ heating for $\log \left\{\mathrm{C}_{\text {neck }} / \mathrm{C}_{\text {mouth }}\right\}$

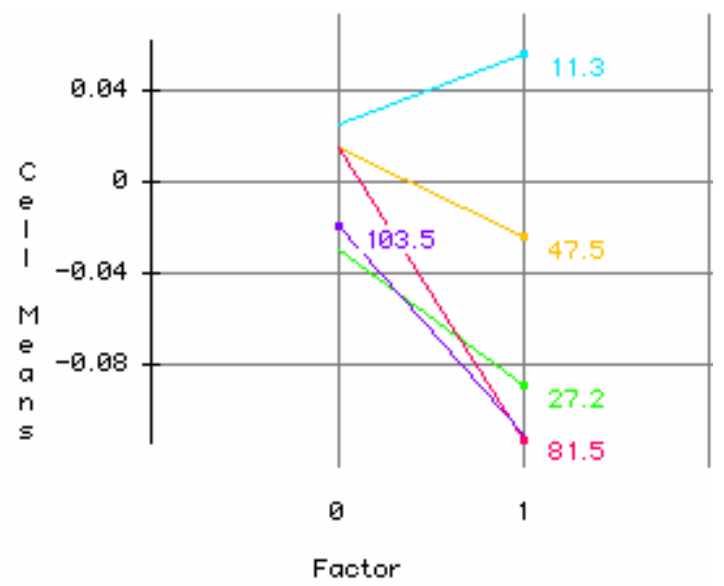

Figure F.21: Interaction plot of velocity $\mathrm{x}$ heating for $\log \left\{\mathrm{C}_{1 . \text { collar }} / \mathrm{C}_{\text {mouth }}\right\}$

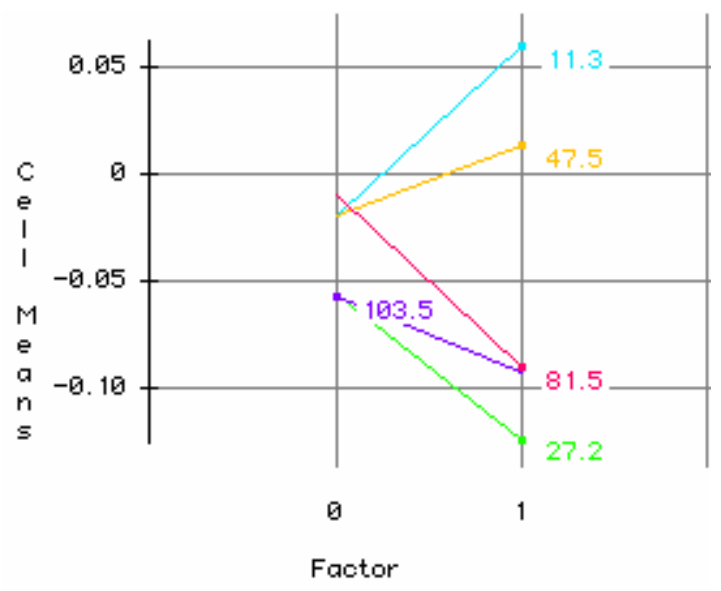

Figure F.22: Interaction plot of velocity $\mathrm{x}$ heating for $\log \left\{\mathrm{C}_{\mathrm{r} \text {.collar }} / \mathrm{C}_{\text {mouth }}\right\}$ 


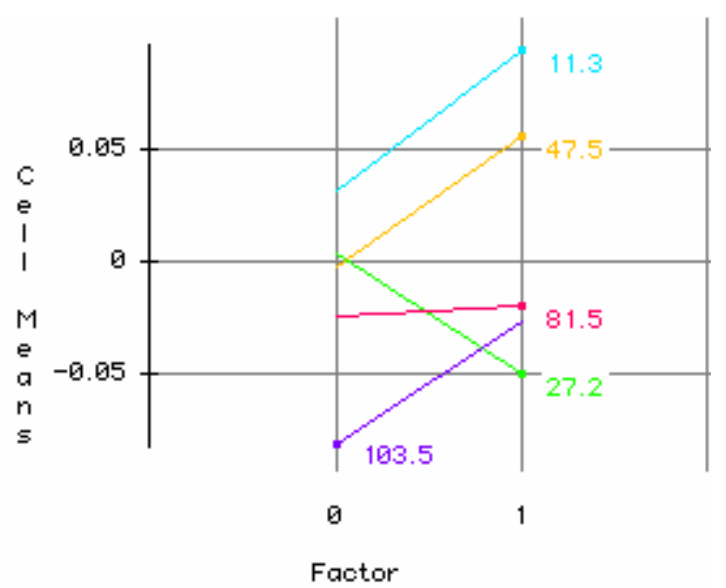

Figure F.23: Interaction plot of velocity $\mathrm{x}$ heating for $\log \left\{\mathrm{C}_{\text {c.chest }} / \mathrm{C}_{\text {mouth }}\right\}$

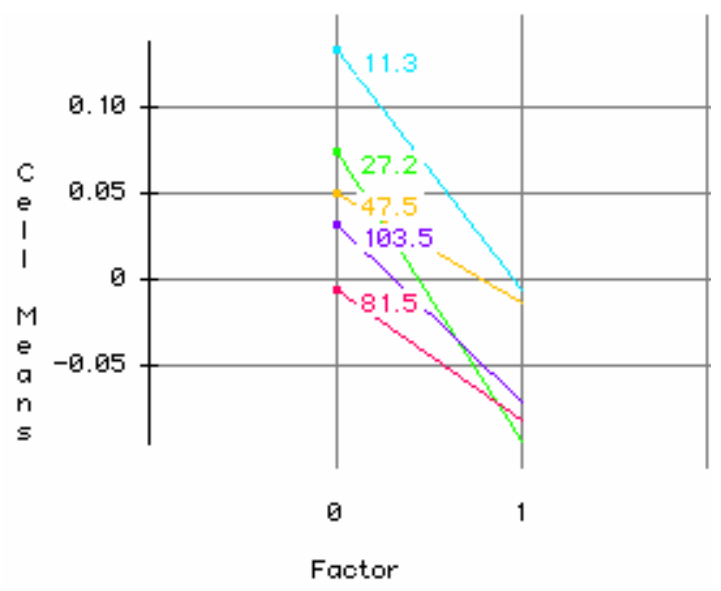

Figure F.24: Interaction plot of velocity $\mathrm{x}$ heating for $\log \left\{\mathrm{C}_{1 . \text { lapel }} / \mathrm{C}_{\text {mouth }}\right\}$

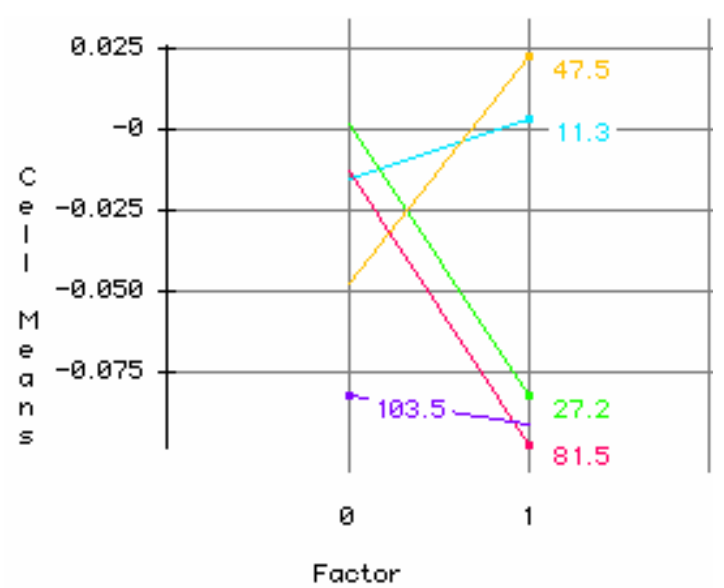

Figure F.25: Interaction plot of velocity $\mathrm{x}$ heating for $\log \left\{\mathrm{C}_{\mathrm{r} . \text { lapel }} / \mathrm{C}_{\mathrm{mouth}}\right\}$ 


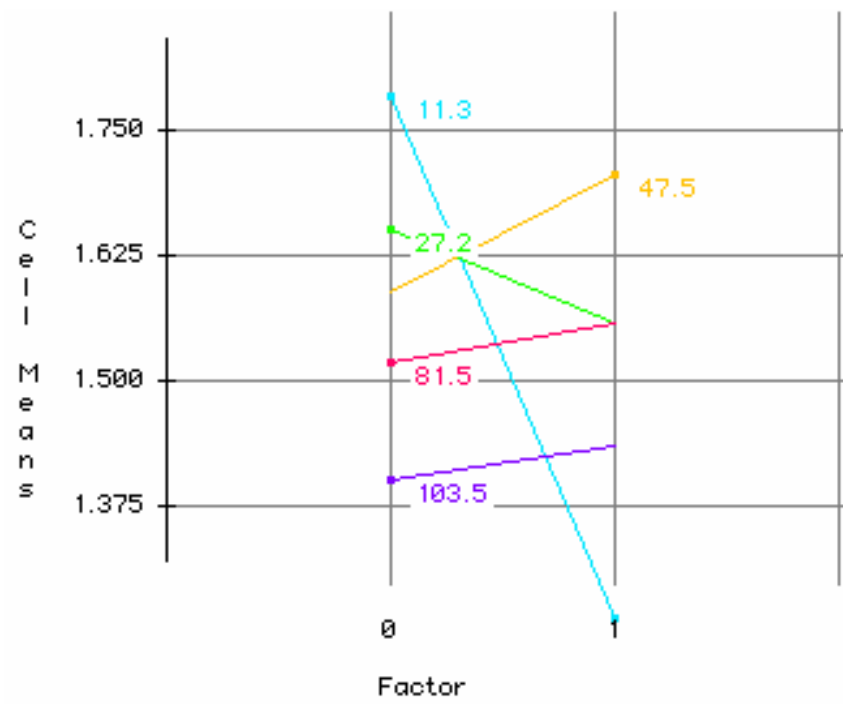

Figure F.26: Interaction plot of velocity $\mathrm{x}$ heating for $\log \mathrm{C}_{\text {inhaled }}$

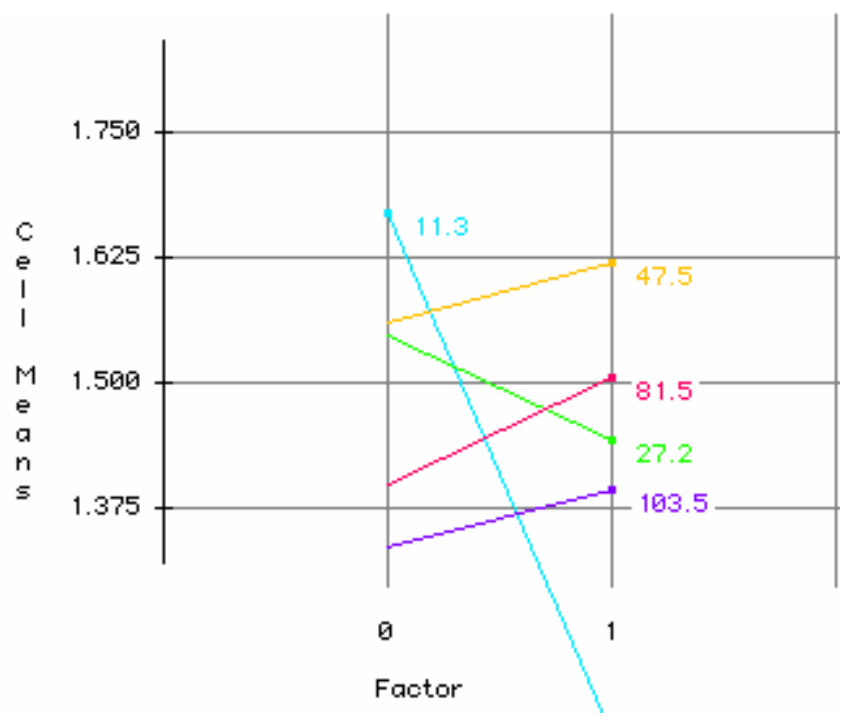

Figure F.27: Interaction plot of velocity $\mathrm{x}$ heating for $\log \mathrm{C}_{\text {forehead }}$ 


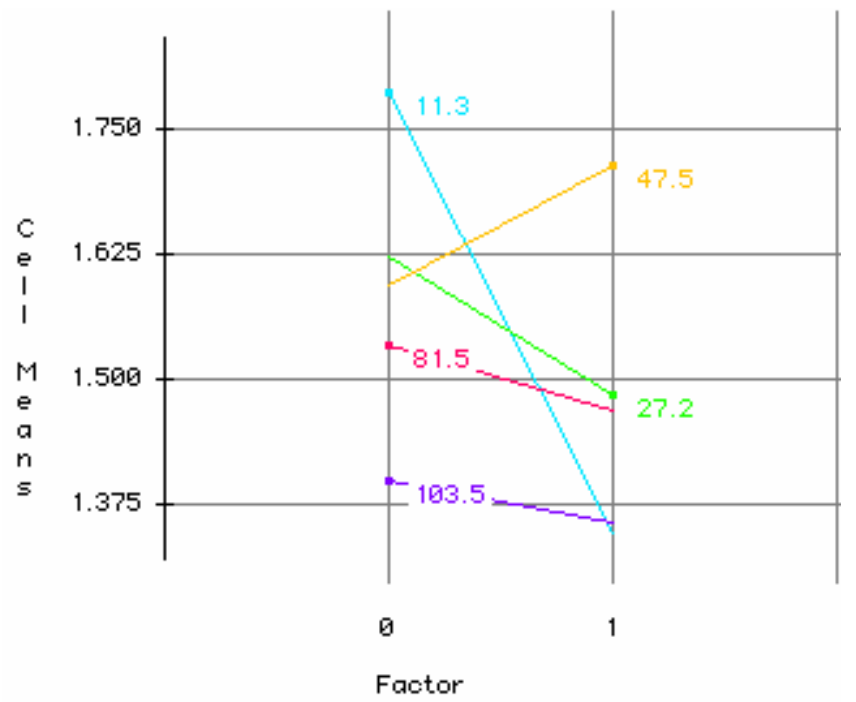

Figure F.28: Interaction plot of velocity $\mathrm{x}$ heating for $\log \mathrm{C}_{\text {uppertorso }}$

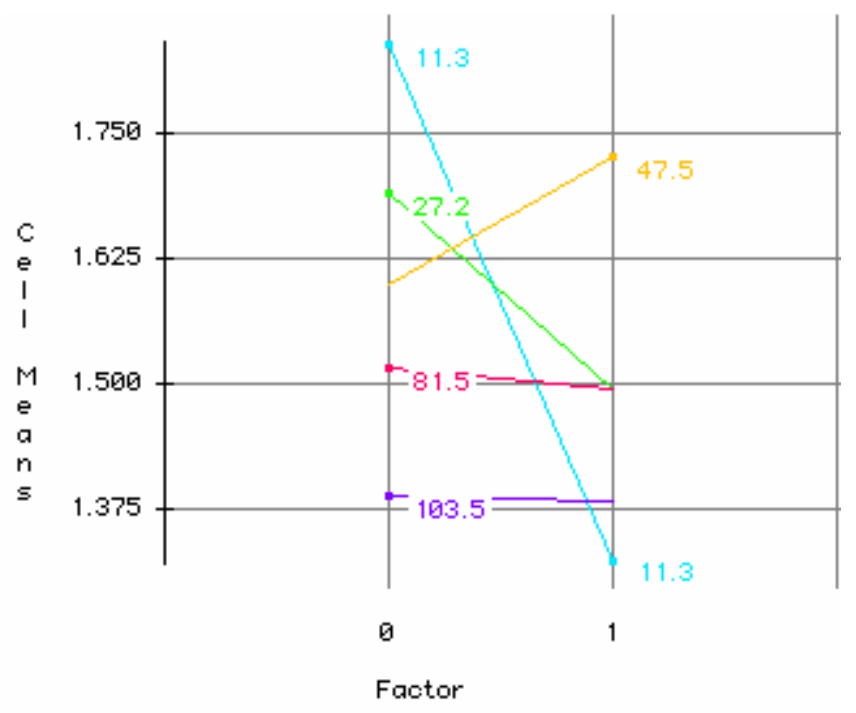

Figure F.29: Interaction plot of velocity $\mathrm{x}$ heating for $\log \mathrm{C}_{\text {lowertorso }}$ 


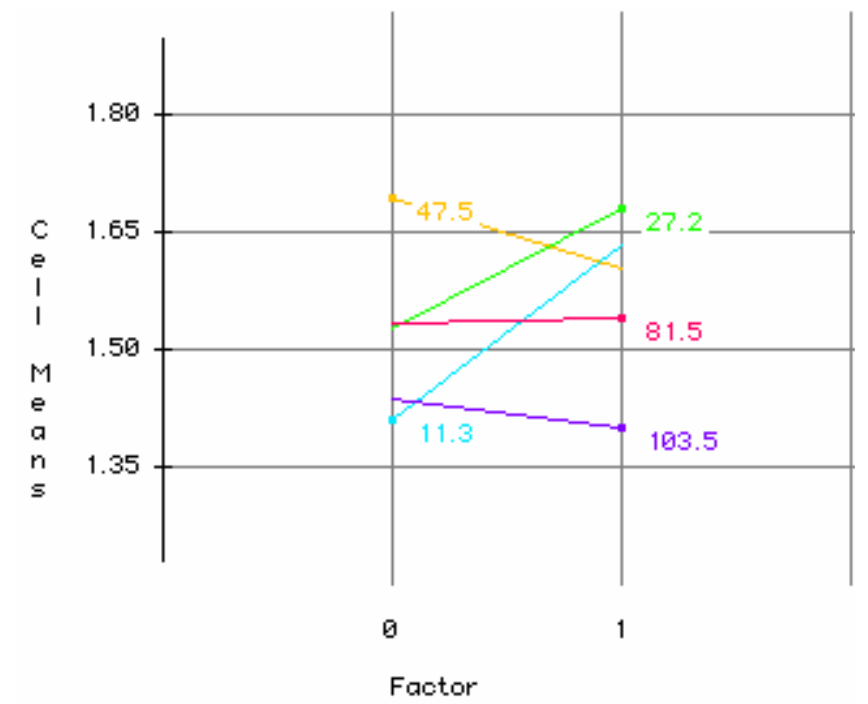

Figure F.30: Interaction plot of velocity x posture for $\log C_{\text {inhaled }}$

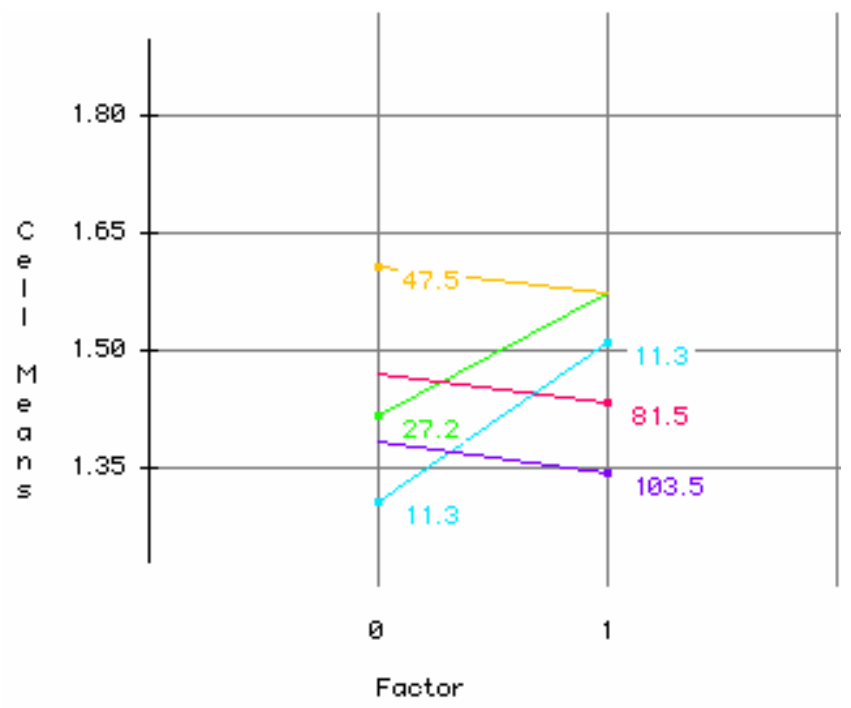

Figure F.31: Interaction plot of velocity x posture for $\log C_{\text {forehead }}$ 


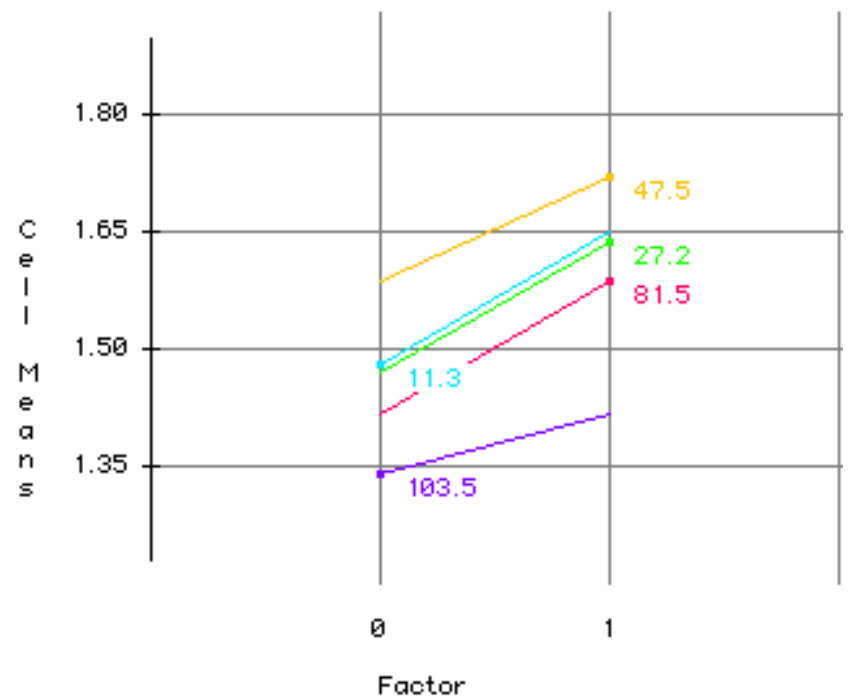

Figure F.32: Interaction plot of velocity x posture for $\log \mathrm{C}_{\text {uppertorso }}$

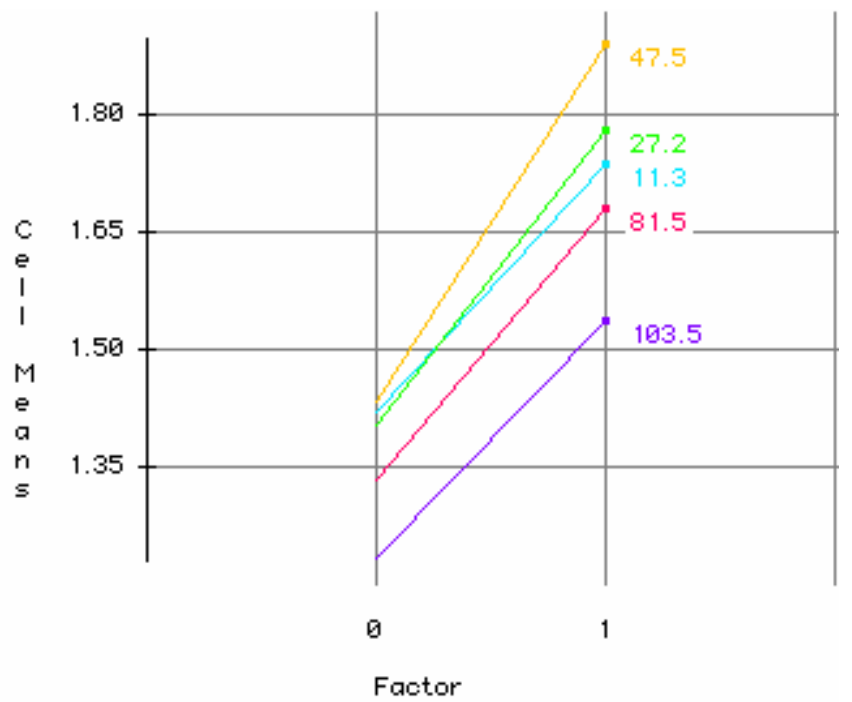

Figure F.33: Interaction plot of velocity x posture for $\log \mathrm{C}_{\text {lowertorso }}$ 


\section{Appendix G: Low Flow Pumps Calibration Sheet}

\begin{tabular}{|c|c|c|c|c|c|c|c|c|c|}
\hline \multirow[t]{2}{*}{$\#$} & \multirow[t]{2}{*}{ Line \# } & \multirow{2}{*}{$\begin{array}{c}\text { Passing } \\
\text { through } \\
\text { wall } \\
\text { hole \# }\end{array}$} & \multicolumn{2}{|c|}{$\begin{array}{l}\text { Who did line } \\
\text { leak tests? }\end{array}$} & \multirow[t]{2}{*}{$\begin{array}{l}\text { Sampling Line } \\
\text { Location }\end{array}$} & \multirow{2}{*}{$\begin{array}{c}\text { Pump \# } \\
\text { of } \\
\text { sampling } \\
\text { line }\end{array}$} & \multirow{2}{*}{$\begin{array}{l}\text { Pump } \\
\text { Model }\end{array}$} & \multirow[t]{2}{*}{$\begin{array}{c}\text { Pump } \\
\text { Serial \# }\end{array}$} & \multirow{2}{*}{$\begin{array}{c}\text { Flow rate } \\
\text { (lpm) } \\
\text { averaged } \\
\text { of } 3 \\
\text { measures }\end{array}$} \\
\hline & & & Earlier & Later & & & & & \\
\hline 1 & 6 & 6 & & W \& A & $\begin{array}{c}\text { RIGHT } \\
\text { COLLAR }\end{array}$ & 6 & $222-3$ & $02-057-08$ & 0.154 \\
\hline 2 & 5 & 5 & & $\mathrm{~W} \& \mathrm{~A}$ & $\begin{array}{l}\text { RIGHT } \\
\text { LAPEL } \\
\end{array}$ & 7 & $222-3$ & 02-057-09 & 0.154 \\
\hline 3 & 13 & 11 & $\mathrm{~W} \& \mathrm{~V}$ & $\mathrm{~W} \& \mathrm{~A}$ & "MOUTH 1 & $\bar{~} 1$ & $222-3$ & 02-121-01 & 0.152 \\
\hline 4 & 8 & 7 & & $\mathrm{~W} \& \mathrm{~A}$ & LEFT LAPEL & 2 & $222-3$ & $02-121-02$ & 0.154 \\
\hline 5 & 2 & 2 & & $\mathrm{~W} \& \mathrm{~A}$ & $\begin{array}{c}\text { LEFT } \\
\text { COLLAR }\end{array}$ & 10 & $222-3$ & $02-172-15$ & 0.153 \\
\hline 6 & 11 & 9 & $\mathrm{~W} \& \mathrm{~V}$ & $\mathrm{~W} \& \mathrm{~A}$ & NOSE & 4 & $222-3$ & $02-175-04$ & 0.149 \\
\hline 7 & 10 & 8 & & $\mathrm{~W} \& \mathrm{~A}$ & NECK & 5 & $222-3$ & 02-175-07 & 0.15 \\
\hline 8 & 4 & 4 & $\mathrm{~W} \& \mathrm{~V}$ & $\mathrm{~W} \& \mathrm{~A}$ & $\begin{array}{c}\text { CENTER } \\
\text { CHEST } \\
\end{array}$ & 8 & $222-3$ & $02-175-10$ & 0.153 \\
\hline 9 & 3 & 3 & $\mathrm{~W} \& \mathrm{~V}$ & $\mathrm{~W} \& \mathrm{~A}$ & FOREHEAD & 15 & $222-3$ & $03-160-02$ & 0.15 \\
\hline 10 & SOURCE & 11 & - & - & SOURCE & 14 & $222-3$ & $03-160-10$ & 0.152 \\
\hline 11 & 9 & 7 & & $\mathrm{~W} \& \mathrm{~A}$ & MOUTH 2 & 13 & $222-3$ & $03-168-32$ & 0.154 \\
\hline
\end{tabular}




\section{Appendix H: Ambient Conditions During Sampling}

\begin{tabular}{|c|c|c|c|c|c|c|c|}
\hline & $\begin{array}{c}\text { Rh } \\
\text { Indoor } \\
\%\end{array}$ & $\begin{array}{l}\text { Rh } \\
\text { Outdoor } \\
\%\end{array}$ & $\begin{array}{l}\text { Outdoor } \\
\text { Temp, F }\end{array}$ & $\begin{array}{c}\text { Pressure } \\
\text { mmHg }\end{array}$ & $\begin{array}{l}\text { Right } \\
\text { Wall } \\
{ }^{\circ} \mathrm{C}\end{array}$ & $\begin{array}{c}\text { Left } \\
\text { Wall } \\
{ }^{0} \mathrm{C}\end{array}$ & $\begin{array}{l}\text { Manikin } \\
\text { Temp_C }\end{array}$ \\
\hline Avg & 58 & 64 & 78 & 739 & 26 & 26 & 35 \\
\hline Std Dev & 8 & 9 & 2 & 3 & 1 & 1 & 2 \\
\hline $\mathrm{CV}$ & 14.6 & 13.6 & 2.8 & 0.4 & 4.8 & 5.1 & 5.2 \\
\hline Min & 40 & 47 & 74 & 733 & 24 & 24 & 33 \\
\hline Max & 76 & 82 & 81 & 744 & 28 & 28 & 37 \\
\hline
\end{tabular}




\section{Appendix I: GC Calibration Curve and Stability for Ethanol}
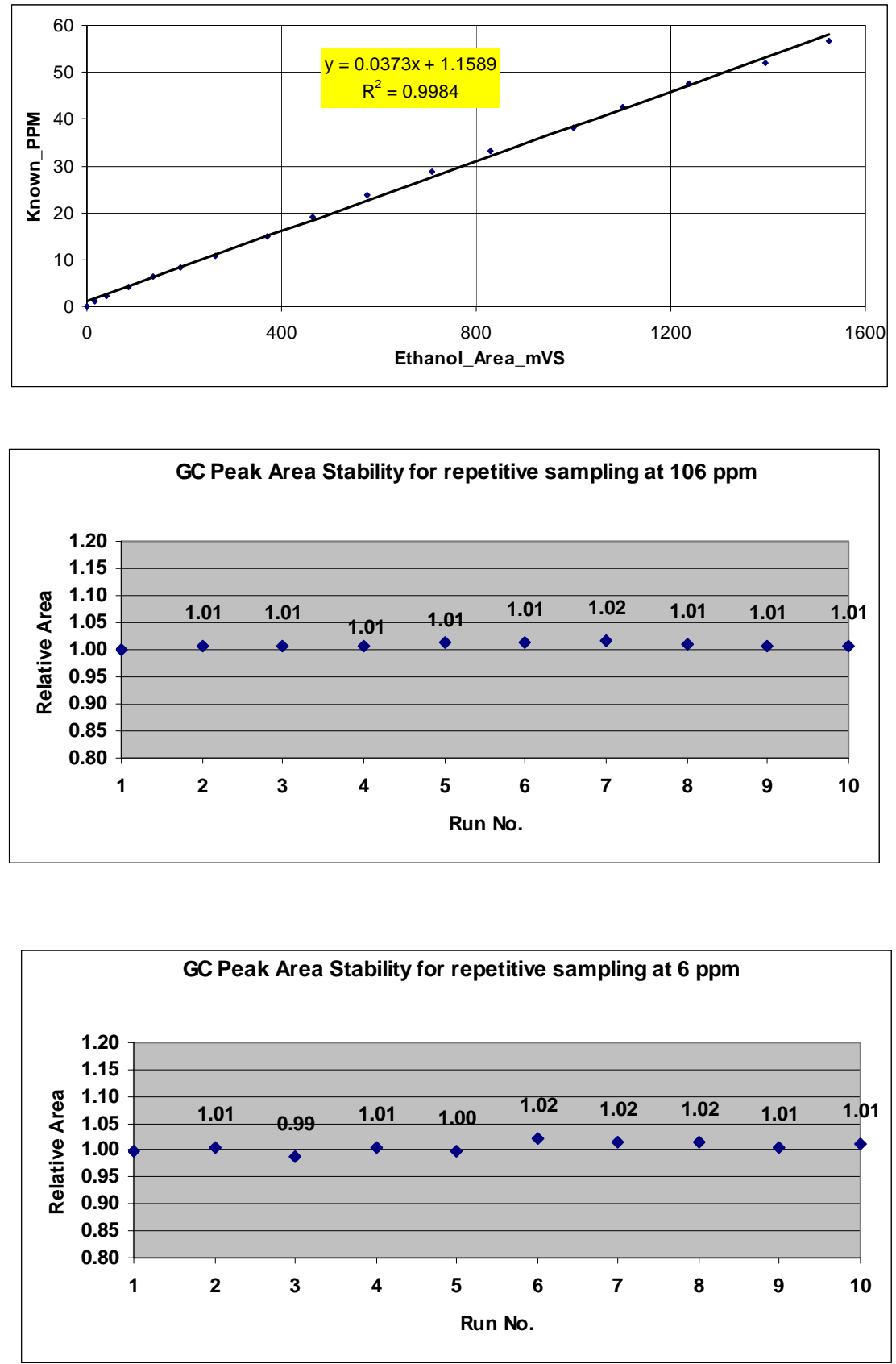


\section{Appendix J: Testing Sampling Line Losses}

Table J.1: Testing Leaks and Losses In Sampling Lines, Tests Performed On July 6, 04

\begin{tabular}{|l|c|c|c|}
\hline & $\begin{array}{c}\text { Ethanol Peak Area } \\
\text { (mVS) }\end{array}$ & $\begin{array}{c}\text { Ethanol Peak Height } \\
\text { (mV) }\end{array}$ & $\begin{array}{c}\text { \% losses in sampling } \\
\text { lines }\end{array}$ \\
\hline Source Before Testing & 2600 & 389 & 0.0 \\
\hline Source Before Testing & 2594 & 391 & 0.2 \\
\hline Source Before Testing & 2596 & 393 & 0.2 \\
\hline Source Before Testing & 2593 & 294 & 0.3 \\
\hline Source Before Testing & 2607 & 394 & -0.3 \\
\hline Right Lapel & 2451 & 367 & 6.1 \\
\hline Left Lapel & 2456 & 369 & 5.9 \\
\hline Center Chest & 2464 & 370 & 5.5 \\
\hline Neck & 2447 & 367 & 6.3 \\
\hline Mouth 1 & 2485 & 371 & 5.2 \\
\hline Nose & 2470 & 371 & 5.3 \\
\hline Forehead & 2438 & 365 & 6.6 \\
\hline Left Collar & 2440 & 366 & 6.6 \\
\hline Right Collar & 2464 & 370 & 5.5 \\
\hline Mouth 2 & 2475 & 371 & 5.6 \\
\hline Source After Testing & 2580 & 390 & 0.8 \\
\hline Source After Testing & 2574 & 391 & 1.0 \\
\hline
\end{tabular}




\section{Appendix K: Comparison of Ethanol and Acetone Adsorption in Tedlar AND TEFLON ${ }^{\mathrm{TM}}$ Bags}

\section{Comparison of Ethanol and Acetone Adsorption in Tedlar ${ }^{\mathrm{TM}}$ Bags}

\section{TABLE OF CONTENTS}

1. Introduction

2. Objective

3. Apparatus

4. Methodology

4.1 Sample preparation using Saturated Headspace Vapor

4.2 GC method development and calibration

5. Procedures

6. Results and Data Analysis

7. Conclusion

8. References

9. Appendices

Appendix A: Sample Calculation for Ethanol and Acetone concentrations Appendix B: General Procedures 


\section{Introduction}

Sampling bags composed of a wide variety of materials. The common types of material used in industrial hygiene applications are Teflon ${ }^{\mathrm{TM}}$ and Tedlar. Bags are commonly used to grab samples of air borne contaminants such as gases and vapors and to prepare laboratory calibration atmospheres. Physical and chemical properties of bag material are important to adapt with the type of solvent being sampled. Chemical and physical properties such as vapor permeability, inertness, storage stability, adsorption, desorption, and thermal and mechanical resistance of the bag material to sampling conditions and contaminants being sampled are important parameters to be studied before sampling. In this work, adsorption of acetone and ethanol vapor concentrations in Tedlar gas sampling bags was studied.

\section{Objective}

The objective of this experiment was to determine adsorption of ethanol and acetone vapor concentration (PPM) with time in Tedlar sampling bags.

\section{Apparatus}

The apparatus used to conduct this experiment is shown in figure 1 and consists of:

1. Photovac portable gas chromatograph with photoionization detector.

2. Five liter Tedlar bag with polypropelene valve.

3. Hamilton Gas tight syringes with side pore needles and of sizes 10 and $500 \mu l$ capacity.

4. Two 40-mL Vials with Teflon ${ }^{\mathrm{TM}_{-}}$-lined septa screw caps, one of them filled with pure liquid ethanol and the other with acetone.

5. Three liter air syringe that is used to measure dilution air volume

6. Lab thermometer hanged on a stand inside the hood used to measure ambient temperature during sample preparation.

7. Compressed hydrocarbon free air cylinder equipped with a single stage regulator and a high pressure air hose used to charge the GC internal carrier gas cylinder. 


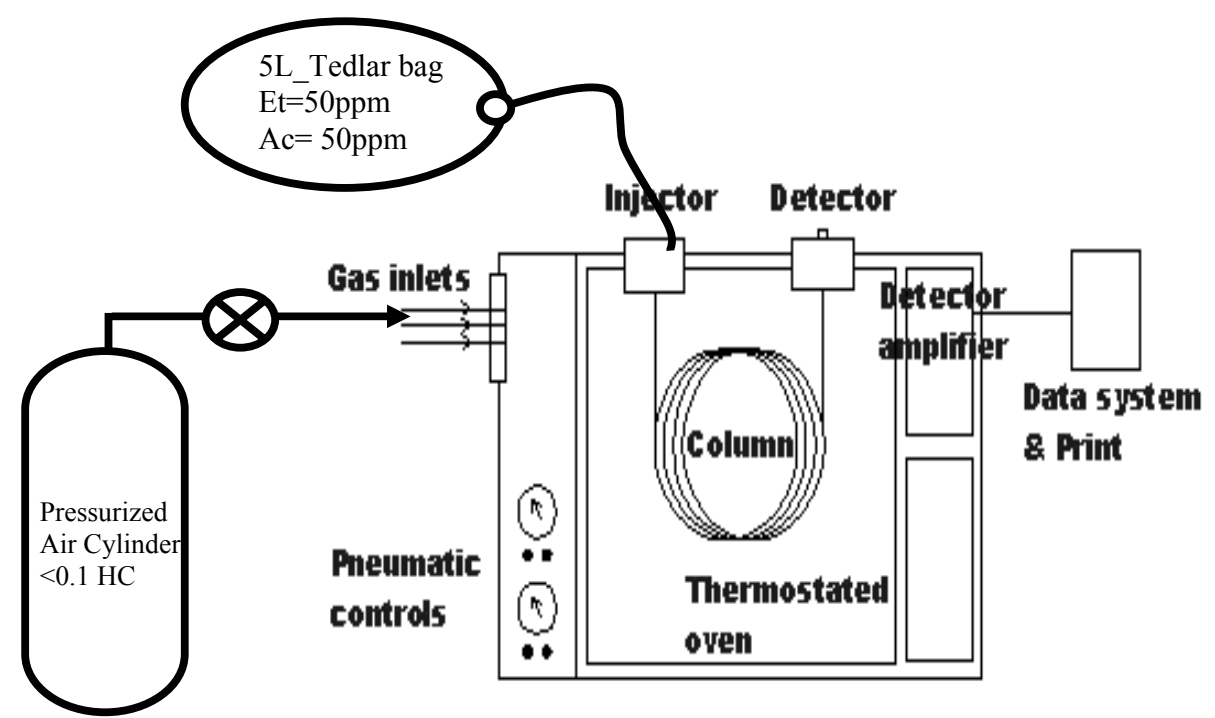

Fig 1: Simple Diagram of apparatus major components

\section{Methodology}

\subsection{Sample preparation using Saturated Headspace Vapor}

Preparation of standard known concentrations in parts per million (PPM) of ethanol and acetone vapors in Tedlar bags was made by diluting the saturated headspace vapor above the pure volatile liquid. This method was commonly used and considered efficient and less expensive than using pressurized cylinders of certified gas standards as illustrated in Thomas Boublik et al 1984. The general formula for preparing a standard from the headspace vapor above a volatile liquid was found in Thomas Boublik et al 1984 as:

where:

$$
\mathrm{V}_{\mathrm{HS}}=\left(101.325 / \mathrm{P}_{\mathrm{VP}}\right)(\mathrm{C})(\mathrm{V})
$$

$\mathrm{V}_{\mathrm{HS}}=$ Volume of headspace, $\mu \mathrm{L}$

$\mathrm{P}_{\mathrm{VP}}=$ Vapor pressure of liquid, $\mathrm{kPa}$

$\boldsymbol{C}=$ Desired concentration, PPM

$\boldsymbol{V}=$ Volume of air sampling bag, liters

The vapor pressure for ethanol and acetone is calculated from the Antoine Equation found in Thomas Boublik et al 1984 was shown as:

where:

$$
\log \mathrm{P}_{\mathrm{VP}}=\mathrm{A}-\mathrm{B} /(\mathrm{t}+\mathrm{C})
$$

$\mathrm{t}=$ Ambient temperature, ${ }^{\circ} \mathrm{C}$

$\mathrm{P}_{\mathrm{VP}}=$ Vapor pressure above the liquid surface, $\mathrm{kPa}$

$A, B, C=$ constants characteristics of each compound

A sample calculation of 50 PPM of ethanol and acetone using the headspace vapor method is found in Appendix A.

\subsection{GC method development and calibration}


Each compound (Ethanol and Acetone) had a unique retention time for each column in the gas chromatograph. The assay required to run column $\mathrm{C}$ to detect acetone and ethanol was made by reconfiguring the existing assay parameters for column $\mathrm{C}$ found in the GC library provided by the manufacture. These parameters were ethanol and acetone retention time, integration parameters, analysis time, backflush time, pump time, injection volume and oven temperature and pressure. Table 1 shows the configuration parameters required to run Ethanol and Acetone in column C of the Voyager GC_PID.

Table 1: Assay Configuration Parameters for acetone and ethanol

\begin{tabular}{|l|c|c|}
\hline Parameter & Configuration & Unit \\
\hline Ethanol Retention time & 144 & $\mathrm{Sec}$ \\
\hline Acetone Retention time & 174 & $\mathrm{Sec}$ \\
\hline Analysis Time & 420 & $\mathrm{Sec}$ \\
\hline Backflush time & 200 & $\mathrm{Sec}$ \\
\hline Pump Time & 15 & $\mathrm{Sec}$ \\
\hline Oven Temperature & 70 & ${ }^{\circ} \mathrm{C}$ \\
\hline Column Pressure & 8 & $\mathrm{Psi}$ \\
\hline Loop Injection & 2 & $\mathrm{Sec}$ \\
\hline PID State & High Sensitivity & - \\
\hline \multicolumn{2}{|c|}{ Integration Parameters } \\
\hline Slope Up & 0.3 & $\mathrm{mV} / \mathrm{S}$ \\
\hline Slope down & 0.2 & $\mathrm{mV} / \mathrm{S}$ \\
\hline Min Height & 0 & $\mathrm{mV}$ \\
\hline Min Area & 0 & $\mathrm{mVS}$ \\
\hline Integration Delay & 100 & $\mathrm{Sec}$ \\
\hline Filter level & 2 & - \\
\hline
\end{tabular}

Once the assay configuration was set, Column $\mathrm{C}$ was calibrated using linear curve fitting equation $\mathrm{y}=\mathrm{mx}+\mathrm{b}$.

Where,

$\mathrm{y}=$ Concentration, PPM

$\mathrm{x}=$ Peak Area, $\mathrm{mVS}$ or Peak Height, $\mathrm{mV}$

$\mathrm{m}=\mathrm{Slope}, \mathrm{PPM} / \mathrm{mVS}$ or $\mathrm{PPM} / \mathrm{mV}$

$\mathrm{b}=$ Intercept

By running blank samples and setting the intercept equal to zero $b=0$, thus, the calibration equation and its coefficient for acetone and ethanol using the above mentioned assay configuration is illustrated in the following table:

\begin{tabular}{|l|l|l|}
\hline Compound & Equation & Slope $=\mathrm{PPM} / \mathrm{mV}$ \\
\hline Acetone & $\mathrm{Y}=\mathrm{mX}$ & 0.0213 \\
\hline Ethanol & $\mathrm{Y}=\mathrm{mX}$ & 0.3 \\
\hline
\end{tabular}

\section{Procedures}

The procedures used to conduct this experiment are illustrated in detailed steps in appendix B. The procedures are divided into sub procedures as each will illustrate common 
steps for running blank samples, sample preparation using headspace vapor, sampling bag reconditioning, GC operation and so forth.

In this experiment, known concentration level of ethanol and acetone was prepared at 50 PPM using the methodology applied in 4.1. A five liter Tedlar bag was selected and tested for leaks at the seams and degassing at the valve by filling it to $50 \%$ capacity and immersing it in water bath. After leak check, the bag is labeled with tag number and identified with ethanol and acetone concentrations and the time and temperature of sample preparation. Then, the bag is flushed with hydrocarbon free air three times and filled up to $80 \%$ of its capacity (4 liter) with ambient air using the air syringe pump. Then, acetone and ethanol headspace vapor was withdrawn from two vials located in the lab hood and label named with acetone and ethanol using a $500 \mu \mathrm{l}$ gas tight syringe. In order to avoid syringe carry over through the glass walls and plunger, the syringe is flushed five times with fresh hood air and then three times with acetone vapor before withdrawing acetone headspace vapor from the vial. Then, the water bath temperature where ethanol and acetone vials were immersed was observed and found to be $21^{\circ} \mathrm{C}$ using the partial immersion mercury thermometer located inside the lab hood. Then, $750 \mu$ l of acetone vapor was withdrawn on two steps from the acetone vial and was injected in the 4 liter Tedlar bag. The same procedures were repeated for preparing ethanol concentration where $3250 \mu \mathrm{l}$ of ethanol headspace vapor were withdrawn and injected in the same bag. After that, the bag is shacked gently for 15 second and kept for ten minutes to allow for ethanol and acetone vapor to diffuse through the bag diluted volume. Then, the sampling bag is hooked to the sample in port and the analysis was performed as listed in appendix C. After conducting this test, contaminated air was discharged inside the lab hood and then the bag was flushed one time using hydrocarbon free air and filled with two liters of air and left for 15 minutes then measurement was taken to determine the residual concentration. The same procedures are repeated to flush the bag two more times.

\section{Results Discussion and Data Analysis}

During measuring acetone and ethanol concentrations using the voyager gas chromatograph, the ambient temperature was recorded for the two hour test and was found to be stable with in the range 24 to $25^{\circ} \mathrm{C}$. Measurements were taken every ten minutes for two hours and then two samples were taken after 8 hours from the beginning of the test. The reason behind this was to measure the adsorption of concentration in Tedlar bags with in short period of time as sampling will take place in the wind tunnel every twenty minutes from ten different locations. The GC analysis time is set to be seven minutes giving a total time of seventy minutes to analyze ten bags. As the number of runs will be extended to 120 minutes, this gives us 60 Tedlar bags for a complete wind tunnel run and 420 minutes for completed GC runs. Figure 1 shows variation of ethanol and acetone vapor concentrations using Tedlar bags at different intervals of time while figure 2 shows the percentage adsorbed of both ethanol and acetone concentrations, PPM, with time. Figure 1 illustrated that, after two hours of storage time inside a Tedlar bag, ethanol vapors have shown more stability than acetone vapors while table 1 had shown that percentage adsorbed of acetone concentration, PPM, after two hours of storage in a tedlar bag was found to be $6.35 \%$ while that of ethanol vapor was found to be $3.5 \%$. On the other hand, after 8 hours of storage time in Tedlar bags, 
the loss in PPM of ethanol vapor was found to be 40 percent of the original concentration value while that of acetone was found to be 50 percent.

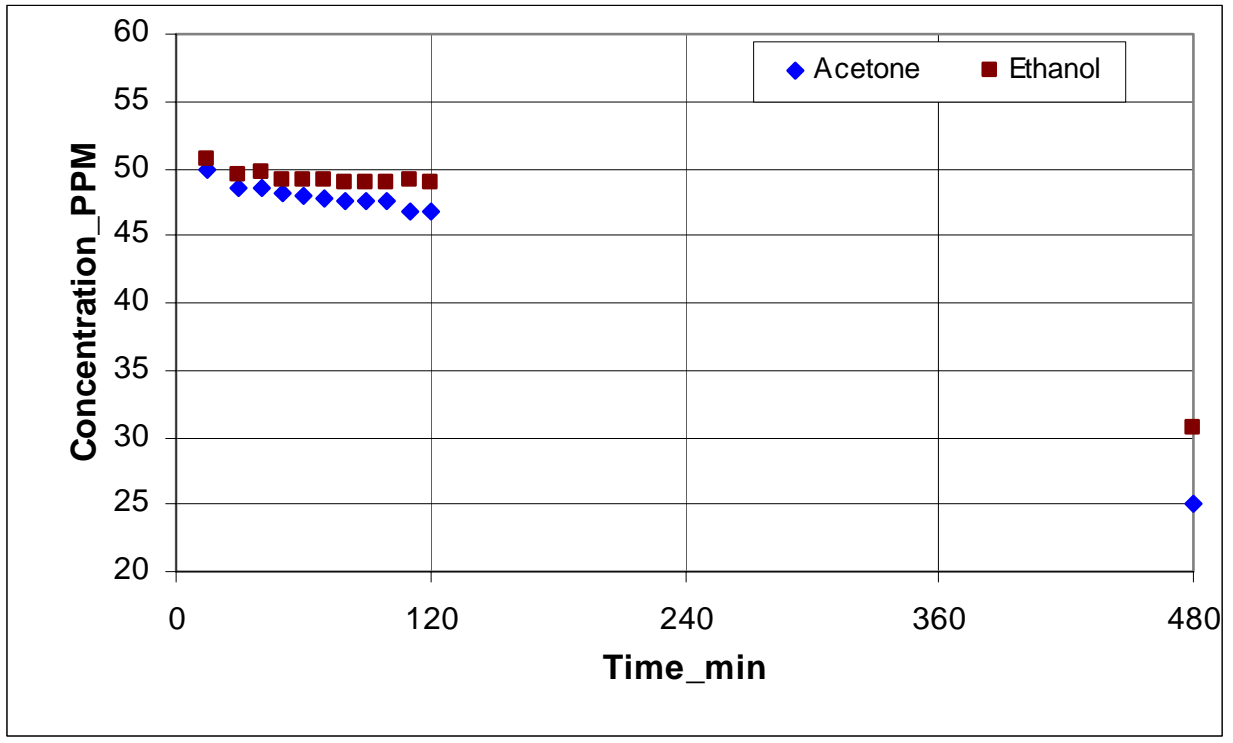

Fig. 1: Variation of ethanol and acetone concentration in Tedlar bags

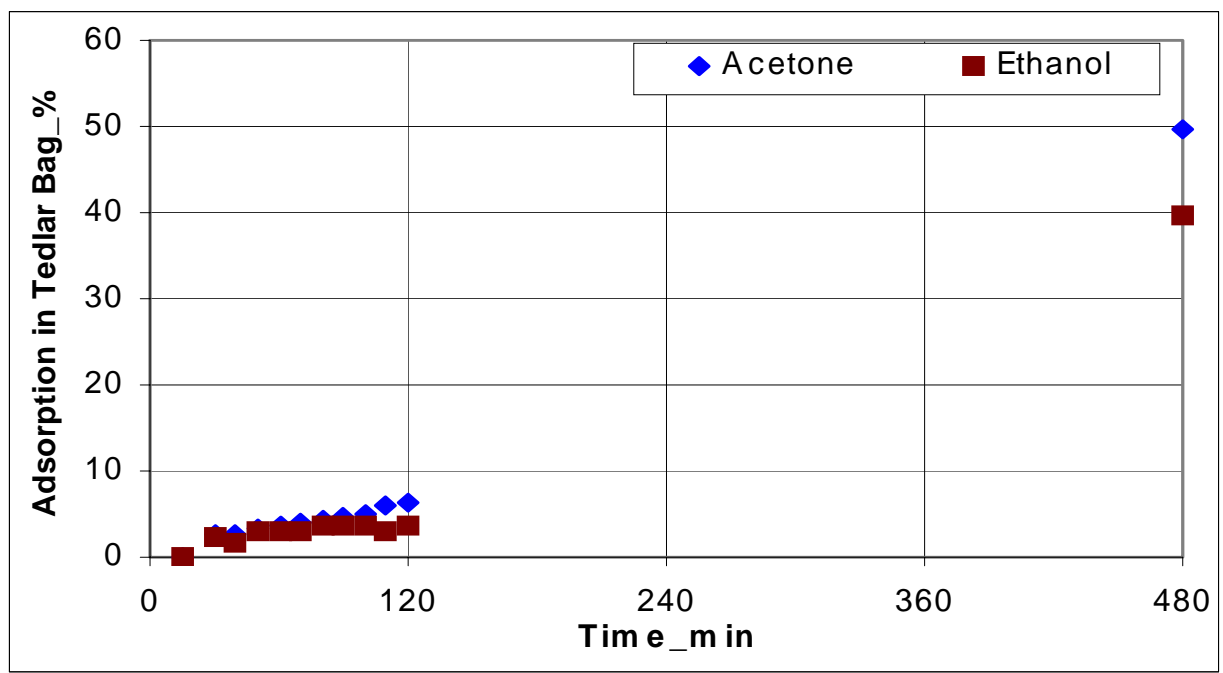

Fig. 2: Adsorption of ethanol and acetone vapors in Tedlar bags 
Table 1: Measured concentrations, PPM, for both Solvents at different interval of time

\begin{tabular}{|c|c|c|c|c|}
\hline$\underline{\text { Time min }}$ & $\underline{\text { Ac PrV PPM }}$ & Et PrV PPM & \% Adsorbed Acetone & \% Adsorbed Ethanol \\
\hline 15 & 49.93 & 50.70 & 0.00 & 0.00 \\
\hline 30 & 48.61 & 49.50 & 2.59 & 2.37 \\
\hline 40 & 48.63 & 49.80 & 2.55 & 1.78 \\
\hline 50 & 48.16 & 49.20 & 3.49 & 2.96 \\
\hline 60 & 48.05 & 49.20 & 3.70 & 2.96 \\
\hline 70 & 47.84 & 49.20 & 4.13 & 2.96 \\
\hline 80 & 47.67 & 48.90 & 4.47 & 3.55 \\
\hline 90 & 47.58 & 48.90 & 4.64 & 3.55 \\
\hline 100 & 47.48 & 48.90 & 4.85 & 3.55 \\
\hline 110 & 46.88 & 49.20 & 6.05 & 2.96 \\
\hline 120 & 46.73 & 48.90 & 6.35 & 3.55 \\
\hline 480 & 25.07 & 30.60 & 49.76 & 39.64 \\
\hline
\end{tabular}

Regarding desorbed amounts of ethanol and acetone vapors in Tedlar bags after bag reconditioning with hydrocarbon free air, figure 3 shows that after one flush the trace amounts of acetone was found to be 3 PPM while that of ethanol was found to be 1.2 PPM. While, flushing the bag two more times reduced the residual concentration by nearly $40 \%$ for both compounds giving a 1.2 PPM of acetone and 0.7 PPM of ethanol residue in the bag.

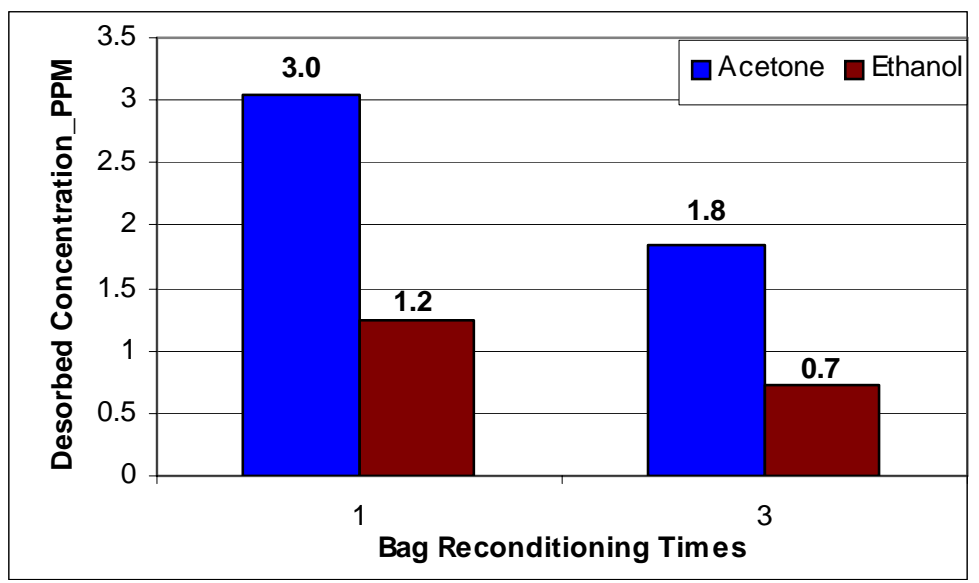

Fig. 3: Residual concentrations (PPM) of ethanol and acetone vapors in Tedlar bags 


\section{$\underline{\text { 7. Conclusion }}$}

In conclusion, Ethanol and Acetone adsorption with time in Tedlar bags was studied at 50 PPM concentration level for both compounds. It was found that Tedlar bags material adsorb higher amounts of acetone vapor than ethanol vapor at similar lab testing conditions. On the other hand both solvents have shown significant loss in PPM after 8 hours of storage in tedlar bags giving 50 percent of acetone vapor adsorbed and 40 percent of ethanol vapor. While, the residual concentration of ethanol was found to be lesser than acetone after flushing the bag three times.

Thus, it is recommended to run similar experiments using another bag material (Teflon ${ }^{\mathrm{TM}}$ ) and to test the difference between them at high and low concentration levels.

\section{References}

1. Thomas Boublik, Vojtech Fried and Eduard Hala: The vapor Pressures of pure substances, Elsvier Science Publishers B.V, The Netherlands, 1984, P. 4

2. The occupational Environment: its evaluation and control

3. Calculation Methods for Industrial Hygiene

4. Air Sampling Instruments for Evaluation of Atmospheric Contaminants

5. Fundamentals of Industrial Hygiene 


\section{Comparison of Ethanol and Acetone Adsorption in Teflon ${ }^{\mathrm{TM}}$ Bags}

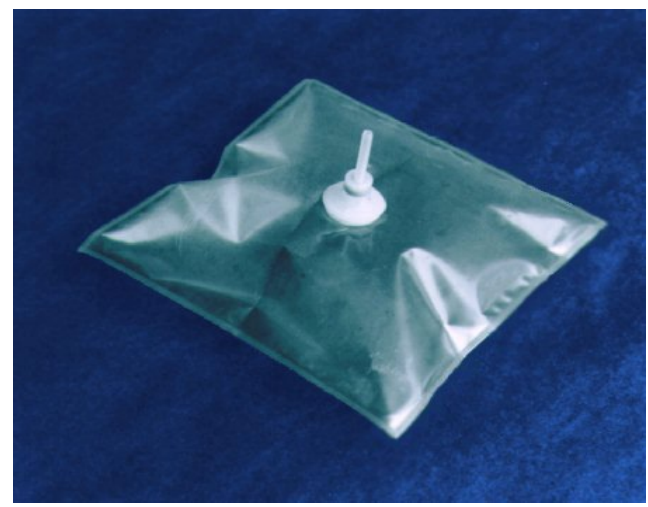

\section{TABLE OF CONTENTS}

1. Introduction

2. Objective

3. Apparatus

4. Methodology

4.1 Sample preparation using Saturated Headspace Vapor

4.2 GC method development and calibration

5. Procedures

6. Results and Data Analysis

7. Conclusion

8. References

9. Appendices

Appendix A: Sample Calculation for Ethanol and Acetone concentrations

Appendix B: General Procedures

Appendix C: Experimental Error Analysis

Appendix D: Theoretical Comparison of Ethanol and Acetone physical properties 


\section{Introduction}

Sampling bags composed of a wide variety of materials. The common types of material used in industrial hygiene applications are Teflon ${ }^{\mathrm{TM}}$ and Tedlar. Bags are commonly used to grab samples of air borne contaminants such as gases and vapors and to prepare laboratory calibration atmospheres. Physical and chemical properties of bag material are important to adapt with the type of solvent being sampled. Chemical and physical properties such as vapor permeability, inertness, storage stability, adsorption, desorption, and thermal and mechanical resistance of the bag material to sampling conditions and contaminants being sampled are important parameters to be studied before sampling. In this work, adsorption of acetone and ethanol vapor concentrations in Teflon ${ }^{\mathrm{TM}}$ gas sampling bags was studied.

\section{Objective}

The objective of this experiment was to determine adsorption of ethanol and acetone vapor concentration (PPM) with time in Teflon ${ }^{\mathrm{TM}}$ sampling bags.

\section{Apparatus}

The apparatus used to conduct this experiment is shown in figure 1 and consists of:

1. Photovac portable gas chromatograph with photoionization detector.

2. Three liter Teflon ${ }^{\mathrm{TM}}$ bag with polypropelene valve.

3. Hamilton Gas tight syringes with side pore needles and of sizes 10 and $500 \mu 1$ capacity.

4. Two 40-mL Vials with Teflon ${ }^{\mathrm{TM}}$-lined septa screw caps, one of them filled with pure liquid ethanol and the other with acetone.

5. Three liter air syringe that is used to measure dilution air volume

6. Lab thermometer hanged on a stand inside the hood used to measure ambient temperature during sample preparation.

7. Compressed hydrocarbon free air cylinder equipped with a single stage regulator and a high pressure air hose used to charge the GC internal carrier gas cylinder.

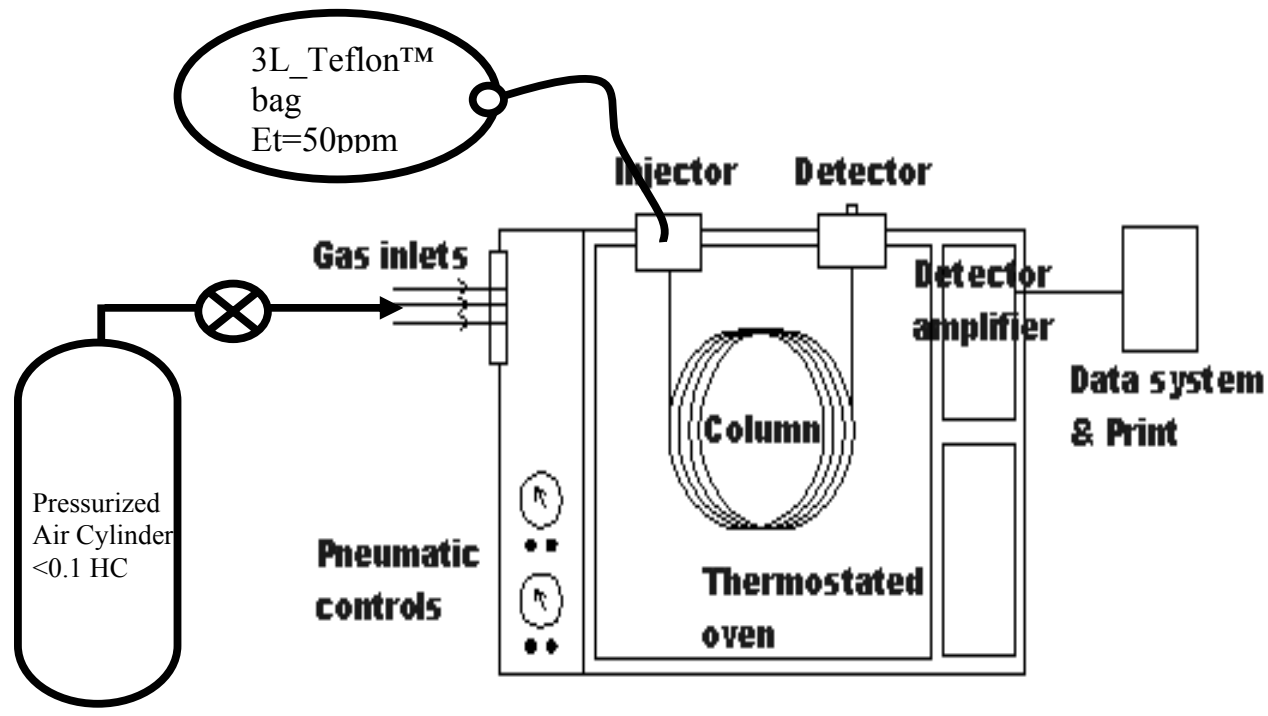

Fig 1: Simple Diagram of apparatus major components 


\section{Methodology}

\subsection{Sample preparation using Saturated Headspace Vapor}

Preparation of standard known concentrations in parts per million (PPM) of ethanol and acetone vapors in Teflon ${ }^{\mathrm{TM}}$ bags was made by diluting the saturated headspace vapor above the pure volatile liquid. This method was commonly used and considered efficient and less expensive than using pressurized cylinders of certified gas standards as illustrated in Thomas Boublik et al 1984. The general formula for preparing a standard from the headspace vapor above a volatile liquid was found in Thomas Boublik et al 1984 as:

$$
\mathrm{V}_{\mathrm{HS}}=\left(101.325 / \mathrm{P}_{\mathrm{VP}}\right)(\mathrm{C})(\mathrm{V})
$$

where:

$\mathrm{V}_{\mathrm{HS}}=$ Volume of headspace, $\mu \mathrm{L}$

$\mathrm{P}_{\mathrm{VP}}=$ Vapor pressure of liquid, $\mathrm{kPa}$

$\boldsymbol{C}=$ Desired concentration, PPM

$\boldsymbol{V}=$ Volume of air sampling bag, liters

The vapor pressure for ethanol and acetone is calculated from the Antoine Equation found in Thomas Boublik et al 1984 was shown as:

$$
\log \mathrm{P}_{\mathrm{VP}}=\mathrm{A}-\mathrm{B} /(\mathrm{t}+\mathrm{C})
$$

where:

$\mathrm{t}=$ Ambient temperature, ${ }^{\circ} \mathrm{C}$

$\mathrm{P}_{\mathrm{VP}}=$ Vapor pressure above the liquid surface, $\mathrm{kPa}$

$A, B, C=$ constants characteristics of each compound

A sample calculation of 50 PPM of ethanol and acetone using the headspace vapor method is found in Appendix A.

Table 1: Assay Configuration Parameters for acetone and ethanol

\begin{tabular}{|l|c|c|}
\hline Parameter & Configuration & Unit \\
\hline Ethanol Retention time & 121 & $\mathrm{Sec}$ \\
\hline Acetone Retention time & 147 & $\mathrm{Sec}$ \\
\hline Analysis Time & 200 & $\mathrm{Sec}$ \\
\hline Backflush time & 75 & $\mathrm{Sec}$ \\
\hline Pump Time & 15 & $\mathrm{Sec}$ \\
\hline Oven Temperature & 65 & ${ }^{\circ} \mathrm{C}$ \\
\hline Column Pressure & 10 & $\mathrm{Psi}$ \\
\hline Loop Injection & 2 & $\mathrm{Sec}$ \\
\hline PID State & High Sensitivity & - \\
\hline \multicolumn{3}{|c|}{ Integration Parameters } \\
\hline Slope Up & 4 & $\mathrm{mV} / \mathrm{S}$ \\
\hline Slope down & 8 & $\mathrm{mV} / \mathrm{S}$ \\
\hline Min Height & 0 & $\mathrm{mV}$ \\
\hline Min Area & 0 & $\mathrm{mVS}$ \\
\hline Integration Delay & 100 & $\mathrm{Sec}$ \\
\hline Filter level & 2 & - \\
\hline
\end{tabular}




\subsection{GC method development and calibration}

Each compound (Ethanol and Acetone) had a unique retention time for each column in the gas chromatograph. The assay required to run column $\mathrm{C}$ to detect acetone and ethanol was made by reconfiguring the existing assay parameters for column $\mathrm{C}$ found in the GC library provided by the manufacture. These parameters were ethanol and acetone retention time, integration parameters, analysis time, backflush time, pump time, injection volume and oven temperature and pressure. Table 1 shows the configuration parameters required to run Ethanol and Acetone in column C of the Voyager GC_PID.

Once the assay configuration was set, Column $\mathrm{C}$ was calibrated using linear curve fitting equation $\mathrm{y}=\mathrm{mx}+\mathrm{b}$.

Where,

$\mathrm{y}=$ Concentration, PPM

$\mathrm{x}=$ Peak Area, $\mathrm{mVS}$ or Peak Height, $\mathrm{mV}$

$\mathrm{m}=$ Slope, $\mathrm{PPM} / \mathrm{mVS}$ or PPM/mV

$\mathrm{b}=$ Intercept

By running blank samples and setting the intercept equal to zero $b=0$, thus, the calibration equation and its coefficient for acetone and ethanol using the above mentioned assay configuration is illustrated in the following table:

\begin{tabular}{|l|l|l|}
\hline Compound & Equation & Slope $=$ PPM $/ \mathrm{mVS}$ \\
\hline Acetone & $\mathrm{Y}=\mathrm{mX}$ & 0.00224 \\
\hline Ethanol & $\mathrm{Y}=\mathrm{mX}$ & 0.0449 \\
\hline
\end{tabular}

\section{Procedures}

The procedures used to conduct this experiment are illustrated in detailed steps in appendix B. The procedures are divided into sub procedures as each will illustrate common steps for running blank samples, sample preparation using headspace vapor, sampling bag reconditioning, GC operation and so forth.

In this experiment, known concentration level of ethanol and acetone was prepared at 50 PPM using the methodology applied in 4.1. A three liter Teflon ${ }^{\mathrm{TM}}$ bag was selected and tested for leaks at the seams and degassing at the valve by filling it to $50 \%$ capacity and immersing it in water bath. After leak check, the bag is labeled with tag number and identified with ethanol and acetone concentrations and the time and temperature of sample preparation. Then, the bag is flushed with hydrocarbon free air three times and filled up to $80 \%$ of its capacity ( 2.5 liter) with ambient air using the air syringe pump. Then, acetone and ethanol headspace vapor was withdrawn from two vials located in the lab hood and label named with acetone and ethanol using a $500 \mu \mathrm{l}$ gas tight syringe. In order to avoid syringe carry over through the glass walls and plunger, the syringe is flushed five times with fresh hood air and then three times with acetone vapor before withdrawing acetone headspace vapor from the vial. Then, the ambient temperature where ethanol and acetone vials were located was measured and found to be $25^{\circ} \mathrm{C}$ using the mercury thermometer located inside the lab hood. Then, $410 \mu 1$ of acetone vapor was withdrawn on from the acetone vial and was injected in the 2.5 liter Teflon ${ }^{\mathrm{TM}}$ bag. The same procedures were repeated for preparing ethanol concentration where $1600 \mu$ l of ethanol headspace vapor were withdrawn and injected in the same bag. After that, the bag is shacked gently for 15 second and kept for ten minutes 
to allow for ethanol and acetone vapor to diffuse and equilibrate through the bag diluted volume. Then, the sampling bag is hooked to the sample in port and the analysis was performed as listed in appendix B. After conducting this test, contaminated air was discharged inside the lab hood and then the bag was flushed one time using hydrocarbon free air and filled with two liters of air and left for 15 minutes then measurement was taken to determine the residual concentration. The same procedures are repeated to flush the bag two more times.

\section{Results Discussion and Data Analysis}

During measuring acetone and ethanol concentrations using the voyager gas chromatograph, the ambient temperature was recorded for the two hour test and was found to be stable with in the range $25 \pm 0.5{ }^{\circ} \mathrm{C}$. Measurements were taken every fifteen minutes for two hours and then two samples were taken after 4 hours and after 24 hours from the beginning of the test. The reason behind this was to measure the adsorption of ethanol and acetone vapor concentrations in Teflon ${ }^{\mathrm{TM}}$ bags with in short period of time as sampling will take place in the wind tunnel every twenty minutes from ten different locations and also after long period of time taking into consideration that some bags will be analyzed next day of runs. The $\mathrm{GC}$ analysis time is set to be seven minutes giving a total time of seventy minutes to analyze ten bags. As the number of runs will be extended to 180 minutes, this gives us 60 Teflon $^{\mathrm{TM}}$ bags for a complete wind tunnel run and 420 minutes for completed GC runs. Figure 1 shows variation of ethanol and acetone vapor concentrations in Teflon ${ }^{\mathrm{TM}}$ bags at different intervals of time while figure 2 shows the percentage adsorbed of both ethanol and acetone concentrations, PPM, with time. Figure 1 illustrated that, after two hours of storage time inside a Teflon ${ }^{\mathrm{TM}}$ bag, ethanol vapors have shown more stability than acetone vapors while table 1 had shown that percentage adsorbed of acetone concentration, PPM, after two hours of storage in a Teflon ${ }^{\mathrm{TM}}$ bag was found to be $3.2 \%$ while that of ethanol vapor was found to be $2.9 \%$. On the other hand, after 24 hours of storage time in Teflon ${ }^{\text {TM }}$ bags, the loss in PPM of ethanol vapor was found to be 10 percent of the original concentration value while that of acetone was found to be 16 percent.

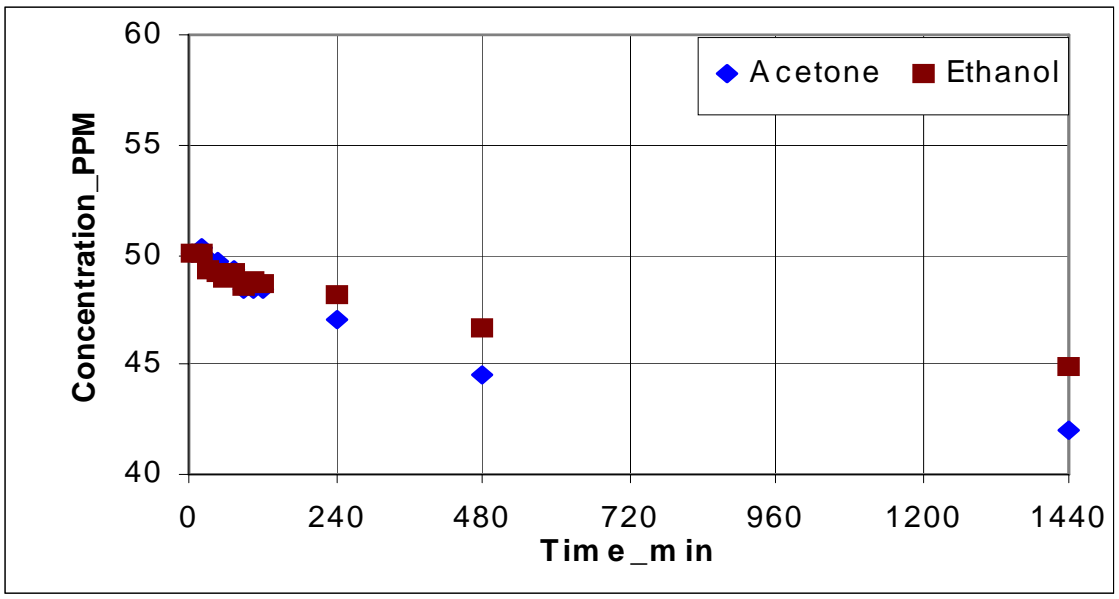

Fig. 1: Variation of ethanol and acetone concentration in Teflon ${ }^{\mathrm{TM}}$ bags 


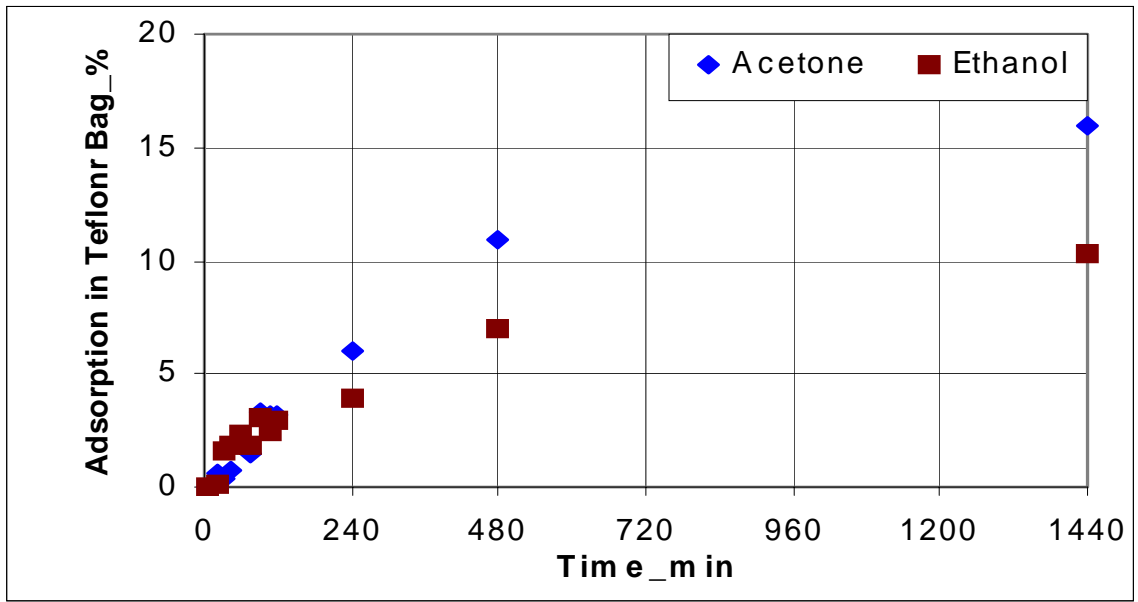

Fig. 2: Adsorption of ethanol and acetone vapors in Teflon ${ }^{\text {TM }}$ bags

Table 1: Measured concentrations, PPM, for both Solvents at different interval of time

\begin{tabular}{|c|c|c|c|c|}
\hline Time min & Ac PrV PPM & Et PrV PPM & \% Adsorbed Acetone & \% Adsorbed Ethanol \\
\hline 5 & 50.02 & 50.02 & 0.00 & 0.00 \\
\hline 20 & 50.30 & 50.06 & 0.55 & 0.07 \\
\hline 30 & 49.83 & 49.30 & 0.38 & 1.60 \\
\hline 45 & 49.64 & 49.17 & 0.75 & 1.87 \\
\hline 60 & 49.01 & 48.94 & 2.03 & 2.31 \\
\hline 75 & 49.28 & 49.17 & 1.48 & 1.87 \\
\hline 90 & 48.38 & 48.54 & 3.28 & 3.12 \\
\hline 105 & 48.45 & 48.85 & 3.14 & 2.49 \\
\hline 120 & 48.40 & 48.63 & 3.23 & 2.94 \\
\hline 240 & 47.01 & 48.13 & 6.01 & 3.93 \\
\hline 480 & 44.58 & 46.61 & 10.88 & 6.97 \\
\hline 1440 & 42.06 & 44.94 & 15.92 & 10.29 \\
\hline
\end{tabular}

Regarding desorbed amounts of ethanol and acetone vapors in Teflon ${ }^{\mathrm{TM}}$ bags after bag reconditioning with hydrocarbon free air, figure 3 shows that after one flush the trace amounts of acetone was found to be 2.2 PPM while that of ethanol was found to be 1.0 PPM. While, flushing the bag two more times reduced the residual concentration by nearly $40 \%$ for both compounds giving a 0.6 PPM of acetone and 0.4 PPM of ethanol residue in the bag.

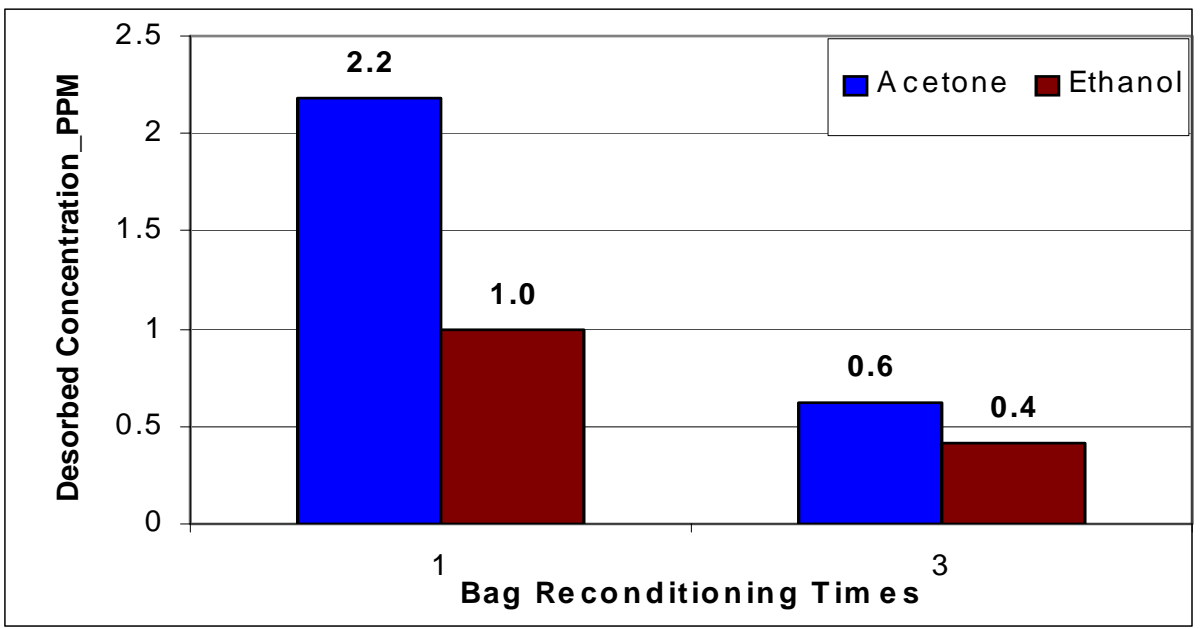

Fig. 3: Residual concentrations (PPM) of ethanol and acetone vapors in Teflon ${ }^{\mathrm{TM}}$ bags 


\section{Conclusion}

In conclusion, Ethanol and Acetone adsorption with time in Teflon ${ }^{\mathrm{TM}}$ bags was studied at 50 PPM concentration level for both compounds. It was found that Teflon ${ }^{\mathrm{TM}}$ bags material adsorb higher amounts of acetone vapor than ethanol vapor at similar lab testing conditions. On the other hand both solvents have shown reasonable loss in PPM after 24 hours of storage in Teflon ${ }^{\mathrm{TM}}$ bags giving 16 percent of acetone vapor adsorbed and 10 percent of ethanol vapor. While, the residual concentration of ethanol was found to be lesser than acetone after flushing the bag three times.

Thus, it is recommended to run similar experiments using another bag material (Teflon ${ }^{\mathrm{TM}}$ ) and to test the difference between them at high and low concentration levels. 


\section{Appendix L: Comparison of Ethanol and Acetone Adsorption in Tygon and Teflon $^{\mathrm{TM}}$ Tubings}

\section{Comparison of Ethanol and Acetone Adsorption in Tygon Tubing}

\section{TABLE OF CONTENTS}

1. Introduction

2. Objective

3. Apparatus

4. Methodology

4.1 Sample preparation using Saturated Headspace Vapor

4.2 GC method development and calibration

5. Procedures

6. Results and Data Analysis

7. Conclusion

8. References

9. Appendices

Appendix A: Sample Calculation for Ethanol and Acetone concentrations Appendix B: General Procedures

Appendix C: Experimental Error Analysis 


\section{Introduction}

Sampling tubes composed of a wide variety of materials. The common types of material used in industrial hygiene applications are Teflon ${ }^{\mathrm{TM}}$ and Tygon. Tubes are commonly used to carry air borne contaminants such as gases and vapors from the sampling location to the gas sampling bag. Physical and chemical properties of tube material are important to adapt with the type of compound being sampled. Chemical and physical properties such as vapor permeability, inertness, adsorption, desorption, and thermal and mechanical resistance of the tube material to sampling conditions and contaminants being sampled are important parameters to be studied before sampling. In this work, adsorption of acetone and ethanol vapor concentrations in Tygon sampling tubes was studied.

\section{Objective}

The objective of this experiment was to determine adsorption of ethanol and acetone vapor concentration (PPM) with time in Tygon Tubes.

\section{Apparatus}

The apparatus used to conduct this experiment is shown in figure 1 and 2 . It consists of:

1. Voyager portable gas chromatograph $10 \mathrm{~S}$ with Photo-ionization detector.

2. Two Five liter Tedlar bag with poly-propelene valve.

3. Hamilton Gas tight syringes with side pore needles and of sizes 10 and $500 \mu 1$ capacity.

4. Two 40-mL Vials with Teflon ${ }^{\mathrm{TM}}$-lined septa screw caps, one of them filled with pure liquid ethanol and the other with acetone.

5. Three liter air syringe that is used to measure dilution air volume

6. Lab thermometer hanged on a stand inside the hood used to measure ambient temperature during sample preparation.

7. Compressed hydrocarbon free air cylinder equipped with a single stage regulator and a high pressure air hose used to charge the GC internal carrier gas cylinder.

8. SKC low flow rate air sampling pump calibrated to $0.251 / \mathrm{min}$

9. A Tygon tube of internal diameter $3 / 16$ " and length $50 \mathrm{ft}$

10. The Tygon tube dimension, transport velocity and scavenging time are illustrated in the following Table:

\begin{tabular}{|l|l|l|l|l|l|l|}
\hline ID_ft & L_ft & Area_ft^2 & Vol_L & PFR_1/min & Vel_ft/min & $\begin{array}{l}\text { Scavenging } \\
\text { time_min }\end{array}$ \\
\hline 0.0156 & 50 & 0.00019 & 0.27 & 0.25 & 46.24 & 1.08 \\
\hline
\end{tabular}




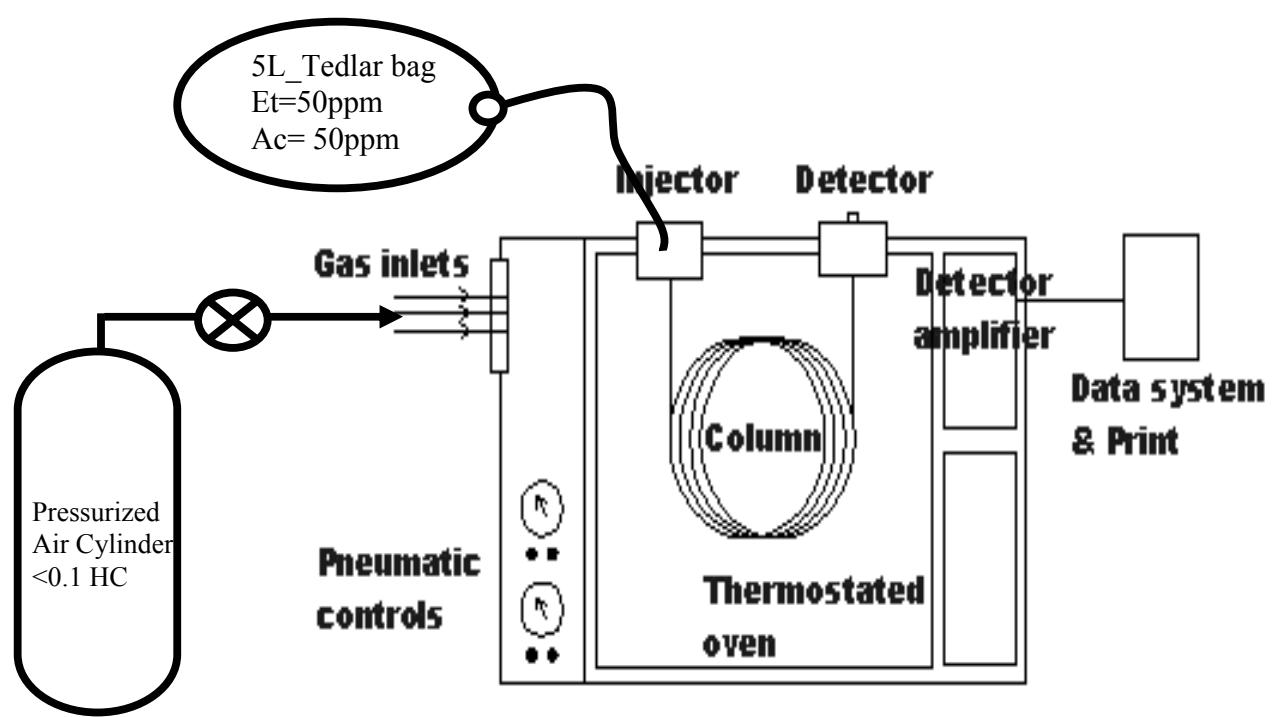

Fig 1: Simple Diagram of apparatus major components

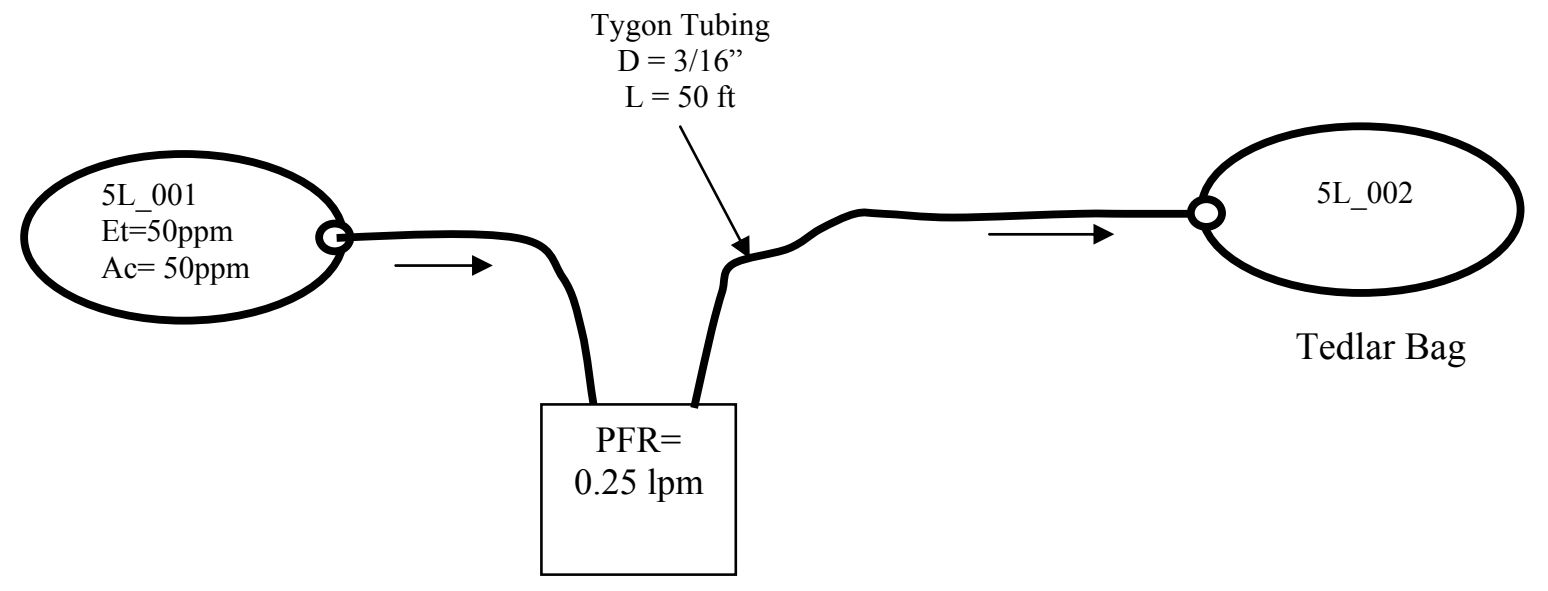

Fig 2: Sampling Train using Tygon Tube 


\section{Methodology}

\subsection{Sample preparation using Saturated Headspace Vapor}

Preparation of standard known concentrations in parts per million (PPM) of ethanol and acetone vapors in Tedlar/Teflon ${ }^{\mathrm{TM}}$ bags was made by diluting the saturated headspace vapor above the pure volatile liquid. This method was commonly used and considered efficient and less expensive than using pressurized cylinders of certified gas standards as illustrated in Thomas Boublik et al 1984. The general formula for preparing a standard from the headspace vapor above a volatile liquid was found in Thomas Boublik et al 1984 as:

$\mathrm{V}_{\mathrm{HS}}=\left(101.325 / \mathrm{P}_{\mathrm{VP}}\right)(\mathrm{C})(\mathrm{V})$

where:

$\mathrm{V}_{\mathrm{HS}}=$ Volume of headspace, $\mu \mathrm{L}$

$\mathrm{P}_{\mathrm{VP}}=$ Vapor pressure of liquid, $\mathrm{kPa}$

$C=$ Desired concentration, PPM

$\boldsymbol{V}=$ Volume of air sampling bag, liters

The vapor pressure for ethanol and acetone is calculated from the Antoine Equation found in Thomas Boublik et al 1984 was shown as:

$\log \mathrm{P}_{\mathrm{VP}}=\mathrm{A}-\mathrm{B} /(\mathrm{t}+\mathrm{C})$

where:

$\mathrm{t}=$ Ambient temperature, ${ }^{\circ} \mathrm{C}$

$\mathrm{P}_{\mathrm{VP}}=$ Vapor pressure above the liquid surface, $\mathrm{kPa}$

$\boldsymbol{A}, \boldsymbol{B}, \boldsymbol{C}=$ constants characteristics of each compound

A sample calculation of 50 PPM of ethanol and acetone using the headspace vapor method is found in Appendix A. 


\subsection{GC method development and calibration}

Each compound (Ethanol and Acetone) had a unique retention time for each column in the gas chromatograph. The assay required to run column $\mathrm{C}$ to detect acetone and ethanol was made by reconfiguring the existing assay parameters for column $\mathrm{C}$ found in the GC library provided by the manufacture. These parameters were ethanol and acetone retention time, integration parameters, analysis time, backflush time, pump time, injection volume and oven temperature and pressure. Table 1 shows the configuration parameters required to run Ethanol and Acetone in column $\mathrm{C}$ of the Voyager GC_PID.

Table 1: Assay Configuration Parameters for acetone and ethanol

\begin{tabular}{|c|c|c|}
\hline Parameter & Configuration & Unit \\
\hline Ethanol Retention time & 160 & Sec \\
\hline Acetone Retention time & 191 & Sec \\
\hline Analysis Time & 400 & Sec \\
\hline Backflush time & 200 & Sec \\
\hline Pump Time & 15 & Sec \\
\hline Oven Temperature & 60 & ${ }^{\circ} \mathrm{C}$ \\
\hline Column Pressure & 8 & Psi \\
\hline Loop Injection & 2 & Sec \\
\hline PID State & High Sensitivity & - \\
\hline \multicolumn{3}{|l|}{ Integration Parameters } \\
\hline Slope Up & 0.3 & $\mathrm{mV} / \mathrm{s}$ \\
\hline Slope down & 0.3 & $\mathrm{mV} / \mathrm{S}$ \\
\hline Min Height & 0 & $\mathrm{mV}$ \\
\hline Min Area & 0 & $\mathrm{mVS}$ \\
\hline Integration Delay & 40 & $\mathrm{Sec}$ \\
\hline Filter level & 2 & - \\
\hline
\end{tabular}

Once the assay configuration was set, Column $\mathrm{C}$ was calibrated using linear curve fitting equation $\mathrm{y}=\mathrm{mx}+\mathrm{b}$.

Where,

$\mathrm{y}=$ Concentration, $\mathrm{ppm}$

$\mathrm{x}=$ Peak Area, $\mathrm{mVS}$ or Peak Height, $\mathrm{mV}$

$\mathrm{m}=$ Slope, $\mathrm{PPM} / \mathrm{mVS}$ or PPM $/ \mathrm{mV}$

$\mathrm{b}=$ Intercept

By running blank samples and setting the intercept equal to zero $b=0$, thus, the calibration equation and its coefficient for acetone and ethanol using the above mentioned assay configuration is illustrated in the following table:

\begin{tabular}{|l|l|l|}
\hline Compound & Equation & Slope $=$ PPM $/ \mathrm{mVS}$ \\
\hline Acetone & $\mathrm{Y}=\mathrm{mX}$ & 0.0026 \\
\hline Ethanol & $\mathrm{Y}=\mathrm{mX}$ & 0.036 \\
\hline
\end{tabular}




\section{Procedures}

The procedures used to conduct this experiment are illustrated in detailed steps in appendix B. The procedures are divided into sub procedures as each will illustrate common steps for running blank samples, sample preparation using headspace vapor, sampling bag reconditioning, GC operation and so forth.

In this experiment, known concentration levels of ethanol and acetone were prepared at 50 ppm using the methodology applied in 4.1. A five liter Tedlar bag was selected and tested for leaks at the seams and degassing at the valve by filling it to $75 \%$ capacity and immersing it in water bath. After leak check, the bag is labeled with tag number and identified with ethanol and acetone concentrations and the time and temperature of sample preparation. Then, the bag is flushed with hydrocarbon free air three times and filled up to $80 \%$ of its capacity ( 4 liter) with ambient air using the air syringe pump. Then, acetone and ethanol headspace vapors were withdrawn from two vials located in the lab hood and label named with acetone and ethanol using a $500 \mu \mathrm{l}$ gas tight syringe. In order to avoid syringe carry over through the glass walls and plunger, the syringe is flushed five times with fresh hood air and then three times with acetone vapor before withdrawing acetone headspace vapor from the vial. Then, the ambient lab temperature where ethanol and acetone vials were located was observed and found to be $22.7^{\circ} \mathrm{C}$ using the mercury thermometer located inside the lab hood. Then, $730 \mu 1$ of acetone vapor was withdrawn on two steps from the acetone vial and was injected in the 4 liter Tedlar bag. The same procedures were repeated for preparing ethanol concentration where $2950 \mu \mathrm{l}$ of ethanol headspace vapor were withdrawn and injected in the same bag. After that, the bag is shacked gently for 15 second and kept for ten minutes to allow for ethanol and acetone vapor to diffuse through the bag diluted volume. Then, the sampling bag is hooked to the sample in port and the analysis was performed to measure acetone and ethanol concentrations in Tedlar bag 1. Then, the bag is hooked in the sampling train shown in figure 2 which consists of Tygon tube, Tedlar bag 2 and low flow rate pump calibrated and adjusted to $0.25 \mathrm{lpm}$. First, the pump was switched on and contaminated air is withdrawn from Tedlar bag 1 and allowed to pass through the $50 \mathrm{ft}$ Tygon tube to the ventilation hood for $120 \mathrm{sec}$ to ensure that the tube is flushed and scavenged from any dilution air. Then, the tube is hooked to Tedlar bag two and the pump is kept running for 12 minutes. After conducting this run, Tedlar bag two is hooked to the GC and analysis of ethanol and acetone took place. Then, a reconditioned bag (Tedlar bag three) is hooked to the sampling train at the same location of Tedlar bag two and the pump is switched on for 15 minutes and ambient air is withdrawn through the Tygon tube to bag three. Then, the same procedure was repeated two more times to determine the time needed to recondition the Tygon tube.

\section{Results Discussion and Data Analysis}

During measuring acetone and ethanol concentrations using the voyager gas chromatograph and running the experiment using the Tygon tube, the ambient temperature was recorded and found to be stable with in the range 24 to $25^{\circ} \mathrm{C}$. Figure 1 shows the percentage adsorbed of both ethanol and acetone concentrations, ppm, in tedlar bag one and two after withdrawing the contaminated air through Tygon tubes while figure 2 shows reconditioning time in minutes for Tygon tubes. Figure 1 illustrated that, after 12 minutes of pumping ethanol and acetone through Tygon tubes, the percentage adsorbed of acetone vapors in Tygon tubes was found to be $58 \%$ and that of ethanol was found to be $53 \%$. On the 
other hand, figure 2 illustrated that Tygon tubes require 50 minutes of withdrawing fresh air until getting the ethanol and acetone concentrations to approximately zero level.

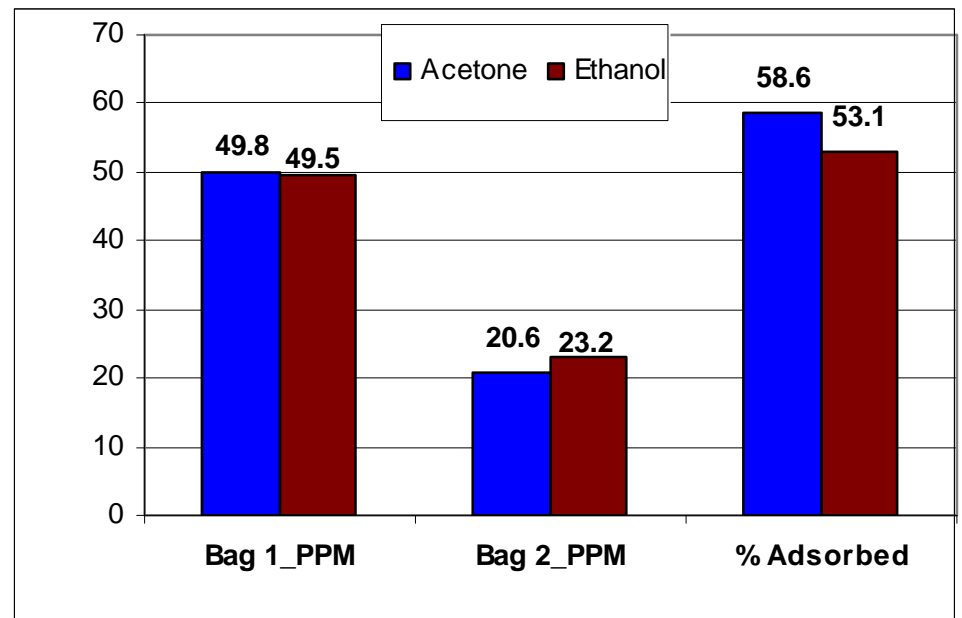

Fig. 1: Concentrations of ethanol and acetone and \% adsorbed in Tedlar bags $1 \& 2$ after withdrawing contaminants through Tygon tube

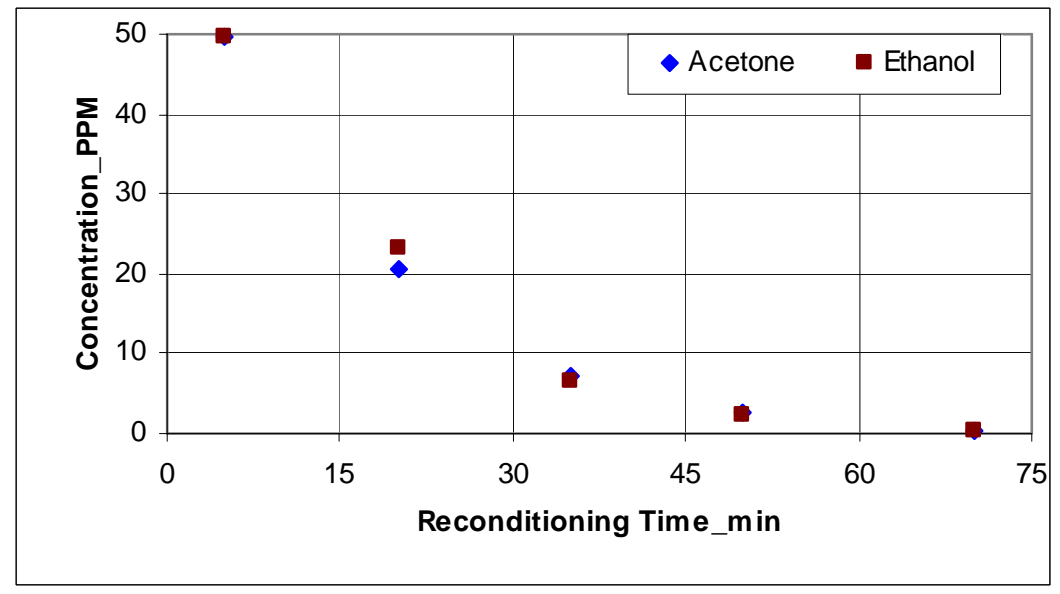

Fig. 2: Tygon tubing reconditioning time in minute

\section{Conclusion}

In conclusion, Ethanol and Acetone adsorption in Tygon tube was studied at 50 PPM concentration level for both solvents. It was found that Tygon tubes material adsorb similar amounts of acetone and ethanol vapors at similar lab testing conditions. On the other hand both solvents have shown significant loss in ppm after withdrawing vapors from bag one to bag two through tygon tube. While, the amount of time taken for tygon tube reconditioning at a flow rate of $0.25 \mathrm{lpm}$ was found to be 50 minutes.

Thus, it is recommended to run similar experiments using another tubing material $\left(\right.$ Teflon $^{\mathrm{TM}}$ ) and to test the difference between them at high and low concentration levels. 


\section{Comparison of Ethanol and Acetone Adsorption in Teflon ${ }^{\mathrm{TM}}$ Tubing}

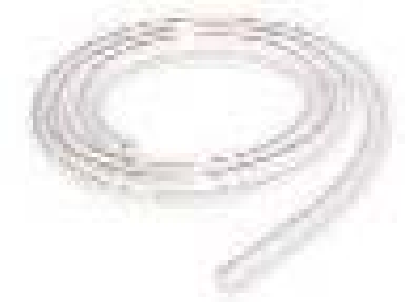

\section{TABLE OF CONTENTS}

1. Introduction

2. Objective

3. Apparatus

4. Methodology

4.1 Sample preparation using Saturated Headspace Vapor

4.2 GC method development and calibration

5. Procedures

6. Results and Data Analysis

7. Conclusion

8. References

9. Appendices

Appendix A: Sample Calculation for Ethanol and Acetone concentrations Appendix B: General Procedures Appendix C: Experimental Error Analysis

Appendix D: Theoretical Comparison of Ethanol and Acetone physical properties 


\section{Introduction}

Sampling tubes composed of a wide variety of materials. The common types of material used in industrial hygiene applications are Teflon ${ }^{\mathrm{TM}}$ and Tygon. Tubes are commonly used to carry air borne contaminants such as gases and vapors from the sampling location to the gas sampling bag. Physical and chemical properties of tube material are important to adapt with the type of compound being sampled. Chemical and physical properties such as vapor permeability, inertness, adsorption, desorption, and thermal and mechanical resistance of the tube material to sampling conditions and contaminants being sampled are important parameters to be studied before sampling. In this work, adsorption of acetone and ethanol vapor concentrations in Teflon ${ }^{\mathrm{TM}}$ sampling tubes was studied.

\section{Objective}

The objective of this experiment was to determine adsorption of ethanol and acetone vapor concentration (PPM) with time in Teflon ${ }^{\mathrm{TM}}$ Tubes.

\section{Apparatus} of:

The apparatus used to conduct this experiment is shown in figure 1 and 2 . It consists

1. Voyager portable gas chromatograph (10S) with Photo-ionization detector.

2. Two three liter Teflon ${ }^{\mathrm{TM}}$ bags with poly-propelene valve.

3. Hamilton Gas tight syringes with side pore needles and of sizes 10 and $500 \mu 1$ capacity.

4. Two 40-mL Vials with Teflon ${ }^{\mathrm{TM}}$-lined septa screw caps, one of them filled with pure liquid ethanol and the other with acetone.

5. Three liter air syringe that is used to measure dilution air volume

6. Lab thermometer hanged on a stand inside the hood used to measure ambient temperature during sample preparation.

7. Compressed hydrocarbon free air cylinder equipped with a single stage regulator and a high pressure air hose used to charge the GC internal carrier gas cylinder.

8. SKC low flow rate air sampling pump calibrated to $0.25 \mathrm{l} / \mathrm{min}$

9. A Teflon ${ }^{\mathrm{TM}}$ tube of internal diameter $3 / 16$ " and length 12 and $36 \mathrm{ft}$

10. The Teflon ${ }^{\mathrm{TM}}$ tube dimension, transport velocity and scavenging time are illustrated in the following Table:

\begin{tabular}{|l|l|l|l|l|l|l|}
\hline ID_ft & L_ft & Area_ft^2 & Vol_L & PFR_1/min & Vel_ft $/ \mathrm{min}$ & $\begin{array}{l}\text { Scavenging } \\
\text { time_min }\end{array}$ \\
\hline 0.0156 & 36 & 0.000191 & 0.2 & 0.125 & 23 & 1.5 \\
\hline
\end{tabular}




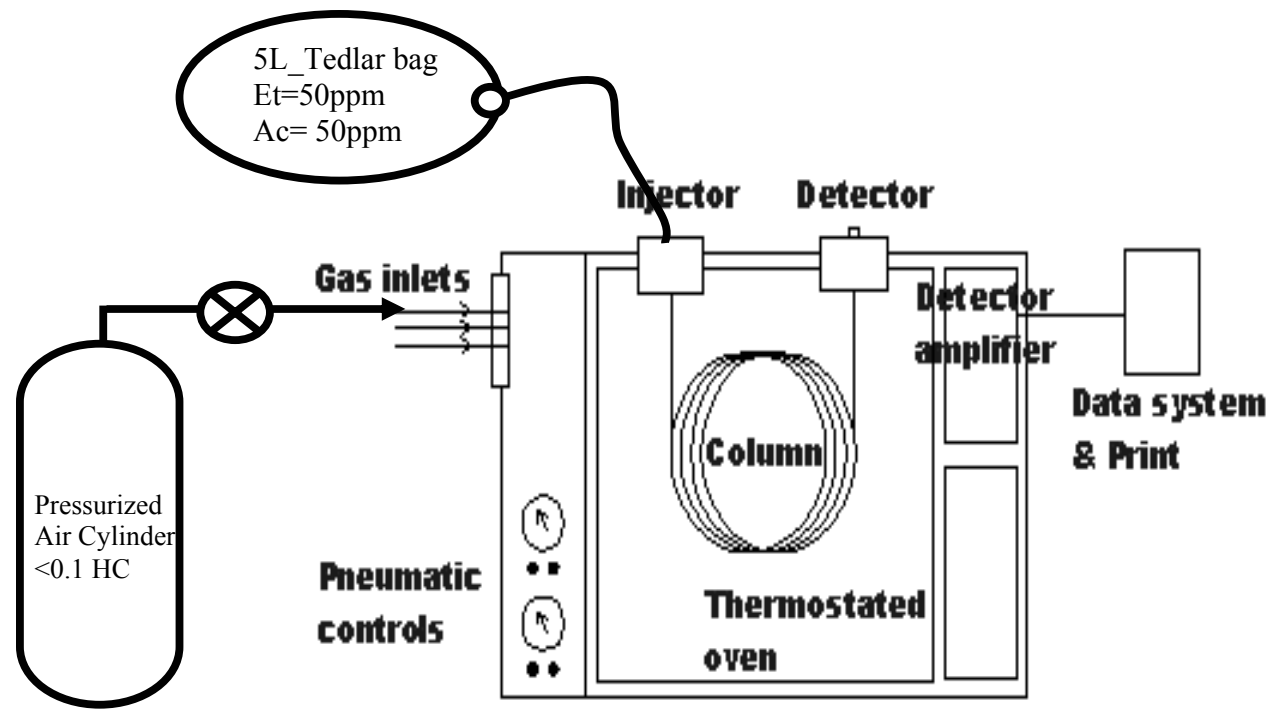

Fig 1: Simple Diagram of apparatus major components

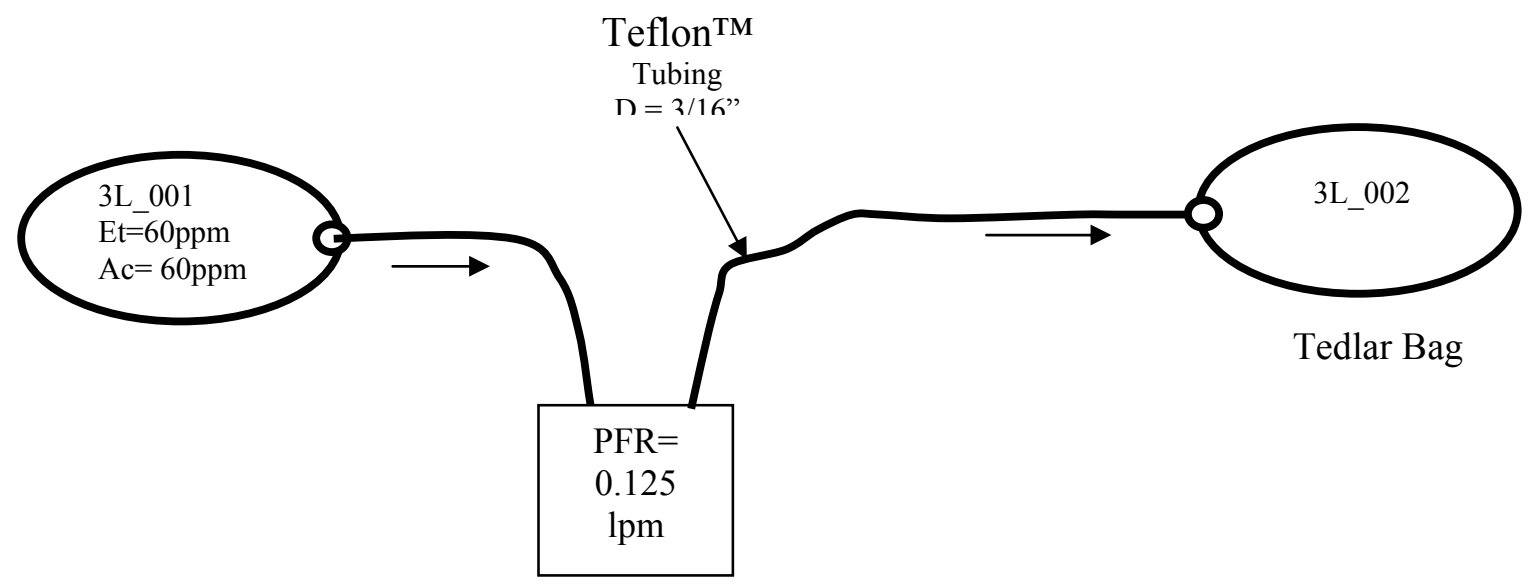

Fig 2: Sampling Train using Teflon ${ }^{\mathrm{TM}}$ Tube 


\section{Methodology}

\subsection{Sample preparation using Saturated Headspace Vapor}

Preparation of standard known concentrations in parts per million (PPM) of ethanol and acetone vapors in Tedlar / Teflon ${ }^{\mathrm{TM}}$ bags was made by diluting the saturated headspace vapor above the pure volatile liquid. This method was commonly used and considered efficient and less expensive than using pressurized cylinders of certified gas standards as illustrated in Thomas Boublik et al 1984. The general formula for preparing a standard from the headspace vapor above a volatile liquid was found in Thomas Boublik et al 1984 as:

$$
\mathrm{V}_{\mathrm{HS}}=\left(101.325 / \mathrm{P}_{\mathrm{VP}}\right)(\mathrm{C})(\mathrm{V})
$$

where:

$\mathrm{V}_{\mathrm{HS}}=$ Volume of headspace, $\mu \mathrm{L}$

$\mathrm{P}_{\mathrm{VP}}=$ Vapor pressure of liquid, $\mathrm{kPa}$

$\boldsymbol{C}=$ Desired concentration, PPM

$\boldsymbol{V}=$ Volume of air sampling bag, liters

The vapor pressure for ethanol and acetone is calculated from the Antoine Equation found in Thomas Boublik et al 1984 was shown as:

$$
\log \mathrm{P}_{\mathrm{VP}}=\mathrm{A}-\mathrm{B} /(\mathrm{t}+\mathrm{C})
$$

where:

$\mathrm{t}=$ Ambient temperature, ${ }^{\circ} \mathrm{C}$

$\mathrm{P}_{\mathrm{VP}}=$ Vapor pressure above the liquid surface, $\mathrm{kPa}$

$\boldsymbol{A}, \boldsymbol{B}, \boldsymbol{C}=$ constants characteristics of each compound

A sample calculation of 50 PPM of ethanol and acetone using the headspace vapor method is found in Appendix A.

\begin{tabular}{|c|c|c|}
\hline Parameter & Configuration & Unit \\
\hline Ethanol Retention time & 122.7 & Sec \\
\hline Acetone Retention time & 148.8 & $\mathrm{Sec}$ \\
\hline Analysis Time & 360 & Sec \\
\hline Backflush time & 110 & $\mathrm{Sec}$ \\
\hline Pump Time & 15 & $\mathrm{Sec}$ \\
\hline Oven Temperature & 65 & ${ }^{\circ} \mathrm{C}$ \\
\hline Column Pressure & 10 & Psi \\
\hline Loop Injection & 2 & $\mathrm{Sec}$ \\
\hline PID State & High Sensitivity & - \\
\hline \multicolumn{3}{|l|}{ Integration Parameters } \\
\hline Slope Up & 0.3 & $\mathrm{mV} / \mathrm{S}$ \\
\hline Slope down & 0.1 & $\mathrm{mV} / \mathrm{S}$ \\
\hline Min Height & 0 & $\mathrm{mV}$ \\
\hline Min Area & 0 & $\mathrm{mVS}$ \\
\hline Integration Delay & 40 & Sec \\
\hline Filter level & 2 & - \\
\hline
\end{tabular}

Table 1: Assay Configuration Parameters for acetone and ethanol 


\subsection{GC method development and calibration}

Each compound (Ethanol and Acetone) had a unique retention time for each column in the gas chromatograph. The assay required to run column $\mathrm{C}$ to detect acetone and ethanol was made by reconfiguring the existing assay parameters for column $\mathrm{C}$ found in the $\mathrm{GC}$ library provided by the manufacture. These parameters were ethanol and acetone retention time, integration parameters, analysis time, back flush time, pump time, injection volume and oven temperature and pressure. Table 1 shows the configuration parameters required to run Ethanol and Acetone in column C of the Voyager GC_PID.

Once the assay configuration was set, Column $\mathrm{C}$ was calibrated using linear curve fitting equation $\mathrm{y}=\mathrm{mx}+\mathrm{b}$.

Where,

$\mathrm{y}=$ Concentration, ppm

$\mathrm{x}=$ Peak Area, $\mathrm{mVS}$ or Peak Height, $\mathrm{mV}$

$\mathrm{m}=$ Slope, $\mathrm{ppm} / \mathrm{mVS}$ or $\mathrm{ppm} / \mathrm{mV}$

$\mathrm{b}=$ Intercept

By running blank samples and setting the intercept equal to zero $b=0$, thus, the calibration equation and its coefficient for acetone and ethanol using the above mentioned assay configuration is illustrated in the following table:

\begin{tabular}{|l|l|l|}
\hline Compound & Equation & Slope $=\mathrm{ppm} / \mathrm{mVS}$ \\
\hline Acetone & $\mathrm{Y}=\mathrm{mX}$ & 0.002 \\
\hline Ethanol & $\mathrm{Y}=\mathrm{mX}$ & 0.031 \\
\hline
\end{tabular}

\section{Procedures}

The procedures used to conduct this experiment are illustrated in detailed steps in Appendix B where they are divided into sub procedures as each will illustrate common steps for running blank samples, sample preparation using headspace vapor, sampling bag reconditioning, GC operation and so forth.

In this experiment, known concentration levels of ethanol and acetone were prepared at 60 ppm using the methodology applied in 4.1. A three liter Teflon ${ }^{\mathrm{TM}}$ bag was selected and tested for leaks at the seams and degassing at the valve by filling it to $75 \%$ capacity and immersing it in water bath. After leak check, the bag is labeled with tag number and identified with ethanol and acetone concentrations and the time and temperature of sample preparation. Then, the bag is flushed with hydrocarbon free air three times and filled up to $83 \%$ of its capacity ( 2.5 liter) with dilution air using the air syringe pump. Then, acetone and ethanol headspace vapors were withdrawn from two vials located in the lab hood and label named with acetone and ethanol using a $500 \mu \mathrm{l}$ gas tight syringe. In order to avoid syringe carry over through the glass walls and plunger, the syringe is flushed five times with fresh hood air and then three times with acetone vapor before withdrawing acetone headspace vapor from the vial. Then, the ambient lab temperature where ethanol and acetone vials were located was observed and found to be $24.7^{\circ} \mathrm{C}$ using the mercury thermometer located inside the lab hood. Then, $500 \mu l$ of acetone vapor was withdrawn from the acetone vial and was injected in the 2.5 liter dilution volume. The same procedures were repeated for preparing ethanol concentration where $2000 \mu \mathrm{l}$ of ethanol headspace vapor were withdrawn and injected in the same bag. After that, the bag is shacked gently for 15 second and kept for ten minutes to 
allow for ethanol and acetone vapor to diffuse through the bag diluted volume. Then, the sampling bag is hooked to the sample in port and the analysis was performed to measure acetone and ethanol concentrations in Teflon ${ }^{\mathrm{TM}}$ bag 1 . Then, the bag is hooked in the sampling train shown in figure 2 which consists of Teflon ${ }^{\mathrm{TM}}$ tube, Teflon ${ }^{\mathrm{TM}}$ bag 2 and low flow rate pump calibrated and adjusted to $0.125 \mathrm{lpm}$. First, the pump was switched on and contaminated air is withdrawn from Teflon ${ }^{\mathrm{TM}}$ bag 1 and allowed to pass through the $36 \mathrm{ft}$ Teflon $^{\mathrm{TM}}$ tube to the ventilation hood for $90 \mathrm{sec}$ to ensure that the tube is flushed and scavenged from any dilution air. Then, the tube is hooked to Teflon ${ }^{\mathrm{TM}}$ bag two and the pump is kept running for 15 minutes. After conducting this run, bag two is hooked to the GC and analysis of ethanol and acetone took place. Then, another bag (bag three) is hooked to the sampling train at the same location of Teflon ${ }^{\mathrm{TM}}$ bag two and the pump is switched on for 10 minutes and air is withdrawn through the Teflon ${ }^{\mathrm{TM}}$ tube to bag three. Then, the same procedure was repeated one more time to determine the time needed for Teflon ${ }^{\mathrm{TM}}$ tube reconditioning.

\section{Results Discussion and Data Analysis}

During measuring acetone and ethanol concentrations using the voyager gas chromatograph and running the experiment using the Teflon ${ }^{\mathrm{TM}}$ tube, the ambient temperature was recorded and found to be stable with in the range 24 to $25^{\circ} \mathrm{C}$. Figure 1 and 3 show the percentage adsorbed of both ethanol and acetone concentrations, ppm, in sampling bags one and two after withdrawing contaminated air through 12 and $36 \mathrm{ft} \mathrm{Teflon}{ }^{\mathrm{TM}}$ tubes while figure 2 shows the time taken in minutes for Teflon ${ }^{\mathrm{TM}}$ tubes reconditioning. While, Figure 4 compares ethanol and acetone vapors adsorption in 12 and $36 \mathrm{ft} \mathrm{Teflon}^{\mathrm{TM}}$ tubes. Figure 1 illustrated that, after 14 minutes of withdrawing ethanol and acetone through Teflon ${ }^{\mathrm{TM}}$ tubing, the percentage adsorbed of acetone vapors in Teflon ${ }^{\mathrm{TM}}$ tubes was found to be $4.1 \%$ and that of ethanol was found to be $3.7 \%$. On the other hand, figure 2 illustrated that Teflon ${ }^{\mathrm{TM}}$ tubes require 20 minutes of withdrawing fresh air until getting the ethanol and acetone concentrations to approximately zero level.

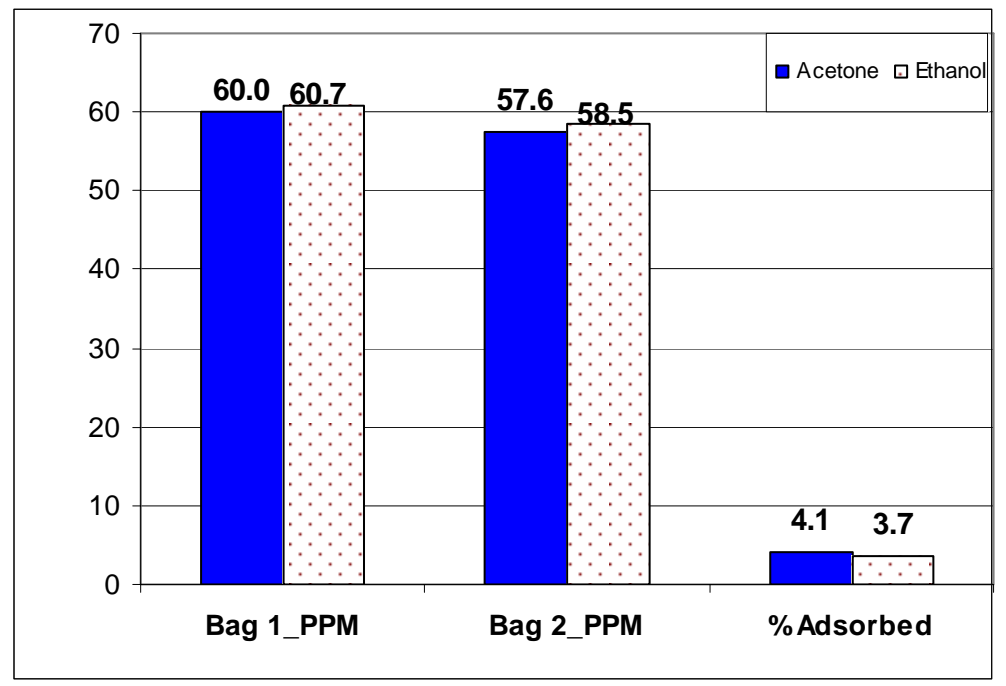

Fig. 1: Concentrations of ethanol and acetone in sampling bags and \% adsorbed after withdrawing vapors through $12 \mathrm{ft}$ Teflon $^{\mathrm{TM}}$ tube 


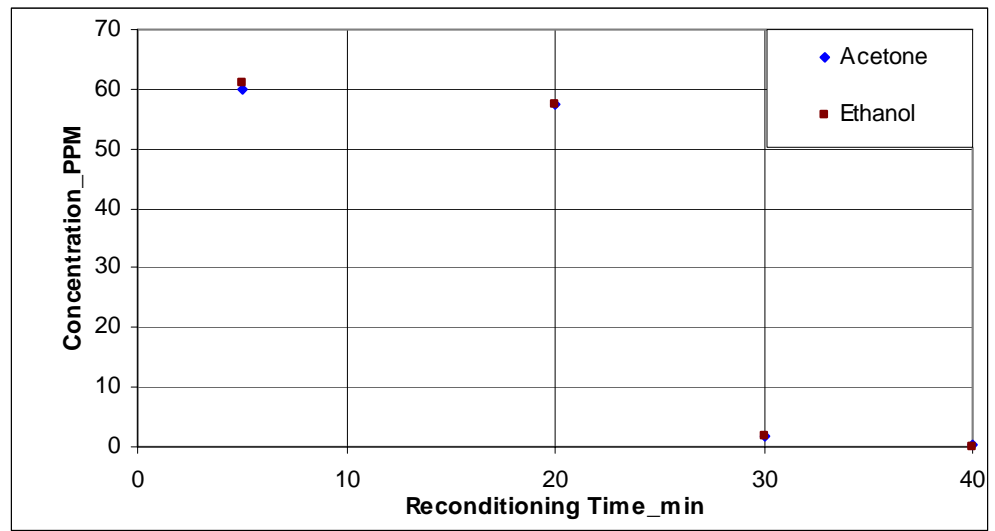

Fig. 2: Teflon ${ }^{\mathrm{TM}}$ tubing reconditioning time in minute

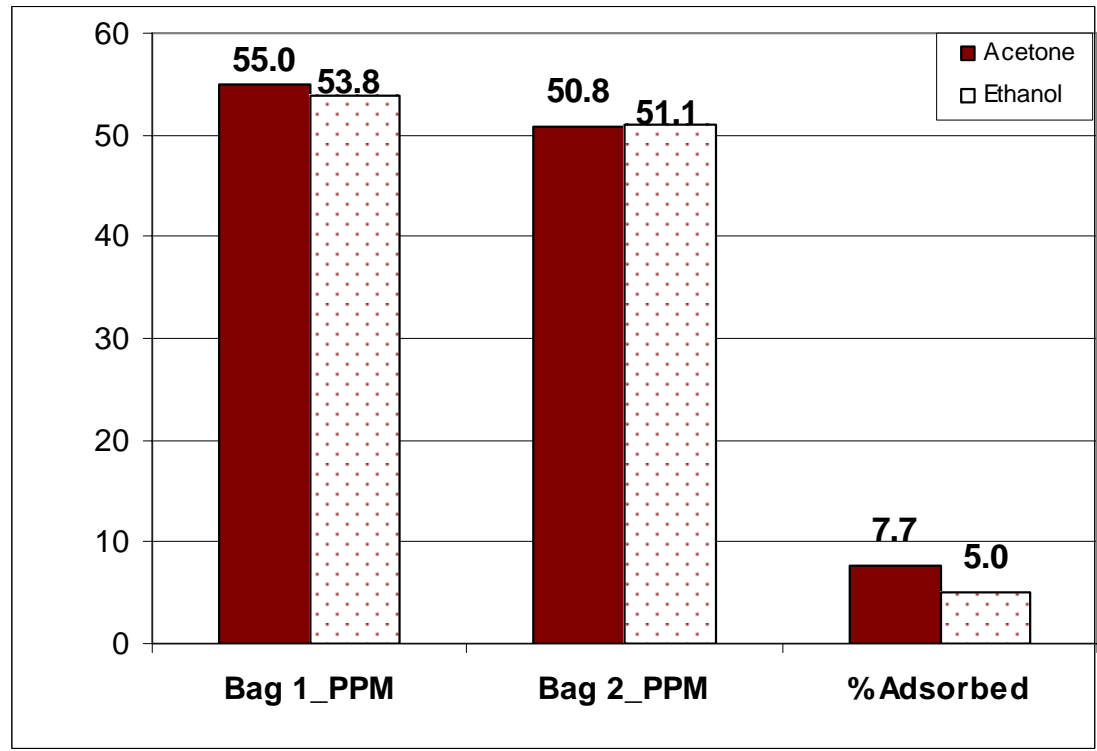

Fig. 3: Concentrations of ethanol and acetone in sampling bags and $\%$ adsorbed after withdrawing vapors through $36 \mathrm{ft}$ Teflon ${ }^{\mathrm{TM}}$ tube

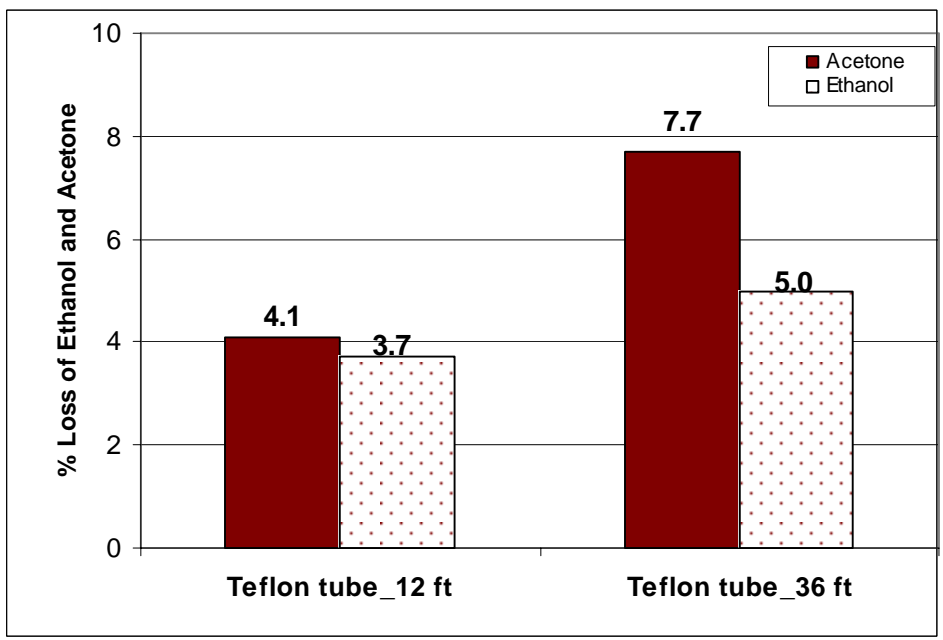

Fig. 4: \% Loss of ethanol and acetone vapors in 12 and $36 \mathrm{ft}$ Teflon ${ }^{\mathrm{TM}}$ tubes 


\section{$\underline{\text { 7. Conclusion }}$}

In conclusion, Ethanol and Acetone adsorption in Teflon ${ }^{\mathrm{TM}}$ tube was studied at 60 PPM concentration level for both solvents. It was found that Teflon ${ }^{\mathrm{TM}}$ tubes material approximately adsorbs similar amounts of acetone and ethanol vapors at similar lab testing conditions. On the other hand, Using Teflon ${ }^{\mathrm{TM}}$ tubes for both solvents have shown better performance and less adsorption values than Tygon tubes as studied in (6). While, the amount of time taken for Teflon ${ }^{\mathrm{TM}}$ tubes reconditioning with a pump flow rate of $0.125 \mathrm{lpm}$ were found to be 20 minutes and that of Tygon tube was 50 minutes as shown in (6).

Thus, it is recommended to run the wind tunnel experiments using Teflon ${ }^{\mathrm{TM}}$ tubing materials.

\section{References}

1. Thomas Boublik, Vojtech Fried and Eduard Hala: The vapor Pressures of pure substances, Elsvier Science Publishers B.V, The Netherlands, 1984, P. 4

2. The occupational Environment: its evaluation and control

3. Calculation Methods for Industrial Hygiene

4. Air Sampling Instruments for Evaluation of Atmospheric Contaminants

5. Fundamentals of Industrial Hygiene 


\section{Appendix M: Calibration of Voyager Portable Gas Chromatograph Using Headspace Vapor Method}

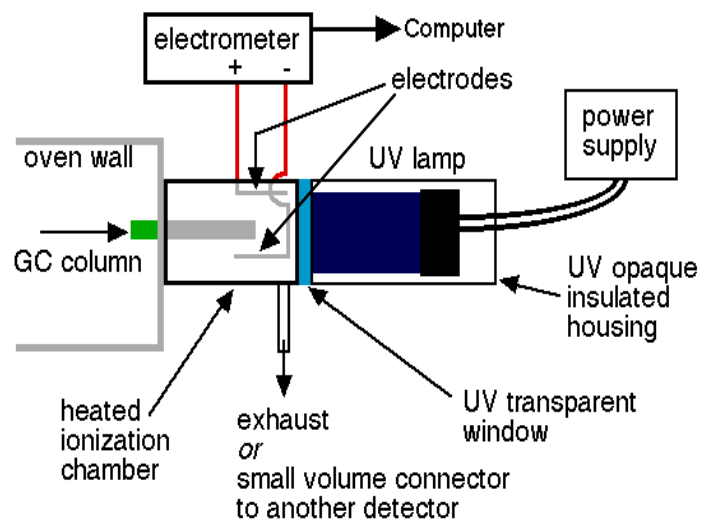

\section{TABLE OF CONTENTS}

1. Introduction

2. Objective

3. Apparatus

4. Methodology

4.1 Standard preparation using saturated headspace vapor

4.2 GC Software configuration and linear regression

5. Procedures

6. Results Discussion and Data Analysis

6.1 GC Linearity for Acetone Concentration Range 0.05 to $120 \mathrm{ppm}$

6.2 Statistical Analysis and Linear Regression

6.2.1 GC calibration data points for acetone using Column C on August 132002

6.2.2 GC calibration data points for acetone using Column C in September 112002

6.2.3 GC multipoint calibration for acetone using Column C in October 152002

6.2.4 GC multipoint calibration for acetone using Column A in Sep 3, 2002

6.2.5 GC calibration data points for acetone using Column C in December 4, 2002

6.2.6 GC Multipoint calibration for acetone using Column $\mathrm{C}$ by Investigators A \& B

6.2.7 GC Precision using Column $\mathrm{C}$ for acetone

7. Conclusion

8. References

9. Appendices

Appendix A: Sample Calculation for Ethanol and Acetone concentrations

Appendix B: General Procedures

Appendix $\quad \mathrm{C}$ : Experimental Error Analysis 


\section{Introduction}

Calibration is the relationship between an instrument response and a known standard. Once the relationship between the instrument response and the known value is established using least squares linear reqression model, the calibration curve is used in reverse so that it predicts measured value from the instrument response. This work focused on establishing a linear calibration curve for Voyager gas chromatograph of integrated peak areas (mVS) and known concentration levels (ppm) for acetone.

\section{Objective}

The objective of this experiment was to determine a linear calibration curve for the Voyager Portable Gas Chromatograph, integrated peak areas (mVS) versus known Concentration levels (ppm), for acetone using headspace vapor method.

\section{Apparatus}

The apparatus used to conduct this experiment is shown in figure 1 and consists of:

1. Photovac portable gas chromatograph with photoionization detector.

2.Five liter Tedlar bag with polypropelene valve.

3.Hamilton Gas tight syringes with side pore needles and of sizes 10 and $500 \mu 1$ capacity. 4.One 40-mL Vial with Teflon ${ }^{\mathrm{TM}}$-lined septa screw caps filled to $50 \%$ of its volume with pure liquid acetone.

5. Three liter calibration syringe used to measure diluted air volume

6.Lab thermometer hanged on a stand inside the hood used to measure ambient temperature during sample preparation.

7.Compressed hydrocarbon free air cylinder equipped with a single stage regulator and a high pressure air hose used to charge the GC internal carrier gas cylinder.

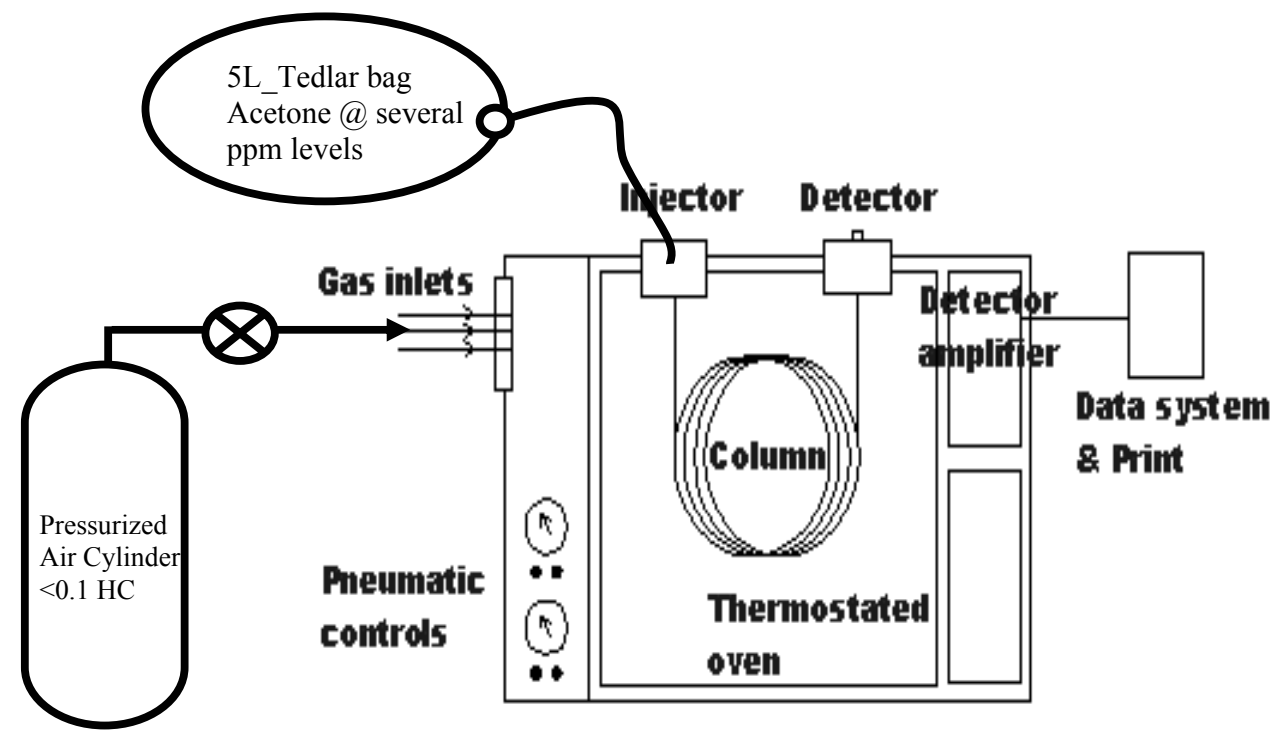

Fig 1: Simple Diagram of apparatus major components 


\section{Methodology}

\subsection{Standard Preparation using Saturated Headspace Vapor}

Preparation of known concentrations in parts per million (ppm) of acetone vapors in Tedlar bags was made by diluting the saturated headspace vapor above the pure volatile liquid. This method was commonly used and considered efficient and less expensive than using pressurized cylinders of certified gas standards as illustrated in Thomas Boublik et al 1984. The general formula for preparing a standard from the headspace vapor above a volatile liquid was found in Thomas Boublik et al 1984 as:

where:

$$
\mathrm{V}_{\mathrm{HS}}=\left(101.325 / \mathrm{P}_{\mathrm{VP}}\right)(\mathrm{C})(\mathrm{V})
$$

$\mathrm{V}_{\mathrm{HS}}=$ Volume of headspace, $\mu \mathrm{L}$

$\mathrm{P}_{\mathrm{VP}}=$ Vapor pressure of liquid, $\mathrm{kPa}$

$C=$ Desired concentration, PPM

$\boldsymbol{V}=$ Volume of air sampling bag, liters

The vapor pressure for acetone is calculated from the Antoine Equation found in Thomas Boublik et al 1984 and was shown as:

where:

$$
\log \mathrm{P}_{\mathrm{VP}}=\mathrm{A}-\mathrm{B} /(\mathrm{t}+\mathrm{C})
$$

$\mathrm{t}=$ Ambient temperature, ${ }^{\circ} \mathrm{C}$

$\mathrm{P}_{\mathrm{VP}}=$ Vapor pressure above the liquid surface, $\mathrm{kPa}$

$\boldsymbol{A}, \boldsymbol{B}, \boldsymbol{C}=$ constants characteristics of acetone

A sample calculation at $50 \mathrm{ppm}$ concentration level of acetone using the headspace vapor method is found in Appendix A.

\begin{tabular}{|c|c|c|}
\hline Parameter & Configuration & Unit \\
\hline Acetone Retention time & 191 & $\mathrm{Sec}$ \\
\hline Analysis Time & 420 & $\mathrm{Sec}$ \\
\hline Backflush time & 200 & $\mathrm{Sec}$ \\
\hline Pump Time & 15 & $\mathrm{Sec}$ \\
\hline Oven Temperature & 60 & ${ }^{\circ} \mathrm{C}$ \\
\hline Column Pressure & 8 & Psi \\
\hline Loop Injection & 2 & $\mathrm{Sec}$ \\
\hline PID State & High Sensitivity & - \\
\hline \multicolumn{3}{|l|}{ Integration Parameters } \\
\hline Slope Up & 0.3 & $\mathrm{mV} / \mathrm{S}$ \\
\hline Slope down & 0.2 & $\mathrm{mV} / \mathrm{S}$ \\
\hline Min Height & 0 & $\mathrm{mV}$ \\
\hline Min Area & 0 & $\mathrm{mVS}$ \\
\hline Integration Delay & 40 & $\mathrm{Sec}$ \\
\hline Filter level & 2 & - \\
\hline
\end{tabular}

Table 1: Assay Configuration Parameters for acetone 


\section{$\underline{4.2 \mathrm{GC} \text { Software configuration and linear regression }}$}

Each compound (Ethanol and Acetone) had a unique retention time for each column in the gas chromatograph. The assay required to run column $\mathrm{C}$ to detect acetone and ethanol was made by reconfiguring the existing assay parameters for column C found in the GC library provided by the manufacture. These parameters were acetone retention time, integration parameters, analysis time, backflush time, pump time, injection volume and oven temperature and pressure. It is important to optimize the assay used to run the GC for acetone before calibration as the integrated peak areas will differ from one integration setting to another as will be discussed later on in optimizing the GC assay configuration and integration parameters. Table 1 shows the configuration parameters required to run acetone in column $\mathrm{C}$ of the Voyager GC_PID.

The least squares method for linear regression for the calibration curve is illustrated by the following equation:

Where,

$$
\mathrm{Y}=\mathrm{aX}+\mathrm{b}
$$

$\mathrm{Y}=$ Acetone known Concentration, ppm

$\mathrm{X}=\mathrm{GC}$ response, acetone integrated peak area, $\mathrm{mVS}$

$\mathrm{a}=$ Slope, $\mathrm{ppm} / \mathrm{mVS}$

$\mathrm{b}=$ Intercept, $\mathrm{ppm}$

Important statistical parameters that are used in evaluating GC linearity and the error associated with the predicted ppm such as the correlation coefficient R-squared, the residual standard error (RSE), relative standard deviation RSD and the mean and standard deviation of repeated measurements are found in regression and calibration by shaun burke, RHM technology ltd, UK.

\section{$\underline{\text { 5. Procedures }}$}

The procedures used to conduct this experiment are illustrated in detailed steps in appendix B. The procedures are divided into sub procedures as each will illustrate common steps for running blank samples, sample preparation using headspace vapor, sampling bag reconditioning, GC operation and so forth.

In this experiment, known concentration levels ppm of acetone were prepared using the methodology applied in 4.1. Five liter Tedlar bags were selected to prepare calibration atmospheres of acetone and were tested for leaks at the seams and degassing at the valves by filling it to $50 \%$ capacity and immersing it in water bath. After leak check, the bag is labeled with a serial number and identified with acetone concentration, time and temperature during sample preparation. Then, the bag is flushed with hydrocarbon free air three times and filled up to $80 \%$ of its capacity ( 4 liter) with ambient air using the air syringe pump. Then, acetone headspace vapor was withdrawn from $40 \mathrm{ml}$ vial, located in the lab hood and labeled with acetone name, using a $500 \mu \mathrm{l}$ gas tight syringe. In order to avoid syringe carry over through the glass walls and plunger, the syringe is flushed five times with fresh hood air and then three times with acetone vapor before withdrawing acetone headspace vapor from the vial. Then, the ambient lab temperature where acetone vial is located was observed using the partial immersion mercury thermometer located inside the lab hood. The amount of acetone headspace vapor volume $\mu 1$ prepared for each concentration level is calculated and attached 
in the excel file in appendix E. Then, acetone vapor was injected in the 4 liter Tedlar bag. After that, the bag is shacked gently for 15 second and kept for ten minutes to allow for acetone vapor to diffuse through the bag diluted volume. Then, the sampling bag is hooked to the sample in port and the analysis was performed as listed in appendix B. After conducting this test, contaminated air was discharged inside the lab hood and then the bag was flushed two times using hydrocarbon free air and refilled with known air volume and used to prepare another concentration level.

\section{Results Discussion and Data Analysis}

\subsection{GC Linearity for Acetone Concentration Range 0.05 to 120 ppm}

During preparation of acetone concentrations and calibration of the voyager gas chromatograph, the ambient temperature was always recorded and found to be stable within $\pm 1^{\circ} \mathrm{C}$. Calibration atmospheres were prepared and measurements were taken every 10 to 15 minutes for each concentration level. One reason behind this was to allow for acetone vapor to diffuse through the bag dilution volume as injection of saturated head space happens at one point through the bag valve septa. The second reason was to analyze the bag within 15 minutes before adsorption of acetone vapor takes place at the bag walls. Figures 1 through 5 studied the linearity of $\mathrm{GC}$ response $\mathrm{mVS}$ versus a working concentration range of 0.05 to $120 \mathrm{ppm}$ for acetone only as will be illustrated. Figure 1 shows a plot of known concentration levels (ppm) versus integrated peak areas (mVS) while Figure 2 shows a plot of known concentration levels (ppm) versus integrated peak height $(\mathrm{mV})$ for acetone through the concentration range $0.05 \mathrm{ppm}$ to $120 \mathrm{ppm}$. Figure 1 illustrated that at high concentration levels of acetone $100 \mathrm{ppm}$ and above, the $\mathrm{GC}$ response is topping out and forming a straight line around the value of $50000 \mathrm{mVS}$. This is due to the fact that at these concentration levels the detector is saturated. While, Figure 2 illustrated that at $50 \mathrm{ppm}$ and above the integrated peak height is flat and topping out around the value of $2500 \mathrm{mV}$. This finding determined that the upper range of concentration levels that we can work on is $50 \mathrm{ppm}$ where above this range peak integration will occur exponentially because the integrator does not see a peak at this level, it is a flat line and the integrated peak area is function in time only. This point caused a slight non linearity in GC response (mVS) within the concentration range of 50 to $100 \mathrm{ppm}$ for acetone as shown in figure 3 .

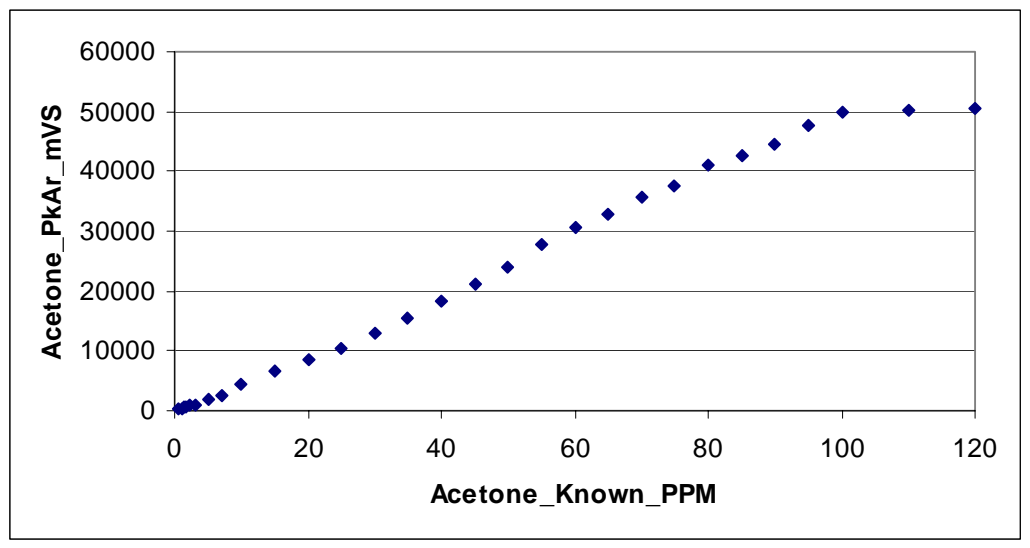

Fig. 1: Plot of known concentration (ppm) versus integrated peak area (mVS) for acetone 


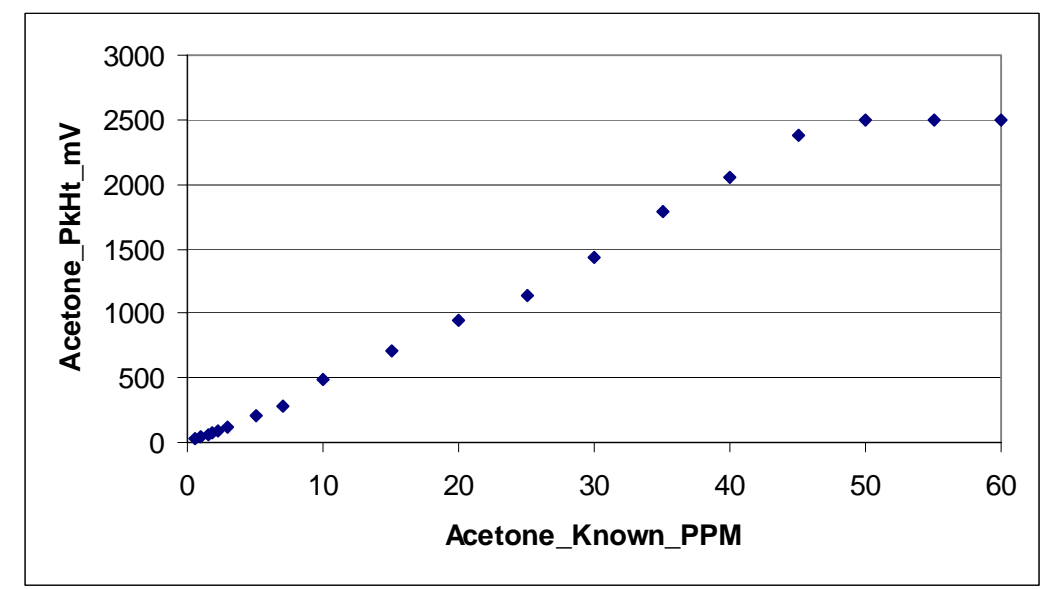

Fig. 2: Plot of known concentration ( $\mathrm{ppm})$ versus integrated peak height $(\mathrm{mV})$ for acetone

Figure 3 illustrated two types of curve fit that helped in studying GC response for the concentration range of $50 \mathrm{ppm}$ and $100 \mathrm{ppm}$. The figure showed that the solid line is a polynomial fit that had a correlation coefficient $\mathrm{R}$-squared value of 0.984 while the dashed line was a linear fit that had an R-squared value of 0.9804. It is apparent that both curve fit can represent the data plotted in this range. It is worth mentioning that correlation coefficients are indicative parameters for linearity through the applied concentration range and not indicative for the errors associated with the predicted concentration values as will be illustrated later on in statistical analysis of regressed data.

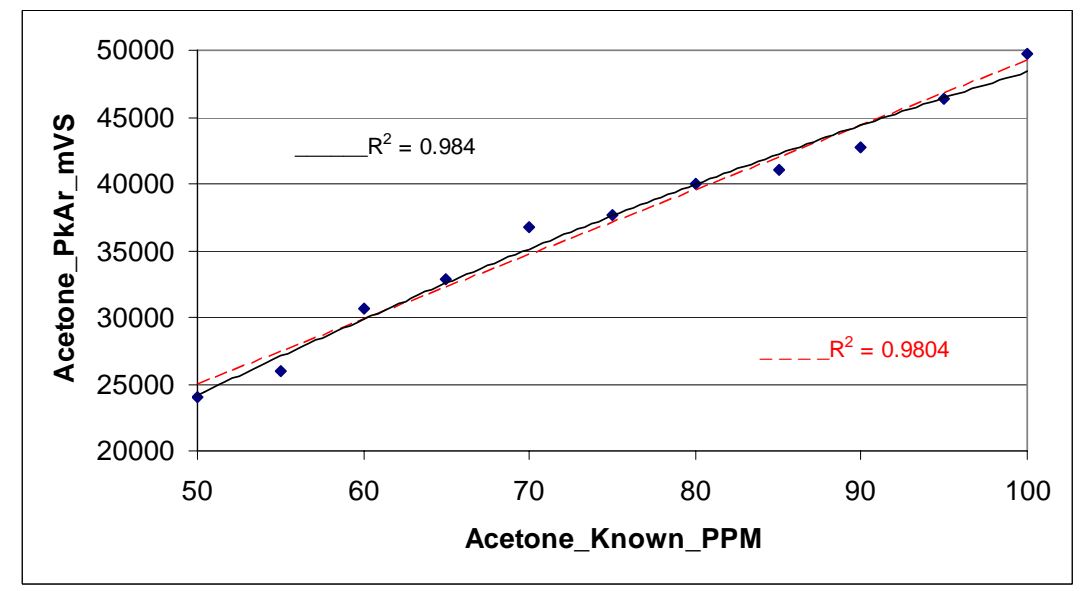

Fig. 3: Plot of known concentration (ppm) versus integrated peak area (mVS) for acetone at concentration range 50 to $100 \mathrm{ppm}$

The reason behind this slight curvature in the line might be referred to some losses in GC injection port and column or due to the limited response ofdetector over wide range of concentrations. Figure 4 shows plotted values of peak area versus concentration at the low concentration levels of $0.05 \mathrm{ppm}$ to $5 \mathrm{ppm}$. The figure illustrated two types of curve fit that helped in studying GC response for this concentration range of $0.05 \mathrm{ppm}$ to $5 \mathrm{ppm}$. The figure showed that the solid line is a polynomial fit that had a correlation coefficient Rsquared value of 0.9931 while the dashed line was a linear fit that had an R-squared value of 0.9656. It is apparent that the GC did not behave linearly at the low concentration range of 
acetone. The reason behind this can be referred to losses in acetone mass (mg) that is being adsorbed through the GC injection port and column before reaching the detector. In addition, the minimum level to be detected was found to be $0.05 \mathrm{ppm}$ although the manufacture detection range is $0.015 \mathrm{ppm}$ which illustrate that there is complete loss of sample below this range. It is worth mentioning that correlation coefficients are indicative parameters for linearity through the applied concentration range and not indicative for the errors associated with the predicted concentration values as will be illustrated later on in statistical analysis of regressed data.

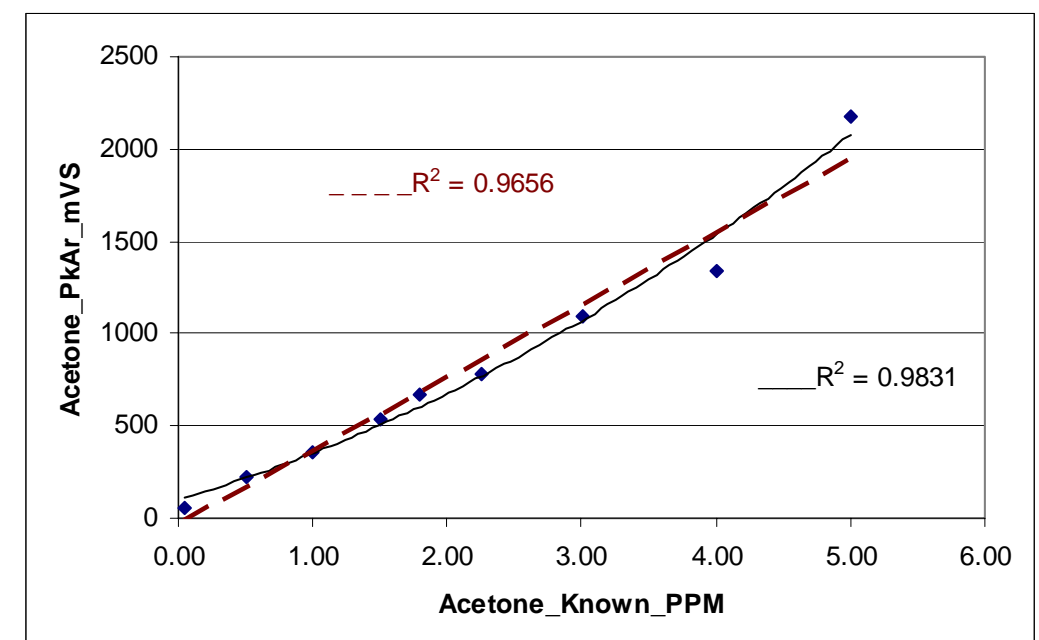

Fig. 4: Plot of known concentration (ppm) versus integrated peak area (mVS) for acetone at concentration range 0.05 to $5 \mathrm{ppm}$

Figure 5 shows plotted values of integrated peak areas versus concentration levels $\mathrm{ppm}$ through the range $10 \mathrm{ppm}$ to $55 \mathrm{ppm}$. The figure showed that the solid line is a linear fit that had a correlation coefficient R-squared value of 0.9951 . It is apparent that the GC responded linearly at the concentration range 10 to $55 \mathrm{ppm}$ of acetone. It is worth mentioning that correlation coefficients are indicative parameters for linearity through the applied concentration range and not indicative for the errors associated with the predicted concentration values as will be illustrated later on in statistical analysis of regressed data.

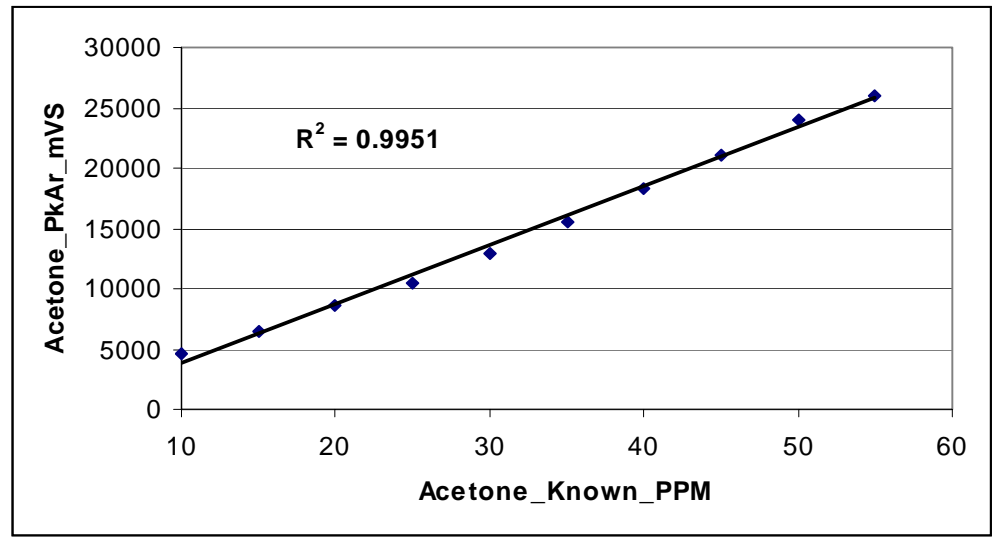

Fig. 5: Plot of known concentration (ppm) versus integrated peak area (mVS) for acetone at 10 to $60 \mathrm{ppm}$ 
This curve lead to the fact of focusing on the above mentioned concentration range and to do a lot of runs at these concentration levels to study GC precision and repeatability at these concentration levels.

\subsection{Statistical Analysis and Linear Regression}

\subsubsection{GC calibration data points for acetone using Column $\underline{\underline{\mathrm{C}}}$ on August 132002}

After studying the GC behavior at the concentration range of $0.05 \mathrm{ppm}$ to $120 \mathrm{ppm}$ for acetone and identifying the ppm range where GC response was linear, statistical analysis was performed to calculate the residual values in predicted ppm and plotting them versus known ppm. In addition, many calibration data points were gathered at different days and different working hours that included measurement in the morning, noon, afternoon and evening to study the precision of the GC from day to day and time to time and to see if there are any confounding parameters in the measured data. Table 1 illustrates the values obtained for GC calibration in August 13 while Table 2 illustrates the regression and statistical parameters used to evaluate this fit.

Table 1: GC calibration data points for acetone in August 13

\begin{tabular}{|c|c|c|c|}
\hline Acetone_P. Area_mVS & Known_PPM & Pred_ppm & Error_Pred \\
\hline 4557 & 10 & 11.32 & 13.17 \\
\hline 6527 & 15 & 15.45 & 3.03 \\
\hline 8645 & 20 & 19.90 & -0.49 \\
\hline 10447 & 25 & 23.69 & -5.25 \\
\hline 12893 & 30 & 28.82 & -3.92 \\
\hline 15468 & 35 & 34.23 & -2.20 \\
\hline 18307 & 40 & 40.19 & 0.48 \\
\hline 21134 & 45 & 46.13 & 2.51 \\
\hline 24018 & 50 & 52.19 & 4.37 \\
\hline 25940 & 55 & 56.22 & 2.22 \\
\hline
\end{tabular}

Table 2: Statistical and Regression Parameters for GC calibration curve

\begin{tabular}{|c|c|c|}
\hline Std Dev_mVS & 7421.9 & 15.1 \\
\hline Mean_mVS & 14793.6 & 32.5 \\
\hline Median_mVS & 14180.5 & 32.5 \\
\hline Standard Error_Predicted Y (RSE) & 1.1 & \\
\hline slope & 0.0020 & \\
\hline Intercept & 2.4 & \\
\hline R-Squared & 0.9951 & \\
\hline
\end{tabular}

Table 2 illustrated that the residual standard error RSE in the regression line for this concentration range is found to be $1.1 \mathrm{ppm}$. While, the slope and intercept of regression line was $0.002 \mathrm{ppm} / \mathrm{mVS}$ and $2.4 \mathrm{ppm}$, respectively. Figure 6 shows plotted values of integrated peak areas mVS versus known concentration levels ppm of 10 to $55 \mathrm{ppm}$ for acetone calibration done in August 13, 2002. The Calibration curve showed that the solid line is a linear fit that had a correlation coefficient $\mathrm{R}$-squared value of 0.9951 . The linear equation that represents the fit is $y=0.002 X+2.4$. Figure 7 shows a plot of the residual values versus known concentrations for acetone. Figure 7 showed that the error in predicted ppm lies 
between $\pm 5 \%$ for the concentration range 15 to 55 ppm while it was higher than $10 \%$ at 10 ppm.

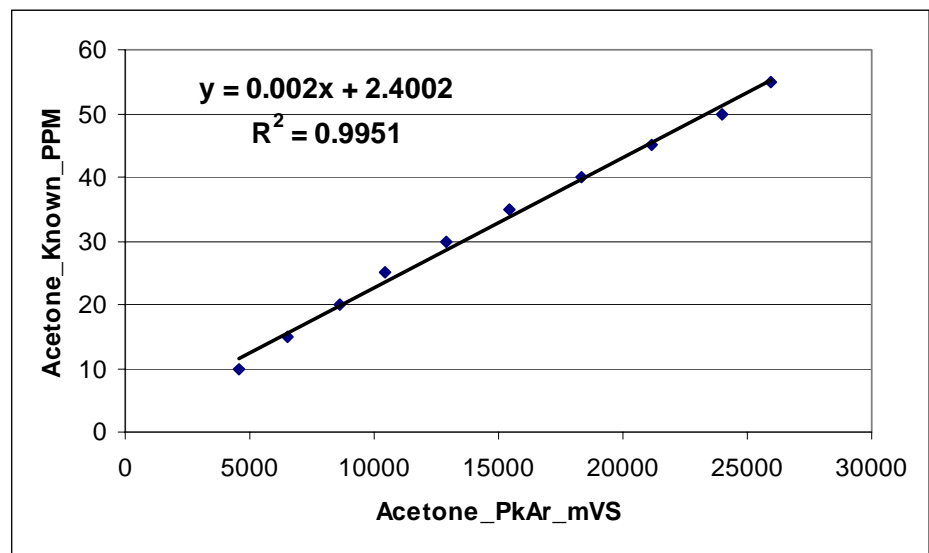

Fig. 6: GC Calibration curve for acetone of 10 to $55 \mathrm{ppm}$

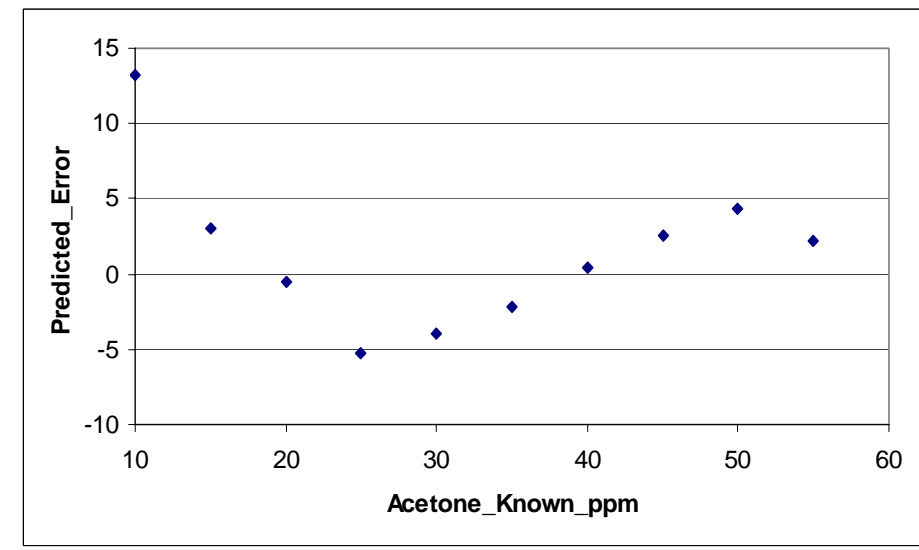

Fig. 7: Plot of residual versus known concentration of 10 to $55 \mathrm{ppm}$

\subsubsection{GC calibration data points for acetone using Column $\underline{\underline{C}}$ in September 112002}

After studying the $\mathrm{GC}$ behavior at the concentration range of $0.05 \mathrm{ppm}$ to $120 \mathrm{ppm}$ for acetone and identifying the ppm range where $\mathrm{GC}$ response was linear, statistical analysis was performed to calculate the residual values in predicted ppm and plotting them versus known ppm. In addition, many calibration data points were gathered at different days and different working hours that included measurement in the morning, noon, afternoon and evening to study the precision of the GC from day to day and time to time and to see if there were any confounded parameters in the measured data. Table 3 illustrates the values obtained for GC calibration in Sep 11 while Table 4 illustrates the regression and statistical parameters used to evaluate this fit. 
Table 3: GC calibration data points for acetone in September 11

\begin{tabular}{|c|c|c|c|c|}
\hline Date & Acetone_PkAr_mVS & Known_PPM & Predicted_ppm & Predicted_Error \\
\hline 11-Sep & 4029 & 10 & 11.60 & 16.00 \\
\hline 11-Sep & 5289 & 15 & 14.75 & -1.67 \\
\hline $11-S e p$ & 6964 & 20 & 18.94 & -5.31 \\
\hline $11-S e p$ & 9161 & 25 & 24.43 & -2.28 \\
\hline 11-Sep & 10811 & 30 & 28.56 & -4.82 \\
\hline 11-Sep & 12993 & 35 & 34.01 & -2.83 \\
\hline $11-S e p$ & 14859 & 40 & 38.68 & -3.31 \\
\hline 11-Sep & 17594 & 45 & 45.51 & 1.14 \\
\hline 11-Sep & 19236 & 50 & 49.62 & -0.76 \\
\hline 11-Sep & 21965 & 55 & 56.44 & 2.62 \\
\hline
\end{tabular}

Table 4: Statistical and Regression Parameters for GC calibration curve

\begin{tabular}{|c|c|c|}
\hline Std Dev_mVS & 6098.1 & 15.1 \\
\hline Mean_mVS & 12290.1 & 32.5 \\
\hline Median_mVS & 11902.0 & 32.5 \\
\hline Standard Error_Predicted Y (RSE) & 1.15 & \\
\hline slope & 0.0025 & \\
\hline Intercept & 2.1 & \\
\hline R-Squared & 0.9949 & \\
\hline
\end{tabular}

Table 4 illustrated that the residual standard error (RSE) in the regression line for this concentration range is found to be $1.15 \mathrm{ppm}$. The slope and intercept of regression line were $0.0025 \mathrm{ppm} / \mathrm{mVS}$ and $2.1 \mathrm{ppm}$, respectively. Figure 8 shows plotted values of integrated peak areas mVS versus known concentration levels ppm of 10 to $55 \mathrm{ppm}$ for acetone calibration done in September 11, 2002. The Calibration curve showed that the solid line is a linear fit that had a correlation coefficient R-squared value of 0.9949 . The linear equation that represents the fit is $y=0.0025 \mathrm{X}+2.1$. Figure 9 showed a plot of the residual values versus known concentrations for acetone. Figure 9 showed that the error in predicted ppm lies between $\pm 4 \%$ for the concentration range 15 to $55 \mathrm{ppm}$ while it was higher than $15 \%$ at $10 \mathrm{ppm}$.

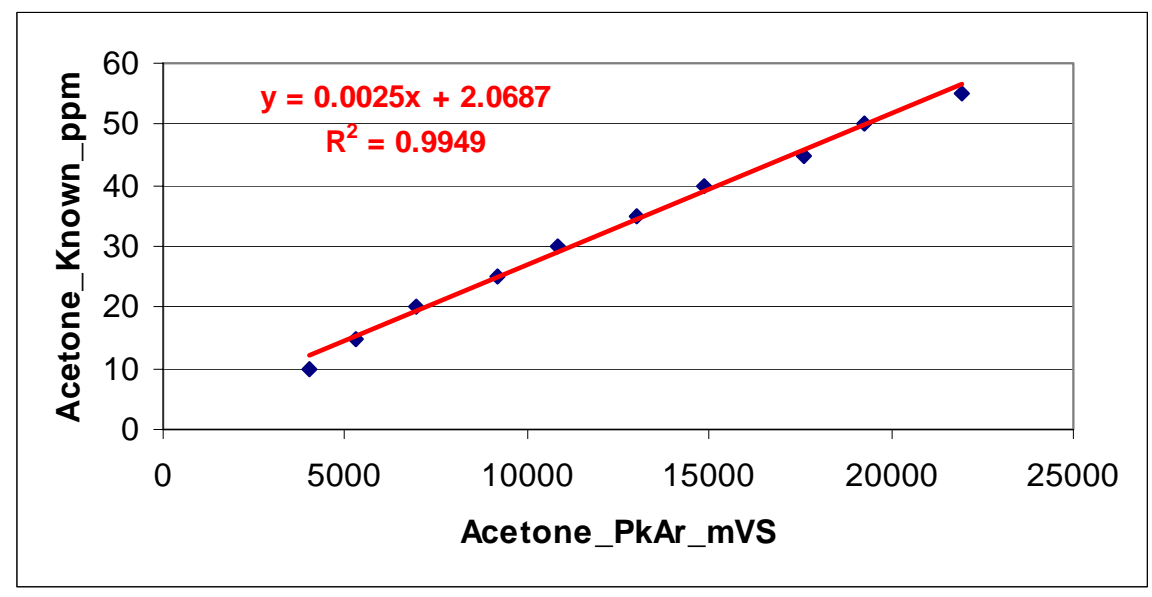

Fig. 8: GC Calibration curve for acetone of 10 to $55 \mathrm{ppm}$ 


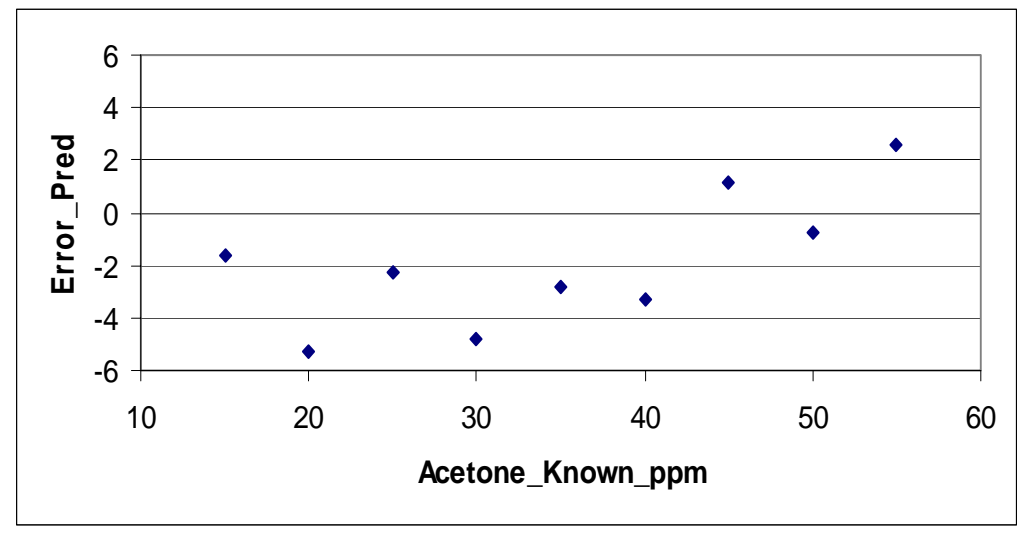

Fig. 9: Plot of residual versus known concentration of 10 to $55 \mathrm{ppm}$

\subsubsection{GC multipoint calibration for acetone using Column $\underline{\underline{\mathrm{C}}}$ in October 152002}

After studying the $\mathrm{GC}$ behavior at the concentration range of $0.05 \mathrm{ppm}$ to $120 \mathrm{ppm}$ for acetone and identifying the ppm range where $\mathrm{GC}$ response was linear, statistical analysis was performed to calculate the residual values in predicted ppm and plotting them versus known ppm. In addition, many calibration data points were gathered at different days and different working hours that included measurement in the morning, noon, afternoon and evening to study the precision of the GC from day to day and time to time and to find any parameters confounded in the measured data. Table 5 illustrates the values obtained for GC calibration in Oct 15 while Table 6 illustrates the regression and statistical parameters used to evaluate this fit.

Table 5: GC calibration data points for acetone_October 15, 2002

\begin{tabular}{|c|c|c|c|c|}
\hline Date & Acetone_PkAr_mVS & Known_PPM & Predicted_ppm & Predicted_Error \\
\hline 15-Oct & 3443 & 10 & 10.60 & 5.98 \\
\hline 15-Oct & 7719 & 20 & 19.58 & -2.11 \\
\hline 15-Oct & 12483 & 30 & 29.58 & -1.39 \\
\hline 15-Oct & 17254 & 40 & 39.60 & -1.00 \\
\hline 15-Oct & 22629 & 50 & 50.89 & 1.78 \\
\hline 15-Oct & 27973 & 60 & 62.11 & 3.52 \\
\hline 15-Oct & 32119 & 70 & 70.82 & 1.17 \\
\hline 15-Oct & 36037 & 80 & 79.05 & -1.19 \\
\hline
\end{tabular}

Table 6: Statistical and Regression Parameters for GC calibration curve

\begin{tabular}{|c|c|c|}
\hline Std Dev_mVS & 11732.3 & 24.5 \\
\hline Mean_mVS & 19957.1 & 45.0 \\
\hline Median_mVS & 19941.5 & 45.0 \\
\hline Standard Error_Predicted Y (RSE) & 1.07 & \\
\hline slope & 0.0021 & \\
\hline Intercept & 3.4 & \\
\hline R-Squared & 0.9984 & \\
\hline
\end{tabular}

Table 6 illustrated that the residual standard error (RSE) in the regression line for this concentration range is found to be $1.07 \mathrm{ppm}$. While, the slope and intercept of regression line were $0.0021 \mathrm{ppm} / \mathrm{mVS}$ and $3.4 \mathrm{ppm}$, respectively. Figure 10 showed plotted values of integrated peak areas $\mathrm{mVS}$ versus known concentration levels for acetone range of 10 to 80 
ppm done in October 15, 2002 while Figure 11 showed a plot of the residual values versus known concentrations for acetone. The Calibration curve showed that the solid line is a linear fit that had a correlation coefficient $\mathrm{R}$-squared value of 0.9984 . The linear equation that represents the fit is $\mathrm{y}=0.0021 \mathrm{X}+3.4$. Figure 11 showed that the error in predicted ppm lies between $\pm 2 \%$ for the concentration range 10 to $80 \mathrm{ppm}$ while it was less than $6 \%$ at $10 \mathrm{ppm}$.

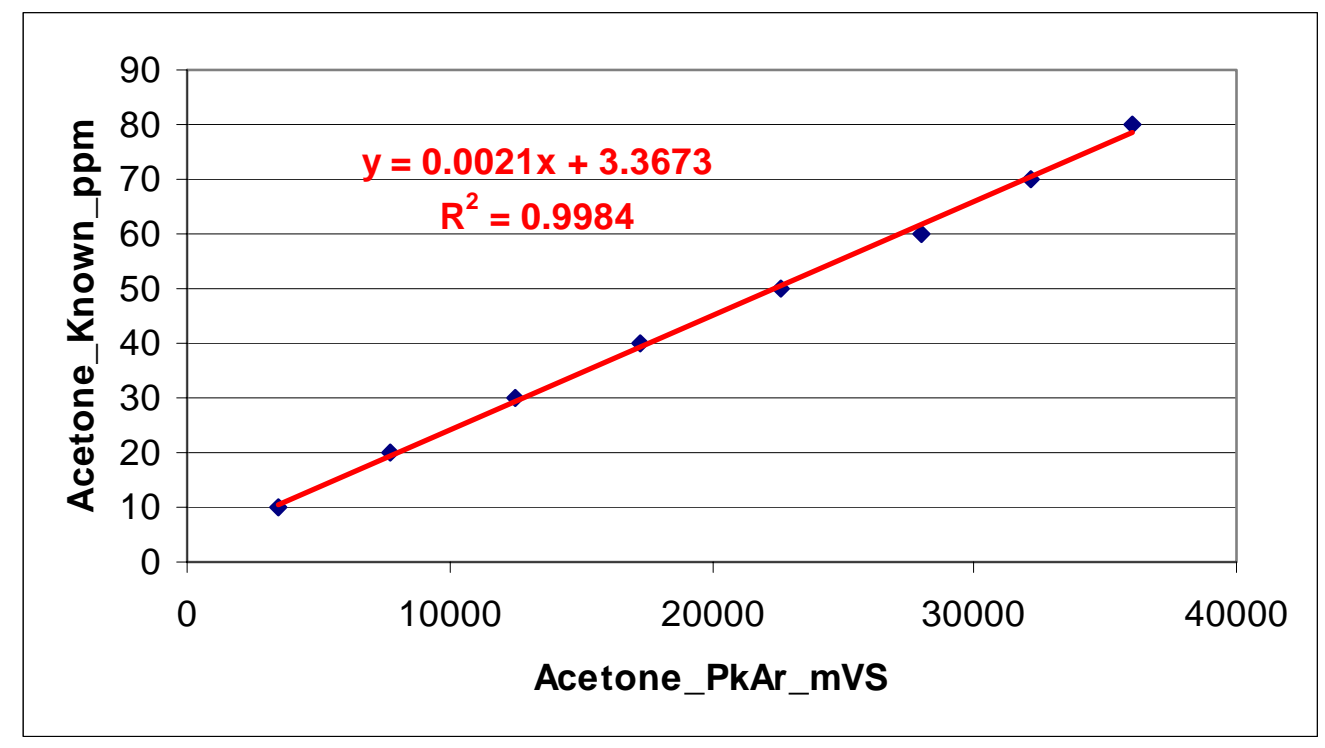

Fig. 10: Multipoint calibration curve for acetone range 10 to $80 \mathrm{ppm}$

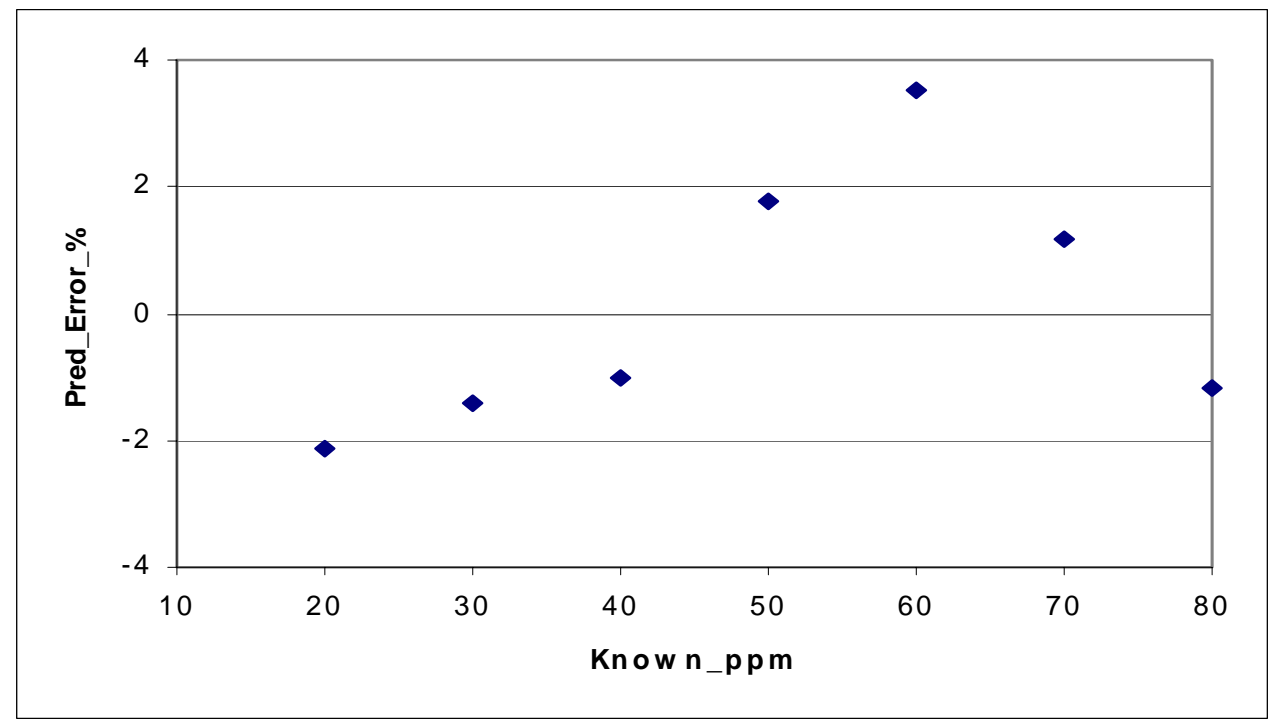

Fig. 11: Plot of residual versus known concentration for acetone range 10 to $80 \mathrm{ppm}$ 


\subsubsection{GC multipoint calibration for acetone using Column $\underline{\underline{\mathrm{A}}}$ in Sep 3, 2002}

This run is done to study the GC behavior at the concentration range of $1 \mathrm{ppm}$ to $50 \mathrm{ppm}$ for acetone using GC column A. The GC response for column A was studied for linearity and statistical analysis was performed to calculate the residual values in predicted ppm and plotting them versus known ppm. In addition, many calibration data points were gathered at different days and different working hours that included measurement in the morning, noon, afternoon and evening to study the precision of the GC from day to day and time to time and to find any parameters confounded in the measured data. Table 7 illustrates the values obtained for GC calibration in Sep 3 while Table 8 illustrates the regression and statistical parameters used to evaluate this fit.

Table 7: GC calibration data points for acetone using Column A_Sep 3, 2002

\begin{tabular}{|c|c|c|c|c|}
\hline Date & Acetone_PkAr_mVS & Known_ppm & Predicted_ppm & Predicted_Error \\
\hline 3-Sep & 1108 & 1 & 1.48 & 47.50 \\
\hline 3-Sep & 2878 & 5 & 5.02 & 0.30 \\
\hline 3-Sep & 4592 & 10 & 8.44 & -15.57 \\
\hline 3-Sep & 10991 & 20 & 21.24 & 6.21 \\
\hline 3-Sep & 25106 & 50 & 49.47 & -1.06 \\
\hline
\end{tabular}

Table 8: Statistical and Regression Parameters for GC calibration curve Column A

\begin{tabular}{|c|c|c|}
\hline Std Dev_mVS & 9779.3 & 19.7 \\
\hline Mean_mVS & 8935.0 & 17.2 \\
\hline Median_mVS & 4592.0 & 10.0 \\
\hline Standard Error_Predicted Y (RSE) & 1.21 & \\
\hline slope & 0.0020 & \\
\hline Intercept & -0.7412 & \\
\hline R-Squared & 0.9971 & \\
\hline
\end{tabular}

Table 8 illustrated that the residual standard error (RSE) in the regression line for this concentration range is found to be $1.21 \mathrm{ppm}$. While, the slope and intercept of regression line were $0.002 \mathrm{ppm} / \mathrm{mVS}$ and $-0.7412 \mathrm{ppm}$, respectively. Figure 12 showed plotted values of integrated peak areas mVS versus known concentration levels for acetone range of 1 to 50 ppm done in Sep 3, 2002 using column A while Figure 13 showed a plot of the residual values versus known concentrations for acetone. The Calibration curve showed that the solid line is a linear fit that had a correlation coefficient R-squared value of 0.9971 . The linear equation that represents the fit is $\mathrm{y}=0.002 \mathrm{X}-0.7412$. Figure 13 showed that the error in predicted ppm lies between -20 and $10 \%$ for the concentration range 5 to $50 \mathrm{ppm}$ while it was lover $40 \%$ at $1 \mathrm{ppm}$. 


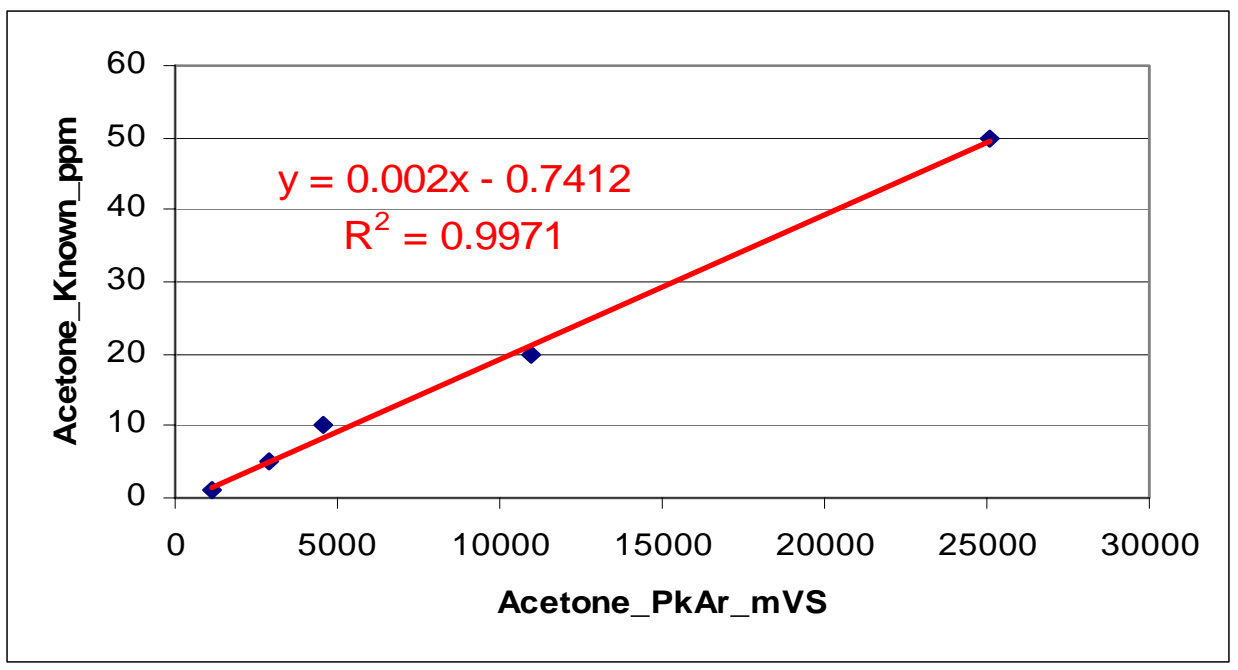

Fig. 12: Multipoint calibration curve for acetone range 1 to $50 \mathrm{ppm}$

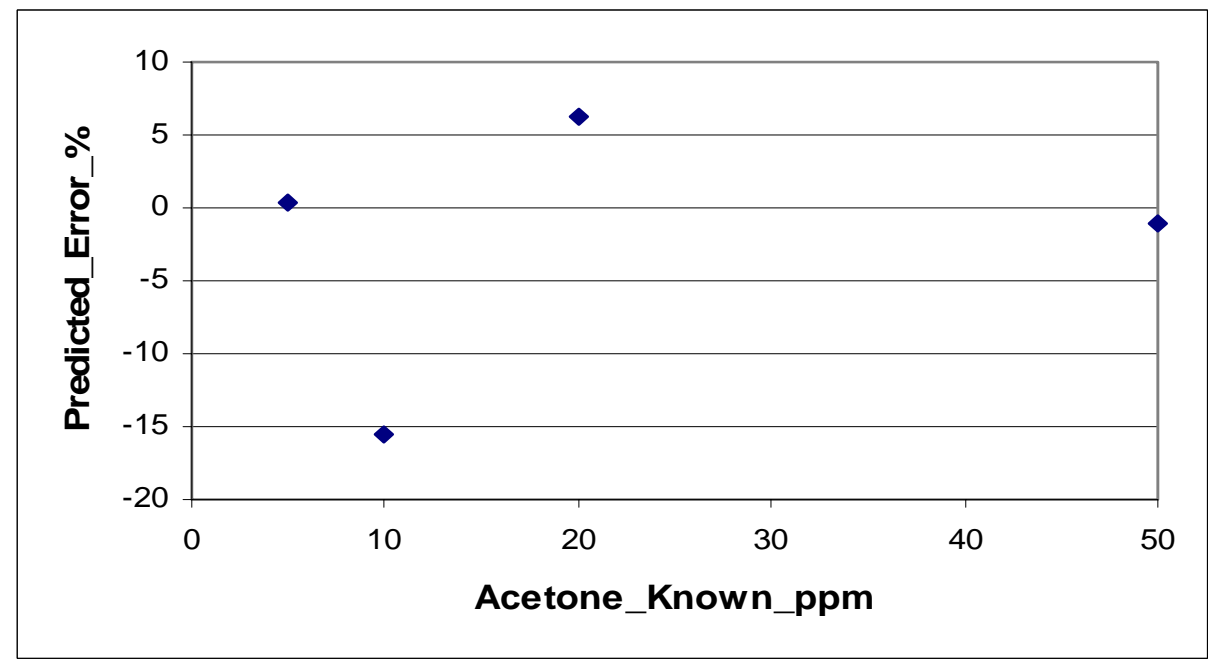

Fig. 13: Plot of residual versus known concentration for acetone range 1 to $50 \mathrm{ppm}$

\subsubsection{GC calibration data points for acetone using Column $\underline{\underline{\mathrm{C}}}$ in December 4, 2002}

After studying the GC behavior at the concentration range of $0.05 \mathrm{ppm}$ to $120 \mathrm{ppm}$ for acetone and identifying the ppm range where $\mathrm{GC}$ response was linear, statistical analysis was performed to calculate the residual values in predicted ppm and plotting them versus known ppm. In addition, many calibration data points were gathered at different days and different working hours that included measurement in the morning, noon, afternoon and evening to study the precision of the GC from day to day and time to time and to find any parameters confounded in the measured data. Table 9 illustrates the values obtained for GC calibration in Dec 4 while Table 10 illustrates the regression and statistical parameters used to evaluate this fit. 
Table 9: Multipoint calibration for acetone_Dec 4, 2002

\begin{tabular}{|c|c|c|c|c|}
\hline Ac_True_PPM & 10 & 20 & 40 & 60 \\
\hline \multirow{2}{*}{ Ac_PkAr_mVS } & 3272 & 7063 & 14603 & 28189 \\
\cline { 2 - 5 } & 3189 & 6811 & 18577 & 23181 \\
\hline Ac_Pred_PPM & 10.8 & 19.0 & 40.2 & 60.2 \\
\hline Pred_Error_\% & 8.4 & -5.0 & 0.6 & 0.4 \\
\hline
\end{tabular}

Table 10: Statistical and Regression Parameters for GC calibration curve

\begin{tabular}{|c|c|c|c|c|}
\hline Mean_mVS & 3230.5 & 6937.0 & 16590.0 & 25685.0 \\
\hline Std Dev_mVS & 58.7 & 178.2 & 2810.0 & 3541.2 \\
\hline RSD & 1.8 & 2.6 & 16.9 & 13.8 \\
\hline \multicolumn{2}{|c|}{$Y=m X+b$} & & & \\
\hline RSE & 0.95 & & & \\
\hline slope_m & 0.0022 & & & \\
\hline Intercept_b & 3.731 & & & \\
\hline R-Sq & 0.999 & & & \\
\hline
\end{tabular}

Table 10 illustrated that the residual standard error (RSE) for this regression model was found to be $0.95 \mathrm{ppm}$ while the slope and intercept of line was $0.0022 \mathrm{ppm} / \mathrm{mVS}$ and 3.73 ppm respectively. In addition, the relative standard deviation (RSD) for the repeated measurement at $10 \mathrm{ppm}$ concentration level was lower than that at $40 \mathrm{ppm}$. One reason behind this is the uncertainity associated with sample preparation and analyst error. More repeated measurement to be done at the high levels to investigate more about the precision of GC. Figure 14 showed plotted values of integrated peak areas mVS versus known concentration levels for acetone range of 10 to $60 \mathrm{ppm}$ while Figure 15 showed a plot of the residual values versus known concentrations for acetone. The Calibration curve showed that the solid line is a linear fit that had a correlation coefficient R-squared value of 0.999 . The linear equation that represents the fit is $y=0.0022 \mathrm{X}+3.73$. Figure 15 showed that the error in predicted ppm lies between $\pm 1 \%$ for the concentration range 20 to $60 \mathrm{ppm}$ while it was less than $9 \%$ at $10 \mathrm{ppm}$.

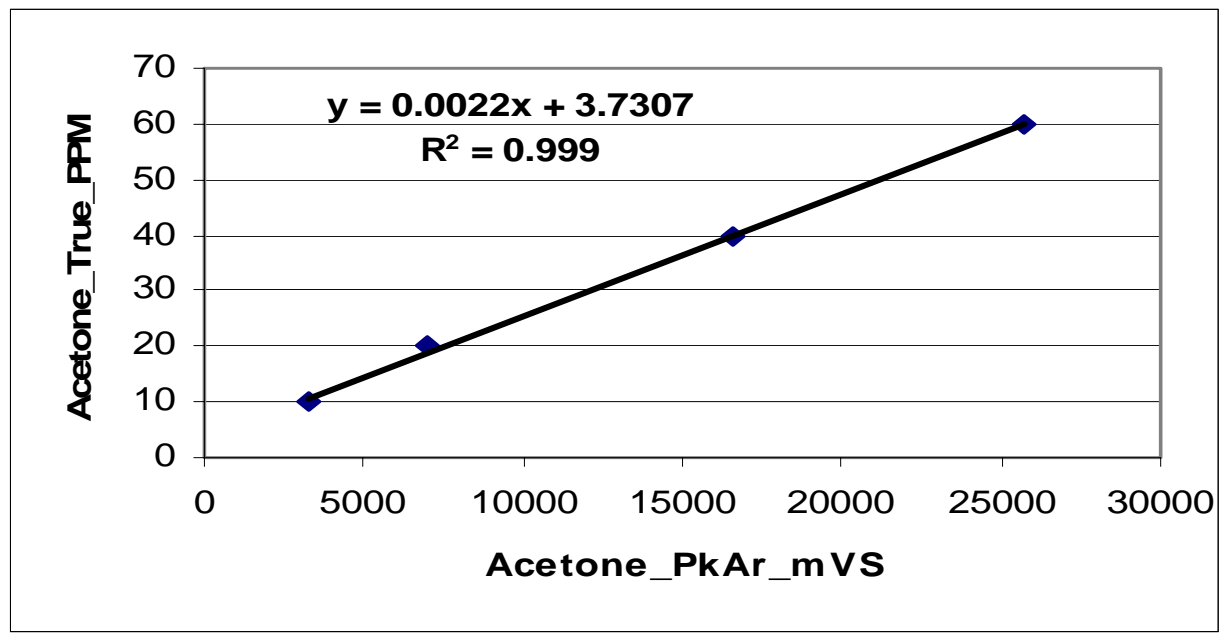

Fig. 14: Multipoint calibration curve for acetone range 10 to $60 \mathrm{ppm}$ 


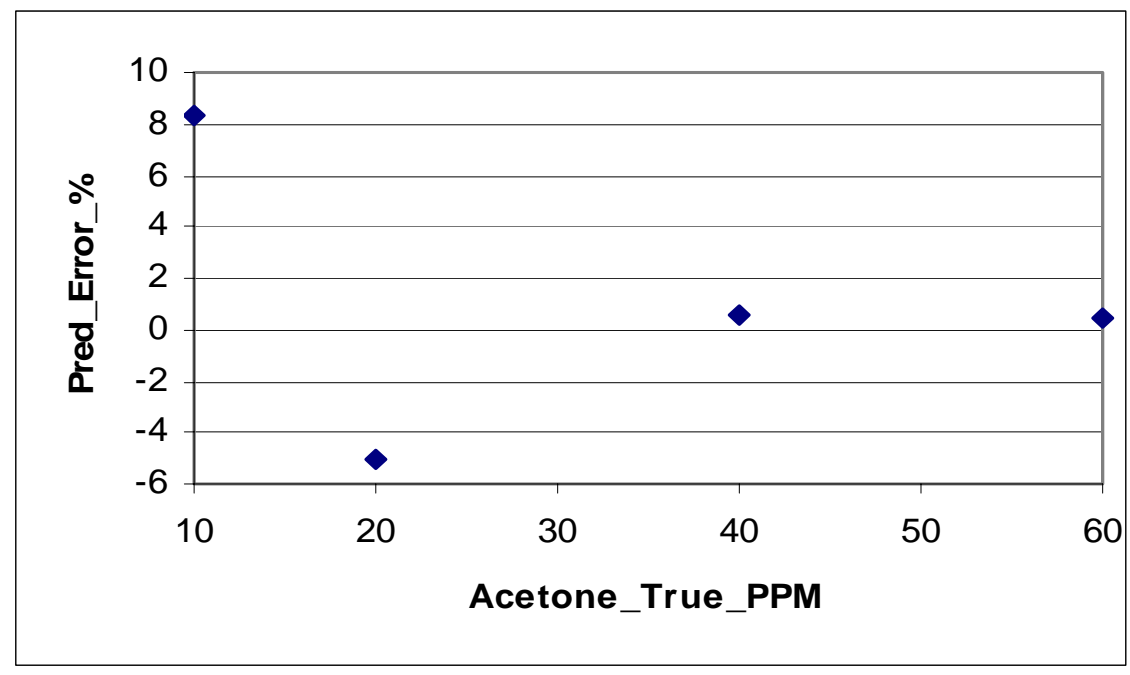

Fig. 15: Plot of residual versus known concentration for acetone range 10 to $60 \mathrm{ppm}$

\subsubsection{GC Multipoint calibration for acetone using Column $\underline{\underline{\mathrm{C}}}$ by Investigators A \& B}

After studying the $\mathrm{GC}$ behavior at the concentration range of $0.05 \mathrm{ppm}$ to $120 \mathrm{ppm}$ for acetone and identifying the ppm range where $\mathrm{GC}$ response was linear, statistical analysis was performed to calculate the residual values in predicted ppm and plotting them versus known ppm. In addition, many calibration data points were gathered at different days and different working hours that included measurement in the morning, noon, afternoon and evening to study the precision of the GC from day to day and time to time and to find any parameters confounded in the measured data. This run was performed by two investigators to study the GC linearity and precision. Table 11 illustrates multipoint calibration for the GC done by investigators A \& B while Table 12 illustrates the regression and statistical parameters used to evaluate the linear model.

Table 11: Multipoint calibration for acetone Investigators A \& B

\begin{tabular}{|c|c|c|c|c|c|c|}
\hline Investegator A & Investegator B & & Investegator A & Investegator B & & \\
\hline Acetone_PkA__mVS & Acetone_PkAr_mVS & Known_PPM & Pred_PPM_A & Pred_PPM_B & Pred_Error_A & Pred_Error_B \\
\hline 4557 & 4135 & 10 & 13.0 & 12.2 & 29.9 & 21.6 \\
\hline 6527 & 6546 & 15 & 16.7 & 16.5 & 11.5 & 10.0 \\
\hline 8645 & 8364 & 20 & 20.8 & 19.8 & 3.8 & -1.1 \\
\hline 10447 & 10758 & 25 & 24.2 & 24.1 & -3.3 & -3.7 \\
\hline 12893 & 13499 & 30 & 28.8 & 29.0 & -3.9 & -3.3 \\
\hline 15468 & 15954 & 35 & 33.7 & 33.4 & -3.7 & -4.5 \\
\hline 18307 & 18211 & 40 & 39.1 & 37.5 & -2.2 & -6.3 \\
\hline 21134 & 20657 & 45 & 44.5 & 41.9 & -1.1 & -6.9 \\
\hline 24018 & 25154 & 50 & 50.0 & 50.0 & -0.1 & 0.0 \\
\hline 25940 & 27366 & 55 & 53.6 & 54.0 & -2.5 & -1.9 \\
\hline 30679 & 32211 & 60 & 62.6 & 62.7 & 4.4 & 4.5 \\
\hline 32808 & 34078 & 65 & 66.7 & 66.1 & 2.6 & 1.6 \\
\hline 34769 & 36675 & 70 & 70.4 & 70.7 & 0.6 & 1.1 \\
\hline
\end{tabular}


Table 12: Statistical and Regression Parameters for GC calibration curve

\begin{tabular}{|c|c|c|c|}
\hline & Investegator A & Investegator B & ppm \\
\hline Std Dev_mVS & 10199.6 & 10873.6 & 19.5 \\
\hline Mean_mVS & 18937.8 & 19508.3 & 38.5 \\
\hline Median_mVS & 18307.0 & 18211.0 & 40.0 \\
\hline Standard Error_Predicted Y (RSE) & 1.6 & 1.8 & \\
\hline slope_ppm/mVS & 0.0019 & 0.0018 & \\
\hline Intercept_ppm & 4.0 & 5.2 & \\
\hline R-Squared & 0.9939 & 0.9920 & \\
\hline
\end{tabular}

Table 12 compares statistical and regression parameters for the runs done by investigators $\mathrm{A}$ and $\mathrm{B}$ for acetone concentration range 10 to $70 \mathrm{ppm}$. The table showed that the residual standard error (RSE) for regression model A was lower than B by $11 \%$ while the difference in slope and intercept for both models was $0.0001 \mathrm{ppm} / \mathrm{mVS}$ and $1.2 \mathrm{ppm}$ respectively. Also, the correlation coefficient R-squared for the Calibration model A was 0.994 while that of model B was 0.992 with a difference of $0.2 \%$ deviation from model $\mathrm{A}$. This closeness in slope $0.2 \%$ concluded that the $\mathrm{GC}$ was behaving linearly through this range as it was tested by different investigators. While, the difference in intercept $1.2 \mathrm{ppm}$ between both investigators was referred to the uncertainity in sample preparation performed by both of them. Figure 16 showed plotted values of integrated peak areas $\mathrm{mVS}$ versus known concentration levels ppm for acetone through the range 10 to $70 \mathrm{ppm}$ while Figure 17 showed a plot of the residual values versus known concentrations for investigators $\mathrm{A}$ and $\mathrm{B}$. The linear equation that represents model $\mathrm{A}$ is $\mathrm{y}=0.0019 \mathrm{X}+4$ while the linear equation that represents model $\mathrm{B}$ was $\mathrm{y}=0.0018 \mathrm{X}+5.2$.

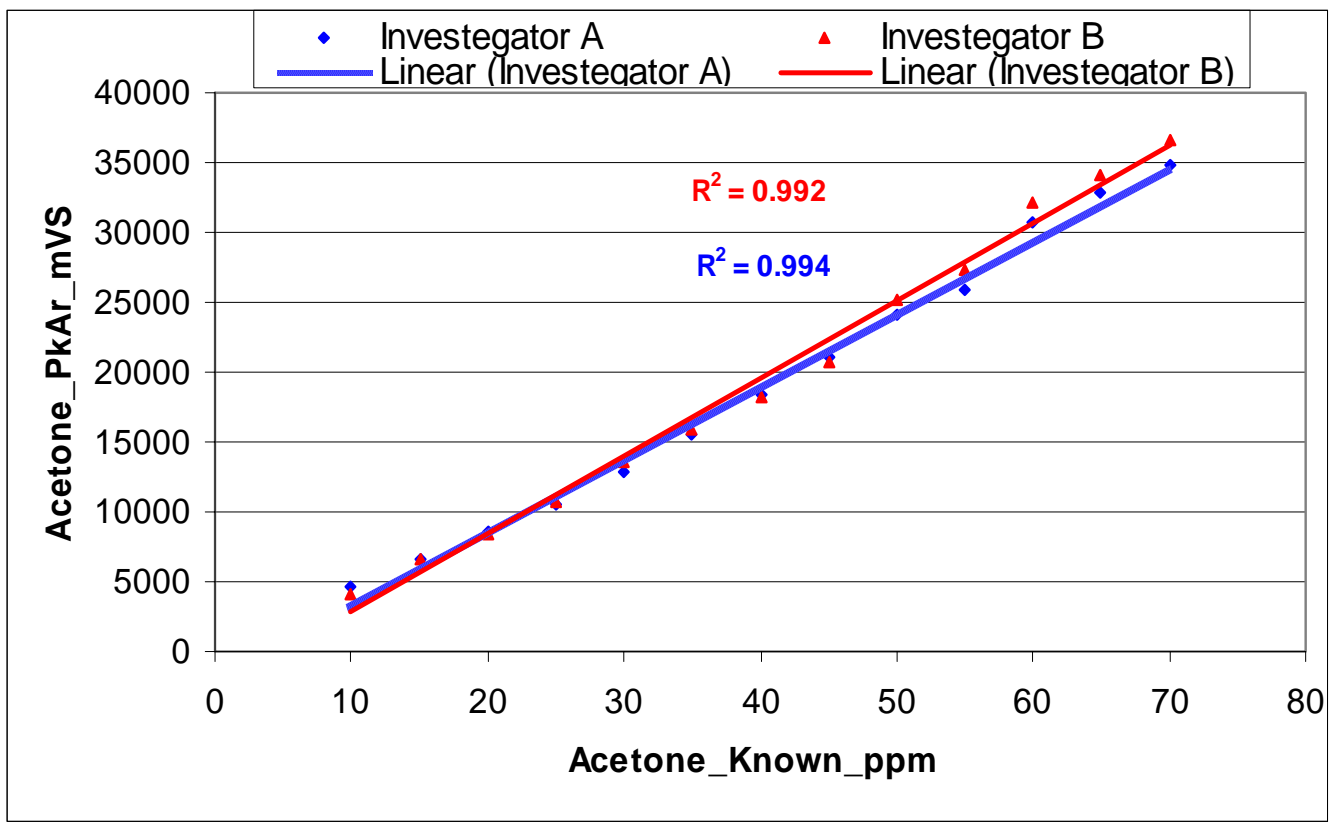

Fig. 16: Multipoint calibration curve for acetone range 10 to $70 \mathrm{ppm}$

Figure 17 showed that the error in predicted ppm lies between $\pm 5 \%$ for the concentration range 20 to $70 \mathrm{ppm}$. The figure also showed that the minimum error in predicted ppm was found at the concentration range 40 to $50 \mathrm{ppm}$ with a value less than $0.1 \%$ for both 
investigators. While, the error in predicted ppm at the borders of the regression models for investigator A and B was found to be $30 \%$ for model A and $21 \%$ for model B at the concentration level $10 \mathrm{ppm}$.

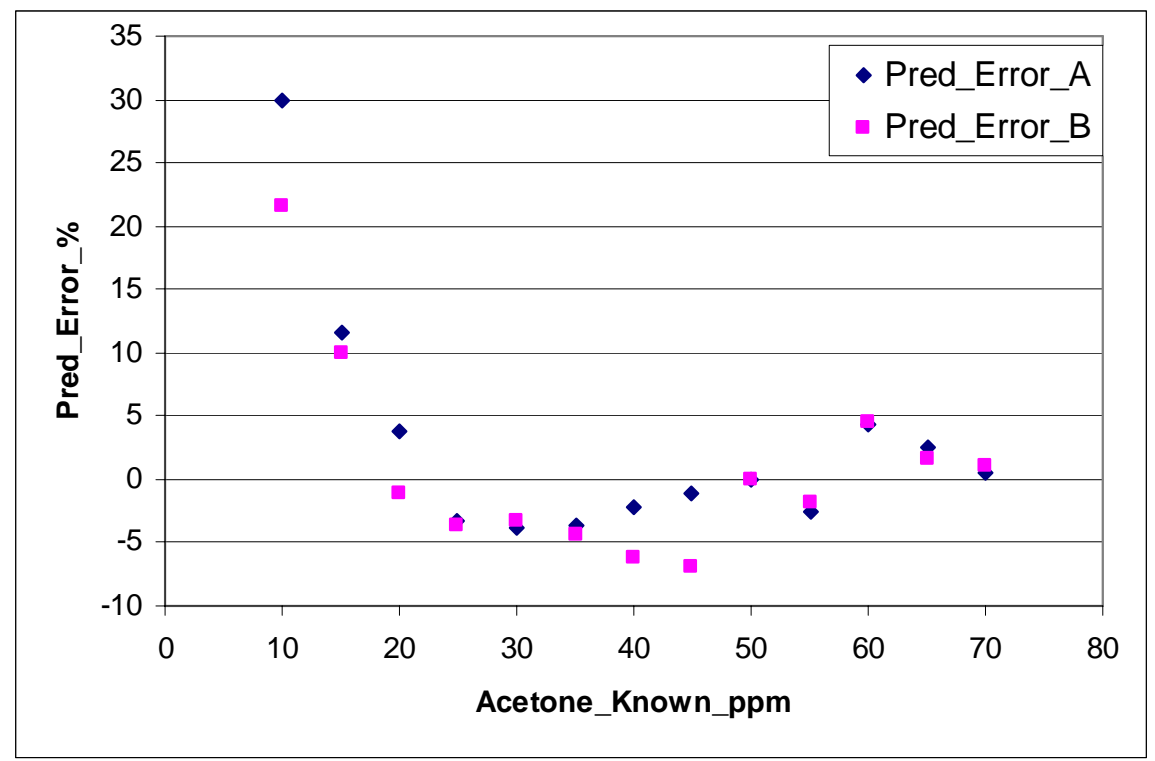

Fig. 17: Plot of residual versus known concentration for acetone range 10 to $70 \mathrm{ppm}$

\subsubsection{GC Precision using Column $\underline{\underline{C}}$ for acetone}

Many calibration data points were gathered at different days and different working hours that included measurement in the morning, noon, afternoon and evening to study the precision of the GC from day to day and time to time and to find any parameters confounded in the measured data. To study GC precision, the mean, standard deviation and relative standard deviation RSD were calculated for the multipoint calibration done by investigators A \& B for acetone range 10 to $70 \mathrm{ppm}$ in one day at noon time as illustrated by Table 13 while Figure 18 is a plot for the relative standard deviation RSD for the data calculated by in table 13 .

Table 13: GC precision studied by Investigators A \& B_14 August 2002

\begin{tabular}{|c|c|c|c|c|c|}
\hline Known_PPM & Acetone_PkAr_mVS & Acetone_PkAr_mVS & Mean_mVS & Std Dev_mVS & RSD \\
\hline 10 & 4557 & 4135 & 4346 & 298.4 & 6.9 \\
\hline 15 & 6527 & 6546 & 6537 & 13.4 & 0.2 \\
\hline 20 & 8645 & 8364 & 8505 & 198.7 & 2.3 \\
\hline 25 & 10447 & 10758 & 10603 & 219.9 & 2.1 \\
\hline 30 & 12893 & 13499 & 13196 & 428.5 & 3.2 \\
\hline 35 & 15468 & 15954 & 15711 & 343.7 & 2.2 \\
\hline 40 & 18307 & 18211 & 18259 & 67.9 & 0.4 \\
\hline 45 & 21134 & 20657 & 20896 & 337.3 & 1.6 \\
\hline 50 & 24018 & 25154 & 24586 & 803.3 & 3.3 \\
\hline 55 & 25940 & 27366 & 26653 & 1008.3 & 3.8 \\
\hline 60 & 30679 & 32211 & 31445 & 1083.3 & 3.4 \\
\hline 65 & 32808 & 34078 & 33443 & 898.0 & 2.7 \\
\hline 70 & 34769 & 36675 & 35722 & 1347.7 & 3.8 \\
\hline
\end{tabular}




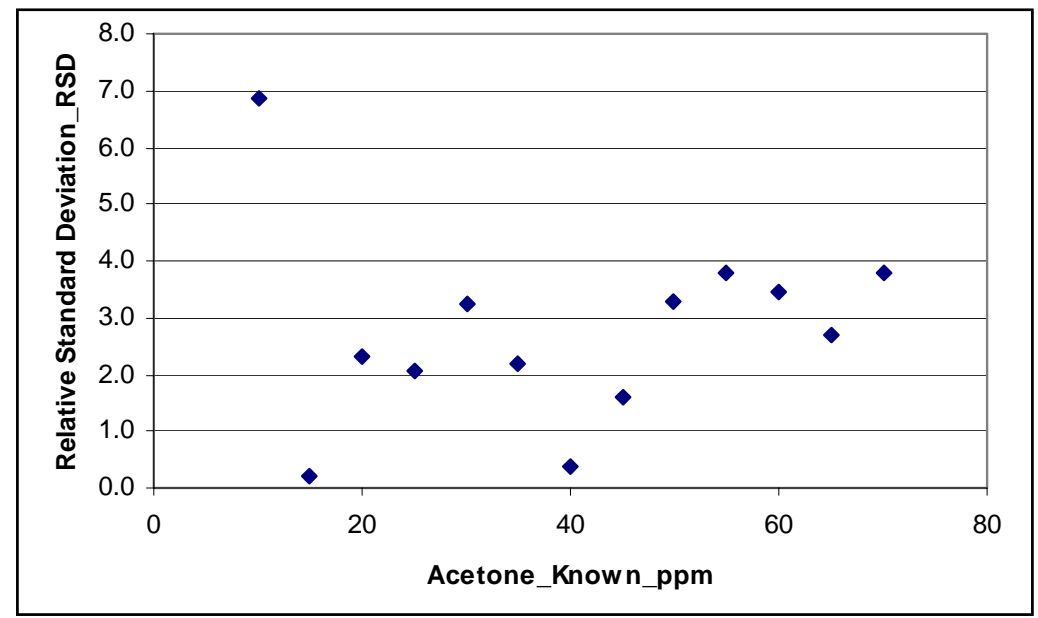

Fig. 18: RSD versus Known Concentration ppm for acetone range 10 to $70 \mathrm{ppm}$

To study GC precision, the mean, standard deviation and relative standard deviation RSD were calculated for the multipoint calibration done at different days and different months for acetone range 10 to 70 ppm as illustrated by Table 14 while Figure 19 is a plot for the relative standard deviation RSD for the data calculated in Table 14.

A comparison for the data plotted in Figures 18 and 19 illustrated the variation of the relative standard deviation RSD with known concentration levels for acetone at one day and at different days and months. As shown in both figures, the relative standard deviation RSD for the runs performed by investigators $A$ and $B$ was less than $4 \%$ for the concentration range 10 to $70 \mathrm{ppm}$ while the RSD for the runs performed at different days and months lied between 6 and 14\%. This is a strong indication that the GC performed precisely for one day calibration than being calibrated at different days and months. While, both figures indicated that the maximum RSD found at the lowest concentration value $10 \mathrm{ppm}$ of the calibration curve.

\section{Conclusion}

In conclusion, Voyager GC response was studied and calibrated for acetone through the concentration range $0.05 \mathrm{ppm}$ to $110 \mathrm{ppm}$. The $\mathrm{GC}$ response was linear throughout the range 10 to $60 \mathrm{ppm}$. Error and regression analysis revealed that the minimum error in predicted ppm value was always in the 40 to $50 \mathrm{ppm}$ range while the maximum error in predicted ppm was at the lowest concentration range at $10 \mathrm{ppm}$. The GC performed linearly with a correlation coefficient of 0.99 through the above mentioned range. The reason behind non linearity in response is reffered to the loss of analyte by absorption through thee inlet ports and column before reaching the detector. Studying the GC precision form day to day and month to month, it was found that the Voyager GC is more precise in day to day calibration with a RSD for the measured values of less than 4 percent for the acetone concentration range 10 to $70 \mathrm{ppm}$.

Thus, it is recommended to run similar experiments and calibrate the GC using ethanol and to test the difference in Voyager precision and linearity for both compounds. 


\section{Appendix A: Calculation of Ethanol and Acetone Concentrations}

The following procedure illustrates the method used to calculate 50 PPM of ethanol and acetone at ambient temperature $25^{\circ} \mathrm{C}$ using the saturated head space vapor equations. The vapor pressure for ethanol and acetone is calculated from the Antoine Equation found in Thomas Boublik et al 1984 was shown as:

where:

$$
\log \mathrm{P}_{\mathrm{VP}}=\mathrm{A}-\mathrm{B} /(\mathrm{t}+\mathrm{C})
$$

$\mathrm{t}=$ Ambient temperature, ${ }^{\circ} \mathrm{C}$

$\mathrm{P}_{\mathrm{VP}}=$ Vapor pressure above the liquid surface, $\mathrm{kPa}$

$\boldsymbol{A}, \boldsymbol{B}, \boldsymbol{C}=$ constants characteristics of each compound

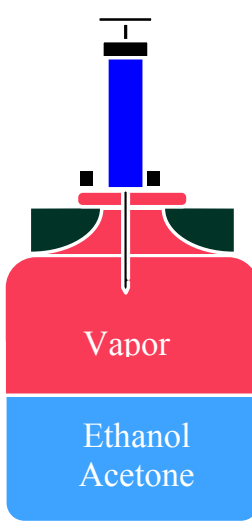

Where, Ethanol and acetone constants and molecular weight are listed in the following table:

\begin{tabular}{|l|l|l|l|l|}
\hline & $\mathrm{A}$ & $\mathrm{B}$ & $\mathrm{C}$ & Mw \\
\hline Ethanol & $\mathbf{7 . 2 4 2 2 2}$ & $\mathbf{1 5 9 5 . 8 1 1}$ & $\mathbf{2 2 6 . 4 4 8}$ & $\mathbf{4 6 . 0 8}$ \\
\hline Acetone & $\mathbf{6 . 2 5 0 1 7}$ & $\mathbf{1 2 1 4 . 2 0 8}$ & $\mathbf{2 3 0 . 0 0 2}$ & $\mathbf{5 8 . 0 8}$ \\
\hline
\end{tabular}

Therefore, For acetone

$$
\begin{aligned}
& \log P_{V P}=A-B /(t+C) \\
&=6.25017-1214.208 /(25+230) \\
&=1.4886 \\
& P_{V P}=31 \mathrm{kPa}
\end{aligned}
$$

Therefore, For Ethanol

$$
\begin{aligned}
& \log \mathrm{P}_{\mathrm{VP}}=\mathrm{A}-\mathrm{B} /(\mathrm{t}+\mathrm{C}) \\
&=7.2422-1595.811 /(25+226.45) \\
&=0.9 \\
& \mathrm{P}_{\mathrm{VP}}=7.86 \mathrm{kPa}
\end{aligned}
$$

The general formula for calculating the concentration, PPM, is explained as:

$$
\mathrm{V}_{\mathrm{HS}}=\left(101.325 / \mathrm{P}_{\mathrm{VP}}\right)(\mathrm{C})(\mathrm{V})
$$

where:

$\mathrm{V}_{\mathrm{HS}}=$ Volume of headspace, $\mu \mathrm{L}$

$\mathrm{P}_{\mathrm{VP}}=$ Vapor pressure of liquid, $\mathrm{kPa}$

$\boldsymbol{C}=$ Desired concentration, PPM 
$\boldsymbol{V}=$ Volume of air sampling bag $=4$ liters

For acetone,

$$
\begin{aligned}
\mathrm{V}_{\mathrm{HS}} & =(101.325 / 31)(50)(4) \\
& =654 \mu \mathrm{L}
\end{aligned}
$$

For Ethanol,

$$
\begin{aligned}
\mathrm{V}_{\mathrm{HS}} & =(101.325 / 7.86)(50)(4) \\
& =2578 \mu \mathrm{L}
\end{aligned}
$$

The concentration of acetone and ethanol inside the bag in $\mathrm{C}_{\mathrm{mg} / \mathrm{m} 3}$ and its mass in $\mathrm{mg}$ are calculated as follows:

$\mathrm{C}_{\mathrm{ppm}}=\mathrm{C}_{\mathrm{mg} / \mathrm{m} 3} \times(24.45 / \mathrm{Mw}) \times(\mathrm{T}+273.15 / 298.15) \times 760 / \mathrm{P}$

At standard conditions, the concentration of Acetone in Tedlar bag

$$
\begin{aligned}
50 & =\mathrm{C}_{\mathrm{mg} / \mathrm{m} 3} \times(24.45 / 58.08) \times(1) \times 1 \\
\mathrm{C}_{\mathrm{mg} / \mathrm{m} 3} & =118.7
\end{aligned}
$$

Mass $=118.7 \times 4(\mathrm{~L}) \times 1 / 1000=0.48 \mathrm{mg}$

Mass $=$ Pvp V Mw $/ \mathrm{RT}=31 / 101.325$ x $654 / 1000,000$ x 58.08x $1000 / 0.08205$ x

$(273.15+25)$

$$
=0.46 \mathrm{mg}
$$

Similar calculations for ethanol will give the following concentrations and mass:

$\mathrm{C}_{\mathrm{mg} / \mathrm{m}}{ }^{3}=94$

Mass $=0.38 \mathrm{mg}$ 


\section{Appendix B: General Procedures}

\begin{tabular}{|c|c|}
\hline \multicolumn{2}{|c|}{ Sub Procedure 1: Run a Blank Sample } \\
\hline 1 & Select a brand new Tedlar sampling bag \\
\hline 2 & Label the bag with a tag number labeled: 5 L_Blank_000 \\
\hline 3 & $\begin{array}{l}\text { Fill the bag with air up to } 50 \% \text { of its volume and immerse the bag in water bath to check for the } \\
\text { leaks at seems and valve }\end{array}$ \\
\hline 4 & Fill the sampling bag with hydrocarbon free air to $75 \%$ of its capacity \\
\hline 5 & Connect the bag to GC sample inlet port and open the bag valve by turning it one turn \\
\hline 6 & $\begin{array}{l}\text { After analysis is complete record readings/observations of acetone and ethanol peak area and peak } \\
\text { height, retention time. If any peak greater than } 50 \mathrm{mVS} \text { is found, re run the blank sample for many } \\
\text { times until contamination is dropped below } 50 \mathrm{mVS}\end{array}$ \\
\hline \multicolumn{2}{|r|}{ Sub Procedure 2: Tedlar \& Teflon ${ }^{\mathrm{TM}}$ bags flushing and reconditioning } \\
\hline 1 & Select a Tedlar/Teflon ${ }^{\mathrm{TM}}$ bag from the available stock \\
\hline 2 & Label the bag with a unique serial number (5L_001), time, date and concentration of used solvent \\
\hline 3 & $\begin{array}{l}\text { Fill the bag with air up to } 50 \% \text { of its volume and immerse the bag in water bath to check for leaks } \\
\text { at seems and valves }\end{array}$ \\
\hline 4 & Flush the bag five times with $\mathrm{HC}$ free air \\
\hline 5 & $\begin{array}{l}\text { Flush the three liters air syringe three times before use (never use the air syringe to dilute acetone } \\
\text { or ethanol concentrations because the oil and grease that lubricate the syringe plunger adsorbs } \\
\text { trace amounts of these solvents) }\end{array}$ \\
\hline 6 & Fill the bag with measured dilution air volume (liter) using the three liters air syringe \\
\hline 7 & Repeat the above steps before each calibration/sampling point \\
\hline \multicolumn{2}{|r|}{ Sub Procedure 3: Flushing and reconditioning Gas Tight Syringe } \\
\hline 1. & Select the syringe required to prepare the sample from the 10,100and 500ul stock \\
\hline 2. & $\begin{array}{l}\text { Flush the syringe five times inside lab hood with fresh air to get rid of any trace amounts of } \\
\text { acetone/ethanol that is carried over by syringe Teflon }{ }^{\mathrm{TM}} / \text { Glass Wall/Plunger }\end{array}$ \\
\hline 3. & Insert the needle in the vial screw capped septa with the plunger at the zero volume position \\
\hline 4. & Fill the syringe with ethanol/acetone saturated vapor to its maximum volume \\
\hline 5. & Discharge the contents in the vial \\
\hline 6. & Repeat the previous step three times before using the syringe in the assigned analysis \\
\hline & Note: It is better to assign different syringes for each compound \\
\hline \multicolumn{2}{|r|}{ Sub Procedure 4: Sample preparation using saturated headspace vapor } \\
\hline 1 & Fill two clean vials of $40 \mathrm{ml}$ capacity with liquid ethanol and acetone up to $3 / 4$ its volume \\
\hline 2 & Shake the vials and leave them for some time to equilibrate \\
\hline 3 & Write a sticker of the name of solvent and put it on the vial \\
\hline 4 & Repeat sub procedure 2 \\
\hline 5 & Repeat sub procedure 3 \\
\hline 6 & $\begin{array}{l}\text { Calculate the head space volume required to prepare ethanol/acetone PPM using the formula listed } \\
\text { in appendix A }\end{array}$ \\
\hline 7 & $\begin{array}{l}\text { Use the } 10 \text { and } 500 \text { ul syringes to draw the desired concentration level as shown in the data } \\
\text { collection sheet }\end{array}$ \\
\hline 8 & $\begin{array}{l}\text { Fill syringe with ethanol/acetone saturated head space volume and adjust plunger to the largest } \\
\text { graduated mark }(10,50,100) \text { to avoid visual errors }\end{array}$ \\
\hline 9 & Purge the gas tight syringe into the bag air dilution volume \\
\hline 10 & Shake the bag for $15 \mathrm{sec}$, then allow prepared concentration to stabilize for 5-10 minutes \\
\hline 11 & Refer to photovac technical bulletin 21 for more details \\
\hline Note & - Do not leave the bag for more than 10 minutes as adsorption of bag contents will take place and \\
\hline
\end{tabular}




\begin{tabular}{|c|c|}
\hline & $\begin{array}{l}\text { this gives misleading concentrations } \\
\text { - Fill the bag to } 80 \% \text { of its volume (Do not over fill) }\end{array}$ \\
\hline \multicolumn{2}{|r|}{ Sub Procedure 5: Calibrate (update) the GC library for acetone and ethanol compounds } \\
\hline 1 & Prepare a calibration atmosphere of ethanol and acetone using sub procedure 4 \\
\hline 2 & Connect the bag to the sample inlet in front of voyager and open the valve by pushing the stem in \\
\hline 3 & After run completion check the peaks of acetone and ethanol in the chromatogram \\
\hline 4 & $\begin{array}{l}\text { Open the analyzer menu in the instrument tab and click on the calibrate icon to calibrate ethanol } \\
\text { and acetone peaks and retention times of the library }\end{array}$ \\
\hline 5 & Refer to the GC operation and training manual for more details \\
\hline \multicolumn{2}{|r|}{ Sub Procedure 5: General Procedures for GC Operation } \\
\hline 1 & Connect the carrier gas high pressure hose to the GC internal cylinder valve \\
\hline 2 & $\begin{array}{l}\text { Turn the black valve so that it points toward the cylinder and fill the voyager internal cylinder to } \\
\text { approximately } 1700 \text { Psi }\end{array}$ \\
\hline 3 & $\begin{array}{l}\text { Turn the regulator black Knob clock wise direction to allow air to flow from the cylinder to the } \\
\text { GC }\end{array}$ \\
\hline 4 & $\begin{array}{l}\text { After reaching the desired internal cylinder pressure }(1700 \text { Psi), turn the regulator black knob } \\
\text { counter clock wise direction to shut of the air flow }\end{array}$ \\
\hline 5 & Turn the black valve the other direction $\left(180^{\circ}\right)$ to purge the high pressure black hose \\
\hline 6 & Disconnect the hose from the internal cylinder valve \\
\hline 7 & Turn on voyager by pressing the on/off button \\
\hline 8 & Allow voyager to warm up for 20 minutes \\
\hline 9 & After 3-5 minutes successful PID lamp tuning is confirmed by a beep \\
\hline 10 & Then Voyager will heat the column to the isothermal operating temperature $60^{\circ} \mathrm{C}$ \\
\hline 11 & Voyager will display a status message Oven not ready until oven reaches $60^{\circ} \mathrm{C}$ \\
\hline 12 & Double click on the site chart icon on the desktop of the computer connected to GC \\
\hline 13 & Site chart software will open the assay tab view \\
\hline 14 & Check the configuration parameters for the assay you are going to use to do the analysis \\
\hline 15 & Check each compound status in the check compound box \\
\hline 16 & Send the customized assay to voyager \\
\hline 17 & Run a blank sample as explained in sub procedure 1 \\
\hline 18 & Run a calibration (update) sample of ethanol and acetone using sub procedure 5 \\
\hline 19 & Record the GC output data in an excel file \\
\hline 20 & Refer to the GC operation and training manual for more details \\
\hline
\end{tabular}




\section{Appendix C: Experimental Error Analysis}

The experimental errors associated with ethanol and acetone concentration due to sample preparation is divided into three parameters which are the temperature, pressure and dilution volume.

1. Errors due to temperature measurement

Assuming an error of $\pm 1{ }^{\circ} \mathrm{C}$ in measuring the ambient temperature at $25{ }^{\circ} \mathrm{C}$ took place. Therefore, the error in head space volume will be calculated as follows

where:

$$
\log \mathrm{P}_{\mathrm{VP}}=\mathrm{A}-\mathrm{B} /(\mathrm{t}+\mathrm{C})
$$

$\mathrm{t}=$ Ambient temperature, ${ }^{\circ} \mathrm{C}$

$\mathrm{P}_{\mathrm{VP}}=$ Vapor pressure above the liquid surface, $\mathrm{kPa}$

$\boldsymbol{A}, \boldsymbol{B}, \boldsymbol{C}=$ constants characteristics of each compound

Where, Ethanol and acetone constants and molecular weight are listed in the following table:

\begin{tabular}{|l|l|l|l|l|}
\hline & $\mathrm{A}$ & $\mathrm{B}$ & $\mathrm{C}$ & Mw \\
\hline Ethanol & $\mathbf{7 . 2 4 2 2 2}$ & $\mathbf{1 5 9 5 . 8 1 1}$ & $\mathbf{2 2 6 . 4 4 8}$ & $\mathbf{4 6 . 0 8}$ \\
\hline Acetone & $\mathbf{6 . 2 5 0 1 7}$ & $\mathbf{1 2 1 4 . 2 0 8}$ & $\mathbf{2 3 0 . 0 0 2}$ & $\mathbf{5 8 . 0 8}$ \\
\hline
\end{tabular}

Therefore, For acetone

$$
\begin{array}{rl}
\log P_{V P} & =A-B /(t+C) \\
& =6.25017-1214.208 /(26+230) \\
& =1.507 \\
P_{V P}=32 & \mathrm{kPa}
\end{array}
$$

Therefore, For Ethanol

$$
\begin{aligned}
& \log \mathrm{P}_{\mathrm{VP}}=\mathrm{A}-\mathrm{B} /(\mathrm{t}+\mathrm{C}) \\
&=7.2422-1595.811 /(26+226.45) \\
&=0.921 \\
& \mathrm{P}_{\mathrm{VP}}=8.3 \mathrm{kPa}
\end{aligned}
$$

The general formula for calculating the concentration, PPM, is explained as:

where:

$$
\mathrm{V}_{\mathrm{HS}}=\left(101.325 / \mathrm{P}_{\mathrm{VP}}\right)(\mathrm{C})(\mathrm{V})
$$

$\mathrm{V}_{\mathrm{HS}}=$ Volume of headspace, $\mu \mathrm{L}$

$\mathrm{P}_{\mathrm{VP}}=$ Vapor pressure of liquid, $\mathrm{kPa}$

$\boldsymbol{C}=$ Desired concentration, PPM

$\boldsymbol{V}=$ Volume of air sampling bag $=4$ liters

For acetone,

$$
\begin{aligned}
\mathrm{V}_{\mathrm{HS}} & =(101.325 / 32)(50)(4) \\
& =633 \mu \mathrm{L}
\end{aligned}
$$

For Ethanol,

$$
\begin{aligned}
\mathrm{V}_{\mathrm{HS}} & =(101.325 / 8.3)(50)(4) \\
& =2442 \mu \mathrm{L}
\end{aligned}
$$

The following table compares the values of ethanol and acetone head space volumes at 25 and $26{ }^{\circ} \mathrm{C}$. Therefore, by comparing these values for ethanol and acetone head space 
volumes at $25{ }^{\circ} \mathrm{C}$, we will find that there is $\pm 5.3 \%$ error in ethanol head space volume and $\pm 3.2 \%$ error in acetone head space volume.

\begin{tabular}{|l|l|l|l|l|}
\hline & $\begin{array}{l}\mathrm{V}_{\mathrm{HS}} @ 25^{\circ} \mathrm{C} \\
\& \mathrm{C}=50 \mathrm{ppm}\end{array}$ & $\begin{array}{c}\mathrm{V}_{\mathrm{HS}} @ 26{ }^{\circ} \mathrm{C} \\
\& \mathrm{C}=50 \mathrm{ppm}\end{array}$ & $\begin{array}{l}\% \text { Error } \mathrm{V}_{\mathrm{HS}} \\
\mathrm{C}_{\mathrm{ppm}}\end{array}$ & \\
\hline Ethanol & $\mathbf{2 5 7 8}$ & $\mathbf{2 4 4 2}$ & $-\mathbf{5 . 3}$ & $\mathbf{5 2 . 6 5}$ \\
\hline Acetone & $\mathbf{6 5 4}$ & $\mathbf{6 3 3}$ & $\mathbf{- 3 . 2}$ & $\mathbf{5 1 . 6}$ \\
\hline
\end{tabular}

2. Errors due to pressure estimation

All samples were prepared in the laboratory assuming atmospheric pressure at sea level (i.e. elevation is zero). The elevation of Morgantown above sea level is estimated to be 800 feet. Therefore, a pressure factor of $F_{p}=0.98$ mentioned in (3) was taken into consideration.

The general formula for calculating the concentration, $\mathrm{PPM}$, at $25^{\circ} \mathrm{C}$ is explained as:

$$
\mathrm{V}_{\mathrm{HS}}=\left(101.325 / \mathrm{P}_{\mathrm{VP}}\right)(\mathrm{C})(\mathrm{V})
$$

where:

$\mathrm{V}_{\mathrm{HS}}=$ Volume of headspace, $\mu \mathrm{L}$

$\mathrm{P}_{\mathrm{VP}}=$ Vapor pressure of liquid, $\mathrm{kPa}$

$C=$ Desired concentration, PPM

$\boldsymbol{V}=$ Volume of air sampling bag $=4$ liters

For acetone,

$$
\begin{aligned}
\mathrm{V}_{\mathrm{HS}} & =(101.325 \times 0.98 / 31)(50)(4) \\
& =620 \mu \mathrm{L}
\end{aligned}
$$

For Ethanol,

$$
\begin{aligned}
\mathrm{V}_{\mathrm{HS}} & =(101.325 \times 0.98 / 7.86)(50)(4) \\
& =2393 \mu \mathrm{L}
\end{aligned}
$$

The following table compares the values of ethanol and acetone head space volumes at 25

\begin{tabular}{|c|c|c|c|c|}
\hline & $\begin{array}{l}\mathrm{V}_{\mathrm{HS}} @ \mathrm{t}=25^{\circ} \mathrm{C} \\
\mathrm{C}=50 \mathrm{ppm} \\
\mathrm{P}=101.325 \mathrm{kpa}\end{array}$ & $\begin{array}{l}\mathrm{V}_{\mathrm{HS}} @ \mathrm{t}=25^{\circ} \mathrm{C} \\
\mathrm{C}=50 \mathrm{ppm} \\
\mathrm{P}=97.88 \mathrm{kPa}\end{array}$ & $\%$ Error $\mathrm{V}_{\mathrm{HS}}$ & True $\mathrm{C}_{\mathrm{ppm}}$ \\
\hline Ethanol & 2578 & 2393 & -7 & 53.5 \\
\hline Acetone & 654 & 620 & -5.2 & 52.5 \\
\hline
\end{tabular}
and for atmospheric pressure of 101.325 at sea level and at elevation of 800 feet. Therefore, by comparing these values for ethanol and acetone head space volumes at $25^{\circ} \mathrm{C}$, we will find that there is $-7 \%$ error in ethanol head space volume and $-5.2 \%$ error in acetone head space volume.

3. Errors in dilution volume

The total dilution volume in a sampling bag in a static system expressed in (VT) can be calculated as:

$\mathrm{VT}=\mathrm{VA}+\mathrm{VB}$

Where,

$\mathrm{VA}=$ the total head space volume of ethanol and acetone, $\mu \mathrm{L}$

$\mathrm{VB}=$ Dilution volume in sampling bag, $\mathrm{L}$ 
Since, the head space volume of ethanol and acetone (VA) injected in sampling bag was neglected, therefore the calculated error will be:

$\mathrm{VT}=(2578+654) / 1,000,000+4=4.003232$ liter

Therefore, the error in neglecting the ethanol and acetone head space volume is calculated as:

$\%$ error $=(\mathrm{VT}-\mathrm{VB}) / \mathrm{VB} \times 100$

$=(4.003232-4.0) / 4 \times 100$

$=0.08 \%$ 